\title{
KĀKĀPŌ REPRODUCTION: IDENTIFICATION OF STEROID RECEPTORS AND OESTROGENIC ACTIVITY IN NATIVE FLORA
}

\section{Catherine Elizabeth Judith Davis}

\author{
A thesis submitted to \\ Victoria University of Wellington \\ in fulfilment of the requirements for the degree of \\ Doctor of Philosophy
}

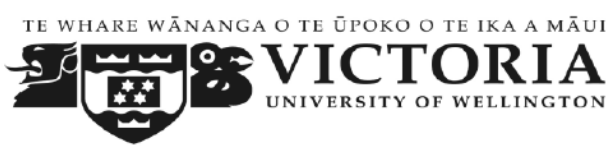

Victoria University of Wellington

Te Whare Wānanga o te Ūpoko o te Ika a Māui 



\section{ABSTRACT}

Kākāpō (Strigops habroptilus) are a critically endangered parrot species endemic to New Zealand that exhibit a reproductive strategy linked to "masting" years. Crucial to their survival is increased reproductive success. It has been hypothesised that their pattern of reproduction is synchronised with a steroidal "trigger" present in plants during intensive masting. If this hypothesis is valid, then Kākāpō and other closely related NZ parrots might be receptive to these masting plants in a manner different from that of other avian species.

The aims of this study were firstly, to identify whether unique amino acid motifs were present in the ligand binding domains (LBD) for the steroid receptors oestrogen receptor $\alpha$ (ER- $\alpha$ ), oestrogen receptor $\beta(E R-\beta)$, androgen receptor $(\mathrm{AR})$ and progesterone receptor $(\mathrm{PR})$ for the New Zealand parrots Kākāpō, Kākāan, Kākāriki and Kea. These LBD amino acid sequences were compared with those in an Australian parrot, the Cockatiel, as well as in Chicken and Japanese Quail. Moreover, the role of these amino acid changes on the binding of ligands (both the native ligand and other steroidogenic compounds) for ER- $\alpha$ was assessed by in silico modelling by comparing the most favourable binding position of the ligands in the three-dimensional structure of Kākāpō ER- $\alpha$ with that of human ER- $\alpha$. The second aim was to test extracts of New Zealand native plants known to be a food source for Kākāpō for their seasonal variation in oestrogenic activity and hence possible involvement in the reproductive cycle of Kākāpō.

The LBD for ER- $\beta$ and AR of the parrot species (New Zealand and Australian) displayed $100 \%$ identity whilst those for ER- $\alpha$ and PR had variations. When the parrot sequences were compared with those for other avian species and human, there were a number of amino acid differences present, with the greatest disparity present in the LBD of ER- $\alpha$. From in silico modelling studies, the amino acid substitutions in this receptor were predicted to have an indirect influence on the binding position of both 17ß-oestradiol and a number of phytoestrogens through changes in the structure of this region. Consequently, this could have an effect on the binding affinity of certain plant chemicals for ER- $\alpha$ and thus their potency.

Plants extracts from the foliage and fruit of native New Zealand species were screened for oestrogenic activity in a yeast bioassay transfected with the human isoform of ER- $\alpha$. The results from these experiments indicated that all the plants tested (excluding Dacrycarpus 


\section{ABSTRACT}

dacrydioides) exhibited detectable oestrogenic activity and a number also displayed variable and sometimes seasonal trends in activity.

In summary, the results in this study identified ER- $\alpha$ LBD amino acid motifs unique to New Zealand parrots. For the other steroid receptors, the ER- $\beta$ LBD had a three amino acid combination of $\mathrm{M}, \mathrm{V}$ and $\mathrm{L}$ that was only present in the parrot species whilst both the AR and PR LBD displayed much greater inter-species conservation. These changes, particularly those in the ER- $\alpha$ LBD, may influence the binding of steroidogenic compounds, known to be present in the plants consumed by Kākāpō as demonstrated by in silico modelling. Thus, this research provides evidence that the diet of Kākāpō may influence their reproductive pattern. However, it remains to be determined whether the steroidogenic potency of these plant extracts is modified when interacting with the unique LBD of native NZ parrots. 


\section{ACKNOWLEDGEMENTS}

Firstly, I would like to thank my primary supervisor, Prof. Ken McNatty, for his guidance, patience and support throughout my $\mathrm{PhD}$. I have learnt an endless amount from him and I could not have asked for a better supervisor. I would also like to acknowledge my secondary supervisor, Dr. Janet Pitman, for her help and unfailing support and patience with all aspects of this project, from experimental design, to the analysis of results and the editing of my work.

This research would not have been possible without the help and support of a number of people. Dr. Murray Williams is to be thanked for both his intellectual and financial support. His limitless knowledge on all aspects of science, coupled with a sharp wit, has made working with him a very enjoyable experience. To the past and present members of the Reproduction lab group, thank you. I would especially like to thank Adrian Bibby, for helping me with many of the experimental procedures carried out in this investigation.

Thank you to Dr. Andrew Fidler for his support with this project and kindly gifting me a number of avian tissue samples. Also, thanks to the Department of Conservation, rangers on Matiu Somes Island, and staff at The Nest, Wellington Zoo, for avian tissue samples. Thanks to Dr. Ron Moorhouse and Yvette Cottam for Rimu samples, and Prof. Phil Garnock-Jones and Dr. Carlos Lehnebach for their assistance in identifying and collecting plant samples.

From the School of Chemical and Physical Sciences, I would like to thank Teresa Gen for providing me with lab space and lab equipment to use, Dr. Jono Singh and Assoc. Prof. Peter Northcote for assistance with compound isolation from plants, and Dr. Jon Dattelbaum for introducing me to Rosetta and guiding me through my initial docking attempts. Thanks also to Les Maiden for the yeast bioassay images and Dafnis Vargas for the Kākāpō design.

I am sincerely indebted to Kevin Buckley from the School of Engineering and Computer Science for his patience and for being one of the easiest people to collaborate with. The in silico modelling was far beyond my limited computer knowledge but Kevin was always willing to meet with me, answer my questions and solve the issues I had. I must also thank Dr. Matthias Lein, Elf Eldridge, Miles Benton and Dr. Monica Gruber for all their assistance with my computer questions. Thank you to Guojie Zhang, Tom Gilbert, Erich Jarvis, Jason Howard and Cai Li (co-ordinators of the avian phylogenomics project) for allowing me access to the unpublished avian database and to Romanos Laskowski for his help with LigPlot.

I am very grateful to the Vice-Chancellor's Strategic Research Scholarship, Pickering Award and Victoria University $\mathrm{PhD}$ Submission Scholarship for financial assistance during my PhD.

Thank you to Te Rōpū Āwhina and especially Liz and Vivian - they have provided me with endless opportunities to grow as both a mentor and critical thinker. I hope to provide others with these opportunities in the future.

Finally, to my family and friends, I offer my thanks for all their support and words of encouragement. I cherish the friendships that I have and am lucky to have such wonderful people in my life. 


\section{TABLE OF CONTENTS}

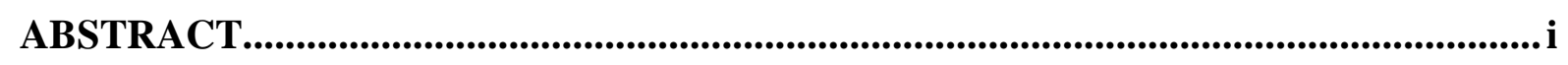

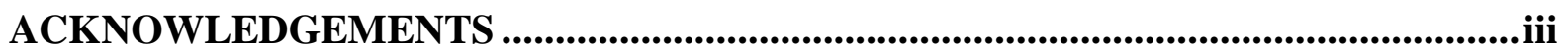

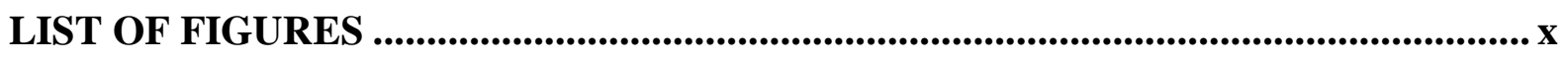

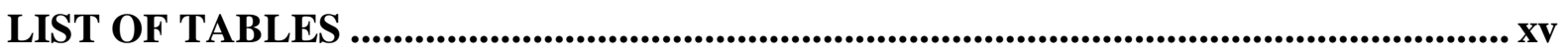

LIST OF ABBREVIATIONS ................................................................................................ xvi

CHAPTER 1: GENERAL INTRODUCTION ....................................................

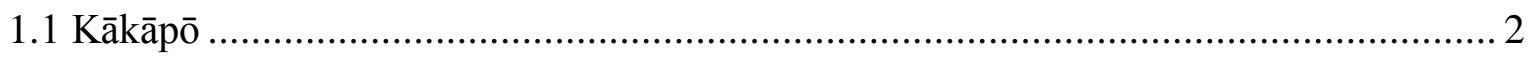

1.1.1 Breeding Behaviour ............................................................................ 3

1.1.2 Kākāpō Recovery Programme .................................................................... 4

1.1.3 Reproductive Strategy Hypothesis ......................................................... 5

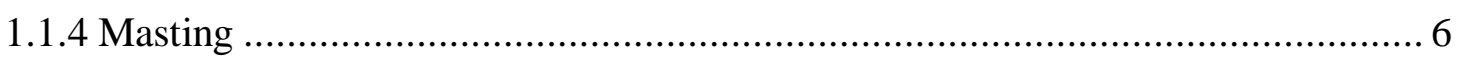

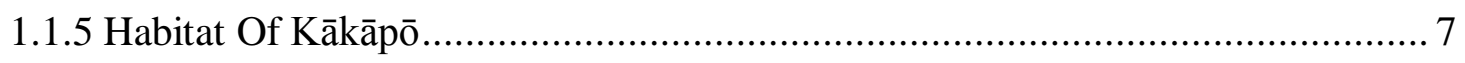

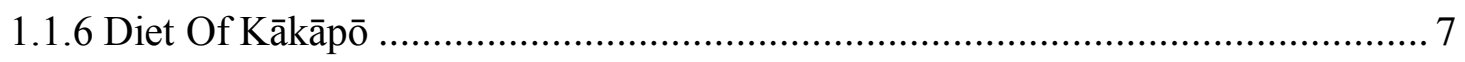

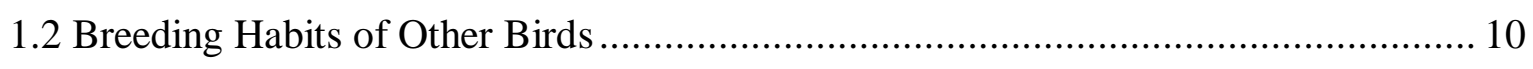

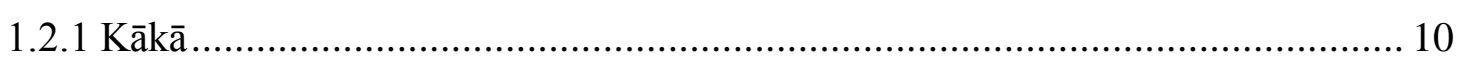

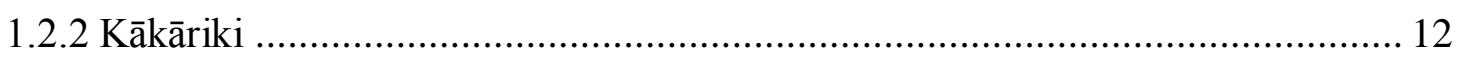

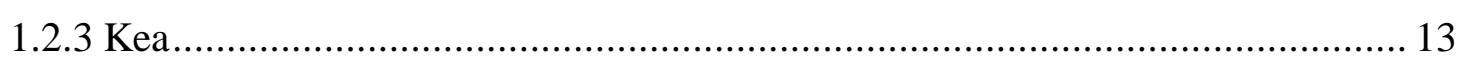

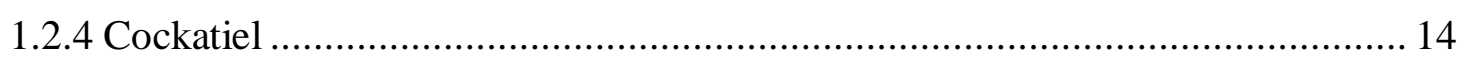

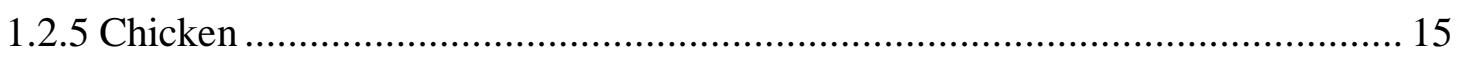

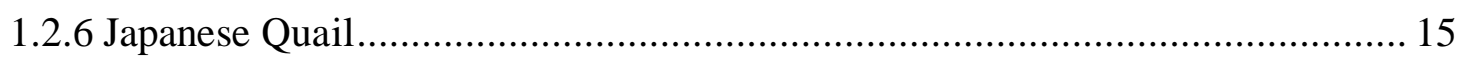

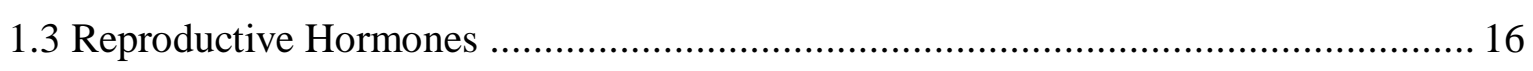

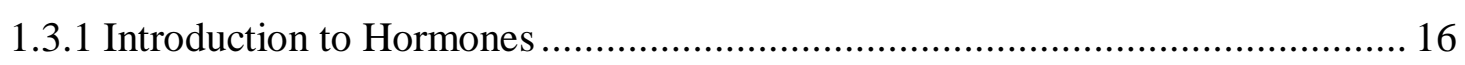

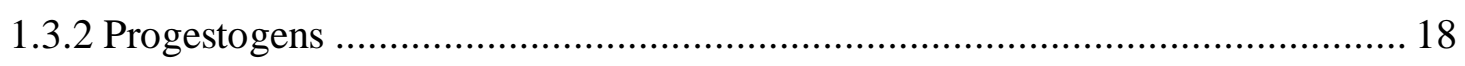

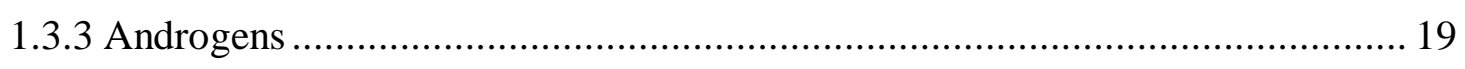

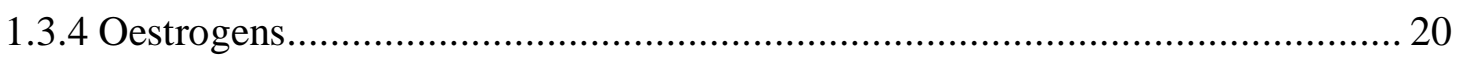

1.3.4.1 Vitellogenin and vitellogenesis.......................................................... 21

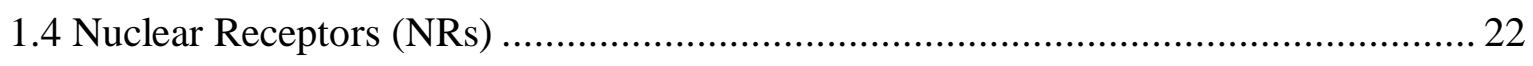

1.4.1 Introduction to Nuclear Receptors (NRs) …........................................... 22

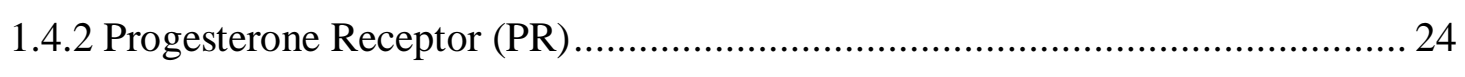

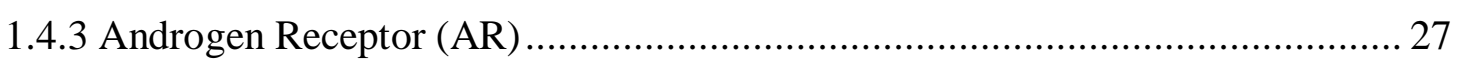




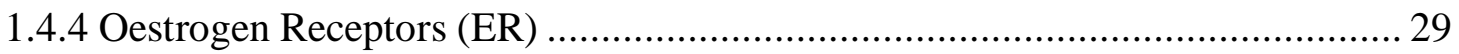

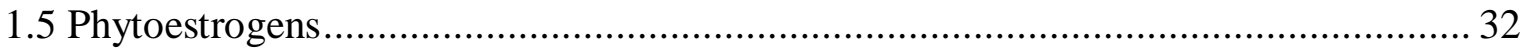

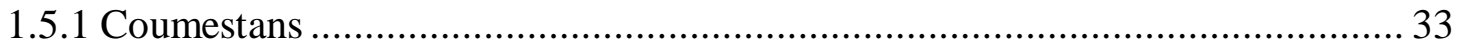

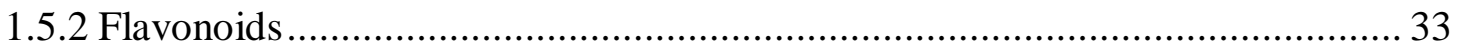

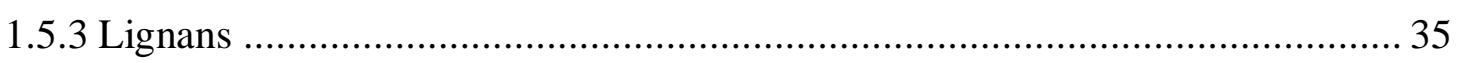

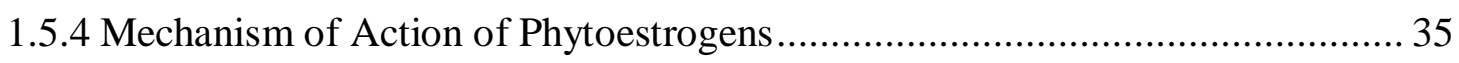

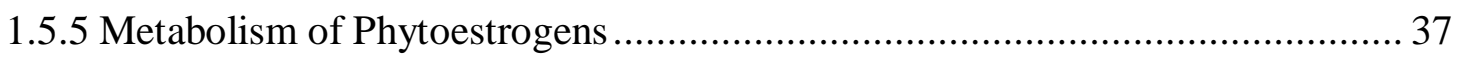

1.5.6 Influence on Wildlife and Domesticated Animals ........................................... 38

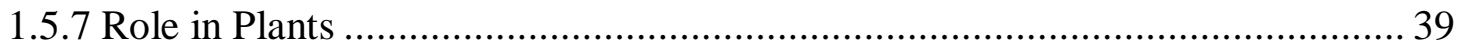

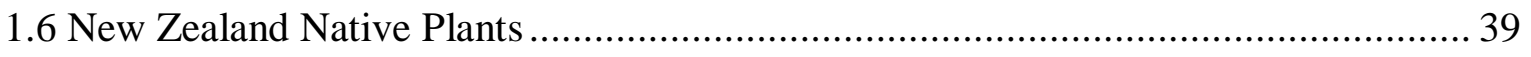

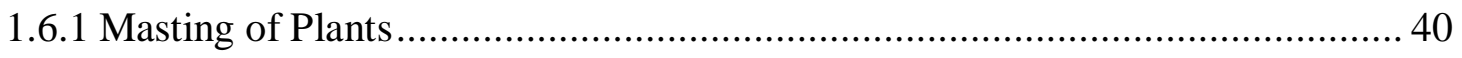

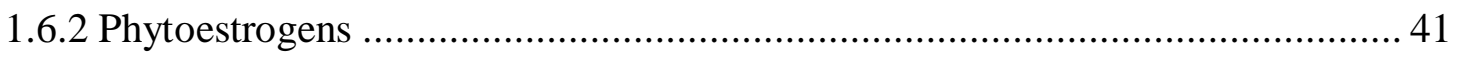

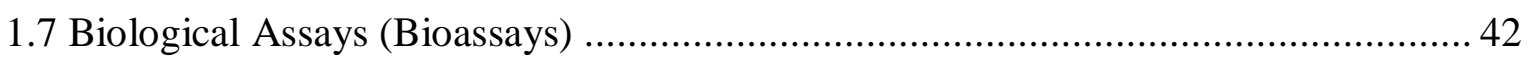

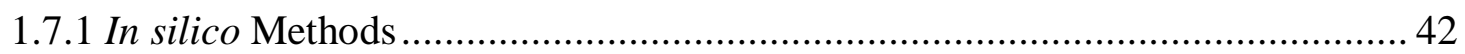

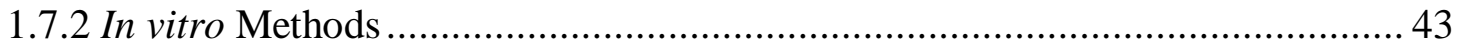

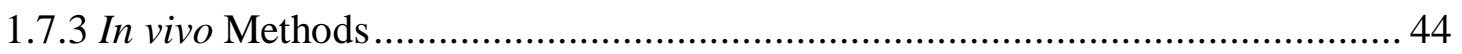

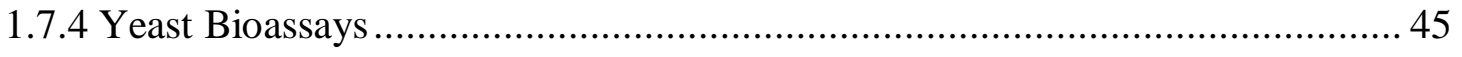

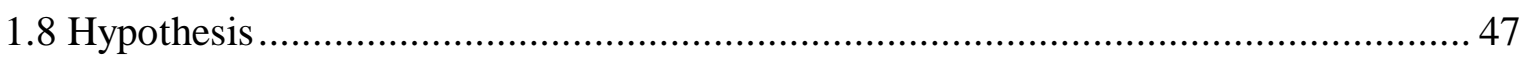

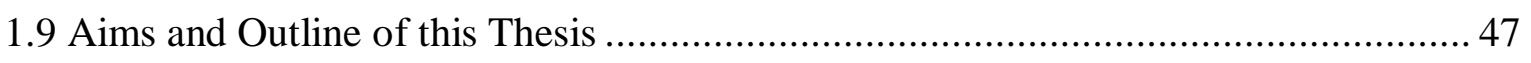

CHAPTER 2: MATERIALS AND METHODOLOGY ............................................. 49

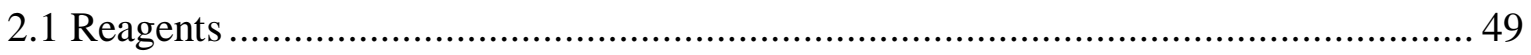

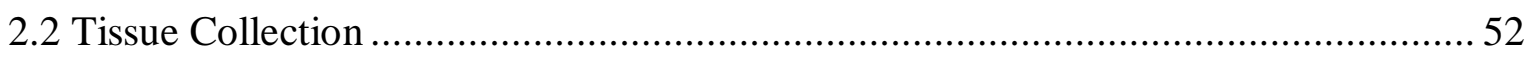

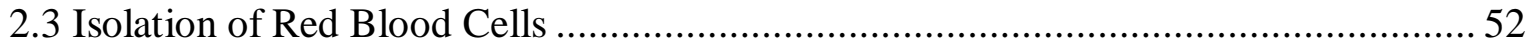

2.4 Red Blood Cell and Tissue RNA Extraction........................................................ 52

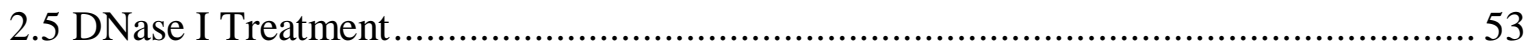

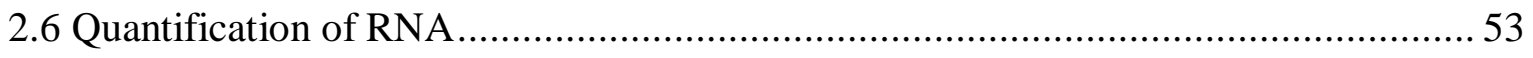

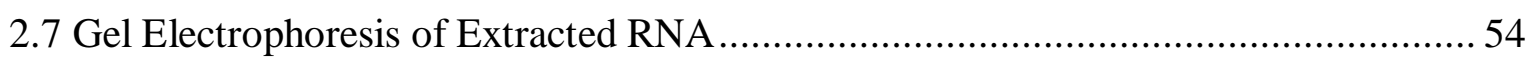

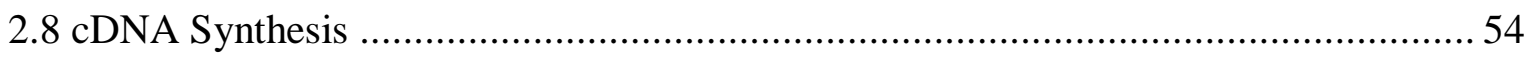

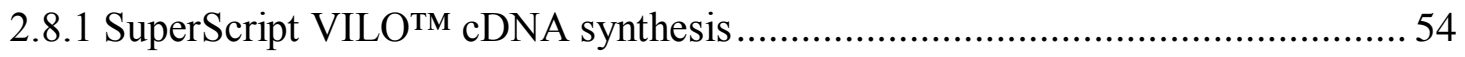

2.8.2 SuperScript III First-Strand Synthesis Supermix cDNA synthesis .................... 55

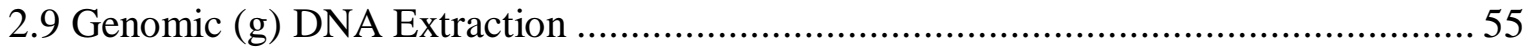

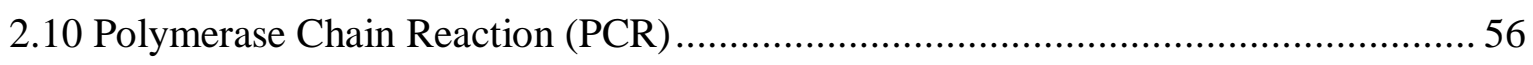

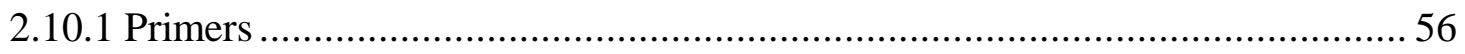

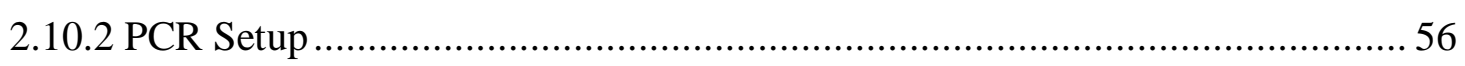

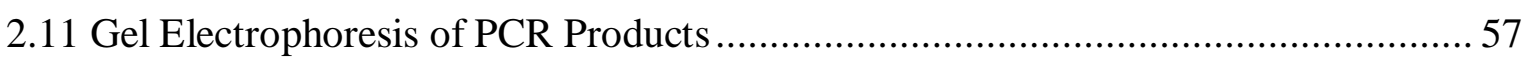

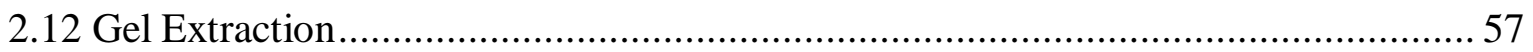




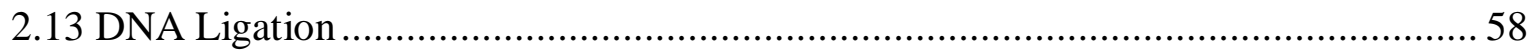

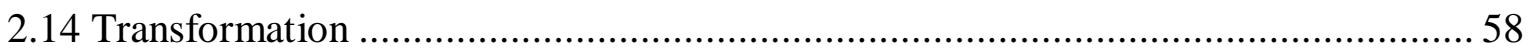

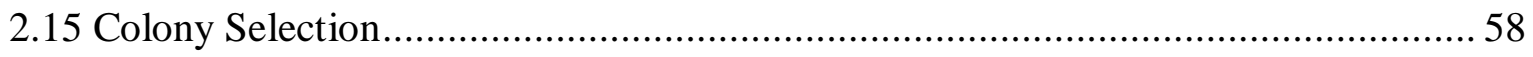

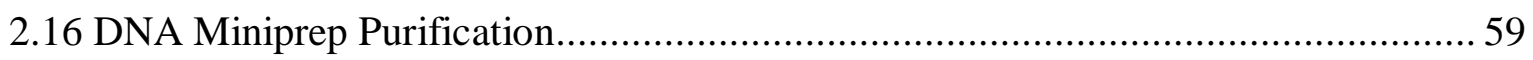

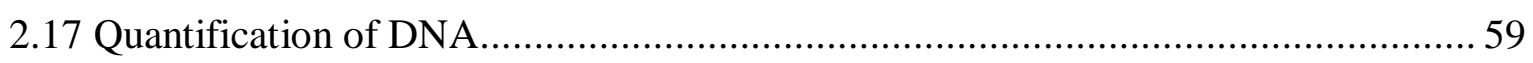

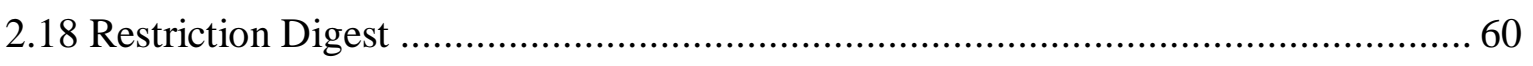

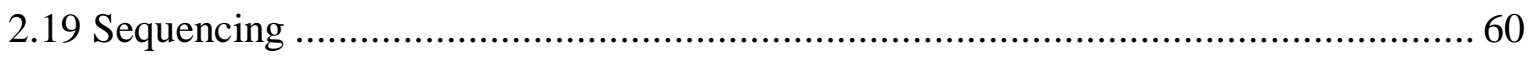

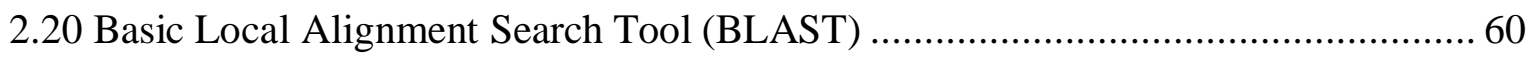

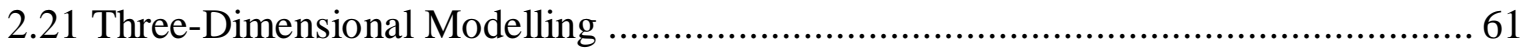

2.22 In Silico Modelling of Compounds Bound in ER- $\alpha$ with RosettaLigand .................. 62

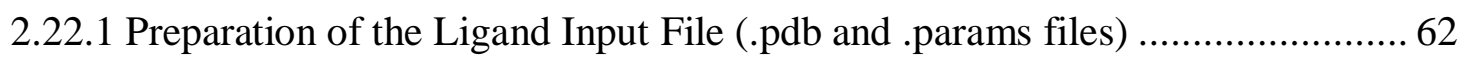

2.22.2 Preparation of the Minimised Kākāpō ER- $\alpha$ Protein PDB File ........................ 62

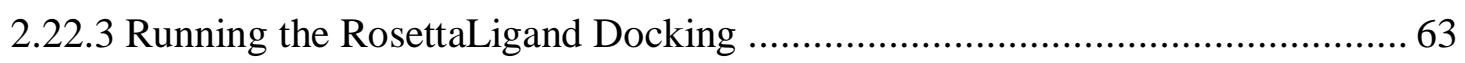

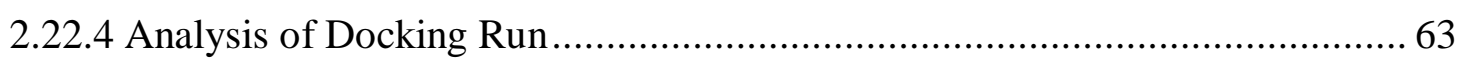

2.22.5 Prediction of Ligand-Receptor Interactions .............................................. 63

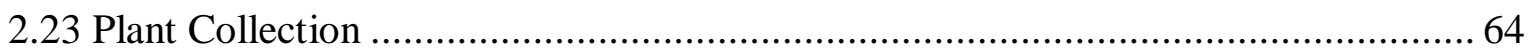

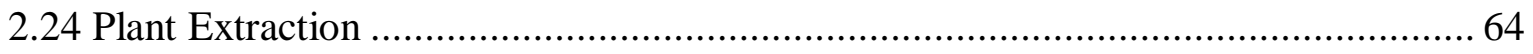

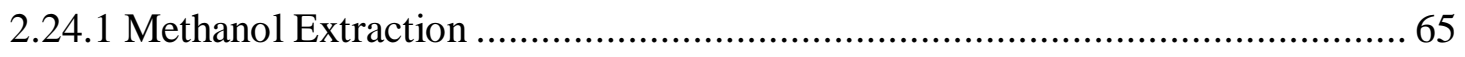

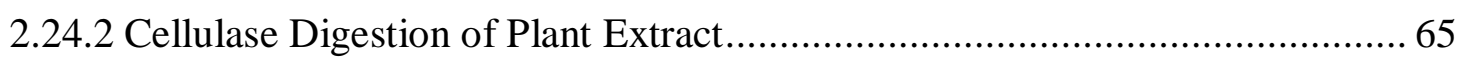

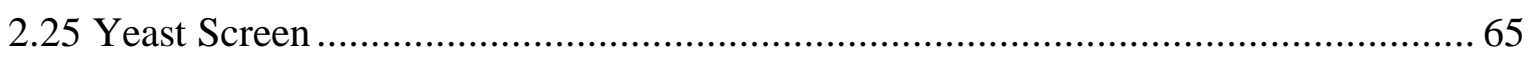

2.25.1 Preparation of Growth Media for the Yeast Strain...................................... 65

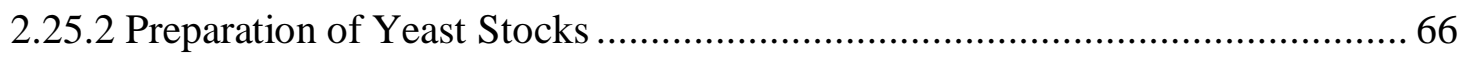

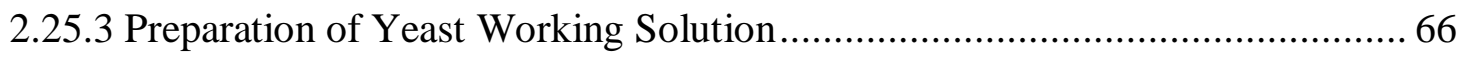

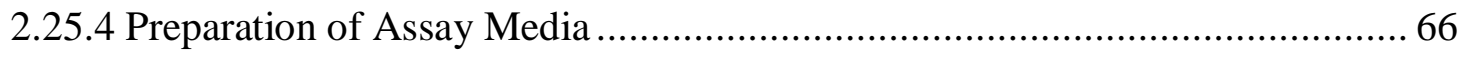

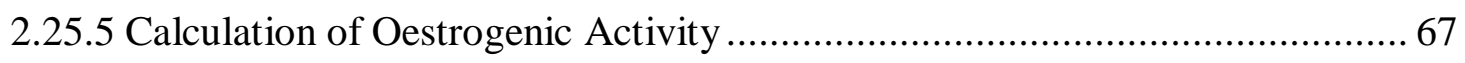

CHAPTER 3: AMPLIFICATION OF STEROID RECEPTOR LIGAND BINDING

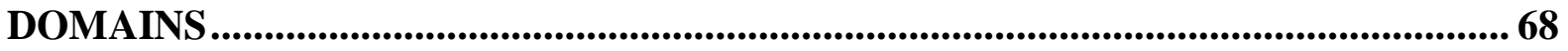

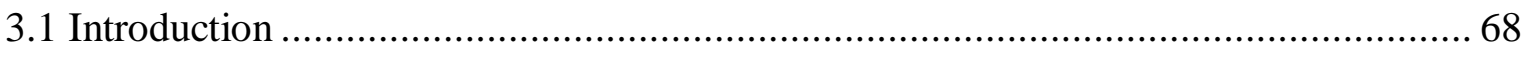

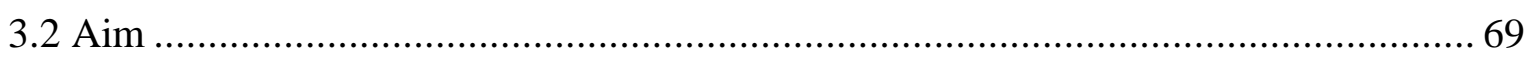

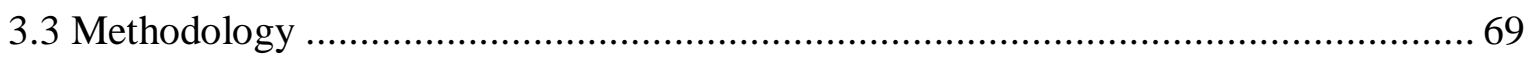

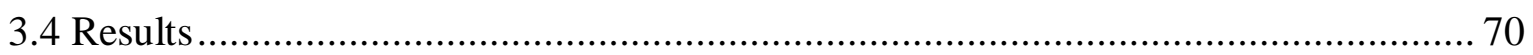

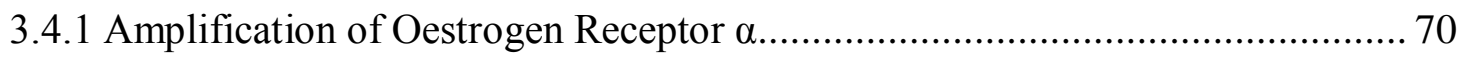

3.4.1.1 Alignment of ER- $\alpha$ LBD of generated sequences ...................................... 70

3.4.1.2 Alignment of ER- $\alpha$ LBD of other species ................................................... 74

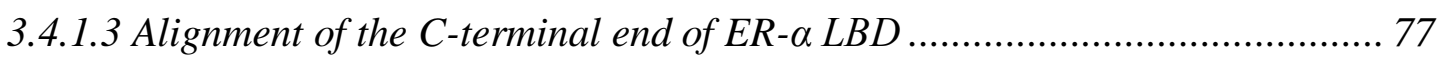

3.4.1.4 Alignment of the C-terminal end of ER- $\alpha$ LBD of other species .................. 81 
3.4.1.5 Three-dimensional modelling of the ER- $\alpha$ LBD ....................................... 86

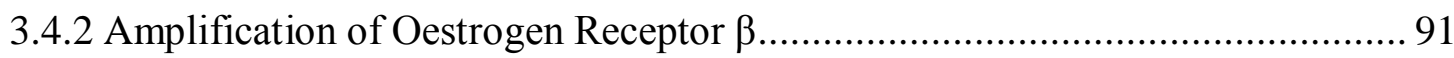

3.4.2.1 Alignment of ER- $\beta$ LBD of generated species .......................................... 91

3.4.2.2 Alignment of ER- $\beta$ LBD of other species .................................................. 94

3.4.2.3 Three-dimensional modelling of ER- $\beta$ LBD ............................................ 97

3.4.3 Amplification of Androgen Receptor ......................................................... 101

3.4.3.1 Alignment of AR LBD of generated sequences........................................ 101

3.4.3.2 Alignment of AR LBD of other species ................................................. 105

3.4.3.3 Three-dimensional modelling of AR LBD ............................................ 107

3.4.4 Amplification of Progesterone Receptor ..................................................... 111

3.4.4.1 Alignment of PR LBD of generated sequences..................................... 111

3.4.4.2 Alignment of PR LBD of other species ............................................... 113

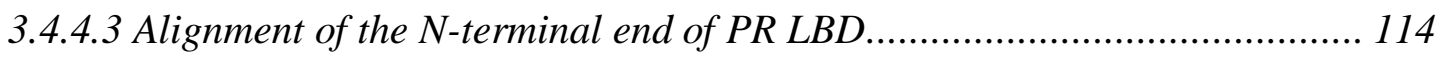

3.4.4.4 Alignment of the $N$-terminal end of PR LBD of other species.................... 116

3.4.4.5 Three-dimensional modelling of PR LBD .............................................. 120

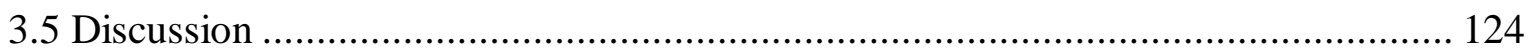

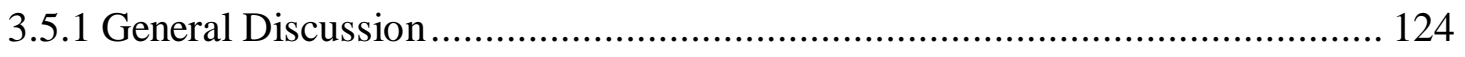

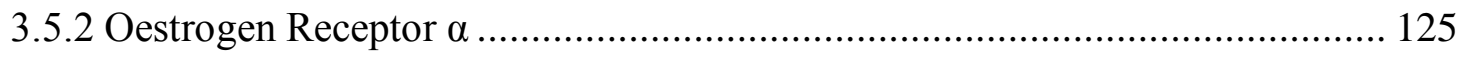

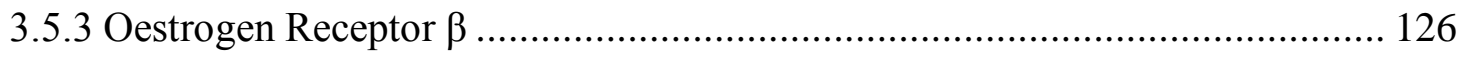

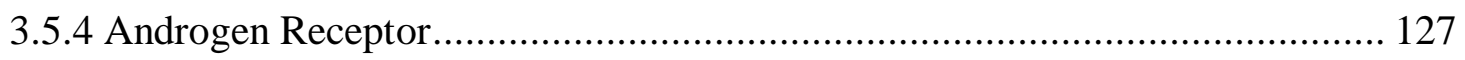

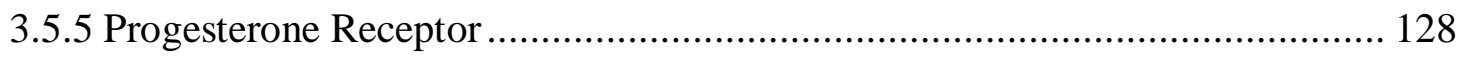

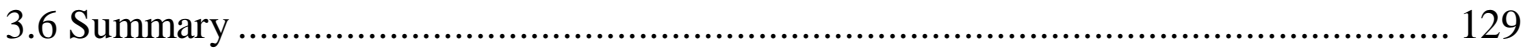

\section{CHAPTER 4: COMPUTER SIMULATED DOCKING OF OESTROGENIC OR} SIMILAR STEROID COMPOUNDS TO KĀKĀPŌ ER- $\alpha$........................................... 130

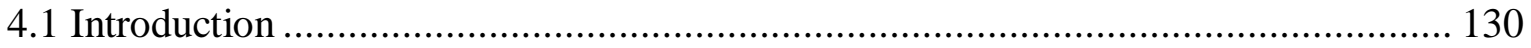

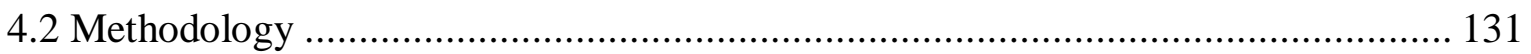

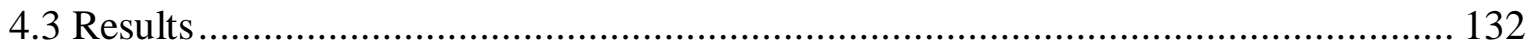

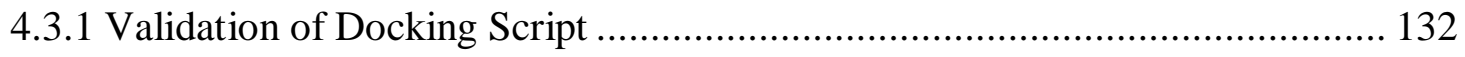

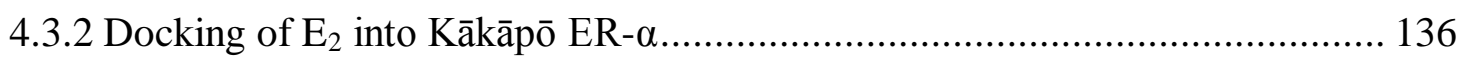

4.3.3 Docking of Bisphenol A (BPA) and Triclosan (TRI) .................................. 138

4.3.4 Docking of Phytoestrogens into Kākāpō ER- $\alpha$........................................... 142

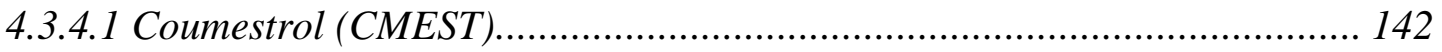

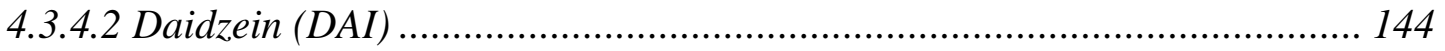

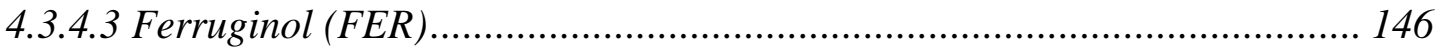

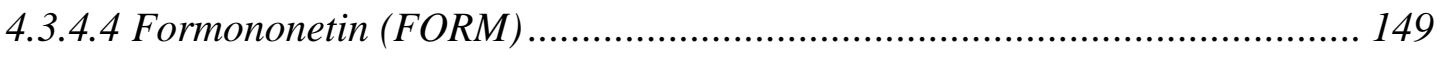

4.3.4.5 Genistein $(G E N)$............................................................................. 150 


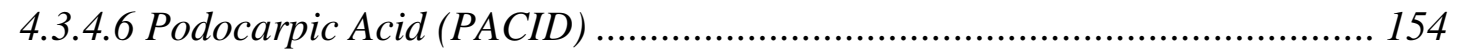

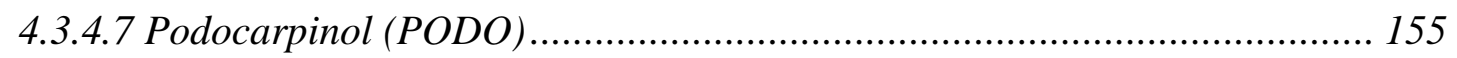

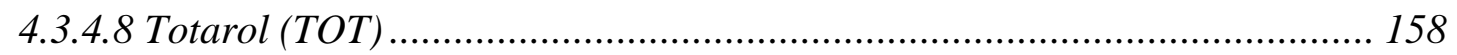

4.3.5 Docking of Other Hormones in Kākāpō ER- $\alpha$............................................ 160

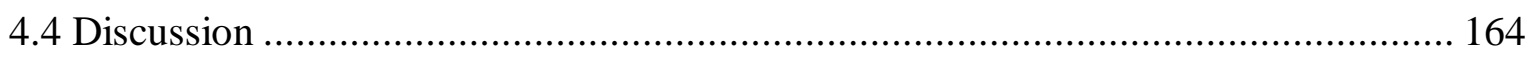

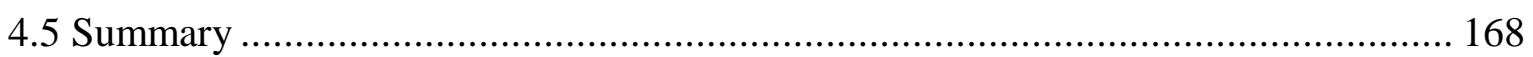

CHAPTER 5: OPTIMISATION AND VALIDATION OF YEAST BIOASSAY ........ 169

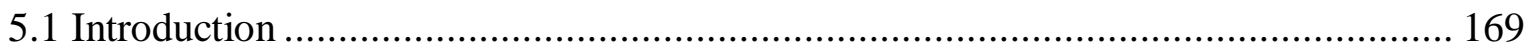

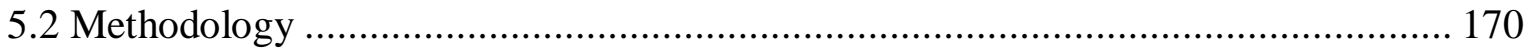

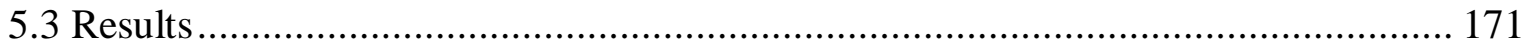

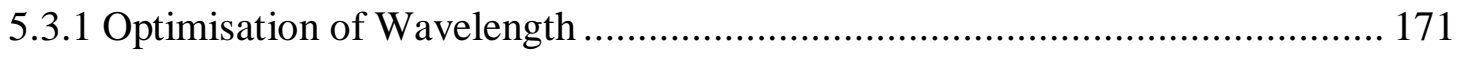

5.3.2 Standard Curve Generation and Detection Limits of the Bioassay................. 173

5.3.3 Optimisation of the Incubation Time of the Bioassay ................................... 173

5.3.4 Optimisation of the Phytoestrogen Extraction Protocol ................................ 174

5.3.5 Optimisation of the Incubation Period for Extraction ................................. 176

5.3.6 Validation of the Yeast Bioassay ................................................................. 177

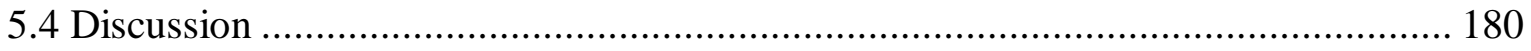

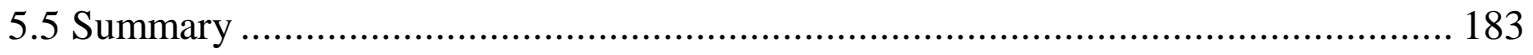

CHAPTER 6: OESTROGENIC ACTIVITY OF NATIVE NEW ZEALAND PLANTS

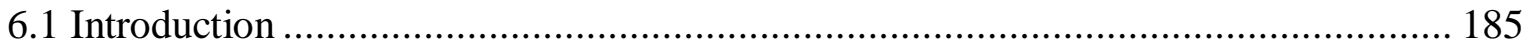

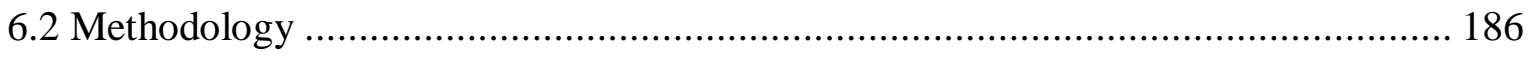

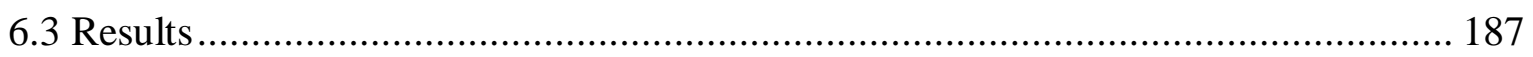

6.3.1 Seasonal Variation in Activity of Native New Zealand Plants ..................... 187

6.3.1.1 Dacrydium cupressinum (Rimu) ......................................................... 187

6.3.1.2 Blechnum novae-zelandiae (Kiokio) .................................................... 189

6.3.1.3 Coprosma robusta (Karamu) ............................................................ 190

6.3.1.4 Dracophyllum longifolium (Inaka) ...................................................... 191

6.3.1.5 Gahnia procera (Mountain Gahnia)................................................... 191

6.3.1.6 Leptecophylla juniperina (Mingimingi) ................................................ 193

6.3.1.7 Leptospermum scoparium (Manuka) ................................................. 193

6.3.1.8 Nothofagus solandri (Southern Beech) ................................................. 194

6.3.1.9 Podocarpus cunninghamii (Montane Totara) ........................................ 194

6.3.1.10 Prumnopitys ferruginea (Miro) ........................................................... 196

6.3.2 Activity Present in Other Native New Zealand Plants .................................. 196 


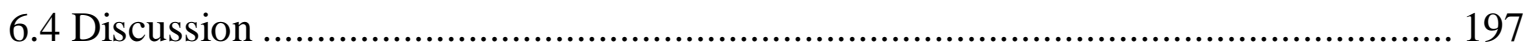

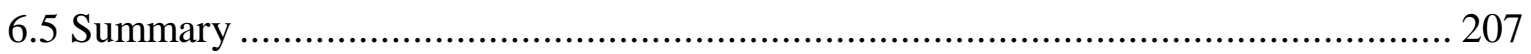

CHAPTER 7: GENERAL DISCUSSION ...................................................................... 209

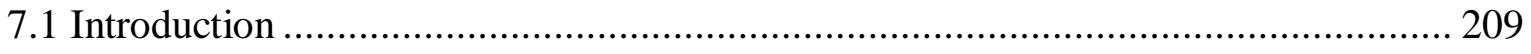

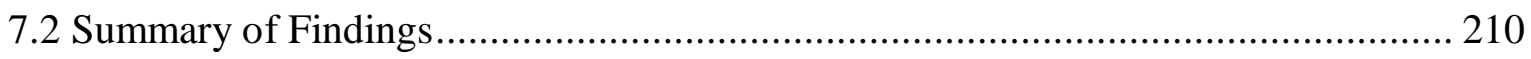

7.2.1 New Zealand parrots display a high level of conservation in the amino acid sequences within the LBD of the four steroid receptors investigated. In some instances

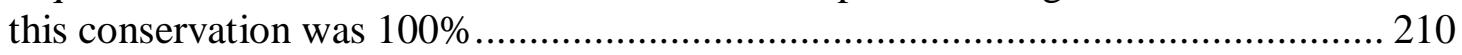

7.2.2 New Zealand parrots demonstrate variation in the LBD of four steroid receptors when compared to other avian and non-avian species: ER- $\alpha$ displays the greatest level of disparity. 210

7.2.3 Amino acids in ER- $\alpha$ that are unique to New Zealand birds may play a role in the binding mode of phytoestrogens in the receptor.

7.2.4 Oestrogenic activity is present in New Zealand native plants browsed by Kākāpō and these activities display seasonal variation.................................................... 211

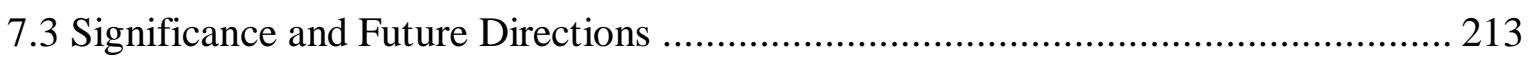

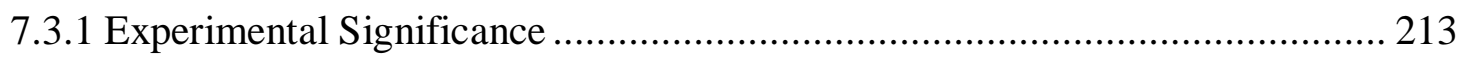

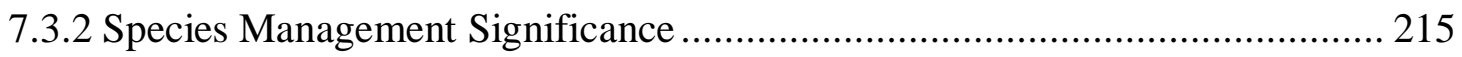

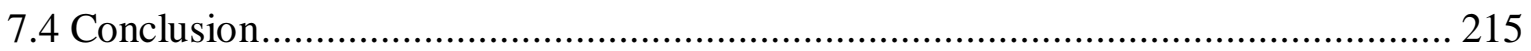

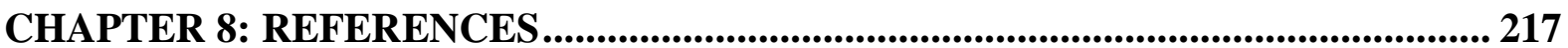

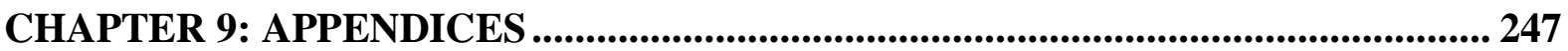

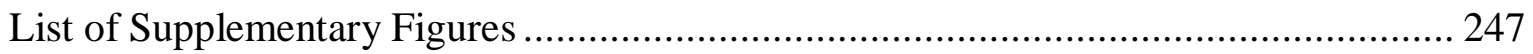

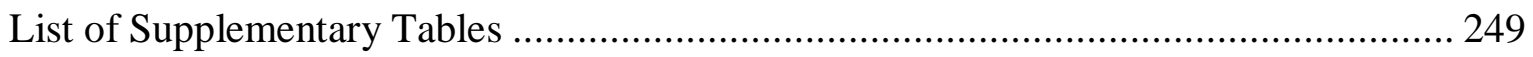

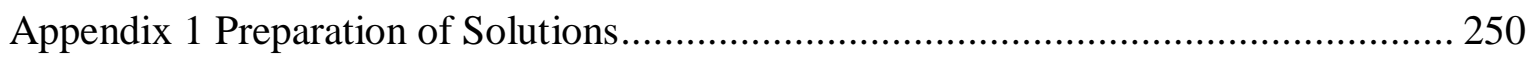

Appendix 2 Scripts for Modelling, Collection and Identification of Plants, Bioassay

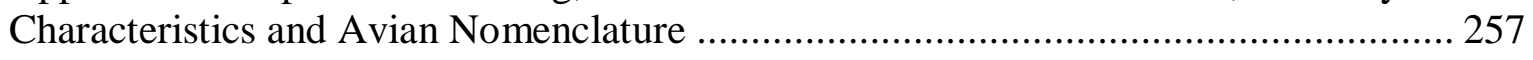

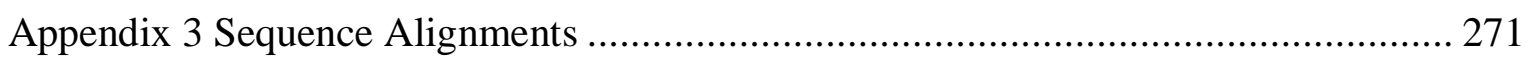




\section{LIST OF FIGURES}

Figure 1.1 An illustration of Kākāpō (Strigops habroptilus) ….............................................................2

Figure 1.2 An illustration of Kākā (Nestor meridionalis) and Kea (Nestor notabilis) ........................ 12

Figure 1.3 An illustration of Red-crowned, Orange-fronted and Yellow-crowned Kākāriki

(Cyanoramphus novaezelandiae, malherbi and auriceps).

Figure 1.4 The core backbone of steroid hormones is cyclopentanophenanthrene .............................. 17

Figure 1.5 The biosynthesis of steroid hormones beginning with cholesterol. .................................... 18

Figure 1.6 The common progestogens include pregnenolone $\left(\mathrm{P}_{5}\right)$, progesterone $\left(\mathrm{P}_{4}\right)$,

$5 \alpha$-dihydroprogesterone (DHP) and 17 $\alpha$-hydroxypregnenolone.

Figure 1.7 The common androgens include dehydroepiandrosterone (DHEA), androstenedione,

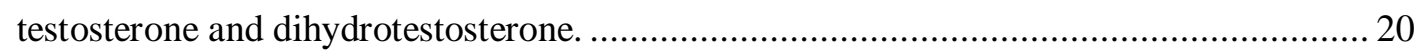

Figure 1.8 The common oestrogens are oestrone $\left(\mathrm{E}_{1}\right), 17 \beta$-oestradiol $\left(\mathrm{E}_{2}\right)$ and oestriol $\left(\mathrm{E}_{3}\right) \ldots \ldots \ldots \ldots . .21$

Figure 1.9 The modular structure of NRs consists of $\mathrm{N}$-terminal regulatory domain (A/B),

DNA-binding domain (DBD) (C), hinge domain (D), ligand binding domain (LBD) (E)

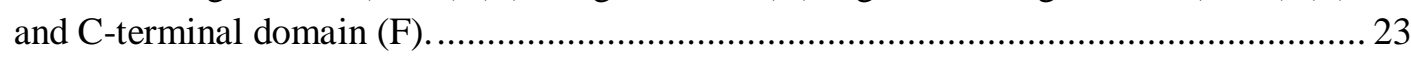

Figure 1.10 Crystal structure of human PR with progesterone bound............................................ 26

Figure 1.11 Crystal structure of human AR with testosterone bound........................................... 28

Figure 1.12 Crystal structures of the two isoforms of human ER. A) ER- $\alpha$ (RSCB structure ID 1A52)

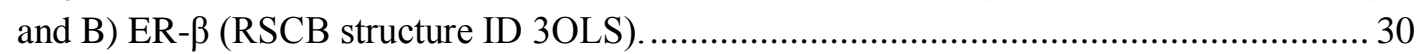

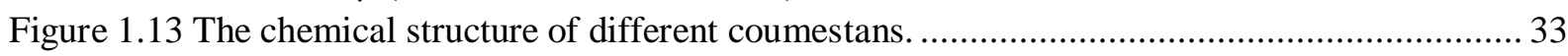

Figure 1.14 The chemical structure of different flavones and a flavanone......................................... 34

Figure 1.15 The chemical structure of a number of major flavonoids and metabolites........................ 34

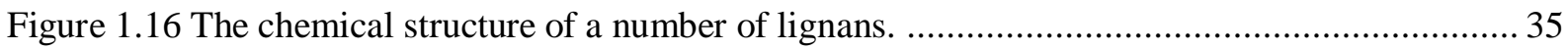

Figure 1.17 Metabolic pathway for catabolism of the phytoestrogens daidzein to equol via

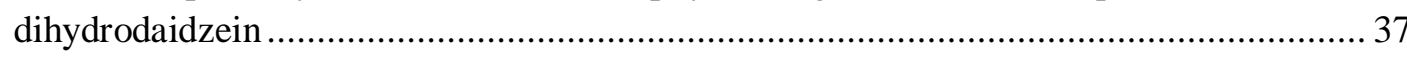

Figure 1.18 Schematic of the conversion of chlorophenol red galactopyranoside (CPRG) to chlorophenol red (CPR) and galactose by $\beta$-galactosidase ........................................... 46

Figure 3.1 Nucleotide sequences that span the amplified region of the ligand binding domain (LBD) of oestrogen receptor $\alpha(\mathrm{ERa})$ of New Zealand parrot species, Cockatiel, Chicken and

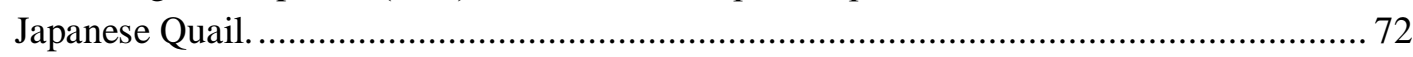

Figure 3.2 Amino acid sequences that span the amplified region of the ligand binding domain (LBD) of oestrogen receptor $\alpha(\mathrm{ERa})$ of New Zealand parrot species, Cockatiel, Chicken and Japanese Quail.

Figure 3.3 Nucleotide sequences that span the amplified region of the ligand binding domain (LBD) of oestrogen receptor $\alpha$ (ERa) of New Zealand species and human (NM_000125).

Figure 3.4 Amino acid sequences that span the amplified region of the ligand binding domain (LBD) of oestrogen receptor $\alpha$ (ERa) of New Zealand species and human (NP_00016)............. 76

Figure 3.5 Nucleotide sequences that span the remaining amplified region of the ligand binding domain (LBD) of oestrogen receptor $\alpha(\mathrm{ERa})$ of New Zealand parrot species, Cockatiel,

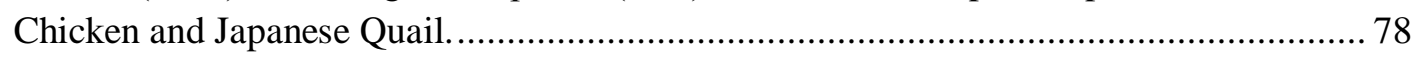

Figure 3.6 Amino acid sequences that span the remaining amplified region of the ligand binding domain (LBD) of oestrogen receptor $\alpha$ (ERa) of New Zealand parrot species, Cockatiel, Chicken and Japanese Quail. 
Figure 3.7 Nucleotide sequences that span the remaining amplified region of the ligand binding domain (LBD) of oestrogen receptor $\alpha$ (ERa) of New Zealand parrot species and human. 82

Figure 3.8 Amino acid sequences that span the remaining amplified region of the ligand binding domain (LBD) of oestrogen receptor $\alpha$ (ERa) of New Zealand parrot species and human. 83

Figure 3.9 Three-dimensional structure of human oestrogen receptor $\alpha(\mathrm{hER}-\alpha)$ and the ligand binding domain (LBD) region amplified in Kākāpō.

Figure 3.10 The amino acid differences between the ligand binding domain (LBD) of oestrogen receptor $\alpha(E R-\alpha)$ of Kākāpō and human.

Figure 3.11 The amino acid differences between the ligand binding domain (LBD) of oestrogen receptor $\alpha(E R-\alpha)$ of Kākāpō and non-native avian species.

Figure 3.12 Nucleotide sequences that span the amplified region of the ligand binding domain (LBD) of oestrogen receptor $\beta$ (ERb) of New Zealand parrot species, Cockatiel, Chicken and Japanese Quail.

Figure 3.13 Amino acid sequences that span the amplified region of the ligand binding domain (LBD) of oestrogen receptor $\beta(\mathrm{ERb})$ of New Zealand parrot species, Cockatiel, Chicken and Japanese Quail.

Figure 3.14 Nucleotide sequences that span the amplified region of the ligand binding domain (LBD) of oestrogen receptor $\beta$ (ERb) for New Zealand parrot species with human.

Figure 3.15 Amino acid sequences that span the amplified region of the ligand binding domain (LBD) of oestrogen receptor $\beta(\mathrm{ERb})$ of the New Zealand parrot species and human.

Figure 3.16 Three-dimensional structure of human oestrogen receptor $\beta$ (hER- $\beta$ ) and the ligand binding domain (LBD) region amplified in the avian species.

Figure 3.17 The amino acid differences between the ligand binding domain (LBD) of oestrogen receptor $\beta$ (ER- $\beta)$ of Kākāpō and human.

Figure 3.18 The amino acid differences between the ligand binding domain (LBD) of oestrogen receptor $\beta$ (ER- $\beta$ ) of Kākāpō and non-native avian species.

Figure 3.19 Nucleotide sequences span the amplified region of the ligand binding domain (LBD) of androgen receptor (AR) of New Zealand parrot species, Cockatiel, Chicken and Japanese Quail.

Figure 3.20 Amino acid sequences that span the amplified region of the ligand binding domain (LBD) of androgen receptor (AR) of New Zealand parrot species, Cockatiel, Chicken and Japanese Quail.

Figure 3.21 Nucleotide sequences that span the amplified region of the ligand binding domain (LBD) of androgen receptor (AR) of New Zealand parrot species and human.

Figure 3.22 Amino acid sequences that span the amplified region of the ligand binding domain of androgen receptor (AR) of New Zealand parrot species and human.

Figure 3.23 Three-dimensional structure of human androgen receptor (hAR) and the ligand binding domain (LBD) region amplified in the avian species.

Figure 3.24 The amino acid differences between the ligand binding domain (LBD) of androgen receptor (AR) of Kākāpō and human.....

Figure 3.25 The amino acid differences between the ligand binding domain (LBD) of androgen receptor (AR) of Kākāpō and non-native avian species.

Figure 3.26 Nucleotide sequences that span the ligand binding domain of the progesterone receptor (PR) of New Zealand parrot species, Cockatiel, Chicken and Japanese Quail.

Figure 3.27 Amino acid sequences that span the ligand binding domain of the progesterone receptor

(PR) of New Zealand parrot species, Cockatiel, Chicken and Japanese Quail.

Figure 3.28 Nucleotide sequences that span the ligand binding domain of the progesterone receptor (PR) of New Zealand parrot species and human. 
Figure 3.29 Amino acid sequences that span the ligand binding domain of the progesterone receptor (PR) of New Zealand parrot species and human.

Figure 3.30 Nucleotide sequences that span the remaining amplified region of the ligand binding domain (LBD) of progesterone receptor (PR) of New Zealand parrot species, Cockatiel, Chicken and Japanese Quail.

Figure 3.31 Amino acid sequences that span the remaining amplified region of the ligand binding domain (LBD) of progesterone receptor (PR) of New Zealand parrot species, Cockatiel, Chicken and Japanese Quail.

Figure 3.32 Nucleotide sequences that span the remaining amplified region of the ligand binding domain of progesterone receptor (PR) of New Zealand parrot species and human.

Figure 3.33 Amino acid sequences that span the remaining amplified region of the ligand binding domain of progesterone receptor (PR) of New Zealand parrot species and human.

Figure 3.34 Three-dimensional structure of human progesterone receptor (hPR) and the ligand binding domain (LBD) region amplified in the avian species.

Figure 3.35 The amino acid differences between the ligand binding domain (LBD) of the progesterone receptor (PR) of Kākāpō and human.

Figure 3.36 The amino acid difference between the ligand binding domain (LBD) of progesterone receptor (PR) of Kākāpō and non-native avian species.

Figure 4.1 Comparison of low energy binding positions of $\mathrm{E}_{2}$ from in silico docking with the known $\mathrm{E}_{2}$ binding site in the experimental structure human ER- $\alpha$ (hER- $\left.\alpha\right)(1 \mathrm{~A} 52)$...

Figure 4.2 Potential interactions between $\mathrm{E}_{2}$ and the amino acids of human ER- $\alpha$ (hER- $\alpha$ ). 135

Figure 4.3 Potential interactions between $\mathrm{E}_{2}$ and the amino acids of human ER- $\alpha$ (hER- $\alpha$ ) and Kākāpō ER- $\alpha$ when docked with the co-ordinates from the crystal structure 1A52.

Figure 4.4 Comparison of the in silico prediction of the $E_{2}$ binding site in Kākāpō ER- $\alpha$ with the known $\mathrm{E}_{2}$ binding site in human ER- $\alpha$ (h ER- $\alpha$ ) (1A52) ............................................ 137

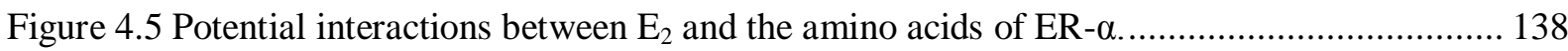
Figure 4.6 Comparison of the lowest binding energy position of BPA in Kākāpō ER- $\alpha$ from in silico docking with that for $E_{2}$ in Kākāpō ER- $\alpha$ and the experimental position of BPA in human ER- $\alpha$ (hER- $\alpha)$ (3UU7).

Figure 4.7 Potential interactions between Kākāpō ER- $\alpha$ and A) BPA, B) E $E_{2}$, C) Kākāpō ER- $\alpha$ and BPA and; D) human ER- $\alpha$ (hER- $\alpha$ ) (RSCB structure ID 3UU7) and BPA.

Figure 4.8 Comparison of the lowest binding energy position of TRI in Kākāpō ER- $\alpha$ from in silico docking with that for $\mathrm{E}_{2}$ in Kākāpō ER- $\alpha$.

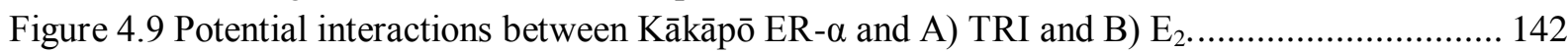

Figure 4.10 Comparison of the lowest binding energy position of CMEST in Kākāpō ER- $\alpha$ from in silico docking with that for $\mathrm{E}_{2}$ in Kākāpō ER- $\alpha$.

Figure 4.11 Potential interactions between Kākāpō ER- $\alpha$ and A) CMEST and B) E E $2 \ldots \ldots \ldots \ldots \ldots \ldots \ldots . . . . . . .144$

Figure 4.12 Comparison of the lowest binding energy position of DAI in Kākāpō ER- $\alpha$ from in silico docking with that for $\mathrm{E}_{2}$ in Kākāpō ER- $\alpha$.

Figure 4.13 Potential interactions between Kākāpō ER- $\alpha$ and A) DAI and B) $E_{2} \ldots \ldots \ldots \ldots \ldots \ldots \ldots \ldots \ldots . . . . . . . . . . .146$

Figure 4.14 Comparison of the lowest binding energy position of FER in Kākāpō ER- $\alpha$ from in silico docking with that for $E_{2}$ in Kākāpō ER- $\alpha$.

Figure 4.15 Potential interactions between Kākāpō ER- $\alpha$ and A) FER and B) $E_{2}$.

Figure 4.16 Comparison of the lowest binding energy position of FORM in Kākāpō ER- $\alpha$ from in silico docking with that for $\mathrm{E}_{2}$ in Kākāpō ER- $\alpha$.

Figure 4.17 Potential interactions between Kākāpō ER- $\alpha$ and A) FORM and B) $E_{2}$. 
Figure 4.18 Comparison of the lowest binding energy position of GEN in Kākāpō ER- $\alpha$ from in silico docking with that for $E_{2}$ in Kākāpō ER- $\alpha$ and the experimental position of GEN in human ER- $\alpha(\mathrm{hER}-\alpha)(2 \mathrm{QA} 8)$.

Figure 4.19 Potential interactions of GEN with ER- $\alpha$.

Figure 4.20 Comparison of the lowest binding energy position of PACID in Kākāpō ER- $\alpha$ from in silico docking with that for $\mathrm{E}_{2}$ in Kākāpō ER- $\alpha$.

Figure 4.21 Potential interactions between Kākāpō ER- $\alpha$ and A) PACID and B) $E_{2}$...................... 155

Figure 4.22 Comparison of the lowest binding energy position of PODO in Kākāpō ER- $\alpha$ from in

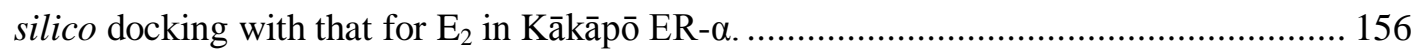

Figure 4.23 Potential interactions between Kākāpō ER- $\alpha$ and A) PODO and B) E E $\ldots \ldots \ldots \ldots \ldots \ldots \ldots \ldots \ldots . . . . . . . .157$

Figure 4.24 Comparison of the lowest binding energy position of TOT in Kākāpō ER- $\alpha$ from in silico docking with that for $E_{2}$ in Kākāpō ER- $\alpha$............................................................... 158

Figure 4.25 Potential interactions between Kākāpō ER- $\alpha$ and A) TOT and B) E 2 ............................ 159

Figure 4.26 Comparison of the lowest binding energy position of $\mathrm{P}_{4}$ in Kākāpō ER- $\alpha$ from in silico docking with that for $E_{2}$ in Kākāpō ER- $\alpha$................................................................... 160

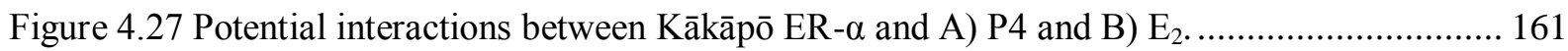

Figure 4.28 Comparison of the lowest binding energy position of TEST in Kākāpō ER- $\alpha$ from in silico docking with that for $\mathrm{E}_{2}$ in Kākāpō ER- $\alpha$........................................................ 162

Figure 4.29 Potential interactions between Kākāpō ER- $\alpha$ and A) TEST and B) E $E_{2} \ldots \ldots \ldots \ldots \ldots \ldots \ldots \ldots . . . . . . . . . . . . .163$

Figure 5.1 Standard curve for 17 $\beta$-oestradiol $\left(\mathrm{E}_{2}\right)$ at different wavelengths as measured by colorimetry

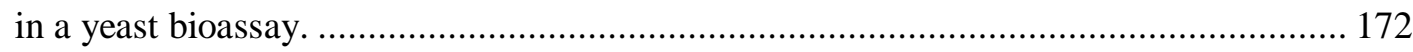

Figure 5.2 Representative standard curve for $17 \beta$-oestradiol $\left(\mathrm{E}_{2}\right)$ as measured by colorimetry in the yeast bioassay.

Figure 5.3 Representative standard curves for $17 \beta$-oestradiol $\left(\mathrm{E}_{2}\right)$ at different incubation time points as measured by colorimetry in the yeast bioassay.

Figure 5.4 Representative standard curves for soya bean as measured by colorimetry in the yeast bioassay.

Figure 5.5 Representative standard curves for broccoli and cauliflower extracts as measured by colorimetry in the yeast bioassay for suitability as negative controls.

Figure 5.6 Representative standard curve of serially diluted soya bean and cauliflower (negative control) extracted by a methanol and cellulase digestion method and absorbance measured by colorimetry in the yeast bioassay.

Figure 5.7 Representative standard curve of soya bean following an 18 and 36 hour extraction time as measured by colorimetry in the yeast bioassay.

Figure 5.8 Representative standard curve for bisphenol A (BPA) as measured by colorimetry in the yeast bioassay.

Figure 5.9 Relationship of the natural logarithm ( $(\mathrm{n})$ of quantity to the natural logarithm of activity of soya bean, BPA and $\mathrm{E}_{2}$.

Figure 5.10 Standard curves for hormones and known oestrogens as measured by colorimetry in the yeast bioassay.

Figure 6.1 Response of the yeast bioassay to extracts of $D$. cupressinum.................................... 188

Figure 6.2 Response of the yeast bioassay to fruit extracts of D. cupressinum from 2007-2008 ...... 189

Figure 6.3 Response of the yeast bioassay to extracts of B. nova-zelandiae .................................. 190

Figure 6.4 Response of the yeast bioassay to extracts of $C$. robusta................................................ 191

Figure 6.5 Response of the yeast bioassay to extracts of $D$. longifolium.......................................... 192

Figure 6.6 Response of the yeast bioassay to extracts of G. procera ............................................... 192

Figure 6.7 Response of the yeast bioassay to extracts of $L$. juniperina.......................................... 193

Figure 6.8 Response of the yeast bioassay to extracts of L.scoparium.............................................. 194 
Figure 6.9 Response of the yeast bioassay to extracts of $N$. solandri............................................ 195

Figure 6.10 Response of the yeast bioassay to extracts of $P$. cunninghamii.................................... 195

Figure 6.11 Response of the yeast bioassay to extracts of $P$. ferruginea........................................... 196 


\section{LIST OF TABLES}

Table 1.1 Examples of plants identified as being browsed by Kākāpō ..............................................

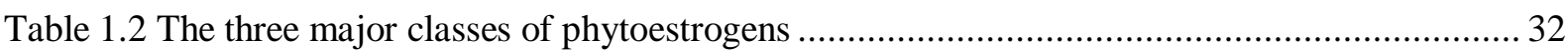

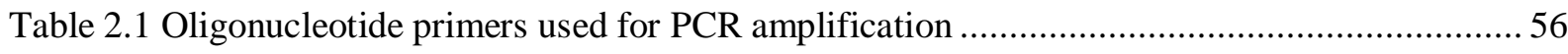

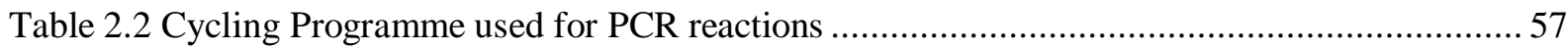

Table 2.3 Primer sequences used for sequencing PCR products in the pGEM $^{\circledR}-\mathrm{T}$ Easy vector ........... 60

Table 2.4 The Protein Data Bank (PDB) IDs for the human steroid receptors.................................. 61

Table 2.5 Native New Zealand plants collected for testing oestrogenic activity ................................. 64

Table 3.1 Accession numbers for the Chicken reference sequences used for amplification of the

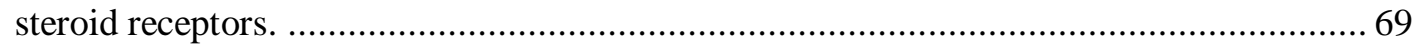

Table 3.2 The amino acids that differed in the ligand binding domain (LBD) of ER- $\alpha$ of the avian

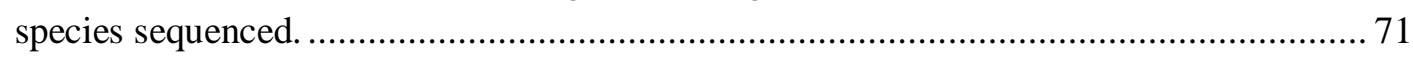

Table 3.3 The amino acids that differed in the $\mathrm{C}$-terminal end of the ligand binding domain (LBD) of

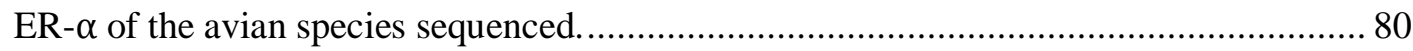

Table 3.4 The amino acids that differed in the C-terminal end of the ligand binding domain (LBD) of ER- $\alpha$ of the avian species and human sequences. ................................................... 83

Table 6.1 The equivalent oestradiol amount (fmol) for the native plant samples collected at one time

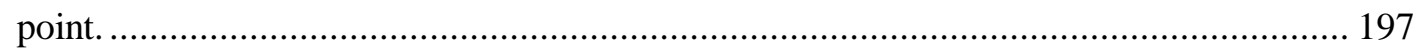




\section{LIST OF ABBREVIATIONS}

$\AA$

$\mathbf{A}_{4}$

AF

AhR

AR

AR grade

BLAST

BPA

CMEST

CPR

CPRG

DAI

DBD

DEPC

DHEA

DHP

DHT

DNA

dNTP

DOC

$\mathrm{E}_{1}$

$\mathrm{E}_{2} / \mathrm{E} 2 / \mathrm{EST}$

$\mathbf{E}_{3}$

EC

EDTA

ERMA

ER

ERE

ERR

EYPG

FER

FORM

g

g

gDNA

GEN

GR

h

hAR

$\mathrm{HCl}$
Angstroms

androstenedione

activation factor

aryl hydrocarbon receptor

androgen receptor

analytical reagent grade

Basic Local Alignment Search Tool

Bisphenol A

coumestrol

chlorophenol red

chlorophenol red- $\beta$-D-galactopyranoside

daidzein

DNA binding domain

diethylpyrocarbonate

dehydroepiandrosterone

$5 \alpha$-dihydroprogesterone

dihydrotestosterone

deoxyribonucleic acid

deoxynucleotide triphosphate

Department of Conservation

oestrone

$17 \beta$-oestradiol

oestriol

effective concentration

ethylenediaminetetraacetic acid

Environmental Risk Management Authority

oestrogen receptor

oestrogen response element

oestrogen-related receptor

egg yolk protein gene

ferruginol

formononetin

grams

$\mathrm{x}$ gravity

genomic deoxyribonucleic acid

genistein

glucocorticoid receptor

hour

human androgen receptor

Hydrochloric acid 


\begin{tabular}{|c|c|}
\hline hER & human oestrogen receptor \\
\hline hPR & human progesterone receptor \\
\hline Hsp & heat shock protein \\
\hline $\mathbf{L B}$ & luria broth \\
\hline LBD & ligand binding domain \\
\hline LC grade & liquid chromatography grade \\
\hline$-\mathbf{M}$ & methanol \\
\hline -MC & methnol and cellulase \\
\hline mg & milligram \\
\hline $\min$ & minute \\
\hline MR & mineralocorticoid receptor \\
\hline mRNA & messenger RNA \\
\hline NR & nuclear receptor \\
\hline $\mathbf{P}_{4} / \mathbf{P 4}$ & progesterone \\
\hline $\mathbf{P}_{5}$ & pregnenolone \\
\hline PACID & podocarpic acid \\
\hline PDB & Protein Data Bank \\
\hline PCR & polymerase chain reaction \\
\hline PES & polyethersulfone \\
\hline PODO & podocarpinol \\
\hline PR & progesterone receptor \\
\hline PXR & pregnane $\mathrm{X}$ receptor \\
\hline RNA & ribonucleic acid \\
\hline rpm & revolutions per minute \\
\hline rt & room temperature \\
\hline RXR & retinoid $X$ receptor \\
\hline sec & second \\
\hline SEM & standard error of the mean \\
\hline SERMs & selective oestrogen receptor modulators \\
\hline T $_{4} /$ TEST & testosterone \\
\hline TAE & tris-acetate-EDTA \\
\hline TE & tris-EDTA \\
\hline TOT & totarol \\
\hline TR & thyroid hormone receptor \\
\hline TRI & triclosan \\
\hline UP & UltraPure \\
\hline $\mathbf{v} / \mathbf{v}$ & volume per volume \\
\hline VDR & vitamin $\mathrm{D}$ receptor \\
\hline $\mathbf{w} / \mathbf{v}$ & weight per volume \\
\hline
\end{tabular}




\section{CHAPTER 1: GENERAL INTRODUCTION}

Many species are experiencing a decline in population and are under threat of extinction. This is a direct result of changes to their environment and habitat by natural events or human influences. Numerous conservation authorities are attempting to reverse these declining numbers through habitat preservation and management of captive populations. This thesis focuses on the native New Zealand parrot Kākāpō, Strigops habroptilus; a species once widespread throughout New Zealand, but now considered to be at high risk of extinction. The reproductive pattern for these birds is very different to that found in other parrot species in that their breeding cycle does not follow a regular or predictable seasonal pattern.

The aim of this dissertation is to examine some of the possible factors influencing Kākāpō reproduction and how these could be altered to increase their success rate. In particular, this thesis focuses on what factors exist in their environment that may provide these birds with the cue(s) that indicate an ideal time to breed. In order to identify factors unique to the Kākāpō, comparisons were made with other New Zealand parrots (Kākā, Kākāriki and Kea), an Australian parrot (Cockatiel) and two non-related but well-characterised bird species (Chicken and Japanese Quail).

In other avian species, a number of different environmental signals have been linked to the timing of breeding. These include photoperiodism, environmental temperatures and rainfall, food resources and the presence of mating partners (Hudelson 1996; Dawson, King et al. 2001). These factors have slightly different weightings for temperate and tropical birds (Hau, Perfito et al. 2008).

Photoperiodism concerns the physiological changes an organism undergoes in response to changes in the length of daylight (Tauber 2001) and plays a significant role in biological processes in both plant and animal species. Photoperiodism is important in regulating moulting, migration and gonadal growth and regression in avian species (Rowan 1925; Rowan 1926; Dawson 2008).

The influence of environmental temperatures is most pronounced in the breeding of temperate zone birds. Birds that live in an arid climate also rely heavily on rainfall; these birds may delay breeding until rain occurs (Zann, Morton et al. 1995; Lloyd 1999). There has 
also been evidence that favourable environmental conditions can override the influence of photoperiodism (Leitner, Van't Hof et al. 2003).

For many species, the availability of food resources can have a major impact on reproduction.

Not only does it determine the overall wellness of an individual, but it also provides an indication of food abundance for new offspring. Finally, the presence of ideal mating partners is a key factor in successful breeding.

\subsection{Kākāpōo}

Kākāpō, Strigops habroptilus (Gray 1845), meaning "parrot of the night", is a large, flightless, nocturnal parrot endemic to New Zealand (Figure 1.1). They are the only species in the Strigops genus (Powlesland, Merton et al. 2006), but are believed to be most closely related to the Nestor parrots (de Kloet and de Kloet 2005; Wright, Schirtzinger et al. 2008). Kākāpō are the heaviest parrots in the world (Bryant 2006; Eason, Elliot et al. 2006) and have an average life expectancy of 90 years with young approaching breeding age around 6-8 years old (Department of Conservation 2012a). With only 126 of these birds known to exist, they are currently classified as critically endangered (BirdLife International 2012d).

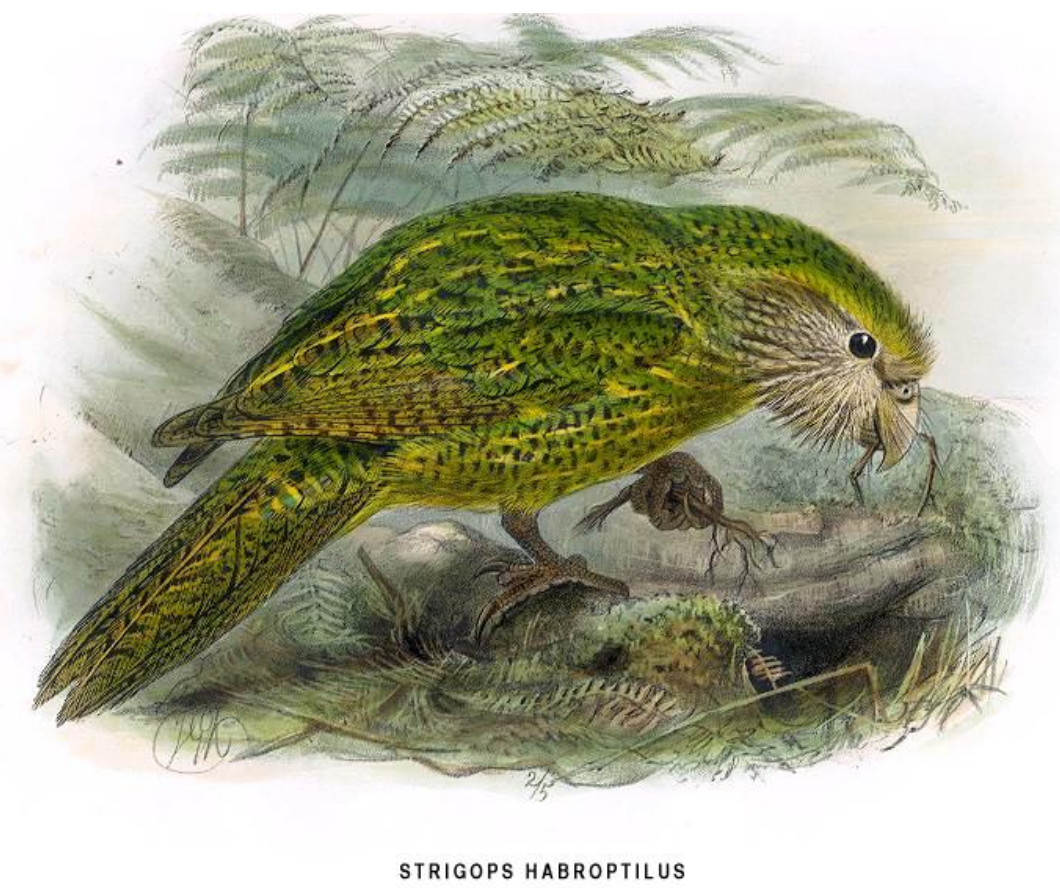

Figure 1.1 An illustration of Kākāpō (Strigops habroptilus) (Buller 1873). 
Prior to Māori colonisation, Kākāpō were prevalent throughout mainland New Zealand, inhabiting almost all regions of both the North and South Islands with fossil records suggesting they were the third most commonly found bird (Worthy and Holdaway 2002). This was despite their inability to fly; a trait believed to be evolutionarily-based in that the lack of mammals in New Zealand meant the parrots had no impetus to fly and so over time lost this ability. But from early days, they were hunted by people for both their flesh and their feathers (Powlesland, Merton et al. 2006). This, together with the introduction of mammalian pests such as rats and stoats in the 1870 s and 1880s, and other predators like feral cats, possums, dogs, weasels and ferrets, have also played a role in their decline (Anderson 1981). The population decline has been exacerbated by the fact that Kākāpō are unable to fly, thus have ground-dwelling habits. Consequently, their habitat is now only on predator-free off-shore islands, primarily Anchor Island in Fiordland and Codfish Island (Whenua Hou) located near Stewart Island.

\subsubsection{Breeding Behaviour}

Although the behaviour of Kākāpō had been monitored for a long time, it was not until 1975 that their breeding was postulated to be a "lek" breeding system (Merton, Morris et al. 1984) and to date, they are the only known parrot species to exhibit this behaviour. Moreover this breeding behaviour has not been observed in other New Zealand avian species. 'Lek' breeding systems are small, organised mating territories within the greater habitat that are protected by the breeding males in the population (Merton, Morris et al. 1984). In the case of Kākāpō, this can be visualised as a system of bowls, much like a railway network and tends to be separated from a male's usual home range. Although these were initially thought to be dust bowls, they have since been found to be the area a male will occupy every night during the breeding season. A "track-and-bowl system" comprises a number of bowl-shaped holes (3-60 cm diameter and 5-20 cm deep) dug in the ground by a male Kākāpō linked by narrow tracks (30-60 cm width) that provide a means for the bird to travel between bowls (Merton, Morris et al. 1984). The complex network can cover a land area as large as 10-20 m in diameter and have neighbouring systems made by another male individual as close as $15 \mathrm{~m}$ away. Habitation of these territories is commonly between October and April of each year with the courtship display occurring between January and March (Eason, Elliot et al. 2006). 
Although males can have aggressive tendencies towards other males in the pre-booming season, this behaviour decreases during the booming period.

Female Kākāpō travel from their large home range to the 'lek' arena and choose a male to mate with. This is primarily based on the booming calls and plumage displays of the males. The females may be able to sense which males are more fertile either through hormonal signals or through these booming noises. The booming can be heard from as far away as $10 \mathrm{~km}$ and so it has been suggested that the call also helps females to locate where the males are (Henry 1903). Following mating, female Kākāpō leave the area and the male is free to mate with another female. In this "lek" breeding system, there is huge variation in the mating outcomes for the males; in one season only a small percentage of them may mate, with some doing so on multiple occasions with different females (polygamy) (Merton, Morris et al. 1984).

Kākāpō do not breed every year but when they do, the mating tends to occur in the first few months of the year (Eason, Elliot et al. 2006) and is followed by egg-laying at nesting sites in mossy areas that are removed from the "track-and-bowl systems" location (Henry 1903; Merton, Morris et al. 1984). Hatching of eggs generally takes place between late February and early April.

\subsubsection{Kākāpō Recovery Programme}

Documented observations of Kākāpō and their behaviour were made as early as the 1900s by the caretaker on Resolution Island, Richard Henry, with the first known recovery attempt of Kākāpō performed by him in the late 1800s and early 1900s (Henry 1903). By 1995, the Kākāpō population was recorded at only 50 known birds. Since then, the population has gradually increased with a current population size of 126 known birds in New Zealand (Department of Conservation 2012b). A population so small means that inbreeding is inevitable. This is a confounding risk factor and elevates the difficulty of increasing numbers. All known remaining birds have been transferred from their original habitats on the mainland to two predator-free off-shore islands - Anchor Island and Codfish Island - from their original habitats of Fiordland and the southeast of Stewart Island. The driving force behind this relocation and population recovery is the "Kākāpō Recovery Programme", a programme established in 1996. 
The recovery programme has nine members of staff who are involved with the daily management of Kākāpō in the wild (monitoring of the birds, feeding and raising of chicks) as well as with research investigating artificial insemination, genetic phylogeny of the birds and supplementary feeding trials. The group has also developed kits to aid in nest-minding and transmitters for tracking the movements of each bird. Currently, the Kākāpō conservation programme is New Zealand's largest single species conservation effort with around NZ $\$ 1$ million being spent per annum on both manpower and resources to ensure survival of the species (Jansen 2006). The present programme includes protection of eggs, assistance in the rearing of chicks if required, and sustained predator controls, together with supplementary feeding and general monitoring. The programme has significant milestones in place (Elliott 2006) and these include generating 53 breeding females of diverse genetic background in one intensively managed population, 150 breeding females distributed in two populations only one of which would be managed, and more than 150 breeding females in multiple unmanaged populations. Crucial to the success of this plan is enhanced breeding through greater understanding of Kākāpō reproduction.

\subsubsection{Reproductive Strategy Hypothesis}

The initial attempts to increase breeding success rates were described by Powlesland (1989); these included numerous and diverse attempts to save the species such as relocation (e.g. to Mt Bruce, Wairarapa), dietary changes, controlling predator numbers and eradication of pests (Powlesland 1989). Supplementary food was also implemented on a number of occasions, the first instance in 1989 after low egg production earlier in the 1980s (Powlesland and Lloyd 1994; Elliott, Merton et al. 2001). The details of each trial will not be discussed but this has been extensively documented (for example, Vol 53 of Notornis (Williams 2006)). Although there appeared to have been improved growth of new chicks and more frequent displays by males, there has been no unequivocal proof that females have responded in a positive way (Eason, Elliot et al. 2006). It has been postulated that the provision of food can lead to a skewed sex ratio (Tella 2001; Clout, Elliot et al. 2002). This skewed sex ratio had previously been observed from fossil records suggesting food abundance may be a factor (Trewick 1997). Additionally, access to an abundant food supply has led to female obesity which is known to negatively affect fertility in other species (Elliott, Merton et al. 2001; Bryant 2006). Hence, it is unlikely that plants in isolation are the reproductive trigger. 
It is believed that Kākāpō are like many other birds in that they are photoperiodic with their reproductive organs growing and regressing in synchrony with day-length (i.e. light-dark) cycles (Cockrem 1995). Males come into condition prior to the female birds in preparation for the females committing to breeding in response to environmental cues (Cockrem 2006). A hypothesis was proposed recently by Fidler et al. (2008) to link the timing of the breeding behaviour of Kākāpō to the presence of chemical triggers in seeds or fruits of certain native plants during masting years (Fidler, Lawrence et al. 2008). It brought together conclusions from previous research into Kākāpō behaviour and surroundings as well as knowledge gained from field work. The strategy hypothesised to be implemented by Kākāpō involved photoperiodism, 'hepatic gene memory' and phytochemicals present in their diet, as well as the influence of masting of native plants. It is this hypothesis that this dissertation is based upon.

In brief, it was hypothesised that when Kākāpō are exposed to low levels of an as yet unknown dietary phytochemical(s) from masting plants, egg yolk protein genes (EYPG) in the liver become sensitised to oestrogens, particularly those originating from developing ovarian follicles. Thus, as the ovarian follicles grow in size and produce oestrogens, expression of EYPG is induced faster and at greater levels, ultimately leading to successful reproduction.

\subsubsection{Masting}

Successful breeding of Kākāpō is believed to be linked to the years where the food supply is in abundance (Powlesland, Lloyd et al. 1992). That is, Kākāpō breed predominately in "mast" years with a large proportion of females laying eggs during a time of excess food availability (Cockrem 2006). They do not appear to reproduce in "non-masting" years. Masting refers to years when there is a significant abundance of fruit. Therefore, as mentioned earlier, it is hypothesised that there is an early trigger mechanism that is identified by Kākāpō to signal that ample food will be available for the rearing of new offspring (Fidler, Lawrence et al. 2008).

The trigger for breeding in Kākāpō is debated. It potentially could be a result of increased weight of the females, nutrition levels after a breeding cycle, habitat quality or a hormonal stimulus (Harper, Elliott et al. 2006; Fidler, Lawrence et al. 2008; Whitehead, Case et al. 2012). Their breeding has been linked to the masting of Dacrydium cupressinum (Rimu) and 
Halocarpus biformis (pink pine) (Powlesland, Lloyd et al. 1992; Elliott, Merton et al. 2001) with studies demonstrating that years in which there was fruit present on more than $10 \%$ of Rimu tips corresponded to a successful breeding year in Kākāpō. (Harper, Elliott et al. 2006). However adding ripened fruit from Rimu and Dacrycarpus dacrydioides (Kahikatea) to the diet of Kakapo, has not appeared to result in successful breeding. Beech (Nothofagus spp.) is another plant species speculated to influence the breeding of Kākāpō. However, one undesirable consequence of masting such as in beech forests is that the populations of predators such as stoats also increase (King 1983).

\subsubsection{Habitat Of Kākāpō}

A major element of the proposed reproductive mechanism involves the native flora present in the habitat of Kākāpō in particular those that exhibit masting tendencies. Prior to human settlement, they had a preference for podocarp and Nothofagus forests (both masting forests) that received significant rainfall (Worthy and Holdaway 2002). Those birds found in the most recent successful search were in the subalpine areas of Fiordland (Atkinson and Merton 2006; Butler 2006). However this area may not be a true representation of their preferred habitat and merely a result of adaptation due to predation and habitat loss. Their current habitat on Codfish Island comprises of a forest of Rimu, Miro and Rata, as well as Pakahi scrubland (Poppelwell 1912; Whitehead 2007). Despite this, Kākāpō have been known to inhabit a wide array of different vegetation types from temperate rainforests to tussock grassland habitats and montane beech forests (Johnson 1976; Worthy and Holdaway 2002; Powlesland, Merton et al. 2006) thus masting of native plants cannot be the sole influence on their reproduction.

\subsubsection{Diet Of Kākāpō}

Kākāpō are herbivorous parrots (Trewick 1996; Higgins 1999). As they have been known to exist as subalpine birds, much of the foliage they consume is that which straddles both the subalpine and alpine regions. Their beaks have grooves in the upper mandible which aids in mastication (Henry 1903). Their diet is comprised of the fruit, stems, leaves, seeds and roots of a variety of plants found throughout New Zealand (Heather and Robertson 2005; Eason and Moorhouse 2006). 
Previous research has uncovered a link between the masting of Rimu and successful reproduction of Kākāpō. Despite this, a number of studies investigating the composition of the Kākāpō's diet through such things as identifying foliage with evidence of browsing on Stewart Island and in the Esperance Valley, Fiordland (Johnson 1976; Best 1984; Atkinson and Merton 2006), and by examining faecal samples for plant content (Wilson, Grant et al. 2006; Horrocks, Salter et al. 2008) have found that feeding is not limited to Rimu (Table 1.1). From these data sets, it appears that they are opportunistic feeders. That is, they can eat a wide variety of plants and base their food intake on the availability at the time and that their diet differs between breeding and non-breeding years (Wilson 2004; Wilson, Grant et al. 2006). This may be pertinent to their abnormal breeding pattern. 
Table 1.1 Examples of plants identified as being browsed by Kākāpō (Best 1984; Wilson 2004; Atkinson and Merton 2006; Wilson, Grant et al. 2006; Horrocks, Salter et al. 2008)

\begin{tabular}{|c|c|}
\hline Plant Species & Common Name \\
\hline Anisotome haastii (foliage, petioles) & Haast's carrot \\
\hline Astelia spp. (fruit, foliage) & - \\
\hline Blechnum spp. (fronds, rhizome) & Fern \\
\hline Brachyglottis spp. (foliage, petioles) & - \\
\hline Carex coriacea (foliage) & Rautahi, cutty grass \\
\hline Carmichaelia arboea (foliage, stems) & South Island Broom \\
\hline Chionochloa spp. (foliage) & Tussock grasses \\
\hline Coprosma spp. (twigs, foliage) & - \\
\hline Dacrydium cupressinum (fruit, foliage) & Rimu \\
\hline Dracophyllum spp. (foliage) & - \\
\hline Gahnia spp. (foliage) & Sedges \\
\hline Halocarpus biformis (fruit, foliage) & Pink pine, Yellow pine \\
\hline Juncus spp. (foliage) & Rushes \\
\hline Leptecophylla juniperina (fruit, seed) & Mingimingi \\
\hline Leptospermum scoparium (bark, foliage) & Manuka \\
\hline Metrosideros umbellata (flowers, nectar, foliage) & Southern Rata \\
\hline Nothofagus spp. (foliage) & Beech \\
\hline Olearia colensoi (foliage) & Leatherwood \\
\hline Phormium spp. (foliage) & Flax \\
\hline Podocarpus spp. (bark, foliage, fruit) & Totara \\
\hline Prumnopitys ferruginea (fruit) & Miro \\
\hline Schoenus pauciflorus (foliage) & Sedge tussock \\
\hline Thelymitra venosa (foliage) & Sun orchid \\
\hline Uncinia sp. (foliage) & Hook grass \\
\hline
\end{tabular}




\subsection{Breeding Habits of Other Birds}

Apart from Kākāpō, other avian species investigated in this study were the New Zealand native parrots Kākā (Nestor meridionalis), Kākāriki (Cyanoramphus spp) and Kea (Nestor notabilis); along with the Australian parrot Cockatiel (Nymphicus hollandicus). Both Red Junglefowl (Chicken) (Gallus gallus) and Japanese Quail (Coturnix japonica) were also included as controls for these experiments. From this point onwards, Red Junglefowl will be referred to as Chicken.

Phylogenetic relationships between different species of Psittaciformes have been undertaken. Kākā, Kākāpō, and Kea all belong to the Strigopoidea superfamily and Kākā and Kea to the Nestoridea family. Kākāriki is a member of the Psittaciformes order but is classified under the Psittacidea family whilst the Australian species Cockatiel belongs to the Cacatuoidea superfamily and Cacatuidae family. Kākā, Kākāpō and Kea have been found to comprise a sister group separate to other parrots. Their divergence from the other parrots has been suggested to have occurred either around 82 million years ago (when Australia and New Zealand separated) or 50 million years ago (based on fossil records) (de Kloet and de Kloet 2005; Wright, Schirtzinger et al. 2008; Worthy, Tennyson et al. 2011). In contrast, both the Chicken and the Japanese Quail belong to the same order and family (Galliformes and Phasianidae) and are thought to have diverged approximately 35 million years ago (van Tuinen and Dyke 2004).

The birds selected in this study all have varied breeding strategies. The breeding habits of Kākāpō are unique and they do not appear to be under the influence of any one environmental signal. Other avian species have both similarities and differences to the breeding cycle of Kākāpō.

\subsubsection{Kākā}

Kākā (Nestor meridionalis) is an endemic parrot of New Zealand (Figure 1.2). Like the Kākāpō, Kākā dwell in areas such as beech forests, although they are less likely to be found in sub-alpine regions, and are florivores (Moorhouse 1997). Their population size is unknown but estimated to be less than 10,000 and although Kākā were originally widespread throughout New Zealand, they are now mainly found in the South Island (Powlesland, Greene et al. 2009). Hence, since 1995, Kākā have been classified as endangered (BirdLife 
International 2012b). The small population size of Kākā reflects the influence that introduced predators have had on their survival and also on their habitat in terms of both decreased quality and loss (Beggs and Wilson 1991). Like many other species in the world, a decline in numbers is also likely to be due to a combination of competition and predation. Kākā predation is primarily by stoats and possums (Greene, Powlesland et al. 2004).

Kākā are episodic breeders (Greene, Powlesland et al. 2004), with the breeding season commencing in November and nesting occurring in the summer (December-February) (Wilson, Karl et al. 1998). This correlates with the time that native plants undergo masting (Greene, Powlesland et al. 2004). Kākā are also able to breed more than once in a breeding season - they might do this, for example, if mast fruiting or seeding occurs more than once (Wilson, Karl et al. 1998). However they do not breed every year and have a low reproductive rate (Beggs and Wilson 1991). There are indications that, like Kākāpō, Kākā are more likely to breed during mast years (Higgins 1999). The females lay multiple eggs in tree hollows slightly above ground level and these are incubated for 24 days on average (Heather and Robertson 2005; Powlesland, Greene et al. 2009). More than a quarter of Kākā's feeding time is spent drinking honeydew (Beggs and Wilson 1991). Beech (Nothofagus spp.), Kahikatea (Dacrycarpus dacrydioides), Rimu (Dacrydium cupressinum), Matai (Prumnopitys taxifolia) and Miro (Prumnopitys ferruginea) are all mast fruiting trees that have been found to be consumed by Kākā as has the honey from Rātā (Metrosideros sp.) trees (Henry 1903; O'Donnell and Dilks 1994; Wilson, Karl et al. 1998; Greene, Powlesland et al. 2004). From studies looking at masting, fruiting of Kahikatea appeared to correspond to successful breeding seasons (Greene, Powlesland et al. 2004). 


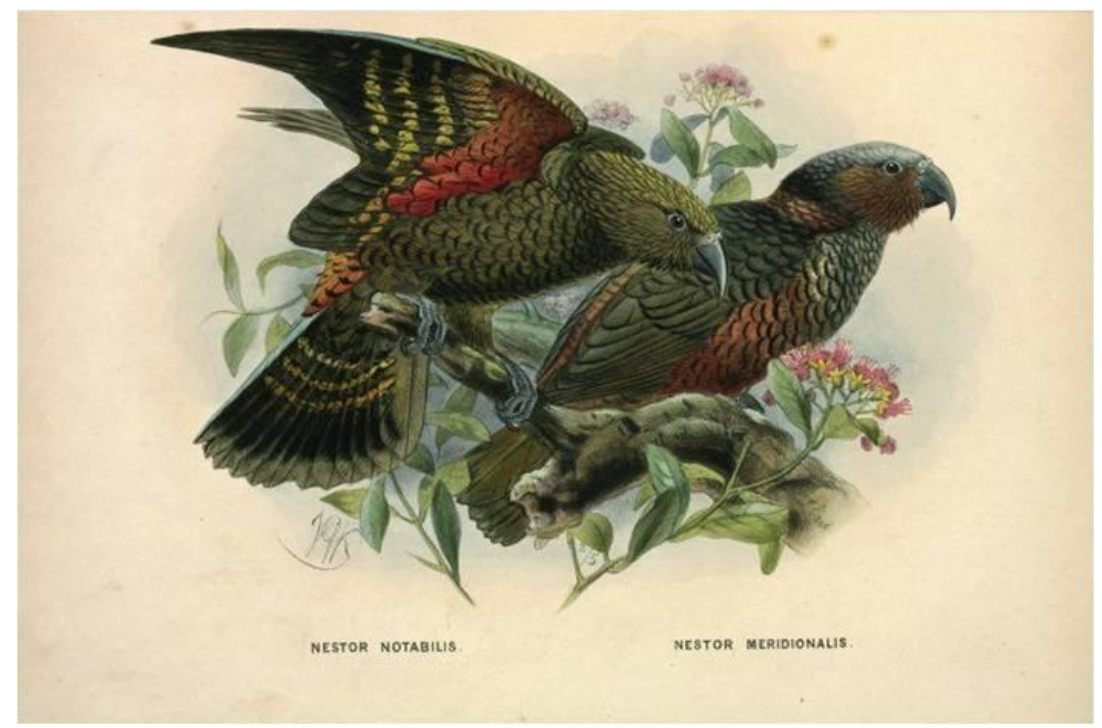

Figure 1.2 An illustration of Kākā (Nestor meridionalis) and Kea (Nestor notabilis) (Buller 1873).

\subsubsection{Kākāriki}

There are a number of parakeets endemic to New Zealand that share the common name Kākāriki. These all fall under the genus Cyanoramphus and include the Chatham Island Red-crowned parakeet (C. novaezelandiae chathamensis), the New Zealand Red-crowned parakeet $(C . \quad n$. novaezelandia), the Orange-fronted parakeet $(C$. malherbi) and the Yellow-crowned parakeet (C. auriceps) (Boon, Kearvell et al. 2001). These species have unique distribution profiles with the Chatham Island Red-crowned parakeet found in the Chatham Islands, the New Zealand Red-crowned parakeet present on Stewart Island and other offshore islands but virtually absent from the mainland, the Orange-fronted parakeet limited to North Canterbury, and the Yellow-crowned parakeet more widespread across all islands, particularly in forests (Boon, Kearvell et al. 2001). 


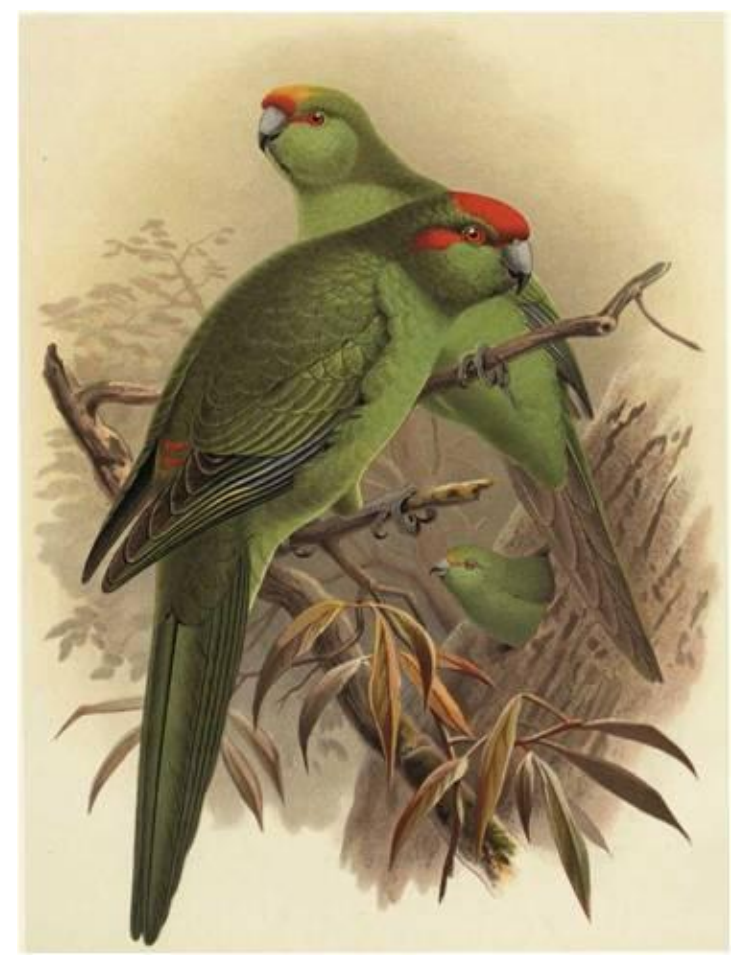

Figure 1.3 An illustration of Red-crowned, Orange-fronted and Yellow-crowned Kākāriki (Cyanoramphus novaezelandiae, malherbi and auriceps) (Buller and G. 1888).

Breeding by Red-crowned parakeets has been observed at all times of the year but this seems to be site-dependent (Higgins 1999) with nesting taking place in late summer in tree hollows (Elliot, Dilks et al. 1996). Although there appears to be only one successful breeding attempt per year from this species, a failed attempt can lead to another try a few weeks later.

However, observations of Yellow-crowned parakeets have suggested something different. Like Kākāpō, these Kākāriki seem to increase their breeding during "mast" years. That is, in years of heavy seeding of Beech trees, Yellow-crowned parakeets can breed continuously while plentiful seed is available (Elliott, Dilks et al. 1996). It was also found that they feed predominantly on beech seed during a masting season. This can result in the raising of more than one brood in a season (Higgins 1999).

\subsubsection{Kea}

Kea (Nestor notabilis) are large mountain parrots and are endemic to New Zealand (Figure 1.2). There are only two extant members of the Nestor genus - the other being Kākā. There are two other species now extinct; the Norfolk Island Kākā (Nestor productus) and Chatham 
Kākā (Nestor sp.). The population of these parrots was once large but is now limited to a level that they have the rating of vulnerable (BirdLife International 2012c). Introduced mammals are thought to have played a role in the demise of the Kea either in the form of competing for resources or as a predator (Elliott and Kemp 1999).

Southern Beech forests and alpine grasslands make up the majority of Kea's habitat. They use cavities in the ground on the forest-floor as their nests (Jackson 1963) with large entrances big enough for some mammalian predators to enter. Egg-laying appears to occur somewhere between late-July and mid-September with fledging of the chicks occurring around January (Elliott and Kemp 1999). They tend to breed every year and if they do, they do not usually re-nest. Some females use the same breeding site for their entire life. A recent study undertaken (Elliott and Kemp 1999) showed that tagged males bred in five out of the six years monitored (1993-1998) thus leading to an estimated breeding frequency of 0.76 .

The four New Zealand parrots/parakeets share the common breeding strategy of utilising cavities for nesting. Both Kākāpō and Kea have these situated on the ground whereas Kākā and Kākāriki make use of holes in trees for nesting. It has been postulated that the timing of breeding for cavity nesting birds influences the likelihood of predation by stoats (Elliott and Kemp 1999).

\subsubsection{Cockatiel}

The cockatiel (Nymphicus hollandicus) is a member of the cockatoo family (Cacatuidae) and a native parrot of Australia. Their habitat is mainly dry, arid regions throughout mainland Australia preferably located near a freshwater source (Dawson 1965; Del Hoyo, Elliott et al. 1997).

Cockatiels are granivorous birds, feeding mainly on grains and small seeds. These dietary components include introduced crops such as wheat, sunflower and sorghum, although sorghum is the most preferred (Jones 1987). They also have the ability to eat small, soft fruit.

Cockatiels are monogamous and generally remain with their mate for at least a year. They have an annual breeding frequency. Nesting takes place in the hollows of trees, such as eucalypts, slightly raised off the ground and like their general habitat, in close proximity to a 
water source (Pizzey 1980; Del Hoyo, Elliott et al. 1997). The breeding of Cockatiel is linked to environmental cues, in particular rainfall. However, another limiting factor is the number of eggs the female already has in the nest. That is, when a breeding pair already have a number of eggs, they will produce fewer eggs as there is a limit to the number a female will keep in the nest at any one time (Millam, Zhang et al. 1996).

\subsubsection{Chicken}

Red Junglefowl (Gallus gallus) or Chicken, are a member of the pheasant family (Phasianidae). There is a domesticated subspecies of Chicken (Gallus gallus domesticus). They were one of the first species to have their full genome sequenced (Hillier, Miller et al. 2004). Although native to a number of Southeast Asian countries, Chicken have also been introduced into many other countries and are widely distributed for food production (BirdLife International 2012a).

The breeding cycle of Chickens is different to those for the birds outlined above as they have the ability to reproduce continuously hence have a relatively high reproductive rate. This is due to their ovulatory cycle length being approximately 24-26 hours.

\subsubsection{Japanese Quail}

Japanese Quail (Coturnix japonica) belong to the same family (Phasianidae) as Chicken. They are indigenous to the East Asia region although they have since been domesticated. They are migratory birds and although originally domesticated for their song, they have since been used for both their meat and eggs (Vali 2008) thus are found on a number of different continents. The habitat of the Japanese Quail in the wild is mainly that of grasslands.

Maturity of the Japanese Quail occurs at 5-6 weeks of age. Although in the wild they reproduce during spring and summer (Mills, Crawford et al. 1997), they are capable of breeding almost continuously. Wild birds will incubate their eggs for a period of around 21 days in secluded nests on the ground although they are known to frequently fail to incubate their eggs (Nichols 1991). Photoperiodic effects on the reproductive behaviour of both male and female birds has been identified (Sachs 1969; Robinson and Follett 1982). 


\subsection{Reproductive Hormones}

\subsubsection{Introduction to Hormones}

Hormones are signalling molecules produced by endocrine cells, and are found throughout living organisms. The main role of hormones is to transfer messages from one cell to another and, in animals these are primarily transported to their site of action via the bloodstream. Hormones are responsible for many bodily processes such as the maintenance of cellular and organelle homeostasis, growth and differentiation, cognitive capability, reproductive function and modulating metabolic activity (Guyton and Hall 2006).

Hormones of reproductive interest can be classified into two groups; proteins and steroids. Members of the protein group are sometimes produced and excreted in a pre and/or pro form before being transformed into their active form when necessary. In contrast, steroid-based reproductive hormones such as $17 \beta$-oestradiol $\left(\mathrm{E}_{2}\right)$, progesterone $\left(\mathrm{P}_{4}\right)$ and testosterone are generally synthesised in their active form (Henry and Norman 2003), but in circulation are often bound to proteins that inhibit receptor binding and activation.

In general, there are two main methods of action for hormones. These are either through binding to specific receptors present on the plasma membrane of the cell or by diffusing into the cell and interacting with receptors within the cell. These interactions occur with high binding affinity to elicit a response (Beato, Chávez et al. 1996). Steroid hormones have the ability to utilise either of these signalling mechanisms, whilst protein hormones only bind to receptors outside of the cell.

A number of exogenous compounds, both naturally occurring and man-made, have been identified that mimic endogenous hormones by interacting with the hormone receptors and eliciting responses in a similar manner. The activity of these exogenous compounds can disrupt the normal hormonal cascade either agonistically or antagonistically.

The steroid hormones can be further divided into five main classes: androgens, glucocorticoids, mineralocorticoids, oestrogens and progestogens. The core backbone of steroid hormones is a 17 carbon molecule arranged as three cyclohexane rings and one cyclopentane ring (cyclopentanophenanthrene) (Figure 1.4). In general, these hormones bind and interact with nuclear receptors to initiate a response. As a number of receptors are 
localised in the cytoplasm, the hormones must cross cellular membranes prior to binding (McEwan 2009). The lipophilic nature of steroids makes this membrane transfer possible.

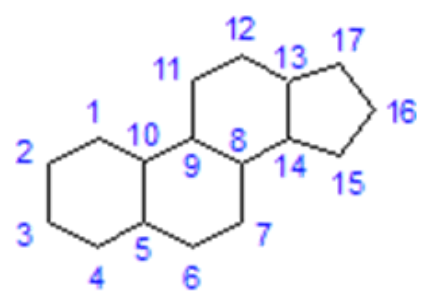

Figure 1.4 The core backbone of steroid hormones is cyclopentanophenanthrene. The numbering of the carbon atoms is shown.

The biosynthesis of all steroid hormones originates from cholesterol (Figure 1.5), which is produced in the adrenal glands, gonads and placenta, and follows a stepwise fashion utilising a plethora of different enzymes belonging to two major classes of proteins: the cytochrome P450s haem-containing proteins and the hydroxysteroid dehydrogenases (Payne and Hales 2004). The cytochrome P450 enzymes are P450scc (cholesterol side-chain cleavage), P450c11 (11ß-hydroxylase), P450c17 (17 $\alpha$-hydroxylase), P450c18 (aldosterone synthase), P450c21 (21-hydroxylase) and P450arom (aromatase). The hydroxysteroid dehydrogenases

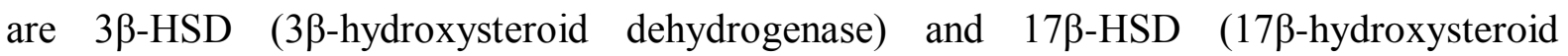
dehydrogenase). Thus the ability of cells to synthesise specific steroids relies on both the availability of substrate and the expression of the appropriate steroidogenic enzymes. 


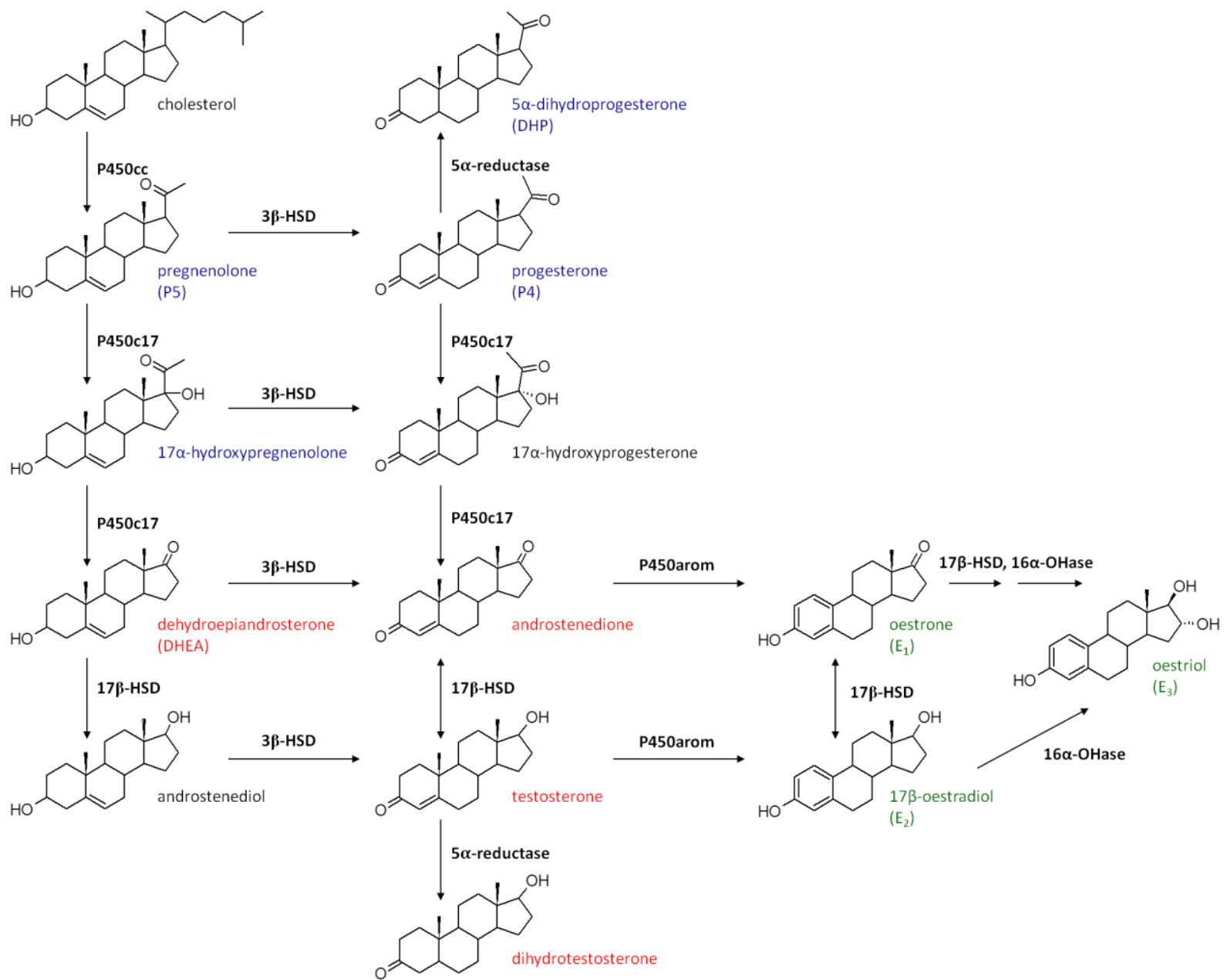

Figure 1.5 The biosynthesis of steroid hormones beginning with cholesterol. The progestogens are labelled in blue, androgens in red and oestrogens in green. The enzymes involved in each step are labelled in black. These are the cytochrome P450 enzymes P450scc (cholesterol side-chain cleavage), P450c11 (11ß-hydroxylase), P450c17 (17 $\alpha$-hydroxylase), P450c18 (aldosterone synthase), P450c21 (21-hydroxylase) and P450arom (aromatase), and the hydroxysteroid dehydrogenases

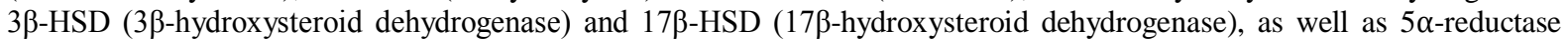
and $16 \alpha$-hydroxylase.

\subsubsection{Progestogens}

Progestogens are a class of steroid hormones consisting of $5 \alpha$-dihydroprogesterone (DHP), $17 \alpha$-hydroxypregnenolone, pregnenolone $\left(\mathrm{P}_{5}\right)$ and progesterone $\left(\mathrm{P}_{4}\right)$ (Figure 1.6). The major naturally-occurring progestogen in most species is $\mathrm{P}_{4}$ (also known as pregn-4-ene-3, 20-dione). However, this is not always the case as, in species such as elephants for example, DHP is the most abundant form (Wierer, Schrey et al. 2012). The precursor of both DHP and $\mathrm{P}_{4}$ is $\mathrm{P}_{5}$, formed by cleavage of the side-chain of cholesterol (Figure 1.5 blue).

Progestogens are produced primarily in the adrenal glands, ovary and placenta. They play an active role in embryogenesis and in the development and maintenance of female reproductive 
organs such as the uterus, ovary, mammary glands and brain (Evans 1988) as well as influencing non-reproductive tissues such as those in the cardiovascular, bone and nervous systems (Scarpin, Graham et al. 2009). Progestogens are probably most well-known for their role in the maintenance of pregnancy (Mulac-Jericevic and Conneely 2004). As is seen in mammals, progesterone is integral to ovulation in birds. It is also associated with behaviours associated with nesting (Wood-Gush and Gilbert 1973; Silver 1978).

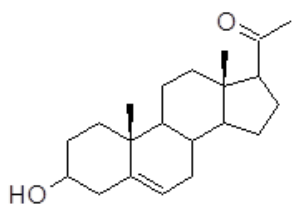

pregnenolone (P5)

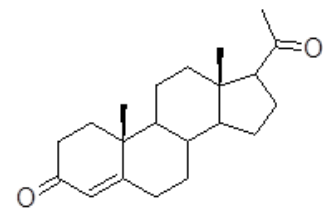

progesterone (P4)

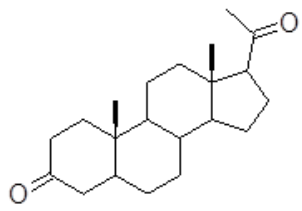

$5 \alpha$-dihydroprogesterone (DHP)

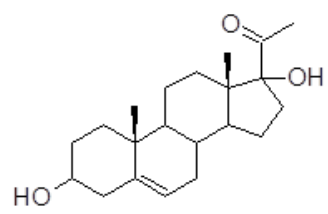

$17 \alpha$-hydroxypregnenolone

Figure 1.6 The common progestogens include pregnenolone $\left(\mathbf{P}_{5}\right)$, progesterone $\left(\mathbf{P}_{4}\right), 5 \alpha$-dihydroprogesterone (DHP) and 17 $\alpha$-hydroxypregnenolone.

\subsubsection{Androgens}

Of the naturally-occurring androgens, there are three that are produced in significant amounts namely androstenedione $\left(\mathrm{A}_{4}\right)$, dehydroepiandrosterone (DHEA) (and its sulphate form), and testosterone $\left(\mathrm{T}_{4}\right)$ although this is species dependent (Figure 1.7). Approximately $5 \%$ of $\mathrm{T}_{4}$ is converted to the minor androgen form, dihydrotestosterone (DHT) which possesses a greater affinity to its receptor. In males, the primary synthesis of androgens occurs in the testes. In females, androgens are produced in the adrenal glands and ovary (McKenna, Fearon et al. 1997). Androgens play important roles in both the development of the embryo and in postnatal development. These include formation of the male urogenital tract, spermatogenesis, testicular development and increasing muscle mass (Chemes, Dym et al. 1979; Guyton and Hall 2006). In females, androgens are also critical for several reproductive processes with the major role as a precursor for the production of $E_{2}$.

$\mathrm{A}_{4}$ can be converted to the oestrogen oestrone $\left(\mathrm{E}_{1}\right)$ by P450arom, or to $\mathrm{T}_{4}$ by $17 \beta-\mathrm{HSD}$ (Figure 1.5). In turn, $\mathrm{T}_{4}$ can be either converted to its more potent androgenic form, DHT by $5 \alpha$-reductase, or to $\mathrm{E}_{2}$ by P450arom (Longcope, Kato et al. 1969; McKenna, Fearon et al. 1997). The former enzymatic conversion takes place in tissues such as the prostate and liver (Thigpen, Silver et al. 1993; Auchus 2004). The best evidence for the latter pattern of steroid 
synthesis occurs in ovarian follicles in females and forms the basis of the ovarian two-cell model where $\mathrm{A}_{4}$ or $\mathrm{T}_{4}$ is first synthesised by the outer theca cells and then passes across the follicular basement membrane to the granulosa cells where P450arom conversion to $\mathrm{E}_{2}$ takes place (Arukwe and Goksøyr 2003).

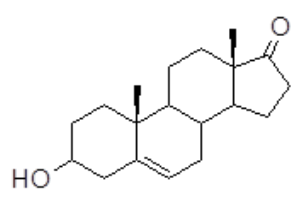

dehydroepiandrosterone (DHEA)

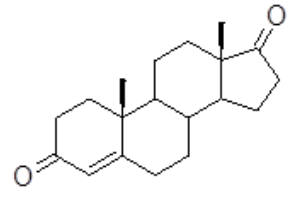

androstenedione

$\left(\mathrm{A}_{4}\right)$

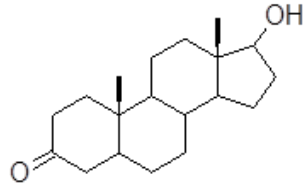

testosterone

$\left(\mathrm{T}_{4}\right)$

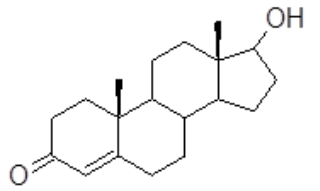

dihydrotestosterone (DHT)

Figure 1.7 The common androgens include dehydroepiandrosterone (DHEA), androstenedione, testosterone and dihydrotestosterone.

\subsubsection{Oestrogens}

Oestrogens are members of the steroid hormone family and play an important and varied physiological role. There are three major oestrogens, $E_{1}, E_{2}$ and oestriol $\left(E_{3}\right)$ (Figure 1.8), and these have significant roles in female reproduction and, to a lesser extent, in male reproduction. The major sites where the synthesis and secretion of oestrogens occurs are those which express P450arom and include the adrenal gland, ovary, placenta and testis (Nelson and Bulun 2001). The primary actions of oestrogens are in the development of female sex characteristics and, in reproduction, play a vital feedback role in the hypothalamic-pituitary-gonadal axis. Oestrogens also play an integral part in other bodily processes both in the very early stages of development (sexual differentiation and embryonic tissue development) and through to adult life (Wang, Ai et al. 2006). Their influence stretches from the nervous system and vascular system, to bone homeostasis and health. Oestrogens are also known to be involved in the production of proteins such as vitellogenin (Bergink, Wallace et al. 1974). The enzyme responsible for conversion of oestrogens, P450arom, does so by catalysing the aromatisation of hexane rings.

The three oestrogens, $E_{1}, E_{2}$, and $E_{3}$, that are endogenous in vertebrates, originate from the conversion of $17 \alpha$-hydroxyprogesterone to $\mathrm{A}_{4}$ (Figure 1.5) and subsequent aromatisation of one of the cyclohexane rings. 


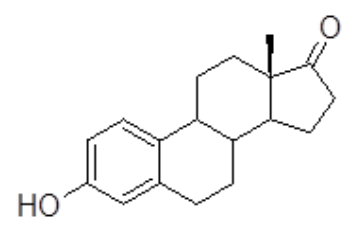

oestrone $\left(E_{1}\right)$

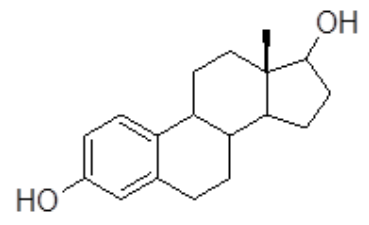

$17 \beta$-oestradiol

$\left(\mathrm{E}_{2}\right)$

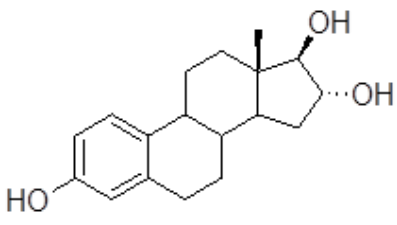

oestriol $\left(E_{3}\right)$

Figure 1.8 The common oestrogens are oestrone $\left(E_{1}\right), 17 \beta$-oestradiol $\left(E_{2}\right)$ and oestriol $\left(E_{3}\right)$.

\subsubsection{Vitellogenin and vitellogenesis}

First discovered in 1936, vitellogenin is a lipoglycoprotein that is a precursor for egg yolk proteins (EYP) and is produced by most oviparous species (Wahli, Dawid et al. 1981). It transports fatty acids that are released from storage to growing oocytes (Tata 1976).

Vitellogenesis is the process by which egg yolk is formed in egg-laying species and ultimately is under the control of the hypothalamus-hypophysial-gonadal axis. Oestrogens induce vitellogenin production in the liver which is then transported via the bloodstream to the ovary. Once there, it is endocytosed by the oocytes and cleaved to give EYPs such as phosvitin and lipovitellin (Polzonetti-Magni, Mosconi et al. 2004). These proteins act on the growing oocyte to provide energy. This growth provides a positive feedback loop as the growing follicles produce more oestrogens which act as stimuli to generate more vitellogenin.

It has been found that if the oestrogen stimulus ceases, the production of vitellogenin will decrease to zero. After oestrogens are reintroduced, there is only a very short period of time before vitellogenin synthesis is restored back to the maximal rate (Shapiro and Taylor 1982). This has been termed hepatic memory. 


\subsection{Nuclear Receptors (NRs)}

\subsubsection{Introduction to Nuclear Receptors (NRs)}

NRs are a very large class of proteins (superfamily) that are responsible for signal transduction after the binding of lipophilic ligands such as steroids and thyroid hormones. They can regulate the level of gene expression by binding to hormone response elements. The family consists of ligand activated transcription factors which can be divided into four main subfamilies depending on the mechanism used for signal transduction or homology (Laudet, Hänni et al. 1992; Mangelsdorf, Thummel et al. 1995; Laudet 1997). The first subfamily consists of thyroid hormone (TR), retinoic acid (RaR), and vitamin D (VDR) receptors. The second subfamily includes retinoid $\mathrm{X}$ receptors (RXRs) and the third includes steroid receptors and oestrogen-related receptors (ERRs). The fourth and final subfamily is largely made up of receptors known as orphan receptors; appropriately named as the ligands for these are often yet to be identified (Aranda and Pascual 2001). More recently, an evolutionary-based superfamily categorisation has divided the receptors into six sub-families (Escriva, Bertrand et al. 2004).

The localisation of NRs at the subcellular level differs; many are present in both the nucleus and cytosol with their level of expression varying in relation to the amount of ligand present. Their presence in the nuclei of cells plays an integral role in a number of functions. These roles include embryonic development, cell differentiation and growth, and cellular homeostasis (Mangelsdorf, Thummel et al. 1995). NRs are capable of forming homodimers and/or heterodimers. Some receptors are capable of binding more than one native ligand (Schupp and Lazar 2010) and a number have the potential for tissue-specific ligands.

In the human genome alone, there are 48 different genes that code for 48 different NRs (McEwan 2009) whilst 270 have been reported in nematodes (Sluder and Maina 2001). As mentioned earlier, in a number of cases, their function and endogenous ligand have yet to be identified.

NRs have a modular structure. They consist of an N-terminal regulatory domain (A/B), DNA-binding domain (DBD) (C), hinge domain (D), ligand binding domain (LBD) (E) and C-terminal domain (F) (Figure 1.9). The DBD and LBD are both essential for the functioning of the receptor and are well-conserved regions. The other regions of the receptors are less 
well conserved (Wurtz, Bourguet et al. 1996). The LBD contains an activation factor (AF-2) and in many cases, an activation factor (AF-1) is also present in the N-terminal domain (Moras and Gronemeyer 1998). NRs are believed to have evolved from a common ancestor that had contained both the DBD and LBD (Escriva, Bertrand et al. 2004).

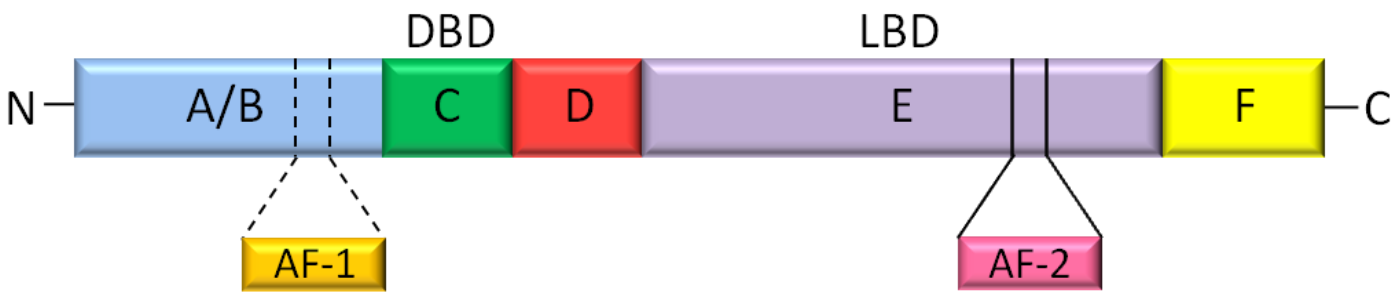

Figure 1.9 The modular structure of NRs consists of $\mathrm{N}$-terminal regulatory domain (A/B), DNA-binding domain (DBD) (C), hinge domain (D), ligand binding domain (LBD) (E) and C-terminal domain (F). AF-2 is present in the LBD of all NRs but AF-1 is only found in some NRs.

The N-terminal domain is a hypervariable region, usually several hundred amino acids long in the steroid receptors. In other non-steroidal NRs it is much shorter in length. For example, AR, glucocorticoid receptor (GR), mineralocorticoid receptor (MR) and PR all have $\mathrm{N}$-terminals almost half the size of the whole receptor (Jenster, van der Korput et al. 1995). The activation factors in this domain are called AF-1, AF-3 (or AF1, AF3) and so on. However, as mentioned previously, this is not common across all NRs (Kumar and Thompson 2003).

The DBD is important for constitutive activity and is highly conserved. It consists of two zinc fingers which in themselves have a high level of conservation and are integral for correct folding of the protein and binding to DNA response elements. These response elements have common nucleotide motifs.

The hinge domain (D) is an area of low conservation and acts to connect the DBD with LBD. It is flexible thus allowing the DBD a considerable amount of movement (Aranda and Pascual 2001). In the case of AR, the hinge domain does more than allow rotation - it plays a role in the binding of DNA and in nuclear translocation (Zhou, Sar et al. 1994; Schoenmakers, Alen et al. 1999; Claessens, Verrijdt et al. 2001), and for TR, is integral to the binding of thyroid hormone (Miyamoto, Kakizawa et al. 2001). 
The LBD is a region of the protein that creates a pocket where the ligand (e.g. hormone) can enter and bind. The LBD comprises of $12 \alpha$-helices (numbered H1 through to H12) and a small $\beta$-turn. Although it displays a reasonable level of conservation amongst different species, this is not to the same degree as that seen for the DBD. The binding of a ligand to the LBD is required for activation. Moreover, upon binding, the shape of the receptor is altered, with $\mathrm{H} 12$ moving and aiding in the formation of a hydrophobic groove. This brings the LBD into contact with the response element for that particular NR (McEwan 2009). Thus, any slight alteration of the amino acid sequence could result in disruption of this process. The pocket formed from the LBD has a large number of hydrophobic residues (Moras and Gronemeyer 1998) and has been found to include a canonical sequence around 20 amino acids long (Wurtz, Bourguet et al. 1996). The LBD is also involved with binding coregulatory proteins and provides a site for dimerisation with another NR to occur (McEwan 2009). Thus, it is seen as the main regulating site for these receptors. Studies are now investigating the potential presence of other sites where NR modulators could interact. These have been termed nuclear receptor alternate-site modulators (Moore, Mayne et al. 2009).

The final region of some NRs is the C-terminal domain. As with the $\mathrm{N}$-terminal domain, this region is highly variable. The role of this final section of NRs remains unknown, although it has been postulated that it may contribute to the stabilisation of the LBD once a ligand has bound (Koide, Zhao et al. 2007).

Transcriptional activity of NRs is controlled by the two transactivation functions; AF-1 and AF-2. AF-1 is a ligand-independent transcription domain, whereas AF-2 requires a ligand for transcription (Moras and Gronemeyer 1998). The activation involves recruiting proteins such as heat shock protein (Hsp) and other chaperone proteins and co-factors necessary for transcription. Other activation factors such as AF-3 have also been identified (Sartorius, Melville et al. 1994).

\subsubsection{Progesterone Receptor (PR)}

The PR is a NR belonging to the same subfamily as AR, GR and MR. It is referred to as NR3C3 (nuclear receptor subfamily 3, group C, member 3) (NRNC 1999) and in humans, the PR gene is located on chromosome 11g22-g23 (National Center for Biotechnology Information 2011). 
The PR protein was first isolated from the oviduct of chicken in the 1970s and subsequently sequenced in 1986 (Sherman, Corvol et al. 1970; Schrader and O'Malley 1972; Conneely, Sullivan et al. 1986). The crystal structure of progesterone complexed to human PR (hPR) was determined over a decade later (Figure 1.10) (Williams and Sigler 1998). Two receptor isoforms termed PR-A and PR-B are expressed from the same PR gene and share a high degree of homology except in the N-terminal domain where PR-B is 164 amino acids longer. This is a result of utilising a different promoter (Wen, $\mathrm{Xu}$ et al. 1994) and results in their abilities to activate different genes and hence provide different physiological outcomes. It is apparent that the two isoforms can form both homodimers and heterodimers (Conneely, Mulac-Jericevic et al. 2001) and the expression of each isoforms varies both between different tissue types and the age of an individual (Camacho-Arroyo, Hernández-Molina et al. 2007). For example, the PR-B isoform has been shown to be the dominant form expressed in the oviduct of quail (Dufrene, Pageaux et al. 1989). A slight sex-dependent expression ratio has also been suggested (Camacho-Arroyo, Hernández-Molina et al. 2007).

As with all NRs, PR is a modular structure that includes a DBD and LBD arranged in an anti-parallel $\alpha$-helical sandwich (Williams and Sigler 1998). Interestingly, PR lacks the 12 $\alpha$-helices seen in other NRs with $\mathrm{H} 2$ absent and H10 and H11 forming one helix. Both AF-1 and AF-2 are present and, in the case of the PR-B isoform, AF-3 exists in the extra region situated at the N-terminal end (Sartorius, Melville et al. 1994). 


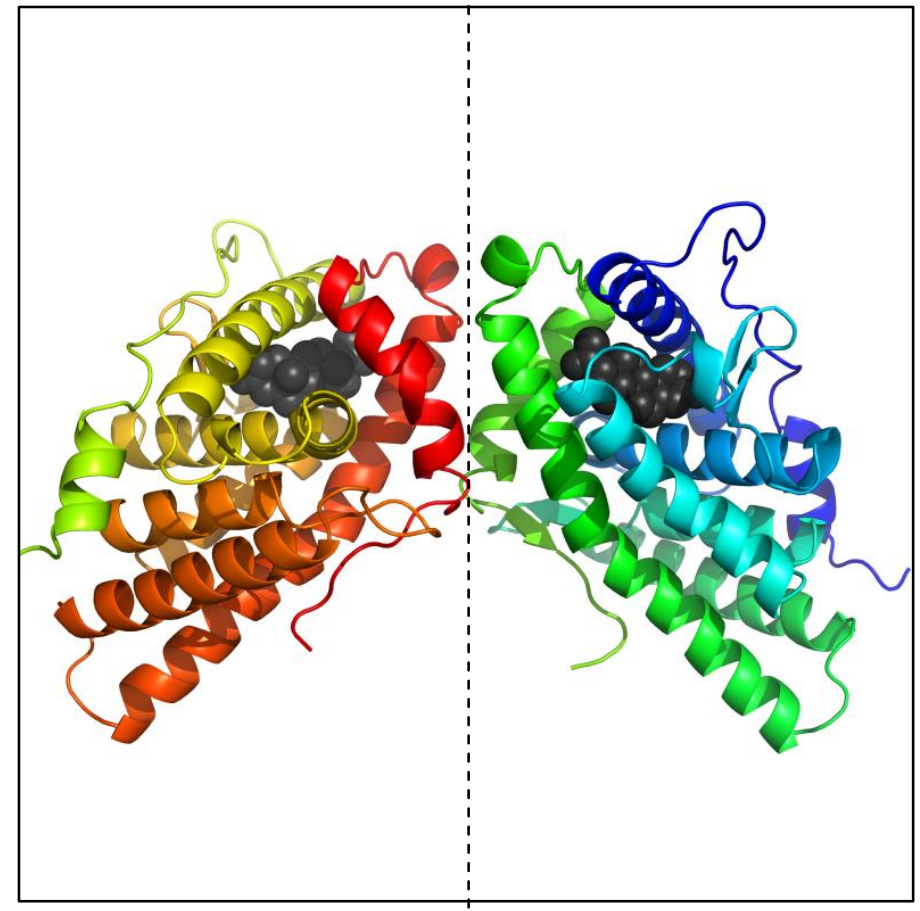

Figure 1.10 Crystal structure of human PR with progesterone bound. The image shows a PR homodimer with a monomer on either side of the dashed line. The different $\alpha$-helices are coloured in different colours and the two molecules of $\mathrm{P}_{4}$ are shown as grey-black spheres in the binding pocket of each monomer.

The PR is present in the cell nucleus in both its bound and unbound forms, although once bound with progestogens, it forms small aggregates (Scarpin, Graham et al. 2009). The mechanism by which PR acts is similar to that found for other steroid receptors with the receptor requiring the ligand to bind to induce a conformational change. Consequently the PR-ligand complex binds to the progesterone response element (PRE) (Allan, Tsai et al. 1992).

Numerous compounds have been identified that exhibit agonistic or antagonistic properties towards PR or are modulators of PR (Spitz 2003; Madauss, Stewart et al. 2007; Winneker, Fensome et al. 2008). The first $\mathrm{P}_{4}$ analogue synthesised was ethinyl testosterone in 1938 and since then a plethora have been produced including tetrahydropyridazines, 6-thiophenehydroquinolines and the potent mifepristone (Palmer, Campen et al. 2000; Zhi, Tegley et al. 2000; Sitruk-Ware and Spitz 2003). 


\subsubsection{Androgen Receptor (AR)}

The AR is a member of the nuclear receptor subfamily known as NR3C4 (nuclear receptor subfamily 3, group C, member 4) and, along with its native ligands (androgens), is involved in reproductive processes such as the development and maintenance of male characteristics as well as influencing non-reproductive tissues such as bone and muscle (Gao, Bohl et al. 2005). It is located in the q11-12 region of the $\mathrm{X}$ chromosome in humans and expression of $\mathrm{AR}$ is mainly found in prostate, liver and skeletal muscle (Brown, Goss et al. 1989; Gao, Bohl et al. 2005; National Center for Biotechnology Information 2008a).

The AR gene was first cloned in the late 1980s (Chang, Kokontis et al. 1988; Lubahn, Joseph et al. 1988; Lubahn, Brown et al. 1989; Tilley, Marcelli et al. 1989). The AR gene encodes for 919 amino acids across eight exons which make up the characteristic domains found in nuclear receptors; an N-terminal domain, DBD, hinge region and a LBD (Lubahn, Brown et al. 1989; Marcelli, Tilley et al. 1990). The DBD is the most highly conserved domain both between species such as human and rat (AR is $100 \%$ conserved in this region) and between different steroid receptors (Choong and Wilson 1998; Claessens, Verrijdt et al. 2001). The LBD spans the last five exons. Like other NRs, two activation functions are present: AF-1 in the N-terminal domain, and AF-2 in the LBD. The latter is found to be the position where interactions between the $\mathrm{NH}_{2^{-}}$and $\mathrm{COOH}-$ terminals occur post ligand-binding $(\mathrm{He}$, Kemppainen et al. 1999). The full sequence of chicken AR was published in 2006 (Katoh, Ogino et al. 2006) and has $70 \%$ conservation with that of human.

The crystal structure of AR was first reported in 2000 (Matias, Donner et al. 2000) and displays $11 \alpha$-helices $(1,3-12)$ rather than the characteristic 12 helical sandwich of many other NRs along with four $\beta$ strands (Figure 1.11) (Sack, Kish et al. 2001). The final helix in the structure still acts in the same way as in other steroid receptors in that it folds to form a lid over the binding pocket once a ligand is bound (Gelmann 2002; Gao, Bohl et al. 2005). 


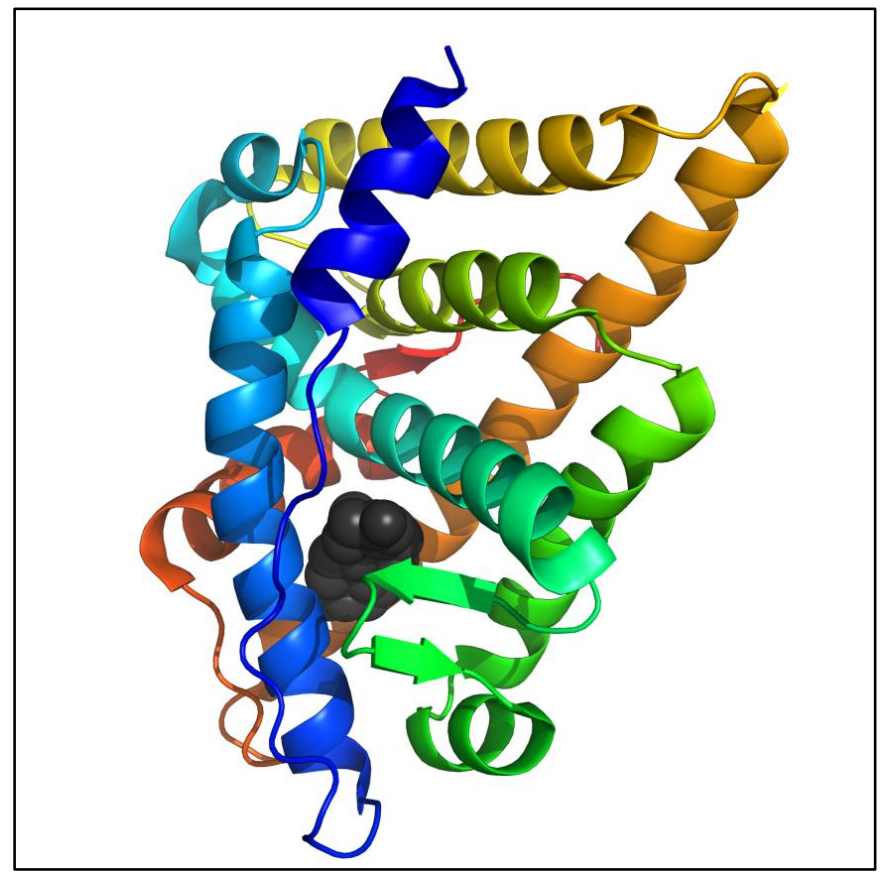

Figure 1.11 Crystal structure of human AR with testosterone bound. The image shows a monomer of AR with the different $\alpha$-helices coloured in different colours and the testosterone molecule shown as grey-black spheres in the binding pocket. The $\beta$-sheets are represented as arrows.

In its inactive state, $A R$ is complexed with numerous proteins such as Hsp90, whose role is to maintain the receptor in an optimal conformation for ligand binding. Upon an androgen passively diffusing into a cell and binding to soluble AR in the cytoplasm, an allosteric change is induced and the bound proteins dissociate. This activates the receptor and homodimerisation can occur (McPhaul, Marcelli et al. 1991; Fang, Fliss et al. 1996). The complex then migrates from the cytoplasm to the nucleus and binds to androgen-responsive elements (AREs), comprising of an inverted repeat 5'-GGTACAnnnTGTTCT-3', thus controlling transcription of androgen-responsive genes (Heemers and Tindall 2007).

The main sites of interaction between the ligand and the receptor are found on the helices 4, 5 and 10 at L704, N705, Q711, M745 and R752 (in human) (Gelmann 2002). A large number of mutations of the AR gene have been detected and the influences of these on the male phenotype have been investigated (McPhaul, Marcelli et al. 1991). In terms of non-native ligands, AR is known to bind much larger compounds than the other nuclear receptors (Hur, Pfaff et al. 2004) and these can be both steroidal and nonsteroidal ligands. Compounds such as bisphenol A (BPA) have been shown to inhibit the transactivation function of AR (Teng, Goodwin et al. 2013). 


\subsubsection{Oestrogen Receptors (ER)}

The oestrogen receptor was the first example of multiple isoforms existing for a steroid receptor, with both $\alpha$ (ER- $\alpha)$ and $\beta$ (ER- $\beta$ ) isoforms identified. They are encoded by two different genes located in humans on chromosomes 6 for ER- $\alpha$ (6q25.1) and 14 for ER- $\beta$ (14q23.2): these have been assigned the nomenclature NR3A1 (nuclear receptor subfamily 3, group A, member 1) and NR3A2 (nuclear receptor subfamily 3, group A, member 2) respectively (NRNC 1999; National Center for Biotechnology Information 2008b; National Center for Biotechnology Information 2008c). These isoforms have been shown to form both homodimers and also heterodimers (Ogawa, Inoue et al. 1998). ERs act as ligand-activated nuclear transcription factors and are expressed in a number of different tissues. Both isoforms are found in the ovary, and are also present in $\mathrm{E}_{2}$ responsive tissues such as brain, bone osteoclast cells and cardiac muscles although their expression in these, and other tissues, differs (Saunders 1998). ER- $\alpha$ has been shown to play an important role in both the differentiation and maintenance of mainly reproductive tissue types (Korach 1994) and ER- $\beta$ has been shown to be necessary for functional ovaries, and for tissue growth regulation in the urogenital tract (Gustafsson 1999). ER- $\alpha$ and ER- $\beta$ can have opposite actions.

ER- $\alpha$ was first isolated and identified from human tissue in 1985 (Walter, Green et al. 1985) and ER- $\beta$ approximately a decade later from rat prostate (Kuiper, Enmark et al. 1996). Since these discoveries, a large amount of data on both isoforms has been gathered. More recently, a third isoform (ER- $\gamma$ ) has been identified in teleosts (Hawkins, Thornton et al. 2000). In fish species, the isoforms have now been renamed as ER- $\alpha$, ER- $\beta 1$ and ER- $\beta 2$ (Hawkins and Thomas 2004). The crystal structures of the two isoforms ( $\alpha$ and $\beta$ ) have been isolated and determined for human (Figure 1.12) as well as for a few other species, and show similarities in the three-dimensional arrangement (Tanenbaum, Wang et al. 1998; Mocklinghoff, Carraz et al. 2010).

Overall, ER- $\alpha$ and ER- $\beta$ exhibit 47\% sequence identity (Pike, Brzozowski et al. 1999) and contain the same domains as those found in other NRs (Kuiper, Enmark et al. 1996; Mosselman, Polman et al. 1996). However, some domains, especially the DBD, have a much greater level of conservation (Pettersson and Gustafsson 2001; Leitman, Paruthiyil et al. 2010). 
The chicken ER sequence was first identified and published in 1986 (Krust, Green et al. 1986). It shares $88 \%$ amino acid conservation with that of human and indications are that both the human and chicken receptor arose from the same primordial gene.
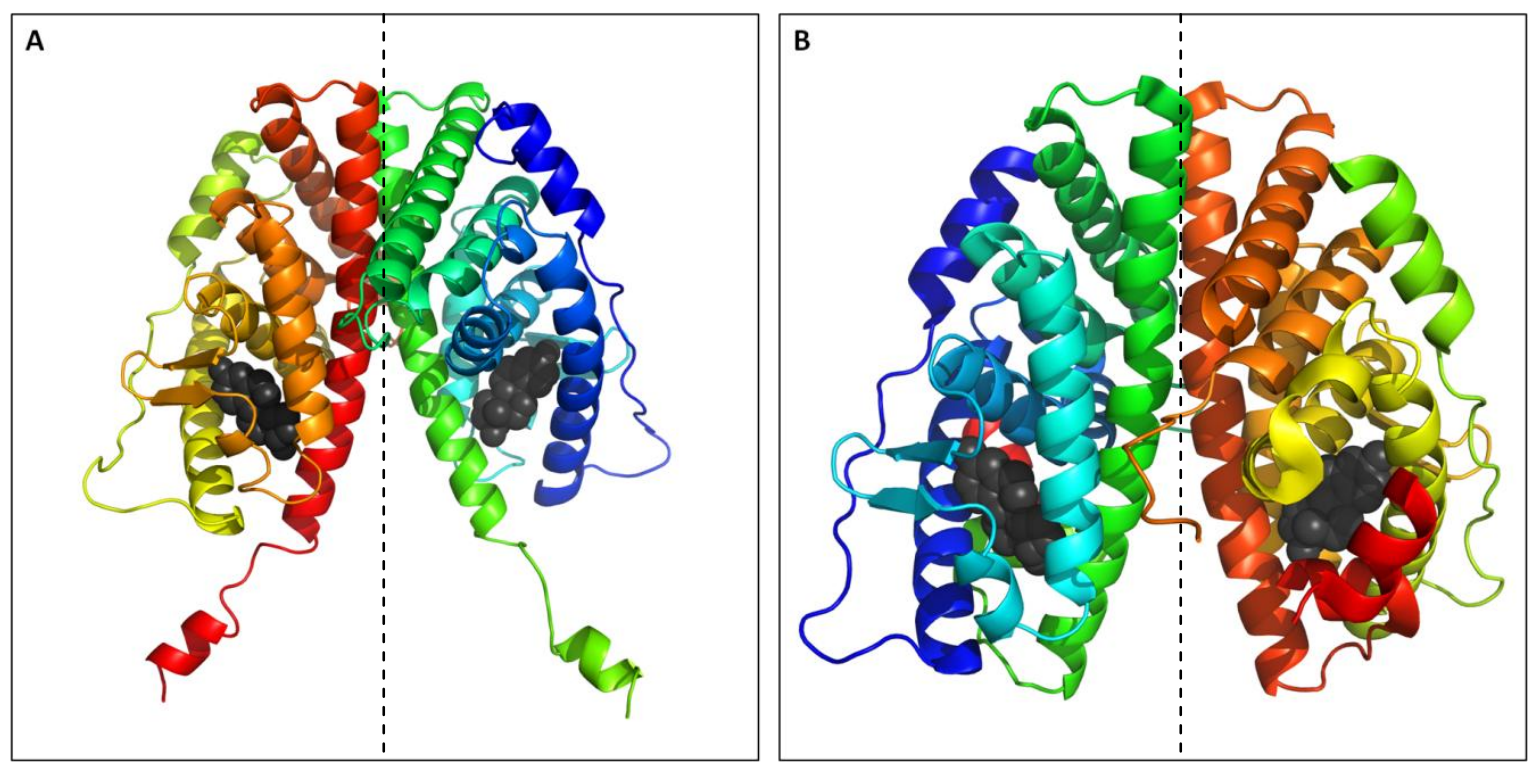

Figure 1.12 Crystal structures of the two isoforms of human ER. A) ER- $\alpha$ (RSCB structure ID 1A52) and B) ER- $\beta$ (RSCB structure ID 3OLS). Both images are of the homodimers with a monomer on either side of the dashed line. The different $\alpha$-helices are coloured in different colours and the two molecules of $E_{2}$ are shown as grey-black spheres in the binding pocket of each monomer. The $\beta$-sheets are represented as arrows.

As discussed with the other steroid receptors, the modular structure of NRs is present in both ER- $\alpha$ and ER- $\beta$. Firstly there is a transactivation domain (region A) for AF-1 at the $\mathrm{N}$-terminal end, followed by a region $\mathrm{B}$, then the $\mathrm{DBD}$ (region $\mathrm{C}$ ), the hinge domain (region D) and the LBD (region E) before the C-terminal region F (Figure 1.9). The two activation factors AF-1 and AF-2 were first identified in ER in human (Kumar, Green et al. 1987; Webster, Green et al. 1988) and mouse (Lees, Fawell et al. 1989). From this it was found that AF-1 present in the N-terminal domain was ligand-independent whereas the other required $\mathrm{E}_{2}$ for activation. The deletion of the N-terminal domain did not inhibit reporter gene activation.

ER in its inactive state is a monomer associated with hsp90. Once a ligand binds, the receptor dissociates from the hsp90 protein and undergoes dimerisation. This dimerisation can be in the form of a homodimer or, due to co-expression of both ER- $\alpha$ and ER- $\beta$ in some tissue types, a heterodimer of both isoforms (Arukwe and Goksøyr 2003). This complex then migrates to the nucleus. 
After $E_{2}$ (or a non-native ligand) enters the cell nucleus, it binds to the LBD of the receptor. This causes conformational changes to the receptor culminating in the binding of the ER-ligand complex to cognate recognition sites, oestrogen response elements (ERE). ERE is upstream of the oestrogen-responsive genes in DNA. These sites were originally thought to consist of a palindromic inverted repeat sequence of 10 base pairs long with three variable nucleotides in the middle 5'-GGTCAnnnTGACC-3' where $\mathrm{n}$ is any nucleotide (Klein-Hitpass, Ryffel et al. 1988). However, it has since been shown that the flanking nucleotides (A at the 5' end and $\mathrm{T}$ at the 3' end) are involved in the affinity of the dimer for ERE (Klinge 2001). From in vitro studies, it has been observed that a number of substitutions to the human ERE still render it functional although there are changes in the binding affinity (Driscoll, Sathya et al. 1998). This result suggests the ERE sequence effects the conformation of ER and thus the interactions of ER with co-regulatory proteins (Klinge, Jernigan et al. 2001). For example, if the number of variable nucleotides in between the palindromic ends is less or more than three, the binding of both ER- $\alpha$ and $-\beta$ changes considerably (El Marzouk, Gahattamaneni et al. 2008). Additionally, when the binding efficiency of the DBD of ER is compared with that of the entire receptor, it is seen to be much stronger with the latter. Therefore, the binding of ER to an ERE leads to transcriptional changes.

Many molecules have been shown to have an effect on nuclear receptors. Pyrimidines were the first to be identified as interacting with ER- $\alpha$ (Rodriguez, Tamrazi et al. 2003). A number of non-native (exogenous) chemicals have been shown to interact with nuclear receptors and ER- $\alpha$ and ER- $\beta$ are no exception. These include synthetically-made compounds and those produced naturally by plants (such as phytoestrogens). Phytoestrogens have been shown to interact with both hER- $\alpha$ and hER- $\beta$ (Morito, Hirose et al. 2001). Other compounds have also been shown to have an effect on the ER binding with coactivator proteins in either an agonistic or antagonistic manner. These effects have been shown to be tissue-type specific and can be isoform-dependent. Compounds that act in this way have been termed selective oestrogen receptor modulators (SERMs) and examples of these include raloxifene and tamoxifen. Tamoxifen is an ER- $\beta$ antagonist but can act as both an agonist and antagonist of ER- $\alpha$ (Watanabe, Inoue et al. 1997; Pettersson and Gustafsson 2001). 


\subsection{Phytoestrogens}

A large number of hormones have been isolated and identified in plants. One such example is melatonin (as phytomelatonin) which has been widely documented in different plants since 1995 (Zohar, Izhaki et al. 2011). Also, there is a group known as the phytoestrogens.

Phytoestrogens are a subset of environmental oestrogens and comprise polyphenolic, non-steroidal compounds of plant origin that are structurally similar to mammalian oestrogens (Brzezinski and Debi 1999; Benassayag, Perrot-Applanat et al. 2002; Ososki and Kennelly 2003). They can exhibit agonistic, partially agonistic and antagonistic behaviours with ER and have been shown to interact with both $\alpha$ and $\beta$ isoforms (Morito, Hirose et al. 2001). However the affinity to each isoform varies.

Phytoestrogens have been detected and isolated from a wide variety of plant species and, structurally, can be divided into three main classes: coumestans, flavonoids and lignans (Table 1.2) (Deluca, Krazeisen et al. 2005).

Table 1.2 The three major classes of phytoestrogens

\begin{tabular}{|c|l|}
\hline Phytoestrogen Class: & Examples: \\
\hline Coumestans & $\begin{array}{l}\text { Coumestrol } \\
\text { Plicadin } \\
\text { Wedelolactone }\end{array}$ \\
\hline Flavonoids & $\begin{array}{l}\text { Biochanin A (isoflavonoid) } \\
\text { Formononetin (isoflavonoid) } \\
\text { Daidzein (metabolite) } \\
\text { Equol (metabolite) } \\
\text { Genistein (metabolite) }\end{array}$ \\
\hline Lignans & $\begin{array}{l}\text { Lariciresinol } \\
\text { Matairesinol } \\
\text { Pinoresinol } \\
\text { Secoisolariciresinol } \\
\text { Enterolactone (metabolite) } \\
\text { Enterodione (metabolite) }\end{array}$ \\
\hline
\end{tabular}

Examples of compounds in each class are outlined below. 


\subsubsection{Coumestans}

Coumestrol is a coumestan widely found in plants such as soya beans, alfalfa, legumes and clovers (Deluca, Krazeisen et al. 2005; Franco, Schwingel et al. 2009). Other coumestans include plicadin, from Psoralea plicata in 1991 (Rasool, Qasim Khan et al. 1991), and wedelolactone, which was first isolated from Wedelia calendulacea in 1956 (Figure 1.13) (Govindachari, Nagarajan et al. 1956).

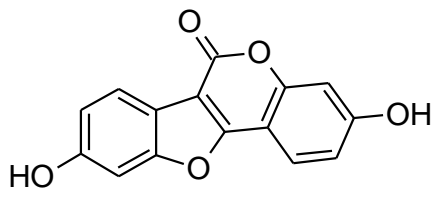

coumestrol<smiles></smiles>

plicadin<smiles>COc1cc(O)c2c(c1)oc(=O)c1c3cc(O)c(O)cc3oc21</smiles>

wedelolactone

Figure 1.13 The chemical structure of different coumestans. The chemical structure of coumestrol, plicadin and wedelolactone are shown.

\subsubsection{Flavonoids}

Flavonoids consist of flavones, flavanones and isoflavones although further sub-categories of anthocyanins, flavanols and flavonols have been used (Nemeth and Piskula 2007). The flavanols include catechins and tannins. All flavonoids contain a common structure of two benzene rings and an oxane ring with most present in plants bound to sugars (Deluca, Krazeisen et al. 2005).

Flavones, include the aglycone apigenin and luteolin, whilst an example of a flavanone is liquiritigenin, a constituent of liquorice (Glycyrrhiza glabra) (Figure 1.14) (Hillerns, Zu et al. 2005). These are found in many fruits, vegetables and herbs (Zhang, Li et al. 2010). 
<smiles>O=c1cc(-c2ccc(O)cc2)oc2cc(O)cc(O)c12</smiles>

apigenin<smiles>O=c1cc(-c2ccc(O)cc2)oc2cc(O)ccc12</smiles>

luteolin<smiles>O=C1CC(c2ccc(O)cc2)Oc2cc(O)ccc21</smiles>

liquiritigenin

Figure 1.14 The chemical structure of different flavones and a flavanone. The chemical structure of apigenin, luteolin and liquiritigenin are shown.

Isoflavones are most commonly found in beans and legumes (Axelson, Sjövall et al. 1982; Brzezinski and Debi 1999). They include biochanin A (5,7dihydrox-4'-methoxyisoflavone), formononetin (7-hydrox-4'-methoxyisoflavone), and glycitein; all three of which are methylated (Figure 1.15). The predominant isoflavones in red clover (Trifolium pratense) are biochanin A and formononetin (Tsao, Papadopoulos et al. 2006). Biochanin A is also found in chickpeas (Cicer arietinum). Soya bean contains the greatest concentration of isoflavones (Morito, Hirose et al. 2001) with both daidzein (found in clover as well) and genistein (5,7,4'-trihydroxyisoflavone)(in peanuts as well) present as is glycitein.

Equol was first isolated from the urine of mares in 1932 (Marrian and Haslewood 1932) and is commonly sourced from soy. Although it is a metabolite of daidzein, it has greater relative binding to ER (Morito, Hirose et al. 2001; Matsumura, Ghosh et al. 2005).<smiles>COc1ccc(-c2coc3cc(O)cc(O)c3c2=O)cc1</smiles>

biochanin $\mathrm{A}$<smiles>O=c1c(-c2ccc(O)cc2)coc2cc(O)ccc12</smiles>

daidzein<smiles>COc1ccc(-c2coc3cc(O)ccc3c2=O)cc1</smiles>

formononetin<smiles>Oc1ccc(C2COc3cc(O)ccc3C2)cc1</smiles>

equol<smiles>COc1cc2c(=O)c(-c3ccc(O)cc3)coc2cc1O</smiles>

glycitein<smiles>O=c1c(-c2ccc(O)cc2)coc2cc(O)cc(O)c12</smiles>

genistein

Figure 1.15 The chemical structure of a number of major flavonoids and metabolites. The chemical structure of biochanin A, formononetin, glycitein, daidzein, equol and genistein are shown. 


\subsubsection{Lignans}

Lignans are the third class of phytoestrogens and are widely distributed in grains (Deluca, Krazeisen et al. 2005). They consist of the basic unit of coniferyl alcohol (Wiseman 2012) and include lariciresinol, pinoresinol and syringaresinol from rye (Nilsson, Aaman et al. 1997) as well as matairesinol ([3R-trans)-dihydro-3,4-bis[(4-hydroxy-3-methoxyphenyl)methyl]-2(3H)-furanone) and secoisolariciresinol ([R- $\left.\left(R^{*}, R^{*}\right)\right]-2,3-b i s[(4-h y d r o x y-3-$ methoxyphenyl)-methyl]-1,4-butanediol) from berries such as blackberry (Rubus fructicosus) and strawberry (Fragaria x ananassa) (Figure 1.16).<smiles>COc1cc(CC2COC(c3ccc(O)c(OC)c3)C2CO)ccc1O</smiles>

lariciresinol<smiles>COc1cc(C2OCC3C(c4ccc(O)c(OC)c4)OCC23)ccc1O</smiles>

pinoresinol<smiles>COc1cc(CC2COC(=O)C2Cc2ccc(O)c(OC)c2)ccc1O</smiles>

matairesinol<smiles>COc1cc(C2OCC3C(c4cc(OC)c(O)c(OC)c4)OCC23)cc(OC)c1O</smiles>

syringaresinol

Figure 1.16 The chemical structure of a number of lignans. The chemical structure of lariciresinol, matairesinol, pinoresinol and syringaresinol are shown.

\subsubsection{Mechanism of Action of Phytoestrogens}

Phytoestrogens exert pleiotropic effects in the body. These include anti-oxidant behaviour, inhibition of angiogenesis and osteoporosis, and regulation of cell cycles (Adlercreutz 1995; Anderson and Garner 1998; Fotsis, Pepper et al. 1998; Wiseman, O'Reilly et al. 1998; Pepper, Hazel et al. 2004; Rüfer and Kulling 2006). They have also been shown to have an effect on reproduction. For example, 6-methoxybenzoxazolinone (6-MBOA), present in immature growing grasses, demonstrated an ability to stimulate reproduction and to increase 
fertility (Sanders, Gardner et al. 1981; Berger, Negus et al. 1987; Schadler, Butterstein et al. 1988; Rodríguez-De Lara, Herrera-Corredor et al. 2007). The mechanism for this has been postulated to be through sensitisation of the pituitary gland to gonadotropin-releasing hormone but, as with many other phytoestrogens, the exact method is not well-understood.

In general, phytoestrogens can mimic or act as precursors to sex hormones through their similar structure and by promoting the effects of oestrogens (Ososki and Kennelly 2003). In a comparable manner to oestrogens, these compounds act on the endocrine system in an oestrogenic or anti-oestrogenic capacity (Dixon 2004). They have been shown to move through cell membranes and cross the placental barrier (Adlercreutz, Yamada et al. 1999; Degen, Janning et al. 2002). From a mechanistic point of view, in vitro effects of phytoestrogens have demonstrated that, as they have the ability to bind to the oestrogen receptors and elicit a response, they are likely to be interacting with oestrogen signalling pathways. For example, genistein has been shown to increase both mitogen-activated protein kinase (MAPK) and nuclear factor kappa B (NF-кB) signalling pathways (Viña, Borrás et al. 2005).

As mentioned previously, phytoestrogens have been shown to imitate oestrogen hormones. However this ability is highly variable and in many cases, binding is specific to one isoform of ER. Despite this, they have been shown to interact with both hER- $\alpha$ and hER- $\beta$ (Morito, Hirose et al. 2001). It has been determined that coumestrol is the most effective phytoestrogen at binding to ER- $\alpha$ (Kostelac, Rechkemmer et al. 2003). Further studies which utilised a rat uterine oestrogen receptor binding assay to test a range of phytoestrogens supported the claim that coumestrol had the greatest affinity to ER- $\alpha$ (Hillerns, $\mathrm{Zu}$ et al. 2005). In contrast, liquiritigenin was shown to be the least potent of those studied. Both genistein and daidzein (Kostelac, Rechkemmer et al. 2003), as well as extracts from juvenile leaves of Millettia dura and Ficus natalensis and bark from Eucalyptus grandis (Wasserman, Taylor-Gutt et al. 2012), display preferential binding to the ER- $\beta$ isoform.

Phytoestrogens have been shown to have activity with other steroid hormone receptors besides ERs, such as AR, TR, pregnane $\mathrm{X}$ receptor (PXR) and aryl hydrocarbon receptor $(\mathrm{AhR})$, as well as reducing the synthesis of $\mathrm{P}_{4}$ through the prevention of lutenising hormone secretion (Fang, Tong et al. 2003; Tiemann, Schneider et al. 2007; Long, Krüger et al. 2012). 


\subsubsection{Metabolism of Phytoestrogens}

Post-ingestion metabolism of a wide range of chemicals occurs frequently in the body so as to increase the activity of the ingested compounds. This is also the case with some phytoestrogens where the phytoestrogen precursor is ingested and then can be converted into biologically-active compounds. Isoflavones and lignans have both been shown to undergo such changes with the conversion of 4-methoxycoumestrol into coumestrol as an example (Shutt, Braden et al. 1969). Metabolic pathways for the catabolism of a number of phytoestrogens have been identified. One such mechanism is for the conversion of daidzein to equol (Figure 1.17) although the precursor to daidzein, formononetin may also be present (Joannou, Kelly et al. 1995).

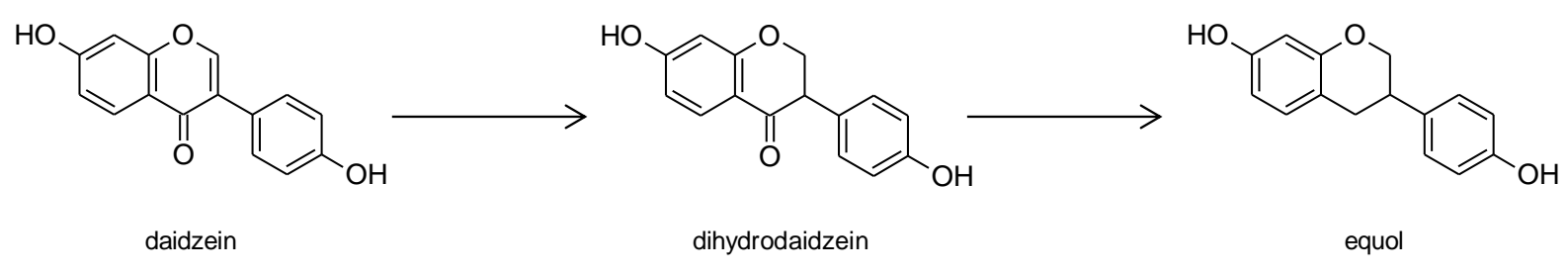

Figure 1.17 Metabolic pathway for catabolism of the phytoestrogens daidzein to equol via dihydrodaidzein (adapted from (Joannou, Kelly et al. 1995)).

These conversions are primarily carried out in the gut via intestinal, mucosal and bacterial enzymes (Benassayag, Perrot-Applanat et al. 2002; Nemeth and Piskula 2007) and it has been suggested that some phytoestrogens are not absorbed until they have undergone enzymatic hydrolysis to remove the sugar moiety (Setchell, Brown et al. 2002a). The variations of phytoestrogen metabolism could correlate with the levels of microflora present in the intestinal area. The detection of both phytoestrogens and their metabolites in urine has been reported (Axelson, Kirk et al. 1982).

It has also been proposed that enzymes present in plants can be ingested in their "active" state alongside the phytoestrogens and so are capable of converting the phytoestrogens to increase their activity (Kingston-Smith and Theodorou 2000). Conversely, some phytoestrogens may reside in the plant in their aglycone (active) state due to the presence of these enzymes.

Equol is an example of a phytoestrogen metabolite that is more oestrogenic than its precursor isoflavonoid, daidzein (Kuiper, Lemmen et al. 1998; Kostelac, Rechkemmer et al. 2003). It exists as both $R$ - and $S$ - enantiomers and has enantiomeric differences in its binding ability to 
ER- $\alpha$ and ER- $\beta$ (Muthyala, Ju et al. 2004). It originates from daidzein (soya beans) or formononetin via daidzein (clover) (Setchell, Brown et al. 2002b) and was identified prior to the isolation of daidzein in 1982 (Axelson, Kirk et al. 1982).

Absorption of phytoestrogens is generally rapid but varies for different compounds. This is primarily due to structural differences that alter the size or polarity of the molecule. The positioning of any sugar moiety also affects the absorption rate. Some phytoestrogens are transported around the body after conjugation with glucuronic acid (Lundh 1995; Nemeth and Piskula 2007).

\subsubsection{Influence on Wildlife and Domesticated Animals}

Several studies investigating the influence of phytoestrogens on the reproductive health of wildlife have been undertaken and, for the most part, these have reported detrimental effects. For example, the breeding of the captive populations of Southern White Rhinos (Ceratotherium simum simum) has only had limited success with females appearing to be subfertile and phytoestrogens have been proposed to be linked to this lack of reproductive success (Patisaul 2012; Tubbs, Hartig et al. 2012). Other studies looking at the effects of phytoestrogens on females have produced conflicting conclusions. An abundance of Vitex sp. (a plant known to contain phytochemicals) in the diet of wild female Phayre's leaf monkeys (Trachypithecus phayrei crepusculus) corresponded to higher levels of progestin in the faecal matter (Lu, Beehner et al. 2010). However whether this was influenced by phytoestrogens in the plant was unable to be determined.

It has been postulated that for some vertebrates it is the seasonal changes in phytoestrogen levels in plants that influence the timing of their reproduction. For example, red kangaroos (Macropus rufus) exhibit reduced fertility during periods of low rainfall, whilst Californian quail (Lophortyx californicus) limit their breeding to wetter years (Leopold, Erwin et al. 1976; Labov 1977). From this, it has been postulated that the fluctuating levels of phytoestrogens in plants is used by species to determine when it is a favourable time to have offspring (Rochester and Millam 2009).

From the perspective of specific phytoestrogens, genistein and daidzein (and precursors) present in clover along with the metabolite equol, have been found to cause reduced fertility and even sterility in domestic cows and sheep (Lightfoot, Smith et al. 1974; Croker, Nichols 
et al. 2005). Furthermore, coumestrol and equol have both been found to influence reproductive tract development in rats as well as DNA synthesis (Tang and Adams 1980; Medlock, Branham et al. 1995; Whitten, Lewis et al. 1995). However, in contrast to the majority of studies which found phytoestrogens to have a detrimental effect on reproductive success, 6-MBOA appears to have a positive effect on reproduction (Berger, Negus et al. 1987).

\subsubsection{Role in Plants}

Although much is known about phytoestrogens in terms of their production, mechanism, effects and even detection of them, limited research has been undertaken into their ecological role from the plant perspective. There appears to be varied distribution of phytoestrogens throughout different regions of a plant and it has been suggested that plants produce phytoestrogens as part of a defence mechanism so that their levels vary throughout the year in response to the size of the pest population (Wiseman 2012). However, administration of genistein and or daidzein to gypsy moth caterpillars did not significantly inhibit the growth or lifespan of the caterpillars suggesting this pest mechanism may not be the case in all plants (Karowe and Radi 2011). The phytoestrogens may also have UV-protective qualities, antioxidant properties, or confer resistance to fungi and aid in the recruitment of nitrogen-fixing bacteria (Mazur and Adlercreutz 1998; Fox, Starcevic et al. 2004; Rüfer and Kulling 2006).

\subsection{New Zealand Native Plants}

New Zealand is home to an extensive range of unique native flora, attributed to its isolation from other countries around 100 million years ago. A considerable amount of information is known about these native plants, both from traditional knowledge and that acquired from research. This is especially true in terms of medicinal properties of plants as well as the role they play in the ecosystem and their life stages. The isolation of compounds from plants is often used for taxonomical purposes and from this a few phytoestrogens have been identified. 


\subsubsection{Masting of Plants}

Masting, or mass seeding, is a worldwide phenomenon known to occur in many trees and herbaceous plants and it has a very high prevalence in New Zealand (Kelly, Harrison et al. 2000). It is defined as high interannual variation in seed crop production that is synchronous in plant populations (Kelly 1994; Boutin, Wauters et al. 2006). Masting appears to be linked to warm temperatures during the summer prior to masting. Although there have been suggestions as to the reason plants exhibit masting, such as for seed predator satiation purposes (Kelly, Turnbull et al. 2008), its occurrence has also been linked to both temperature and precipitation (Schauber, Kelly et al. 2002; Burns 2012).

Nothofagus species are masting plants in lowland and montane habitats. Some of these are endemic to New Zealand whilst others are found in Australia, New Caledonia, southern South America and New Guinea. A relationship between their seed production and environmental factors such as temperature and wind pollination efficiency has been determined (Burrows and Allen 1991; Monks and Kelly 2006). Interestingly, the masting of beech leads to a greater effort by Kākā and yellow-crowned Kākāriki to reproduce (Elliott, Dilks et al. 1996; Wilson, Karl et al. 1998).

Like Beech trees, Dacrydium cupressinum (Rimu) is found throughout lowland and montane New Zealand forests. They are dioecious trees with male and female plants synchronising their reproduction. The cones of Rimu are wind-pollinators whilst the seeds are dispersed by birds eating the fruit. The masting process has been recorded on numerous occasions in Rimu and has been found to correlate with increases in rat and mice populations (Norton and Kelly 1988; Ruscoe, Wilson et al. 2004; Harper 2005).

Chionochloa species such as Chionochloa rigida (Snow tussock) thrive in alpine/subalpine regions and produce wind-pollinated seeds and flowers. Chionochloa species exhibit extreme masting which correlates with both temperatures in the early part of the year and hormonal cues (Webb and Kelly 1993; Kelly, Harrison et al. 2000; Rees, Kelly et al. 2002; Turnbull, Pharis et al. 2012). The major impetus for tussock to undergo masting is thought to be for seed predator satiation (Kelly, Turnbull et al. 2008).

Phormium tenax (Flax) is another species endemic to New Zealand that experiences periodic heavy flowering (Brockie 1986). 


\subsubsection{Phytoestrogens}

Although a considerable amount of research has been undertaken into the isolation, characterisation and determination of activity of phytoestrogens, only a small amount is known about chemicals isolated from native New Zealand plants and even less about the phytoestrogens present in them and their potential biological activity. A few tests that have been undertaken on New Zealand plant extracts include antiviral, antimicrobial and cytotoxicity screens (Bloor 1995).

Analysis of Chionochloa species has included different minerals as well as the presence of water-soluble sugars and lignins (Williams, Cooper et al. 1976). A number of flavonoids have been isolated from Coprosma species including luteolin and apigenin (flavones), and quercetin, myricetin and kaempferol (flavonols). Fructans have been characterised from leaf extracts of $P$. tenax and Cordyline australis, whilst terpene-derived compounds were detected in Rimu and Anistome species such as Anistome haastii (Haast's carrot) (Perry and Weavers 1985; Brasch, Fankhauser et al. 1988; Hinkley, Perry et al. 1994; Sims, Cairns et al. 2001; Zidorn, Sturm et al. 2002; Sims 2003)

Compounds with known oestrogenic activity have also been identified. Ferruginol has been found to be present in D. dacrydioides (Kahikatea), Rimu and Podocarpus totara (Totara) (Brandt 1952; Briggs, Cambie et al. 1959; Cox, Yamamoto et al. 2007). As the name suggests, podocarpic acid has been isolated from the heartwood of Podocarpus species such as $P$. acutifolius and P. dacrydioides (actually now Dacrycarpus) (Bennett and Cambie 1967). Although it originally did not appear to have oestrogenic capabilities, studies since have suggested it may be mildly oestrogenic (Sherwood and Short 1938; Brandt and Ross 1948; Fidler, Zwart et al. 2000). Another chemical shown to exhibit oestrogenic properties that is present in New Zealand native species is totarol. Totara, Podocarpus cunninghamii (Hall's totara) and Rimu have all been found to produce it as well as derivatives (Brandt 1952; Cambie and Mander 1962; Cambie, Simpson et al. 1963; Bennett and Cambie 1967). Finally, genistein, a known phytoestrogen, was discovered in the heartwood of Podocarpus spicatus (black pine) (Briggs and Cebalo 1959).

Experimentation with a number of Nothofagus species sampled from Austraila, Chile and New Zealand has yielded 42 flavonoids including apigenin, galangin, kaempferol, quercetin and myricetin as well as the stilbene pinosylvin (Wollenweber, Stüber et al. 1997; Russell, 
Bowers et al. 2000; Wollenweber, Stevens et al. 2003). Although galangin does not appear to have strong oestrogenic properties, apigenin, kaempferol, myricetin and quercetin are known to be at least weak phytoestrogens and pinoslyvin has been shown to be oestrogenic in MCF-7 cells (Mellanen, Petänen et al. 1996; Kuiper, Lemmen et al. 1998; Maggiolini, Recchia et al. 2005; Aquila, Santoro et al. 2013).

\subsection{Biological Assays (Bioassays)}

Biological assays, or more commonly termed bioassays, are assays carried out to elucidate the effects of compounds on biological systems or to mimic bodily processes. Often the effect measured is bioactivity and this can be in a quantitative or qualitative manner. A major advantage is that many bioassays have the capacity to be both high-throughput and performed at relatively low cost. Many of these screening methods have been employed for determining endocrine-disrupting chemicals, phytosteroids and other compounds with steroidogenic activity. One particular area that has received considerable interest is the hormonal effect of chemicals that accumulate in the environment (LeBlanc, Norris et al. 2011). As these compounds can often mimic the actions of hormones, act as antagonists of hormones or alter hormonal expression, a range of assays are required to study these.

The different approaches for bioassaying can be classified as in silico, in vitro and in vivo methods.

\subsubsection{In silico Methods}

In silico (or computational) methods are regularly used for pre-screening potential "active" compounds prior to investigation with in vitro and/or in vivo protocols. "Shape Signatures" is a computational tool that uses chemical properties such as polarity and molecule shape to compare different chemicals (Wang, Ai et al. 2006) whilst protein-ligand computational docking with software packages such as AMBER, AutoDock, FlexX and Rosetta (Pearlman, Case et al. 1995; Rarey, Kramer et al. 1996; Meiler and Baker 2006; Morris, Huey et al. 2009), can be used to assess possible interactions between a ligand and receptor and thus determine the likelihood of binding occurring. Examples of these include the use of AMBER to analyse the binding affinity of steroid hormones for the human GR and to determine the binding interactions of $\mathrm{P}_{4}$ to hPR (Hillisch, von Langen et al. 2003; von Langen, Fritzemeier 
et al. 2005) whilst AutoDock has been implemented to investigate the binding conformations of BPA and derivatives in ERR- $\gamma$ and for interactions between xenoestrogens and phytoestrogens and hAR (Wang, Li et al. 2010; Babu, Vellore et al. 2012).

Determination of structure-activity relationships (SAR) can also be implemented in a similar manner so as to predict other potentially active chemicals. This can be extended further so as to give a quantitative assessment (QSAR) of compound binding (Tong, Perkins et al. 1997; Shi, Fang et al. 2001). A slightly different approach that has been implemented to learn more about the receptor itself involves the prediction of NR response elements (Podvinec, Kaufmann et al. 2002).

\subsubsection{In vitro Methods}

In vitro methods are routinely used to determine steroidogenic activity. These include receptor binding assays, transcriptional activation assays, and cell proliferation assays (Charles 2004). These methods are evaluated by enzyme immunoassays, reporter gene assays, radioactive labelling, cell proliferation, and DNA- or ligand-binding assays.

Receptor binding assays are a well-established method that can be in the form of a competitive binding system and often involve radioactivity with ${ }^{3} \mathrm{H}$ labelled hormone. This approach has been reported for screening large numbers of compounds (200+) for potential interactions with $\mathrm{AR}$ and environmental chemicals and phytoestrogens for oestrogenic activity (Kuiper, Lemmen et al. 1998; Blair, Fang et al. 2000; Fang, Tong et al. 2003). The limitation of an assay such as this is that any agonists cannot be differentiated from antagonists.

Transcriptional activation assays typically utilise yeast or mammalian cells, and incorporate reporter proteins such as $\beta$-galactosidase, chloramphenicol acetyl transferase and luciferase (Collins-Burow, Burow et al. 2000; Tully, Cox et al. 2000; Gunther, Parent et al. 2009; Nose, Tokunaga et al. 2009). The main theory behind an assay such as this is that when a ligand binds to a NR, the resulting complex interacts with a response element present in the DNA which ultimately leads to downstream activation of a reporter gene. These quantitative cell-based assays have been used to measure hormone-induced gene expression by compounds such as phytoestrogens and environmental contaminants (Gaido, Leonard et al. 1997; Tully, Cox et al. 2000). The co-transfection of hER- $\alpha$ and $-\beta$ with ERE into MCF-7 (a 
mammary adenocarcinoma cell line) displayed differential affinities for the phytoestrogens tested, depending on the isoform (Harris, Besselink et al. 2005). A similar result was observed with oestrogenic compounds present in animal feeds (Welshons, Rottinghaus et al. 1990). Recombinant yeast has been utilised to test different ER mRNA species co-expressed in breast tumour to determine which were active forms (Balmelli-Gallacchi, Schoumacher et al. 1999).

Cell proliferation assays are a further way of monitoring steroidogenic effects. A common cell line utilised for this are MCF-7 cells. Examples include measuring the proliferation of MCF cells (transfected with aromatase) when treated with mushroom phytochemical extracts, the effect of specific phytoestrogens on the proliferation of MCF-7 and BG-1 cells (an ovarian carcinoma cell line) and the influence of phytoestrogens and $\mathrm{E}_{2}$ combined on MCF-7 cell proliferation (termed E-SCREEN assay) (Soto, Sonnenschein et al. 1995; Grube, Eng et al. 2001; Schmitt, Dekant et al. 2001; Schmidt, Michna et al. 2005). Using the cell proliferation assay method, the flavonoid quercetin has been shown to cause proliferation of both MCF-7 and T47D cells (a mammary ductal carcinoma cell line) that is dependent on ER (van der Woude, ter Veld et al. 2005).

Enzyme immunoassays have been used to evaluate the effect of environmental samples on biological systems by detecting steroids or steroid-like compounds present (Hintemann, Schneider et al. 2006; Allinson, Shiraishi et al. 2010) as well as the effect of phytoestrogens (Dalais, Meliala et al. 2004). They are based on the principle of antibodies being capable of binding selectively and reversibly to organic molecules.

\subsubsection{In vivo Methods}

In vivo models for investigating hormonal-related effects are less varied compared with the in vitro methods that have been developed. The main advantage of an in vivo approach is that it demonstrates a whole system effect whereas in vitro often focuses on isolated effects. It can also be used to study an effect at any stage of the life cycle and is a good complement to results obtained from other types of studies.

One method for in vivo testing is to develop a transgenic model. In 2000, a transgenic zebrafish assay was developed which has an ER-mediated luciferase reporter gene construct stably introduced into the zebrafish. The level of induction of luciferase in different tissue 
types can be directly related to the activation of ER (Legler, Broekhof et al. 2000). This has been used to test numerous compounds at a number of different life stages of zebrafish (Schreurs, Lanser et al. 2002; Vethaak, Lahr et al. 2005; Bogers, Mutsaerds et al. 2006).

Another in vivo method to determine oestrogenicity is through monitoring vitellogenin. Vitellogenin is a common biological indicator and this approach has been used in many different fish species such as rainbow trout, California halibut and zebrafish (Christiansen, Pedersen et al. 1998; Schlenk, Sapozhnikova et al. 2005; Sun, Wen et al. 2010).

Finally, uterotrophic assays, particularly those with rodents, have been used for oestrogenic detection (Odum, Lefevre et al. 1997; Ashby and Tinwell 1998; Kang, Kim et al. 2000; Dixon, Reed et al. 2012; Hu, Zhang et al. 2013). The principle behind this method is that uterine growth is under the influence of oestrogens and so the rate of growth when oestrogenic compounds are present can be measured. This gives an indication of their oestrogenic activity.

\subsubsection{Yeast Bioassays}

Yeast (Saccharomyces cerevisiae) is commonly utilised in bioassays partly because the entire genome has been sequenced (Goffeau, Barrell et al. 1996), and also because it is efficient and cost-effective to grow. From the perspective of developing an assay to measure steroids and the effects of steroids, yeast is an ideal candidate as it lacks many of the receptors to be investigated. This means these naturally absent receptors can be transfected into the genome. Hence many transfected yeast assays exist for the different steroid receptors.

One of the first examples of a steroid receptor being incorporated and expressed in yeast was the hER in 1988 (Metzger, White et al. 1988). The ER produced by the transfected yeast was indistinguishable from the form expressed in humans and demonstrated hormonally-dependent transcription after ERE recognition. This was confirmed to be under the control of the hormone and not influenced by the yeast cell itself.

Numerous other publications show nuclear receptors being ectopically expressed in Saccharomyces cerevisiae. These include not only ER, but also AR, PR, GR and AhRs (e.g. Gaido, Leonard et al. 1997; Lee, Lee et al. 2003; Death, McGrath et al. 2004; Michelini, Leskinen et al. 2005). 
Since the initial study in 1988, a multitude of different approaches using yeast assays for oestrogenic activity have been published. For example, it has been used to screen animal feed, calf urine and heavy metals for potential oestrogenic activity (Bovee, Bor et al. 2006; Denier, Couteau et al. 2008; Bovee, Bor et al. 2009) as well as to detect SERMs and other chemicals and extracts (Routledge and Sumpter 1996; Gaido, Leonard et al. 1997; Takamura-Enya, Ishihara et al. 2003; Bovee, Thevis et al. 2010).

The activity of phytoestrogens has also been determined using recombinant yeast (e.g. Coldham, Dave et al. 1997). These recombinant yeast assays usually consist of an ER isoform and at least one ERE. A gene downstream of the ERE is incorporated into the genome for the detection of successful binding and quantification of potency of the compound being investigated. As stated earlier, the downstream genes that have been used include $\beta$-galactosidase, alkaline phosphatase or chloramphenicol acetyltransferase and luciferase.

One method for measuring $\beta$-galactosidase expression, as used by Routledge and Sumpter in 1996 , is to use chlorophenol red- $\beta$-galactopyranoside (CPRG) (Routledge and Sumpter 1996). This involves measuring the colour change as the substrate CPRG (yellow-orange) is converted to chlorophenol red (CPR) by the freshly synthesised $\beta$-galactosidase (Figure 1.18). The level of conversion is dependent on how much $\beta$-galactosidase is produced which is directly related to how oestrogenic a compound is.<smiles>[NH3+]c1ccccc1C(c1ccc(OC2OC(CO)C(O)[C@H](O)C2O)c(Cl)c1)C1C=CC(=O)C(Cl)=C1</smiles>

chlorophenol red galactopyranoside (CPRG)

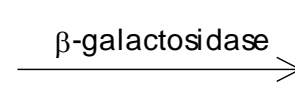<smiles>OCC1OC(O)C(O)C(O)C1O</smiles>

galactose<smiles>O=C1C=CC(C(c2cccc(Cl)c2)c2ccccc2[O-])C=C1Cl</smiles>

chlorophenol red (CPR)

Figure 1.18 Schematic of the conversion of chlorophenol red galactopyranoside (CPRG) to chlorophenol red (CPR) and galactose by $\beta$-galactosidase. 


\subsection{Hypothesis}

Based on the aforementioned hypothesis proposed by Fidler et al., the central hypothesis of this study is that the food eaten by Kākāpō contains phytochemicals, the levels of which fluctuate seasonally. It is these phytochemicals that act to increase the fertility of the female birds by binding to steroid receptors and mimicking the actions of steroids. As other native avian species have a similar habitat to that of Kākāpō, and thus browse on the same native plants, it is postulated that there might be something different in the sequence or three-dimensional structure of Kākāpō steroid receptors which leads to different binding behaviour of the phytochemicals, and hence the different reproductive strategy seen with Kākāpō. A key aspect of this hypothesis is that it is the LBDs of these proposed steroid receptors that bind the phytochemicals that exhibit differences in Kākāpō when compared to other avian species. As the reproduction of Kākāpō does share similarities to other New Zealand parrots such as Kākā, the LBDs may however demonstrate degrees of similarity to other New Zealand parrots.

\subsection{Aims and Outline of this Thesis}

The aims of this project were to investigate the potential relationship between the breeding of Kākāpō and "masting" of native plants by (i) identifying and characterising the LBD sequences of a number of nuclear receptors in Kākāpō, related New Zealand parrots and unrelated avian species and (ii) elucidating the seasonal presence of compounds in native seeds or fruit with steroidogenic activity.

These aims are explored in four Chapters (3-6). Chapter Three investigated the nucleotide and translated protein sequences of the ligand binding domain (LBD) in multiple steroid receptors involved in reproductive success. These include AR, ER- $\alpha$, ER- $\beta$ and PR. The amplification of the LBDs of these receptors was carried out in Kākāpō, Kākāa, Kākāriki and Kea as well as Cockatiel, Chicken and Japanese quail. Three-dimensional modelling of each LBD using representative crystal structures as a template was used to visualise and compare the changed residues and examine their potential impacts on the overall structure. 
Chapter Four employed computational modelling to investigate the binding of known phytoestrogens and xenoestrogens in the LBD of Kakapo ER- $\alpha$ so as to determine the amino acids involved in the ligand-receptor interactions.

Chapter Five addressed the validation and optimisation of a yeast bioassay capable of detecting oestrogenic activity of compounds.

Finally, Chapter Six utilised the yeast bioassay to investigate the presence of seasonal trends in oestrogenic activity of New Zealand native plant samples collected over a four year period. 


\section{CHAPTER 2: MATERIALS AND METHODOLOGY}

\subsection{Reagents}

The reagents used in these studies are listed below together with their catalogue numbers and suppliers.

17ß-oestradiol ( $\left.\mathrm{E}_{2}\right)$ (E8875, Sigma-Aldrich, St Louis, MO, USA)

Adenine (A2786, Sigma-Aldrich, St Louis, MO, USA)

Agilent RNA 6000 Nano Assay kit (5067-1511, Agilent Technologies, Waldbronn,

Germany)

Ammonium sulphate (( $\left.\left.\mathrm{NH}_{4}\right)_{2} \mathrm{SO}_{4}\right)(\mathrm{A} 4418$, Sigma-Aldrich, St Louis, MO, USA)

Ampicillin, sodium salt (A0166, Sigma-Aldrich, St Louis, MO, USA); (70043426, Roche

Diagnostics, Mannheim, Germany)

Bacto $^{\text {TM }}$ Agar (BD Ref 214010, Becton Dickinson, Sparks, MD, USA)

Bacto $^{\text {TM }}$ Tryptone pancreatic digest of casein (BD Ref 211705, Becton Dickinson, Sparks, MD, USA)

Bacto $^{\text {TM }}$ Yeast Extract, extract of autolysed yeast cells (BD Ref 212750, Becton Dickinson, Sparks, MD, USA)

Biotin (B4501, Sigma-Aldrich, St Louis, MO, USA)

Bisphenol A (BPA) (239658, Sigma-Aldrich, St Louis, MO, USA)

Bromophenol blue (B6131, Sigma-Aldrich, St Louis, MO, USA)

Buffer H (SuRE/Cut 11417991001, Roche, Manneheim, Germany)

Cellulase, from Aspergillus niger (C1184, Sigma-Aldrich, St Louis, MO, USA)

Copper sulphate $\left(\mathrm{CuSO}_{4}\right)$ (C1297, Sigma-Aldrich, St Louis, MO, USA)

Chloroform (C2432, Sigma-Aldrich, St Louis, MO, USA)

Chlorophenol Red- $\beta$-D-galactopyranoside (CPRG) (59767, Sigma-Aldrich, St Louis, MO, USA)

DH5 $\alpha$ cells (Sub cloning Efficiency ${ }^{\mathrm{TM}}$ DH5 $\alpha^{\mathrm{TM}}$ competent cells, 18265-017, Life

Technologies, Carlsbad, CA, USA)

Diethylpyrocarbonate (DEPC) (D5758, Sigma-Aldrich, St Louis, MO, USA)

dNTP set (10297-018, Life Technologies, Carlsbad, CA, USA)

D-pantothenic acid hemicalcium salt (P2250, Sigma-Aldrich, St Louis, MO, USA) 
EcoR I (10U/ $\mu L, 175084001$, Roche Diagnostics, Mannheim, Germany)

Ethylenediaminetetraacetic acid (EDTA) (100935V, AnalR, BDH, Poole, England)

Ethanol (RNase free molecular biology grade, A3678, VWR International, Darmstadt,

Germany)

Ethanol (absolute, 200-9985.2500, PureScience, Wellington, New Zealand)

Ferric sulphate $\left(\mathrm{Fe}_{2}\left(\mathrm{SO}_{4}\right)_{3} . x \mathrm{H}_{2} \mathrm{O}\right)$ (307718, Sigma-Aldrich, Munich, Germany)

Formaldehyde (FO00102500, Scharlau, Sentmenat, Spain)

GeneRuler $^{\mathrm{TM}} 1 \mathrm{~Kb}$ Plus DNA Ladder $(0.5 \mu \mathrm{g} / \mu \mathrm{L}, \mathrm{SM} 1331$, Fermentas, Thermo Fisher

Scientific, Waltham, MA, USA)

Glacial acetic acid (AC03522500, Scharlau, Sentmenat, Spain)

Glucose (G4500, Sigma-Aldrich, St Louis, MO, USA)

Glycerol (G5516, Sigma-Aldrich, St Louis, MO, USA)

HotMaster $^{\text {TM }}$ Taq DNA polymerase kit (2200300, 5 PRIME, Hamburg, Germany)

Hydrochloric acid (HCl) (AR grade, 1367-2.5L, UNIVAR, Seven Hills, Australia)

Isoamyl alcohol (A2610, VWR International, Darmstadt, Germany)

Isopropanol (RNase free molecular biology grade, A3928, VWR International, Darmstadt,

Germany)

Isopropanol (AR grade, 102246L, BDH, Poole, England)

L-arginine HCl (A6969, Sigma-Aldrich, St Louis, MO, USA)

L-aspartic acid (A9256, Sigma-Aldrich, St Louis, MO, USA)

L-glutamic acid (G8415, Sigma-Aldrich, St Louis, MO, USA)

L-histidine (H8000, Sigma-Aldrich, St Louis, MO, USA)

L-isoleucine (I2752, Sigma-Aldrich, St Louis, MO, USA)

L-lysine HCl (L8662, Sigma-Aldrich, St Louis, MO, USA)

L-methionine (M9625, Sigma-Aldrich, St Louis, MO, USA)

L-phenylalanine (P5482, Sigma-Aldrich, St Louis, MO, USA)

L-serine (S4311, Sigma-Aldrich, St Louis, MO, USA)

L-threonine (T8625, Sigma-Aldrich, St Louis, MO, USA)

L-tyrosine (T8566, Sigma-Aldrich, St Louis, MO, USA)

L-valine (V0513, Sigma-Aldrich, St Louis, MO, USA)

Magnesium sulphate $\left(\mathrm{MgSO}_{4}\right)$ (M1880, Sigma-Aldrich, St Louis, MO, USA)

Methanol (LC grade, 106018, Merck, Darmstadt, Germany)

3-(N-morpholino)propanesulfonic acid (MOPS) (BDH4522, BDH, Poole, England) 
Myo-Inositol (57569, Fluka, Steinheim, Germany)

$N, N$-Dimethylformamide (D4537, Sigma-Aldrich, St Louis, MO, USA)

pGEM $^{\circledR}$-T Easy plasmid vector kit (A1360, Promega, Madison, WI, USA)

Phenol (P4557, Sigma-Aldrich, St Louis, MO, USA)

Potassium hydroxide (KOH) (P1767, Sigma-Aldrich, St Louis, MO, USA)

Potassium phosphate $\left(\mathrm{KH}_{2} \mathrm{PO}_{4}\right)$ (P9791, Sigma-Aldrich, St Louis, MO, USA)

Progesterone (P0130, Sigma-Aldrich, St Louis, MO, USA)

Proteinase K (from Tritirachium album, P2308, Sigma-Aldrich, St Louis, MO, USA)

Pyridoxine HCl (P9755, Sigma-Aldrich, St Louis, MO, USA)

QIAprep® Spin Miniprep Kit (27106, Qiagen, Hilden, Germany)

QIAquick® Gel Extraction Kit (28704, Qiagen, Hilden, Germany)

RiboPure ${ }^{\mathrm{TM}}-$ Blood Kit (AM1928, Ambion, Austin, TX, USA)

SeaKem® LE Agarose (50004, LONZA, Alphatech, Rockland, ME, USA)

Sodium acetate (102363P, AnalaR, BDH, Poole, England)

Sodium chloride $(\mathrm{NaCl})$ (reagent grade, SO02270500, Scharlau, Sentmenat, Spain)

Sodium dodecyl sulphate (SDS) (BD166, Fisher Scientific, Loughborough, UK)

SuperScript VILO ${ }^{\text {TM }}$ cDNA (11754-050, Life Technologies, Carlsbad, CA, USA)

SuperScript $^{\mathrm{TM}}$ III First-Strand Synthesis Supermix Kits (18080-400, Life Technologies,

Carlsbad, CA, USA)

SYBR $^{\circledR}$ Safe DNA gel stain (SYBR green) (S33102, Life Technologies, Carlsbad, CA, USA)

Testosterone (T1500, Sigma-Aldrich, St Louis, MO, USA)

Thiamine HCl (T4625, Sigma-Aldrich, St Louis, MO, USA)

Triclosan (Irgasan) (72779, Sigma-Aldrich, St Louis, MO, USA)

Tris (Ultrapure, A1086,1000, VWR International, Darmstadt, Germany)

TRIzol@ Reagent (15596-018, Life Technologies, Carlsbad, CA, USA)

UltraPure $^{\mathrm{TM}}$ (UP) distilled water (DNAse, RNAse free, 10977, Gibco ${ }^{\circledR}$, Life Technologies,

Carlsbad, CA, USA)

Urea (molecular biology grade, A1049,0500, VWR International, Darmstadt, Germany)

X-gal (A4978,0001, VWR International, Darmstadt, Germany)

All solutions used for the following procedures are described in Appendix 1. 


\subsection{Tissue Collection}

Tissue samples used for this research were kindly gifted to the laboratory by Dr Andrew Fidler (Cawthron Institute, Nelson) and the Department of Conservation (DOC). These samples had been collected from throughout New Zealand and were stored under a DOC permit (SO-27143-DOA). Environmental Risk Management Authority (ERMA) approval was obtained to identify and characterise reproductive genes in Kākā, Kākāpō, Kākāriki and Kea (200183). Two additional ERMA approvals (200423 and GMD08037) covered the investigation of other species.

\subsection{Isolation of Red Blood Cells}

Blood was collected in a $4 \mathrm{~mL}$ heparin-coated vacutainer (lithium heparin 68 I.U., Becton Dickinson, Franklin Lakes, NJ) and transported on wet ice to the laboratory. Samples were then centrifuged at $4^{\circ} \mathrm{C}$ at $1,500 \mathrm{~g}$ for 15 minutes (min) (the brake decreased to 6) (Model 5810R Centrifuge, Eppendorf, Germany) to fractionate the blood into plasma and red blood cells. The supernatant (plasma layer) was discarded and the red blood cells transferred to a sterile microcentrifuge tube and stored at $-80^{\circ} \mathrm{C}$.

\subsection{Red Blood Cell and Tissue RNA Extraction}

The red blood cell and tissue RNA extractions were initially carried out in a fume hood and subsequently in a laminar hood once all TRIzol ${ }^{\circledR}$ was removed. A standard TRIzol RNA extraction protocol was undertaken at room temperature unless otherwise stated.

For RNA extractions of red blood cells, $1 \mathrm{~mL}$ TRIzolß Reagent was added to $200 \mu \mathrm{L}$ red blood cells and mixed for 20 seconds (sec) by inverting the tube. Following a $5 \mathrm{~min}$ incubation, $200 \mu \mathrm{L}$ chloroform was added and the tube was shaken vigorously for 15 seconds and incubated for a further $5 \mathrm{~min}$. The extract was then centrifuged for $15 \mathrm{~min}$ at 12,000 $\mathrm{g}$ (Model 5415R Centrifuge, Eppendorf, Germany) at $4^{\circ} \mathrm{C}$. The upper aqueous phase was transferred into a sterile microcentrifuge tube and RNA was precipitated by the addition of $500 \mu \mathrm{L}$ isopropanol (RNase free molecular biology grade). The sample was then mixed gently and incubated for $10 \mathrm{~min}$. Following centrifugation at $12,000 \mathrm{~g}$ for $10 \mathrm{~min}$ at $4^{\circ} \mathrm{C}$, the 


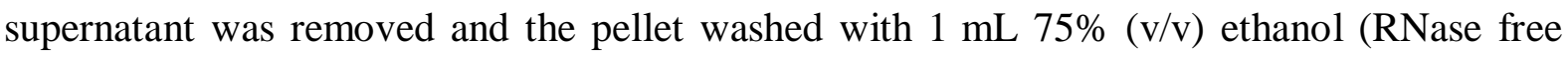
molecular biology grade). The extract was then vortexed briefly and centrifuged at $7,400 \mathrm{~g}$ for $5 \mathrm{~min}$ at $4^{\circ} \mathrm{C}$. After removing the supernatant and air drying the pellet for $10 \mathrm{~min}$, the pellet was resuspended in $10 \mu \mathrm{L}$ UltraPure ${ }^{\mathrm{TM}}$ (UP) distilled water, incubated for $10 \mathrm{~min}$ at $55^{\circ} \mathrm{C}$ and placed on wet ice to chill. For some samples, up to $30 \mu \mathrm{L}$ of UP distilled water was added to fully dissolve the RNA pellet. RNA samples were stored at $-80^{\circ} \mathrm{C}$ until use.

Extraction of RNA from tissue samples was carried out as described above for red blood cells except that the quantities were based on $100 \mathrm{mg}$ of tissue sample. Following the addition of TRIzol® Reagent, the sample was homogenised using a T25 digital ULTRA-TURRAX ${ }^{\circledR}$ with a $4 \mathrm{~mm}$ blade (IKA ${ }^{\circledR}$, Malaysia) in $5 \mathrm{sec}$ bursts while chilled on ice. The homogenised samples were incubated at room temperature (rt) for $5 \mathrm{~min}$ after which chloroform was added. The sample was then transferred to a sterile microcentrifuge tube and the remainder of the extraction procedure was undertaken as described above.

\subsection{DNase I Treatment}

Any genomic DNA (gDNA) present in the extracted RNA samples was removed using a RiboPure ${ }^{\mathrm{TM}}$-Blood Kit (Ambion). Briefly, $1.5 \mu \mathrm{L}$ 20X DNase buffer and $1 \mu \mathrm{L}$ DNase I (8 units $/ \mu \mathrm{L}$ ) was added to $30 \mu \mathrm{L}$ of RNA sample. The sample was gently mixed and then incubated for $30 \mathrm{~min}$ at $37^{\circ} \mathrm{C}$ to digest the gDNA. After the incubation, $6 \mu \mathrm{L}$ DNase Inactivation Reagent (20\% RNA sample volume) was added. The sample was then vortexed briefly $(5 \mathrm{sec}$ ) and incubated for $2 \mathrm{~min}$ at $\mathrm{rt}$. The treated RNA sample was centrifuged at 3,300 $g$ for $1 \mathrm{~min}$ in a benchtop centrifuge. The supernatant containing DNA-free RNA was transferred into a sterile microcentrifuge tube and then either stored at $-80^{\circ} \mathrm{C}$ or used for RNA quantification.

\subsection{Quantification of RNA}

Quantification of RNA within the extracted samples was undertaken using an Agilent 2100 Bioanalyzer (Agilent Technologies, Germany). An Agilent RNA 6000 Nano Assay kit providing all the required reagents including the RNA ladder, and samples for RNA quantification were prepared by following the manufacturer's instructions. Briefly, an 
aliquot $(1 \mu \mathrm{L})$ of RNA ladder and extracted RNA sample were heat denatured for 2 min at $70^{\circ} \mathrm{C}$ and placed on ice. One well of the chip was loaded with $9 \mu \mathrm{L}$ of RNA 6000 Nano gel matrix-RNA 6000 Nano dye mixture. The chip was then primed using a priming station and applying pressure to the well with a syringe for $30 \mathrm{sec}$ before adding $9 \mu \mathrm{L}$ gel-dye mixture and $5 \mu \mathrm{L}$ RNA 6000 Nano marker to the other wells. After the chip was primed, $1 \mu \mathrm{L}$ RNA ladder and $1 \mu \mathrm{L}$ RNA sample were pipetted into the appropriate wells. The chip was vortexed for 60 seconds at 2,400 rpm (Vortexer, IKA ${ }^{\circledR}$ WORKS, Malaysia) and the samples were then analysed using Eukaryote Total RNA Nano Series II programme (Agilent 2100 Expert Software, Agilent Technologies).

\subsection{Gel Electrophoresis of Extracted RNA}

The samples of extracted RNA were electrophoresed on $1.5 \%$ (w/v) SeaKem® LE Agarose gels at $85 \mathrm{~V}$ in $1 \mathrm{X}$ MOPS running buffer and visualised by the addition of 100X SYBR green and 6X RNA loading dye. The GeneRuler ${ }^{\mathrm{TM}} 1 \mathrm{~Kb}$ DNA Ladder Plus ladder was used for estimation of molecular weight.

\section{8 cDNA Synthesis}

For the synthesis of cDNA, SuperScript VILO ${ }^{\mathrm{TM}}$ cDNA and SuperScript ${ }^{\mathrm{TM}}$ III First-Strand Synthesis Supermix Kits were used in accordance with manufacturer's instructions.

\subsubsection{SuperScript VILOTM ${ }^{\mathrm{TMN}}$ A synthesis}

The cDNA synthesis for PCR was carried out by combining $4 \mu \mathrm{L} 5 \mathrm{X}$ VILO ${ }^{\mathrm{TM}}$ Reaction Mix, $2 \mu \mathrm{L}$ 10X SuperScript ${ }^{\circledR}$ Enzyme Mix and $2.5 \mu \mathrm{g}$ total RNA in a $1.7 \mathrm{~mL}$ tube on ice and adding UP water to give a final volume of $20 \mu \mathrm{L}$. The tube was well mixed and then incubated for $10 \mathrm{~min}$ at $25^{\circ} \mathrm{C}, 60 \mathrm{~min}$ at $42^{\circ} \mathrm{C}$ and $5 \mathrm{~min}$ at $85^{\circ} \mathrm{C}$ using a Rotor-Gene 6000 system (Corbett Research Ltd., model no RG6000, United Kingdom). The cDNA sample was thereafter stored at $-80^{\circ} \mathrm{C}$. 
2.8.2 SuperScript III First-Strand Synthesis Supermix cDNA synthesis

For cDNA synthesis using the SuperScript III First-Strand Synthesis Kit, $5 \mu \mathrm{g}$ RNA, $1 \mu \mathrm{L}$ primer $(50 \mathrm{ng} / \mu \mathrm{L}$ random hexamer) and $1 \mu \mathrm{L}$ annealing buffer were added to a $0.2 \mathrm{~mL}$ thin-walled PCR tube on ice. Thereafter, $5 \mu \mathrm{g}$ RNA and UP water was added to give a final volume of $8 \mu \mathrm{L}$. The tubes were incubated for $5 \mathrm{~min}$ at $65^{\circ} \mathrm{C}$ to denature the RNA in a Rotor-Gene 6000 instrument and then chilled on ice. Subsequently, $10 \mu \mathrm{L} 2 \mathrm{X}$ First-Strand Reaction Mix and $2 \mu \mathrm{L}$ Superscript III/RNaseOUT Enzyme Mix was then added to the PCR tube which was vortexed briefly $(3 \mathrm{sec}$ ) before being incubated in the Rotor-Gene 6000 cycler for $10 \mathrm{~min}$ at $25^{\circ} \mathrm{C}, 50 \mathrm{~min}$ at $50^{\circ} \mathrm{C}$ and $5 \mathrm{~min}$ at $85^{\circ} \mathrm{C}$. The sample was thereafter stored at $-80^{\circ} \mathrm{C}$ or used directly for PCR.

\subsection{Genomic (g) DNA Extraction}

In those samples where total RNA extraction was not possible, extraction of gDNA was undertaken using a phenol:chloroform extraction method. All phenol steps were performed in a fumehood, whilst subsequent steps were carried out in a laminar flow hood (type II) once the phenol was removed. Lysis buffer was added to the sample (100 $\mu \mathrm{L} / 10 \mathrm{mg}$ tissue) and $10 \mathrm{mg} / \mathrm{mL}$ Proteinase $\mathrm{K}(1 \mu \mathrm{L} / 10 \mathrm{mg})$, vortexed and the sample tubes incubated at $55^{\circ} \mathrm{C}$ for $18 \mathrm{~h}$. Centrifugation at $1500 \mathrm{~g}$ was carried out for $5 \mathrm{~min}$ at $10^{\circ} \mathrm{C}$ and the supernatant then transferred to a sterile microcentrifuge tube. A $400 \mu \mathrm{L}$ phenol:chloroform:isoamyl alcohol (25:24:1) solution was added to the tube which was vortexed briefly $(3 \mathrm{sec})$ before centrifugation $(2,300 \mathrm{~g}$ for $5 \mathrm{~min})$ at $10^{\circ} \mathrm{C}$. Subsequently, the supernatant was transferred to a new tube, $900 \mu \mathrm{L}$ ethanol (absolute) was added and then the tube was vortexed and incubated for $2 \mathrm{~min}$ at rt. Following centrifugation as described above, the supernatant was discarded and $1 \mathrm{~mL}$ of $70 \%$ ethanol was added to the pellet and the tube was centrifuged as before. The ethanol was then aspirated and the pellet left to air dry for $10 \mathrm{~min}$ at $\mathrm{rt}$. Resuspension was achieved by adding $30 \mu \mathrm{L}$ of TE Buffer ( $\mathrm{pH} 8.0$ ), vortexing (5 sec) and then a brief centrifugation before snap freezing on dry ice. The samples were stored in sterile microcentrifuge tubes at $-20^{\circ} \mathrm{C}$ before further use. 


\subsection{Polymerase Chain Reaction (PCR)}

\subsubsection{Primers}

The primers used for the PCR reaction were designed using either NetPrimer or Beacon Designer (PREMIER Biosoft International, Palo Alto, CA) and manufactured by Life Sciences (Australia) (Table 2.1). Primers were reconstituted in $1 \mu \mathrm{L}$ TE Buffer ( $\mathrm{pH}$ 8.0) per 1 nmol primer and then aliquots $(2 \mu \mathrm{L})$ were added to sterile microcentrifuge tubes and diluted 100 times with UP water before being stored at $-20^{\circ} \mathrm{C}$. This gave a final concentration of $10 \mathrm{pmol} / \mu \mathrm{L}$.

Table 2.1 Oligonucleotide primers used for PCR amplification

\begin{tabular}{|c|c|c|c|}
\hline Gene & Primer Name & Primer Sequence $\left(5^{\prime} \rightarrow 3^{\prime}\right)$ & Accession Number \\
\hline \multirow[t]{2}{*}{$\beta$-actin } & $\beta$-actin forward & TGGTATTGTGATGGACTC & \multirow{2}{*}{ NM_205518 } \\
\hline & $\beta$-actin reverse & AAGAAAGATGGCTGGAAG & \\
\hline \multirow{4}{*}{$\begin{array}{l}\text { Oestrogen Receptor } \\
\alpha(E R-\alpha)\end{array}$} & ER- $\alpha$ forward 1 & TGACAGCAGAACAGATGG & \multirow{4}{*}{ NM_205183 } \\
\hline & ER- $\alpha$ reverse 1 & TGATGTGAGAGAGGATAAGGAGGA & \\
\hline & ER- $\alpha$ forward 2 & TAGCACCTTGAAATCTCTGGAAGA & \\
\hline & ER- $\alpha$ reverse 2 & GCTAATGTCATTGGAGTGTT & \\
\hline \multirow{2}{*}{$\begin{array}{l}\text { Oestrogen Receptor } \\
\beta(\text { ER- } \beta)\end{array}$} & ER- $\beta$ forward & TTGATCTCAGCCTCTATGAC & \multirow{2}{*}{ NM_204794 } \\
\hline & ER- $\beta$ reverse & CATTGCCTTGACACACAG & \\
\hline \multirow{2}{*}{$\begin{array}{l}\text { Androgen Receptor } \\
\text { (AR) }\end{array}$} & AR forward & TTGCATGTGGATGACCAGATGT & \multirow{2}{*}{ NM_001040090 } \\
\hline & AR reverse & CACGGAGTCCAGGACCTTG & \\
\hline \multirow{4}{*}{$\begin{array}{l}\text { Progesterone } \\
\text { Receptor (PR) }\end{array}$} & $P R$ forward 1 & GGAAGGTCTAAGAAGTCAAAGCCA & \multirow{4}{*}{ NM_205262 } \\
\hline & $P R$ reverse 1 & TACAAAACTGATGGATTCCATGCA & \\
\hline & PR forward 2 & AATTCGTAGGAAGAACTGTC & \\
\hline & $P R$ reverse 2 & $\overline{A A C C G A C C C A G A A A T C A T}$ & \\
\hline
\end{tabular}

\subsubsection{PCR Setup}

PCR reactions were set up in a laminar flow hood (type II). The quality of cDNA sample was determined firstly through amplification of the $\beta$-actin gene before the different steroid receptor ligand binding domains (LBD) were amplified. Each $50 \mu \mathrm{L}$ PCR reaction consisted of $200 \mu \mathrm{M}$ of each dNTP, $0.2 \mu \mathrm{M}$ of forward primer, $0.2 \mu \mathrm{M}$ of reverse primer, $5 \mu \mathrm{L} 10 \mathrm{x}$ HotMaster $^{\mathrm{TM}}$ Taq buffer, $1.5-2.5 \mathrm{U}_{\text {of HotMaster }}{ }^{\mathrm{TM}}$ Taq DNA polymerase, the appropriate amount of cDNA (to give the equivalent of $1 \mu \mathrm{g}$ RNA) and UP water. After brief mixing and centrifugation, the samples were incubated in an Eppendorf PCR machine (Mastercycler ${ }^{\circledR}$ Pro, Eppendorf, Germany) using the cycling programme defined in Table 2.2. The annealing temperature was decreased to $56^{\circ} \mathrm{C}$ for difficult amplifications. 
Table 2.2 Cycling Programme used for PCR reactions

\begin{tabular}{|l|c|c|c|}
\hline Step & Temperature & Time & Number of Cycles \\
\hline Initial denaturation & $95^{\circ} \mathrm{C}$ & $3 \mathrm{~min}$ & 1 \\
\hline Denaturing & $95^{\circ} \mathrm{C}$ & $20 \mathrm{sec}$ & \multirow{2}{*}{$35-40$} \\
\hline Annealing & $58^{\circ} \mathrm{C}$ & $25 \mathrm{sec}$ & \\
\hline Extension & $72^{\circ} \mathrm{C}$ & $50 \mathrm{sec}$ & 1 \\
\hline Final Extension & $72^{\circ} \mathrm{C}$ & $7 \mathrm{~min}$ & 1 \\
\hline Hold & $4^{\circ} \mathrm{C}$ & HOLD & \\
\hline
\end{tabular}

\subsection{Gel Electrophoresis of PCR Products}

To estimate the size and amount of product amplified, the PCR amplification products were mixed with 100X SYBR green $(1.5 \mu \mathrm{L})$ and 6X DNA loading dye $(6 \mu \mathrm{L})$ for visualisation, and electrophoresed on $1.0 \%-2.0 \%$ SeaKem ${ }^{\circledR}$ LE Agarose gels at $85 \mathrm{~V}-95 \mathrm{~V}$ constant voltage in $1 \mathrm{X}$ TAE buffer. The ladder used for estimation of molecular weight was GeneRuler ${ }^{\mathrm{TM}} 1 \mathrm{~Kb}$ DNA Ladder Plus (Fermentas, Thermo Fisher Scientific).

\subsection{Gel Extraction}

To verify the sequence of the amplification product following successful amplification by PCR, bands were excised from the gel using a clean scalpel blade. Gel extraction was undertaken using a QIAquick ${ }^{\circledR}$ Gel Extraction Kit (Qiagen) according to the manufacturer's instructions. Briefly, Buffer QG was added at three times the amount of the gel sample (w/v) and samples were incubated in a $55^{\circ} \mathrm{C}$ water bath for 20 min with periodic vortexing to dissolve the agarose. To precipitate the DNA, $1 \mathrm{x}$ volume of isopropanol (Analytical reagent (AR) grade) was added and, following mixing, the sample was loaded onto a QIAquick spin column and centrifuged for one min at $14,000 \mathrm{~g}$. The column was then washed with $500 \mu \mathrm{L}$ Buffer QG and the centrifugation step repeated. After discarding the eluate, $750 \mu \mathrm{L}$ Buffer 
PE was added and the column was centrifuged for $1 \mathrm{~min}$ at $14,000 \mathrm{~g}$. The column was transferred to a sterile microcentrifuge tube, 30-50 $\mu \mathrm{L}$ Buffer EB (10 mM Tris.Cl, $\mathrm{pH}$ 8.5) was pipetted onto the membrane and the column incubated for $1 \mathrm{~min}$ at $\mathrm{rt}$ to release the DNA from the silica column. The column was then centrifuged for $1 \mathrm{~min}$ at $14,000 \mathrm{~g}$ and the eluate containing the eluted DNA was stored at $-20^{\circ} \mathrm{C}$.

\subsection{DNA Ligation}

The DNA eluted from the gel extraction was ligated into the pGEM $^{\circledR}$-T Easy plasmid vector by combining 2 X Ligase buffer $(5 \mu \mathrm{L}), 50 \mathrm{ng}$ of pGEM $^{\circledR}-\mathrm{T}$ Easy vector $(1 \mu \mathrm{L})$, the eluted DNA $(3 \mu \mathrm{L})$ and 3 units of T4 DNA Ligase $(1 \mu \mathrm{L})$, and mixing gently. The solution was then incubated for $2 \mathrm{~h}$ at $\mathrm{rt}$.

\subsection{Transformation}

The pGEM $^{\circledR}$-T Easy plasmid vector containing the amplified DNA insert was transformed into DH5 $\alpha$ cells. Briefly, $50 \mu \mathrm{L} \mathrm{DH} 5 \alpha$ cells $\left(\sim 6 \times 10^{8}\right.$ cells) were mixed gently with $5 \mu \mathrm{L}$ of ligated DNA in a $15 \mathrm{~mL}$ centrifuge tube and then incubated for $30 \mathrm{~min}$ on ice. The cells were then heat-shocked for $2 \mathrm{~min}$ in a $37^{\circ} \mathrm{C}$ water bath and chilled for $2 \mathrm{~min}$ on ice. An aliquot of $950 \mu \mathrm{L}$ Luria Broth (LB) was added and the samples shaken for $60 \mathrm{~min}$ in a shaking $37^{\circ} \mathrm{C}$ incubator (250 rpm) (BIOLINE Shaker, BIA620, Edwards Instrument Company, Australia). After incubation, the cells were centrifuged for $5 \mathrm{~min}$ at $\sim 1800 \mathrm{~g}$ and the supernatant was discarded. The remaining pellet was resuspended in $200 \mu \mathrm{L} \mathrm{LB}$ and then pipetted onto LB-ampicillin $(50 \mu \mathrm{g} / \mathrm{mL})$ plates pre-spread with $50 \mu \mathrm{L} 2 \%$ X-gal. The plates were subsequently incubated for $18 \mathrm{~h}$ at $37^{\circ} \mathrm{C}$.

\subsection{Colony Selection}

The colonies containing the plasmid vector insert were white and easily distinguished from those without (blue). The blue colour is due to the inability of the non-transfected cells to metabolise X-gal. Thus, individual white colonies were selected using sterilised inoculating loops (LPT30118, Thermo Fisher Scientific, Waltham, MA, USA) and grown to confluence 
in glass vials containing $10 \mathrm{~mL} \mathrm{LB}$ and $10 \mu \mathrm{L}$ ampicillin $(50 \mathrm{mg} / \mathrm{mL})$ in a shaking $37^{\circ} \mathrm{C}$ incubator (250 rpm) for $18 \mathrm{~h}$.

\subsection{DNA Miniprep Purification}

The DNA miniprep purification was carried out using QIAprep® Spin Miniprep Kit (Qiagen) according to manufacturer's instructions. All buffers used for this procedure were supplied in the kit. In brief, cultures grown from selected colonies (see above) were pelleted by centrifugation for $10 \mathrm{~min}$ at $\sim 1800 \mathrm{~g}$ and the supernatant was discarded. The transformed bacterial cells were resuspended in $250 \mu \mathrm{L}$ Buffer P1 and then transferred to a sterile microcentrifuge tube. After the addition of $250 \mu \mathrm{L}$ Buffer P2 and gentle mixing, the tube was incubated for $5 \mathrm{~min}$ at $\mathrm{rt}$ to lyse the cells. Following the incubation, $350 \mu \mathrm{L} \mathrm{N} 3$ was added and the tube was inverted. Cell debris was removed by centrifugation for $10 \mathrm{~min}$ at $13,000 \mathrm{~g}$ and the supernatant was passed through a QIAprep spin column by centrifugation for $1 \mathrm{~min}$. The column was then washed with Buffer PE before being placed in a sterile microcentrifuge tube. The sample was incubated with $50 \mu \mathrm{L}$ Buffer EB for 1 min at rt to release the DNA from the silica column and then eluted by centrifugation for $1 \mathrm{~min}$ at $13,000 \mathrm{~g}$.

\subsection{Quantification of DNA}

The DNA content was quantified using a UV spectrophotometer (WPA Biowave II, Biochrom Ltd., Cambridge, England). Briefly, a $2 \mu \mathrm{L}$ aliquot of the miniprep sample was diluted in TE buffer ( $\mathrm{pH} 8.0$ ) to a final volume of $200 \mu \mathrm{L}$ and the absorbance was measured at $260 \mathrm{~nm}$. The concentration of DNA within the sample was estimated using the following equation:

$$
\mathrm{mg} / \mu \mathrm{L}=\mathrm{A}_{260} \mathrm{x} \text { dilution factor } \times \mathrm{K}
$$

where $\mathrm{K}=50$ for dsDNA.

The absorbance at $280 \mathrm{~nm}$ was also measured to determine whether any protein contamination was present in the sample. Samples were determined not to be contaminated with protein if the 260:280 absorbance ratio was close to 2 . 


\subsection{Restriction Digest}

To confirm successful ligation, a restriction digest of the miniprep sample was carried out by combining $10 \mu \mathrm{L}$ of the miniprep sample, $1.5 \mu \mathrm{L}$ Buffer $\mathrm{H}$ (50 mM Tris- $\mathrm{HCl}, 10 \mathrm{mM} \mathrm{MgCl}$, $100 \mathrm{mM} \mathrm{NaCl}, 1 \mathrm{mM}$ dithioerythritol,), $1.0 \mu \mathrm{L}$ EcoR I and $2.5 \mu \mathrm{L}$ UP water. The solution was then incubated for 2 hours in a $37^{\circ} \mathrm{C}$ water bath. The reaction was terminated by incubating the sample for $5 \mathrm{~min}$ at $65^{\circ} \mathrm{C}$ and then cooled on wet ice. Products were visualised by $1.5 \%$ agarose gel electrophoresis.

\subsection{Sequencing}

To confirm the sequence of the PCR products, double pass sequencing of amplified products was performed by the Waikato DNA Sequencing Facility on an ABI 3130XL instrument (Applied Biosciences, USA) fitted with $50 \mathrm{~cm}$ capillary arrays and utilising Applied Biosystems Big Dye v3.1 dye terminator chemistry. Sequences were analysed and aligned using Geneious software (Geneious v.5.5.8, Biomatters. Available from http://www.geneious.com). The primers used for the sequencing were pUC/M13 forward and reverse primers as they were sequences found in pUC derived vectors such as $\mathrm{pGEM}^{\circledR}-\mathrm{T}$ Easy (Table 2.3).

Table 2.3 Primer sequences used for sequencing PCR products in the pGEM ${ }^{\circledR}$-T Easy vector

\begin{tabular}{|c|c|}
\hline Primer Name & Primer Sequence $(\mathbf{5}, \rightarrow \mathbf{3}$ ') \\
\hline pUC/M13 forward & CCCAGTCACGACGTTGTAAAACG \\
\hline pUC/M13 reverse & AGCGGATAACAATTTCACACAGG \\
\hline
\end{tabular}

\subsection{Basic Local Alignment Search Tool (BLAST)}

The NCBI BLAST tool (http://blast.ncbi.nlm.nih.gov/) was used to find sequences with similarity to those obtained from the PCR. Both the nucleotide and amino acid sequences 
were aligned against avian genomes available on the online database using blastn and blastp. This was also undertaken against the human genome.

To find areas of sequence similarity between the Kākāpō nucleotide sequences obtained for the steroid receptor LBDs and other avian species, BLAST searches were also undertaken against an unpublished database of avian coding DNA sequences downloaded from phybirds.genomics.org.cn (provided by G. Zhang, T. Gilbert and E. Jarvis, co-ordinators of the avian phylogenomics project). These searches were run on the Victoria University of Wellington high performance computing facility and utilised the blastn algorithm (Zhang, Schwartz et al. 2000).

\subsection{Three-Dimensional Modelling}

The sequences obtained for the steroid receptors of interest were modelled three-dimensionally. The templates used for the modelling were from the relevant human crystallographic data sourced from the Protein Databank (www.rcsb.org) (Table 2.4). These were visualised with PyMol (The PyMOL Molecular Graphics System, Version 1.5.0.4 Schrödinger, LLC) and the sequences for the New Zealand parrots aligned to that of the available human models. The amino acids that were different between the New Zealand parrots and human were mutated using the mutagenesis wizard available within PyMol.

Table 2.4 The Protein Data Bank (PDB) IDs for the human steroid receptors. (http://www.rcsb.org/pdb/home/home.do)

\begin{tabular}{|l|c|}
\hline Steroid Receptor: & PDB file: \\
\hline Oestrogen Receptor- $\alpha$ (ER- $\alpha)$ & $1 \mathrm{~A} 52$ \\
\hline Oestrogen Receptor- $\beta$ (ER- $\beta$ ) & $3 \mathrm{OLS}$ \\
\hline Androgen Receptor (AR) & $1 \mathrm{E} 3 \mathrm{G}$ \\
\hline Progesterone Receptor (PR) & $1 \mathrm{~A} 28$ \\
\hline
\end{tabular}




\subsection{In Silico Modelling of Compounds Bound in ER-a with RosettaLigand}

The software RosettaLigand was used to carry out computational modelling to predict the binding site of $E_{2}$ and various steroids and phytoestrogens in ER- $\alpha$. RosettaLigand is part of the Rosetta software suite and was downloaded from http://www.rosettacommons.org. Appropriate documentation on running Rosetta was obtained from the same website. The docking studies were performed on a 22-node Linux computer cluster with two AMD processors running at $2.2 \mathrm{GHz}$ in the Victoria University of Wellington high performance computing facility. All .py scripts were run with Python 2.7. Examples of files required for a successful docking run are in Appendix 2 Supplementary Figure 2A.

2.22.1 Preparation of the Ligand Input File (.pdb and .params files)

The ligand of interest was downloaded in .sdf format and converted to .mol format. The molfile_to_params.py script was then used to generate a ligand.params file (e.g. EST.params) as well as a ligand.pdb file.

\subsubsection{Preparation of the Minimised Kākāpō ER- $\alpha$ Protein PDB File}

The PDB file to be used for the modelling (1A52) was obtained from http://www.rcsb.org/pdb/home/home.do. Using a text editor, all the co-ordinates apart from that for one protein chain were removed. This protein chain was then modified to have the correct amino acids for the Kākāpō ER- $\alpha$ sequence (Kakapo_no_lig.pdb) and minimised using the options_ligand_rpkmin file (Appendix 2 Supplementary Figure 2A). From running this command, ten output files (in the format Kākāpō_no_lig_000*.pdb) were generated and the file with the lowest energy chosen (renamed Kakapo_input.pdb).

The ligand PDB file prepared in 2.22.1 was then appended to the end of the Kakapo_input.pdb file. The pdb file with the $\mathrm{E}_{2}$ ligand pdb file (EST.pdb) appended to the end was named Kakapo_native.pdb. 
2.22.3 Running the RosettaLigand Docking

The ligand_dock.xml script and options_ligand_dock file (Appendix 2 Supplementary Figure 2A) were edited to contain the appropriate parameters prior to each docking run. The starting co-ordinates employed for the $\mathrm{E}_{2}$ docking were those for the crystal structure of $\mathrm{E}_{2}$ bound in human ER- $\alpha$. For the other ligands, the generated ligand PDB file in 2.22.1 was aligned with the $E_{2}$ molecule in PyMol and the co-ordinates generated for the molecule from this alignment were used as the starting co-ordinates. Each docking study included 2500 runs with each run comprising of 50 translation iterations and 1000 rotation iterations. After the iterations, a high-resolution docking protocol was undertaken (included in the ligand_dock.xml file).

\subsubsection{Analysis of Docking Run}

On the completion of a docking study, a score.sc file was generated along with all the docking models produced. Analysis of this was carried out by firstly removing any structure in which the ligand did not bind in the receptor. The remaining structures were then ranked in order of lowest energy profile. The top $5 \%$ of these were then ranked by their interface_delta score. The structure with the lowest interface_delta score was determined to contain the most favourable binding position of the ligand and hence visualised with PyMol.

\subsubsection{Prediction of Ligand-Receptor Interactions}

For the prediction of potential hydrophobic interactions and hydrogen-bonding between the Kākāpō ER- $\alpha$ receptor and the docked ligand, the software package LigPlot ${ }^{+}$v.1.4.4 (Laskowski and Swindells 2011) was used. 


\subsection{Plant Collection}

Native plant samples that have been identified as a food source of Kākāpō (Best 1984; Wilson 2004; Butler 2006; Wilson, Grant et al. 2006) were collected at different time points. The following plant species were sampled at least once for this study (Table 2.5) and the collection time points and locations are outlined in Appendix 2 Supplementary Table $2 \mathrm{~A}$ and 2B. Plants that were to act as positive (soya bean; Glycine max) and negative (cauliflower; Brassica oleracea) controls, included in every bioassay, were also extracted.

Table 2.5 Native New Zealand plants collected for testing oestrogenic activity

\begin{tabular}{|l|l|}
\hline Plant Species: & Common Name \\
\hline Anisotome haastii & Haast's carrot \\
\hline Blechnum nova-zelandiae & Fern \\
\hline Carmichaelia arboea & South Island Broom \\
\hline Chionochloa rigida & Snow tussock \\
\hline Coprosma robusta & Karamu \\
\hline Cordyline australis & Cabbage tree \\
\hline Dacrycarpus dacrydioides & Kahikatea \\
\hline Dacrydium cupressinum & Rimu \\
\hline Dracophyllum longifolium & Inanga \\
\hline Gahnia procera & Mountain Ghania \\
\hline Leptecophylla juniperina & Mingimingi \\
\hline Leptospermum scoparium & Manuka \\
\hline Metrosideros umbellata & Southern Rata \\
\hline Nothofagus solandri var. solandri & Black Beech \\
\hline Olearia colensoi & Leatherwood \\
\hline Phormium tenax & Flax \\
\hline Podocarpus acutifolius & Westland Totara \\
\hline Podocarpus cunninghamii & Hall's Totara \\
\hline Podocarpus nivalis & Snow Totara \\
\hline Prumnopitys ferruginea & Miro \\
\hline Prumnopitys taxifolia & Matai \\
\hline
\end{tabular}

\subsection{Plant Extraction}

The plant samples collected for analysis were extracted and tested with an assay utilising a yeast strain expressing a mutated version of $h E R-\alpha$. The tissue grinders used for grinding the plant specimens to a powder were cleaned in a chromic acid bath and rinsed well with ethanol and distilled water between samples. 


\subsubsection{Methanol Extraction}

Following collection, plant samples were frozen at $-80^{\circ} \mathrm{C}$. Shortly thereafter, samples were freeze-dried for 48-72 h (VirTis benchtop K, USA with Trivac external vacuum pump) and a $2 \mathrm{~g}$ portion of the dried specimen was then ground to a powder with a tissue grinder. This ground sample was then transferred to a falcon tube together with $10 \mathrm{~mL}$ methanol (LC grade) and dispersed by a sonicator for $15 \mathrm{~min}$. The tubes were shaken at $1500 \mathrm{rpm}$ (IKA VIBRAX VXR basic) for $18 \mathrm{~h}$ at rt. Following brief centrifugation $\left(2,500 \mathrm{~g}\right.$ at $18^{\circ} \mathrm{C}$ for 5 $\min$ ), the supernatant was filtered through glass wool into an oestradiol-free glass vial. The solvent was then removed by rotary-evaporation and the sample was either reconstituted in $500 \mu \mathrm{L}$ fresh methanol and vortexed gently or digested with cellulase (Section 2.25.2).

\subsubsection{Cellulase Digestion of Plant Extract}

For cellulase digestion, $1 \mathrm{~mL}$ of $5 \mathrm{X}$ cellulase (100 Units, in $0.1 \mathrm{M}$ sodium acetate buffer, $\mathrm{pH} 5)$ and $4 \mathrm{~mL}$ of $0.1 \mathrm{M}$ sodium acetate buffer ( $\mathrm{pH} 5)$ was added to the methanol-extracted and evaporated sample (Section 2.25.1) and vortexed briefly. The sample was then incubated overnight at $37^{\circ} \mathrm{C}$ whilst shaking at $250 \mathrm{rpm}$. The digestion was terminated by incubating the sample at $65^{\circ} \mathrm{C}$ for $5 \mathrm{~min}$ before cooling on wet ice.

\subsection{Yeast Screen}

A yeast strain incorporating hER- $\alpha$ was kindly gifted by Brunel University, London, UK. Known xenoestrogens and phytoestrogens screened were kindly gifted by Dr Andrew Fidler (Cawthron Institute, Nelson). These were diluted to the appropriate concentrations with either ethanol or methanol.

\subsubsection{Preparation of Growth Media for the Yeast Strain}

For the preparation of stock solutions used to prepare the growth media, see Appendix 1.

The growth media was prepared by combining the following stock solutions into a sterile conical flask: $45.0 \mathrm{~mL}$ minimal media, $5.0 \mathrm{~mL} \mathrm{20 \% (w/v)} \mathrm{glucose,} 1.25 \mathrm{~mL} 30 \mathrm{mM}$ L-aspartic acid, $0.5 \mathrm{~mL}$ vitamin solution, $0.4 \mathrm{~mL} 0.2 \mathrm{M}$ L-threonine and $0.125 \mathrm{~mL} 20 \mathrm{mM}$ copper (II) sulphate. 


\subsubsection{Preparation of Yeast Stocks}

A colony of the yeast strain containing hER- $\alpha$ was inoculated in approximately $50 \mathrm{~mL}$ of growth media and incubated for $24 \mathrm{~h}$ at $28^{\circ} \mathrm{C}$ whilst shaking at $250 \mathrm{rpm}$. Thereafter a $1 \mathrm{~mL}$ aliquot of the culture was added to $52 \mathrm{~mL}$ of new growth media and grown for a further $24 \mathrm{~h}$ at $28^{\circ} \mathrm{C}$ whilst shaking at $250 \mathrm{rpm}$. After the culture had reached confluence, it was transferred into falcon tubes and centrifuged at $3000 \mathrm{~g}$ for $10 \mathrm{~min}$ at $4^{\circ} \mathrm{C}$. Thereafter, the pellet was resuspended in $5 \mathrm{~mL}$ minimal media/15\% glycerol, vortexed thoroughly, and then divided into $0.35 \mathrm{~mL}$ aliquots in cryovials on dry ice. These aliquots were then stored at $-80^{\circ} \mathrm{C}$.

\subsubsection{Preparation of Yeast Working Solution}

To prepare the yeast at the appropriate confluence, a yeast stock aliquot (as prepared above) was added to a sterile flask containing $52 \mathrm{~mL}$ growth media and incubated for $48 \mathrm{hr}$ at $30^{\circ} \mathrm{C}$ whilst shaking at $250 \mathrm{rpm}$. A $10 \mathrm{~mL}$ aliquot of the culture was added to $52 \mathrm{~mL}$ growth media and grown at $30^{\circ} \mathrm{C}$ until an $\mathrm{OD}_{620}$ value of 1.0 was measured.

\subsubsection{Preparation of Assay Media}

To prepare the assay media, $0.5 \mathrm{~mL}$ CPRG $(10 \mathrm{mg} / \mathrm{mL})$ was mixed with $52 \mathrm{~mL}$ of the growth media (2.25.1). Thereafter, $2 \mathrm{~mL}$ of the yeast working solution was added and the solution was swirled well to mix.

Plant extracts (either resuspended in $500 \mu \mathrm{L}$ methanol or in $5 \mathrm{~mL}$ cellulase buffer solution), steroids and known phytoestrogens were serially diluted two-fold in methanol (LC grade) and the first three or four dilutions (including the raw plant extract) were initially screened. Samples that were above the highest standard were diluted further and tested as required.

The diluted plant extracts $(10 \mu \mathrm{L})$ were aliquoted into the well bottom of an untreated 96-well tissue culture plate (Jet BIOFIL, TCP000096, Jet Bio-Filtration Products Company Co., Ltd., China) in a laminar flow hood (Type II). The dilutions were carried out in triplicate for each dilution and left until the methanol had completely evaporated. Three wells in the plate were loaded with $10 \mu \mathrm{L}$ of methanol only. The soya bean extract and cauliflower extracts were used as controls in each plate. For each assay run, a plate containing serially diluted $\mathrm{E}_{2}$ was prepared as the standard curve for the assay. 
Once each well in the plate was dry, $200 \mu \mathrm{L}$ of the assay media (containing the mutant hER strain of yeast and CPRG) was pipetted into each well using a multichannel pipette and the plate was shaken for 2 minutes at $850 \mathrm{rpm}$ (MixMate, Eppendorf, Germany). The samples were initially measured (EnSpire ${ }^{\circledR} 2300$ Multimode Plate Reader, PerkinElmer, USA) at absorbances of $570 \mathrm{~nm}$ (for colour change) and $620 \mathrm{~nm}$ (cell growth) before being incubated at $30^{\circ} \mathrm{C}$ for $72 \mathrm{~h}$, with shaking every $24 \mathrm{~h}$ as described above. Following incubation, the absorbances were measured again. Relative colour change and cell growth was calculated using readings from the methanol-only wells. Oestrogenic activity for each plant extract was calculated in relation to the $\mathrm{E}_{2}$ standard curve (see section 2.25.5).

\subsubsection{Calculation of Oestrogenic Activity}

To determine the colour change of a sample, the differences between the Day 0 and Day 3 $(72 \mathrm{~h})$ readings was calculated for both the $570 \mathrm{~nm}$ and $620 \mathrm{~nm}$ wavelengths. The ratio (A570:A620) was obtained and the average for each triplicate was determined. This was then corrected for any background signal by dividing by the ratio obtained for the "methanol-only" wells.

To determine the activity of each sample equivalent to $E_{2}$ (i.e. oestrogenic activity), the above calculations were first carried out for the $E_{2}$ standard curve. The equation for the curve was then used to calculate the amount of activity for each plant extract. 


\section{CHAPTER 3: AMPLIFICATION OF STEROID RECEPTOR LIGAND BINDING DOMAINS}

\subsection{Introduction}

Steroid receptors are known to play an important role in reproduction in many species by facilitating sexual differentiation, development and maintenance of reproductive organs. These processes are mediated through the actions of steroid hormones within cells to regulate transcription (Brzozowski, Pike et al. 1997).

Steroid receptors possess a modular structure with each region having a known function. Specific areas within each receptor are highly conserved between both closely- and distantly-related species. These conserved regions can be exploited for the purposes of steroid receptor amplification in species that have not been investigated before. The LBD, whose primary role is to bind compounds, exhibits a high degree of inter-species conservation, thus lending itself as an ideal candidate for sequencing of these regions in little-studied species.

It is well-documented that small alterations to the amino acid sequence can have a considerable influence on the receptor activity (Danielsen, Hinck et al. 1989; Eng, Lee et al. 1997). This may be due to altered interactions between different side chains and through adjustments in the tertiary structure of the protein such as the $\alpha$-helices, $\beta$-sheets and turns. Overall this may result in a change to the ligand binding environment due to an alteration in the overall shape of the binding pocket that may cause different interactions between the steroid and the residues lining the pocket.

A number of ligand-bound steroid receptors have had their crystal structures elucidated in other species. Thus the proximity of any amino acid substitutions to the native ligand bound in the receptor can be determined. 


\subsection{Aim}

The aims of this chapter were to (i) identify unique nucleotide and amino acid motifs in Kākāpō and other native New Zealand parrots and subsequently to (ii) predict the effects of these unique sequences on ligand-receptor interactions using in silico modelling techniques. Specifically, the LBDs of ER- $\alpha$, ER- $\beta$, AR and PR were sequenced in four different New Zealand native parrots (Kākā, Kākāpō, Kākāriki and Kea) and compared to that in Cockatiel, Chicken and Japanese Quail.

\subsection{Methodology}

The full details of the methodologies employed for amplifying, sequencing and analysing the nuclear receptor LBDs of ER- $\alpha, \mathrm{ER}-\beta, \mathrm{AR}$ and $\mathrm{PR}$ are reported in the materials and methodology section (Chapter 2.2-2.21).

In brief, blood and tissue samples from Kākā, Kākāpō, Kākāriki, Kea, Cockatiel, Chicken and Japanese Quail were collected for the isolation of RNA or gDNA. For the New Zealand parrots, at least three different tissue types were sampled from three individuals. These included brain, heart, kidney, liver, muscle, ovary and testis. The resulting cDNA or gDNA was utilised to amplify the nucleotide region that corresponded to the LBD of the receptors in the Chicken (which were used as reference sequences) (Table 3.1). The quality of the cDNA or gDNA was assessed by sequencing a short region (354 nucleotides) of $\beta$-actin (Appendix 3 Supplementary Figure 3A).

Table 3.1 Accession numbers for the Chicken reference sequences used for amplification of the steroid receptors. Sequences were obtained from http://ncbi.nlm.nih.gov.

\begin{tabular}{ll}
\hline Receptor & Accession Number \\
\hline Oestrogen receptor $\alpha(E R-\alpha)$ & NM_205183 \\
Oestrogen receptor $\beta(E R-\beta)$ & NM_204794 \\
Androgen receptor (AR) & NM_001040090 \\
Progesterone receptor (PR) & NM_205262 \\
\hline
\end{tabular}


Sequence information obtained from the Waikato University Sequencing Facility was analysed using Geneious software (version 5.3.4). Additionally, BLAST searches (blastn and blastp; NCBI database) were undertaken to determine sequences of high similarity with other members of the Aves taxon and from an unpublished database of avian species (phybirds.genomics.org.cn). All the avian species identified are listed in Appendix 2 Supplementary Table 2D and 2E). Unless stated otherwise, amino acid differences are written in the following format: New Zealand parrot amino acid, amino acid position, amino acid that is different in another species. To determine whether amino acid substitutions were conserved or non-conserved, the charges and polarities of the amino acid sidechains were compared.

A three-dimensional model was generated for each receptor using the sequence determined in each New Zealand parrot species. The structures of these receptor sequences were predicted using the crystallographic data of the human sequence (1A52, 3OLS, 1E3G and 1A28) as a template and were visualised using the computer programme PyMol.

\subsection{Results}

\subsubsection{Amplification of Oestrogen Receptor $\alpha$}

The primers listed in Table 2.1 (Chapter 2) for ER- $\alpha$ (ER- $\alpha$ forward 1 and ER- $\alpha$ reverse 1) were used to span the ligand binding domain (nucleotides 1115-1726 in NM_205183) resulting in an amplicon of 616 nucleotides in length. This corresponded to a translated sequence of 204 amino acids.

\subsubsection{Alignment of ER- $\alpha$ LBD of generated sequences}

Alignment of the nucleotide sequences for the four New Zealand native parrots showed a total of 16 positions where the nucleotides differed and is shown in Figure 3.1. Overall the ER- $\alpha$ LBD exhibited $97 \%$ conservation across the 616 nucleotides. When the sequences from different tissue samples for each bird were compared, it was found that there were no tissue-specific differences in the sequences obtained.

Despite the 16 nucleotide differences in the ER- $\alpha$ LBD of the New Zealand parrots, the translation of the generated nucleotide sequences did not change the amino acid sequences 
(Figure 3.2). Thus, as the amino acid sequences were identical between all New Zealand parrots, this will hereafter be referred to as the New Zealand parrot consensus ER- $\alpha$ sequence.

Alignment of the New Zealand parrot nucleotide sequences with those identified in Cockatiel, Chicken and Japanese Quail showed an overall conservation of 92\% (Figure 3.1). There were 27 positions where the nucleotide for Chicken differed from that of any of the New Zealand parrot species (96\% identity) and one position (position 107) where the Chicken was different to all the New Zealand parrots except Kākāpō. Cockatiel and Japanese Quail showed $99 \%$ and $96 \%$ identity respectively with the New Zealand parrots. That is, there were only four positions where the Cockatiel sequence differed from that in all the New Zealand parrots, one case where the nucleotide was the same as Kākāpō (position 107) and one instance where the nucleotide was the same as Kākāriki (position 569). For the Japanese Quail, there were 27 nucleotides that did not match any of the New Zealand parrots but in 21 of these instances, the nucleotide was identical to that in the Chicken.

In terms of translation homogeneity to the New Zealand parrot consensus ER- $\alpha$ sequence, the Cockatiel exhibited 100\% identity whilst the Chicken and Japanese Quail exhibited 99\% and 98\% identity respectively (Figure 3.2). Three of the four amino acid differences observed for the Japanese Quail ER- $\alpha$ were also observed in that of the Chicken. Of these four differences, only that at position 7 (Arg and Ser) was a non-conserved change (Table 3.2).

Table 3.2 The amino acids that differed in the ligand binding domain (LBD) of ER- $\alpha$ of the avian species sequenced. Amino acids that were conserved changes are in blue and those that were non-conserved are in red.

\begin{tabular}{|l|l|l|l|l|l|l|l|}
\hline Position & Kākāpo & Kākā & Kākāriki & Kea & Cockatiel & Chicken & $\begin{array}{c}\text { Japanese } \\
\text { Quail }\end{array}$ \\
\hline $\mathbf{7}$ & Arg & Arg & Arg & Arg & Arg & Ser & Ser \\
\hline $\mathbf{3 8}$ & Ser & Ser & Ser & Ser & Ser & Asn & Asn \\
\hline $\mathbf{1 6 2}$ & Lys & Lys & Lys & Lys & Lys & Arg & Arg \\
\hline $\mathbf{1 7 9}$ & Leu & Leu & Leu & Leu & Leu & Leu & Phe \\
\hline
\end{tabular}


CHAPTER 3: STEROID RECEPTOR LBD AMPLIFICATION

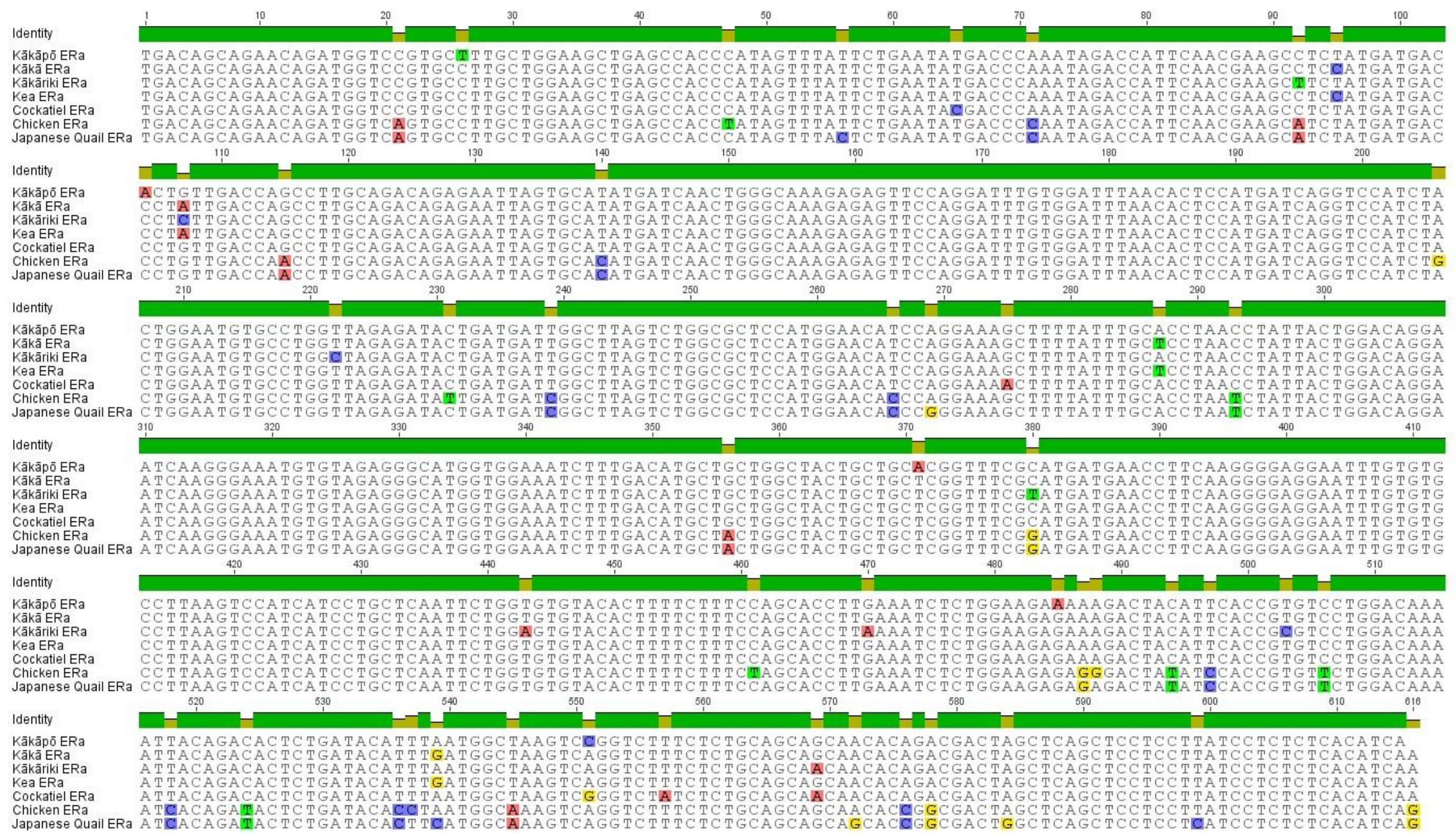

Figure 3.1 Nucleotide sequences that span the amplified region of the ligand binding domain (LBD) of oestrogen receptor $\alpha$ (ERa) of New Zealand parrot species, Cockatiel, Chicken and Japanese Quail. Highlighted nucleotides (red = adenine, blue = cytosine, yellow = guanine and green = thymine) depict a change in the base . 
Identity

Kākāpō ERa

Kākā ERa

Kākāriki ERa

Kea ERa

Cockatiel ERa

Chicken ERa

Japanese Quail ERa

Identity

Kākāpō ERa

Kākā ERa

Kākāriki ERa

Kea ERa

Cockatiel ERa

Chicken ERa

Japanese Quail ERa

Identity

Kākāpō ERa

Kākā ERa

Kākāriki ERa

Kea ERa

Cockatiel ERa

Chicken ERa

Japanese Quail ERa

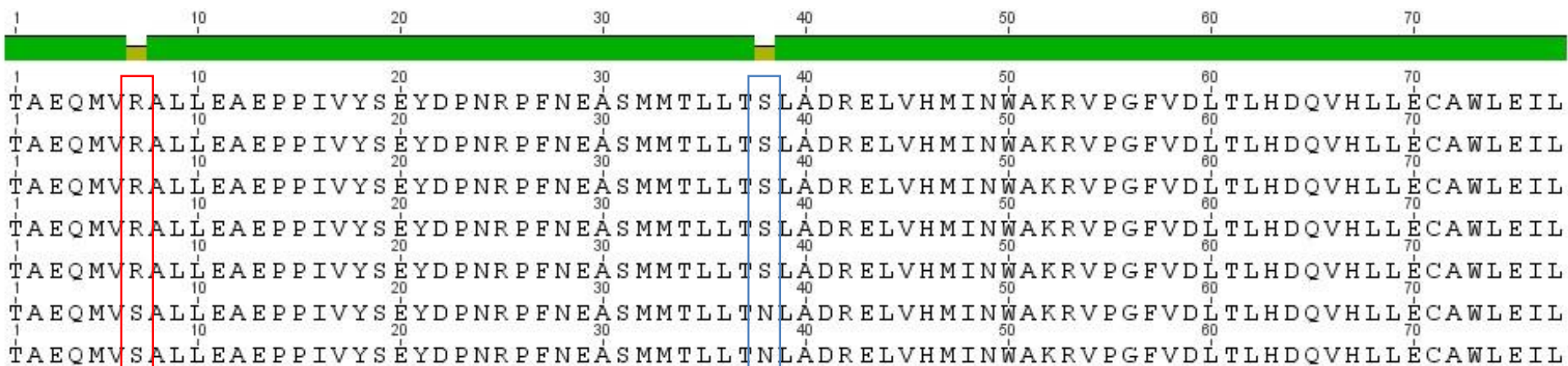

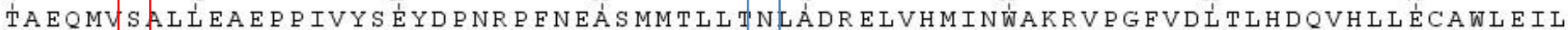

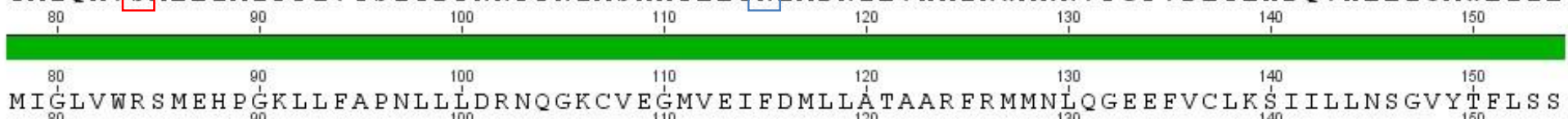

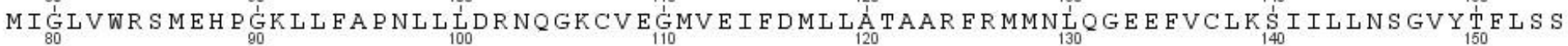

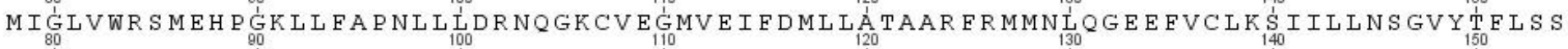

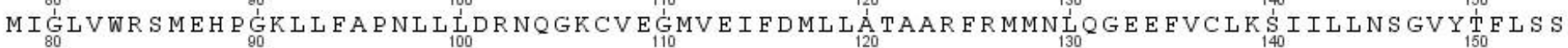

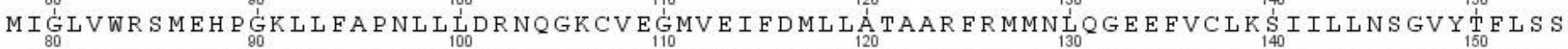

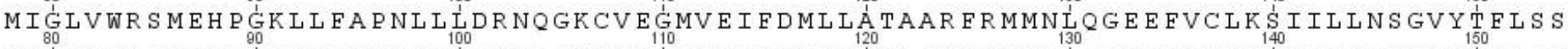
MIGLVWRSMEHPGKLLFAPNLLLDRNQGKCVEGMVEIFDMLLẢTAAR FRMMNLGEEFVCLKS IILLNSGVYTELSS

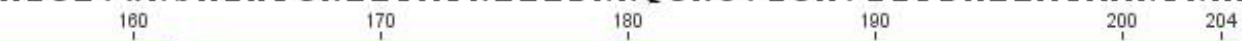

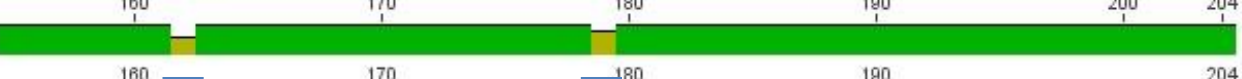

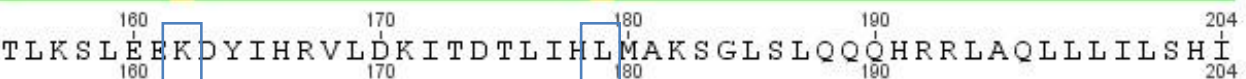
TLKS L $\underset{160}{\dot{E}}$ KK DYIHRVL ${ }_{170}^{\prime} K$ ITDTLIHL MAKS GLS LQQ

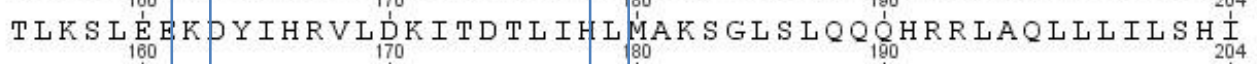
TLKS L E EKDYIHRVLDK I T TLIHL MAKS GLSLQQ

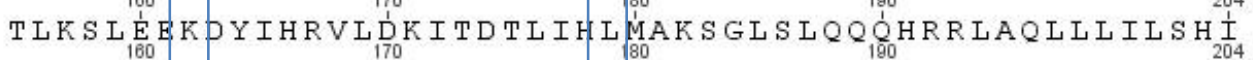

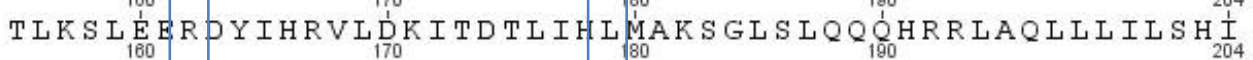
TLKSLEERDYIHRVLDK ITDTLIHFMAKSGSLQQ

Figure 3.2 Amino acid sequences that span the amplified region of the ligand binding domain (LBD) of oestrogen receptor $\alpha$ (ERa) of New Zealand parrot species, Cockatiel, Chicken and Japanese Quail. Blue boxes represent conserved amino acid changes whilst red boxes represent non-conserved changes. 


\subsubsection{Alignment of ER- $\alpha$ LBD of other species}

The hER- $\alpha$ nucleotide sequence (NM_000125) was aligned with the corresponding New Zealand parrot ER- $\alpha$ nucleotide sequences (Figure 3.3). There were a total of 111 positions where the human sequence did not match the New Zealand parrot ER- $\alpha$ nucleotide sequences resulting in $82 \%$ conservation. However at three of these positions the nucleotide matched that present in Kākāriki (positions 92, 222 and 443).

The translated sequence of hER- $\alpha$ (NP_000116) had much higher identity with the New Zealand parrot consensus ER- $\alpha$ sequence than the corresponding nucleotide sequences (Figure 3.4). There were a total of 14 locations where the human amino acid differed to the New Zealand parrot consensus ER- $\alpha$ sequence, resulting in $93 \%$ conservation. Seven of these were non-conserved amino acid differences (red boxes: R7S, T34G, A122S, A123S, Y164H, S183A and R192Q) whilst the remaining seven were conserved amino acids (blue boxes).

The blastn tool was used to identify nucleotide sequences derived from the Aves taxon that were similar to those nucleotide sequences from the New Zealand parrots. A total of 14 species were identified (including the Chicken and Japanese Quail). Five of these sequences were incomplete and so did not span the entire segment amplified. There were a total of 103 positions where there were differing nucleotides and eight of these positions were nucleotides that only differed in the New Zealand parrots (Appendix 3 Supplementary Figure 3B).

The blastp tool was used to identify protein sequences derived from the Aves taxon that were similar to the New Zealand parrot consensus ER- $\alpha$ sequence. A total of 11 species were identified (including the Chicken and Japanese Quail) with only one not spanning the full length of the query sequence. Alignment of these sequences showed seven amino acid differences (97\% conservation) (Appendix 3 Supplementary Figure 3C). Of these variations, two amino acids in the New Zealand parrot species differed from the amino acids found in all other species, i.e. R7S (non-conserved) and S38N (conserved). Of the other positions where substitutions were present, only that at 41 (G41 in African black coucal and D41 in all other species) was a non-conserved change.

Blastn of the unpublished avian species identified 34 species (translated sequeences shown in Appendix 3 Supplementary Figure 3D). There were only 88 positions where the amino acids were identical, but if Barn Owl is removed, this increases dramatically. R7 and S38 was only present in the New Zealand parrot consensus ER- $\alpha$ sequence. 


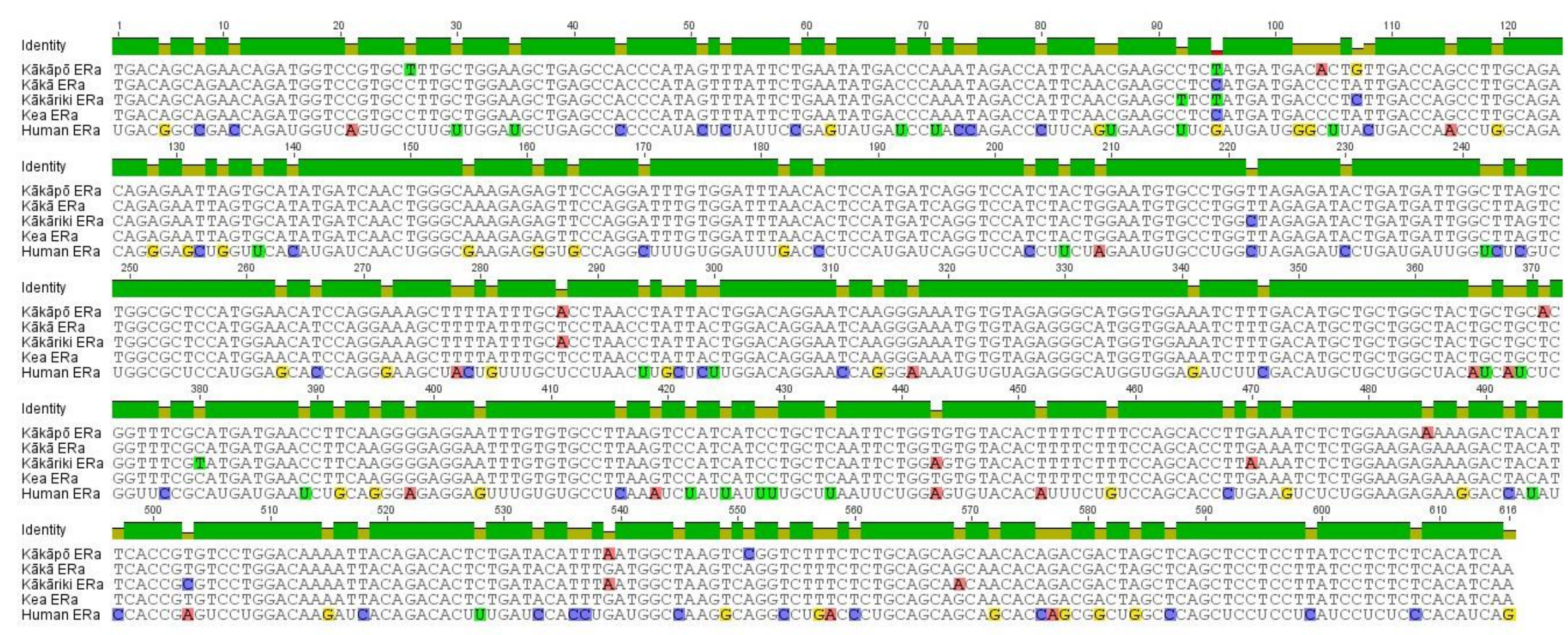

Figure 3.3 Nucleotide sequences that span the amplified region of the ligand binding domain (LBD) of oestrogen receptor $\alpha$ (ERa) of New Zealand species and human (NM_000125). Highlighted nucleotides (red = adenine, blue = cytosine, yellow = guanine and green = thymine) depict a change in the base. 
CHAPTER 3: STEROID RECEPTOR LBD AMPLIFICATION

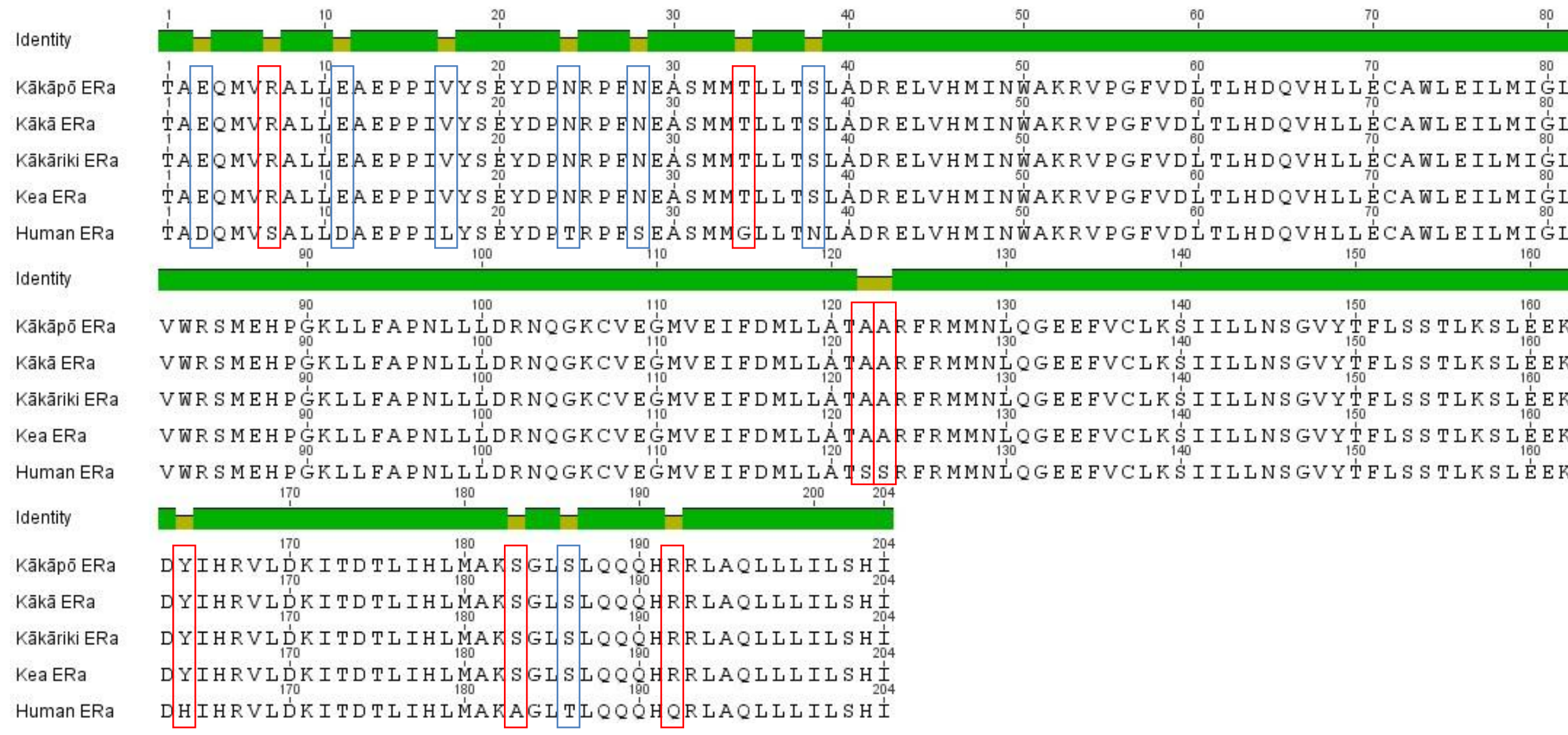

Figure 3.4 Amino acid sequences that span the amplified region of the ligand binding domain (LBD) of oestrogen receptor $\alpha$ (ERa) of New Zealand species and human (NP_00016). Blue boxes represent conserved amino acid changes whilst red boxes represent non-conserved changes. 


\subsubsection{Alignment of the C-terminal end of ER- $\alpha$ LBD}

Further preliminary sequencing of the ER- $\alpha$ LBD was undertaken in the seven avian species examined herein to specifically amplify a region of ER- $\alpha$ at the C-terminal end. The primers used for this were ER- $\alpha$ forward 2 and ER- $\alpha$ reverse 2 primers (Chapter 2 Table 2.1) which amplified a further 245 nucleotides (nucleotides 1728-1972 in NM_205183) of the LBD. In turn, this translated to an extra 82 amino acids (based on the Chicken sequence).

Nucleotide sequences for the four New Zealand native parrots showed a total of 16 positions where the nucleotides differed; 11 of these only differed in Kākāriki (Figure 3.5). This corresponded to $94 \%$ conservation across the 266 nucleotides. Alignment of the nucleotide sequences of the New Zealand parrots with that of Cockatiel, Chicken and Japanese Quail showed 88\% conservancy. When the Cockatiel sequence was compared to that in New Zealand birds, there were five positions where Cockatiel did not match any of the New Zealand parrots and a further seven positions where Cockatiel and Kākāpō and/or Kākāriki were the same but differed to the others. The level of conservation decreased when Chicken and Japanese Quail were compared to the New Zealand parrots (Figure 3.5). This alignment showed a three nucleotide indel (nucleotides 203-205) and a four nucleotide indel further downstream (nucleotides 223-226). On both of these occasions the parrots were different to Chicken and Japanese Quail. Between Chicken and Japanese Quail there were seven different nucleotide positions ( $97 \%$ conservation).

The translated region of 89 amino acids was $78 \%$ conserved amongst the seven species with differences in 20 positions (Figure 3.6). The sequences for the four New Zealand parrots differed at eight positions meaning 90\% conservancy. Alignment of the New Zealand parrots with Cockatiel yielded a further two positions that were different ( $89 \%$ conservancy).

As a result of the longer nucleotide sequence in the New Zealand parrots and Cockatiel, the translated sequence was eight amino acids longer than that of the Chicken and Japanese Quail. The three nucleotide indel seen at positions 203-205 led to ser71 in the Chicken and Japanese Quail but not in the other sequences. Comparing Chicken and Japanese Quail sequences, there was only one amino acid difference; N52S (Chicken c.f. Japanese Quail). Out of the 20 positions of differing amino acids, there were 11 non-conserved and six conserved changes in the length of the Chicken and Japanese Quail sequences and one amino acid insertion (Table 3.3). 


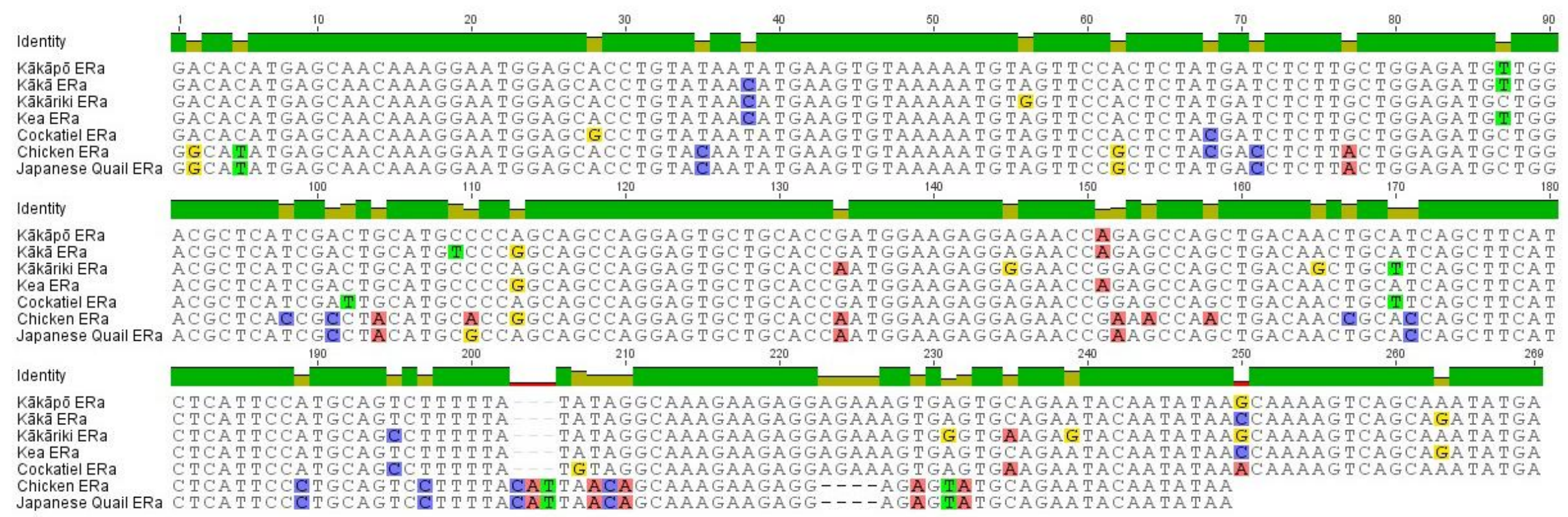

Figure 3.5 Nucleotide sequences that span the remaining amplified region of the ligand binding domain (LBD) of oestrogen receptor $\alpha$ (ERa) of New Zealand parrot species, Cockatiel, Chicken and Japanese Quail. Highlighted nucleotides ( $\mathrm{red}=$ adenine, blue $=$ cytosine, yellow $=$ guanine and green $=$ thymine) depict a change in the base . 
Identity

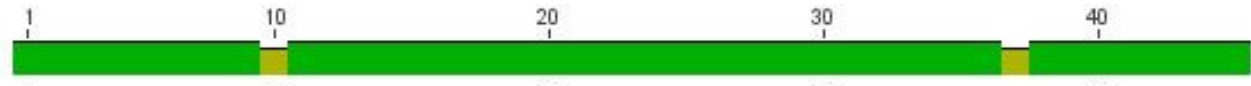

Kākāpō ERa

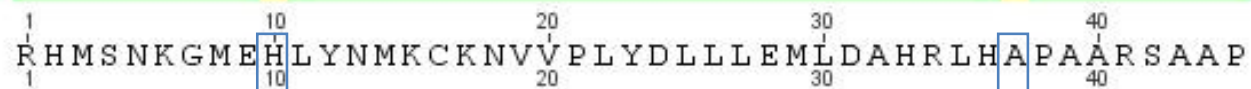

Kākā ERa

Kākāriki ERa

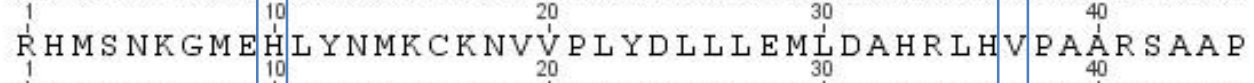

Kea ERa

Cockatiel ERa

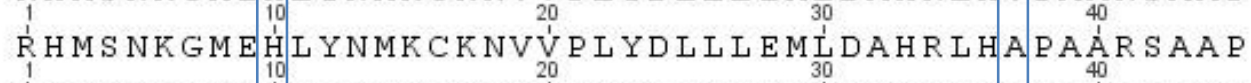
Chicken ERa

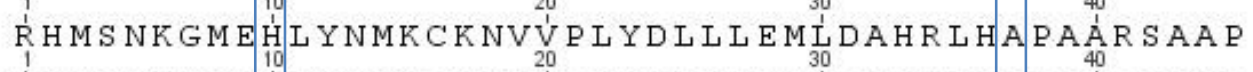

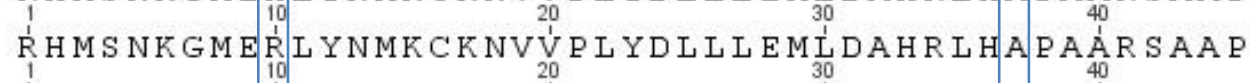

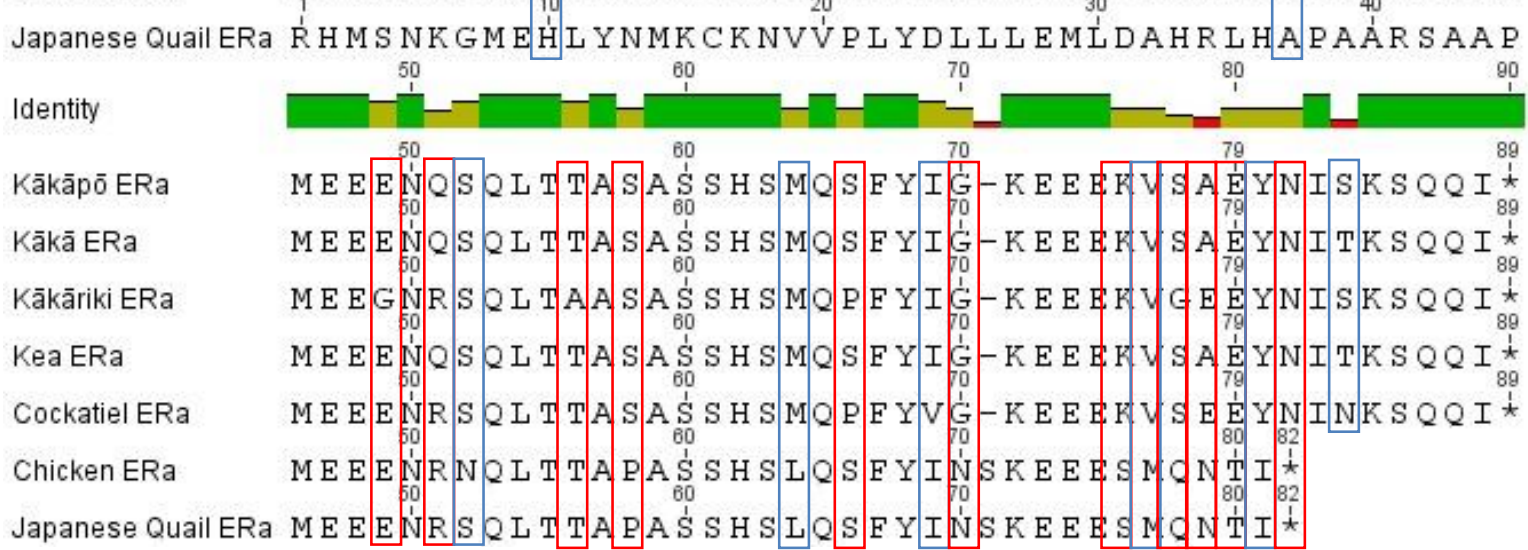

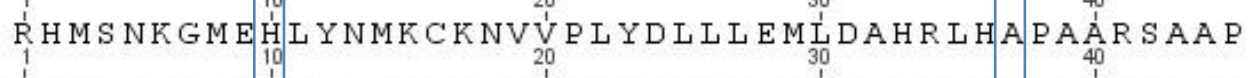

Figure 3.6 Amino acid sequences that span the remaining amplified region of the ligand binding domain (LBD) of oestrogen receptor $\alpha$ (ERa) of New Zealand parrot species, Cockatiel, Chicken and Japanese Quail. Blue boxes represent conserved amino acid changes whilst red boxes represent non-conserved changes. 
Table 3.3 The amino acids that differed in the C-terminal end of the ligand binding domain (LBD) of ER- $\alpha$ of the avian species sequenced. Amino acids that were conserved changes are in blue and those that were non-conserved are in red. The amino acid that was only present in Chicken and Japanese Quail is in black.

\begin{tabular}{|c|c|c|c|c|c|c|c|}
\hline Position & Kākāpo & Kākā & Kākāriki & Kea & Cockatiel & Chicken & $\begin{array}{c}\text { Japanese } \\
\text { Quail }\end{array}$ \\
\hline 10 & His & His & His & His & Arg & His & His \\
\hline 37 & Ala & Val & Ala & Ala & Ala & Ala & Ala \\
\hline 49 & Glu & Glu & Gly & Glu & Glu & Glu & Glu \\
\hline 51 & Gln & Gln & Arg & Gln & Arg & Arg & Arg \\
\hline 52 & Ser & Ser & Ser & Ser & Ser & Asn & Ser \\
\hline 56 & Thr & Thr & Ala & Thr & Thr & Thr & Thr \\
\hline 58 & Ser & Ser & Ser & Ser & Ser & Pro & Pro \\
\hline 64 & Met & Met & Met & Met & Met & Leu & Leu \\
\hline 66 & Ser & Ser & Pro & Ser & Pro & Ser & Ser \\
\hline 69 & Ile & Ile & Ile & Ile & Val & Ile & Ile \\
\hline 70 & Gly & Gly & Gly & Gly & Gly & Arg & $\operatorname{Arg}$ \\
\hline 71 & - & - & - & - & - & Ser & Ser \\
\hline 76 & Lys & Lys & Lys & Lys & Lys & Ser & Ser \\
\hline 77 & Val & Val & Val & Val & Val & Met & Met \\
\hline 78 & Ser & Ser & Gly & Ser & Ser & Gln & Gln \\
\hline 79 & Ala & Ala & Glu & Ala & Glu & Asn & Asn \\
\hline 80 & Glu & Glu & Glu & Glu & Glu & Thr & Thr \\
\hline 81 & Tyr & Tyr & Tyr & Tyr & Tyr & Ile & Ile \\
\hline 82 & Asn & Asn & Asn & Asn & Asn & $*$ & $*$ \\
\hline
\end{tabular}




\subsubsection{Alignment of the C-terminal end of ER- $\alpha$ LBD of other species}

The human ER- $\alpha$ (hER- $\alpha$ ) nucleotide sequence (NM_000125) was aligned with the corresponding final region of New Zealand parrot ER- $\alpha$ sequences (Figure 3.7). There were a total of 73 positions where the human sequence did not match what was present in any of the New Zealand parrot species resulting in $74 \%$ conservation. There were a further three positions where the human and Kākāriki sequence matched.

The translated sequence of hER- $\alpha$ (NP_000116) was slightly more conserved with the New Zealand parrot ER- $\alpha$ amino acid sequences than the nucleotide sequences (Figure 3.8). There were a total of 24 locations where it differed; resulting in $70 \%$ conservation (Table 3.4). The human sequence was also eight amino acids shorter than the New Zealand parrots, although it contained an inserted amino acid $(\mathrm{G})$ at position 58. There were a total of 17 non-conserved amino acid differences. 


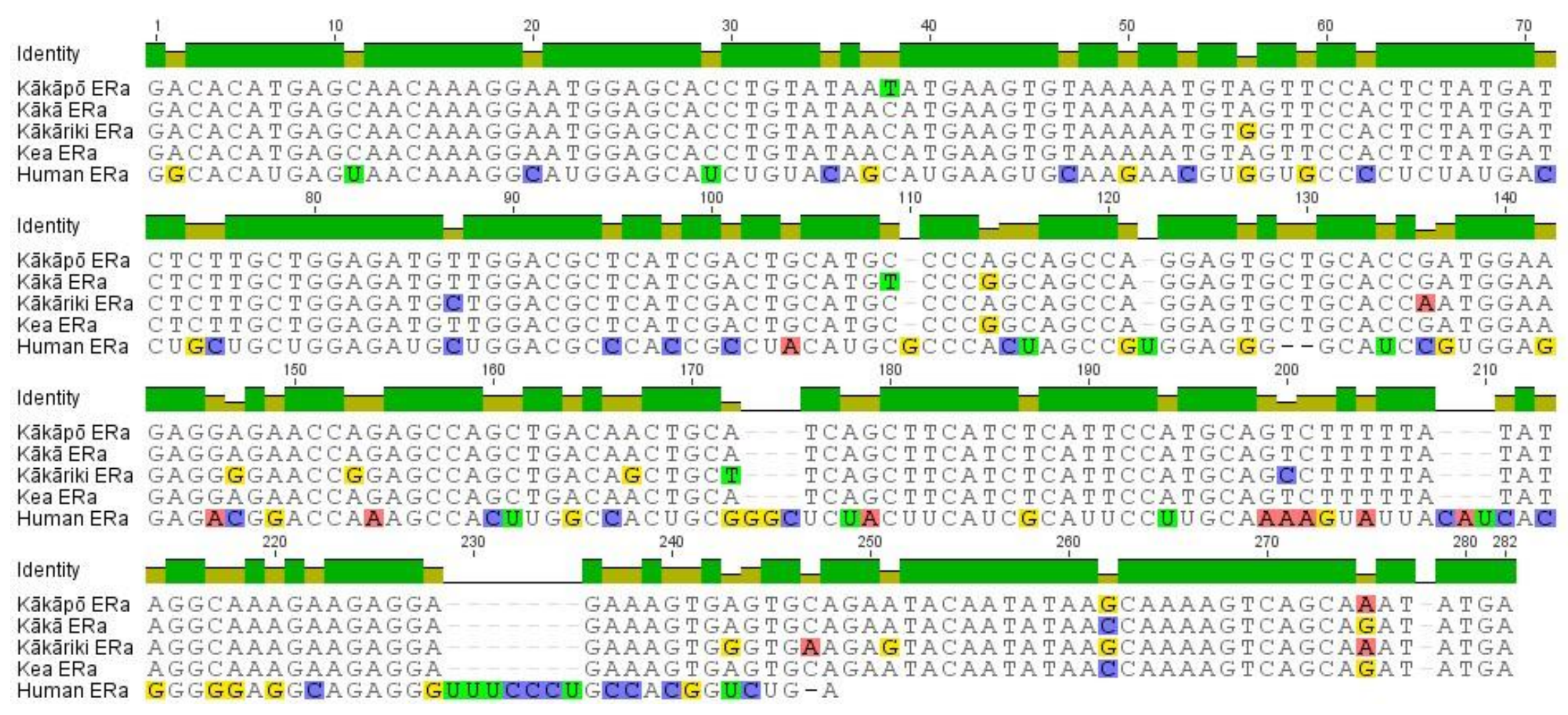

Figure 3.7 Nucleotide sequences that span the remaining amplified region of the ligand binding domain (LBD) of oestrogen receptor $\alpha$ (ERa) of New Zealand parrot species and human. Highlighted nucleotides (red $=$ adenine, blue $=$ cytosine, yellow $=$ guanine and green $=$ thymine) depict a change in the base. 


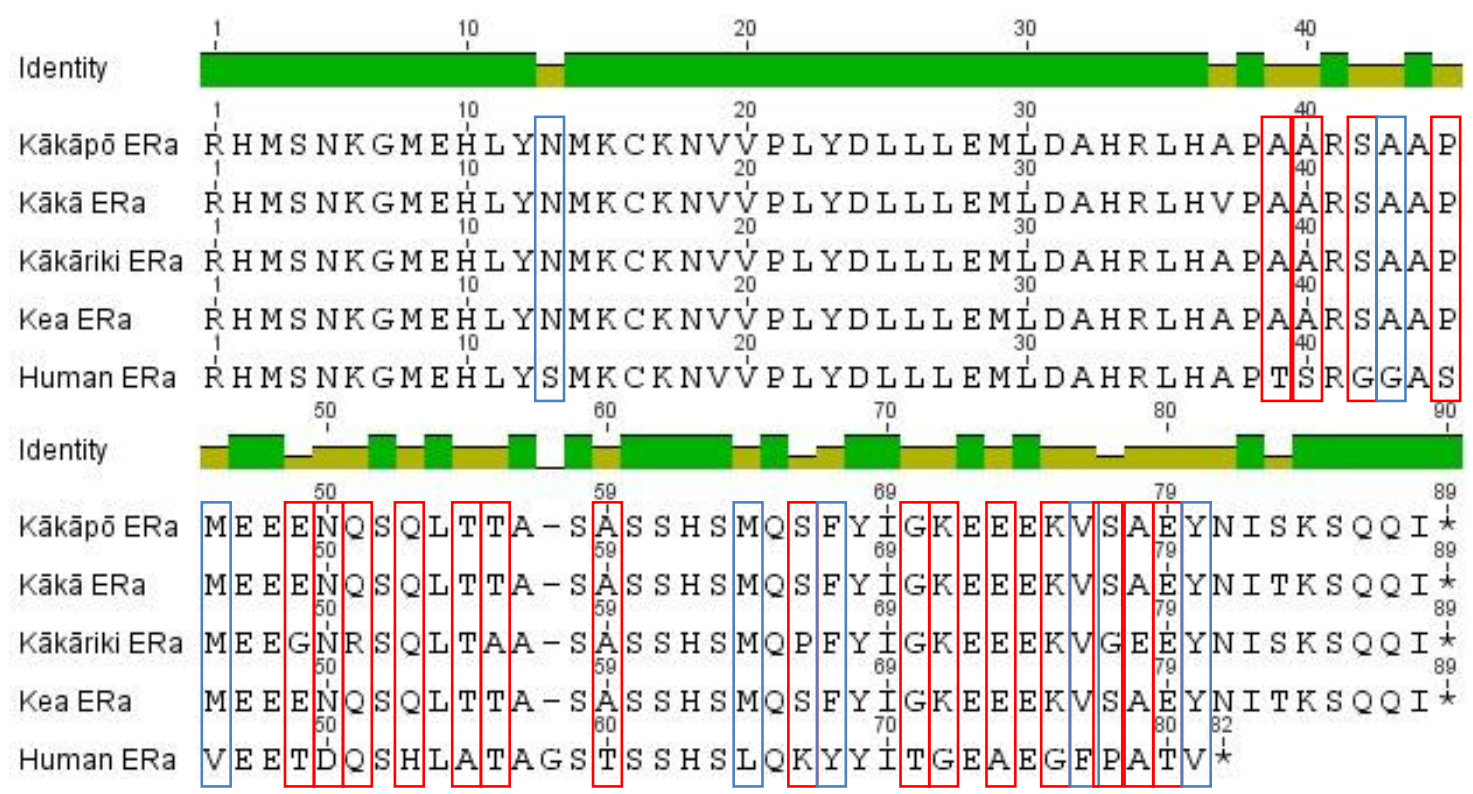

Figure 3.8 Amino acid sequences that span the remaining amplified region of the ligand binding domain (LBD) of oestrogen receptor $\alpha($ ERa) of New Zealand parrot species and human. Blue boxes represent conserved amino acid changes whilst red boxes represent non-conserved changes.

Table 3.4 The amino acids that differed in the C-terminal end of the ligand binding domain (LBD) of ER- $\alpha$ of the avian species and human sequences. Amino acids that were conserved changes are in blue and those that were non-conserved are in red. The amino acid that was only present in the human sequence is in black.

\begin{tabular}{|c|c|c|}
\hline Position & NZ Parrots & Human \\
\hline $\mathbf{1 3}$ & Arg & Ser \\
\hline $\mathbf{3 9}$ & Ala & Thr \\
\hline $\mathbf{4 0}$ & Ala & Ser \\
\hline $\mathbf{4 2}$ & Ser & Gly \\
\hline $\mathbf{4 3}$ & Ala & Gly \\
\hline $\mathbf{4 5}$ & Pro & Ser \\
\hline $\mathbf{4 6}$ & Met & Val \\
\hline $\mathbf{4 9}$ & Glu/Gly & Thr \\
\hline
\end{tabular}


CHAPTER 3: STEROID RECEPTOR LBD AMPLIFICATION

\begin{tabular}{|c|c|c|}
\hline $\mathbf{5 0}$ & Asn & Asp \\
\hline $\mathbf{5 3}$ & Gln & His \\
\hline $\mathbf{5 5}$ & Thr & Ala \\
\hline $\mathbf{5 8}$ & - & Gly \\
\hline $\mathbf{6 0}$ & Ala & Thr \\
\hline $\mathbf{6 5}$ & Met & Leu \\
\hline $\mathbf{6 7}$ & Ser/Pro & Lys \\
\hline $\mathbf{6 8}$ & Phe & Tyr \\
\hline $\mathbf{7 1}$ & Gly & Thr \\
\hline $\mathbf{7 2}$ & Lys & Gly \\
\hline $\mathbf{7 4}$ & Glu & Ala \\
\hline $\mathbf{7 6}$ & Lys & Gly \\
\hline $\mathbf{7 7}$ & Val & Phe \\
\hline $\mathbf{8 0}$ & Ser/Gly & Pro \\
\hline & Glu & Thr \\
\hline $\mathbf{8 1}$ & Tyr & Val \\
\hline
\end{tabular}


The blastn tool was again used to identify sequences derived from the Aves taxon that were similar to those from the New Zealand parrots for the remaining section of ER- $\alpha$ LBD. A total of six species were identified which included Chicken and Japanese Quail (Appendix 3 Supplementary Figure 3E). The alignment of these sequences showed that there was relatively high identity $(81 \%)$ between species. However, as was seen with the alignment of the New Zealand parrots with Cockatiel, Chicken and Japanese Quail, there was a three nucleotide and four nucleotide indel present.

The blastp tool identitfied the same six species that differed from the New Zealand parrots in regards to their ER- $\alpha$ LBD nucleotide sequence. Two other species, Turkey and White-throated Sparrow were also found to have high conservation. Analysis of the results of the 90 amino acid-long sequence showed there were 8 amino acids at the end of the parrot sequence that did not exist in any other avian species sequence. From the remaining 82 amino acids, there were 16 positions where there was variation (80\% conservation) (Appendix 3 Supplementary Figure 3F).

From the blastn search of the unpublished avian species, it was found that none of the species contained the eight amino acids seen at the end of the parrot sequence when they were translated (Appendix 3 Supplementary Figure 3G). There were 29 positions where the amino acid differed although in many instances this difference was only present in one species. As with the alignment from the blastp search of the NCBI database, New Zealand parrots were the only species to have M64 (all others were L64).

As a result of the eight additional amino acids present in the New Zealand parrots and Cockatiel that were not observed in any of the published avian species, the blastp search of the complete ER- $\alpha$ sequence was widened to non-avian species (Appendix 3 Supplementary Figure $3 \mathrm{H}$ ). None of the species that were found to have an ER- $\alpha$ sequence of reasonable conservation to that for the New Zealand parrots displayed the eight amino acids at the C-terminal end. 


\subsubsection{Three-dimensional modelling of the ER- $\alpha$ LBD}

The template used for the modelling in this study was the crystal structure of hER- $\alpha$ (1A52). This consisted of two homodimers of ER- $\alpha$ with two molecules of bound 17 $\beta$-oestradiol (Figure 3.9A). The region of the LBD that had been sequenced consisted of seven $\alpha$-helices and one $\beta$-sheet. When visualised as a space-fill model, the pocket that $\mathrm{E}_{2}$ bound in was visible (Figure 3.9B). The human crystal structure used as the template was missing the last 51 amino acids that had been amplified in the bird species in this study.

There were 14 amino acids that differed between the human and Kākāpō ER- $\alpha$ LBD (Figure 3.10A). A number of the amino acids that differed between the Kākāpō and human ER- $\alpha$ sequence were shown to be in a region around the oestradiol molecule. One amino acid residue was located near the opening of the pocket (Figure 3.10B) and three were present on one face of an $\alpha$-helix (Figure 3.10A red ring). In the Kākāpō sequence, the differing residues had similar side-chains to those in human (Figure 3.10C and D).

The ER- $\alpha$ LBD region in Kākāpō had four amino acids that were different to those in Chicken and Japanese Quail (Figure 3.11A and C). One of these (S38N), was located in the $\alpha$ helix situated in close proximity to the docking position of the native ligand, 17ß-oestradiol (Figure 3.11A and C red circles). When the receptor was represented as a space-fill model, the short distance between it and the binding pocket was visible (Figure 3.11B \& D). At position 10 of the C-terminal section of the LBD amplified, the H10 observed in all species

except Cockatiel was $2.7 \AA$ from $\mathrm{E}_{2}$ compared to R10 which was $4.4 \AA$ away (Figure $3.11 \mathrm{E}$ and F). 

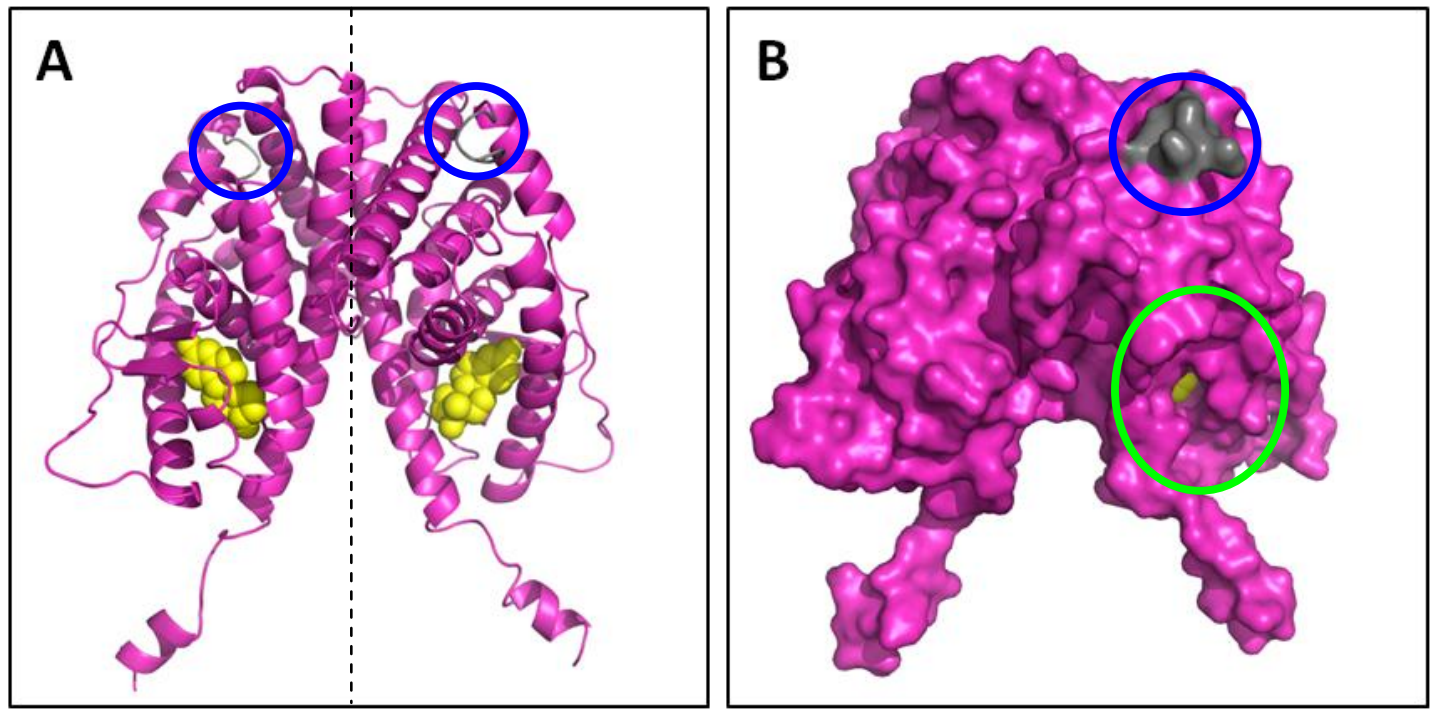

Figure 3.9 Three-dimensional structure of human oestrogen receptor $\alpha$ (hER- $\alpha$ ) and the ligand binding domain (LBD) region amplified in Kākāpō. A) The 3D model of hER- $\alpha$ was obtained (1A52) and visualised as a cartoon model with the amplified region in pink and the unamplified region in grey (circled in blue). This is as a homodimer (with a monomer to the left and right of the dashed line) with the native ligand $17 \beta$-oestradiol $\left(\mathrm{E}_{2}\right)$ docked into the receptor pocket of each monomer represented as yellow spheres. B) A space-fill model of the hER- $\alpha$ homodimer with the region not amplified in grey (circled in blue) and the pocket containing the bound $\mathrm{E}_{2}$ circled in green. All pictures were made with PyMol. 

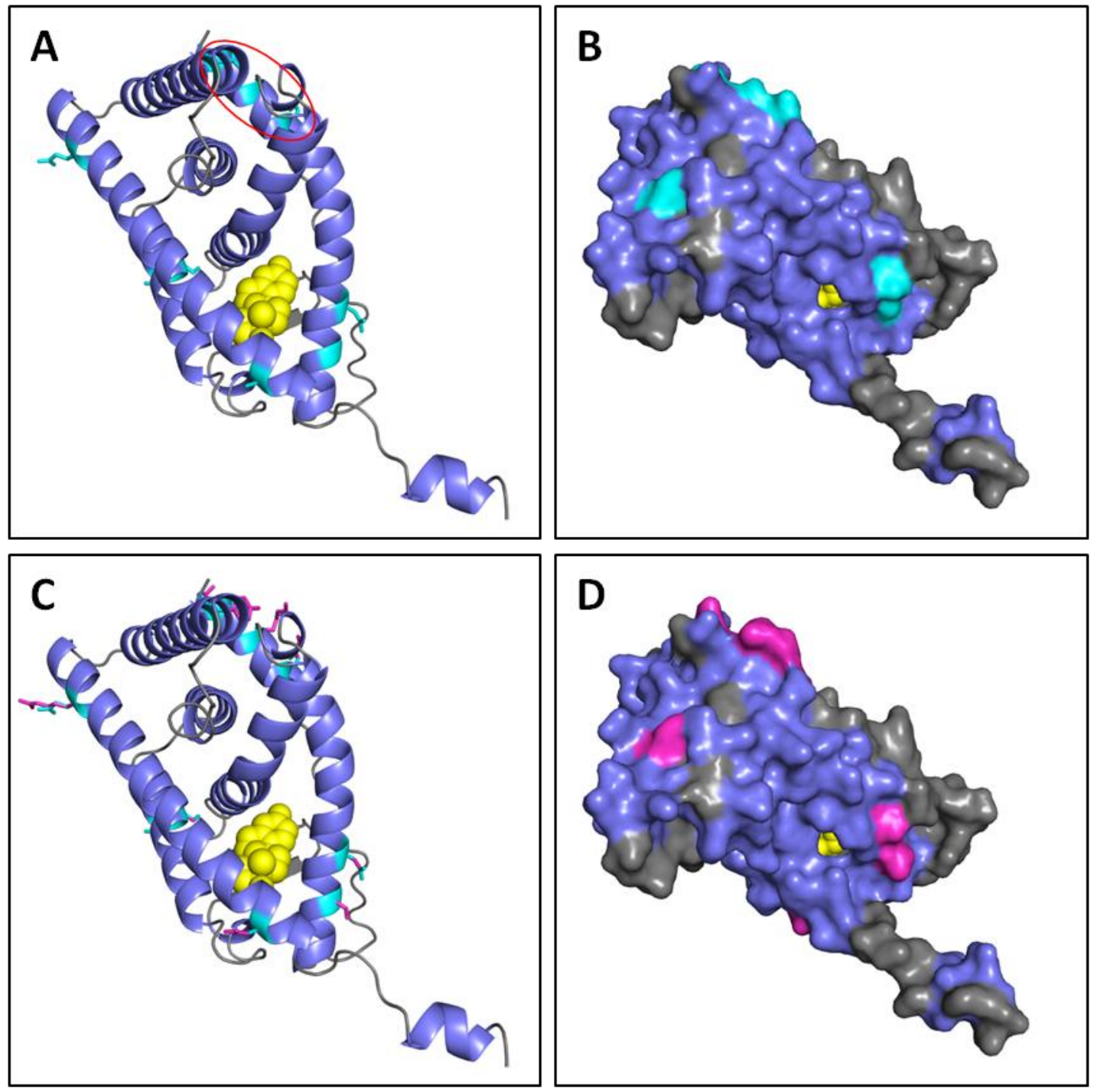

Figure 3.10 The amino acid differences between the ligand binding domain (LBD) of oestrogen receptor $\alpha$ (ER- $\alpha)$ of Kākāpō and human. A) The LBD of human ER- $\alpha$ was visualised as a cartoon model with the $\alpha$-helices in blue and the $\beta$-sheets and loops in grey. The 14 amino acids that differed to Kākāpō ER- $\alpha$ are shown with their side-chains in light blue. The native ligand $17 \beta$-oestradiol $\left(\mathrm{E}_{2}\right)$ is in yellow. The red ring highlights the residues that are found on the same face of an $\alpha$-helix. B) A space-fill model of this region with the differing residues shown in light blue. The grey areas are $\beta$-sheets and loops. C) The LBD of human ER- $\alpha$ is again shown as a cartoon model with the $\alpha$-helices in blue and the $\beta$-sheets and loops in grey. The 14 amino acids with their side-chains that are seen in human are in light blue and those seen in Kākāpō in pink. D) A space-fill model with the Kākāpō residues at the 14 positions in pink. The grey areas are $\beta$-sheets and loops. All pictures were made with PyMol. 

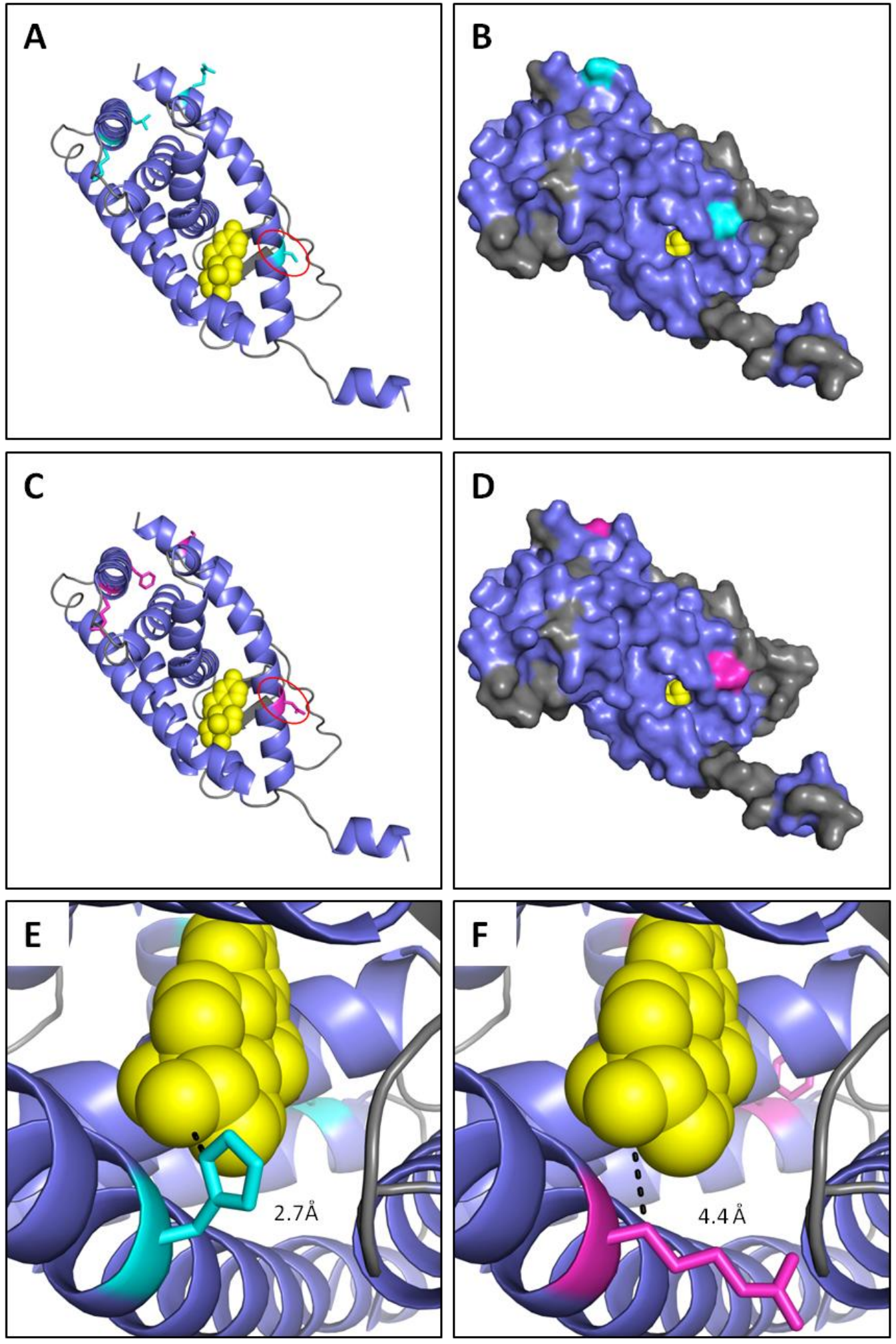

Figure 3.11 The amino acid differences between the ligand binding domain (LBD) of oestrogen receptor $\alpha$ (ER- $\alpha)$ of Kākāpō and non-native avian species. A) The Kākāpō LBD was visualised as a cartoon model with $\alpha$-helices in blue and $\beta$-sheets and loops depicted in grey. The five amino acid residues that differed from the non-native avian species are shown in light blue. $17 \beta$-oestradiol $\left(\mathrm{E}_{2}\right)$ is shown in yellow. B) A space-fill model of the LBD region with the $\beta$-sheets and loops depicted in grey. The positions where the amino acid differed are shown in light blue. C) The LBD of the other avian species as a cartoon model with the five differing amino acids in pink. D) A space-fill model of the LBD region for the other avian species with the three positions that differed for the non-native species in pink. E) The amino acid substitution at position 10 of the C-terminal amplified region for Kākāpō (H) was 2.7 Angstroms (A) from the docked $E_{2}$ whereas F) the amino acid substitution at position 10 of the C-terminal amplified region for Cockatiel (R) was $4.4 \AA$ from the $17 \beta$-oestradiol. All pictures were made with PyMol. 


\section{Summary:}

The LBD of ER- $\alpha$ was elucidated in the four New Zealand parrots as well as in the Cockatiel, Chicken and Japanese Quail. Despite 16 nucleotide differences in the N-terminal of the LBD, there was $100 \%$ amino acid identity between the New Zealand birds. This same region displayed three conserved amino acid changes when the other three (non-native) avian species were compared. There was also one non-conserved change between the parrots and Chicken and Japanese Quail. A comparison of the parrots with Chicken and Japanese Quail showed a lower level of conservancy. This included a three nucleotide and a four nucleotide indel, resulting in the parrot species having an amino acid sequence that was eight amino acids longer. 


\subsubsection{Amplification of Oestrogen Receptor $\beta$}

The primers listed in Table 2.1 (Chapter 2) for oestrogen receptor $\beta$ (ER- $\beta$ forward and $E R-\beta$ reverse primers) were used to span the ligand binding domain (nucleotides 818-1068 in NM_204794) to give an amplicon of 251 nucleotides in length. This gave a translated region of 83 amino acids (from amino acid 274-356 in NP_990125).

\subsubsection{Alignment of ER- $\beta$ LBD of generated species}

Alignment of the nucleotide sequences between the four New Zealand native parrots showed eight positions where the nucleotides differed in at least one species and is shown in Figure 3.12. Overall the ER- $\beta$ LBD exhibited $97 \%$ conservation. There was a tissue-specific difference in the nucleotide sequence obtained when the ovary sequence was compared to that from the kidney (not shown). However, even with the differences in the ER- $\beta$ LBD of the New Zealand parrots, the corresponding 83 amino acid sequences were $100 \%$ conserved (Figure 3.13). Thus, as the amino acid sequences were identical, this will hereafter be referred to as the New Zealand parrot consensus ER- $\beta$ sequence.

Comparison of the New Zealand parrot nucleotide sequences with those for Cockatiel, Chicken and Japanese Quail showed a further 20 positions where there were differences (Figure 3.12) giving a total of 28 positional differences between the seven species. This meant there was $89 \%$ identity between the seven species with respect to the LBD sequences.

Overall, when the amino acid sequences of the seven avian species were aligned, there were three sites where the amino acids were not identical, indicating there was $96 \%$ conservation (Figure 3.13). The Cockatiel exhibited 100\% identity to the New Zealand parrots whilst the Chicken and Japanese Quail exhibited $98 \%$ and $96 \%$ identity respectively. The alignment indicated that two amino acids were different (blue boxes in Figure 3.13): V21I and L67F. Additionally, the Japanese Quail sequence had one unique amino acid difference (M16L) All three substitutions were conserved changes. 


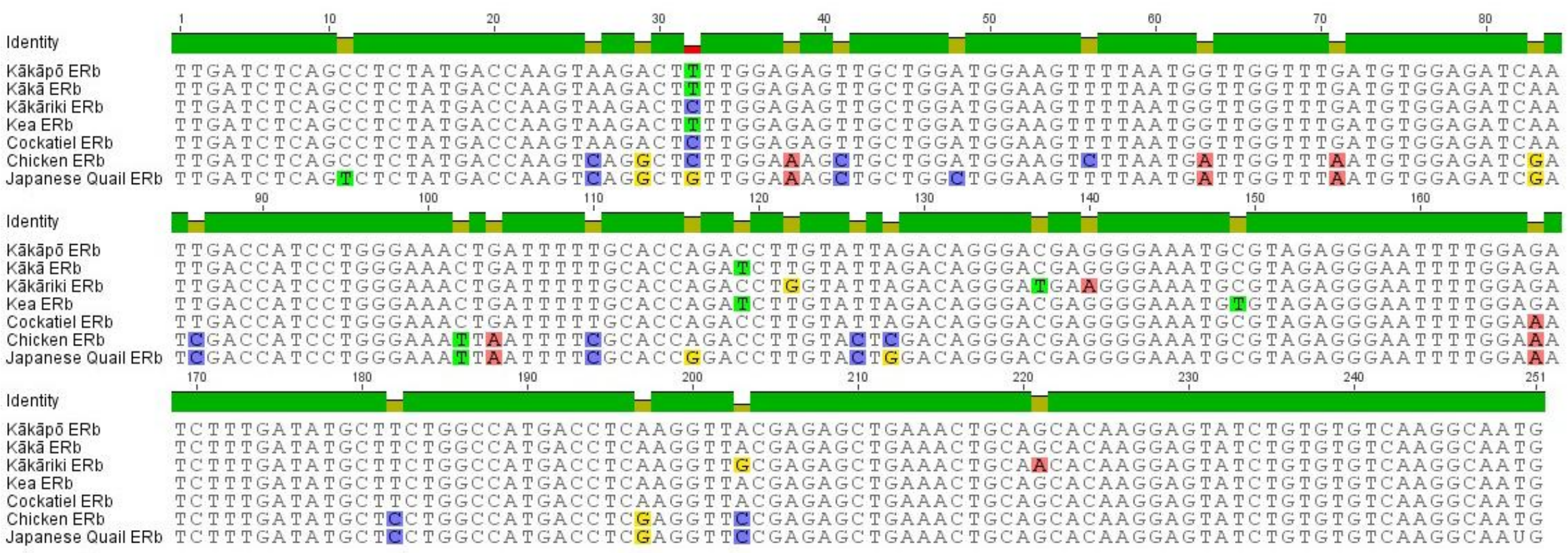

Figure 3.12 Nucleotide sequences that span the amplified region of the ligand binding domain (LBD) of oestrogen receptor $\beta$ (ERb) of New Zealand parrot species, Cockatiel, Chicken and Japanese Quail. Highlighted nucleotides (red = adenine, blue = cytosine, yellow = guanine and green = thymine) depict a change in the base 


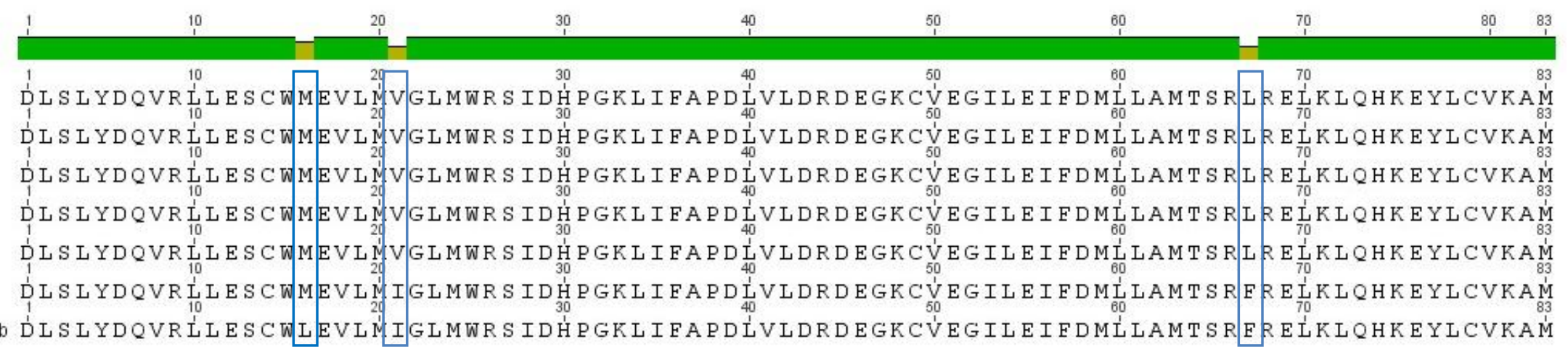

Figure 3.13 Amino acid sequences that span the amplified region of the ligand binding domain (LBD) of oestrogen receptor $\beta$ (ERb) of New Zealand parrot species, Cockatiel, Chicken and Japanese Quail. The conserved changes in amino acid have blue boxes around them. 


\subsubsection{Alignment of ER- $\beta$ LBD of other species}

The human ER- $\beta$ nucleotide sequence (NM_001437) was aligned with the corresponding New Zealand parrot nucleotide sequences (Figure 3.14). There were a total of 45 nucleotide positions where the nucleotide in the human sequence did not match what was present in any of the New Zealand parrot sequences (82\% conservation). At a further three positions (32, 137 and 221) the human nucleotide and Kākāriki were the same but different to the other parrots and at another position (119), the nucleotide for human matched that found in both the Kākā and Kea sequences but not those of Kākāpō and Kākāriki.

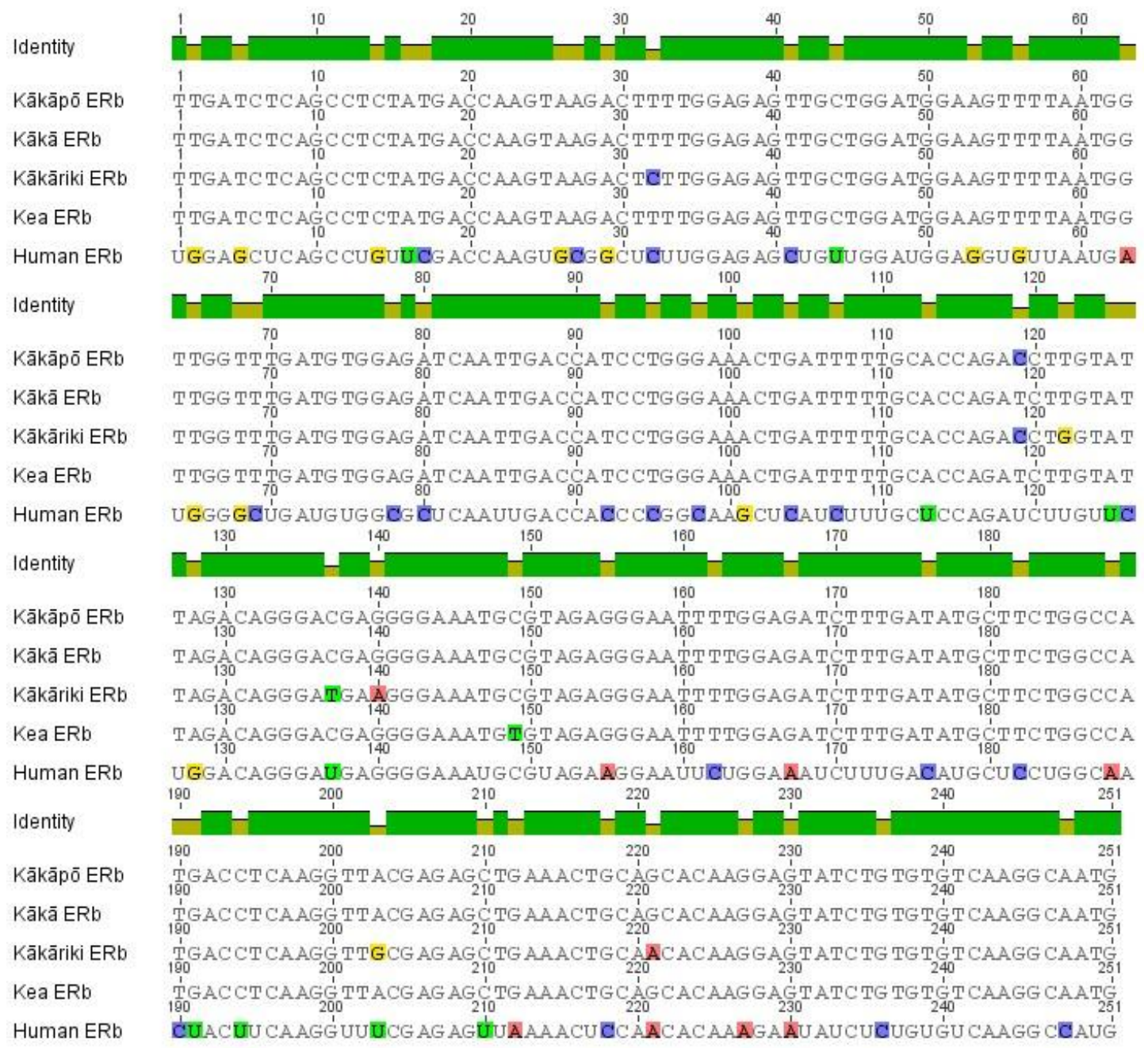

Figure 3.14 Nucleotide sequences that span the amplified region of the ligand binding domain (LBD) of oestrogen receptor $\beta(E R b)$ for New Zealand parrot species with human. Highlighted nucleotides (red = adenine, blue = cytosine, yellow $=$ guanine and green $=$ thymine) depict a change in the residue .

The translated sequence from human ER- $\beta$ (NP_001428) was aligned with the New Zealand parrot consensus ER- $\beta$ sequence and found to have 94\% conservation with five amino acid 
differences (Figure 3.15). Two of these were in the same position as what was observed from the alignment of the seven avian species. When the human ER- $\beta$ sequence was compared with that in New Zealand parrots and the other avian species, several amino acid differences were identified: L67F (parrot c.f. human), V21M (parrots c.f. human), I21M (non-parrots c.f. human), D1E (all birds c.f. human), Y5F (all birds c.f. human) and M63T (all birds c.f. human). The M63T was non-conserved (red box) whilst the others were conserved (blue boxes).

Blastn was used to identify nucleotide sequences derived from the Aves taxon that were similar to those nucleotide sequences from the four native New Zealand parrots. A total of seven species were identified (including Chicken (NM_204794) and Japanese Quail (AF045149)). These seven sequences all had greater similarity to the New Zealand parrots than either Chicken or Japanese Quail did (Appendix 3 Supplementary Figure 3I). There were four positions (32, 182, 197 and 203) where the New Zealand parrot sequence differed from that of the other species and a total of 36 sites where at least one nucleotide in a sequence did not match that of other sequences.

When blastp was used to identify protein sequences derived from the Aves taxon that were similar to the New Zealand parrot consensus ER- $\beta$ sequence, the same seven species were identified. Alignment showed three positions where the amino acid differed (Appendix 3 Supplementary Figure 3J) which were the same three positions as were seen when the seven generated sequences were aligned (Figure 3.13). At position 67, the New Zealand parrot consensus ER- $\beta$ sequence had a different amino acid to all the other avian species (L67F).

From the alignment of the non-published avian species, there were a total of four positions where the amino acid differed (Appendix 3 Supplementary Figure 3K). Once again, at position 67, only the New Zealand parrots (and Anna's hummingbird) had L67 whereas the other 34 species had F67. 


\subsubsection{Three-dimensional modelling of ER- $\beta$ LBD}

The template used to model a three-dimensional structure for Kākāpō ER- $\beta$ LBD was the crystal structure of the human ER- $\beta$ (3OLS) (Figure 3.16A and B). A visual representation of the LBD region amplified showed three $\alpha$-helices with a $\beta$-sheet (Figure 3.16C) that encloses the native ligand, 17 $\beta$-oestradiol, when bound to the receptor (Figure 3.16D). 

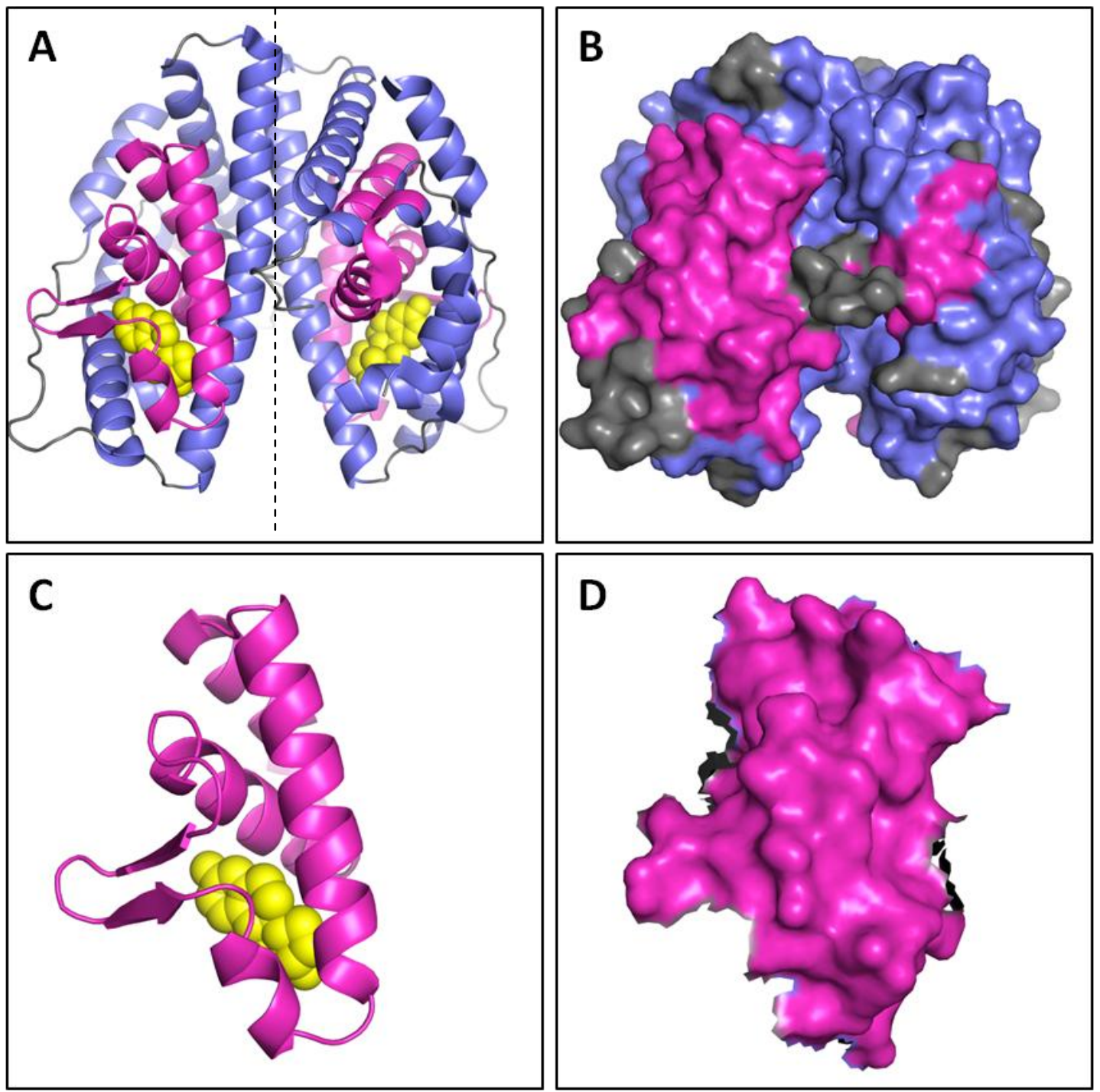

Figure 3.16 Three-dimensional structure of human oestrogen receptor $\beta$ (hER- $\beta$ ) and the ligand binding domain (LBD) region amplified in the avian species. A) The 3D model of hER- $\beta$ (3OLS) was visualised as a cartoon model with the amplified region in pink and the unamplified region in blue (loops are in grey). The $\beta$-sheets are represented as arrows. This is as the homodimer (with a monomer to the left and right of the dashed line) with the native ligand 17 $\beta$-oestradiol $\left(\mathrm{E}_{2}\right)$ docked in the receptor pocket of each monomer depicted as yellow spheres. B) A space-fill model of the hER- $\beta$ homodimer with the same colours as for A. C) A cartoon model of the section of the LBD of ER- $\beta$ amplified in the different avian species. D) The amplified section of ER- $\beta$ in C represented as a space-fill model. All pictures were made with PyMol.

Comparison of Kākāpō and human ER- $\beta$ sequences showed five amino acids that were not identical (Figure 3.17), three of which were close to the bound $\mathrm{E}_{2}$ (Figure 3.17A and B). The side-chains of the Kākāpō at the five differing positions were similar in structure (Figure 3.17C and D). 

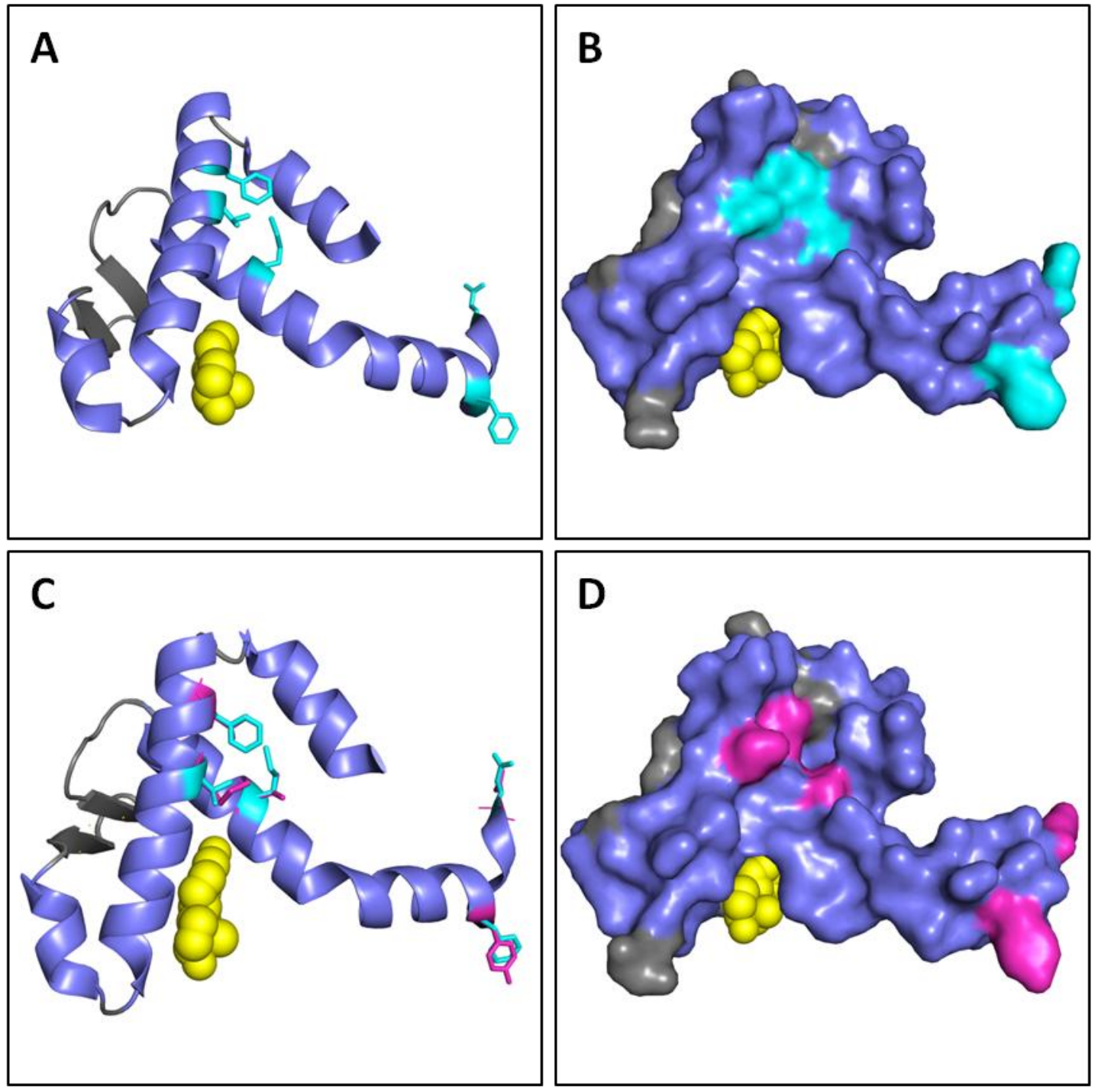

Figure 3.17 The amino acid differences between the ligand binding domain (LBD) of oestrogen receptor $\beta$ (ER- $\beta$ ) of Kākāpō and human. A) The LBD of human ER- $\beta$ (hER- $\beta$ ) was visualised as a cartoon model with the $\alpha$-helices in blue and the $\beta$-sheets and loops in grey. The $\beta$-sheets are represented as arrows. The five amino acids that differed to Kākāpō ER- $\beta$ are shown with their side-chains in light blue. The native ligand $17 \beta$-oestradiol $\left(\mathrm{E}_{2}\right)$ is depicted as yellow spheres. B) A space-fill model of this region with the differing residues shown in light blue. Grey is $\beta$-sheets and loops. C) The LBD of hER- $\beta$ is again shown as a cartoon model with the side-chains of the five differing amino acids for human in light blue and those for Kākāpō in pink. D) A space-fill model with the Kākāpō residues at the five positions in pink. All pictures were made with PyMol.

The LBD region in Kākāpō had three amino acids that were different to those in Chicken and Japanese Quail (Figure 3.18A for Kākāpō; and Figure 3.18C for Chicken and Japanese Quail). Two of these were located on one $\alpha$-helix near the position where $17 \beta$-oestradiol binds; the amino acid that was different in Japanese Quail (L16) to the others (M16) was on an $\alpha$-helix that formed the side of the pocket (circled in red). The space-fill model demonstrated its close proximity to the bound $17 \beta$-oestradiol (Figure 3.18B and D). The side-chain of met16 was found to be $3.5 \AA$ from the ligand whereas the side-chain for leu16 in Japanese Quail was $5.5 \AA$ (Figure 3.18E and F). 

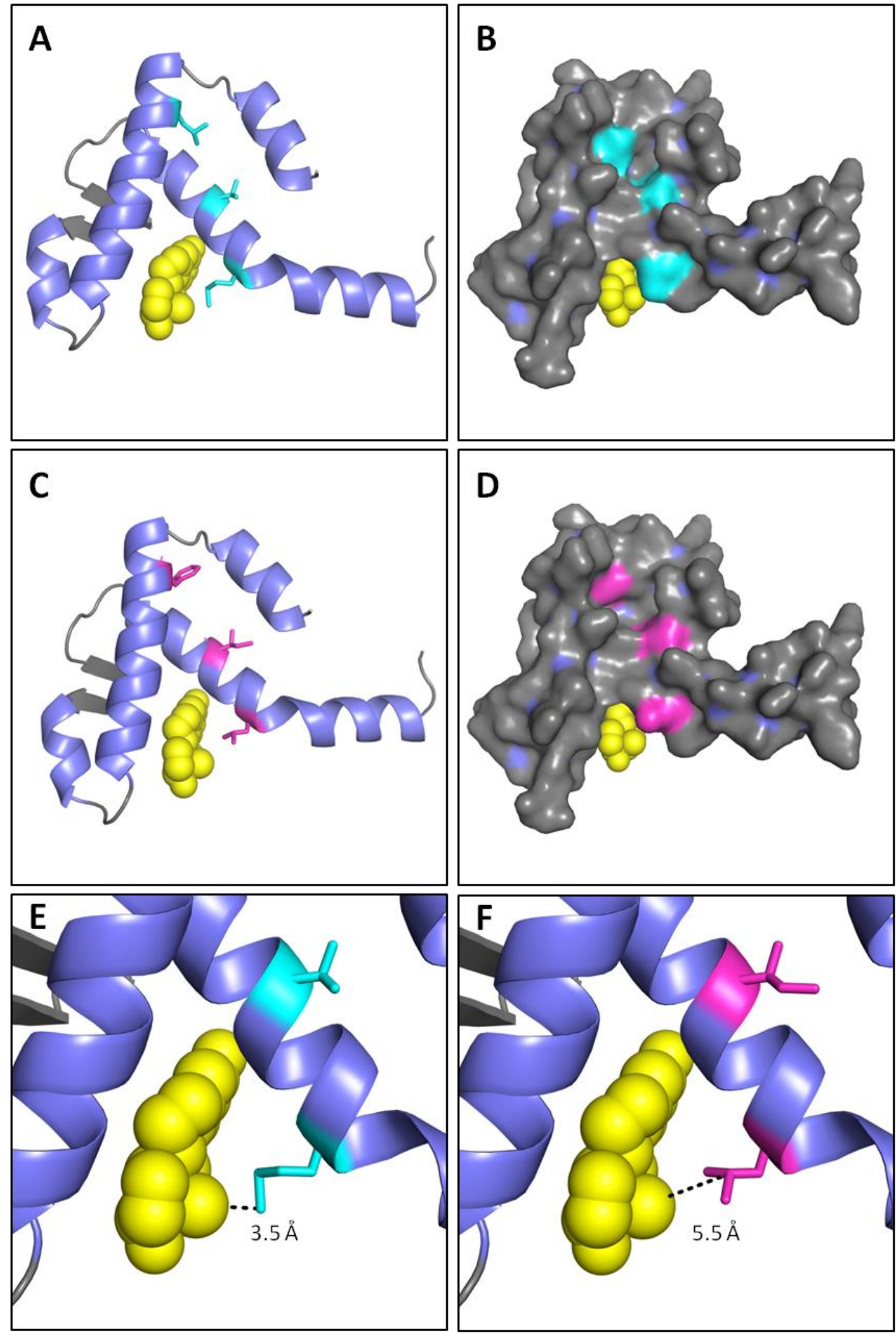

Figure 3.18 The amino acid differences between the ligand binding domain (LBD) of oestrogen receptor $\beta$ (ER- $\beta$ ) of Kākāpō and non-native avian species. A) The Kākāpō LBD was visualised as a cartoon model with $\alpha$-helices in blue and $\beta$-sheets and loops depicted in grey. The $\beta$-sheets are represented as arrows. The three amino acid residues that differed from the non-native avian species are shown in light blue. $17 \beta$-oestradiol $\left(\mathrm{E}_{2}\right)$ is shown in yellow. B) A space-fill model of the LBD region with the $\beta$-sheets and loops depicted in grey. The positions where the amino acid differed are shown in light blue. C) The LBD of the other avian species as a cartoon model with the three differing amino acids in pink. D) A space-fill model of the LBD region for the other avian species with the three positions that differed for the non-native species in pink. E) The amino acid substitution at position 16 for Kākāpō (M) was 3.5 Angstroms ( $\AA$ ) from the docked $E_{2}$ whereas $\left.F\right)$ the amino acid substitution at position 16 for Japanese Quail (L) was 5.5 from the $\mathrm{E}_{2}$. All pictures were made with PyMol. 


\section{Summary}

The eight nucleotides that differed amongst the New Zealand parrot species were all synonymous hence there was $100 \%$ identity in the translated protein. There was slightly less protein conservation when the other avian species sequenced and those from the blastp search were compared (96\%) with the difference in amino acid at position 16 leading to closer proximity of the side-chain with the bound $17 \beta$-oestradiol. When the human sequence was compared to that for the New Zealand birds, the translated sequence was $94 \%$ conserved (five different amino acids).

\subsubsection{Amplification of Androgen Receptor}

The primers listed in Table 2.1 (Chapter 2) for androgen receptor (AR forward and AR reverse primers) were used to span the ligand binding domain (nucleotides 2662-3078 in NM_001040090) to give an amplicon of 418 nucleotides in length. This corresponded to a translated sequence of 139 amino acids (amino acids 512-650 in NP_001035179).

\subsubsection{Alignment of AR LBD of generated sequences}

Alignment of the nucleotide sequences for the four New Zealand native parrots showed a total of 11 positions where the nucleotides differed and is shown in Figure 3.19. Overall the AR LBD exhibited $97 \%$ conservation. When the sequences from different tissue samples for each bird were compared, there were no tissue-specific differences in the sequences obtained. However, the sequence for Kākāriki, as determined in this study, did not span the whole amplified region.

Translation of the generated AR LBD nucleotide sequences for the New Zealand parrots led to amino acid sequences that were 99\% conserved (Figure 3.20) as there was one non-conserved amino acid change in Kākāriki (L74P) (Kākāriki c.f. other New Zealand parrots). Hereafter, the sequence with P74 will be referred to as the New Zealand parrot consensus AR sequence.

Alignment of the parrot nucleotide sequences with those identified in Cockatiel, Chicken and Japanese Quail showed an overall conservation of 91\% (Figure 3.19). There were 39 positions where a nucleotide differed in at least one of the species. The AR LBD sequence in 
Cockatiel showed 98\% identity to the New Zealand parrots. Chicken and Japanese Quail showed $95 \%$ and $94 \%$ identity to the consensus AR sequence of New Zealand parrots respectively. That is, there were 22 positions where Chicken contained a nucleotide that did not match any of the New Zealand parrots and for Japanese Quail, there were 23 nucleotides that did not match.

In terms of translation homogeneity to the New Zealand parrot consensus AR sequence, the Cockatiel exhibited $99 \%$ identity with one unique conserved amino acid difference (S55N). Both Chicken and Japanese Quail were found to have $99 \%$ and $98 \%$ identity to the New Zealand parrot consensus AR sequence (two and three amino acid changes respectively) (Figure 3.20). These included V19I and H62Q (parrots c.f. Chicken and Japanese Quail) with the latter a non-conserved change. Additionally, the Japanese Quail sequence had one unique amino acid difference (V58I) which was a conserved change. 


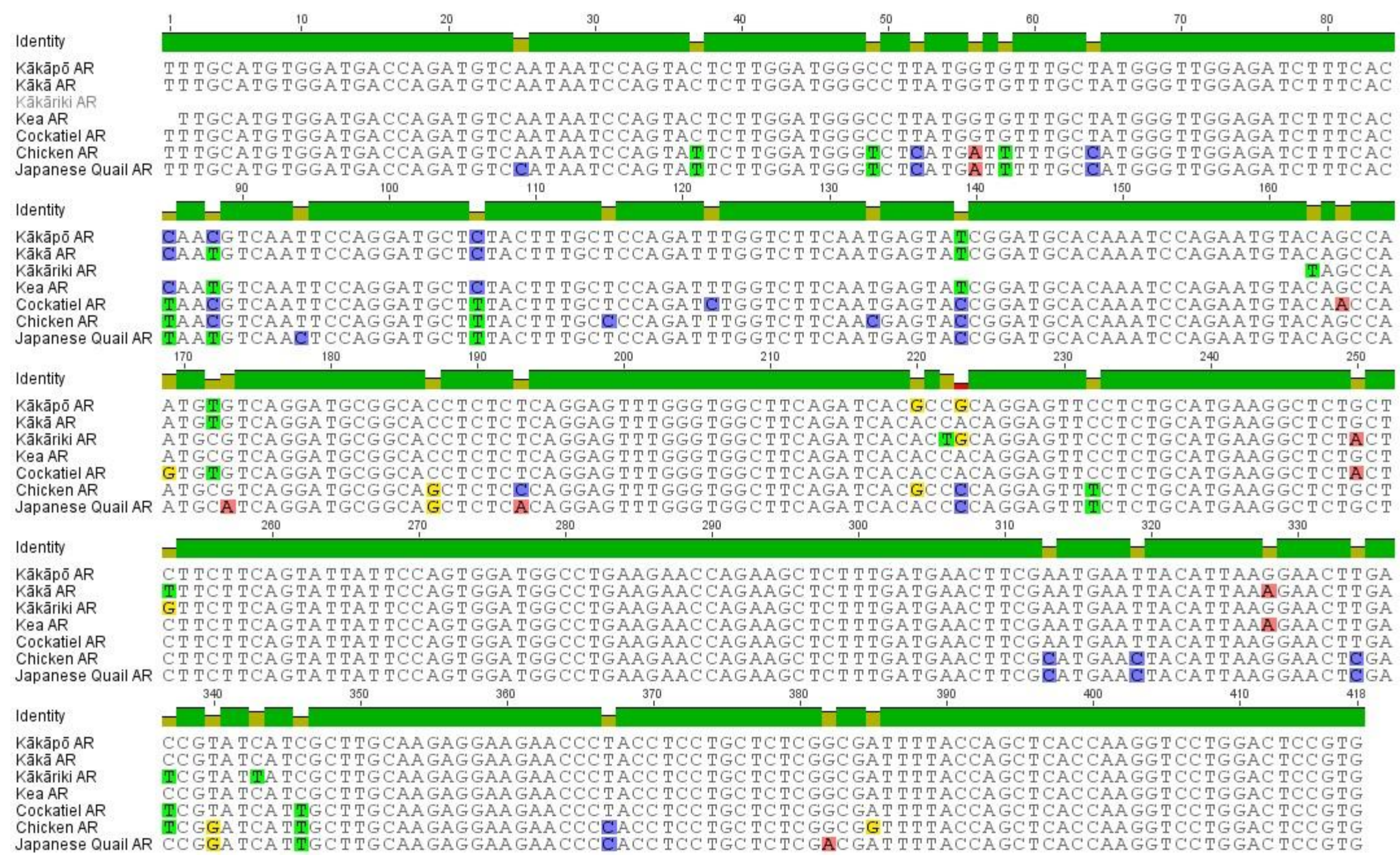

Figure 3.19 Nucleotide sequences span the amplified region of the ligand binding domain (LBD) of androgen receptor (AR) of New Zealand parrot species, Cockatiel, Chicken and Japanese Quail. Highlighted nucleotides (red = adenine, blue = cytosine, yellow = guanine and green = thymine) depict a change in the base). 


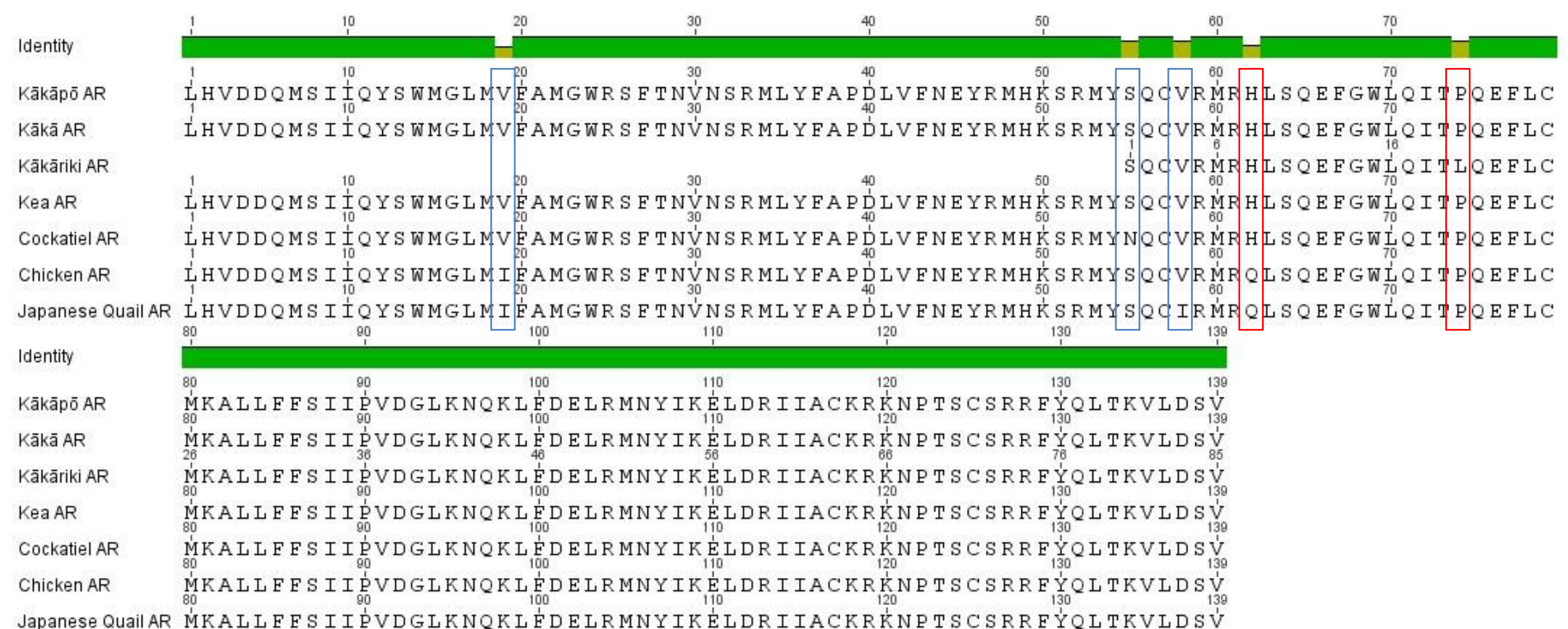

Figure 3.20 Amino acid sequences that span the amplified region of the ligand binding domain (LBD) of androgen receptor (AR) of New Zealand parrot species, Cockatiel, Chicken and Japanese Quail. Blue boxes represent conserved amino acid changes whilst red boxes represent non-conserved changes. 


\subsubsection{Alignment of AR LBD of other species}

The human AR nucleotide sequence (NM_000044) was aligned against those that were generated for the New Zealand parrots in this study (Figure 3.21). There were a total of 67 positions where the nucleotide in the human sequence did not match what was found in any of the parrot sequences (84\% conservation) and one position where it did match the Kākāriki sequence but not the other New Zealand parrots.

Despite there being a large number of differences when nucleotide sequences were compared, the hAR amino acid sequence (AAA51775) only had five amino acid differences when compared with that of the New Zealand parrot consensus AR sequence (Figure 3.22), none of which were at positions where changes were seen when the seven avian species were compared (Figure 3.20). Thus, there was $96 \%$ identity. Four of these were conserved amino acid differences (blue boxes: I9V, F85L, L99F and V135L) whilst the remaining difference (S8A) was non-conserved (red box).

The blastn tool was used to identify avian species with nucleotide sequences similar to that for the New Zealand parrots. 16 species with similar sequences were identified (Appendix 3 Supplementary Figure $3 \mathrm{~L}$ ). There were a total of 80 positions where nucleotide substitutions were present ( $81 \%$ conservation). Five of these sequences were incomplete and so did not span the full 418 nucleotides.

The blastp tool was used to identify protein sequences from the Aves taxon that were similar to the New Zealand parrot consensus AR sequence. A total of eight species were identified (including the Chicken and Japanese Quail) (Appendix 3 Supplementary Figure 3M). Alignment of these sequences showed six amino acid differences, which included the four positions where the Chicken and Japanese Quail differed to the New Zealand parrots. Of the amino acid changes present, only those at 62 and 76 (H62Q and E76G) were non-conserved.

Alignment of the AR amino acid sequences from the unpublished avian species showed differences at six positions for the 34 species (Appendix 3 Supplementary Figure 3N). None of these were unique to the New Zealand parrot consensus AR sequence but three were at the same positions as with the other avian species alignment (Appendix 3 Supplementary Figure $3 \mathrm{M})$. 
Identity

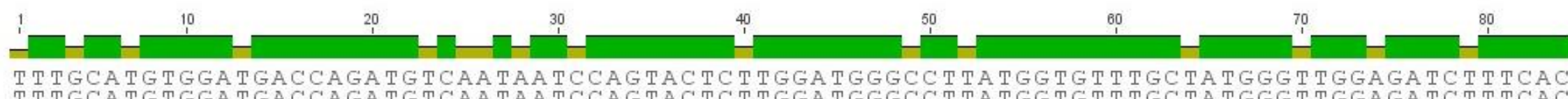

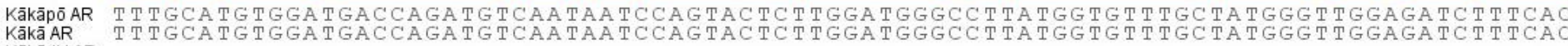

Kea AR

Human AR

Identity

Kākāpō AR

Kākā AR

Kākāriki AR

Kea AR

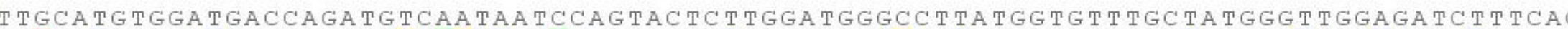

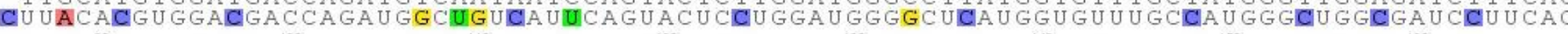

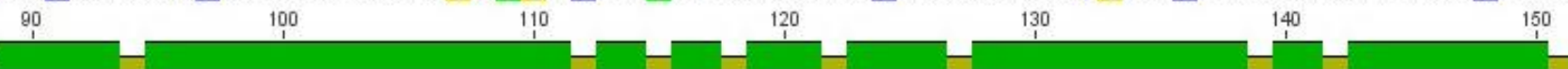

CAACGTCAAT TCCAGGATGCTCTACTTTGCTCCAGATT TGGTCT TCAATGAGTATCGGATGCACAAATCCAGAATG TAAGCCA CAATGTCAAT TCAGGATGCTCTACTTTGCTCCAGATT TGGTCTTCAATGAGTATCGGATGCACAAATCCAGAATGACAGCCA CAATGTCATTCCAGGATGCTCTACTTTGCTCAGATTTGTCTTCAATGAGTATCGGATGCACAAATCCAGAATGACAGCCA

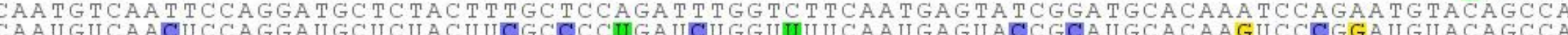

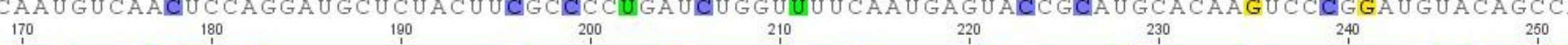

Identity

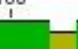
$1-$ $-1$

Kākāpō AR A TTGTCAGGATGCGGCACCTCTCTCAGGAGTTTGGGTGGCTTCAGATCACGCCGCAGGAGTTCCTCTGCATGAAGGCTCTGCT

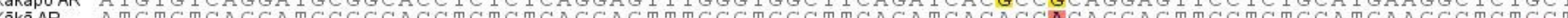
KäkārikiR ATGCGTCAGGATGCGGCACCTCTCTCAGGAGTTTGGGTGGCTTCAGATCACACTGCAGGAGTTCCTCTGCATGAAGGCTCTICT KeaAR ATGCG Human AR GUGUGU CCGAAU GAGGCACCUCUCUCAAGAGUUUGGAUGGCUCCAAAUCACCC CCCAGGAAUUCCUGUGCAUGAAAGCACUGCU

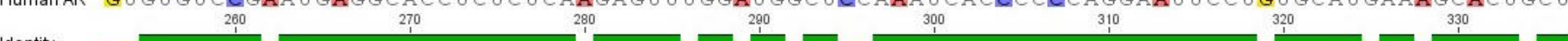
Identity Kākāpō AR Kākā AR Kākāriki AR Kea AR Human AR

Identity CTTCTTCAGTATTATTCCAGTGGATGCCTGAAGAACCAGAAGCTCTTTGATGAACT TCGAATGATTACATTAAGGAACTTGA TTTCTTAGTATTATTCCAGTGGATGGCCTGAAGAACCAGAAGCTCTTTGATGAACTTCGAATGAATTACATTAAAGAACTTGA GTTCTTCAGTATTATTCAGTGGATGGCCTGAAGAACCAGAAGCTCTTTGATGAACTTCGATGAATTACATTAAGAACTTGA

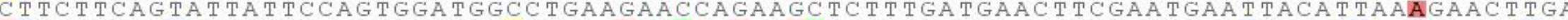

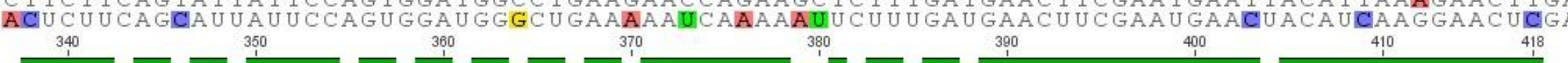

KākāpōAR CCGTATCATCGCTTGCAAGAGAAGAACCTACCTCCTGCTCTCGGCGATTTACCAGCTCACCAAGGTCCTGGACTCCGTG KākāAR CCGTATCATCGCTTGCAAGAGGAAGAACCCTACCTCCTGCTCTCGGCGATTTTACCAGCTCACCAAGGTCCTGGACTCCGTG Kăkäriki AR TCGTATTATCGCTTGCAAGAGGAAGAACCCTACCTCCTGCTCTCGGCGATTTTACCAGCTCACCAAGGTCCTGGACTCCGTG KeaAR CCGTATCATCGCTTGCAAGAGGAAGAACCCTACCTCCTGCTCTCGGCGATTT TACCAGCTCACCAAGGTCCTGGACTCCGTG
HumanAR UCGUAUCAUUGCAUGCAAAAGAAAAAAUCCCACAUCCUGCUCAAGACGCUUCUACCAGCUCACCAAGCUCCUGGACUCCGUG

Figure 3.21 Nucleotide sequences that span the amplified region of the ligand binding domain (LBD) of androgen receptor (AR) of New Zealand parrot species and human. Highlighted nucleotides (red $=$ adenine, blue $=$ cytosine, yellow $=$ guanine and green $=$ thymine $)$ depict a change in the base . 


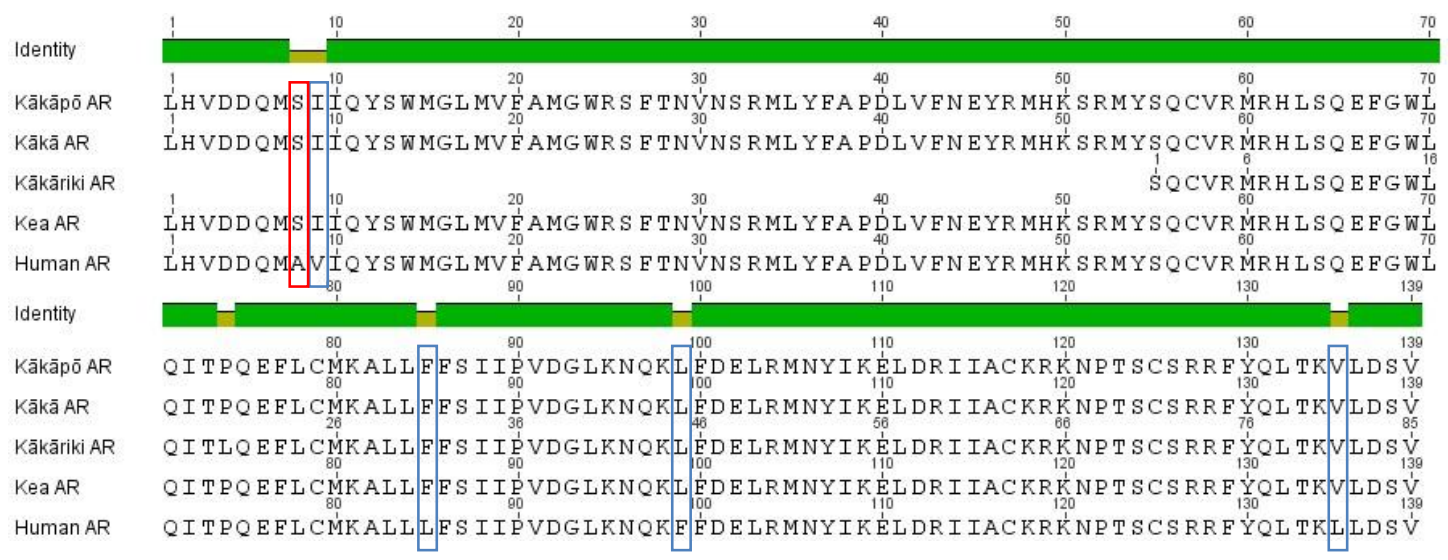

Figure 3.22 Amino acid sequences that span the amplified region of the ligand binding domain of androgen receptor (AR) of New Zealand parrot species and human. Blue boxes represent conserved amino acid changes whilst red boxes represent non-conserved changes.

\subsubsection{Three-dimensional modelling of AR LBD}

The molecular modelling studies utilised the crystal structure of human androgen receptor (2AM9) focussing specifically on the LBD region that had been amplified in the avian species (Figure 3.23A, B and C). When the LBD region was represented as a space-fill model, the pocket that the native ligand testosterone docked in was evident (Figure 3.23D).

The AR LBD region had five amino acids that differed between human and Kākāpō (Figure 3.24A and C). These were all present on different $\alpha$-helices (apart from the two that were directly next to each other) and two had their side-chains facing into each other (positions 99 and 135). When this was shown as a space-fill model, two of these amino acids were visible on the top face whilst one was on the underside of the model and one buried inside (Figure 3.24B and D). There were only slight differences in the sidechains of three amino acids (positions 8, 9 and 135) whereas for the leu-phe substitution seen at positions 85 and 99 there was a change to the size of the side-chain (Figure 3.24C and D).

The AR LBD region in Kākāpō had four amino acids that were different to those in Chicken and Japanese Quail. Three of these were present on one face of the $\alpha$-helix situated near the docking site (i.e. binding) of testosterone with the LBD (Figure 3.25A and C). The fourth amino acid (which was the one only different in Japanese Quail) was immediately adjacent to testosterone in the docking site. In the space-fill model it could be seen that these amino acids were all present in one region (Figure 3.25B and D). For both Kākāpō and Chicken and 
Japanese Quail, the side-chain at position 19 was $4.0 \AA$ away from the bound testosterone (Figure 3.25E and F).
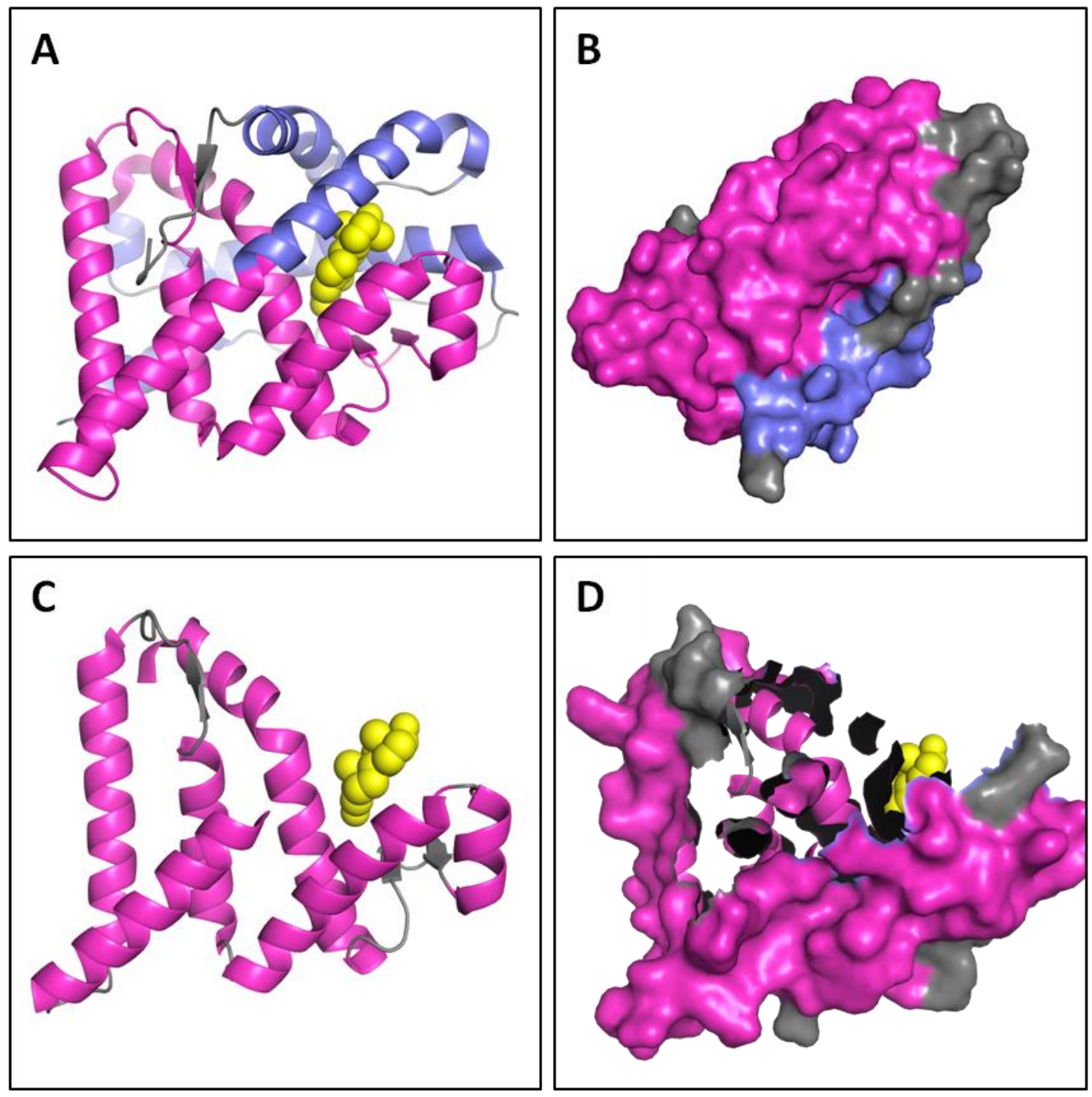

Figure 3.23 Three-dimensional structure of human androgen receptor (hAR) and the ligand binding domain (LBD) region amplified in the avian species. A) The 3D model of hAR (2AM9) was visualised as a cartoon model with with the amplified region in pink and the unamplified region in blue ( $\beta$-sheets and loops in grey). The $\beta$-sheets are represented as arrows. The native ligand testosterone $\left(\mathrm{T}_{4}\right)$ docked in the receptor is depicted as yellow spheres. B) A space-fill model of the hAR with the same colours as for A. C) A cartoon model of the section of the LBD of AR amplified in the different avian species. D) The amplified section of AR in C represented as a space-fill model. All pictures were made with PyMol. 

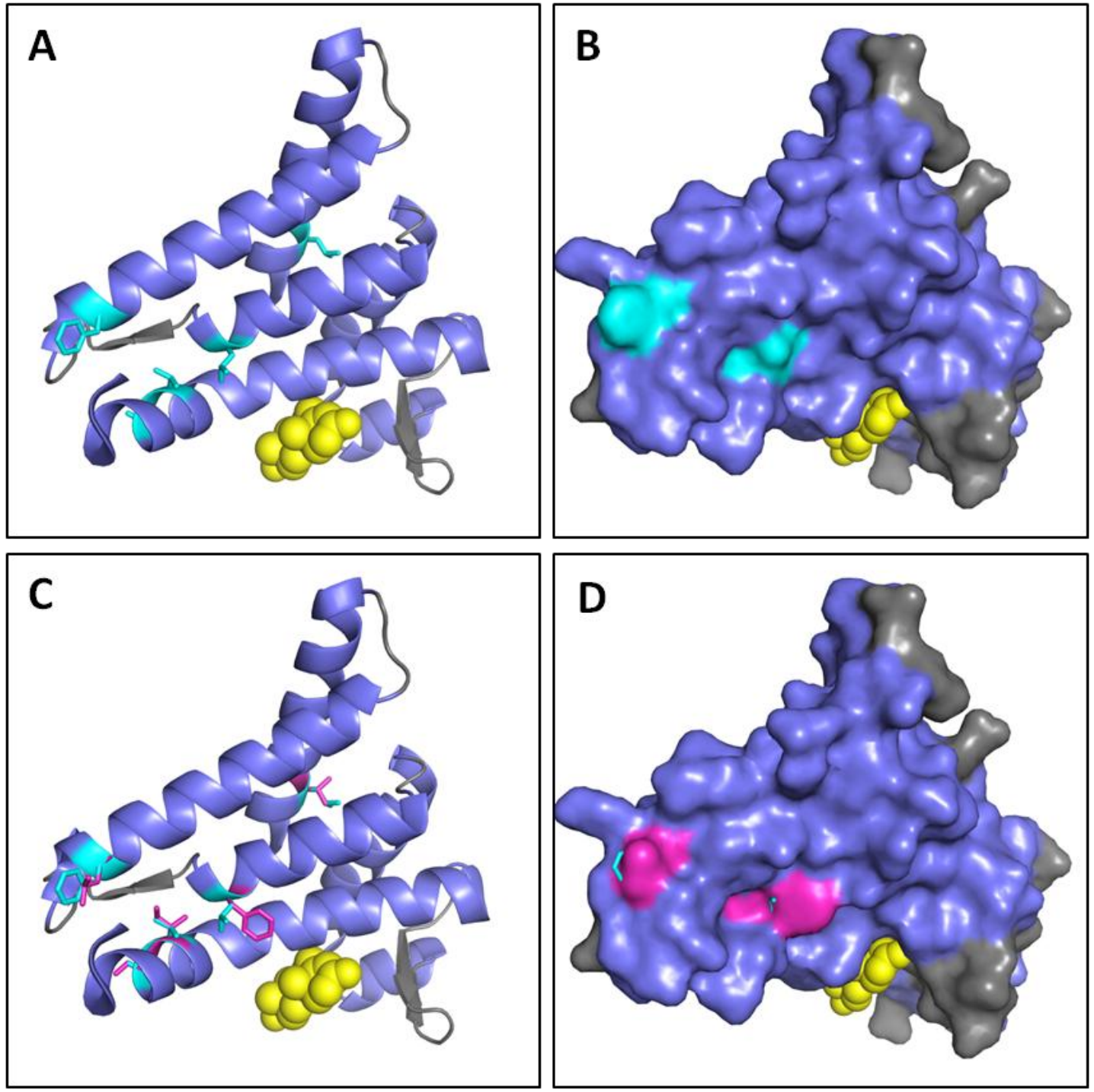

Figure 3.24 The amino acid differences between the ligand binding domain (LBD) of androgen receptor (AR) of Kākāpō and human. A) The LBD of human AR (hAR) was visualised as a cartoon model with $\alpha$-helices in blue and the $\beta$-sheets and loops in grey. The $\beta$-sheets are represented as arrows. The five amino acid residues that differed to Kākāpō AR are shown with their side-chains in light blue. The native ligand testosterone $\left(\mathrm{T}_{4}\right)$ is depicted as yellow spheres. B) A space-fill model of this region with the differing residues shown in light blue. Grey is $\beta$-sheets and loops. C) The LBD of hAR is again shown as a cartoon model with the side-chains of the five differing amino acids for human in light blue and those seen in Kākāpō in pink. D) A space-fill model with the Kākāpō residues at the five positions in pink. All pictures were made with PyMol. 

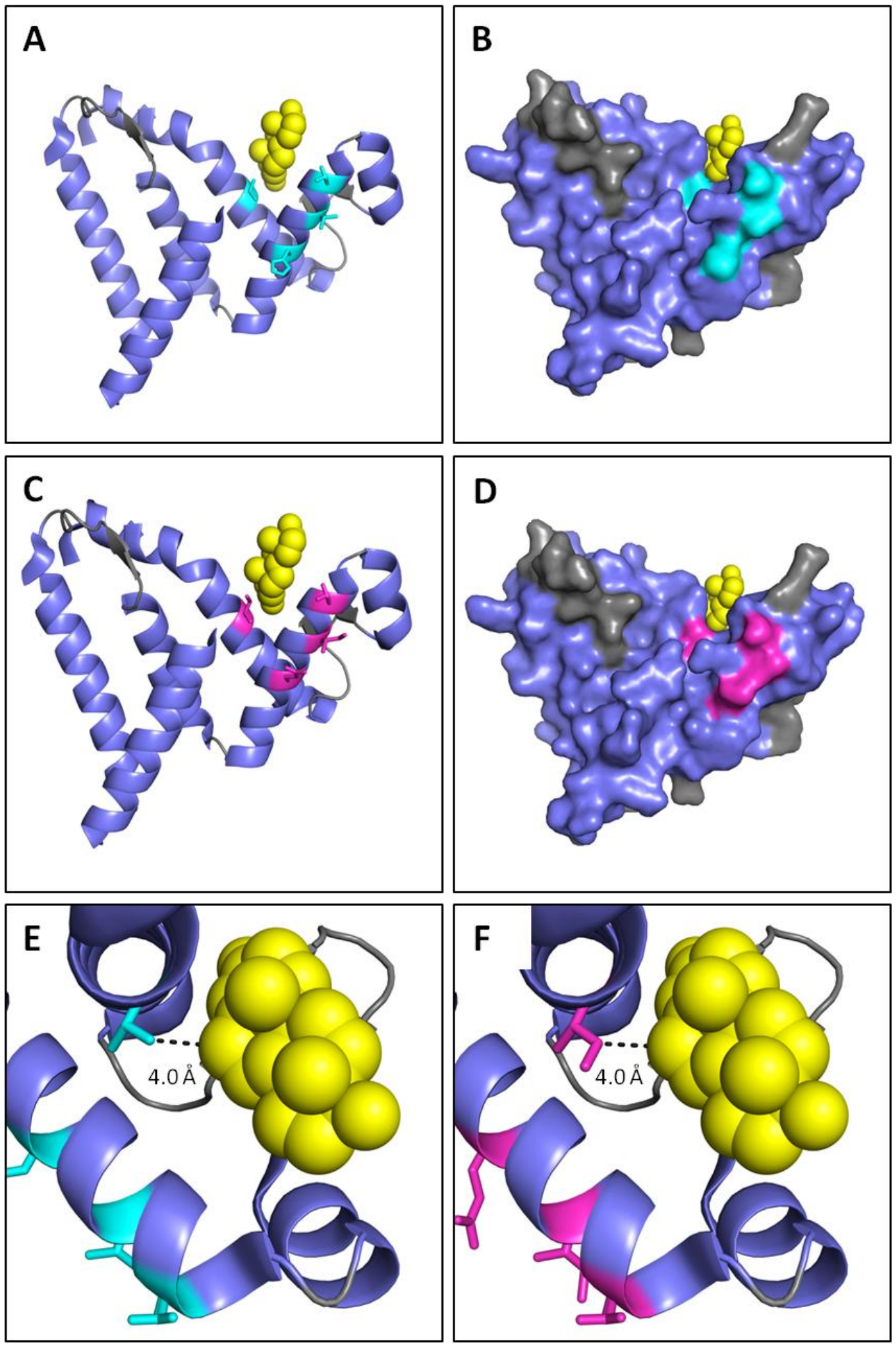

Figure 3.25 The amino acid differences between the ligand binding domain (LBD) of androgen receptor (AR) of Kākāpō and non-native avian species. A) The Kākāpō LBD was visualised as a cartoon model with $\alpha$-helices in blue and $\beta$-sheets and loops depicted in grey. The $\beta$-sheets are represented as arrows. The four amino acid residues in Kākāpō that differed to the non-native avian species are shown in light blue. Testosterone $\left(\mathrm{T}_{4}\right)$ is shown in yellow. B) A space-fill model of the LBD region with the $\beta$-sheets and loops depicted in grey. The positions where the amino acid differed in Kākāpō is shown in light blue. C) The LBD of the other avian species as a cartoon model with the four differing amino acids shown in pink. D) A space-fill model of the LBD region for the other avian species with the four positions that differed from Kākāpō shown in pink. E) The amino acid substitution at position 19 for Kākāpō (V) was 4.0 Angstroms ( $⿱$ ) from the docked $\mathrm{T}_{4}$ as was F) the amino acid substitution at position 19 for Chicken and Japanese Quail (I). All pictures were made with PyMol. 


\section{Summary}

The 97\% conservation of nucleotides in the New Zealand species for AR translated to only one amino acid difference (in Kākāriki). When the other three species were aligned, the level of nucleotide conservation decreased to $91 \%$. There were only four positions where the amino acids differed. The amino acid that was only different in Japanese Quail was close to testosterone, although the distance between the side-chain and the ligand did not change. Despite the human having many differences in its nucleotides, only five amino acids differed; none of which were in very close proximity to the bound testosterone.

\subsubsection{Amplification of Progesterone Receptor}

The primers listed in Table 2.1 (Chapter 2) for progesterone receptor ( $P R$ forward 1 and $P R$ reverse 2 primer) were used to span the ligand binding domain to give an amplicon of 147 nucleotides in length (from nucleotide 2775-2921 in Chicken NM_205262).

\subsubsection{Alignment of PR LBD of generated sequences}

Alignment of the nucleotide sequences for the four New Zealand parrots showed three positions where the nucleotides were not identical (Figure 3.26). Therefore, overall the PR LBD exhibited $98 \%$ conservation. There were no tissue-specific differences in the sequences obtained.

The translation of the nucleotides in the PR LBD of the New Zealand parrots gave $100 \%$ identity between all New Zealand parrots (Figure 3.27). Hereafter this will be referred to as the New Zealand parrot consensus PR sequence.

Alignment of the New Zealand parrot nucleotide sequences with those identified in Cockatiel, Chicken and Japanese Quail, showed an overall sequence conservation of 92\% (Figure 3.26). More specifically, the PR LBD sequence in Cockatiel, Chicken and Japanese Quail showed 99\%, 96\% and 95\% identity respectively with the New Zealand parrots. The Japanese Quail exhibited the largest variance from the other species with eight nucleotides differing to those in the New Zealand parrots, but five of these were also different in Chicken. 


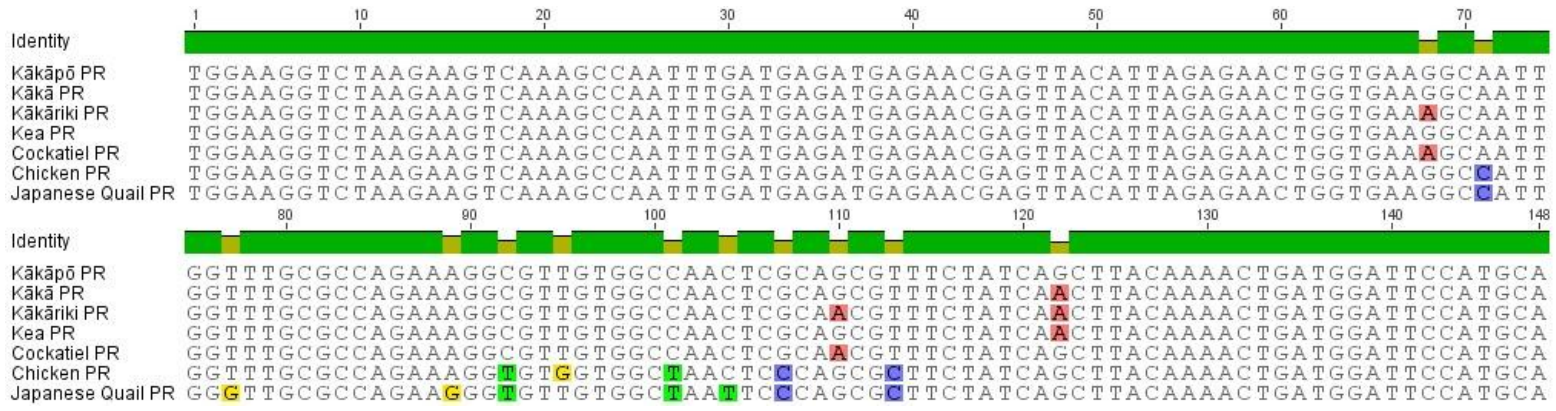

Figure 3.26 Nucleotide sequences that span the ligand binding domain of the progesterone receptor (PR) of New Zealand parrot species, Cockatiel, Chicken and Japanese Quail. Highlighted nucleotides (red = adenine, blue = cytosine, yellow $=$ guanine and green $=$ thymine $)$ depict a change in the residue .

Despite the differences present in the PR LBD nucleotide sequences of the seven species, alignment of the amino acids for the New Zealand parrots with Cockatiel, Chicken and Japanese Quail showed 100\% conservation (Figure 3.27).

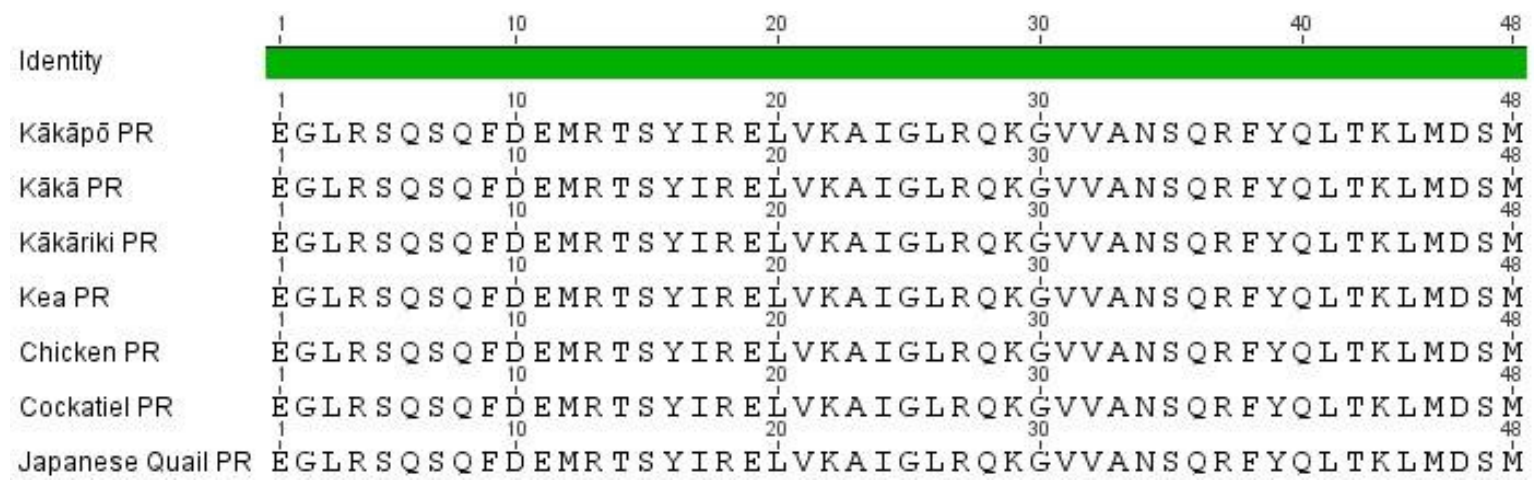

Figure 3.27 Amino acid sequences that span the ligand binding domain of the progesterone receptor (PR) of New Zealand parrot species, Cockatiel, Chicken and Japanese Quail. 


\subsubsection{Alignment of PR LBD of other species}

The human PR nucleotide sequence (NM_000926) was aligned against those generated for the New Zealand parrots. There were a total of 27 nucleotide positions where the nucleotide in the human sequence did not match those found in any of the New Zealand parrot PR LBD sequences resulting in $82 \%$ conservation (Figure 3.28).

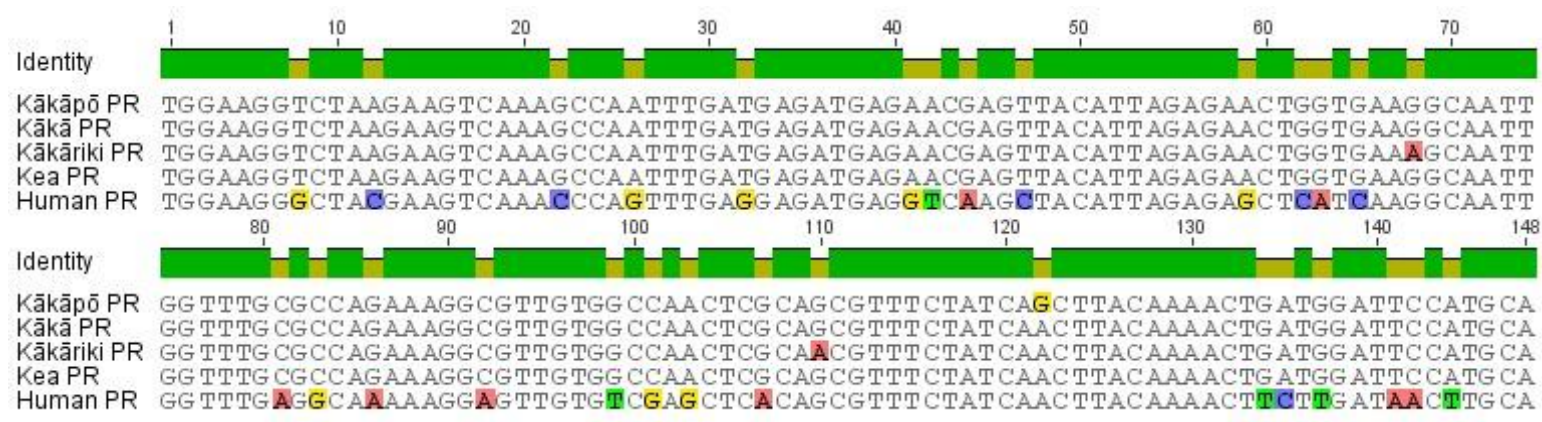

Figure 3.28 Nucleotide sequences that span the ligand binding domain of the progesterone receptor (PR) of New Zealand parrot species and human. Highlighted nucleotides $(\mathrm{red}=$ adenine, blue $=$ cytosine, yellow $=$ guanine and green $=$ thymine) depict a change in the base.

When the corresponding human protein sequence was aligned, there were ten amino acids that differed to those of the New Zealand parrots indicating $80 \%$ conservation between the New Zealand consensus PR sequence and human (Figure 3.29). Two of these were non-conserved amino acid differences (red boxes: A33S and Q49H) whilst the remaining eight were conserved amino acid differences (blue boxes). Four of the differences were found to be at the end of the sequence.

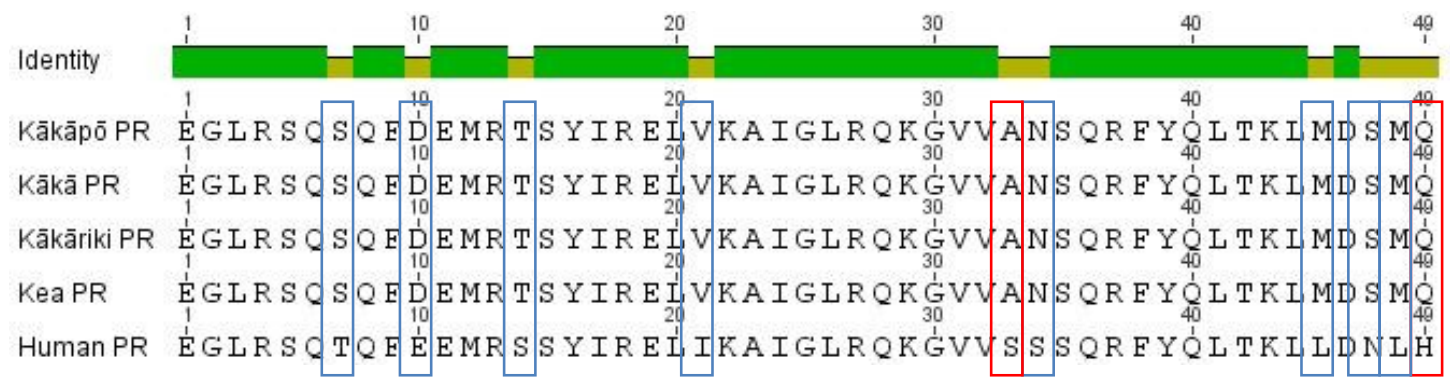

Figure 3.29 Amino acid sequences that span the ligand binding domain of the progesterone receptor (PR) of New Zealand parrot species and human. Blue boxes represent conserved amino acid changes whilst red boxes represent non-conserved changes. 
The blastn tool was used to identify nucleotide sequences from the Aves taxon that were similar to the nucleotide sequences for the four native New Zealand parrots. Seven species were identified including the Chicken and Japanese Quail (Appendix 3 Supplementary Figure $30)$. Overall there were 22 differences in the nucleotides resulting in $77 \%$ identity.

The blastp tool was used to identify protein sequences from the Aves taxon that were similar to the parrot consensus sequence. The same seven species were identified as well as Rock Pigeon and exhibited 94\% identity with the New Zealand parrot consensus PR sequence (Appendix 3 Supplementary Figure 3P). None of the differences seen were unique to the New Zealand parrot consensus PR sequence. Alignment of the PR amino acid sequences for the unpublished avian species showed differences at four positions (Appendix 3 Supplementary Figure $3 \mathrm{Q}$ ). None of these were unique to the New Zealand parrot consensus PR sequence nor were they at positions where differences were seen in the alignment of the avian species from the NCBI database (Appendix 3 Supplementary Figure 3P).

\subsubsection{Alignment of the $N$-terminal end of PR LBD}

Further preliminary sequencing of the PR LBD was undertaken in five avian species of interest (not Kea or Japanese Quail) to amplify a region of PR at the N-terminal end. The primers used for this were $P R$ forward 2 and $P R$ reverse 2 in Table 2.1 (Chapter 2). This gave an amplicon of 650 (nucleotides 2121-2763 in NM_205262) which translated to a further 216 amino acids. The Kea sequence used was that provided in the bird database and the incomplete Japanese Quail nucleotide and protein sequences used in the alignments were AB265142 and BAE97646.

Nucleotide sequences for the four New Zealand native parrots showed a total of 35 positions where there were nucleotide differences (Figure 3.30). This corresponded to 95\% conservation. Alignment of the nucleotide sequences of the New Zealand parrots with that of Cockatiel, Chicken and Japanese Quail showed 94\% conservation. When the Cockatiel sequence was compared to that in New Zealand birds, there were three positions where Cockatiel did not match any of the New Zealand parrots. The level of conservation decreased when Chicken and Japanese Quail were compared to the New Zealand parrots with 42 and 19 differences respectively (although in the case of the Japanese Quail this was not the full sequence). 
Kākāpō N-terminal PR
Kăkā N-terminal PR

Kākā N-terminal PR

Kea N-terminal PR

Cockatiel N-terminal PR
Chicken N-terminal PR

Identity

Kāāāpō N-terminal PR
K Kăā̂ N-terminal PR

Kăkariki N-terminal PR

Kea N-terminal PR

Chicken N-terminal PR

Identity

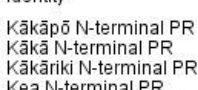

Cockatiel N-terminal

Chicken N-terminal PR
Japanese Quail N-termina $P R$

Identity

Kākāpō N-terminal PR

Kăkā N-terminal PR
Kăkăriki N-terminal $P R$

Kea N-terminal PR

Cockatiel N-terminal PR
Chicken N-terminal PR

Identity

Kākā̄ōon N-terminal PR

Kăkâriki N-terminal PR

Kea N-terminal PR

Chicken N-terminal PR

Identity
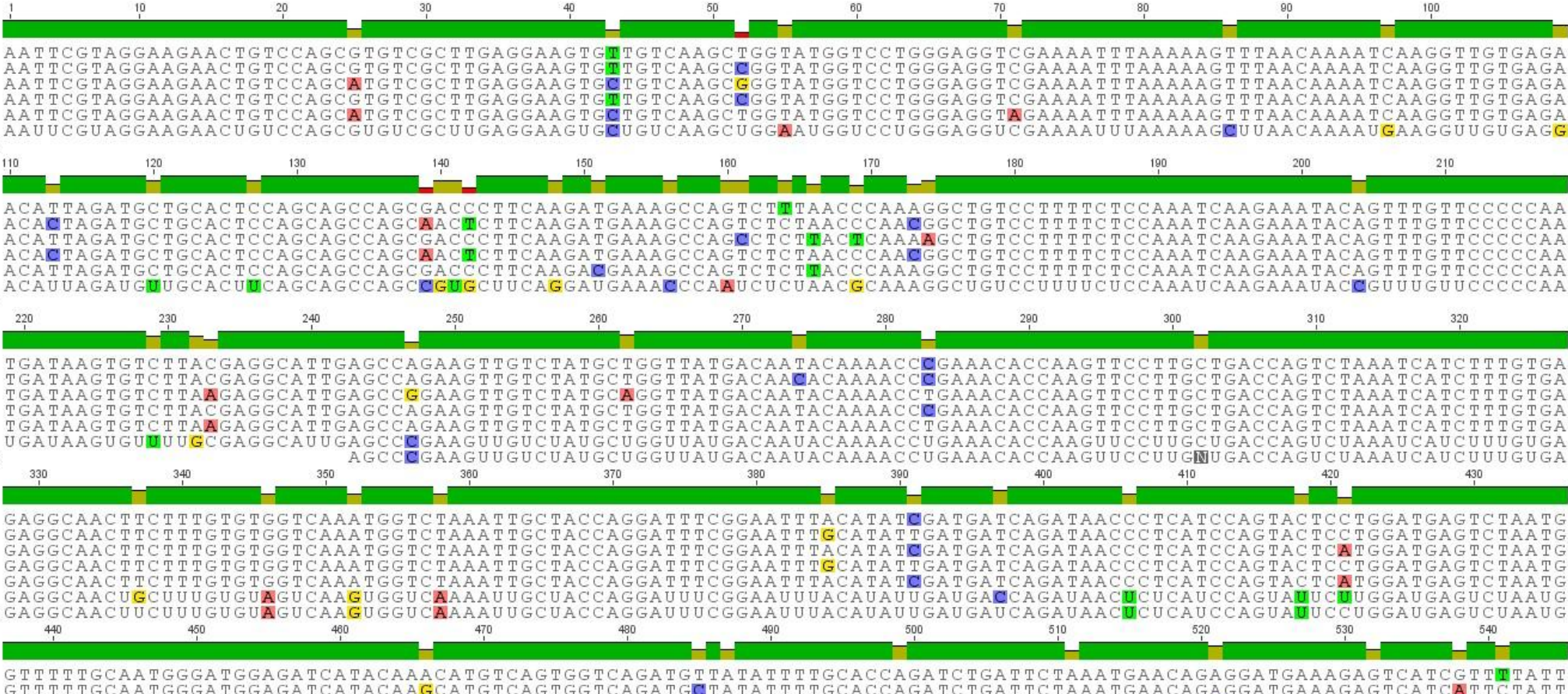

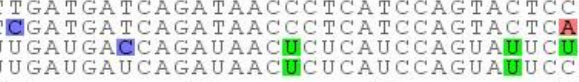

ATGGATGAGTCTAATG
UUGGAUGAGUUAAUG

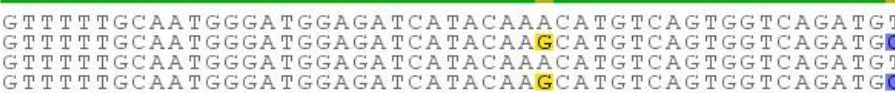

GTTTTTGCAATGGGA.GGAGATCATACAAGCATGTCAGTGGTCAGATGCT

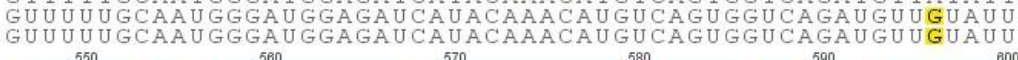

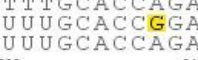

Kākā N-terminal PR

Kea N-terminalPR

Cockatiel N-terminal PR

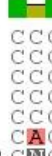

GCCTATCCATGTGGCAAC
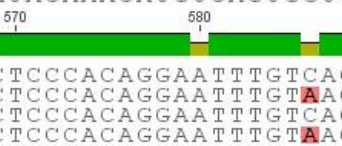

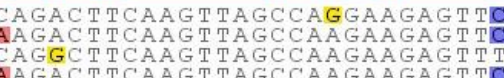

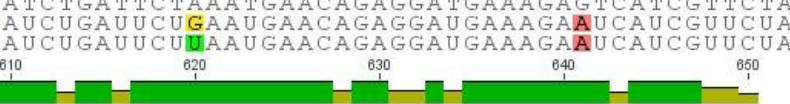

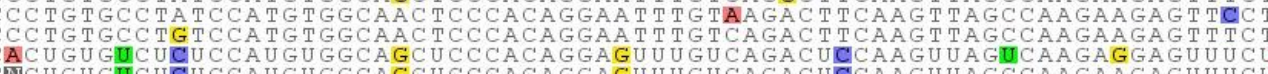

Figure 3.30 Nucleotide sequences that span the remaining amplified region of the ligand binding domain (LBD) of progesterone receptor (PR) of New Zealand parrot species, Cockatiel, Chicken and Japanese Quail. Highlighted nucleotides (red = adenine, blue = cytosine, yellow = guanine and green = thymine) depict a change in base. 
The translated region sequence was $99 \%$ homologous between the four New Zealand parrot species (Figure 3.31). There were three positions where Kākāriki did not match the other New Zealand birds: non-conserved changes of S54P and I216R and a conserved change of R58K (New Zealand parrots c.f. Kākāriki). When Cockatiel was compared to the New Zealand parrots, there was $100 \%$ identity whilst Chicken had $97 \%$ identity. The Japanese Quail had 100\% identity although the sequence did not span all 216 amino acids.

\subsubsection{Alignment of the N-terminal end of PR LBD of other species}

The human PR nucleotide sequence was aligned with the corresponding N-terminal region of the New Zealand parrot PR sequences (Figure 3.32). There were a total of 128 positions where the human sequence did not match what was present in any of the New Zealand parrot species PR sequence resulting in $80 \%$ conservation. However, in 11 of these positions the human sequence matched the nucleotide in at least one of the New Zealand parrots. There was also a three nucleotide indel near the beginning of the sequence alignment.

The translated sequence of human PR displayed $81 \%$ identity with that for the New Zealand parrot species (Figure 3.33). There were a total of 37 amino acid changes; 14 of which were non-conserved changes. The human PR sequence also contained an inserted amino acid (V) at position 41 .

The blastn tool was used to identify nucleotide sequences from the Aves taxon that were similar to those nucleotide sequences from the New Zealand parrot species. A total of seven species were identified including the Chicken and Japanese Quail (Appendix 3 Supplementary Figure 3R). There were a total of 147 positions where there were differing nucleotides.

The blastp tool was used to identify protein sequences from the Aves taxon that were similar to the New Zealand parrot sequences. The same seven species were identified along with Rock Pigeon. Alignment of these sequences showed 11 amino acid differences (95\% identity) (Appendix 3 Supplementary Figure 3S). Alignment of the remaining PR region of the unpublished avian species showed much greater variation with differences at 23 positions (Appendix 3 Supplementary Figure 3T). 
CHAPTER 3: STEROID RECEPTOR LBD AMPLIFICATION

\begin{tabular}{|c|c|}
\hline & $\begin{aligned} 50 \\
\end{aligned}$ \\
\hline \multicolumn{2}{|l|}{ dentity } \\
\hline tākāpō N-terminal PR & 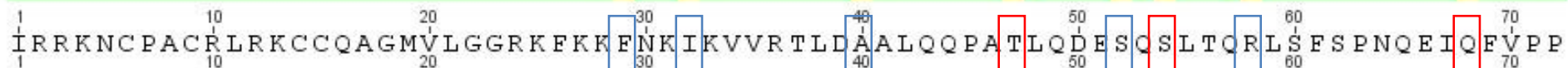 \\
\hline tākā N-terminal PR & 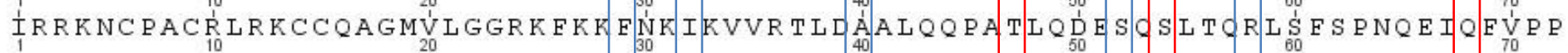 \\
\hline Kākāriki N-terminal PR & 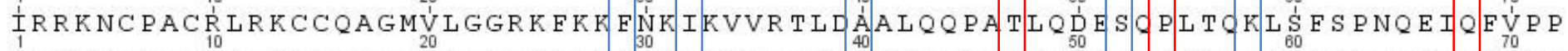 \\
\hline ea N-terminal PR & 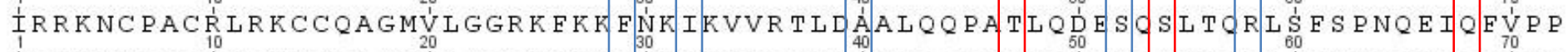 \\
\hline Cockatiel N-terminal PR & 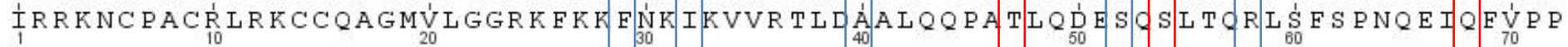 \\
\hline hicken N-terminal PR & IRRKNCPACRLRKCC \\
\hline \multicolumn{2}{|l|}{ Japanese Quail N-terminal PR } \\
\hline & $\begin{array}{c}130 \\
1\end{array}$ \\
\hline \multicolumn{2}{|l|}{ entity } \\
\hline Kākāpō N-terminal PR & 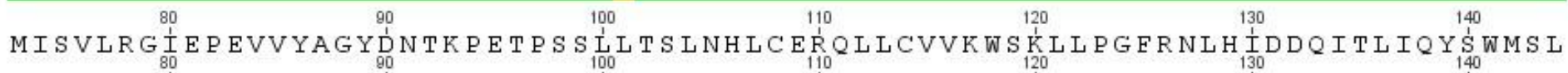 \\
\hline (ākā N- & MISVLRG $\underset{80}{\perp}$ E P EVVYAGY \\
\hline kākāriki N-terminal P & 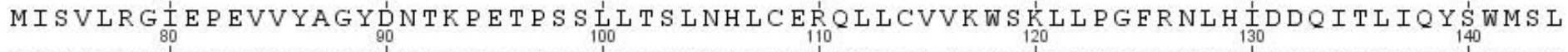 \\
\hline Kea N-terminal PR & 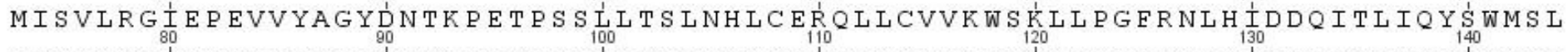 \\
\hline Cockatiel N-terminal PR & 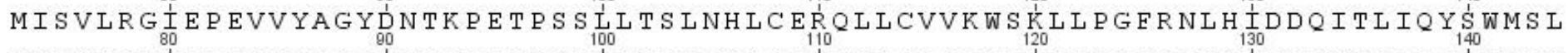 \\
\hline Chicken N-terminal PR & MISVLRGIE P EVVYAGY \\
\hline apanes & PEVVYAGYDNTKPETPSSLXTSLNHLCER \\
\hline \multicolumn{2}{|l|}{ Identity } \\
\hline & \\
\hline 〈ākāpō I & 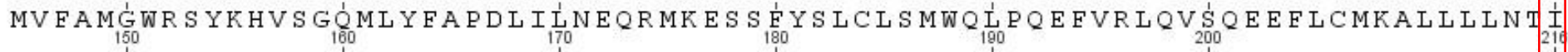 \\
\hline Kākā l & 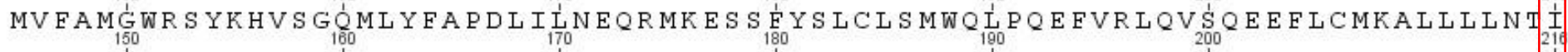 \\
\hline Kākāriki N-terminal PR & 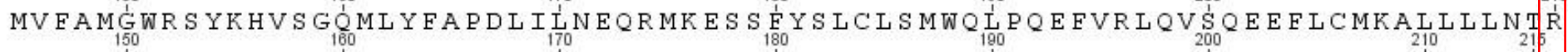 \\
\hline Kea $N$ & 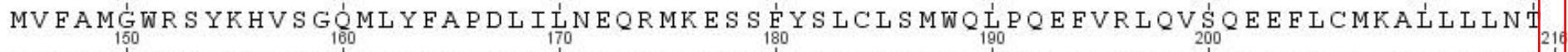 \\
\hline Cockatiel N-terminal PR & 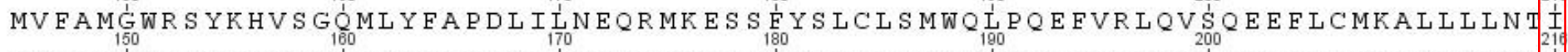 \\
\hline Chicken N-term & MVFAMǴ \\
\hline & \\
\hline
\end{tabular}

Figure 3.31 Amino acid sequences that span the remaining amplified region of the ligand binding domain (LBD) of progesterone receptor (PR) of New Zealand parrot species, Cockatiel, Chicken and Japanese Quail. Blue boxes represent conserved amino acid changes whilst red boxes represent non-conserved changes. 
20

$30 \quad 40$

50

60

70

80

90

Kākāpō N-terminal PR AA TTCGTAGGAAGAACTGTCCAGCGTGTCGCTTGAGGAAGTGTTGTCAAGCTGGTATGGTCCTGGGAGGTC GAAAATTTAAAAAGTTTAACAAAATCAAGGTTGTGA. TA Käkā N-terminal PR AATT Kākāriki N-terminal PR AA TTC GTAGGAAGAACTGTC CAGC A TG TC GC TT GAGGAAGTGCTGTCAAGC GGGTA TGGTCCTGGGAGG TC GAAAA TTTAAAAA.GTTTAACAAAATCAAGGTTGTGAGA Kea N-terminal PR AATTCGTAGGAAGAACTGTCCAG

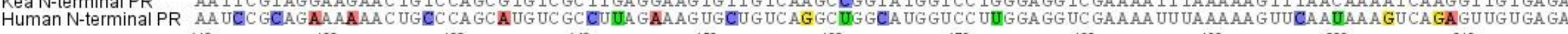

Identity 110 $120-140$ 180 170
180 210

Kākāpō N-terminal PR ACATTAGATGC TGCACTCCAGCAGCCAGCGACCCTTCAAGATGAAAGCCAGTCTTTAACCCAAAGGCTGTCCTTTTC TCCAAATCAAGAAATACAGTTTGTTCC CC Kākā N-terminal PR ACACTAGATGC TGCACTCCAGCAGCCAGCAAC TCTTCAAGA TGAAAGCCAGTC TC TAACCCAACGGCTGTCCTTTTC TCCAAATCAAGAAATACAGTTTGTTCCCC Kākāriki N-terminal PR ACATTAGATGC TGCACTCCAGCAGCCAGCGACCCTTCAAGA TGAAAGC CAGCC TC TTACTCAAAAGCTGTCCTITTC TCCA.AATCAAGAAA TACAGTTTGTTCCCC Kea N-terminal PR ACACTAGATGC TGCACC

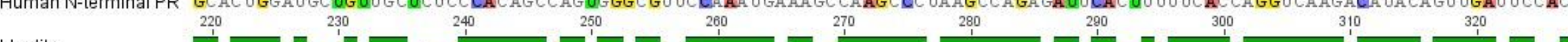
Identity

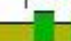
-1-

Kākāpō N-terminal PR CAATGATAAGTGTCTTACGAGGCATTGAGCCAGAAGTTGTCTATGCTGGTTATGACAATACAAAACCCGAAACACCAAGTTCCTTGC TGACCAGTC TAAATCATCTTTG Kăkā N-terminal PR CAATGATAAGTGTCTTACGAGGCA TTGAGCCAGAAGTTGTCTATGCTGG TTATGACAACACAAAACC CGAAACACCAAGTTC CTTGC TGACCAGTC TAAATCATC TTTG Kakâriki N-terminal PR CAATGATAAGT GTCTTAAGAGGCATTGAGCCGGAAGTTGTCTATGCAGGTTATGACAA TACAAAACC TGAAACACCAAGTTCCTTGC TGACCAGTC TAAA TCATC TTT

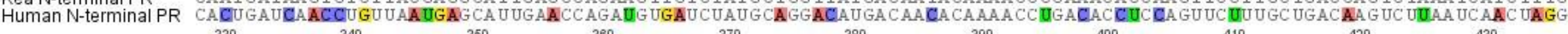
Identity$$
340
$$
$-350$ 360 -'-10 380 400 410

Kākāpō N-terminal PR TGAGAGGCAAC TTCTTTGTGTGGTCAAATGGTC TAAATTGCTACCAGGATTTC GGAATTTACATATCGATGATCAGATAACCCTCATCCAGTACTCCTGGATGAGTC TA Kākā N-terminal PR TGAGAGGCAAC TTCTTTG TG TG GTCAAAT GG TC TAAATTGCTACCAGGA TTTC GGAATTTGCATA TTGA TGATCAGATAACCCTCATCCAGTAC TCCTGGATGAGTC TA

Kea N-terminal PR
Tuman N-terminal PR CGAGAGCAAC TTCTTTG TG TGGTCAAATGG TC TAAATTGCTACCAGGA TT TCGGAAT TTGCATA TTGA TGATCAGATAACCCTCATCCAG TAC TCCTGGATGAGTC TA 520 470 490 500
1 $\begin{array}{r}510 \\ -1 \\ \hline\end{array}$ 530
1

\section{Identity}

Kākāpō N-terminal PR ATGGTTTTTGCAATGGGATGGAGATCATACAAACATGTCAGTGGTCAGATGTTATATTTTGCACCAGATCTGATTC TAAATGAACAGAGGATGAAAGAGTCATCGTTTT Kākā N-terminal PR ATGGTTTTTGCAATGGGA TGGAGA TCA TACAAGCATGTCAGTGGTCA GA TGCTATA TTTTGCACCAGATCT GA TTC TAAA TGAACAGAGGA TGAAAGAGTCA TC ATTC'

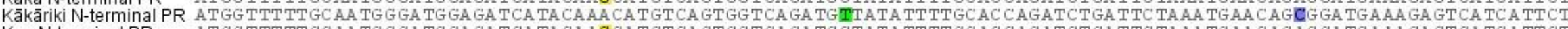

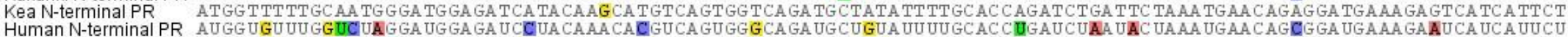

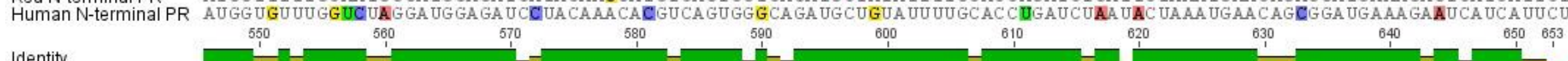

\section{dentity}

ATTCCCTGTGCCTATCCATGTGGCAACTCCCACAGGAATTGTCAGACTTCAAGTTAGCCAGGAAGAGTTCCTATGTATGAAAGCGCTGTTACTTCTCAATACAATTM Kākā N-terminal PR ATTCCCTGTGCCTATCCATGTGGCAAC TCCCACAGGAATTTGTAAGACTHCAAGTTAGCCAAGAAGAGTTCCTGTGTATGAAAGCGC TGTTACTTCTCAACACAATTC Kea N-terminal PR ATTCCCTGTGCCTATCCATGTGGCAACTCCCACAGGAATTTGTAAGACTTCAAGTTAGCCAAGAAGAGTTCCTGTGTATGAAAGCGCTGTTAC TTC TCAACACA

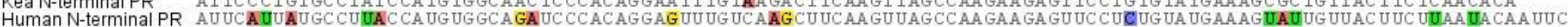

Figure 3.32 Nucleotide sequences that span the remaining amplified region of the ligand binding domain of progesterone receptor (PR) of New Zealand parrot species and human. Highlighted nucleotides (red $=$ adenine, blue $=$ cytosine, yellow $=$ guanine and green $=$ thymine) depict a change in the base . 


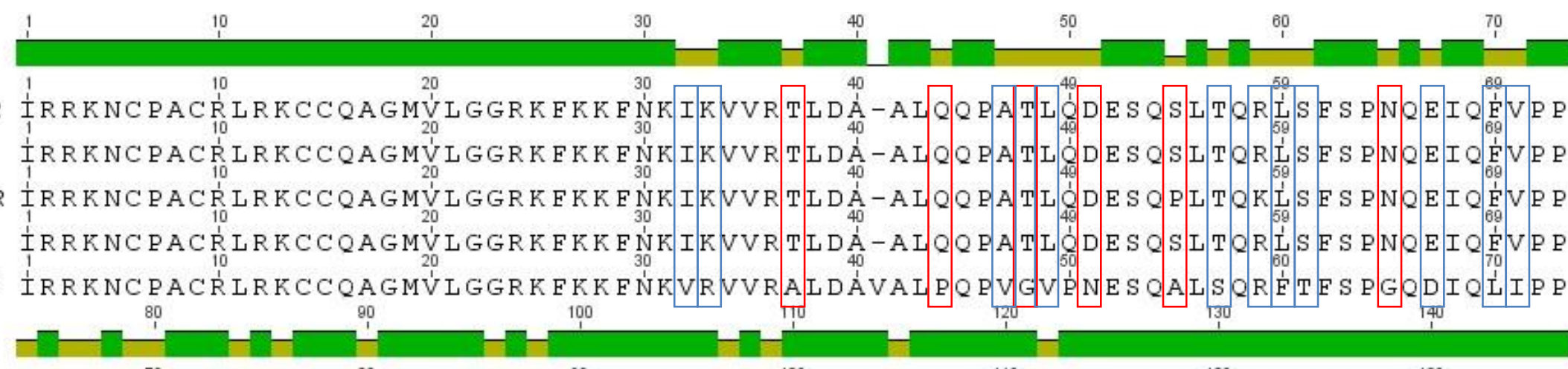

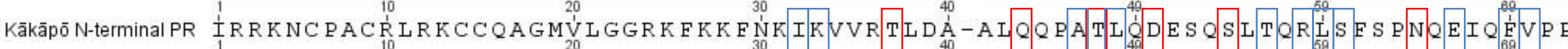

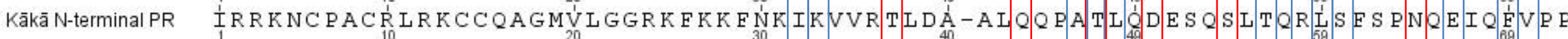

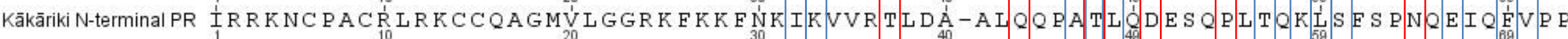
Kea N-terminal PR T⿱㇒日勺

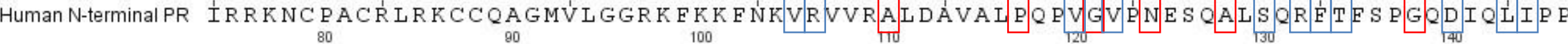
Identity

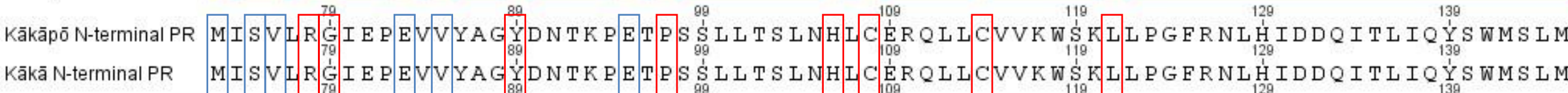
Kākā N-terminal PR Kākāriki N-terminal PR Kea N-terminal PR Human N-terminal PR Identity

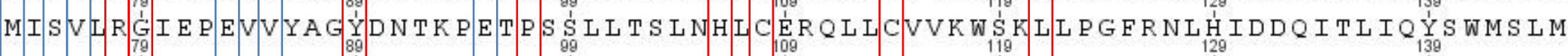
MIS S LR G

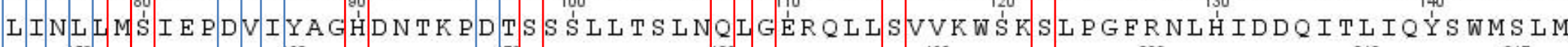

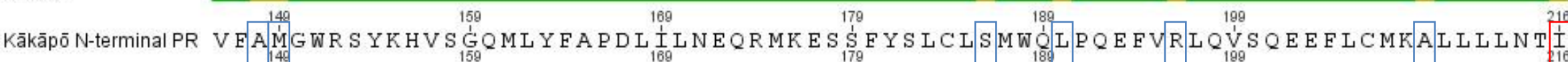

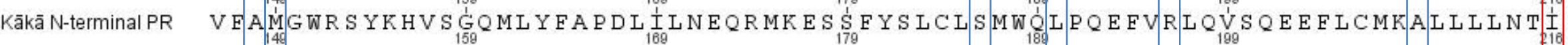

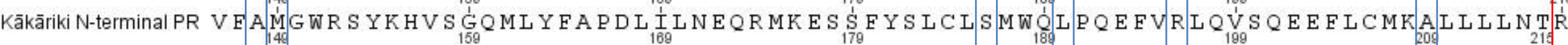

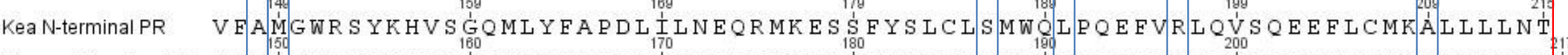
Human N-terminal PR VEGLGWRS YKHVS GQMLYFAPDL I LNEQRMKES S FYS LCL TMW I I PQEFVKLQV́SQEEFLCMKVLLLLNTI

Figure 3.33 Amino acid sequences that span the remaining amplified region of the ligand binding domain of progesterone receptor (PR) of New Zealand parrot species and human. Blue boxes represent conserved amino acid changes whilst red boxes represent non-conserved changes. 


\subsubsection{Three-dimensional modelling of PR LBD}

The template used for the molecular modelling in this study was the crystal structure of hPR (1A28). This consisted of two homodimers of PR with two molecules of bound progesterone (Figure 3.34A and B). A visual representation of the LBD region amplified showed a number of $\alpha$-helices (Figure 3.34C) that form a pocket around the bound progesterone (Figure 3.34D). The images that were generated are shown as both a cartoon (Figure 3.34A and C) and space-fill model (Figure 3.34B and D).

The crystal structure used as the template only started at the amino acid at position 68 of the New Zealand parrot species (Figure 3.31) and in this region there were 35 amino acids that differed between human and Kākāpō (Figure 3.35A and B). A number of these sites were in close proximity to the bound progesterone. In many instances, the side chains of the amino acids for Kākāpō at these positions were changed considerably (Figure 3.35C and D).

When the amino acids for Kākāpō represented in the crystal structure were compared to that of the non-native avian species, there was only the one difference at position 68 (Figure 3.36). The carbon side chain for Q68 (Figure 3.36A and B) changed to a five-membered ring for P68 in Chicken (Figure 3.36C and D). 

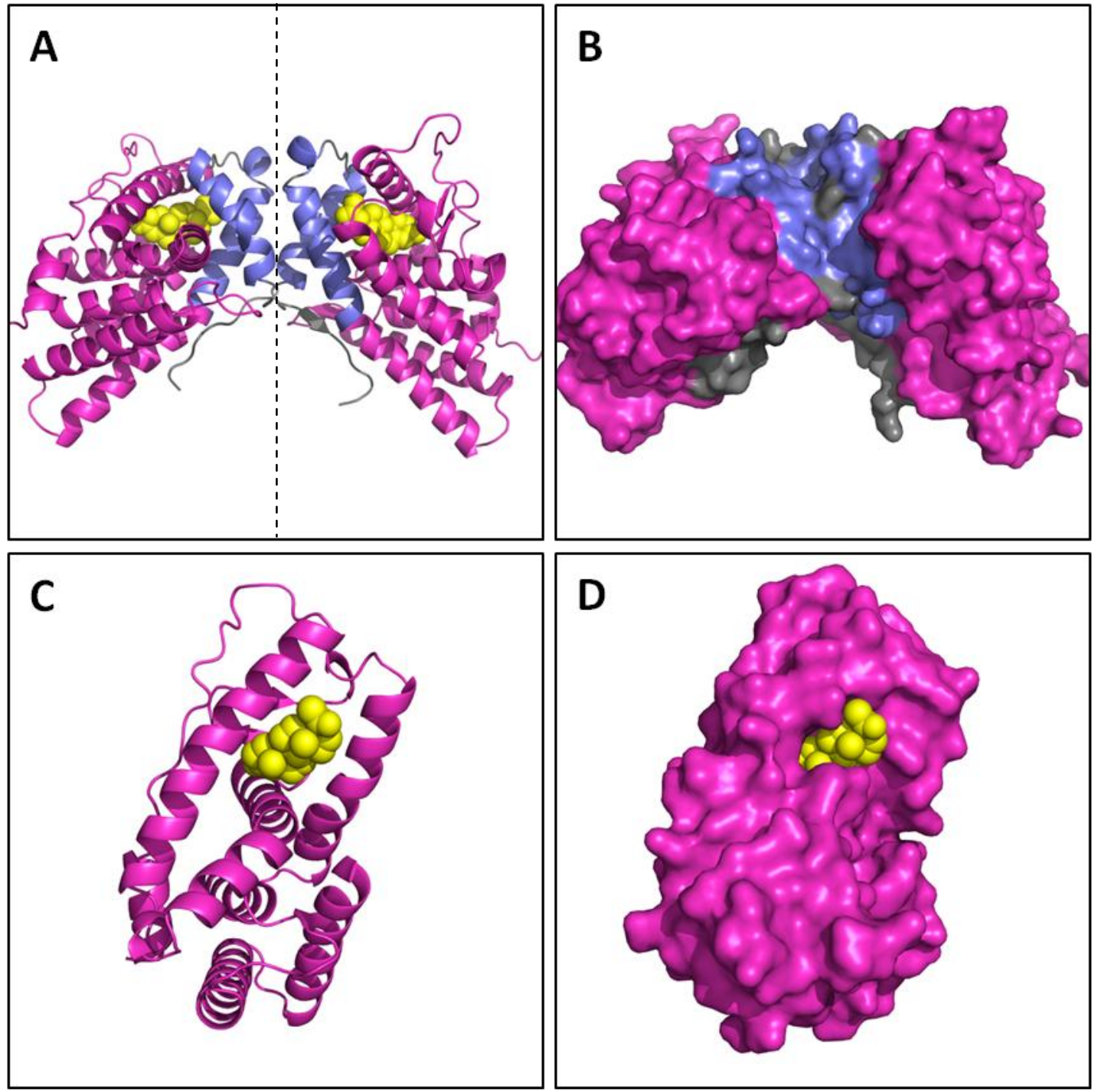

Figure 3.34 Three-dimensional structure of human progesterone receptor (hPR) and the ligand binding domain (LBD) region amplified in the avian species. A) The 3D model of hPR (1A28) was visualised as a cartoon model with the amplified region in pink and the unamplified region in blue (loops are in grey). This is as a homodimer (with a monomer to the left and right of the dashed line) with the native ligand progesterone $\left(\mathrm{P}_{4}\right)$ docked in the receptor pocket of each monomer depicted as yellow spheres. B) A space-fill model of the hPR homodimer with the same colours as for A. C) A cartoon model of the section of the LBD of PR amplified in the different avian species. D) The amplified section of PR in C represented as a space-fill model. All pictures were made with PyMol. 

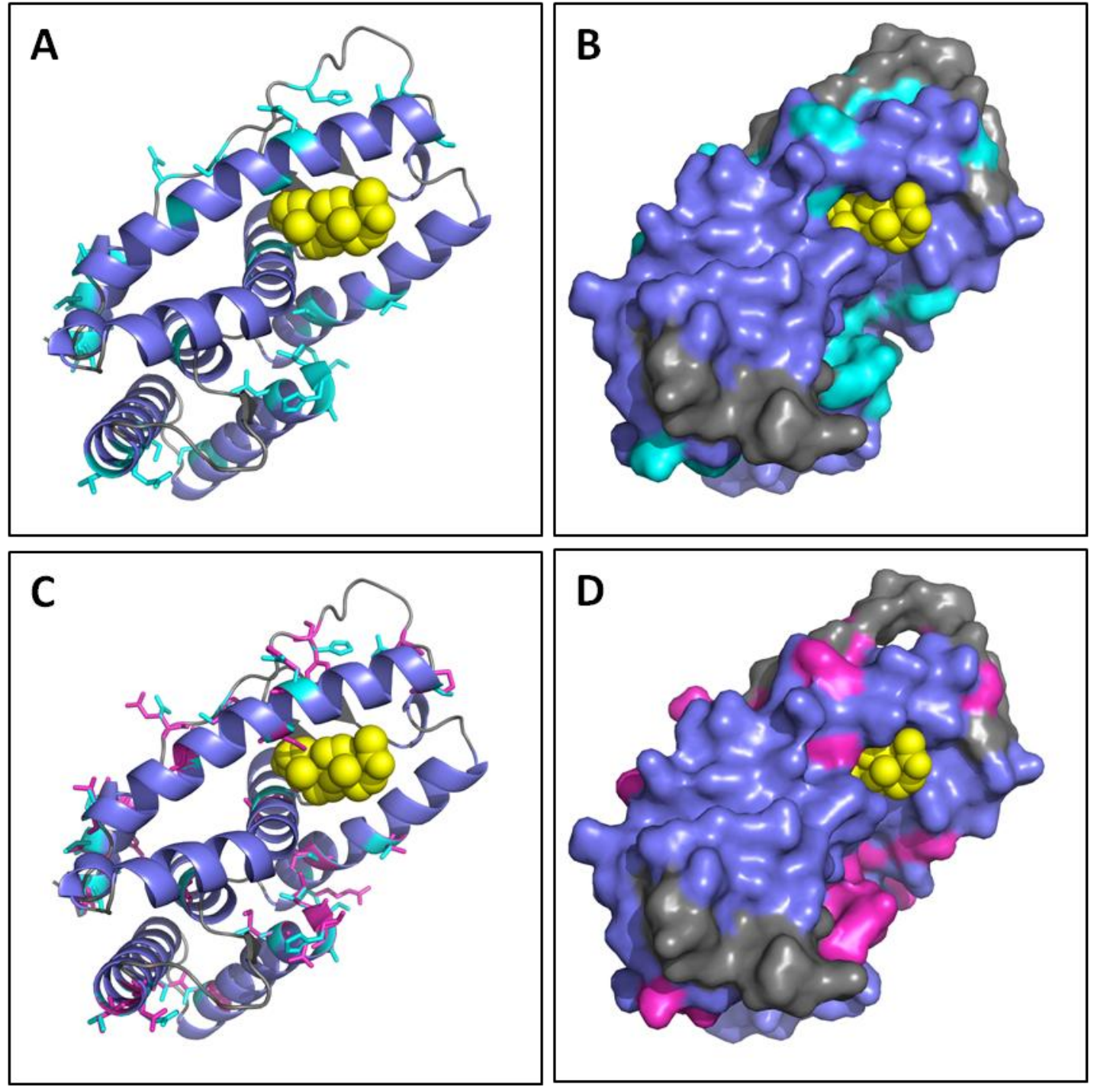

Figure 3.35 The amino acid differences between the ligand binding domain (LBD) of the progesterone receptor (PR) of Kākāpō and human. A) The LBD of human PR (hPR) was visualised as a cartoon model with $\alpha$-helices in blue and the $\beta$-sheets and loops depicted in grey. The 33 amino acid residues in human that differed to Kākāpō PR are shown with their side-chains in light blue. The native ligand progesterone $\left(\mathrm{P}_{4}\right)$ is in yellow. B) A space-fill model of this region with the differing residues in human shown in light blue. Grey is $\beta$-sheets and loops. C) The LBD of hPR is again shown as a cartoon model with the side-chains of the 33 differing amino acids for human in light blue and those for Kākāpō in pink. D) A space-fill model with the Kākāpō residues at the 33 positions in pink. All pictures were made with PyMol. 

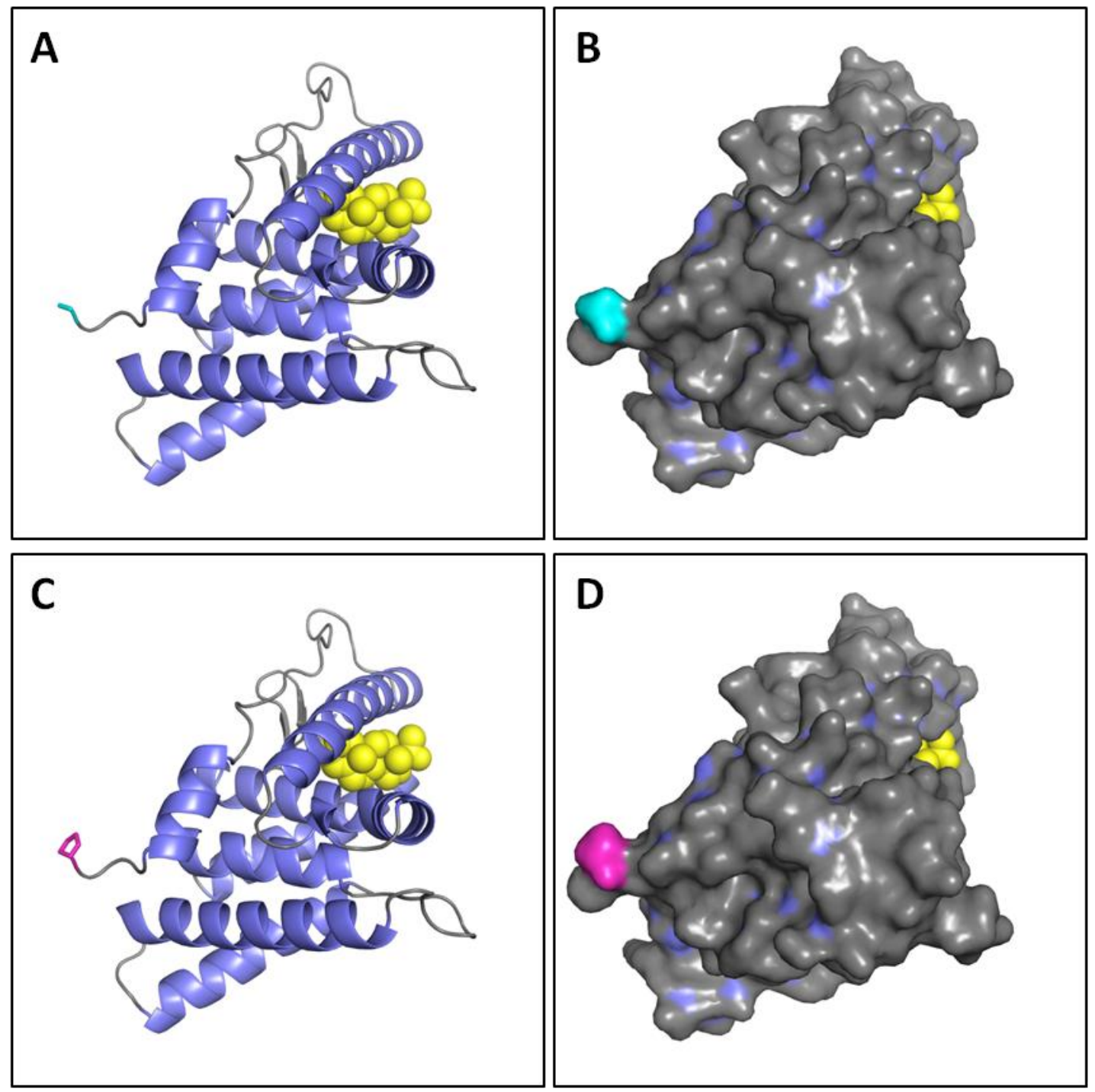

Figure 3.36 The amino acid difference between the ligand binding domain (LBD) of progesterone receptor (PR) of Kākāpō and non-native avian species. A) The Kākāpō LBD was visualised as a cartoon model with $\alpha$-helices in blue and $\beta$-sheets and loops depicted in grey. The one amino acid residue that differed to the non-native avian species is shown in light blue. Progesterone $\left(\mathrm{P}_{4}\right)$ is shown in yellow. B) A space-fill model of the LBD region with with the $\beta$-sheets and loops depicted in grey. The position where the amino acid differed is shown in light blue. C) The LBD of the other avian species as a cartoon model with the one differing amino acid in pink. D) A space-fill model of the LBD region for the other avian species with the one position that differed in pink. All pictures were made with PyMol.

\section{Summary}

There were very few differences in the nucleotide sequences of the New Zealand parrot species, Cockatiel, Chicken and Japanese Quail for the initial region sequenced and these corresponded to $100 \%$ amino acid identity. Additionally, the extra amplified section proffered greater variation between these species with $95 \%$ identity for the nucleotides of the New Zealand species and three differing amino acids in Kākāriki. When the other three avian species were taken into consideration, there were a further seven differing amino acids. 
There was considerable variation between the New Zealand parrots and human sequence, both in the nucleotide and corresponding amino acid sequences. This increased when the extra section was compared with a total of 47 positions in PR LBD where the amino acid differed.

\subsection{Discussion}

\subsubsection{General Discussion}

The LBD sequences of four key steroid receptors were elucidated for the first time in Kākāpō, Kākā, Kākāriki and Kea to identify unique amino acid motifs that may influence the three-dimensional structure of the ligand binding pocket.

The current study suggests that the ER- $\alpha$ in parrots (both New Zealand native parrots as well as Cockatiel) contains a unique isoform which is longer in length than that reported in any other avian species. Moreover, preliminary results of the PR also suggested a number of extra amino acids were present in the parrot sequences (both New Zealand native parrots as well as Cockatiel) that were absent in the sequences of other avian species. However in the case of $\mathrm{PR}$, some of these amino acids were present in the human protein thereby negating the possibility of a parrot-specific sequence.

There was a high degree of conservation amongst the New Zealand parrots with all but the final section of ER- $\alpha$ LBD and initial section of PR LBD demonstrating $100 \%$ identity in the amino acid sequence. This is consistent with what was observed when a larger cohort of avian species were compared (see Appendix 3). In terms of New Zealand parrot comparisons, the species that was the most divergent was the Kākāriki. When a nucleotide in Kākāriki differed from the other three parrot species, it generally corresponded to the same nucleotide as that in the Cockatiel. However, in most instances, the corresponding amino acid sequence for Cockatiel was the same as that in New Zealand parrots. Considering Cockatiel is a parrot species, this was not unexpected. However, when the sequences from all parrot species were compared to that of Chicken and Japanese Quail, both conserved and non-conserved amino acid differences were apparent.

Large interspecies differences within the LBD of these key steroid hormone receptors were not expected as previously reported nucleotide and amino acid comparisons between different 
species revealed a high degree of conservation. Indeed, there was a high degree of conservation in the nucleotide sequences for all the species for the steroid receptors investigated, and for the majority of nucleotide mismatches, these were synonymous. In the case of PR, the results from the blastp search included matches for AR, GR and MR sequences.

\subsubsection{Oestrogen Receptor $\alpha$}

The area within ER- $\alpha$ that $17 \beta$-oestradiol is known to bind to was the largest region sequenced in this study and exhibited the most diversity out of all the steroid receptors investigated. The potential implication of this amino acid diversity is an alteration in the pocket structure or shape that changes the receptors affinity to different compounds.

The initial 616 nucleotide region of ER- $\alpha$ amplified resulted in $100 \%$ identity between all the New Zealand avian species and the Cockatiel (Figure 3.2), but was not observed with Chicken, Japanese Quail, or any of the species identified from the BLAST search. At two positions, the amino acids in the parrots were not seen in any other avian sequence (R7S and $\mathrm{S} 38 \mathrm{~N})$. This trend continued when the C-terminal region sequenced was compared with no other avian species displaying the extra amino acids present in the parrots. Thus this result suggests there is a parrot-specific ER- $\alpha$ LBD sequence.

A comparison of the avian sequences with that of human (NM_000125) was carried out as the three-dimensional modelling used the hER- $\alpha$ crystal structure as a template. In the initial ER- $\alpha$ region that was amplified, the amino acid differences observed between the New Zealand parrots and the Chicken and Japanese Quail (and avian species identified from the blastp search) at amino acid positions 7 and 38 were also sites of disparity in the human sequence. This suggests that these positions may be more variable than other sites in the protein and is supported by the fact these same differences are seen for the alignments for the other avian species (Appendix 3 Supplementary Figure 3C and 3D). Alignment of the C-terminal region of ER- $\alpha$ of the New Zealand parrot species with human demonstrated $74 \%$ conservation in the nucleotide sequence and only $70 \%$ conservation in the subsequent amino acid translation. This result meant this section of ER- $\alpha$ was the least conserved between New Zealand parrots and humans out of the LBDs sequenced. As the hER- $\alpha$ amino acid sequence lacked the extra eight amino acids at the end of the parrot sequences, this supports the 
hypothesis that this eight amino acid extension is a feature of the ER- $\alpha$ LBD that is unique to parrot species.

Three-dimensional representation of the ER- $\alpha$ LBD using the hER- $\alpha$ crystal structure as a template unfortunately did not encompass the entire region amplified, instead finishing at position 30 of the final section sequenced (Figure 3.8). Therefore, there were 51 amino acids from the sequencing in this study that were not represented in the crystal structure of hER- $\alpha$. This included the eight amino acid extension in the parrot species.

As the modelling demonstrated, the final section of the LBD at the $\mathrm{C}$ terminus made up an $\alpha$-helix that extended over the top of the $17 \beta$-oestradiol molecule docked in the receptor. It is unknown what the remaining eight amino acids exact location in the three-dimensional structure is, although it was predicted that they made a helical structure. The reference file for the Chicken ER- $\alpha$ sequence (NM_205183) outlines amino acids considered to be sites for $17 \beta$-oestradiol interactions. None of these are positions where substitutions were observed in the New Zealand parrots. However, three of the sites noted as providing interactions were positions 36, 41 and 43 (according to the numbering in this initial region of ER- $\alpha$ amplified in this study), thus the parrot-specific amino acid substitution at position 38 (S38N) was in close vicinity to these. It is therefore possible that this residue could influence the interaction of the receptor with the native ligand by altering the position of other amino acid residues.

A further step to this investigation would be to generate a crystal structure of Kākāpō ER- $\alpha$ LBD to see how it folds in vitro. If this was carried out, it would be beneficial to have the entire ER- $\alpha$ receptor sequence and not just the LBD to get a true representation of the positioning of amino acids relative to each other.

\subsubsection{Oestrogen Receptor $\beta$}

The 251 nucleotide region of ER- $\beta$ that was sequenced in the four New Zealand parrot species contained very few differences (Figure 3.12). A total of only seven nucleotide differences, with the majority of these in Kākāriki, indicated very high inter-species conservation. This high conservation between the New Zealand parrots was emphasised when the translated nucleotide sequences were aligned and exhibited 100\% conservation (Figure 3.13). As the amino acid sequence for Cockatiel was also identical, the ER- $\beta$ LBD of the 
Kākāpō is not unique. The $96 \%$ identity seen when the New Zealand parrot consensus ER- $\beta$ sequence was compared to the ER- $\beta$ LBD sequences for Chicken and Japanese Quail is higher than that seen when other species have been compared. For example, in relation to hER- $\beta$, rat LBD has 93\% amino acid homology and mouse has $92 \%$; lower than the $96 \%$ seen in the avian species investigated (Saunders 1998). However as they are all from the Aves taxon whereas human, rat and mouse are more distantly related, this cannot be directly compared. The amino acid combination of M16, V21 and L67 present in the parrots sequence was not seen with other species of the Aves taxon. Thus, this supports the argument that parrots differ to other avian species.

The nucleotide alignment of hER- $\beta$ with the New Zealand parrots exhibited 82\% conservation whilst the resulting protein alignment displayed five amino acid differences only two of which were non-conserved changes. This was a similar level of identity to what was present between human and the New Zealand parrots for the other steroid receptors of interest.

The three-dimensional representation of the ER- $\beta$ LBD, comprising of three $\alpha$-helices and one $\beta$-sheet, showed that although the three amino acids that differed amongst the avian species sequenced were situated near the area that $17 \beta$-oestradiol docks, none of them had significant side-chain alterations. However, the conserved change seen between the avian species and Japanese Quail (M16L) had a significant impact on the proximity of the amino acid to the bound $E_{2}$, with the M16 side-chain being much closer (Figure 3.18). As M16 was not a unique amino acid to parrot species, this did not appear to be of great significance.

Despite there being very little variation in either the sequences obtained for the ER- $\beta$ LBD region amplified or with the other species obtained through the NCBI database, further investigation of the ER- $\beta$ is warranted because there could be amino acid differences in other regions of the receptor which influence the three-dimensional conformation. This could mean compounds have different binding affinities and could influence the interactions ER- $\beta$ has with ER- $\alpha$ when forming a heterodimer.

\subsubsection{Androgen Receptor}

The region of AR LBD amplified was found to be well-conserved between the seven avian species. The $99 \%$ nucleotide conservation found for the four New Zealand species (Figure 
3.19) resulted in a $100 \%$ identical translated sequence of 139 amino acids (Figure 3.20). As there was slightly less conservation when Cockatiel was compared to the New Zealand parrot consensus AR sequence, and even less when the Chicken and Japanese Quail were compared, these results are suggestive of a New Zealand parrot specific sequence.

Although there was considerably more variation in the nucleotides of human and New Zealand species, there was very little difference in the amino acid sequences with three conserved changes and only one non-conserved change (S8A). This meant the amplified AR LBD had the greatest conservation between the New Zealand birds and the human out of all the receptors that were sequenced.

Three-dimensional representation of the AR LBD modelled with the human AR crystal structure, showed that none of the four amino acid positions where variation was observed between human and New Zealand parrot species were localised in the binding pocket for testosterone. However, when the four amino acids that varied amongst the seven avian species were highlighted, these all appeared to be in close vicinity to the testosterone molecule. Although the amino acid at position 19 was present with its side-chain facing the testosterone molecule, the side-chain in both New Zealand parrot species and human was approximately $4.0 \AA$ away from where the testosterone was docked. Thus it is unlikely that this amino acid change would have a large impact on the binding of testosterone. The other three substitutions were also unlikely to have a significant influence on the binding position of testosterone as the side-chains were on one face of an $\alpha$-helix away from the ligand.

\subsubsection{Progesterone Receptor}

As shown in Figure 3.26, it was found that in the initial amplification of the PR LBD, two nucleotides differed in Kākāriki and one in Kākāpō when the four native species were aligned. The nucleotides that were different in Kākāriki were also different in Cockatiel. Kākāriki was a much more recent arrival in New Zealand than the other three New Zealand birds suggesting that it is more closely related to Cockatiel hence why the sequences would be more similar. However, unlike the other steroid receptors sequenced, the amino acid sequences for all seven avian species had $100 \%$ identity. When a further region ( $\mathrm{N}$-terminal region) was amplified, only one of the six amino acids found to differ between the parrots 
and Chicken was also different in all other birds (A40V; parrots c.f. other birds). This suggests that there is a not a PR sequence unique to parrots.

The presence of ten amino acid differences between the New Zealand parrots and human in the very short initial sequence (49 amino acids in length) along with the $81 \%$ identity for the $\mathrm{N}$-terminal region, meant the three-dimensional model of PR was the least accurate representation of the four steroid receptors. Also, as the template did not cover the complete region sequenced, there was only one amino acid that differed between the avian sequences that could be represented in the model, and this was a considerable distance from the bound P4. Thus, from these results, the PR is the least likely to be responsible for the unique reproductive strategy of Kākāpō.

\subsection{Summary}

These results are significant for a number of reasons. Firstly, no sequences (either partial or full) have been publicly reported for AR, ER- $\alpha$, ER- $\beta$ or PR from native New Zealand avian species. There is also limited data for these steroid receptors for avian species in general.

Secondly, the results provide evidence that the sequences of these receptors in avian species may have characteristics specific to parrots. The AR LBD was the only instance where the amino acid sequence for Cockatiel differed to that of the New Zealand birds. The fact that Cockatiel has the identical amino acid sequence to Kākāpō and the like, could suggest that the similarities are Southern Hemisphere 'motifs' or parrot-specific sequences.

However, in the case of the extended region sequence for ER- $\alpha$ and PR, these results are only preliminary as the sample size was not large. Further sequencing to include more individuals needs to be undertaken. It also would be useful to determine the likely orientation of the side-chains that differ in the New Zealand parrots.

None of the birds identified from the relevant BLAST searches (blastn and blastp) were of the psittaciformes order. It would be useful to compare the sequences generated in this study with other species from the same order. 


\section{CHAPTER 4: COMPUTER SIMULATED DOCKING OF OESTROGENIC OR SIMILAR STEROID COMPOUNDS TO KĀKĀPŌ ER-a}

\subsection{Introduction}

Determining the crystal structure of a protein is useful for gaining an insight into its three-dimensional structure. From this knowledge, it is possible to predict and visualise how the conformation of a putative ligand may interact and bind within a specific binding domain of the protein. However, generating crystal structures of recombinant proteins can be both labour and time-intensive and is often an expensive exercise.

An alternative approach is to use computer simulated models. These can use a known known crystal structure from a closely-related molecule or a similar protein from a different species as a template. The main reason in silico methods are used is that they are relatively inexpensive after the initial setup and can be carried out in a timely fashion. Moreover, the methodology is now well-established and is frequently used to pre-screen potential drugs.

As described in Chapter 1, ROSETTA is an open-source computational software package that has been developed to investigate protein structure and function (Gray, Moughon et al. 2003). More specifically, the ligand docking module (RosettaLigand) has been used to predict the binding affinity of specific inhibitors to HIV-1 protease (Lemmon, Kaufmann et al. 2012), binding of an anti-depressant $S$-citalopram to human serotonin transporter (Combs, Kaufmann et al. 2010) and to compare the binding energies for single mutants of purine nucleoside phosphorylase with their substrates (Nannemann, Kaufmann et al. 2010). RosettaLigand has been found to be comparable to other programmes that are commercially available (Davis, Raha et al. 2009). A major advantage of RosettaLigand over other software packages is that it allows flexibility in both the protein and the ligand (Meiler and Baker 2006; Davis, Raha et al. 2009).

The primary role of ER- $\alpha$ is to regulate the effects of oestrogens, and antioestrogens, in specific cells. Integral to the mechanism of action of ER- $\alpha$ is the conformational change to the receptor shape after a ligand has bound to it. Thus, slight mutations to the amino acid sequence could have an impact on this conformational change and thus influence the binding 
capabilities of different compounds known to bind to hER- $\alpha$. Although the protein sequence of the ligand binding domain of ER- $\alpha$ in Kākāpō (and other parrot species) has been identified in Chapter 3, no information about the three-dimensional structure of the ER- $\alpha$ isoform is known in any avian species. To date, the complete crystal structure for ER- $\alpha$ has only been determined for human (Tanenbaum, Wang et al. 1998).

The aim of this section of the research was to model the potential binding interaction of $E_{2}$, as well as that for other known phytoestrogens and similar steroids, and Kākāpō ER- $\alpha$. By comparing these docking positions to that seen in hER- $\alpha$, the influence of parrot-specific amino acids within ER- $\alpha$ could be postulated. A consequence of this is a better understanding of how significant these amino acid changes are to the bioactivity of oestrogenic compounds.

\subsection{Methodology}

The methodology used for docking different ligands with known oestrogenic activity (primarily known phytoestrogens) into the Kākāpō ER- $\alpha$ LBD region is described in detail in Chapter 2. In brief, the macromolecular modelling software, RosettaLigand was employed. The hER- $\alpha$ receptor was used as the protein template (RCSB structure ID 1A52) and modified to include the changes in residues for Kākāpō ER- $\alpha$ LBD as presented in Chapter 3 to give Kākāpō ER- $\alpha$. The modified receptor structure was minimised using the code provided and the generated file used as the protein for the docking study (Appendix 2 Supplementary Figure 2A). A number of different ligands known to exhibit oestrogenic activity were examined for docking into the receptor binding region. The ligands investigated were 17 $\beta$-oestradiol $\left(\mathrm{E}_{2}\right)$, bisphenol A (BPA), coumestrol (CMEST), daidzein (DAI), ferruginol (FER), formononetin (FORM), genistein (GEN), podocarpic acid (PACID), podocarpinol (PODO), totarol (TOT) and triclosan (TRI). Progesterone $\left(\mathrm{P}_{4}\right)$ and testosterone (TEST) were also docked as they are steroids with similar structures to $\mathrm{E}_{2}$. Each ligand was docked using a total of 2500 runs with each run comprising 50 iterations in terms of movement and 1000 iterations of rotation. At the end of the iterations, the file was then optimised 100 times through a high-resolution docking protocol. The co-ordinates for $\mathrm{E}_{2}$ bound into hER- $\alpha$ were used as the initial position of the ligand. 
From the 2500 runs, the top 5\% corresponding to the lowest overall energy profile were then ranked according to the lowest energy recorded between the protein and ligand. The most energetically favourable docking position was then visualised using PyMol.

The software package $\operatorname{LigPlot}^{+}$v.1.4.4 (Laskowski and Swindells 2011) was utilised to identify potential interactions between the side-chains of amino acids in ER- $\alpha$ and the ligand that had been docked in the position determined to be the most energetically favourable.

\subsection{Results}

\subsubsection{Validation of Docking Script}

To validate the ability of Rosetta to simulate docking of ligands into steroid receptors, the native ligand $E_{2}$ was docked into the crystal structure of unbound hER- $\alpha$ (1A52) using computational modelling and then this binding position was compared to that recorded for $\mathrm{E}_{2}$ in the experimentally determined crystal structure 1A52. The co-ordinates of the two most energetically favourable docking positions (lowest interaction energy between the protein and ligand) were both found to be similar to the position of $E_{2}$ in the experimentally-derived structure 1A52 (Figure 4.1A-B). The positioning of $E_{2}$ in the position of least energy (pink) was inverted $180^{\circ}$ along one axis in relation to $\mathrm{E}_{2}$ in $1 \mathrm{~A} 52$ (Figure 4.1C). However, the second most energetically favourable position was almost identical to the known binding position of $\mathrm{E}_{2}$ (Figure 4.1D). 

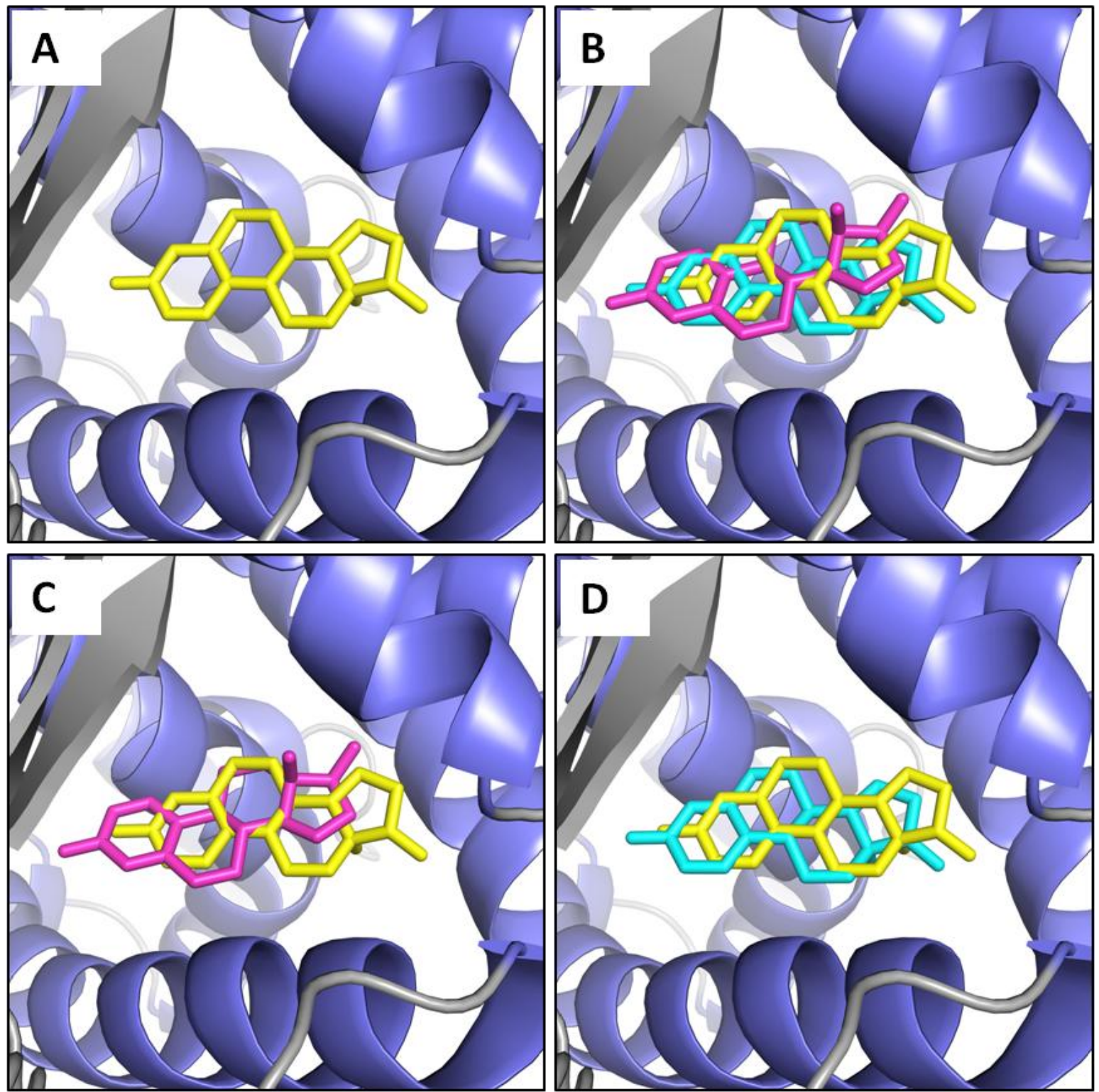

Figure 4.1 Comparison of low energy binding positions of $E_{2}$ from in silico docking with the known $E_{2}$ binding site in the experimental structure human ER- $\alpha($ hER- $\alpha)(\mathbf{1 A 5 2})$. The crystal structure of hER- $\alpha$ is depicted as a cartoon model with the $\alpha$-helices in blue and the $\beta$-sheets and loops depicted in grey. A) The position of $E_{2}$ (yellow) recorded in the crystal structure of hER- $\alpha, B$ ) The two most favourable docking positions for $E_{2}$ determined from in silico modelling (pink and cyan) compared with the known binding position of $\mathrm{E}_{2}$ (yellow) in the receptor, $\mathrm{C}$ ) The most favourable docking position for $\mathrm{E}_{2}$ in hER- $\alpha$ (pink) compared with the known (yellow) and; D) the second most favourable position for $\mathrm{E}_{2}$ (cyan) compared with the known (yellow).

The projected interactions between the side-groups of the amino acids lining the pocket of hER- $\alpha$ and the "optimal" docking position (as determined by RosettaLigand) was estimated and compared with that determined experimentally between $E_{2}$ and hER- $\alpha$ in 1A52 (Figure 4.2). The co-ordinates for $E_{2}$ in the crystal structure $1 \mathrm{~A} 52$ provided eight hydrophobic interactions and three instances of hydrogen bonding (Figure 4.2A). Glu353 was $2.41 \AA$ from the oxygen of $\mathrm{E}_{2}$ and $\arg 394$ was $3.19 \AA$ in the opposite direction. Finally His524 was $2.70 \AA$ from the other oxygen of $E_{2}$. 
Even with the slightly different positioning of $\mathrm{E}_{2}$ in the two lowest energy dockings, there were eight amino acids that were involved in interactions with $\mathrm{E}_{2}$ in both the original crystal structure (Figure 4.2A) and the two computer generated models (Figure 4.2B and C). One of these interactions (Arg394) involved hydrogen bonding in all three instances, present $2.72 \AA$ from $\mathrm{E} 2$ for the most preferred docking position (Figure 4.2B) and $2.82 \AA$ in the second-most preferred position (Figure 4.2C). In the case of Glu353, which had hydrogen bonding with the 1A52 structure, it displayed hydrophobic interactions for the two computer-generated models. In the computer simulated models shown, there were a further two amino acids providing hydrophobic interactions (Leu349 and Met421) not seen in 1A52. 

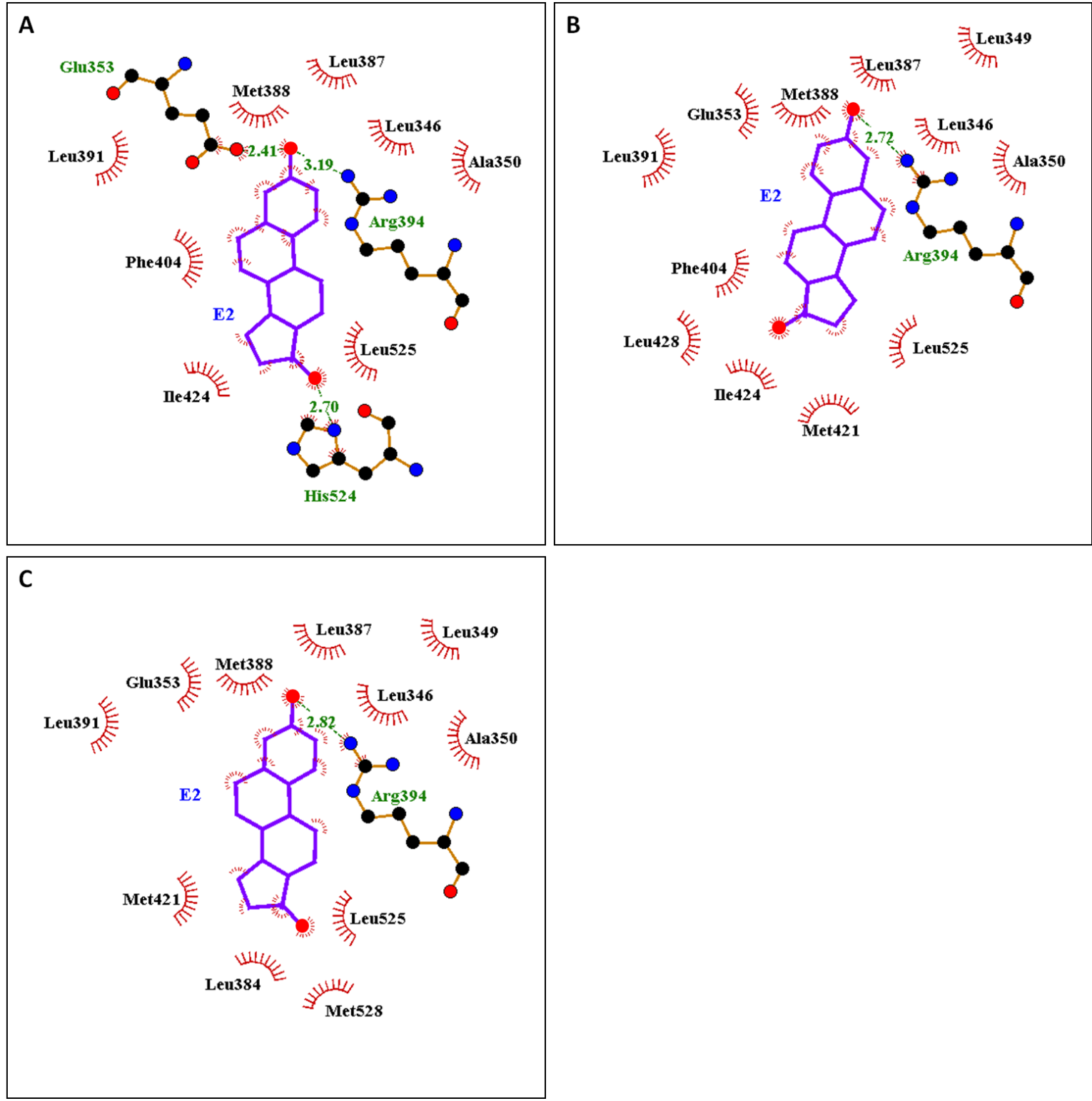

Figure 4.2 Potential interactions between $\mathbf{E}_{\mathbf{2}}$ and the amino acids of human ER- $\boldsymbol{\alpha}$ (hER- $\boldsymbol{\alpha}$ ). 17 $\beta$-oestradiol (E2) (purple with red circles representing oxygen atoms) is shown in its docked position for each model with red lines indicating atoms involved in hydrophobic interactions. The amino acids involved in hydrophobic interactions are labelled and also indicated with red lines. The side-chains of amino acids involved in hydrogen bonding to E2 are shown with the distance in Angstroms (A) and amino acid labelled in green. A) The interactions between E2 and hER- $\alpha$ as found in the crystal structure 1A52; B) the interactions between $\mathrm{E} 2$ and hER- $\alpha$ of the most preferred docking position in silico; and C) those interactions between E2 and hER- $\alpha$ when docked in the second most favourable position. 


\subsubsection{Docking of $E_{2}$ into Kākāpō ER- $\alpha$}

Prior to attempting to dock exogenous compounds such as phytoestrogens and steroid hormones to Kākāpō ER- $\alpha$ using Rosetta, the structurally minimised Kākāpō ER- $\alpha$ was visualised with $E_{2}$ in the same position as that seen for hER- $\alpha$ in 1A52 (Figure 4.3). The potential interactions between the protein and ligand were found to be similar with H-bonding occurring between Glu353 and the oxygen of the phenyl ring of $E_{2}(2.4 \AA$ in length) in both (Figure 4.3A and B). The other amino acids that were shown to interact in both receptors were Leu346, Ala350, Leu387, Leu391 and Leu525. However the H-bonding observed between Arg394 and His524 and the ligand in hER- $\alpha$ 1A52 (Figure 4.3A) was absent from that of Kākāpō ER- $\alpha$ (Figure 4.3B).
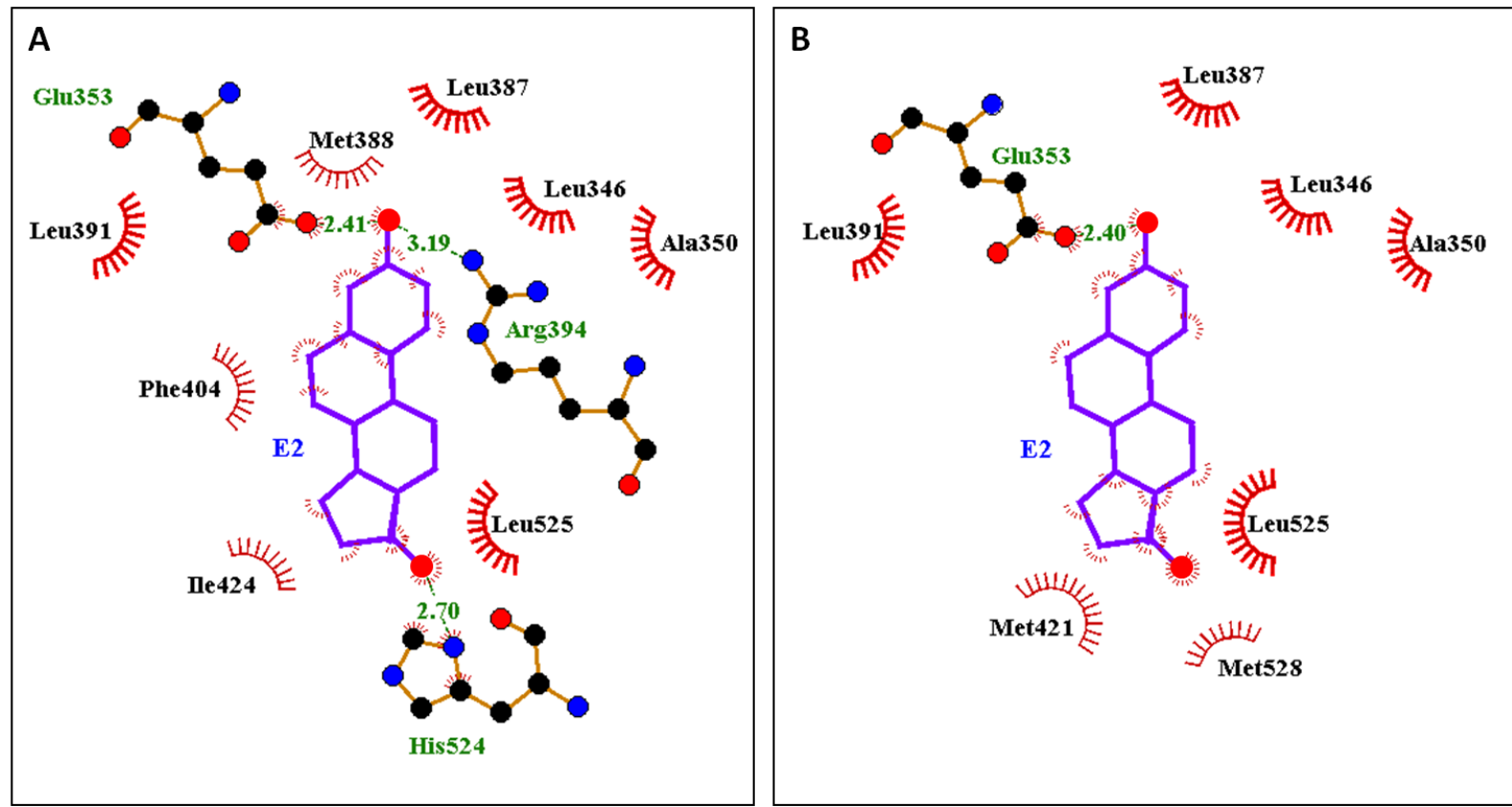

Figure 4.3 Potential interactions between $E_{2}$ and the amino acids of human ER- $\alpha$ (hER- $\alpha$ ) and Kākāpō ER- $\alpha$ when docked with the co-ordinates from the crystal structure 1A52. 17ß-oestradiol (E2) (purple with red circles representing oxygen atoms) is shown in its docked position for both A) hER- $\alpha$ crystal structure 1A52 and B) Kākāpō ER- $\alpha$. The co-ordinates used for E2 in both cases were those from 1A52. The amino acids involved in hydrophobic interactions are labelled and indicated with red lines and the atoms of E2 involved in the hydrophobic interactions are also indicated with red lines. The side-chains of amino acids involved in hydrogen bonding to E2 are shown with the distance in Angstroms $(\AA)$ and amino acid labelled in green. Those amino acids that are present in both models are in bold.

After this, a computer simulation of $E_{2}$ docked into the binding pocket of Kākāpō ER- $\alpha$ was performed with RosettaLigand to generate a potential binding site for $E_{2}$. The location of $E_{2}$ in its most favourable position was found to be inverted $180^{\circ}$ to that seen with the human 
receptor (Figure 4.4A). However the next lowest energy conformation determined from the in silico modelling had a very similar binding site to $\mathrm{E}_{2}$ in hER- $\alpha$ (Figure 4.4B).
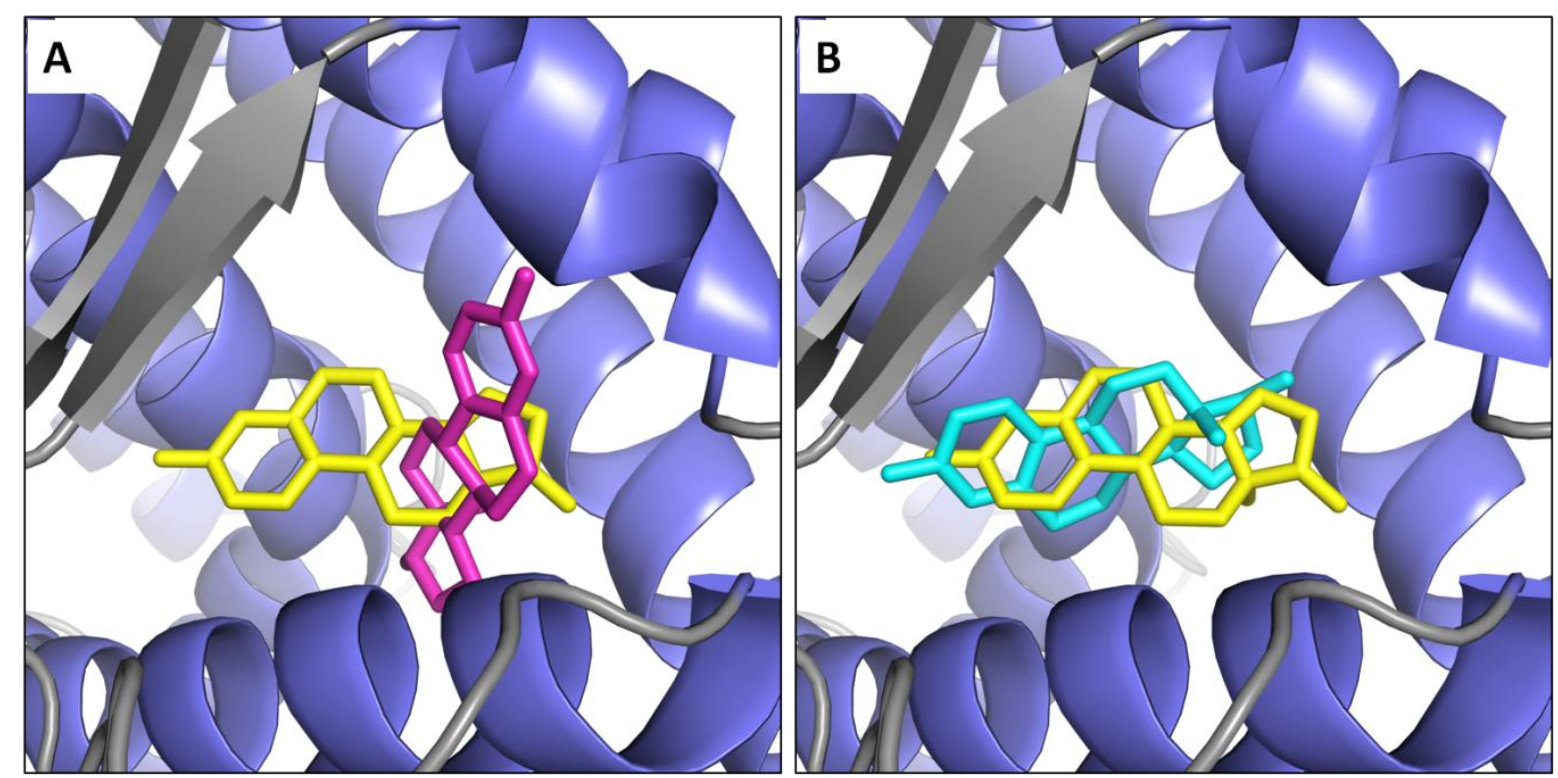

Figure 4.4 Comparison of the in silico prediction of the $E_{2}$ binding site in Kākāpō ER- $\alpha$ with the known $E_{2}$ binding site in human ER- $\alpha$ (h ER- $\alpha)$ (1A52). The crystal structure of hER- $\alpha$ is depicted as a cartoon model with the $\alpha$-helices in blue and the $\beta$-sheets and loops depicted in grey. A) The most favourable docking position for $\mathrm{E}_{2}$ in Kākāpō ER- $\alpha$ (pink) determined by in silico docking compared with the known binding position of $E_{2}$ (yellow) in hER- $\alpha$ (1A52) and; B) the second most favourable position for $\mathrm{E}_{2}$ (cyan) compared with the known position of $\mathrm{E}_{2}$ in hER- $\alpha$ (yellow).

There were four amino acids that interacted with the $\mathrm{E}_{2}$ ligand in both the most favourable docking position in Kākāpō ER- $\alpha$ (Figure 4.5A) and that reported in the hER- $\alpha$ crystal structure 1A52 (Figure 4.5B). These were Leu346, Phe404, Ile424 and Leu525. However none of these were residues unique to New Zealand parrots. There were a further seven amino acids that were found to have hydrophobic interactions with $\mathrm{E}_{2}$ in the simulated model (Figure 4.5A). This compared with four hydrophobic interactions and three instances of H-bonding in the human version (Figure 4.5B). 


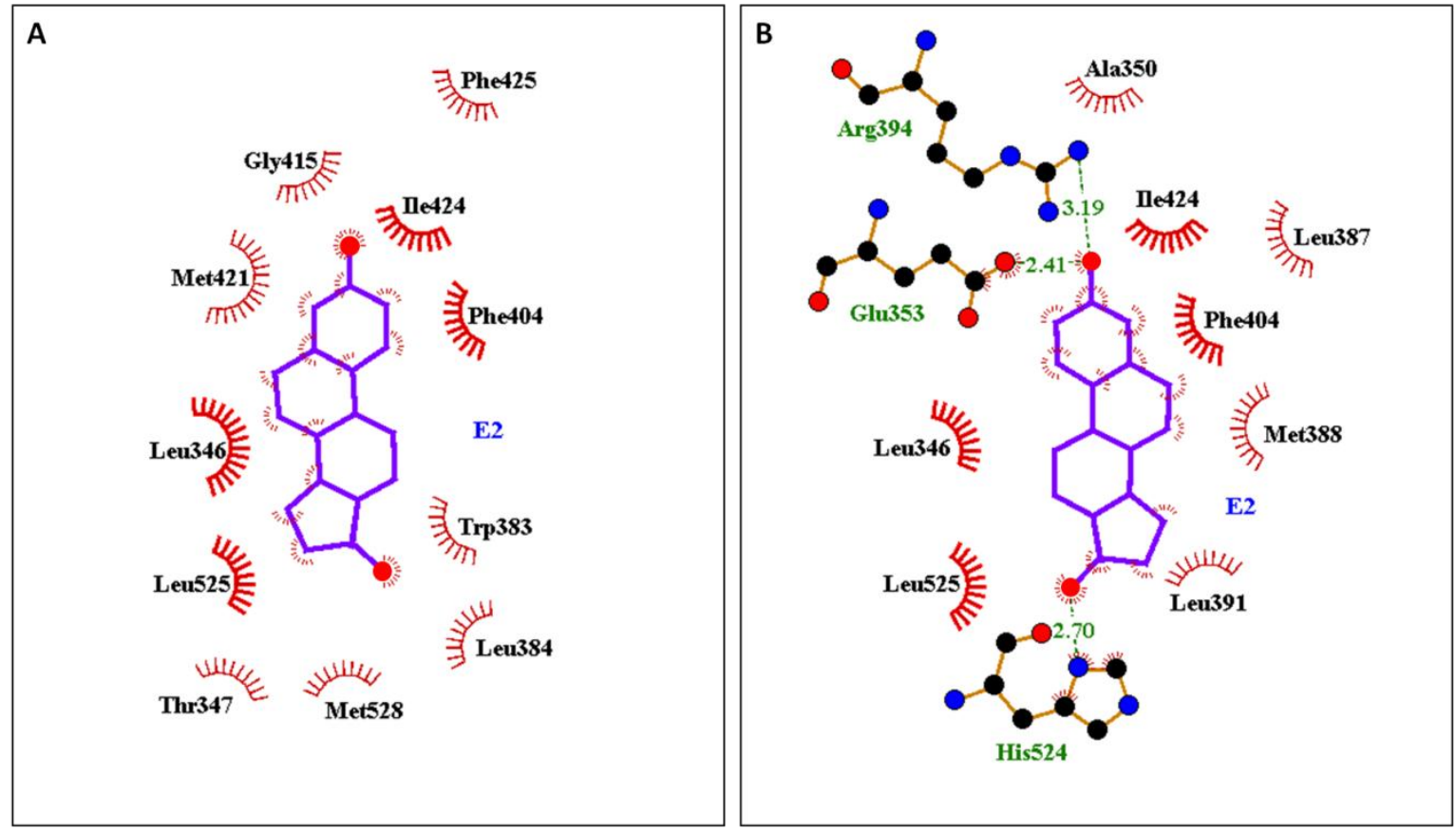

Figure 4.5 Potential interactions between $\mathbf{E}_{\mathbf{2}}$ and the amino acids of ER- $\boldsymbol{\alpha}$. 17ß-oestradiol (E2) (purple with red circles representing oxygen atoms) is shown in its docked position for both A) the predicted binding site of $E_{2}$ in Kākāpō ER- $\alpha$ and; B) human ER- $\alpha$ (hER- $\alpha$ ) crystal structure 1A52. The amino acids involved in hydrophobic interactions are labelled and indicated with red lines and the atoms of E2 involved in the hydrophobic interactions are also indicated with red lines. The side-chains of amino acids involved in hydrogen bonding to E2 are shown with the distance in Angstroms $(\AA)$ and amino acid labelled in green. Those amino acids that are present in both models are in bold.

\subsubsection{Docking of Bisphenol A (BPA) and Triclosan (TRI)}

In silico modelling of two known oestrogen mimics, BPA and TRI, was carried out to determine potential binding positions in Kākāpō ER- $\alpha$.

Firstly, the most favourable position for BPA to bind in Kākāpō ER- $\alpha$ was in a very similar manner to $\mathrm{E}_{2}$ to Kākāpō ER- $\alpha$ (Figure 4.6A-C). One of the phenyl rings was slightly offset to the equivalent in $\mathrm{E}_{2}$ and the bent structure of BPA prevented the molecule from lying in the same plane as $E_{2}$. When the docking of BPA in Kākāpō ER- $\alpha$ was compared with that experimentally determined for BPA in hER- $\alpha$ (RSCB structure ID 3UU7), it was found to be almost identical (Figure 4.6D). 

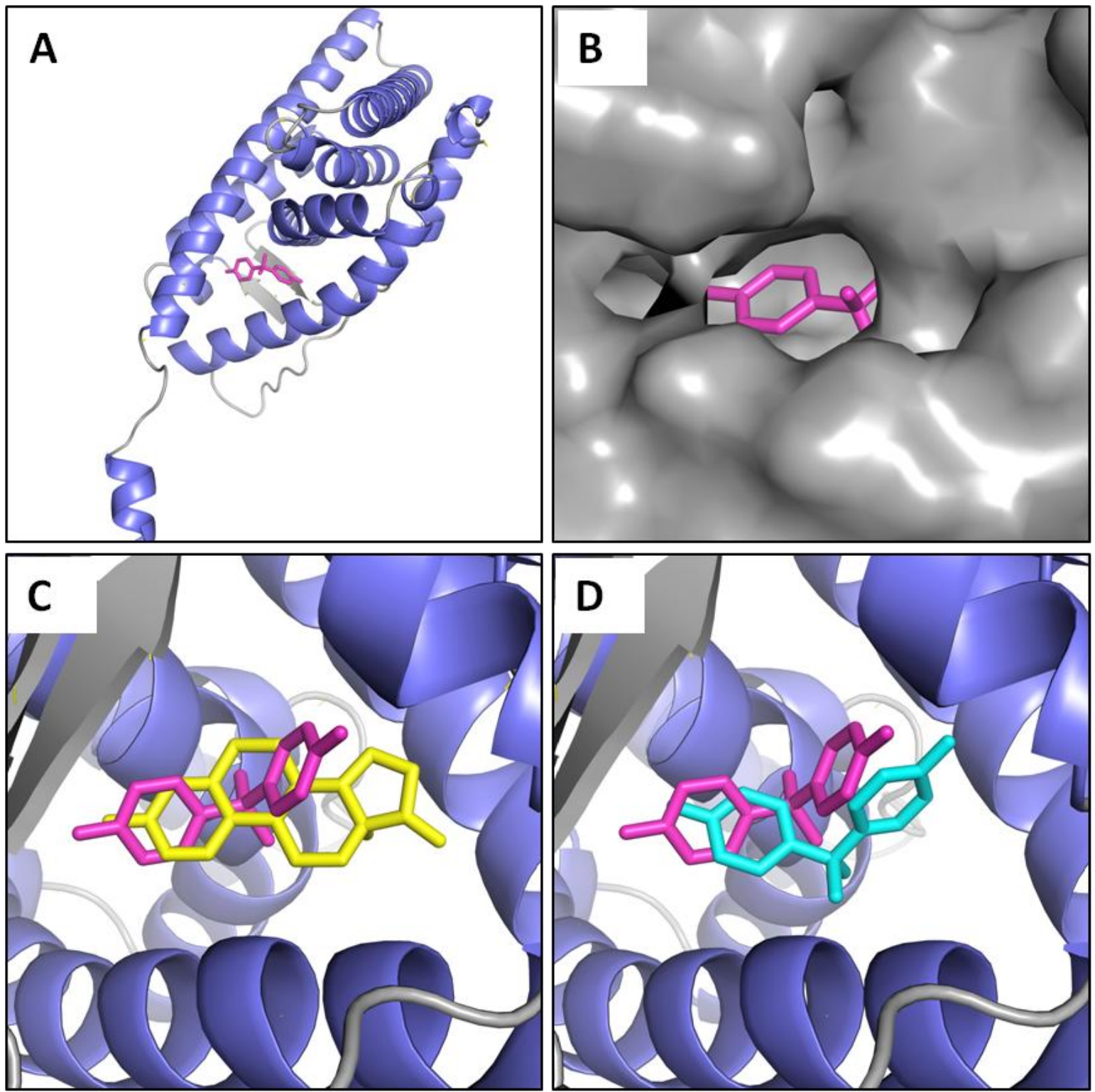

Figure 4.6 Comparison of the lowest binding energy position of BPA in Kākāpō ER- $\alpha$ from in silico docking with that for $E_{2}$ in Kākāpō ER- $\alpha$ and the experimental position of BPA in human ER- $\alpha$ (hER- $\alpha$ ) (3UU7). The crystal structures of Kākāpō and hER- $\alpha$ are depicted as cartoon models with the $\alpha$-helices in blue and the $\beta$-sheets and loops depicted in grey. A) shows the full receptor with the predicted position of BPA (pink) in the pocket of Kākāpō ER- $\alpha$, B) a section of the receptor magnified as a space-fill model with the predicted position of BPA (pink) in the pocket, C) a magnified view of a section of the ligand binding domain with the most favourable docking position of BPA (pink) compared with that predicted for $E_{2}$ (yellow) in Kākāpō ER- $\alpha$ and; D) a magnified view of a section of the ligand binding domain with the most favourable docking position of BPA (pink) compared with the known binding position of BPA in hER- $\alpha$ (cyan).

Analysis of the interactions predicted between BPA and Kākāpō ER- $\alpha$ protein backbone, suggested a total of 13 interactions (Figure 4.7A). One of these involved hydrogen bonding between $\operatorname{Arg} 394(2.65 \AA)$ and a hydroxyl group on BPA whereas the other 12 were hydrophobic interactions. None of the residues involved were unique to the sequences of the New Zealand parrots. Of these 13 postulated interactions, five were also predicted to occur between $\mathrm{E}_{2}$ and the amino acids in Kākāpō ER- $\alpha$ (Figure 4.7B). Although BPA was bound in 
a similar position in both Kākāpō and hER- $\alpha$, the different orientation meant only four residues were involved in interactions in both instances (Figure 4.7C and D) In the case of BPA bound in hER- $\alpha$, two of these interactions were involved in hydrogen bonding between the side-chains of Glu353 and Met421.
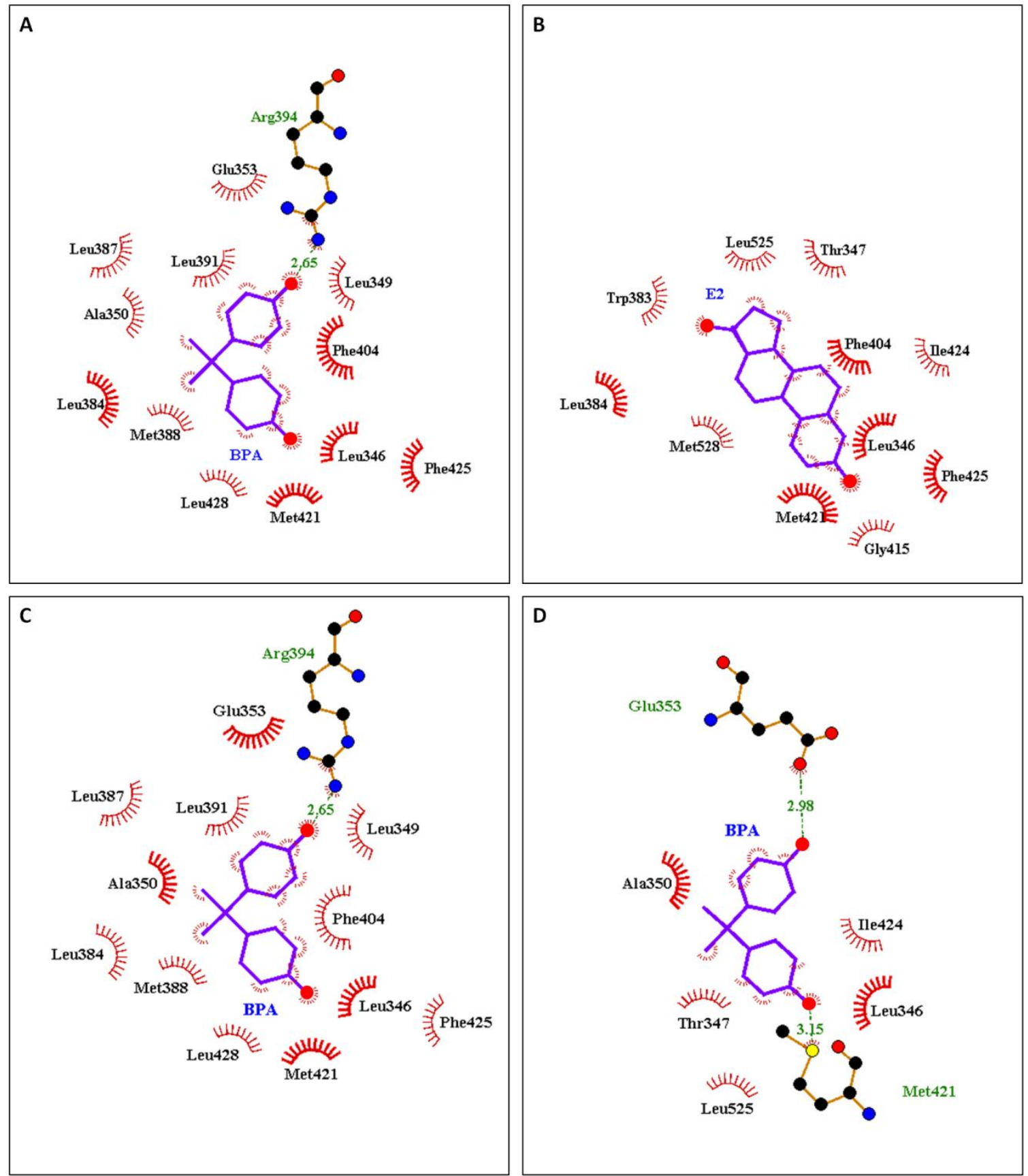

Figure 4.7 Potential interactions between Kākāpō ER- $\alpha$ and A) BPA, B) $E_{2}$, C) Kākāpō ER- $\alpha$ and BPA and; D)

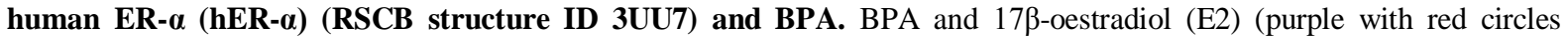
representing oxygen atoms) are shown in their predicted docked position. The amino acids involved in hydrophobic interactions are labelled and indicated with red lines and the atoms of the ligand involved in the hydrophobic interactions are also indicated with red lines. The side-chains of amino acids involved in hydrogen bonding to the ligand are shown with the distance in Angstroms ( $⿱$ $)$ and amino acid labelled in green. Those amino acids that are present in both models A and B, and those that are present in both models $\mathrm{C}$ and $\mathrm{D}$ are in bold. 
TRI was used for docking studies in Kākāpō ER- $\alpha$. The most favourable binding position of TRI in Kākāpō ER- $\alpha$ (based on the lowest binding energy) was determined and visualised (Figure 4.8A-C). The docking site was found to be in close proximity to that predicted for $\mathrm{E}_{2}$ in Kākāpō ER- $\alpha$ but, as with BPA, the bent structure meant TRI did not lie in the exact same plane as $\mathrm{E}_{2}$ (Figure 4.8D).
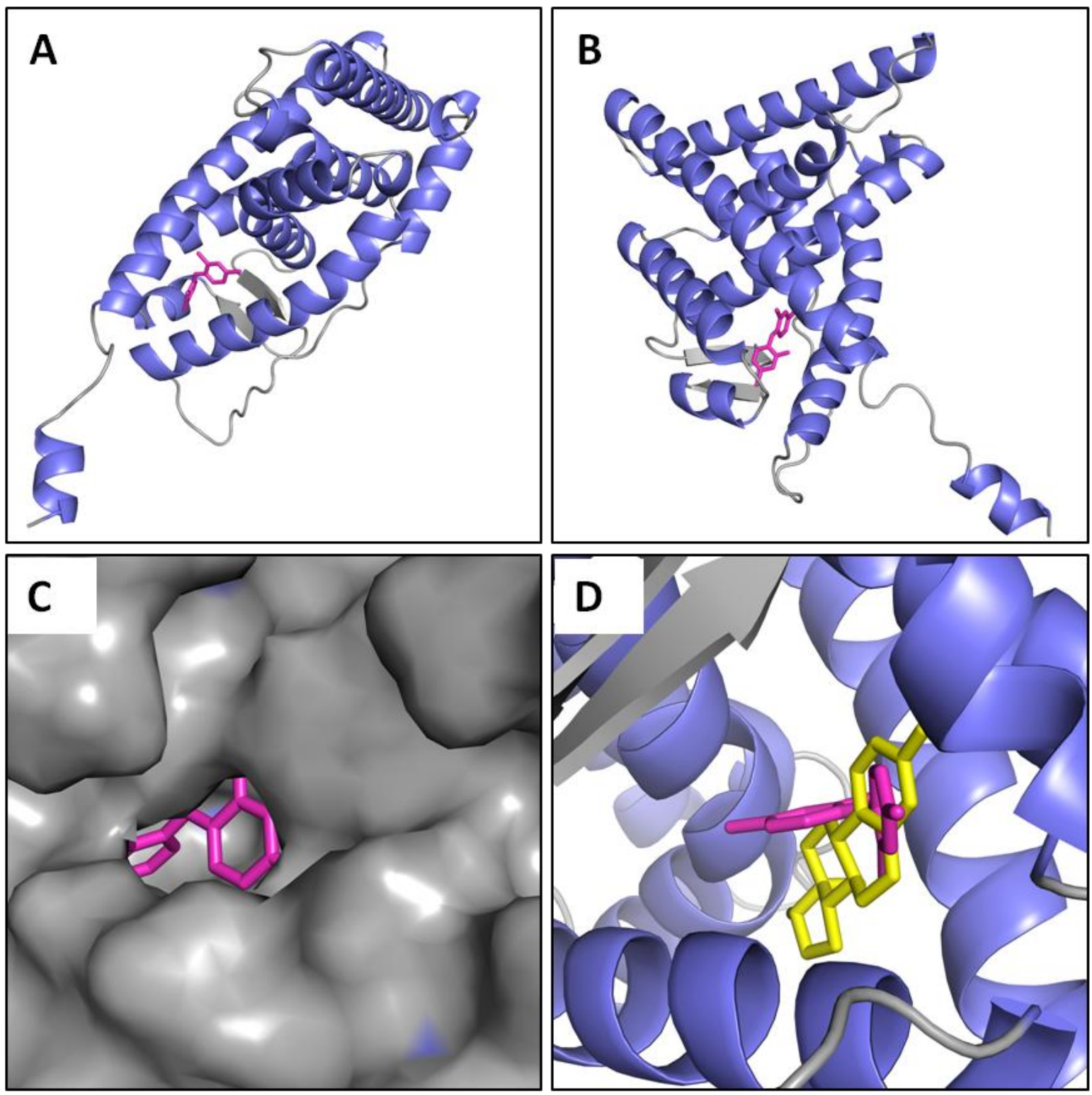

Figure 4.8 Comparison of the lowest binding energy position of TRI in Kākāpō ER- $\alpha$ from in silico docking with that for $\mathbf{E}_{2}$ in Kākāpō ER- $\alpha$. The crystal structure of Kākāpō ER- $\alpha$ is depicted as a cartoon model with the $\alpha$-helices in blue and the $\beta$-sheets and loops depicted in grey. A) and B) show the full receptor from different angles with the predicted position of TRI (pink) in the pocket of Kākāpō ER- $\alpha, C$ ) a section of the receptor magnified as a space-fill model with the predicted position of TRI (pink) in the pocket of Kākāpō ER- $\alpha$; and D) a magnified view of a section of the receptor with the most favourable docking position of TRI (pink) compared with that predicted for $\mathrm{E}_{2}$ (yellow) in Kākāpō ER- $\alpha$. 
When the position of TRI in the receptor and the amino acids surrounding it were analysed, there were found to be only four hydrophobic interactions involved in the docking (Figure 4.9A). None of the interacting residues were unique to New Zealand parrots. Three of the four interactions predicted were consistent with those observed between $E_{2}$ and Kākāpō ER- $\alpha$, namely Leu346, Phe404 and Met421 (Figure 4.9B).
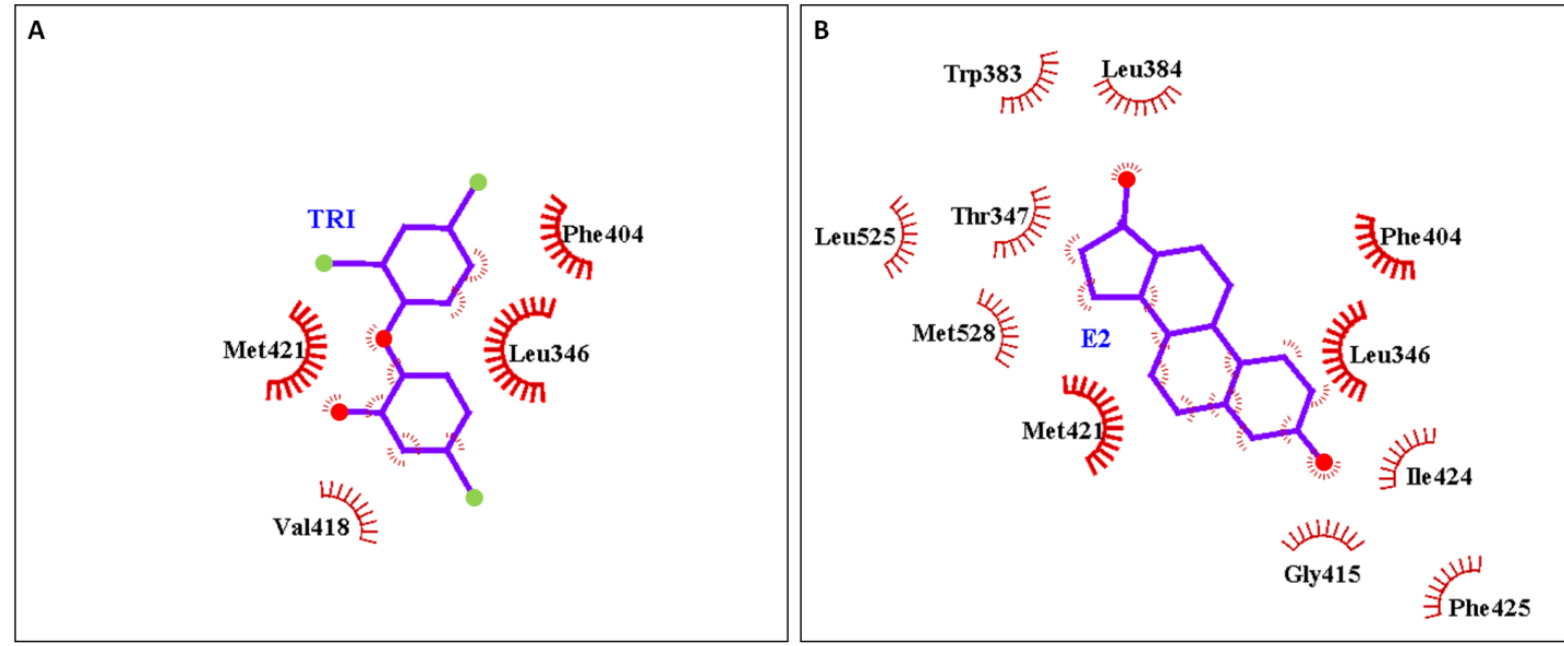

Figure 4.9 Potential interactions between Kākāpō ER- $\alpha$ and A) TRI and B) $\mathbf{E}_{2}$. Triclosan (TRI) and 17 $\beta$-oestradiol (E2) (purple with red circles representing oxygen atoms and green circles for chlorine atoms) are shown in their predicted docked position. The amino acids involved in hydrophobic interactions are labelled and indicated with red lines and the atoms of the ligand involved in the hydrophobic interactions are also indicated with red lines. Those amino acids that are present in both models are in bold.

\subsubsection{Docking of Phytoestrogens into Kākāpō ER- $\alpha$}

In silico docking of a number of known phytoestrogens and structurally similar compounds was carried out to explore potential binding positions for each of them in Kākāpō ER- $\alpha$.

\subsubsection{Coumestrol (CMEST)}

Modelling of CMEST in Kākāpō ER- $\alpha$ was performed. The conformation with the lowest energy was obtained and visualised (Figure 4.10). The CMEST molecule was found to be well-surrounded by the protein in the binding pocket (Figure 4.10A-C). The co-ordinates for CMEST were found to be almost identical to those observed for the generated model of $E_{2}$ in Kākāpō ER- $\alpha$ (Figure 4.10D). 

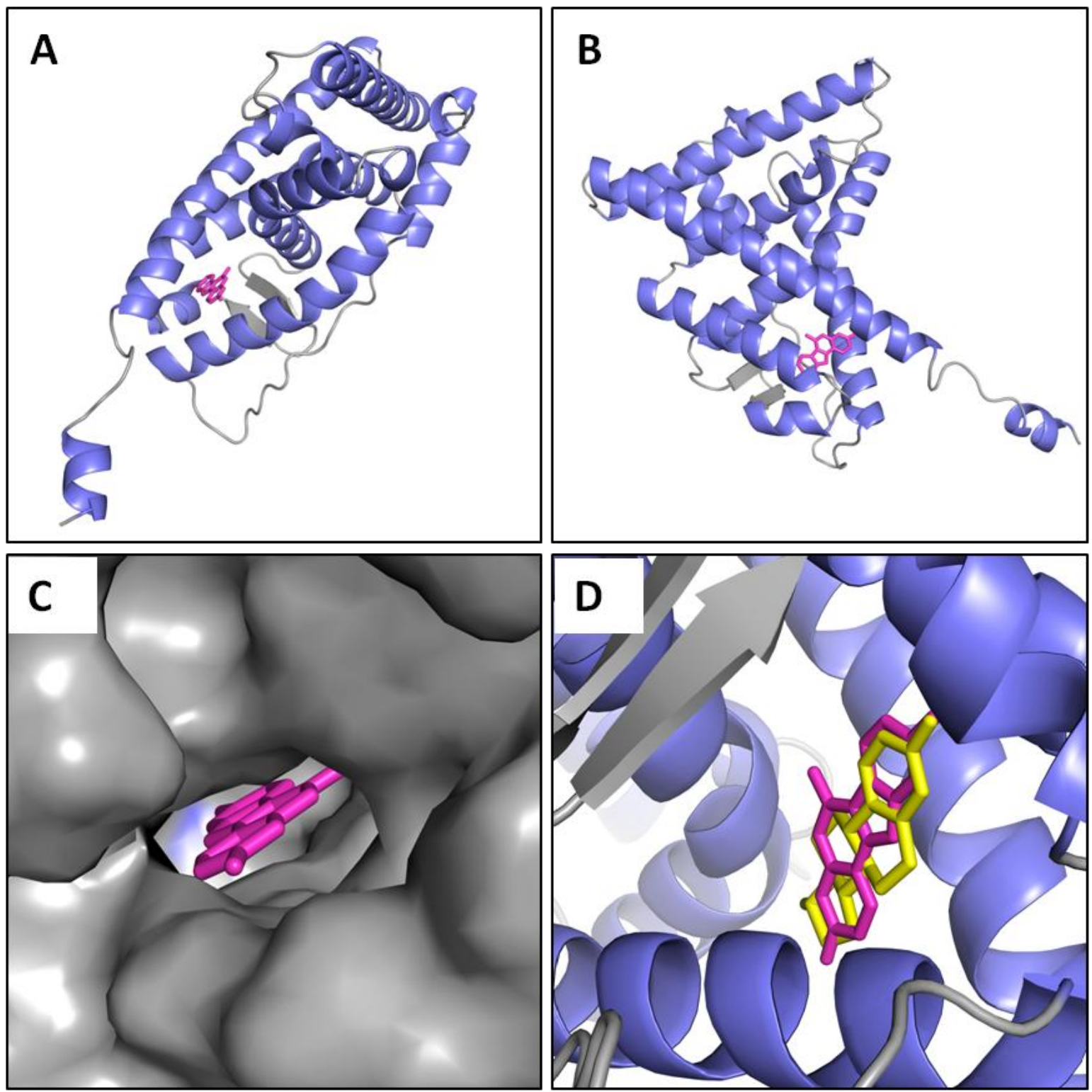

Figure 4.10 Comparison of the lowest binding energy position of CMEST in Kākāpō ER- $\alpha$ from in silico docking with that for $\mathbf{E}_{2}$ in Kākāpō ER- $\alpha$. The crystal structure of Kākāpō ER- $\alpha$ is depicted as a cartoon model with the $\alpha$-helices in blue and the $\beta$-sheets and loops depicted in grey. A) and B) show the full receptor from different angles with the predicted position of CMEST (pink) in the pocket of Kākāpō ER- $\alpha, C$ ) a section of the receptor magnified as a space-fill model with the predicted position of CMEST (pink) in the pocket of Kākāpō ER- $\alpha$; and D) a magnified view of a section of the receptor with the most favourable docking position of CMEST (pink) compared with that predicted for $\mathrm{E}_{2}$ (yellow) in Kākāpō ER- $\alpha$.

There were a total of ten interactions predicted to occur between the CMEST molecule and the Kākāpō ER- $\alpha$ protein backbone (Figure 4.11A). Nine of these were consistent with that seen when $\mathrm{E}_{2}$ was bound in Kākāpō ER- $\alpha$ (Figure 4.11B). However none of the interacting amino acids were unique to New Zealand parrots. The side chain of Thr347 was found to be $2.84 \AA$ away from one of the phenyl groups of coumestrol and thus H-bonding was detected 
between the two groups at that position. The different structure of $\mathrm{E}_{2}$ meant this hydrogen bonding was not observed between $\mathrm{E}_{2}$ and Kākāpō ER- $\alpha$.
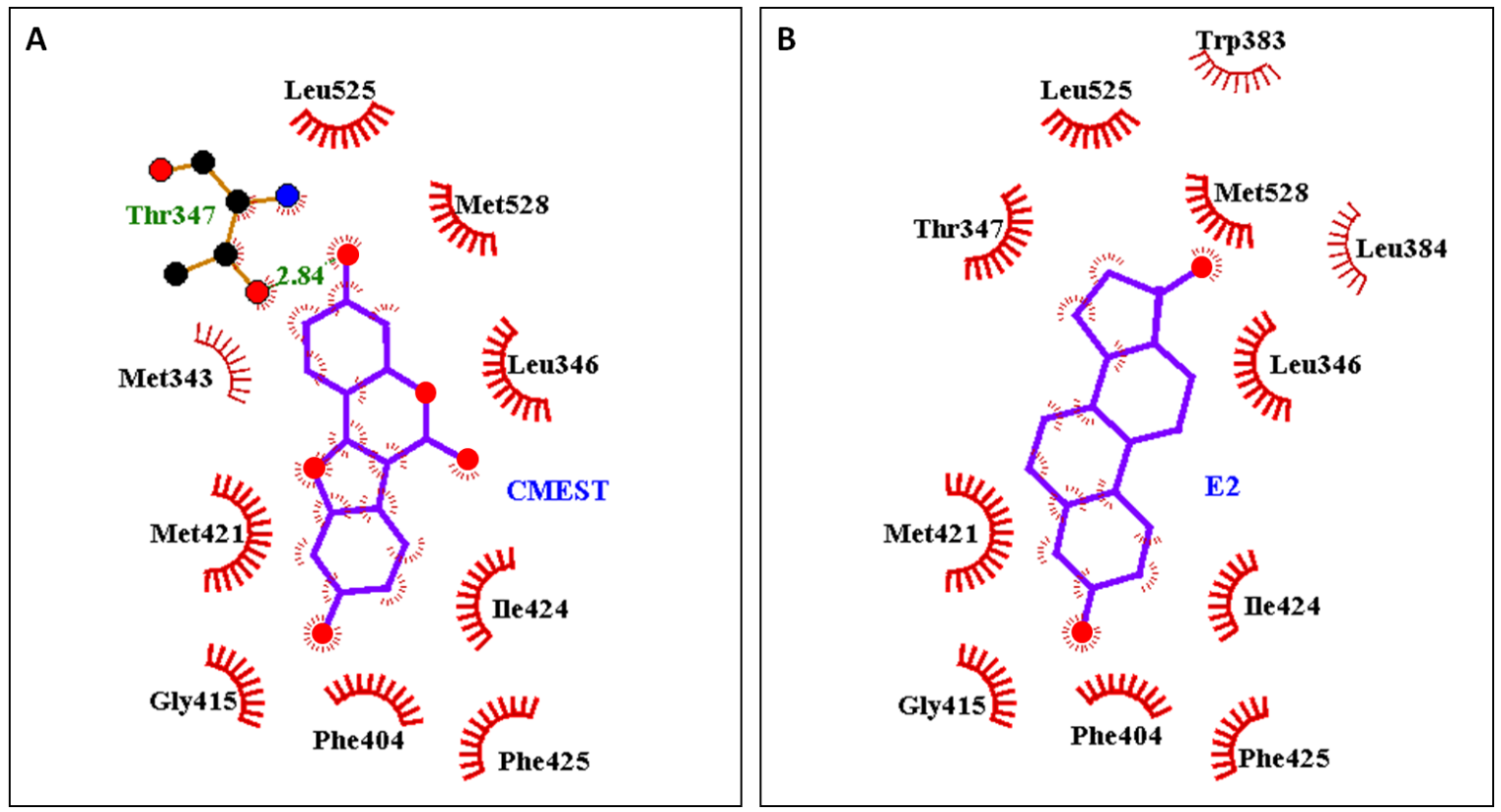

Figure 4.11 Potential interactions between Kākāpō ER- $\alpha$ and A) CMEST and B) $\mathbf{E}_{2}$. Coumestrol (CMEST) and $17 \beta$-oestradiol (E2) (purple with red circles representing oxygen atoms) are shown in their predicted docked position. The amino acids involved in hydrophobic interactions are labelled and indicated with red lines and the atoms of the ligand involved in the hydrophobic interactions are also indicated with red lines. The side-chains of amino acids involved in hydrogen bonding to the ligand are shown with the distance in Angstroms $(\AA)$ and amino acid labelled in green. Those amino acids that are present in both models are in bold.

\subsubsection{Daidzein (DAI)}

After simulating the docking of DAI into Kākāpō ER- $\alpha$, the binding position with the lowest energy was then determined (Figure 4.12A and B). In this position DAI appeared to fit well into the cavity (Figure 4.12C). This orientation was found to be at an angle to that observed for $E_{2}$ in Kākāpō ER- $\alpha$ (Figure 4.12D). 

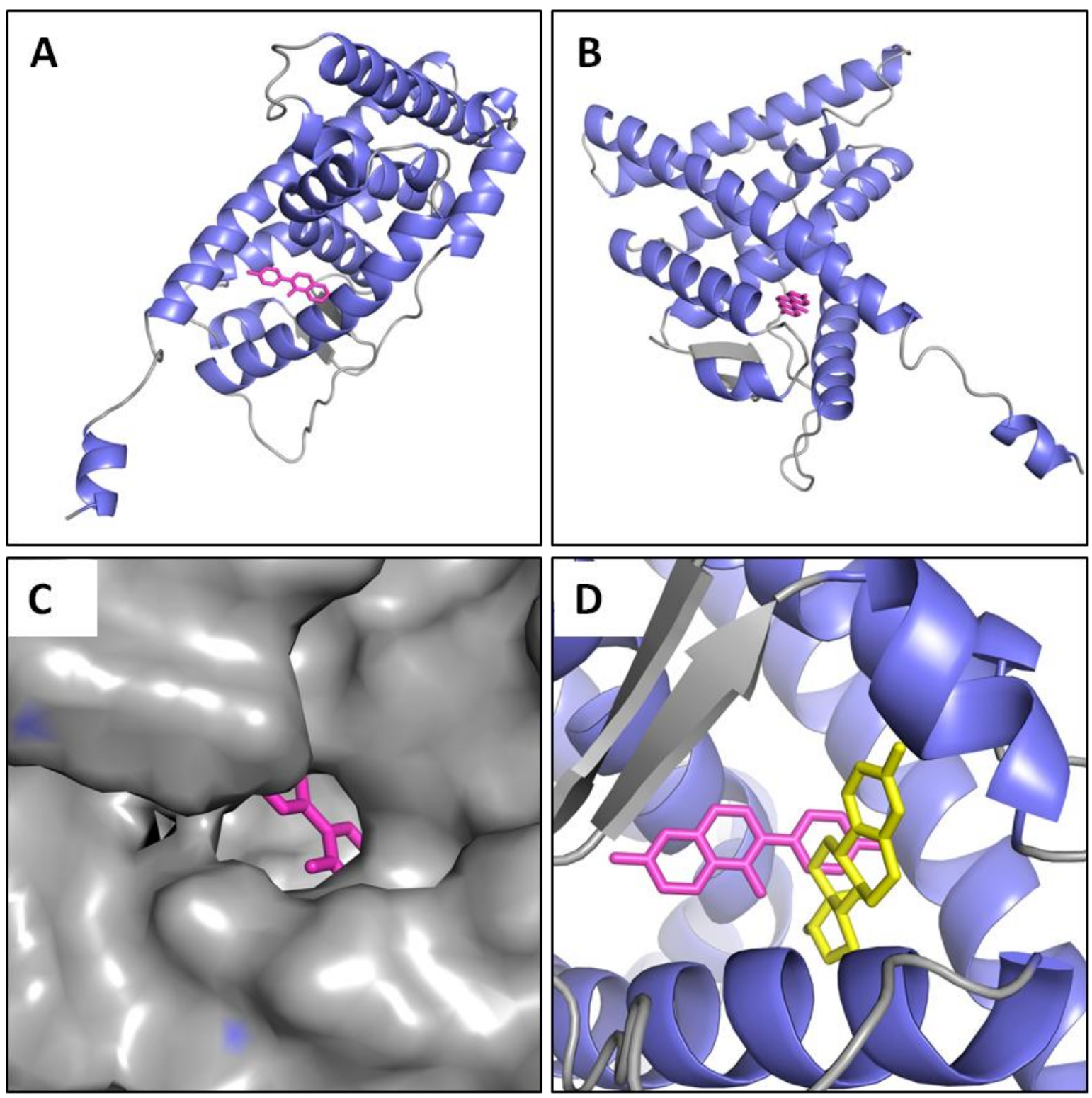

Figure 4.12 Comparison of the lowest binding energy position of DAI in Kākāpō ER- $\alpha$ from in silico docking with that for $\mathbf{E}_{2}$ in Kākāpō ER- $\alpha$. The crystal structure of Kākāpō ER- $\alpha$ is depicted as a cartoon model with the $\alpha$-helices in blue and the $\beta$-sheets and loops depicted in grey. A) and B) show the full receptor from different angles with the predicted position of DAI (pink) in the pocket of Kākāpō ER- $\alpha, C$ ) a section of the receptor magnified as a space-fill model with the predicted position of DAI (pink) in the pocket of Kākāpō ER- $\alpha$; and D) a magnified view of a section of the receptor with the most favourable docking position of DAI (pink) compared with that predicted for $\mathrm{E}_{2}$ (yellow) in Kākāpō ER- $\alpha$.

Analysis of the docking position of lowest energy showed a total of ten amino acids in close proximity (within $3 \AA$ ) to DAI (Figure 4.13A). Two of these were conserved interactions with that determined for $E_{2}$ in Kākāpō ER- $\alpha$ (Figure 4.13B). It was also found that none of the interactions seen between the ligand and protein involved residues unique to New Zealand parrots. Hydrogen bonding was observed between an oxygen atom of DAI and Arg394 (2.87 Å) (Figure 4.13A). 

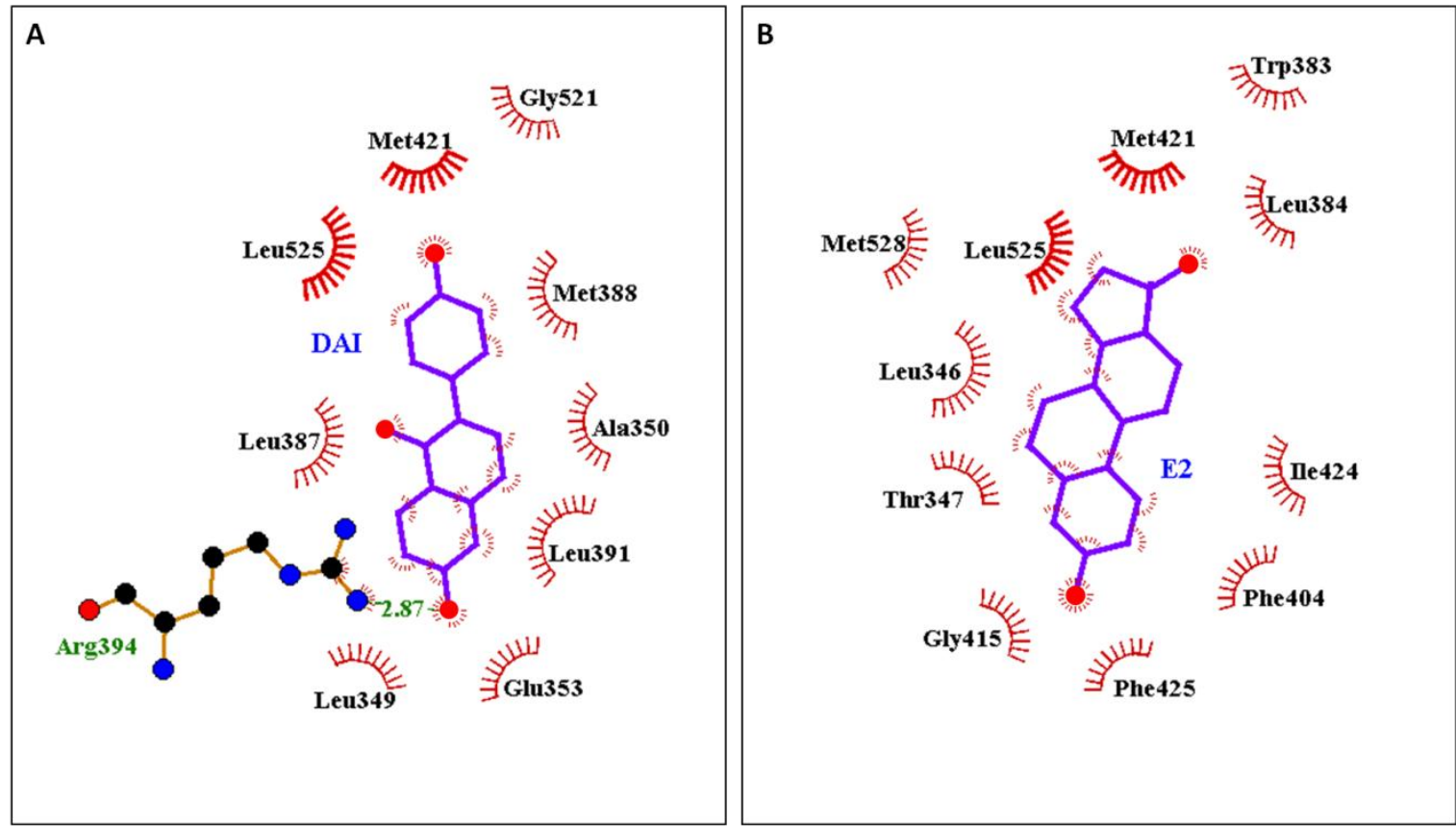

Figure 4.13 Potential interactions between Kākāpō ER- $\alpha$ and A) DAI and B) E . Daidzein (DAI) and 17 $\beta$-oestradiol (E2) (purple with red circles representing oxygen atoms) are shown in their predicted docked position. The amino acids involved in hydrophobic interactions are labelled and indicated with red lines and the atoms of the ligand involved in the hydrophobic interactions are also indicated with red lines. The side-chains of amino acids involved in hydrogen bonding to the ligand are shown with the distance in Angstroms $(\AA)$ and amino acid labelled in green. Those amino acids that are present in both models are in bold.

\subsubsection{Ferruginol (FER)}

FER was docked into Kākāpō ER- $\alpha$ using RosettaLigand and the binding position of lowest energy was determined (Figure 4.14A-C). This was situated in the ligand binding pocket of the receptor but at a different position to that determined for $E_{2}$ in Kākāpō ER- $\alpha$ (Figure 4.14D). 

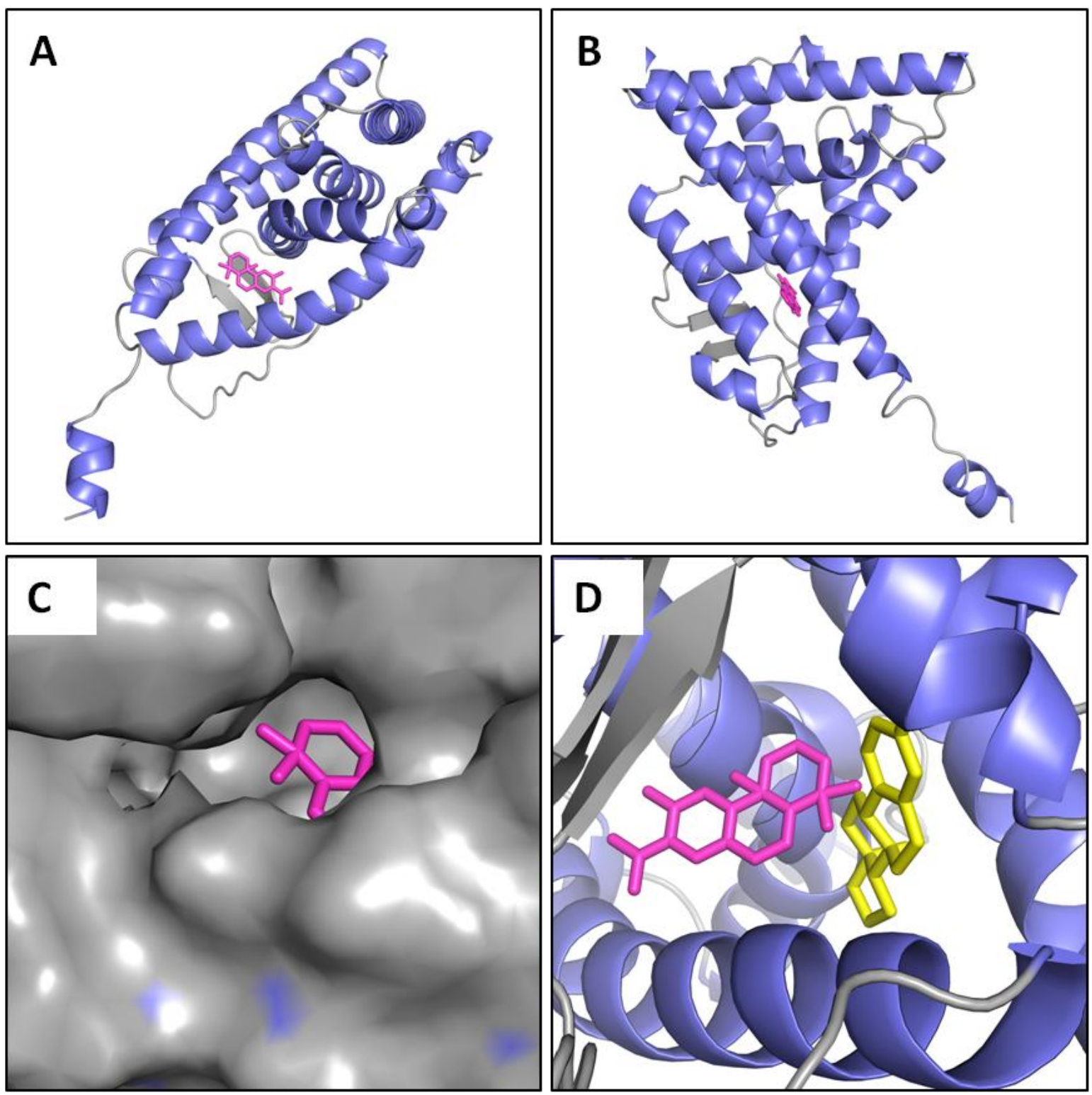

Figure 4.14 Comparison of the lowest binding energy position of FER in Kākāpō ER- $\alpha$ from in silico docking with that for $\mathbf{E}_{2}$ in Kākāpō ER- $\alpha$. The crystal structure of Kākāpō ER- $\alpha$ is depicted as a cartoon model with the $\alpha$-helices in blue and the $\beta$-sheets and loops depicted in grey. A) and B) show the full receptor from different angles with the predicted position of FER (pink) in the pocket of Kākāpo ER- $\alpha, C$ ) a section of the receptor magnified as a space-fill model with the predicted position of FER (pink) in the pocket of Kākāpō ER- $\alpha$; and D) a magnified view of a section of the receptor with the most favourable docking position of FER (pink) compared with that predicted for $\mathrm{E}_{2}$ (yellow) in Kākāpō ER- $\alpha$.

Analysis of the docking position of lowest energy for FER showed a total of nine amino acids of Kākāpō ER- $\alpha$ in close proximity (within $3 \AA$ A ) to this compound (Figure 4.15A). It was found that none of the interactions observed between the ligand and protein were residues that were unique to New Zealand parrots. Five of the interacting amino acids for FER were conserved interactions with that determined for $E_{2}$ in Kākāpō ER- $\alpha$ (Figure 4.15B). 

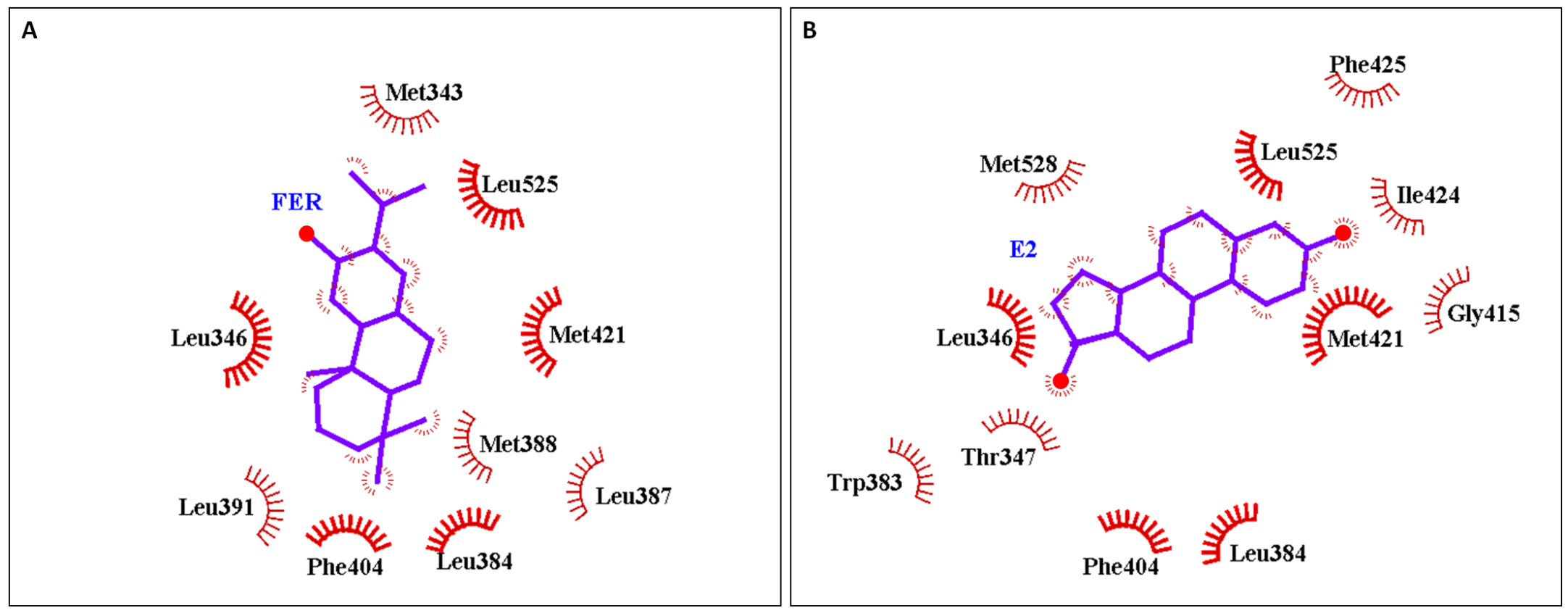

Figure 4.15 Potential interactions between Kākāpō ER- $\boldsymbol{\alpha}$ and A) FER and B) $\mathbf{E}_{\mathbf{2}}$. Ferruginol (FER) and 17ß-oestradiol (E2) (purple with red circles representing oxygen atoms) are shown in their predicted docked position. The amino acids involved in hydrophobic interactions are labelled and indicated with red lines and the atoms of the ligand involved in the hydrophobic interactions are also indicated with red lines. Those amino acids that are present in both models are in bold. 


\subsubsection{Formononetin (FORM)}

The docking of FORM into the binding pocket of Kākāpō ER- $\alpha$ resulted in a position of lowest interaction energy in the ligand binding pocket of the receptor but this was in a different position to that seen for $E_{2}$ in Kākāpō ER- $\alpha$ (Figure 4.16A-D).
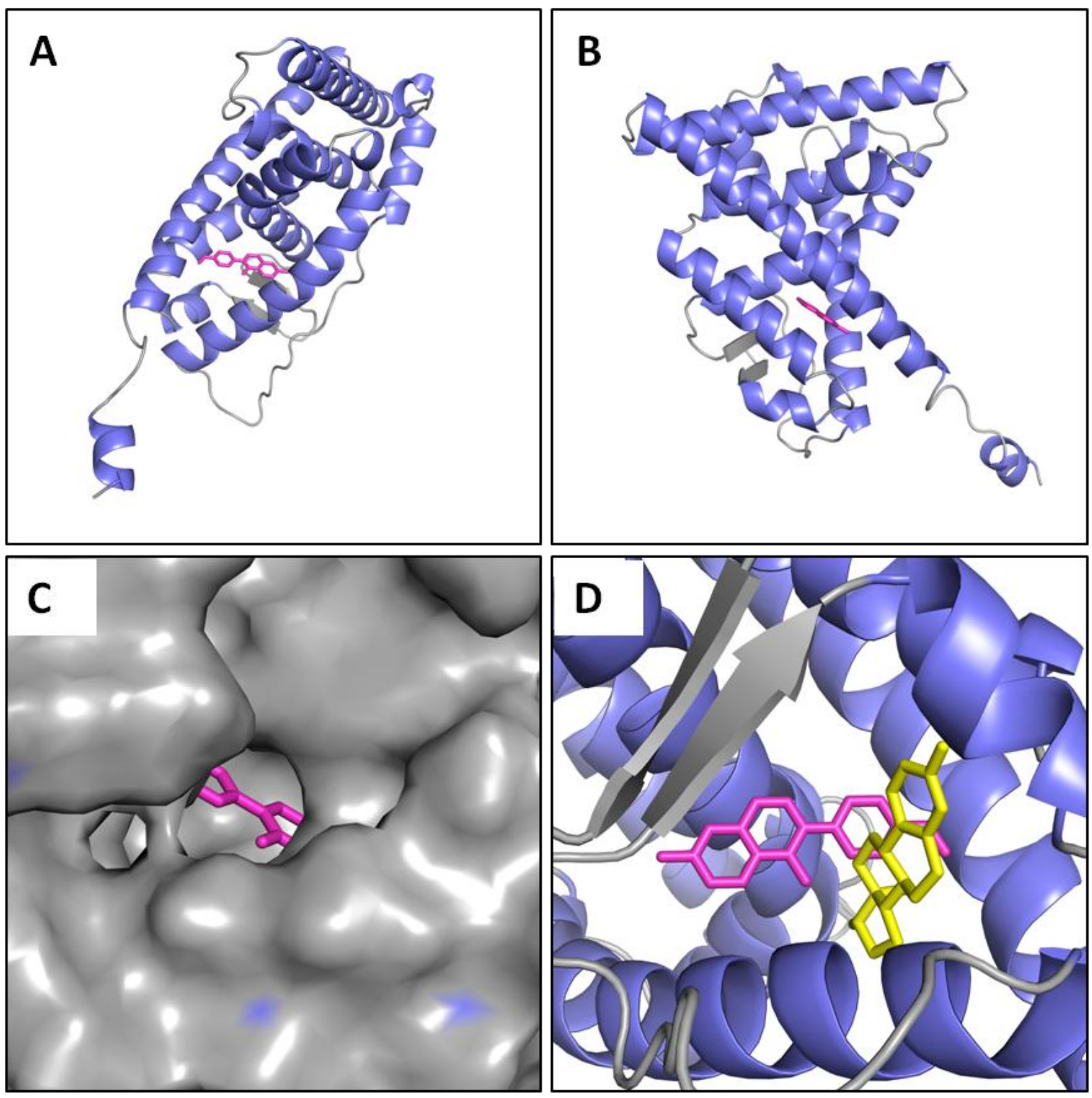

Figure 4.16 Comparison of the lowest binding energy position of FORM in Kākāpō ER- $\alpha$ from in silico docking with that for $\mathbf{E}_{2}$ in Kākāpō ER- $\alpha$. The crystal structure of Kākāpō ER- $\alpha$ is depicted as a cartoon model with the $\alpha$-helices in blue and the $\beta$-sheets and loops depicted in grey. A) and B) show the full receptor from different angles with the predicted position of FORM (pink) in the pocket of Kākāpō ER- $\alpha, C$ ) a section of the receptor magnified as a space-fill model with the predicted position of FORM (pink) in the pocket of Kākāpō ER- $\alpha$; and D) a magnified view of a section of the receptor with the most favourable docking position of FORM (pink) compared with that predicted for $\mathrm{E}_{2}$ (yellow) in Kākāpō ER- $\alpha$. 
Analysis of the most favourable docking position suggested ten potential interactions between FORM and the amino acids in the protein (Figure 4.17A). None of the residues involved were unique to New Zealand parrots. One of these interactions involved hydrogen bonding between an oxygen of FORM and the side-chain of Arg394 (approximately $2.87 \AA$ away) Two of the interactions observed for FORM were present between $E_{2}$ and Kākāpō ER- $\alpha$ (Figure 4.17B).

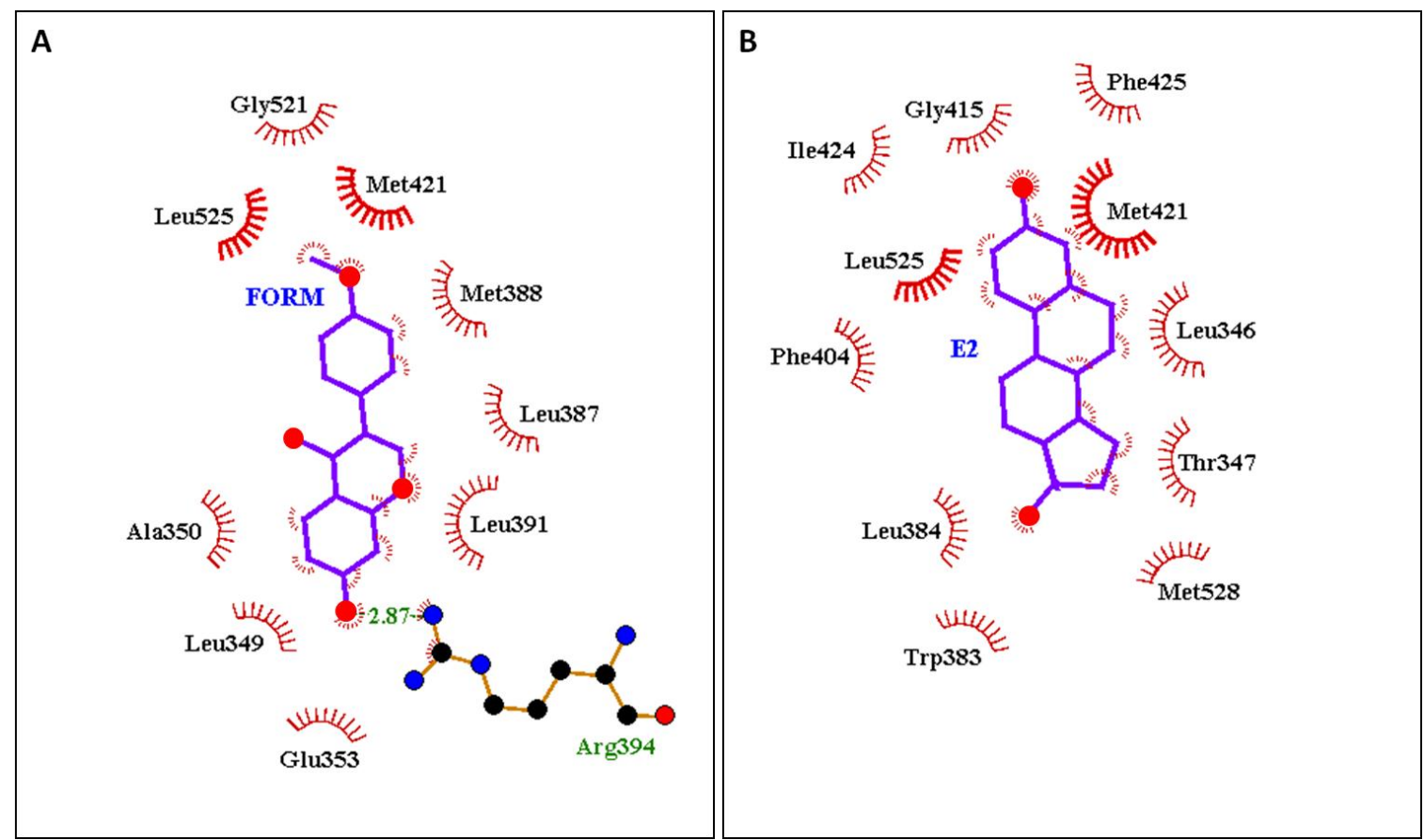

Figure 4.17 Potential interactions between Kākāpō ER- $\alpha$ and A) FORM and B) E$_{2}$. Formononetin (FORM) and $17 \beta$-oestradiol (E2) (purple with red circles representing oxygen atoms) are shown in their predicted docked position. The amino acids involved in hydrophobic interactions are labelled and indicated with red lines and the atoms of the ligand involved in the hydrophobic interactions are also indicated with red lines. The side-chains of amino acids involved in hydrogen bonding to the ligand are shown with the distance in Angstroms ( $\mathrm{A}$ ) and amino acid labelled in green. Those amino acids that are present in both models are in bold.

\subsubsection{Genistein (GEN)}

Simulation of the docking of GEN in Kākāpō ER- $\alpha$ was performed and found to bind optimally in the region defined as the ligand binding pocket (Figure 4.18A and B). The lowest energy binding orientation for genistein was found to be at a different orientation (approximately $90^{\circ}$ angle) to where $\mathrm{E}_{2}$ is predicted to bind in the same protein (Figure 4.18C). As the crystal structure of hER- $\alpha$ with GEN bound in it has been experimentally determined (RSCB structure ID 2QA8), the docked genistein in Kākāpō ER- $\alpha$ was compared to this and found to be in a similar plane but in the reverse orientation (Figure 4.18D). 

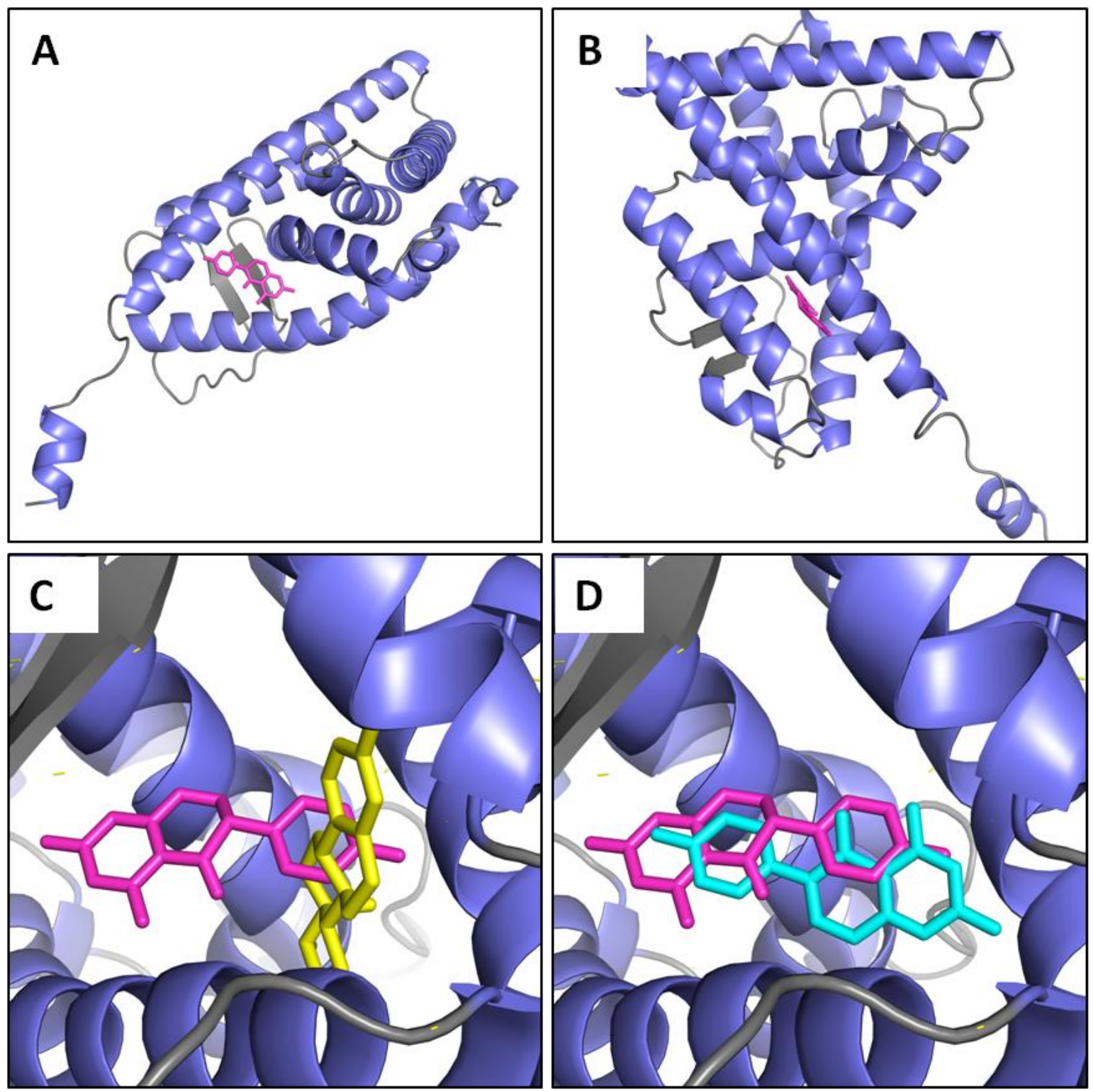

Figure 4.18 Comparison of the lowest binding energy position of GEN in Kākāpō ER- $\alpha$ from in silico docking with

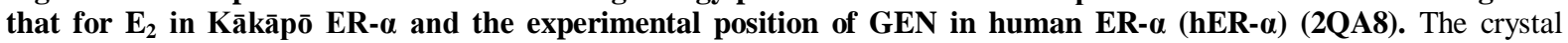
structures of Kākāpō and hER- $\alpha$ are depicted as cartoon models with the $\alpha$-helices in blue and the $\beta$-sheets and loops depicted in grey. A) shows the full receptor from different angles with the predicted position of GEN (pink) in the pocket of Kākāpō ER- $\alpha$, B) a section of the receptor magnified with the predicted position of GEN (pink) in the pocket, C) a magnified view of a section of the ligand binding domain with the most favourable docking position of GEN (pink) compared with that predicted for $\mathrm{E}_{2}$ (yellow) in Kākāpō ER- $\alpha$ and; D) a magnified view of a section of the ligand binding domain with the most favourable docking position of GEN (pink) compared with the known binding position of GEN in hER- $\alpha$ (cyan).

There were nine interactions predicted between GEN and the side-chains of the protein backbone of Kākāpō ER- $\alpha$ although none of these were involving amino acid residues unique to the New Zealand parrots (Figure 4.19A). One of these interactions was predicted to be through hydrogen bonding; the amino acid involved was Arg394 (2.94 A). Of the nine interactions, two were identical to those found when $\mathrm{E}_{2}$ was bound in Kākāpō ER- $\alpha$ (Figure 
4.19B). A comparison of the postulated binding site of GEN in Kākāpō ER- $\alpha$ with an experimentally-derived binding site for genistein in mutated hER- $\alpha$ (2QA8) generated seven conserved amino acid interactions (Ala350, Glu353, Leu387, Met388, Arg394, Met421 and Leu525) although the molecule was in the reverse orientation in hER- $\alpha$ (Figure 4.19C and D) In both cases, hydrogen bonding with Arg394 was present. 

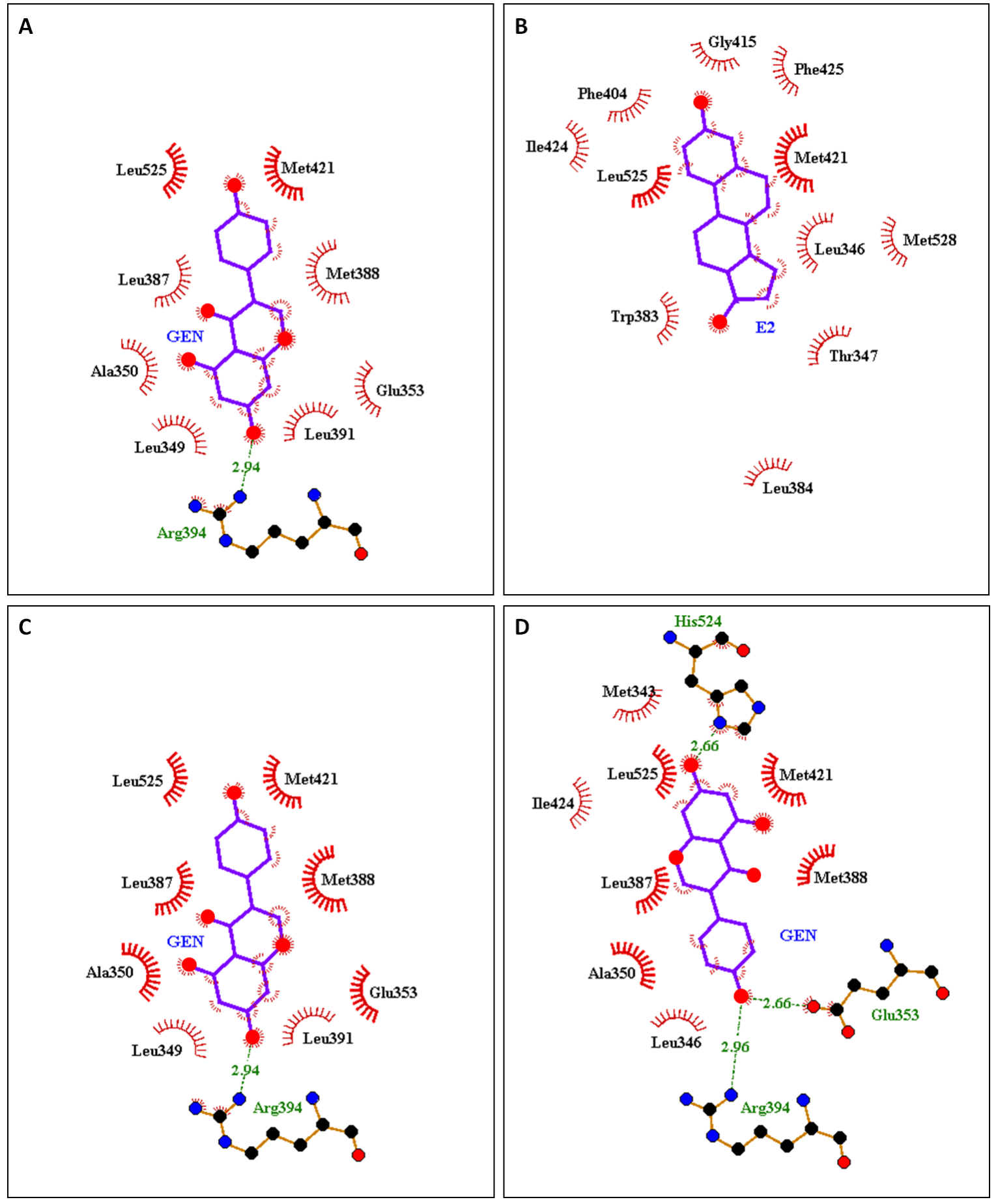

Figure 4.19 Potential interactions of GEN with ER- $\alpha$. A and C) are genistein (GEN) bound to Kākāpō ER- $\alpha$; B) is $17 \beta$-oestradiol (E2) bound in Kākāpō ER- $\alpha$; and D) experimentally derived docking of GEN in human ER- $\alpha$ (hER- $\alpha$ ) (2QA8). GEN and E2 (purple with red circles representing oxygen atoms) are shown in their predicted docked position. The amino acids involved in hydrophobic interactions are labelled and indicated with red lines and the atoms of the ligand involved in the hydrophobic interactions are also indicated with red lines. The side-chains of amino acids involved in hydrogen bonding to the ligand are shown with the distance in Angstroms ( $\mathrm{A}$ ) and amino acid labelled in green. Those amino acids that are present in both models $\mathrm{A}$ and $\mathrm{B}$, and in both $\mathrm{C}$ and $\mathrm{D}$ are in bold. 


\subsubsection{Podocarpic Acid (PACID)}

When PACID was docked into Kākāpō ER- $\alpha$, the most energetically favourable position was found to be within the ligand binding pocket of the protein (Figure 4.20A-C) but at a slightly different orientation from the predicted position of $E_{2}$ in Kākāpō ER- $\alpha$ (Figure 4.20D). There was minimal overlap present between the two molecules.
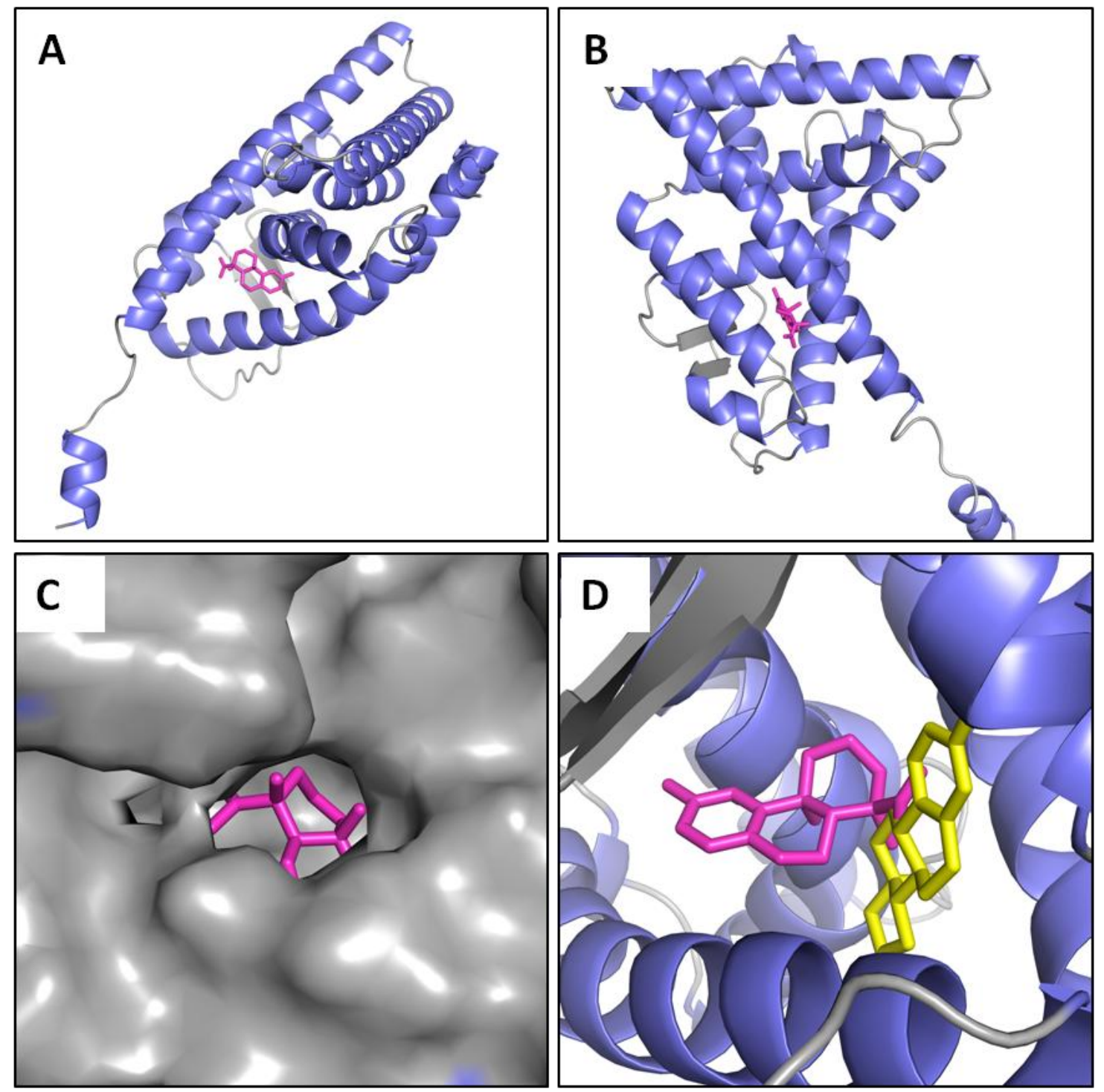

Figure 4.20 Comparison of the lowest binding energy position of PACID in Kākāpō ER-a from in silico docking with that for $\mathbf{E}_{2}$ in Kākāpō ER- $\alpha$. The crystal structure of Kākāpō ER- $\alpha$ is depicted as a cartoon model with the $\alpha$-helices in blue and the $\beta$-sheets and loops depicted in grey. A) and B) show the full receptor from different angles with the predicted position of PACID (pink) in the pocket of Kākāpō ER- $\alpha, C$ ) a section of the receptor magnified as a space-fill model with the predicted position of PACID (pink) in the pocket of Kākāpō ER- $\alpha$; and D) a magnified view of a section of the receptor with the most favourable docking position of PACID (pink) compared with that predicted for $\mathrm{E}_{2}$ (yellow) in Kākāpō ER- $\alpha$.

PACID had 11 interactions with Kākāpō ER- $\alpha$, none of which were involving residues unique to New Zealand parrots (Figure 4.21A). Three of these interactions formed a cluster of 


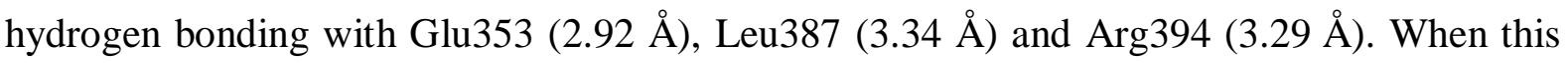
interaction map was compared to that for $E_{2}$ in Kākāpō ER- $\alpha$, there were four amino acids the same as that for PACID (Figure 4.21B).
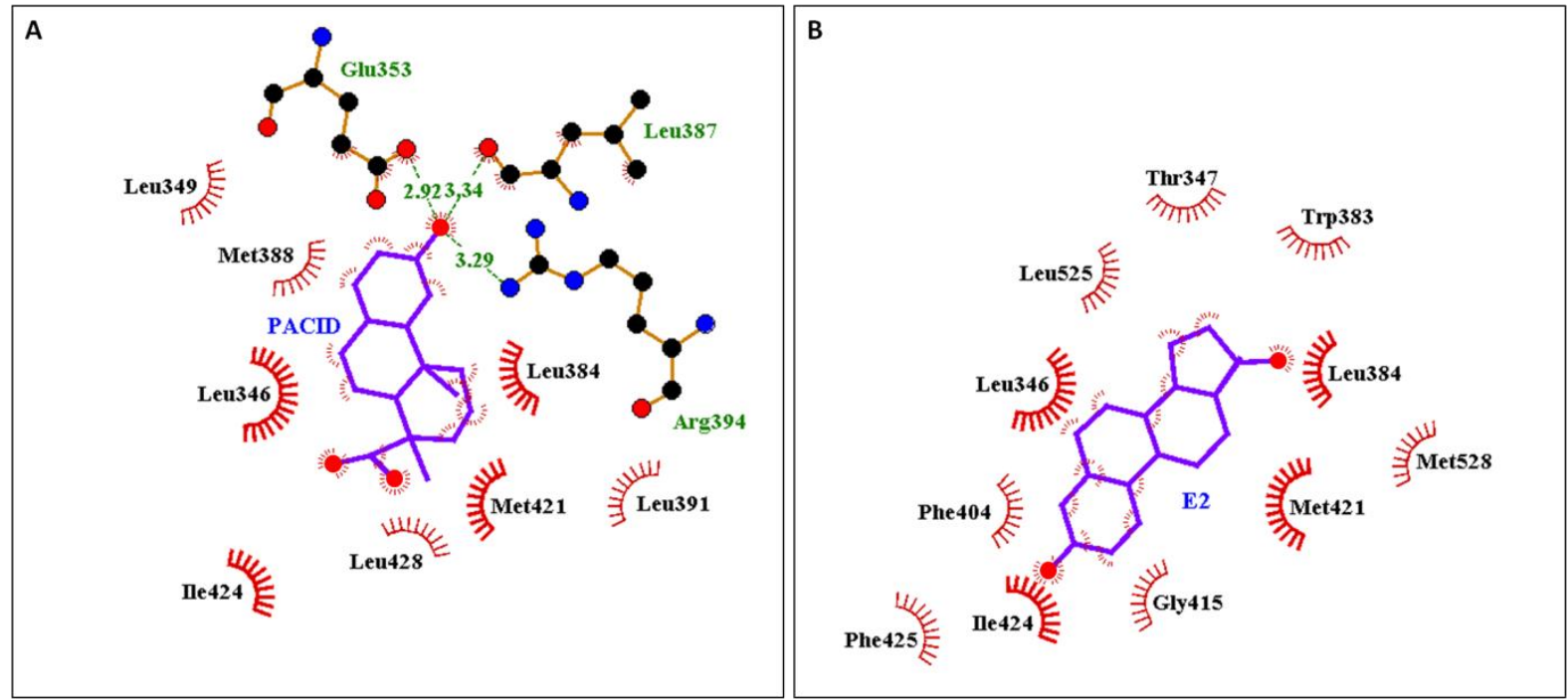

Figure 4.21 Potential interactions between Kākāpō ER- $\alpha$ and A) PACID and B) $\mathbf{E}_{2}$. Podocarpic acid (PACID) and $17 \beta$-oestradiol (E2) (purple with red circles representing oxygen atoms) are shown in their predicted docked position. The amino acids involved in hydrophobic interactions are labelled and indicated with red lines and the atoms of the ligand involved in the hydrophobic interactions are also indicated with red lines. The side-chains of amino acids involved in hydrogen bonding to the ligand are shown with the distance in Angstroms $(\AA)$ and amino acid labelled in green. Those amino acids that are present in both models are in bold.

\subsubsection{Podocarpinol (PODO)}

When PODO was docked into Kākāpō ER- $\alpha$, the most energetically favourable position was found to be in very close vicinity to where $E_{2}$ is predicted to bind in Kākāpō ER- $\alpha$ (Figure 4.22). It was in the same orientation although a little offset from $E_{2}$. 

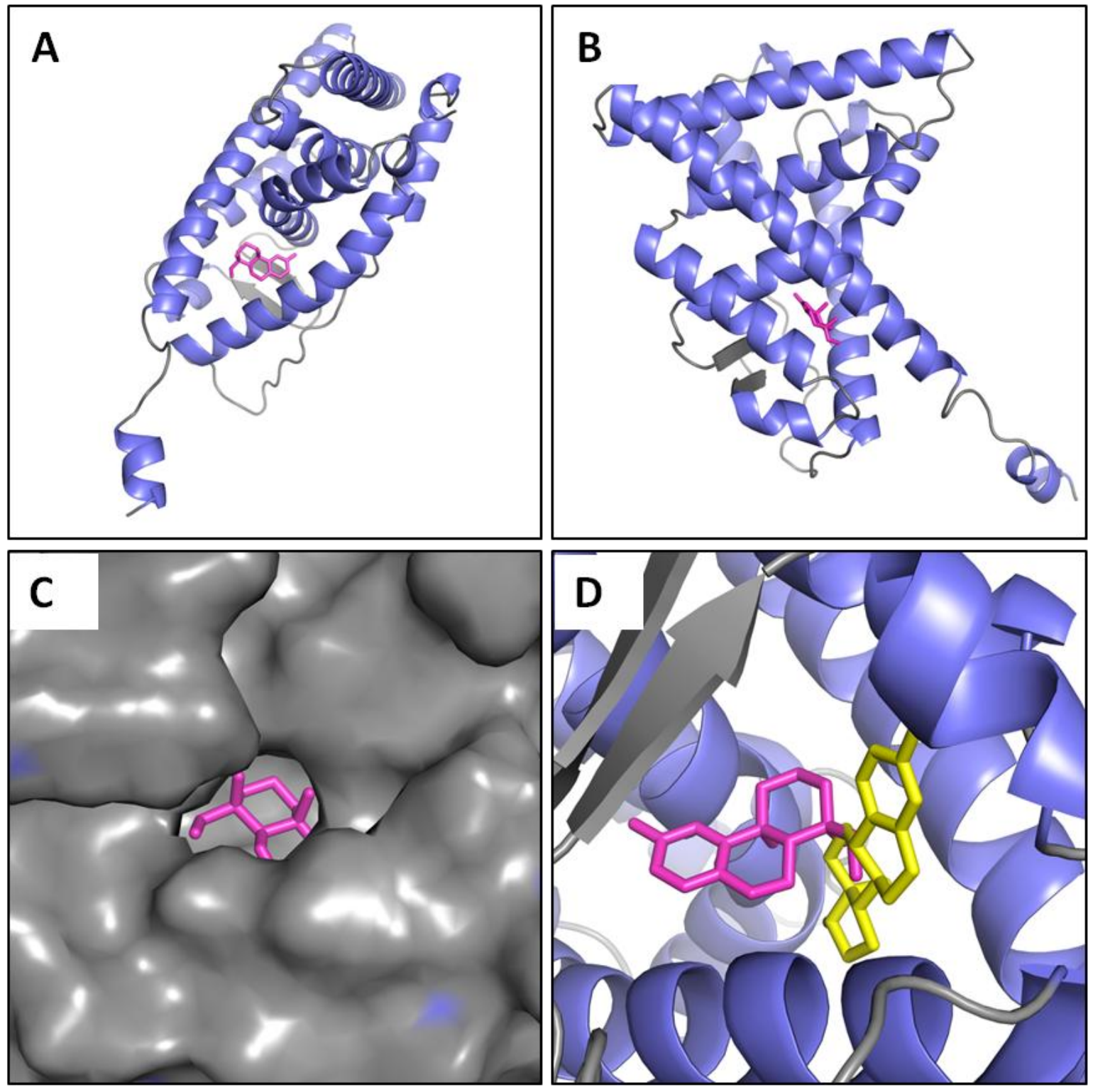

Figure 4.22 Comparison of the lowest binding energy position of PODO in Kākāpō ER- $\alpha$ from in silico docking with that for $\mathbf{E}_{2}$ in Kākāpō ER- $\alpha$. The crystal structure of Kākāpō ER- $\alpha$ is depicted as a cartoon model with the $\alpha$-helices in blue and the $\beta$-sheets and loops depicted in grey. A) and B) show the full receptor from different angles with the predicted position of PODO (pink) in the pocket of Kākāpō ER- $\alpha, C$ ) a section of the receptor magnified as a space-fill model with the predicted position of PODO (pink) in the pocket of Kākāpō ER- $\alpha$; and D) a magnified view of a section of the receptor with the most favourable docking position of PODO (pink) compared with that predicted for $\mathrm{E}_{2}$ (yellow) in Kākāpō ER- $\alpha$.

There were ten interactions predicted between PODO and the side-chains of the protein backbone of Kākāpō ER- $\alpha$ (Figure 4.23A). Two amino acids were involved in hydrogen bonding: Glu353 (2.79 $\AA$ ) and Leu387 (3.18 ̊). None of these were involving residues unique to New Zealand parrots. Of the ten interactions, three were present in the docking of $\mathrm{E}_{2}$ in Kākāpō ER- $\alpha$ (Figure 4.23B). 


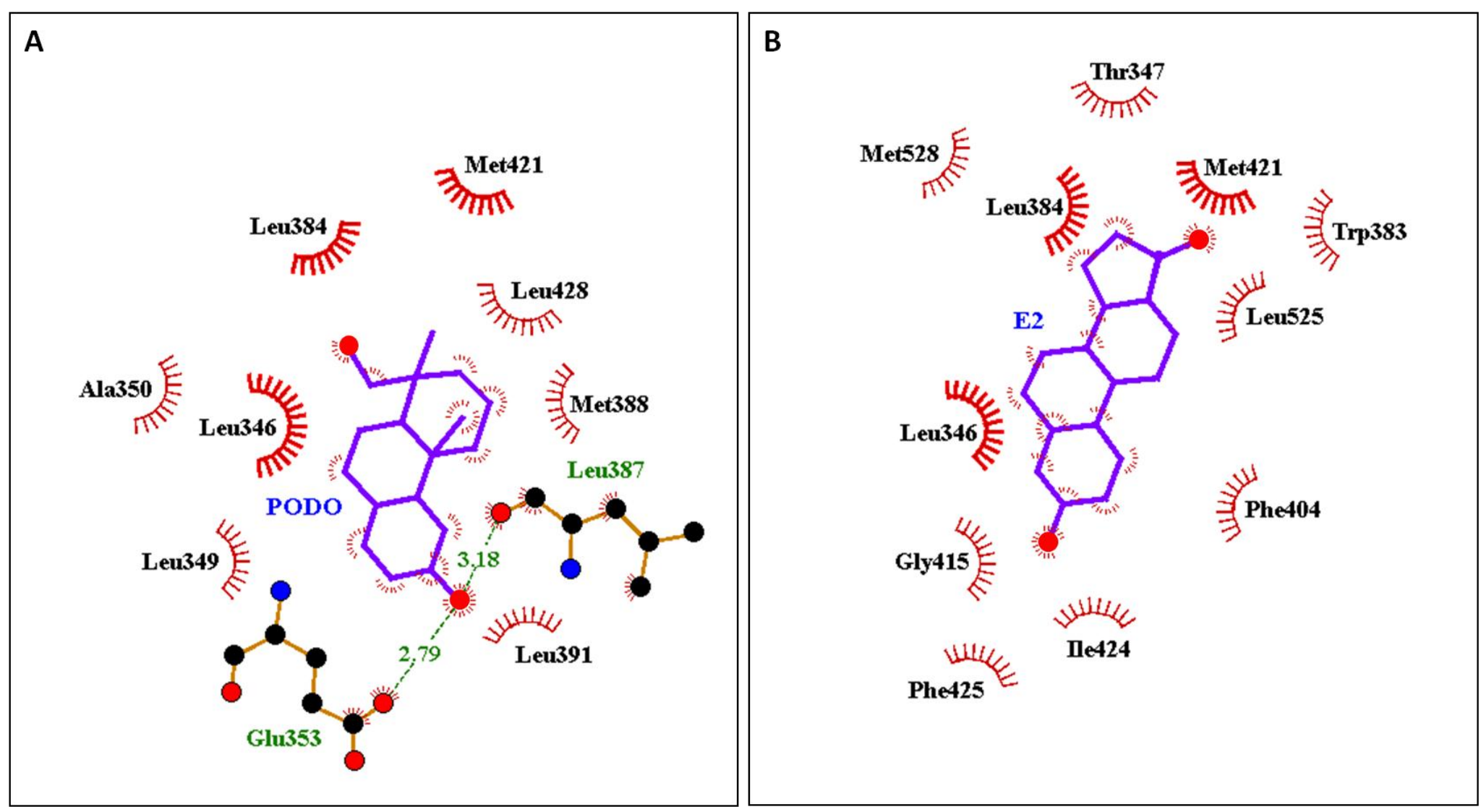

Figure 4.23 Potential interactions between Kākāpō ER- $\boldsymbol{\alpha}$ and A) PODO and B) $\mathbf{E}_{2}$. Podocarpinol (PODO) and 17ß-oestradiol (E2) (purple with red circles representing oxygen atoms) are shown in their predicted docked position. The amino acids involved in hydrophobic interactions are labelled and indicated with red lines and the atoms of the ligand involved in the hydrophobic interactions are also indicated with red lines. The side-chains of amino acids involved in hydrogen bonding to the ligand are shown with the distance in Angstroms ( $)$ and amino acid labelled in green. Those amino acids that are present in both models are in bold. 


\subsubsection{Totarol (TOT)}

When TOT was docked into Kākāpō ER- $\alpha$, the most energetically favourable position was found to be within the ligand binding pocket of the protein but removed from the predicted position of $E_{2}$ in Kākāpō ER- $\alpha$ (Figure 4.24A-C). There was not significant overlap in the atoms of TOT with those for $\mathrm{E}_{2}$ (Figure 4.24D).
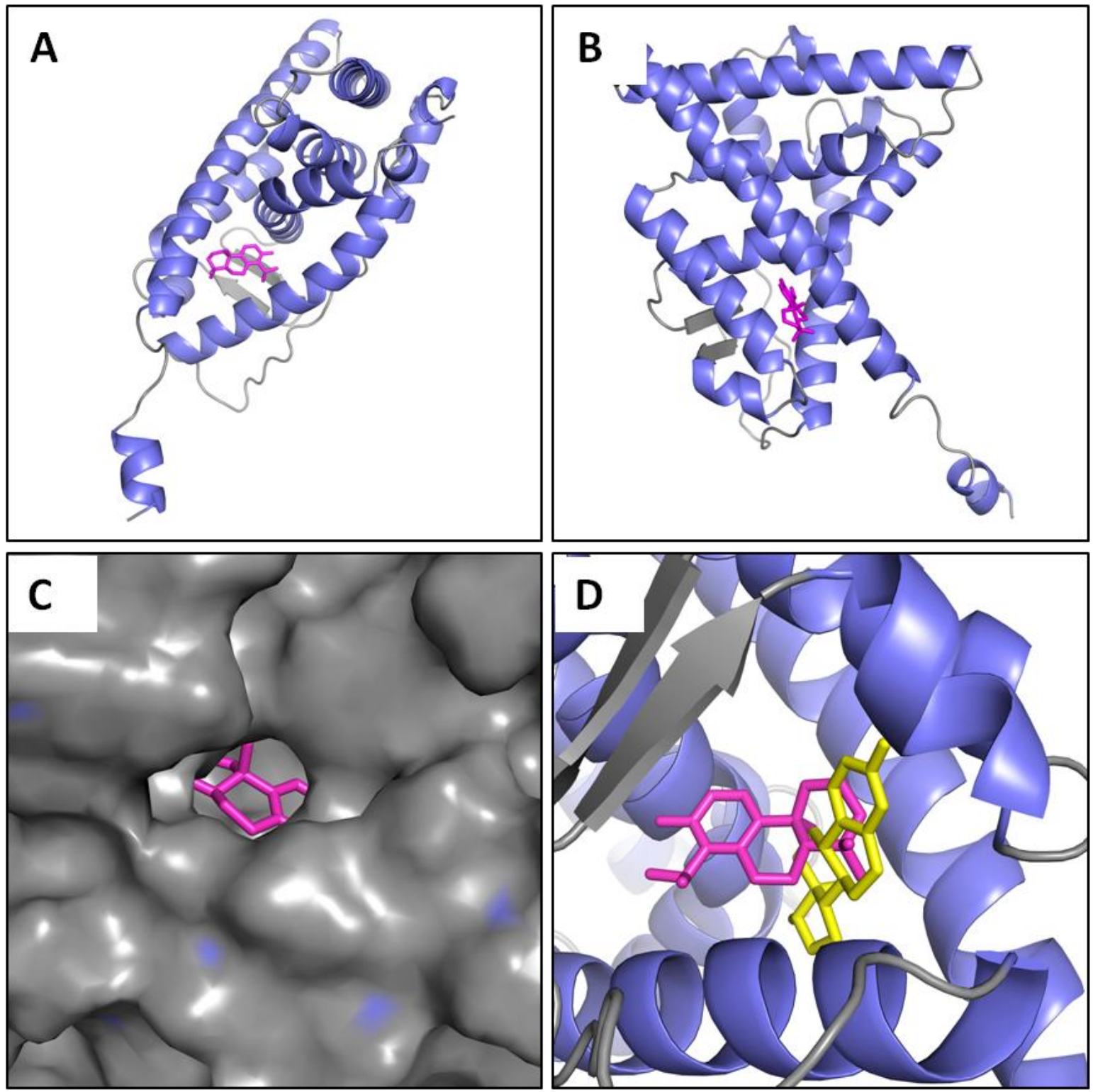

Figure 4.24 Comparison of the lowest binding energy position of TOT in Kākāpō ER- $\alpha$ from in silico docking with that for $\mathbf{E}_{2}$ in Kākāpō ER- $\alpha$. The crystal structure of Kākāpō ER- $\alpha$ is depicted as a cartoon model with the $\alpha$-helices in blue and the $\beta$-sheets and loops depicted in grey. A) and B) show the full receptor from different angles with the predicted position of TOT (pink) in the pocket of Kākāpo ER- $\alpha, C$ ) a section of the receptor magnified as a space-fill model with the predicted position of TOT (pink) in the pocket of Kākāpō ER- $\alpha$; and D) a magnified view of a section of the receptor with the most favourable docking position of TOT (pink) compared with that predicted for $\mathrm{E}_{2}$ (yellow) in Kākāpō ER- $\alpha$. 
There were 13 interactions predicted between TOT in its most favourable position and the side-chains of the protein backbone of Kākāpō ER- $\alpha$ and all were hydrophobic interactions (Figure 4.25A). None of the predicted interactions involved residues unique to New Zealand parrots. Of the 13 interactions, six were also found in the docking of $E_{2}$ in Kākāpō ER- $\alpha$ (Figure 4.25B).
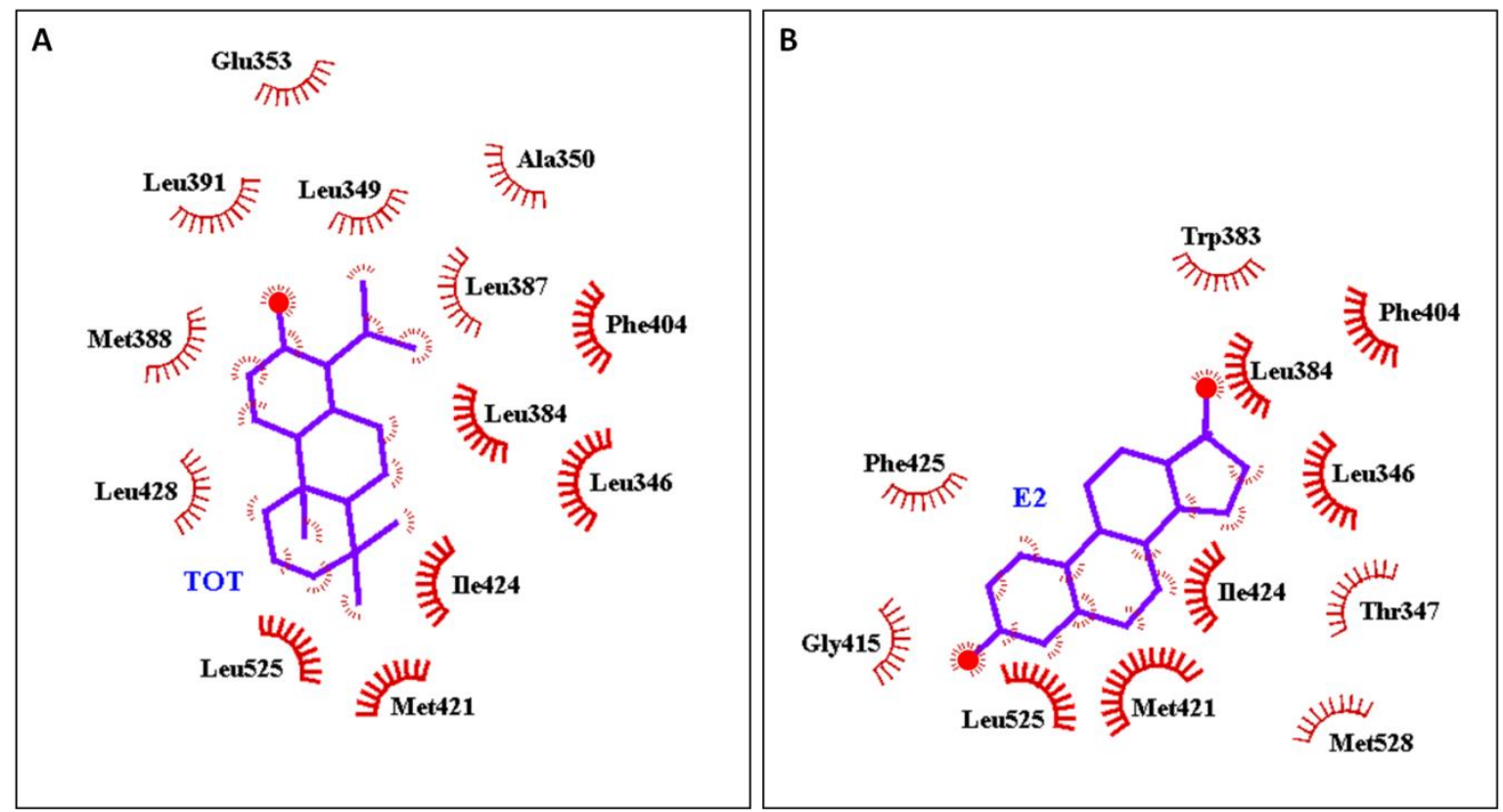

Figure 4.25 Potential interactions between Kākāpō ER- $\alpha$ and A) TOT and B) $\mathbf{E}_{2}$. Totarol (TOT) and 17 $\beta$-oestradiol (E2) (purple with red circles representing oxygen atoms) are shown in their predicted docked position. The amino acids involved in hydrophobic interactions are labelled and indicated with red lines and the atoms of the ligand involved in the hydrophobic interactions are also indicated with red lines. Those amino acids that are present in both models are in bold. 


\subsubsection{Docking of Other Hormones in Kākāpō ER- $\alpha$}

In silico modelling of two other natural steroid hormones, $\mathrm{P}_{4}$ and testosterone TEST was carried out to give an indication of potential binding positions in Kākāpō ER- $\alpha$.

When $\mathrm{P}_{4}$ was docked in Kākāpō ER- $\alpha$, the position with the lowest energy was in the ligand binding pocket close to the position estimated for $\mathrm{E}_{2}$ in the same receptor but in a different orientation (Figure 4.26A and B).
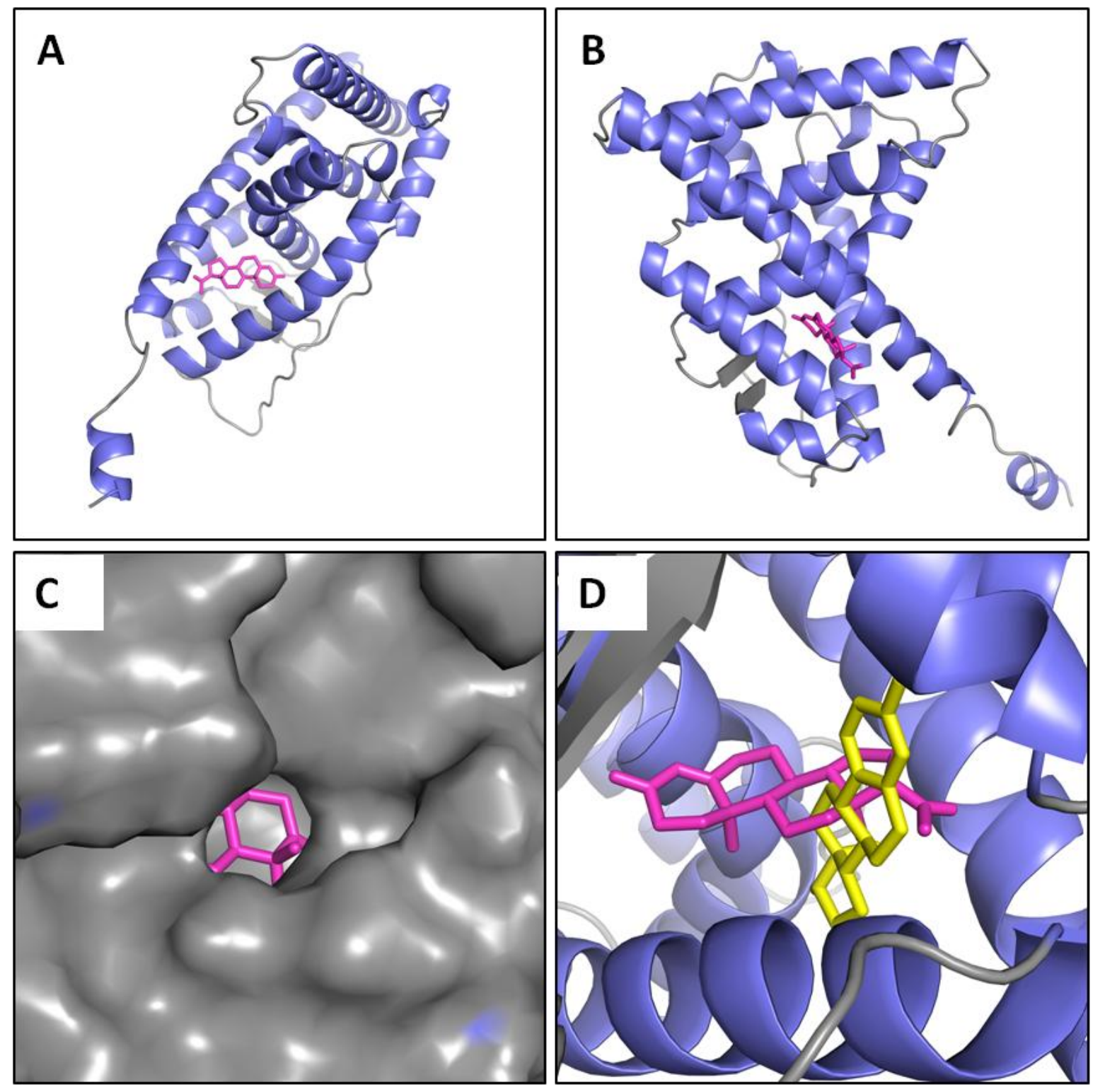

Figure 4.26 Comparison of the lowest binding energy position of $P_{4}$ in Kākāpō ER- $\alpha$ from in silico docking with that for $\mathbf{E}_{\mathbf{2}}$ in Kākāpō ER- $\alpha$. The crystal structure of Kākāpō ER- $\alpha$ is depicted as a cartoon model with the $\alpha$-helices in blue and the $\beta$-sheets and loops depicted in grey. A) and B) show the full receptor from different angles with the predicted position of $\mathrm{P}_{4}$ (pink) in the pocket of Kākāpō ER- $\alpha, \mathrm{C}$ ) a section of the receptor magnified as a space-fill model with the predicted position of $\mathrm{P}_{4}$ (pink) in the pocket of Kākāpō ER- $\alpha$; and D) a magnified view of a section of the receptor with the most favourable docking position of P4 (pink) compared with that predicted for $\mathrm{E}_{2}$ (yellow) in Kākāpō ER- $\alpha$. 
There were a total of 14 interactions predicted between $\mathrm{P}_{4}$ and the amino acids of Kākāpō ER- $\alpha$ with one (Arg394) involved in hydrogen bonding with an oxygen atom of P4 (2.74 $⿱$ ) (Figure 4.27A). None of the interacting residues were unique to New Zealand parrots. Six of the interactions seen between $\mathrm{P}_{4}$ and the receptor were also observed in the docking of $\mathrm{E}_{2}$ to Kākāpō ER- $\alpha$ (Figure 4.27B).
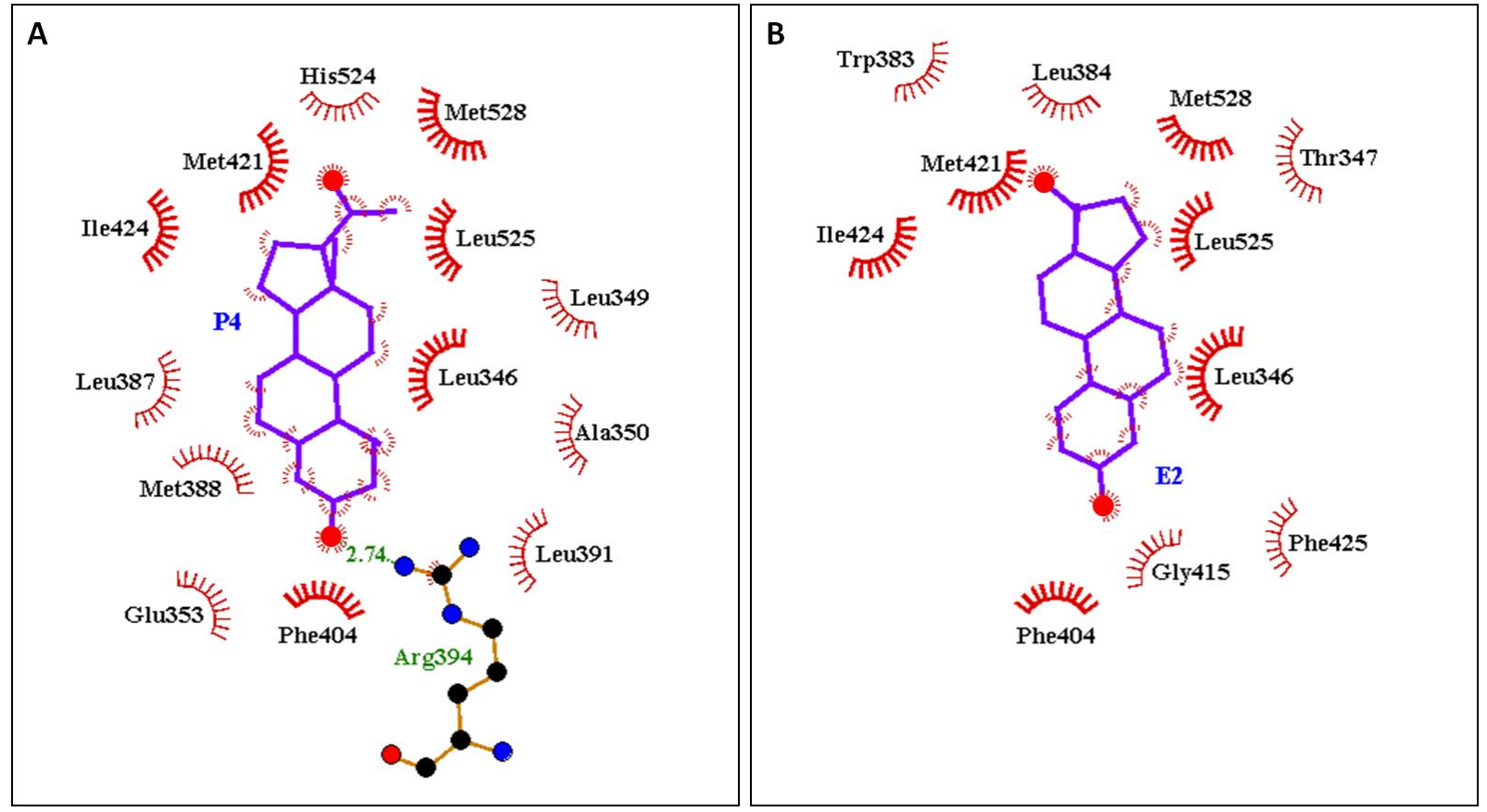

Figure 4.27 Potential interactions between Kākāpō ER- $\alpha$ and A) $\mathbf{P 4}$ and B) $\mathbf{E}_{2}$. Progesterone $\left(\mathrm{P}_{4}\right)$ and $17 \beta$-oestradiol (E2) (purple with red circles representing oxygen atoms) are shown in their predicted docked position. The amino acids involved in hydrophobic interactions are labelled and indicated with red lines and the atoms of the ligand involved in the hydrophobic interactions are also indicated with red lines. The side-chains of amino acids involved in hydrogen bonding to the ligand are shown with the distance in Angstroms $(\AA)$ and amino acid labelled in green. Those amino acids that are present in both models are in bold.

TEST was found to bind in the lowest energy position in Kākāpō ER- $\alpha$ in the binding pocket (Figure 4.28A-C). This was in the same vicinity as where $\mathrm{E}_{2}$ was predicted to bind but at a different angle (Figure 4.28D). It was very similar to that observed for P4 (Figure 4.26). 

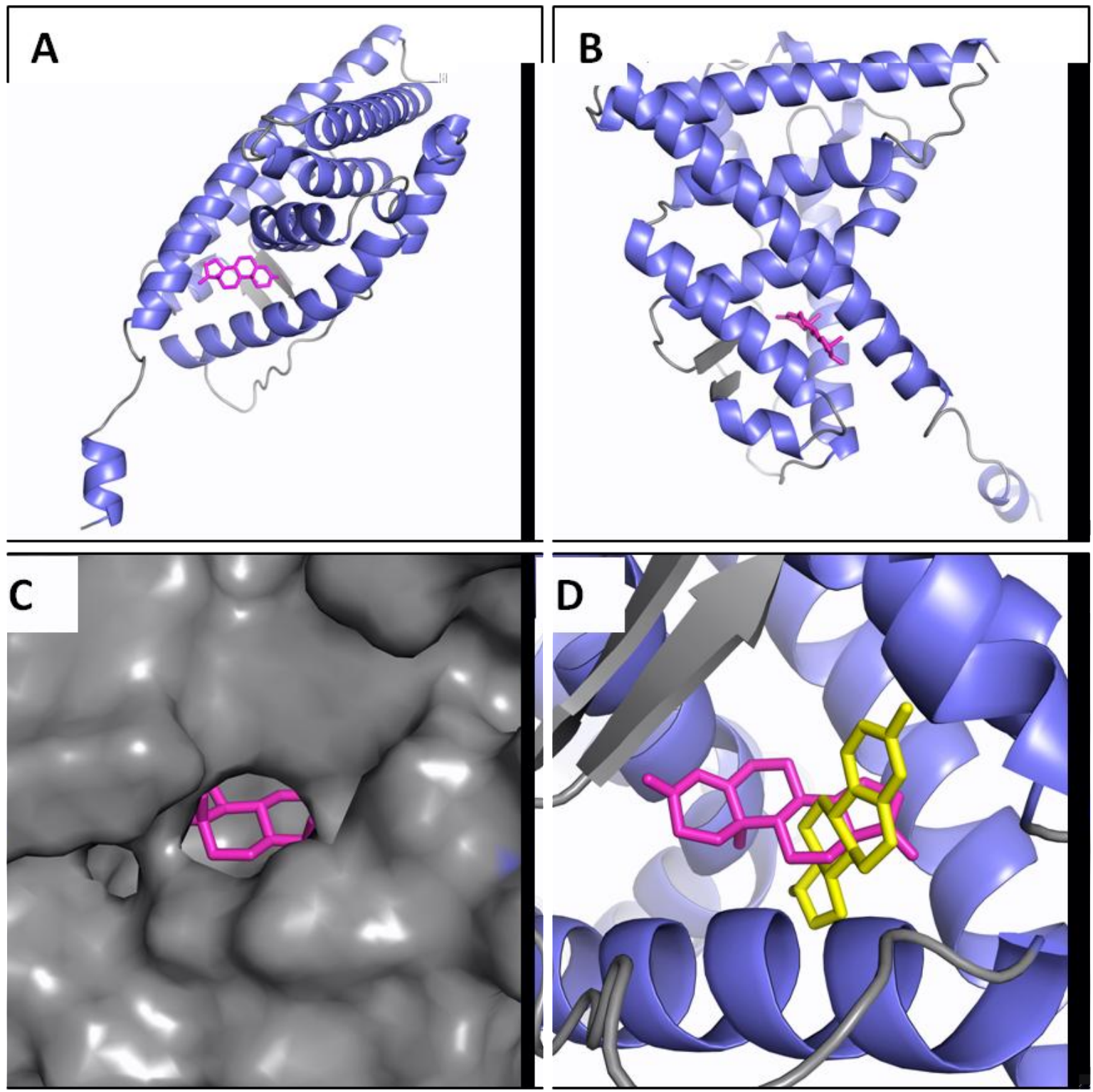

Figure 4.28 Comparison of the lowest binding energy position of TEST in Kākāpō ER- $\alpha$ from in silico docking with that for $\mathbf{E}_{2}$ in Kākāpō ER-a. The crystal structure of Kākāpō ER- $\alpha$ is depicted as a cartoon model with the $\alpha$-helices in blue and the $\beta$-sheets and loops depicted in grey. A) and B) show the full receptor from different angles with the predicted position of TEST (pink) in the pocket of Kākāpō ER- $\alpha, C$ ) a section of the receptor magnified as a space-fill model with the predicted position of TEST (pink) in the pocket of Kākāpō ER- $\alpha$; and D) a magnified view of a section of the receptor with the most favourable docking position of TEST (pink) compared with that predicted for $\mathrm{E}_{2}$ (yellow) in Kākāpō ER- $\alpha$.

Analysis of the interactions predicted between TEST in its most favourable position and Kākāpō ER- $\alpha$ protein backbone, suggested nine hydrophobic interactions (Figure 4.29A). None of these were residues unique to ER- $\alpha$ of New Zealand parrots. Of the nine predicted interactions, four were consistent with those predicted between $\mathrm{E}_{2}$ and amino acids in Kākāpō ER- $\alpha$ (Figure 4.29B). 

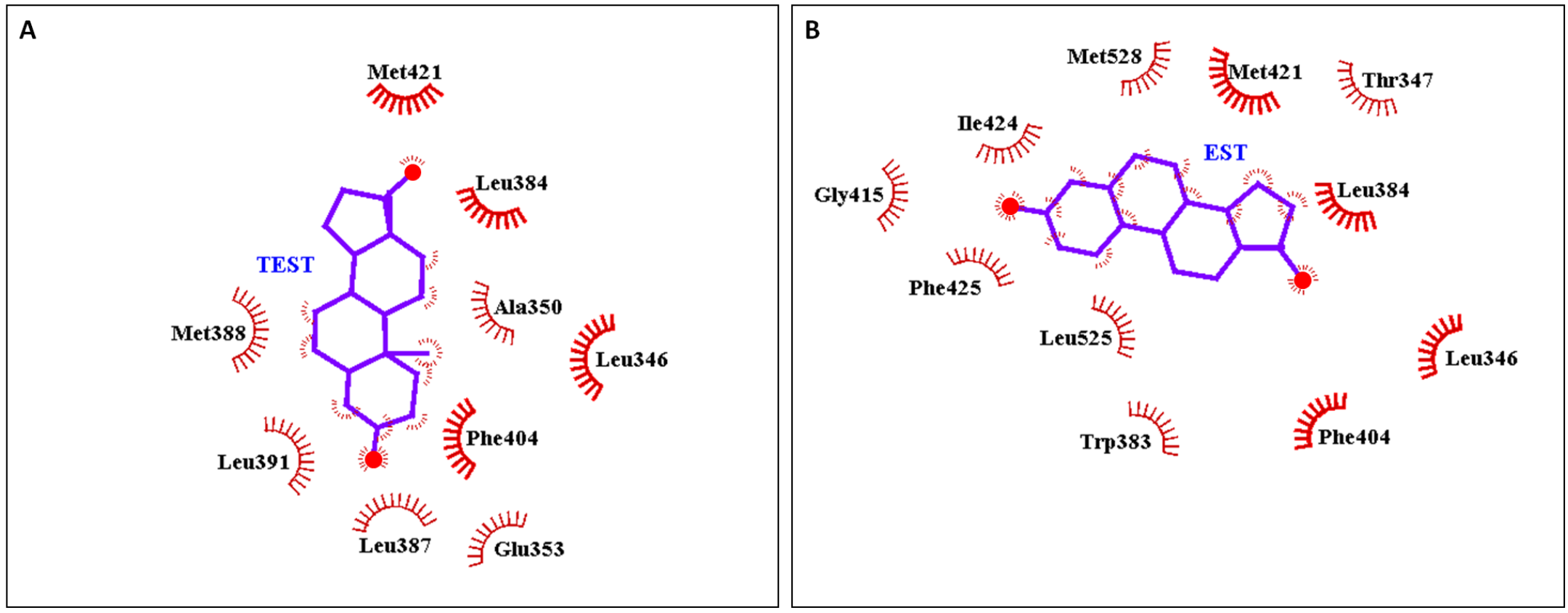

Figure 4.29 Potential interactions between Kākāpō ER- $\boldsymbol{\alpha}$ and A) TEST and B) $\mathbf{E}_{2}$. Testosterone (TEST) and 17ß-oestradiol (E2) (purple with red circles representing oxygen atoms) are shown in their predicted docked position. The amino acids involved in hydrophobic interactions are labelled and indicated with red lines and the atoms of the ligand involved in the hydrophobic interactions are also indicated with red lines. Those amino acids that are present in both models are in bold. 


\subsection{Discussion}

The purpose of this chapter was to investigate whether the amino acids found to be unique to the ER- $\alpha$ of New Zealand parrots had any influence on the potential binding of $E_{2}$. In addition, the secondary aim was to predict the likely docking positions of known phytoestrogens and other steroid hormones in Kākāpō ER- $\alpha$. To do this, in silico modelling with RosettaLigand was performed utilising the sequence for Kākāpō ER- $\alpha$ LBD generated earlier in the study. This computational approach was determined to be the best predictor of possible binding, short of generating a crystal structure for Kākāpō ER- $\alpha$. With the exception of BPA and GEN, which have each been crystallised in a mutant form of hER- $\alpha$, the compounds that were docked in this study have not had their binding site determined experimentally hitherto.

To determine that RosettaLigand was able to generate realistic binding modes, a docking procedure was first carried out involving an ER- $\alpha$ protein structure with a known binding position for $E_{2}$, namely hER- $\alpha$ (1A52). The results of this were found to emulate the binding site of $E_{2}$ with a high degree of accuracy (Figure 4.1) and thus demonstrated the capability of RosettaLigand to be used for ligand-binding predictions in Kākāpō ER- $\alpha$. The reverse orientation of $E_{2}$ in the predicted most energetically favourable position does not necessarily suggest that this method is flawed, especially as the orientation of the second most favourable position was the same as that for $\mathrm{E}_{2}$ in $1 \mathrm{~A} 52$. It is possible that the position of a ligand in an experimental crystal structure may not be its "true" docking mode.

The majority of the hydrophobic interactions reported between $E_{2}$ and the hER- $\alpha$ crystal structure (Tanenbaum, Wang et al. 1998) were observed in the two most favourable binding positions of $\mathrm{E}_{2}$ predicted by Rosetta (Figure 4.2).

As documented in Chapter 3, there were a number of amino acids present in the ER- $\alpha$ sequence of Kākāpō and other New Zealand parrots that were not present in other avian species in this study. Comparisons with hER- $\alpha$ demonstrated even more discrepancies in the amino acid sequences. A consequence of this was that predictions of potential binding sites for compounds known to interact with ER- $\alpha$ using the hER- $\alpha$ as a template would not account for any changes in the three-dimensional conformation of the protein caused by these amino acid variations. 
Therefore, after modification of the relevant amino acids in the template receptor (1A52) to make it identical to the Kākāpō ER- $\alpha$ sequence, the mutated receptor was minimised. This was done to ensure the receptor was in the lowest energy state possible prior to being used as the representative protein structure for the in silico docking experiments. Whilst the possibility existed that the three-dimensional structure was not identical to the obtained structure generated from crystallisation, it was considered to be a reasonable assumption for an initial set of experiments. This was because the same movement in the three-dimensional structure reflected the small number of amino acids that had changed, and because it was in the conformation of lowest energy. One consequence of the calculations used to generate the minimised representative protein was that the side-chains of a number of (identical) amino acids were in slightly different positions in Kākāpō ER- $\alpha$ to that seen in 1A52. Potentially this could influence the hydrogen bonding properties between the ligand and protein in the simulated model such that they might differ from those in the experimental crystal structure. Hence, hydrogen bonding with $\mathrm{E}_{2}$ and Arg394 and His524 in the human model was not observed in the equivalent Kākāpō ER- $\alpha$.

The initial representation of $E_{2}$ in the hER- $\alpha$ and in the minimised Kākāpō ER- $\alpha$ (with the same $\mathrm{E}_{2}$ co-ordinates used in 1A52) showed clearly that there were visible differences in the hydrophobic interactions (Figure 4.3). This included the absence of hydrophobic interactions with the residues Met388, Phe404, Ile424 and hydrogen bonding with Arg394 and His524, and the presence of interactions with Met421 and Met528 (Figure 4.3). This indicated that, even with a small number of amino acid changes, the overall configuration of the receptor backbone was altered.

When RosettaLigand was used to dock $E_{2}$ to the minimised Kākāpō ER- $\alpha$, it predicted a different binding orientation to that seen in the human receptor as the lowest energy form (Figure 4.4). Although the number of amino acids involved in interactions with $\mathrm{E}_{2}$ was 11 in both cases (Figure 4.5), only four of these were identical across the two models. Despite lacking three hydrogen bond interactions that were present in the human version, $\mathrm{E}_{2}$ was still surrounded by potential hydrophobic interactive moieties. The different orientation of the docked ligand suggests that, although the different amino acids present in the Kākāpō ER- $\alpha$ sequence do not have direct hydrophobic interactions with $E_{2}$, they have a pronounced effect on the optimal binding position in the pocket. 
Environmental oestrogens such as BPA and TRI are believed to mimic oestrogen by binding to the isoforms of ER (Gee, Charles et al. 2008; Adewale, Jefferson et al. 2009). Thus, it was not surprising that the results from the docking studies showed both of them to be in almost identical positions as predicted for $\mathrm{E}_{2}$ (Figure 4.6 and Figure 4.8). Despite their similar chemical structure, there were substantially more interactions between BPA and the protein than was seen for TRI, due in part to the chlorine groups present in TRI. As mentioned previously, BPA was one of only two molecules that has a published crystal structure of it bound in a mutated hER- $\alpha$ (RSCB structure ID 3UU7). The binding of BPA with the putative Kākāpō ER- $\alpha$ that was generated in this study was within $4 \AA$ of BPA in hER- $\alpha$ at its furthermost point (Figure 4.6D). One interpretation of this is that, because the binding of BPA to Kākāpō ER- $\alpha$ is very similar to that for BPA with hER- $\alpha$, it is possible that BPA could have a similar oestrogenic potency.

CMEST (Figure 4.10) and PODO (Figure 4.22) both had very similar docking positions to $\mathrm{E}_{2}$ in Kākāpō ER- $\alpha$. A key factor in the positioning of each molecule was the energy between the protein and ligand itself and so the structure of the docked ligand played an important role. Both of these molecules have somewhat similar structures to each other and to $E_{2}$. As the docking modes were analogous to that for $\mathrm{E}_{2}$, it could be postulated that these compounds may exhibit an oestrogenic effect. In the case of CMEST, all but two of the interactions seen between $\mathrm{E}_{2}$ and Kākāpō ER- $\alpha$ were present between CMEST and Kākāpō ER- $\alpha$.

In contrast, DAI (Figure 4.12), FER (Figure 4.14), FORM (Figure 4.16), GEN (Figure 4.18) and TOT (Figure 4.24) had somewhat different binding orientations to that determined for $\mathrm{E}_{2}$ in Kākāpō ER- $\alpha$. This is most likely attributed to the structural differences, and thus polarities, they exhibit when compared to $E_{2}$. This different orientation was consistent to what was also seen when the docking of GEN in Kākāpō ER- $\alpha$ was compared with its equivalent in hER- $\alpha$ (Figure 4.18D).

For DAI, FORM and GEN, only two hydrophobic protein-ligand interactions were consistent with those for $E_{2}$ and Kākāpō ER- $\alpha$ (Figure 4.13, Figure 4.17 and Figure 4.19 respectively). There were more identical hydrophobic protein-ligand interactions for PACID (four; Figure 4.21), FER (five; Figure 4.15) and TOT (six; Figure 4.25). However, they each exhibited a large number of total interactions (at least nine) and, in the case of PACID, one oxygen in the PACID molecule formed three hydrogen bonds with the amino acids of the receptor. As a 
result, despite the lack of similarity between the docking positions of the above five molecules with that for $\mathrm{E}_{2}$, they potentially could still act in an oestrogenic manner.

It was anticipated that both $\mathrm{P}_{4}$ and TEST would bind in a comparable position to $\mathrm{E}_{2}$, mainly due to their similar structure. Despite this, both molecules were at an angle to the most favourable position predicted for $\mathrm{E}_{2}$, and were almost identical to each other (Figure 4.26 and Figure 4.28). This suggests that factors other than structure may depict the binding angle of ligands in the LBD of receptor molecules.

In all attempted docking simulations in this study, there were no observable interactions between the ligand and the amino acids specific to the ER- $\alpha$ sequence of New Zealand parrots. Nor were there any detected between the ligand and the residues in avian species that were different to the human receptor sequence. In a number of instances the residues unique to New Zealand parrots were directly alongside the amino acids involved in the binding of the ligand. For example both Leu346 and Thr347 appeared repeatedly to interact with the bound ligand and Ser348 is specific to New Zealand parrots. Despite the lack of direct interaction, the results provide evidence that these differences may influence the overall binding of compounds to Kākāpō ER- $\alpha$ primarily through slight changes in the three-dimensional folding of the protein.

Half of the compounds tested in this study exhibited hydrogen bonding with the residue Arg394. As stated previously, the absence of hydrogen bonding in some models could be due to the side-chain being rotated away from the position of the ligand. An alternative explanation is that it may be due to placement of the ligand; for example, the different angle/plane that the ligand is docked in means it is not in the optimal orientation for hydrogen bonding.

As most of the compounds tested had somewhat similar structures in terms of molecular weight, with the exception of BPA and TRI, and because a number are known to act in a similar manner to native oestrogens, it was assumed that they were all capable of entering the ligand binding pocket. Thus, in all the docking simulations presented in this study, initial co-ordinates for the ligand were given based on those for $E_{2}$ in $1 \mathrm{~A} 52$. This resulted in limiting the potential docking area to prevent unrealistic binding, such as to the outer face of the receptor. It would be beneficial to run similar simulations without providing co-ordinates already in the LBD region. This would give an indication of how good RosettaLigand was at 
predicting the binding site. However it would be worthwhile to firstly obtain the full sequence of Kākāpō ER- $\alpha$ prior to running these simulations.

One disadvantage of using the LigPlot software package to convey the potential hydrophobic interactions and hydrogen bonding between a ligand and the protein is that the representation is two-dimensional in comparison to the three-dimensional structures.

The in silico evidence suggests that as all the aforementioned ligands can be positioned within the LBD of the putative Kākāpō ER- $\alpha$, that these compounds would be potentially oestrogenic to $\mathrm{NZ}$ native parrots. However, without testing the compounds in an assay system that contained the Kākāpō ER- $\alpha$, their relative potencies compared to those in humans and other species remains uncertain.

\subsection{Summary}

The crystal structure of hER- $\alpha$ was altered to incorporate the LBD of Kākāpō ER- $\alpha$ (determined in Chapter 3) in it and docking studies undertaken with both the native ligand and other compounds to determine their respective binding site. The results of this computational modelling suggests that the amino acids unique to the ER- $\alpha$ LBD of New Zealand parrots not only alter the three-dimensional arrangement of the receptor backbone but also influence the binding position of $E_{2}$. The docking sites of other compounds differed to that for $E_{2}$ mainly due to differences in their chemical structure. This, in turn, is likely to affect their oestrogenicity. The results of computational modelling should be seen as an initial screen - in silico studies cannot currently replace experimentally determining the structure through crystallisation. However the preliminary results support further studies in terms of experimental work and specifically, assessments by bioassays involving the Kākāpō receptor. 


\section{CHAPTER 5: OPTIMISATION AND VALIDATION OF YEAST BIOASSAY}

\subsection{Introduction}

One of the major aims of this $\mathrm{PhD}$ project was to identify New Zealand native plant species that contain oestrogenic compounds that may influence the breeding of Kakapo. One reliable way to measure oestrogenic activity in plant samples is through utilising an appropriate bioassay. However, the appropriateness and repeatability of a bioassay must be validated prior to use.

The bioassay employed for measuring the level of oestrogenic activity in plant extracts utilised a strain of yeast (Saccharomyces cerevisiae) that had hER- $\alpha$ transfected into the genome. Therefore, compounds with oestrogen-like properties would be expected to bind to hER- $\alpha$ thereby leading to an interaction with the ERE present in the plasmid that had been transfected into the yeast. Incorporated into this construct downstream of the ERE was the Lac- $Z$ gene which, when activated, results in the production of $\beta$-galactosidase. In turn, this catalyses the cleavage of galactose from CPRG to CPR resulting in a colour change from yellow to red (a photo example is in Appendix 2 Supplementary Figure 2B).

Thus, the aims of this chapter were to:

i) optimise the conditions of the bioassay to enable the accurate measurement of oestrogenic compounds;

ii) verify the accuracy of the assay to measure oestrogenic compounds by testing both xenoestrogenic and phytoestrogenic compounds and;

iii) check the cross-reactivity of other closely related steroids. 


\subsection{Methodology}

The methodology used in validating the screen for detecting phytoestrogens in plant samples is described in detail in Chapter 2. In brief, extracts from soya bean (G. max), broccoli and cauliflower (different cultivars of $B$. oleracea), as well as commercially purchased $\mathrm{E}_{2}$, phytoestrogens (ferruginol, podocarpic acid and totarol), xenoestrogens, BPA and triclosan, and other steroids, $\mathrm{P}_{4}$ and testosterone, were tested in the bioassay.

Samples of soya bean (bean), broccoli (flowerheads and stalks) and cauliflower (flowerheads and stalks) were freeze-dried and then crushed using a glass tissue homogeniser. The extraction methods involved adding $2 \mathrm{~g}$ of freeze-dried soya bean, broccoli or cauliflower into $10 \mathrm{~mL}$ of ethanol, methanol or water. The samples were then put on a shaker (IKA Vibrax VXR basic) at $1500 \mathrm{rpm}$ for $18 \mathrm{~h}$. The extraction time for the soya bean and cauliflower samples was also extended to $36 \mathrm{~h}$ by extracting the plant sample for $18 \mathrm{~h}$ and then re-extracting the residue for a further $18 \mathrm{~h}$. A subsequent digestion of the soya bean and cauliflower methanol extracts (after removal of the solvent) with 100 units of cellulase in 0.1 $\mathrm{M}$ sodium acetate buffer was carried out at $37^{\circ} \mathrm{C}$ for $18 \mathrm{~h}$. For the initial cellulase digestions, the digested samples were divided into $1 \mathrm{~mL}$ aliquots and $400 \mu \mathrm{L}$ ethyl acetate was added. The aliquots were mixed well by repeated inversion and then centrifuged at $14,000 \mathrm{~g}$ for $1 \mathrm{~min}$. The upper (organic) layer was removed and the lower (aqueous) layer was re-extracted in a similar manner a further two times. The organic layers were combined and both organic and aqueous layers were stored at $\mathrm{rt}$.

The extracts and chemicals were serially diluted two-fold with methanol, aliquoted into 96 well plates (a total volume of $10 \mu \mathrm{L}$ in each well) and left to evaporate to dryness in a type II laminar flow hood. Each serial sample was prepared in triplicate. Once the samples had dried, $200 \mu \mathrm{L}$ of assay media (containing the yeast and CPRG) was added to each sample. Plates were incubated at $30^{\circ} \mathrm{C}$ for different time durations over 90 hours to determine the optimal incubation time. Within each well, cell growth was measured at a $620 \mathrm{~nm}$ wavelength and the colour change denoting the presence of an oestrogenic compound was initially measured from wavelengths of $350 \mathrm{~nm}$ to $670 \mathrm{~nm}$ (in $10 \mathrm{~nm}$ increments). 


\subsection{Results}

\subsubsection{Optimisation of Wavelength}

The data showing the absorbance wavelength at $10 \mathrm{~nm}$ increments proportional to that of cell growth $(620 \mathrm{~nm})$ plotted against the $\log$ concentration of an $\mathrm{E}_{2}$ standard is shown in Figure 5.1. The optimal wavelength defined as the wavelength that resulted in the highest absorbance ratio for each concentration of $E_{2}$ was $570 \mathrm{~nm}$ (shown in red). Thus the wavelength for assessing colour change hereafter was $570 \mathrm{~nm}$. Cell growth continued to be measured at the wavelength of $620 \mathrm{~nm}$.

To determine the oestrogenic content of a sample, the absorbance differences between Day 0 and the final day for both the $570 \mathrm{~nm}$ and $620 \mathrm{~nm}$ wavelengths were calculated to give the $570 \mathrm{~nm}$ : $620 \mathrm{~nm}$ ratio. This was then normalised to the ratio for the control group (methanol only). 


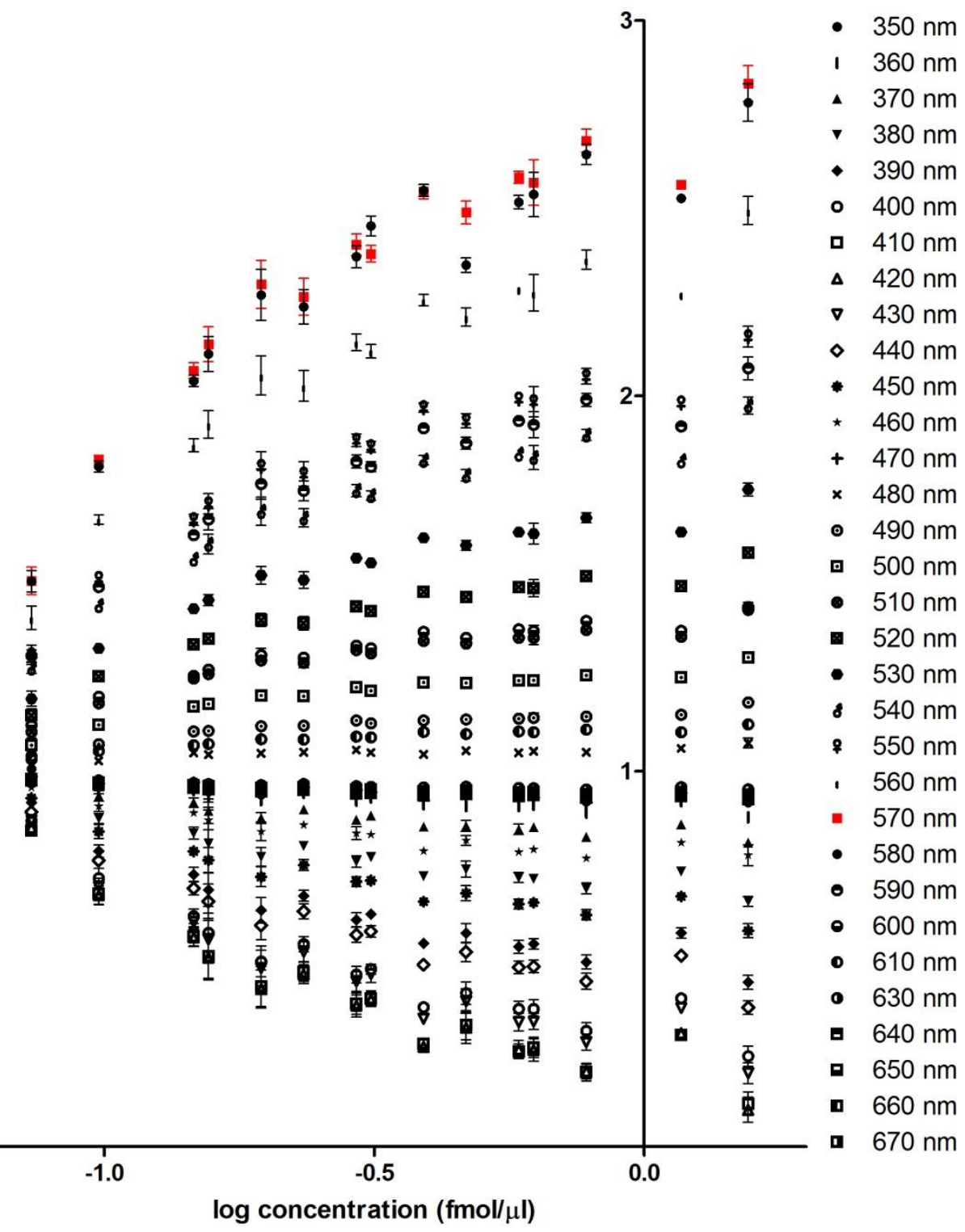

Figure 5.1 Standard curve for17ß-oestradiol $\left(E_{2}\right)$ at different wavelengths as measured by colorimetry in a yeast bioassay. The figure illustrates the $\log$ concentration of serially diluted $\mathrm{E}_{2}$ against the level of oestrogenic activity in the yeast hER- $\alpha$ assay measured at wavelengths between $350 \mathrm{~nm}$ and $670 \mathrm{~nm}$ (calculated as the difference in absorbance between Day 0 and Day 3 at a particular wavelength / difference in absorbance between Day 0 and Day 3 at $620 \mathrm{~nm}$ relative to the ratio of the control). The values for $570 \mathrm{~nm}$ are in red. The plotted values are the mean \pm SEM $(\mathrm{n}=3)$. 
5.3.2 Standard Curve Generation and Detection Limits of the Bioassay

A serial dilution of $E_{2}$ from $0.07 \mathrm{fmol} / \mu \mathrm{L}$ to $6.24 \mathrm{fmol} / \mu \mathrm{L}$ was used to generate a standard curve and to determine the lower and upper detection limits of the bioassay. Detection limits were defined as those concentrations that gave $10 \%$ and $90 \%$ of the maximal colour change (i.e. $10 \%$ and $90 \%$ of maximal $\beta$-galactosidase activity; $\mathrm{EC}_{10}$ and $\mathrm{EC}_{90}$ respectively). Using this criterion, the lower and upper detectable limits were determined to be $0.31 \mathrm{fmol} / \mu \mathrm{L}$ and $1.69 \mathrm{fmol} / \mu \mathrm{L}$ (Figure 5.2). Furthermore, the $\mathrm{E}_{2}$ concentration that resulted in $50 \%$ of the maximal activity of $\beta$-galactosidase (i.e. $\mathrm{EC}_{50}$ ) was $1.1 \mathrm{fmol} / \mu \mathrm{L}$.

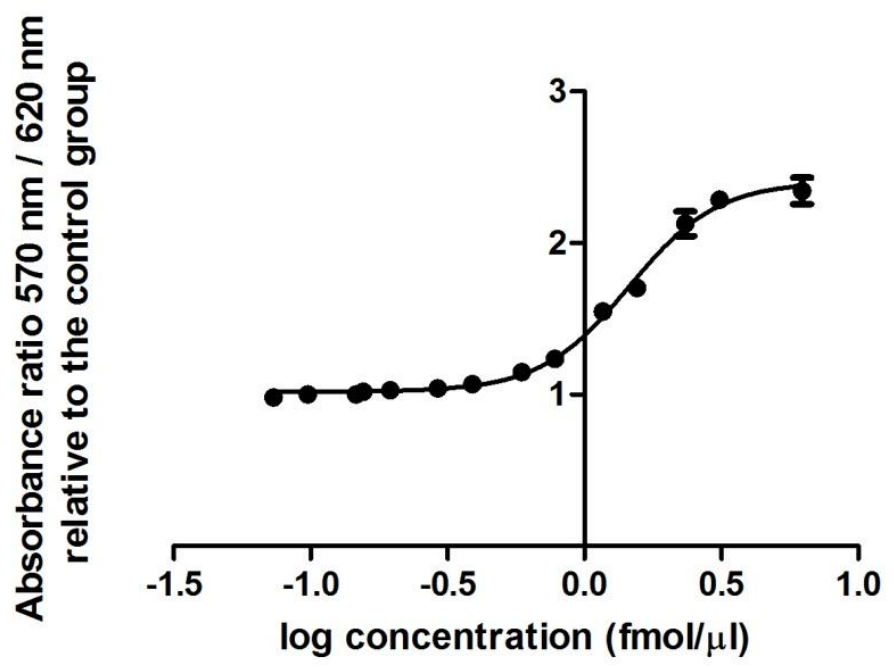

Figure 5.2 Representative standard curve for $17 \beta$-oestradiol $\left(E_{2}\right)$ as measured by colorimetry in the yeast bioassay. The figure illustrates the log concentration of serially diluted $\mathrm{E}_{2}$ against the level of oestrogenic activity in the yeast hER- $\alpha$ assay (calculated as the difference in absorbance between Day 0 and Day 3 at $570 \mathrm{~nm} /$ difference in absorbance between Day 0 and Day 3 at $620 \mathrm{~nm}$ relative to the ratio of the control). The plotted values are means \pm SEM $(\mathrm{n}=3)$.

\subsubsection{Optimisation of the Incubation Time of the Bioassay}

Following the addition of serially diluted $E_{2}$ from $0.07 \mathrm{fmol} / \mu \mathrm{L}$ to $3.12 \mathrm{fmol} / \mu \mathrm{L}$ to the bioassay, the duration of incubation time at the temperature of $30^{\circ} \mathrm{C}$ was tested by measuring differences in absorbances at multiple time points over four days (Figure 5.3). The optimal incubation time, defined as that which gave the most sensitive standard curve, was $72 \mathrm{~h}$. Whilst an incubation time of $90 \mathrm{~h}$ gave the highest absorbance level at a number of $\mathrm{E}_{2}$ concentrations, the concentration range was smaller as the absorbancy level had reached its maximum at a lower concentration of $\mathrm{E}_{2}$. 


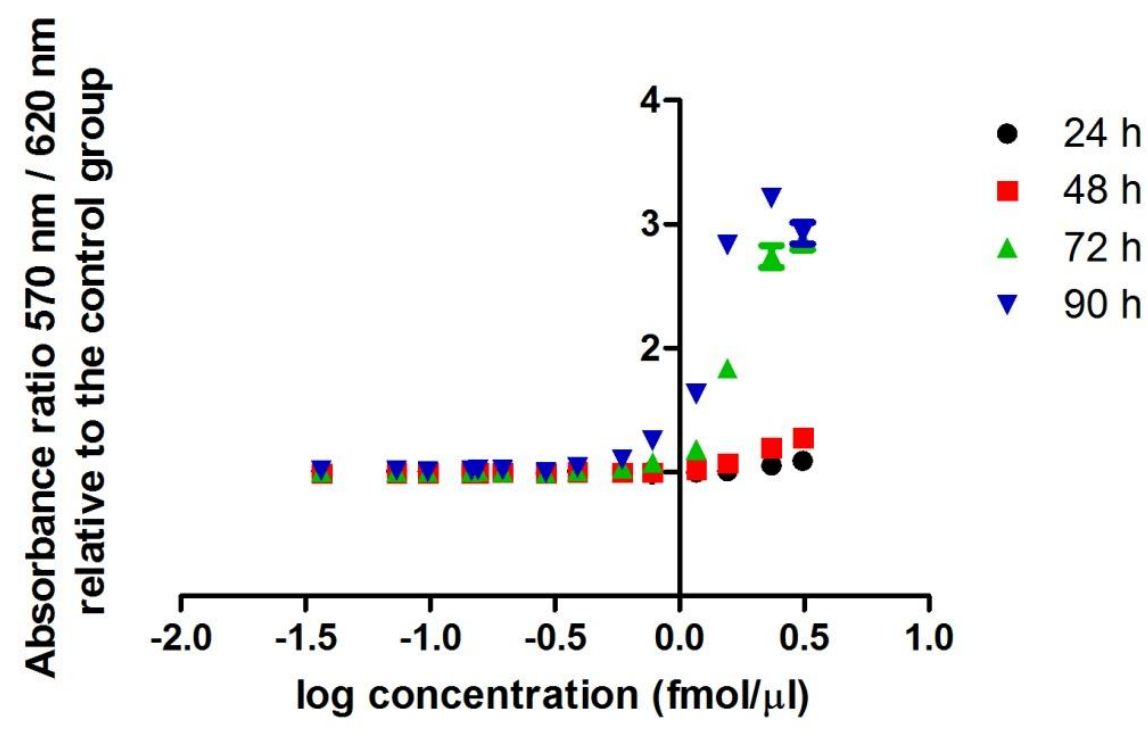

Figure 5.3 Representative standard curves for 17ß-oestradiol $\left(E_{2}\right)$ at different incubation time points as measured by colorimetry in the yeast bioassay. The figure illustrates the $\log$ concentration of serially diluted $\mathrm{E}_{2}$ against the level of oestrogenic activity in the yeast hER- $\alpha$ assay (calculated as the difference in absorbance ratio of $570 \mathrm{~nm} / 620 \mathrm{~nm}$ between the initial and final readings relative to that of the control) measured at $24 \mathrm{~h}(\bullet), 48 \mathrm{~h}(\boldsymbol{\square}), 72 \mathrm{~h}(\boldsymbol{\Delta})$ and $90 \mathrm{~h}(\boldsymbol{\nabla})$. The plotted values are the mean \pm SEM $(n=3)$; where SEM are not evident they are included within the area of the datapoints.

\subsubsection{Optimisation of the Phytoestrogen Extraction Protocol}

Samples of freeze-dried and crushed soya bean were used as positive controls to test three different sample extraction methods; namely ethanol, methanol and water extraction. Freeze-dried and crushed broccoli and cauliflower were tested for suitability as negative controls. Two-fold serial dilutions of soya bean, broccoli and cauliflower extracts were carried out to give a total of 12 samples for each extract per extraction method. For the purposes of comparing the different plant extracts, the most concentrated solution was given an arbitrary value of $1000 \mathrm{fmol} / \mu \mathrm{L}$.

The extraction solvent that resulted in a detectable colorimetric change with soya bean extracts, as measured by the yeast bioassay, was methanol (Figure 5.4). Conversely, no colorimetric change was detected in soya bean samples extracted using ethanol as the solvent. The water-extraction method (results not shown) was discarded as the broccoli sample reabsorbed the water meaning there was very little supernatant recovered for testing. Thus, an extract of soya bean became the positive control for each bioassay and methanol was used as the extraction solvent for the plant samples. 


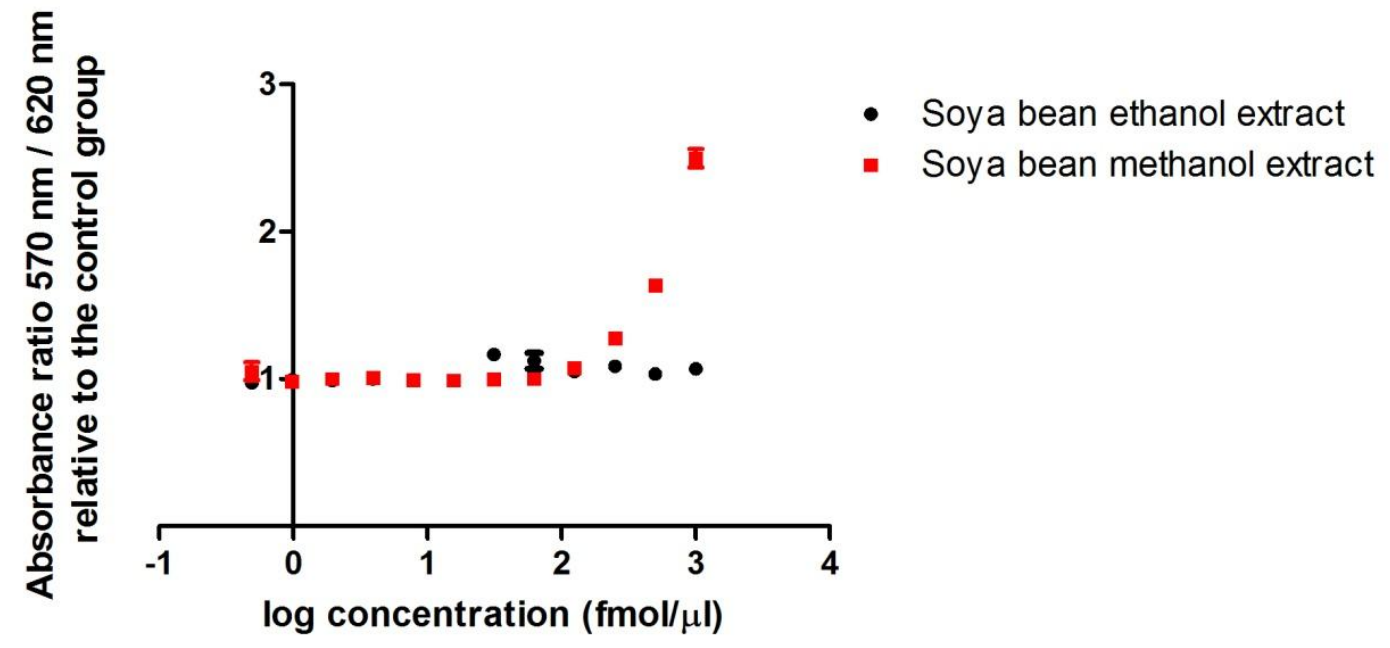

Figure 5.4 Representative standard curves for soya bean as measured by colorimetry in the yeast bioassay. The figure

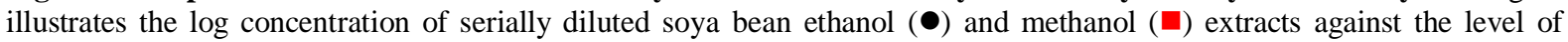
oestrogenic activity in the yeast hER- $\alpha$ assay (calculated as the absorbance ratio at $570 \mathrm{~nm} / 620 \mathrm{~nm}$ relative to the value for methanol alone). The most concentrated solution was assigned an arbitrary concentration of $1000 \mathrm{fmol} / \mu \mathrm{L}$. The plotted values are the mean $\pm \operatorname{SEM}(n=3)$; where SEM are not evident they are included within the area of the datapoints.

Surprisingly, both the methanol and ethanol extraction of broccoli gave a weak colorimetric change and therefore broccoli was found to be unsuitable as a negative control. In contrast, the methanol extraction of the cauliflower sample did not result in a colorimetric change, affirming its suitability as a negative control (Figure 5.5).

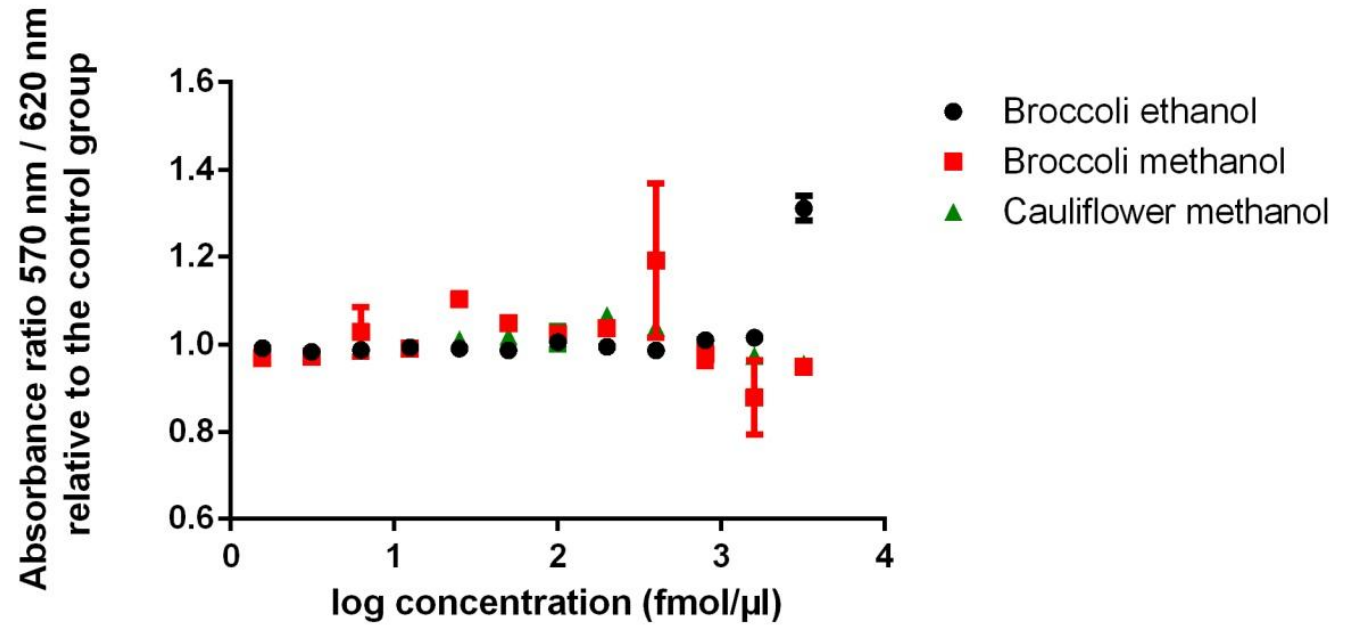

Figure 5.5 Representative standard curves for broccoli and cauliflower extracts as measured by colorimetry in the yeast bioassay for suitability as negative controls. The figure illustrates the log concentration of serially diluted broccoli extracted with ethanol $(\bullet)$ and with methanol $(\boldsymbol{\square})$ digestion, and of serially diluted cauliflower extracted with methanol $(\boldsymbol{\Delta})$ compared with the level of oestrogenic activity in the yeast hER- $\alpha$ assay (calculated as the absorbance ratio at $570 \mathrm{~nm} / 620$ $\mathrm{nm}$ relative to that of the control). The most concentrated solution was assigned an arbitrary concentration of $1000 \mathrm{fmol} / \mu \mathrm{L}$. The plotted values are the mean \pm SEM $(n=3)$; where SEM are not evident they are included within the area of the datapoints. 
The methanol extraction method was further investigated. As biological compounds are known to contain adducts such as sugars, a digestion of the methanol extracts with cellulase for $18 \mathrm{~h}$ was performed. The extract from the cellulase digestion had slightly greater activity than that of methanol-only (Figure 5.6). A subsequent ethyl acetate separation was employed to separate the glycones from the aglycones for both the soya bean and cauliflower extracts.

The fraction that was insoluble in ethyl acetate, and thought to contain sugars (termed the sugar fraction) resulted in very little colorimetric change. Thus, it was unlikely it was the sugars giving the oestrogenic activity.

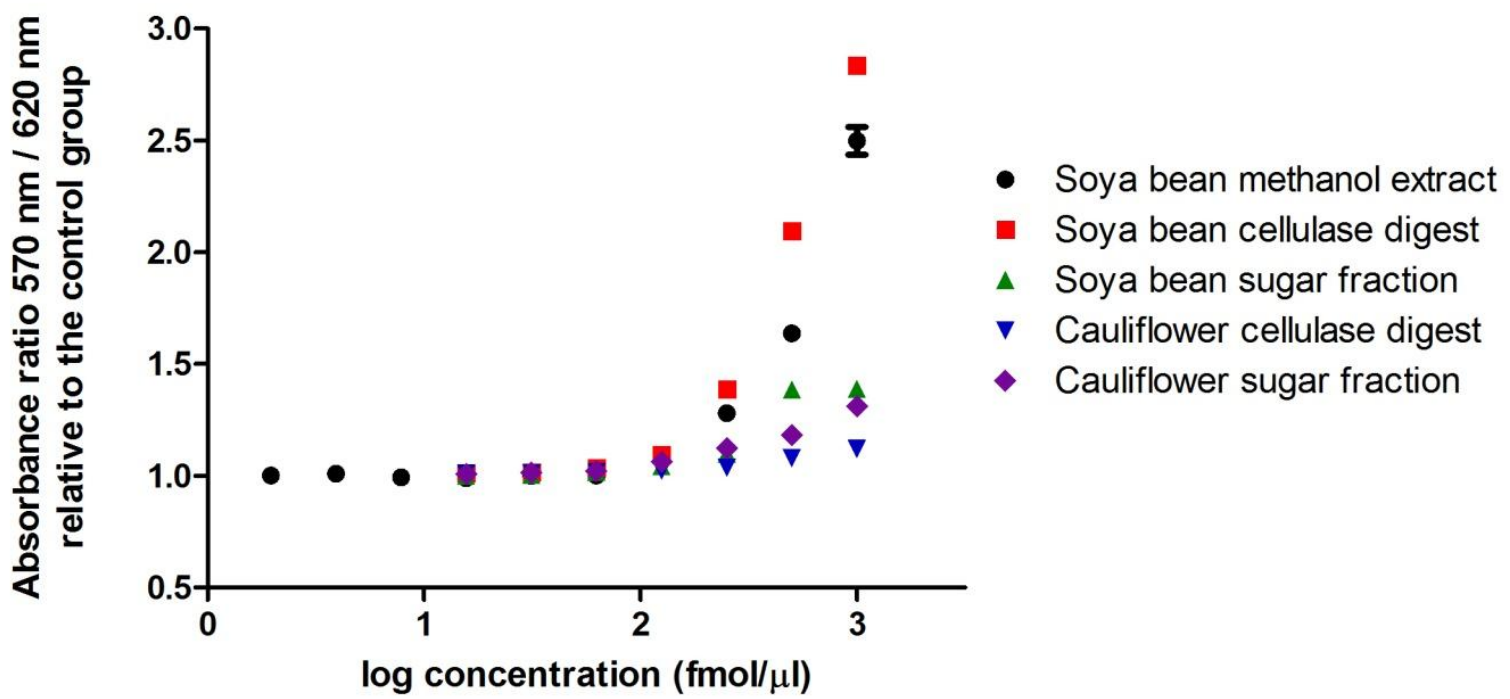

Figure 5.6 Representative standard curve of serially diluted soya bean and cauliflower (negative control) extracted by a methanol and cellulase digestion method and absorbance measured by colorimetry in the yeast bioassay. The figure illustrates the $\log$ concentration of serially diluted soya bean extracted with methanol $(\bullet)$, digested with cellulase ( $\square)$, and the sugar fraction $(\boldsymbol{\Delta})$, and of serially diluted cauliflower digested with cellulase $(\boldsymbol{\nabla})$ and of the sugar fraction $(\bullet)$ compared with the level of oestrogenic activity in the yeast hER- $\alpha$ assay (calculated as the absorbance ratio at $570 \mathrm{~nm} / 620 \mathrm{~nm}$ relative to that of the control). The most concentrated solution was assigned an arbitrary concentration of $1000 \mathrm{fmol} / \mu \mathrm{L}$. The plotted values are the mean \pm SEM $(n=3)$; where SEM are not evident they are included within the area of the datapoints.

Therefore, a methanol extraction followed by a cellulase digestion was the most effective extraction procedure. However, due to the uncertainty of the degree of glycoslyation in other plant species, both extraction methods were used.

\subsubsection{Optimisation of the Incubation Period for Extraction}

The optimal time taken to extract phytoestrogens from plant samples was tested by comparing extraction times of 18 and 36 hours. An extraction time of 18 hours was observed 
to result in the highest $570 \mathrm{~nm} / 620 \mathrm{~nm}$ absorbance ratio (Figure 5.7). Hence, an extraction period of 18 hours with methanol was employed for all of the plant samples as well as for the positive and negative controls.

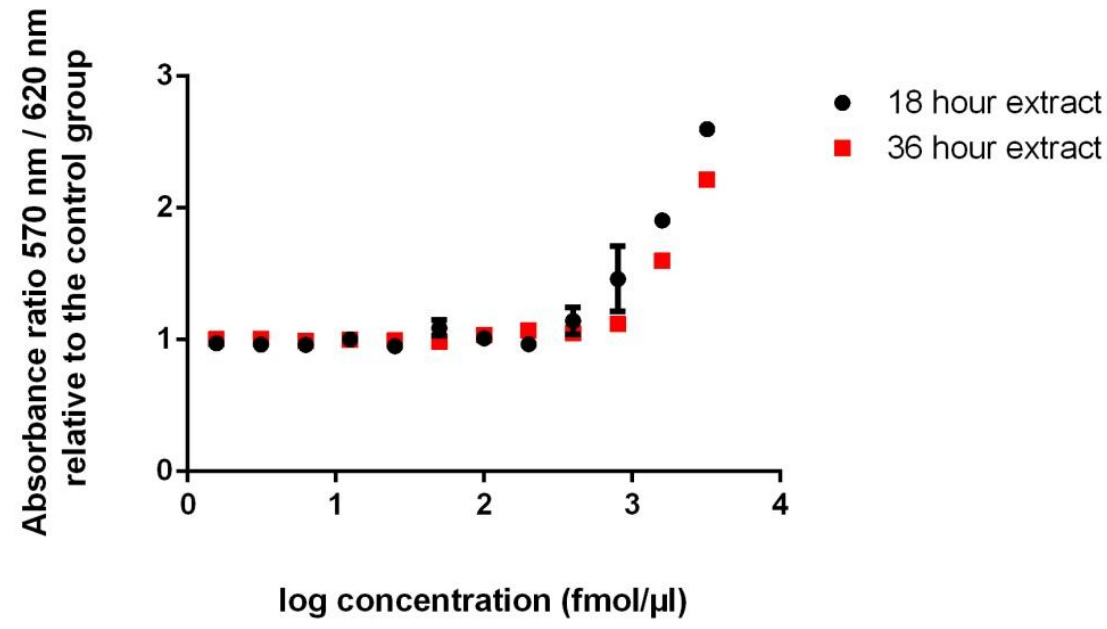

Figure 5.7 Representative standard curve of soya bean following an 18 and 36 hour extraction time as measured by colorimetry in the yeast bioassay. The figure illustrates the log of serially diluted soya bean extracted for $18 \mathrm{~h}(\bullet)$ and $36 \mathrm{~h}$ (匹) against the level of oestrogenic activity in the yeast hER- $\alpha$ assay (calculated as the absorbance ratio at $540 \mathrm{~nm} / 620 \mathrm{~nm}$ relative to the value for methanol alone). The soya bean had been extracted with methanol for 18 hours and was then re-extracted for a further 18 hours with methanol. The most concentrated solution was assigned an arbitrary concentration of $1000 \mathrm{fmol} / \mu \mathrm{L}$. The plotted values are the mean $\pm \mathrm{SEM}$.

\subsubsection{Validation of the Yeast Bioassay}

A bisphenol A (BPA) standard was serially diluted from $2.38 \mathrm{pmol} / \mu \mathrm{L}$ to $76 \mathrm{pmol} / \mu \mathrm{L}$ to generate a standard curve to test the ability of the bioassay to recognise a known xenoestrogen (Figure 5.8). The $\mathrm{EC}_{50}$ was estimated to be $20.0 \mathrm{pmol} / \mu \mathrm{L}$ (red dashed line). 


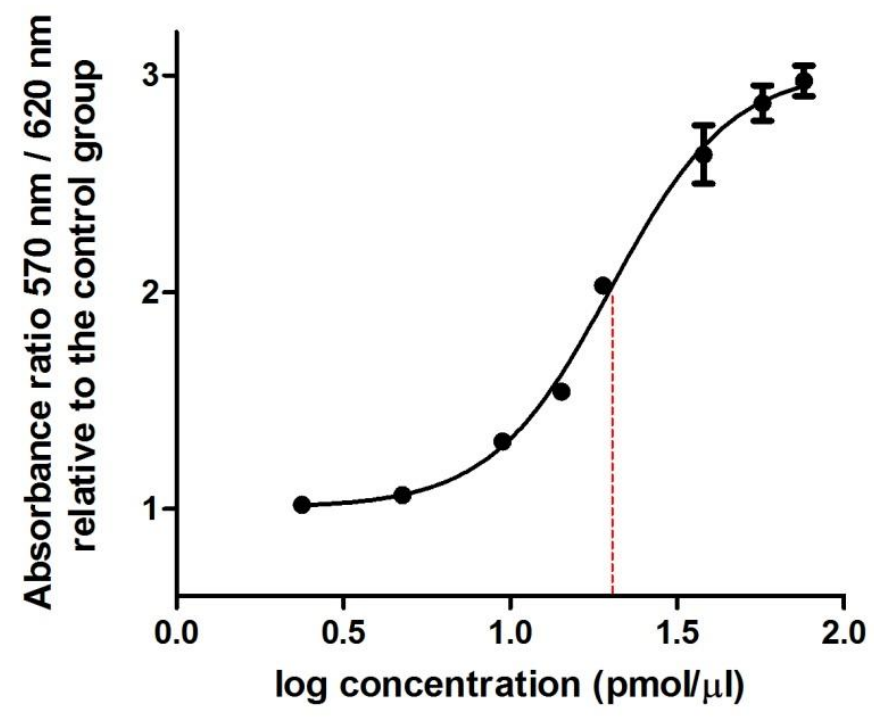

Figure 5.8 Representative standard curve for bisphenol A (BPA) as measured by colorimetry in the yeast bioassay. The figure illustrates the log concentration of serially diluted BPA against the level of oestrogenic activity in the yeast hER- $\alpha$ assay (calculated as the difference in absorbance ratio of $570 \mathrm{~nm} / 620 \mathrm{~nm}$ between Day 0 and Day 3 relative to that of the control). The plotted values are the mean $\pm \operatorname{SEM}(n=3)$.

Serial dilutions of soya bean and BPA extracts were measured for parallelism compared to the $E_{2}$ standard curve. The linear sections of the plot for both dilutions were parallel to the linear section of the $\mathrm{E}_{2}$ standard curve (Figure 5.9). The correlation co-efficients ( $\mathrm{R}^{2}$ values) for each of the curves were all $>0.95 \%$ indicating that the regression lines that were generated fitted the data well. Moreover, the slopes of the regression lines were found not to be different from one another. 


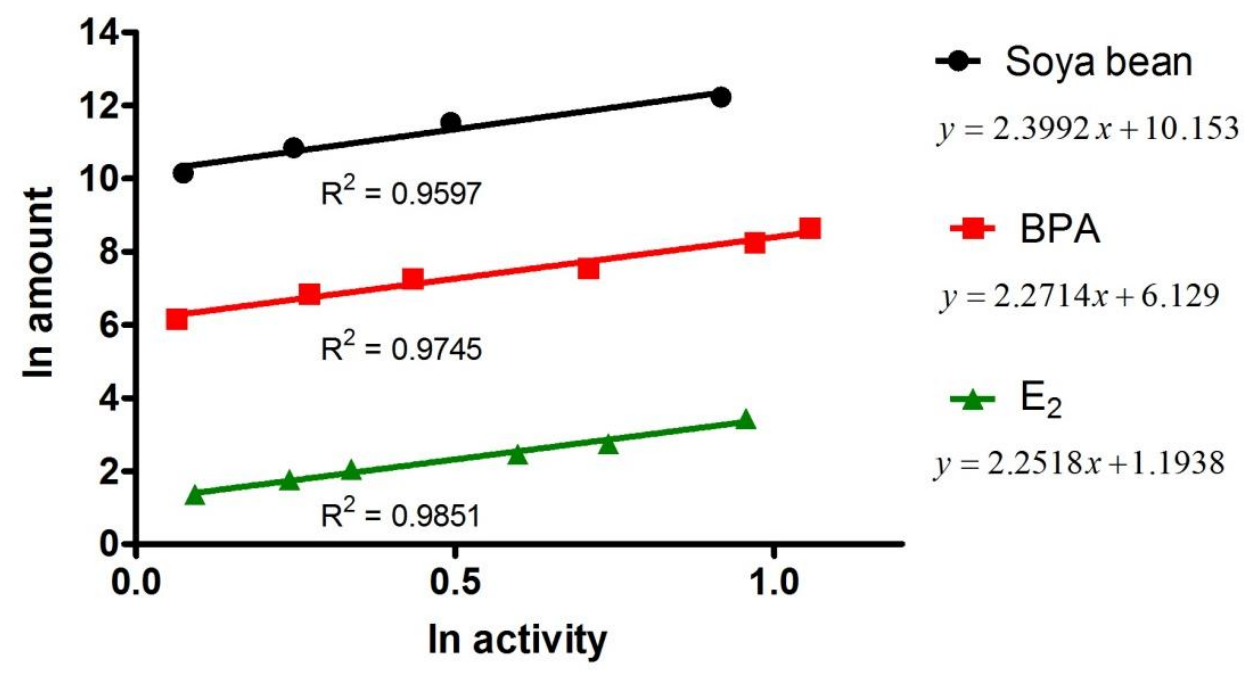

Figure 5.9 Relationship of the natural logarithm (ln) of quantity to the natural logarithm of activity of soya bean, BPA and $E_{2}$.

The intra-assay coefficient of variation for a high (soya bean) control was $9.4 \%$ and the inter-assay coefficient of variation for a high (soya bean) control was $10.2 \%$.

The sensitivity of the assay defined as twice the standard deviation of the zero standard was determined from assessing all the data points obtained for methanol-only samples from soya bean and was found to be $0.024(\mathrm{fmol} / \mu \mathrm{L})$.

Serial dilutions of progesterone and testosterone to test for cross-reactivity in the yeast bioassay resulted in no colorimetric change at any of the concentrations tested (Figure 5.10). Moreover, no colourimetric change was detected for ferruginol, or triclosan at concentrations of $8.8-500$ and $3.9-250 \mathrm{nmol} / \mu \mathrm{L}$ respectively. However, colourimetric changes were recorded for podocarpic acid at $1.56-12.5 \mathrm{nmol} / \mu \mathrm{L}$ and a slight colourimetric change for totarol at $128 \mu \mathrm{mol} / \mu \mathrm{L}$. 


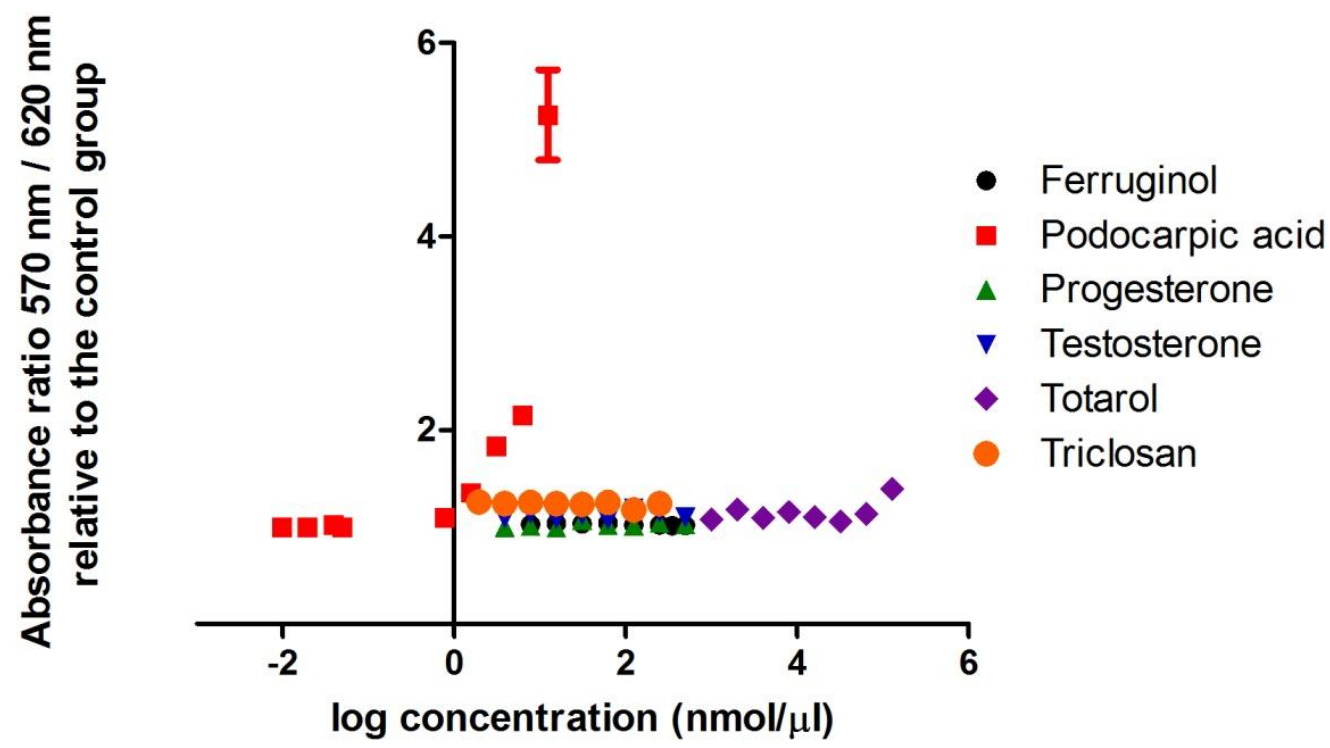

Figure 5.10 Standard curves for hormones and known oestrogens as measured by colorimetry in the yeast bioassay. The figure illustrates the $\log$ concentration of serially diluted ferruginol $(\bullet)$, podocarpic acid $(\boldsymbol{\square})$, progesterone $(\boldsymbol{\Delta})$, testosterone $(\boldsymbol{\nabla})$, totarol $(\diamond)$ and triclosan $(\bullet)$ against the level of oestrogenic activity in the yeast hER- $\alpha$ assay (calculated as the difference in absorbance ratio of $570 \mathrm{~nm} / 620 \mathrm{~nm}$ between Day 0 and Day 3 relative to that of the control). The plotted values are the mean \pm SEM $(n=3)$; where SEM are not evident they are included within the area of the datapoints.

Interestingly, triclosan exhibited high anti-microbial properties as represented by the low absorbancy values at $620 \mathrm{~nm}$ (data not shown).

\subsection{Discussion}

In summary, this study reports the successful optimisation and validation of an adapted and previously published yeast bioassay that utilises an ER- $\alpha$ reporter system (Routledge and Sumpter 1996). The bioassay described in this study produced detection limits for $\mathrm{E}_{2}$ at a concentration range of 0.31 and $1.69 \mathrm{fmol} / \mu \mathrm{L}$. The sensitivity of the assay was determined to be $0.024 \mathrm{fmol} / \mu \mathrm{L}$. The optimal extraction time for the plant samples in $10 \mathrm{~mL}$ of methanol was 18 hours and the incubation time for the optimal colorimetric change in the bioassay was 72 hours. No cross-reactivity of progesterone or testosterone was observed.

As this bioassay involves a colorimetric change that is dependent not only on the binding of oestrogenic compounds to the transfected ER- $\alpha$ but also on yeast proliferation, an optimal incubation time of 72 hours was determined. This incubation period involved shaking the 
plates for 2 minutes every 24 hours. After 72 hours of incubation, both the rate of colour change and cell growth decreased.

Serial dilutions of methanol-extracted soya bean and of the combination of methanol-extracted and cellulase-assisted digestion of soya bean were used to create a standard curve of oestrogenic activity. The assay successfully demonstrated that responsiveness was proportional to the amount of soya bean present for both types of extracts. However it was found that by digesting the extract with cellulase, the activity generated in the bioassay increased slightly. Cellulase is capable of cleaving sugar moieties (Swiss Institute of Bioinformatics 2008) and so this change in activity suggests that glycosylation modifications are present on some plant compounds that exhibit oestrogenic activity and that by removing the sugars, the solubility of the product in methanol is increased or the original compound is the precursor to a more "active" compound. This could mean that in a biological system, such as the gut of Kākāpō, sugar cleavage occurs to release the oestrogenic compound.

Two other solvents tested for the extraction of oestrogenic compounds from botanical material were ethanol and water. In the case of ethanol, there was no detectable activity. Water was discarded as a potential solvent as plants such as freeze-dried broccoli absorbed the liquid so that no supernatant could be successfully removed. Therefore, methanol was the only successful solvent tested using this extraction method.

Freeze-drying was used to prepare the plant samples as it made the plant material easier to grind into a fine powder. This was advantageous as it allowed maximum surface area for the solvent extraction. Dehydrating the legumes rapidly with this method also decreased the possibility of degradation of the compounds present in the foliage. For sample extraction, the plant grounds were shaken with solvent for 18 hours. This time period was found to be optimal because when the sample that had been previously extracted for 18 hours was then re-extracted for a further 18 hours with another $10 \mathrm{~mL}$ of solvent, the level of activity of the extract had decreased suggesting that the majority of biologically active compounds were in the methanol after 18 hours (Figure 5.7). However, as the second extract did exhibit some activity, albeit at low levels, it might have been advantageous to combine both extracts to increase the total phytoestrogens present. This would perhaps have extended the detectable range on concentrations of the various plant extracts. 
In this study, two plants were tested for suitability of use as a negative control. Cauliflower was determined to have no detectable level of activity after either methanol extraction or cellulase digestion. Broccoli showed a weak measurable change in absorbance and thus was deemed unsuitable as a negative control. This concurs with studies that have found high levels of flavonols in broccoli and isolated compounds such as quercetin (Hertog, Hollman et al. 1992; Mazur and Adlercreutz 1998).

A number of different compounds with known oestrogenic activity were tested in the assay to determine whether similar responses were evident notwithstanding variations in their potencies. That is, standard curves were generated for $\mathrm{E}_{2}, \mathrm{BPA}$ and soya bean and the linear regions of these curves compared. These were found to be parallel (Figure 5.9) thus confirming that the assay performed similarly regardless of the level of activity. This also demonstrated that the receptor binding and downstream effects were not altered by the type of compound present i.e. whether it was a native ligand, a synthetic oestrogen or a phytoestrogen.

A potential drawback of using an isolated system to model a biological pathway is the potential for false positives to be present in the bioassay that would not have oestrogenic activity in the natural system. For this reason, progesterone and testosterone, which are both similar in structure to $E_{2}$ and produced in the same biosynthetic pathway, were serially diluted and tested in the yeast assay. Neither compounds resulted in significant activity in the bioassay (Figure 5.10) demonstrating that there was no cross-reactivity with similar steroid structures in the assay.

Phytoestrogens that have been shown to exhibit oestrogenic activity previously were serially diluted and tested with the modified yeast assay method developed herein. These included ferruginol and podocarpic acid (Brandt 1952; Bennett and Cambie 1967; Cox, Yamamoto et al. 2007). The synthetic xenoestrogen, triclosan was also tested. The purpose of these tests was to assess whether activity observed with the yeast bioassay was consistent with the published data. The finding that podocarpic acid was an active compound was consistent with that shown in an earlier study (Fidler, Zwart et al. 2000). Previously, triclosan has been found to be a weakly oestrogenic compound (Gee, Charles et al. 2008), whilst in this study it was found to exhibit no activity. However, this could be attributed to the ability of triclosan to inhibit the yeast growth (McMurry, Oethinger et al. 1998) as was seen in this assay. 
Various methods have been employed by researchers to assess compounds for steroidogenic activity. The assay employed in this study was adapted from that published by Routledge and Sumpter (1996) where it was utilised to detect the oestrogenic activity of surfactants and their related products (Routledge and Sumpter 1996). The dilution range of $\mathrm{E}_{2}$ that was reported to cause a colourimetric change in this bioassay was $0.55 \mathrm{amol} / \mu \mathrm{L}$ to $0.56 \mathrm{fmol} / \mu \mathrm{L}$. This concentration range is slightly more sensitive than that in this study. The dilution range that elicited a response for the present study was 0.07 to $6.24 \mathrm{fmol} / \mu \mathrm{L}$ and the detection limit of $0.31 \mathrm{fmol} / \mu \mathrm{L}$ and $1.69 \mathrm{fmol} / \mu \mathrm{L}$. However, this comparison does not take into account that the data presented in this study is the absorbance ratio of 570/620 nm whereas in the surfactant study the absorbance levels at $540 \mathrm{~nm}$ were plotted directly and cell growth/death was not accounted for. The initial study also used absorbances at $540 \mathrm{~nm}$ whereas in this study the wavelength of $570 \mathrm{~nm}$ was employed. Although $540 \mathrm{~nm}$ was tested in this study, it was shown that $570 \mathrm{~nm}$ gave a higher reading.

In another study using this yeast bioassay, a detection limit or sensitivity was reported to be $1.3 \mathrm{amol} / \mu \mathrm{L}$ (Fidler, Zwart et al. 2000). This was similar but slightly less sensitive than that in the Routledge and Sumpter study. This emphasises the variability present when an assay employing living organisms is used. This variability could be caused, at least partly, by the different wavelength used for measuring the colour change. Also, the detection limit in the Fidler et al. study was determined by subtracting the absorbance at $620 \mathrm{~nm}$ from that at $540 \mathrm{~nm}$.

With an assay such as this one, it is imperative that the detection of "oestrogens" is not limited to native ligands of ER- $\alpha$. The purpose of the assay in this study was to detect phytoestrogens present in native plant material. The compounds present in soya bean with oestrogenic activity have been well-characterised and so this legume was an ideal candidate to test as a positive control.

\subsection{Summary}

This chapter reports the optimisation and validation of a yeast to measure extracts of plant samples for oestrogenic activity. For this bioassay, the optimal wavelength for measuring the colorimetric change was $570 \mathrm{~nm}$, the optimal time for extracting oestrogenic compounds from plant samples using methanol was 18 hours followed by a further cellulase digestion 
and the optimal incubation time was 72 hours. The lower and upper detectable limits of $\mathrm{E}_{2}$ were $0.31 \mathrm{fmol} / \mu \mathrm{L}$ and $1.69 \mathrm{fmol} / \mu \mathrm{L}$, respectively. Soya bean exhibited high levels of oestrogenic activity and hence is a suitable positive control. On the other hand, cauliflower had no detectable oestrogenic activity and thus is suitable for use as a negative control. No cross-reactivity was detected for closely-related steroid compounds (progesterone and testosterone). Only compounds of known oestrogenic activity (BPA, podocarpic acid) showed positive oestrogenic activity whilst those with little or no known oestrogenic activity (i.e. triclosan, ferruginol, and totarol) did not. 


\section{CHAPTER 6: OESTROGENIC ACTIVITY OF NATIVE NEW ZEALAND PLANTS}

\subsection{Introduction}

Oestrogens play an integral role in reproduction, both in the development and maintenance of the reproductive system. There are three major natural oestrogens produced in animals, $E_{1}, E_{2}$ and $E_{3}$, but there also a number of other compounds (xenoestrogens) both synthetic and naturally-occurring, that exhibit activity in much the same way.

Phytoestrogens are naturally-occurring compounds that have been detected in many plant species that can function in a similar manner as oestrogenic hormones. Their mainly phenolic chemical structure is such that they are capable of passing through cellular membranes such as intestinal epithelial cells and the placenta (Degen, Janning et al. 2002; Tsao, Papadopoulos et al. 2006) and binding to both ER- $\alpha$ and ER- $\beta$ (Nikov, Hopkins et al. 2000; Morito, Hirose et al. 2001). In many cases, there is selectivity over which ER isoform a particular phytoestrogen has increased affinity towards. For example, coumestrol, daidzein and genistein all bind with greater affinity to the $\beta$ isoform (Kuiper, Lemmen et al. 1998; Mueller, Simon et al. 2004; Harris, Besselink et al. 2005).

There is also variation in the distribution of phytoestrogens within a plant. An increased presence of isoflavones was detected in the leaves of red clover (Trifolium pratense) when compared to the other parts of the plant (Booth, Overk et al. 2006; Tsao, Papadopoulos et al. 2006). Booth also observed a seasonal variation in the levels of isoflavones.

A number of studies of the phytoestrogenic content of native New Zealand plants have been reported. Examples of these include Kahikatea (Dacrycarpus dacrydioides) which contains podocarpic acid at low levels (0.3\%) as well as ferruginol (Briggs and Cebalo 1959) and seven New Zealand native Podocarpus species which contain a number of phytoestrogens including ferruginol, genistein, podocarpic acid and totarol (Briggs and Cebalo 1959; Bennett and Cambie 1967).

The aim of this study was to utilise the bioassay involving yeast transfected with hER- $\alpha$ to: 
i) assess the level of oestrogenic activity present in extracts isolated from different segments of New Zealand native plants and;

ii) determine whether there was seasonal and/or between sample variation in this activity.

\subsection{Methodology}

Full details of the methodology used for testing New Zealand native plants for oestrogenic activities are outlined in the Materials and Methodology section (Chapter 2.24-2.26.5).

In brief, samples from ten different native plant species were collected at different time points over a five year period as outlined in Appendix 2 Supplementary Table 2A-2C. These species were B. novea-zelandiae, C. robusta, D. cupressinum, D. longifolium, G. procera, L. juniperina, L. scoparium, N. solandri, P. cunninghamii and P. ferruginea and consisted of leaves, fine sticks, fruit, seeds, flower stems and spores. A further 11 species were collected at a single time point and included leaves, fine sticks, fruit, seeds, flower stems and spores.

The plant samples were freeze-dried and a known weight of up to $2 \mathrm{~g}$ of each material was ground to a fine powder. Each powder was then combined with $10 \mathrm{~mL}$ methanol, sonicated for $15 \mathrm{~min}$ and then shaken $(250 \mathrm{rpm})$ at $\mathrm{rt}$ for $18 \mathrm{~h}$. The fruit, seeds and spore samples were extracted separately to the other parts of the plant and, in most cases, the quantities available were less than $2 \mathrm{~g}$. The methanol was then removed by rotary evaporation and a subsequent digestion of the extract with cellulase in $0.1 \mathrm{M}$ sodium acetate buffer was carried out at $37^{\circ} \mathrm{C}$ for $18 \mathrm{~h}$. The sample ID assigned to each plant extract is listed in Appendix 2 Supplementary Table $2 \mathrm{~B}$ and $2 \mathrm{C}$.

The extracts were serially diluted two-fold with methanol in 96 well plates starting with the initial extract to give a total of three or four different concentrations (equivalent to $10 \mu \mathrm{L}$, $5 \mu \mathrm{L}, 2.5 \mu \mathrm{L}$ and $1.25 \mu \mathrm{L}$ of initial methanol extract). These were left in a type II laminar hood for the methanol to evaporate to dryness and then $200 \mu \mathrm{L}$ of the assay media was added to each well. The plate was shaken for $2 \mathrm{~min}$ at $850 \mathrm{rpm}$, the absorbance at $570 \mathrm{~nm}$ and $620 \mathrm{~nm}$ measured, and then incubated for $72 \mathrm{~h}$ at $30^{\circ} \mathrm{C}$ (with periodic shaking at $24 \mathrm{~h}$ intervals). The absorbances at $570 \mathrm{~nm}$ and $620 \mathrm{~nm}$ were then measured again (at $72 \mathrm{~h}$ ) and the oestrogenic activity for each plant extract calculated in terms of the equivalent $E_{2}$ amount (fmol) that gave the same level of activity as described in Chapter 2 (2.26.5). 
Extracts that had activity values that fell between the $10 \%$ and $90 \%$ confidence intervals for the serially diluted $17 \beta$-oestradiol $\left(\mathrm{E}_{2}\right)$ standard curve in the bioassay were considered to be "active". These were then expressed in terms of moles of equivalent $E_{2}$. Methanol extracts are referred to as $-\mathrm{M}$ and the extracts with methanol and a cellulase digestion are -MC. When graphed, those extracts originating from leaf samples are outline symbols and those for fruit, seeds, fertile fronds or flower stems are coloured-in symbols.

\subsection{Results}

\subsubsection{Seasonal Variation in Activity of Native New Zealand Plants}

Ten New Zealand plants that were collected at different time points were extracted with methanol only or also digested with cellulase as well. These extracts were then tested at three or four different concentrations in the yeast bioassay. Regardless of the extraction method used, the extract tested was crude and so contained organic material. Preliminary results suggested that, over the concentrations tested, dose-response curves were not present for many of the samples. Therefore, the results of the assay shown below only indicate when oestrogenic activity was detected for $10 \mu \mathrm{L}$ of extract (unless stated otherwise). Each sample dilution was tested in triplicate, although in some cases the error is too small to be visible on the graph.

\subsubsection{Dacrydium cupressinum (Rimu)}

For D. cupressinum, there were a total of five extracts out of the 14 tested that exhibited detectable oestrogenic activity with the yeast bioassay (Figure 6.1). For the DCK-M extracts, this activity was detectable in the samples collected in July 2010 and July 2012; for the DCK-MC extracts the activity was measurable in the samples collected in December 2010 and March 2011. Finally, the unripe Rimu fruit (DCFC) collected from Codfish Island in December 2010, the -MC extract showed a low level of activity at $5 \mu 1$. 


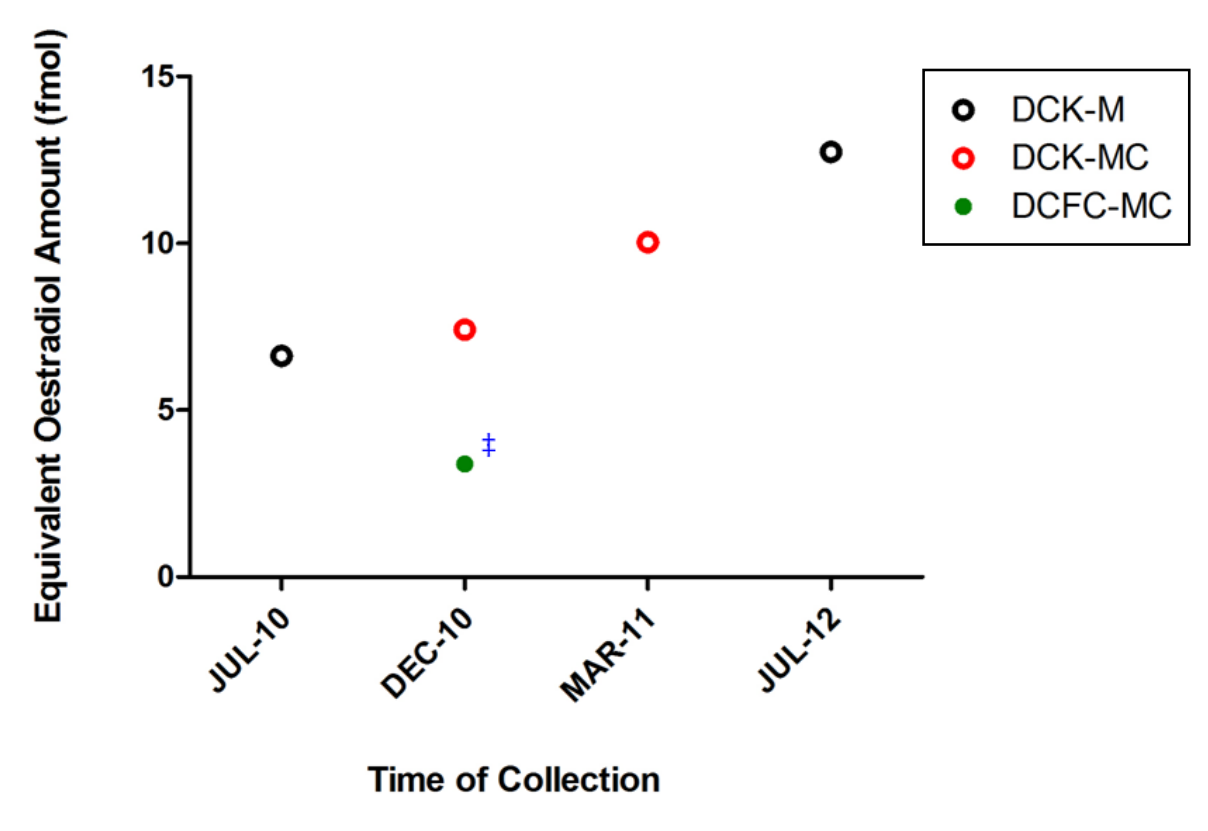

Figure 6.1 Response of the yeast bioassay to extracts of $\boldsymbol{D}$. cupressinum. Oestrogenic activity detected in $10 \mu \mathrm{L}$ of extracts DCK-M (O), DCK-MC (O) and $5 \mu \mathrm{L}$ of DCFC-MC ( $\bullet$ ) (denoted by a $\vdots$ ) of D. cupressinum collected during different seasons was measured and expressed as equivalent oestradiol amount (fmol). Each data point represents the mean of 2-3 replicates in the same assay.

Between May 2007 and February 2008, D. cupressinum fruit at various stages of maturity was collected from "Tree 1" (DCFC-T1-) and "Tree 18" (DCFC-T18-) on Codfish Island. DCFC-S- samples were from the collection of fruit (serial collection) from a number of trees over the same period of time that were pooled together. Activity was observed in the -MC extracts of DCFC-T18-NOV07, -9JAN08, -21JAN08, -6FEB08, -FEB08 and all of the DCFC-S- samples (Figure 6.2). None of the -M extracts or any of the DCFC-T1- samples exhibited any detectable activity. 


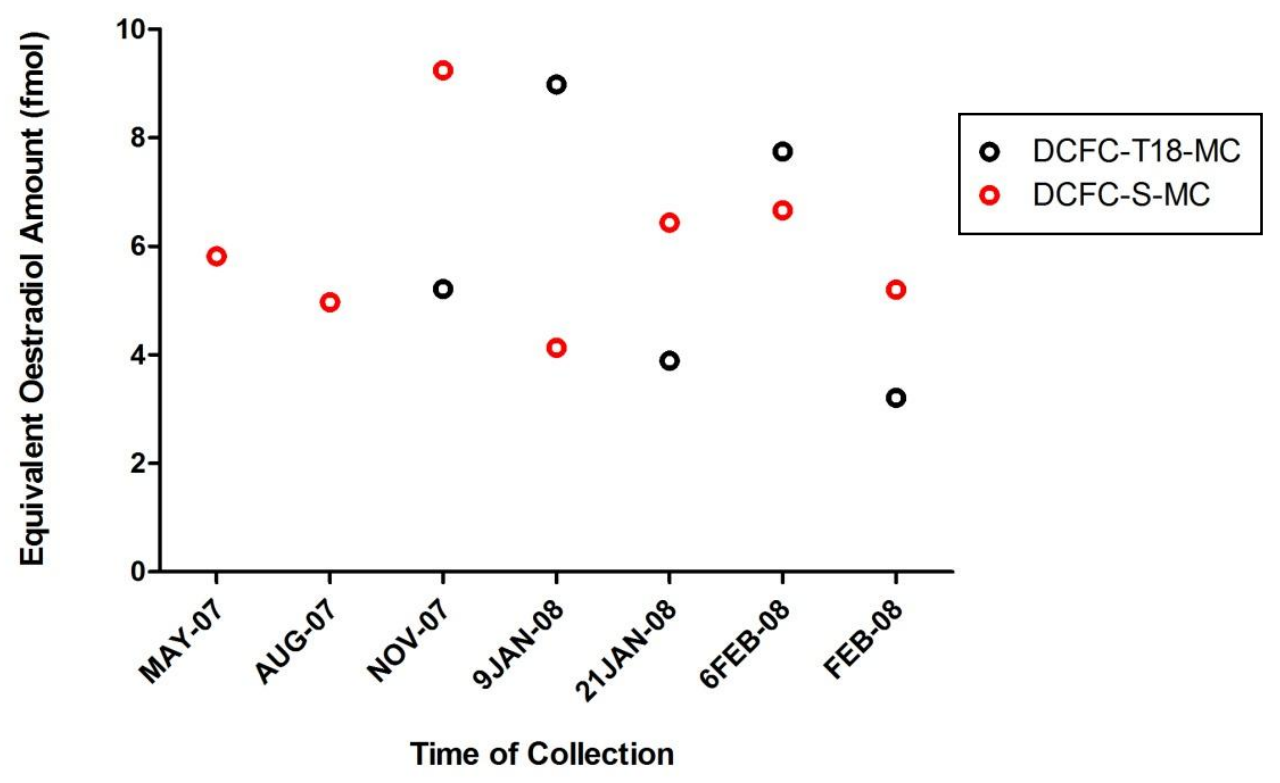

Figure 6.2 Response of the yeast bioassay to fruit extracts of $D$. cupressinum from 2007-2008. Oestrogenic activity detected in $10 \mu \mathrm{L}$ of extracts DCFC-T18-MC (O) and DCFC-S-MC (O) of D. cupressinum collected during 2007-2008 was measured and expressed as equivalent oestradiol amount (fmol). Each data point represents the mean of 2-3 replicates in the same assay.

\subsubsection{Blechnum novae-zelandiae (Kiokio)}

For B. novae-zelandiae there were a total of 14 extracts from five different collection times that were tested. All samples were frond specimens except for BNFF-M and -MC which were fertile fronds with spores. Of these, nine extracts from five different collection times had detectable activity (Figure 6.3).

For the BN-MC extracts, activity was observed at all five time points. The greatest level of activity was seen in the sample from December 2010 with those from April 2009, March 2011 and July 2012 having very similar activity profiles. BN-M only exhibited activity from the July 2010 and July 2012 samples. In the case of the fertile frond samples (BNFF) both the -M and -MC extracts from July 2010 had activity, although this was greater for the -M extract. 


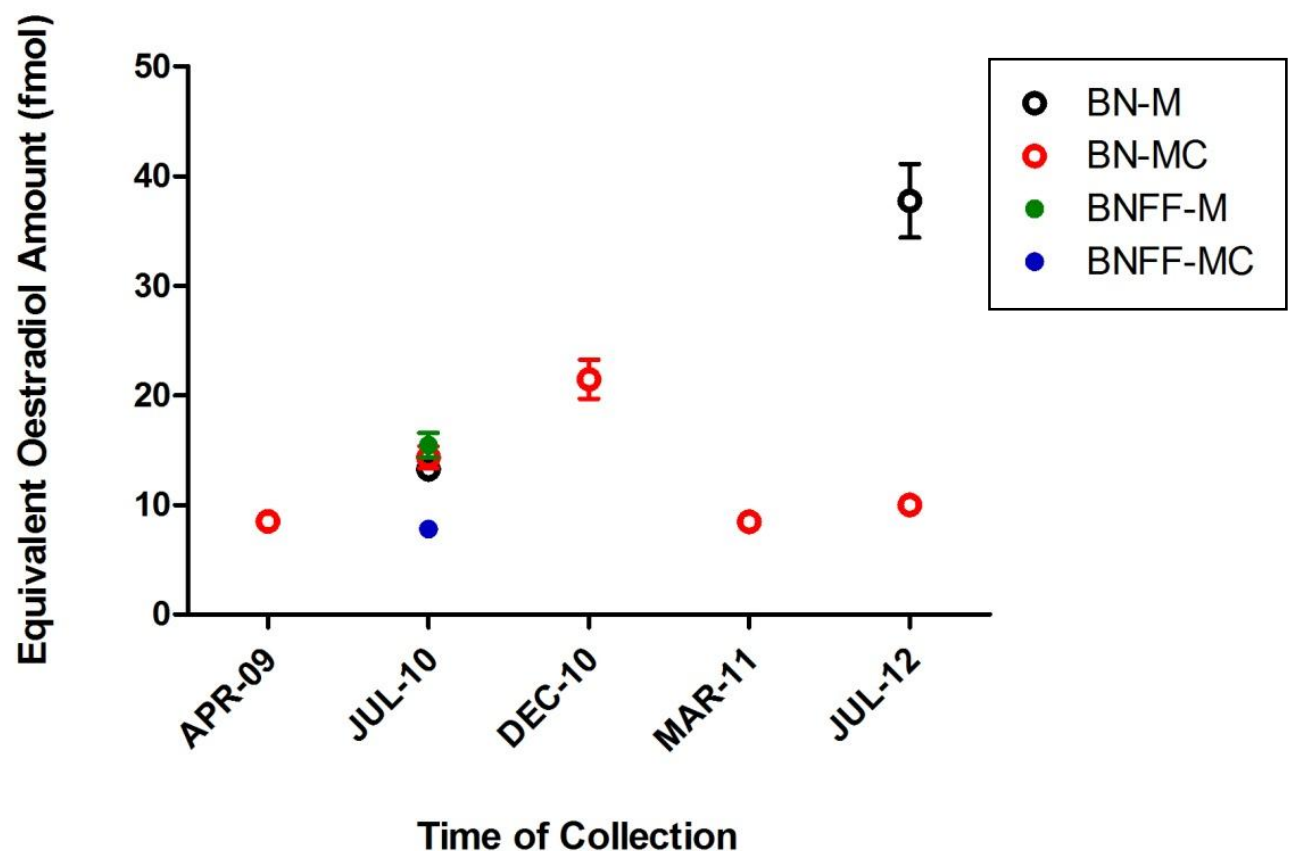

Figure 6.3 Response of the yeast bioassay to extracts of B. nova-zelandiae. Oestrogenic activity detected in $10 \mu \mathrm{L}$ of extracts BN-M (O), BN-MC (O), BNFF-M (•), and BNFF-MC $(\bullet)$ of B. nova-zelandiae collected during different seasons was measured and expressed as equivalent oestradiol amount (fmol). Each data point represents the mean of 2-3 replicates in the same assay.

\subsubsection{Coprosma robusta (Karamu)}

For $C$. robusta, there was a total of 14 extracts from four different collection times screened. Of these, five extracts from three different collection times exhibited detectable activity (Figure 6.4). The CR-M extract only exhibited activity in the sample from July 2012 whereas CR-MC had activity in the sample collected in July 2010, March 2011 and July 2012. Finally, the -MC extract from C. robusta berries (CRF-MC) collected in July 2012 showed 3 fmol of activity at $10 \mu \mathrm{L}$. 


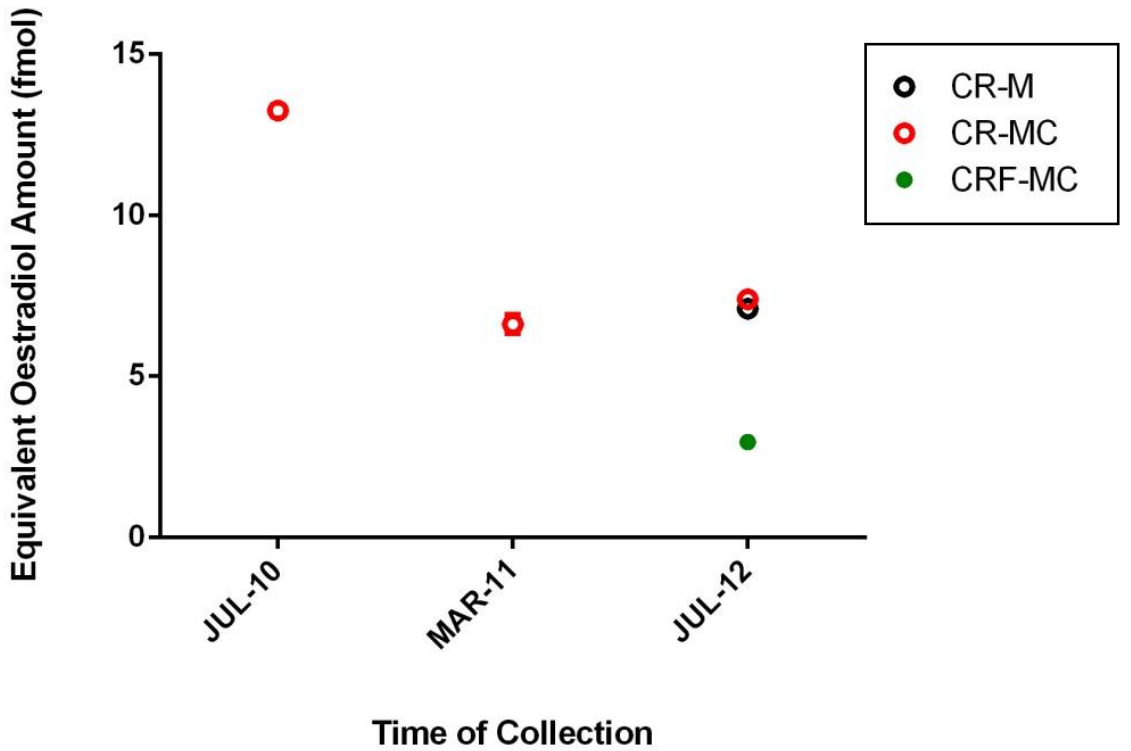

Figure 6.4 Response of the yeast bioassay to extracts of $\boldsymbol{C}$. robusta. Oestrogenic activity detected in $10 \mu \mathrm{L}$ of extracts CR-M (O), CR-MC (O) and CRF-JUL12-M (•) of C. robusta collected during different seasons was measured and expressed as equivalent oestradiol amount (fmol). Each data point represents the mean of 2-3 replicates in the same assay.

\subsubsection{Dracophyllum longifolium (Inaka)}

For D. longifolium, there were a total of four extracts from two different collection times tested. Three of the four extracts exhibited activity in the yeast bioassay (Figure 6.5). The DL-M sample was only detectable in the $10 \mu \mathrm{L}$ sample from July 2012 whereas for the DL-MC extracts, both samples (April 2009 and July 2012) had measurable activity. The two extracts from July 2012 had comparable activity which was less than that seen from April 2009.

\subsubsection{Gahnia procera (Mountain Gahnia)}

For G. procera, there were a total of ten samples from four different collection times. Of these, five extracts from three different collection times exhibited oestrogenic activity (Figure 6.6). For the -M extracts, this was from the samples collected in July 2010 and 2012 whilst for -MC there was detectable activity in the samples from July 2010 and 2012 as well as March 2011. However, in the case of the March 2011 sample, activity was observed from $5 \mu \mathrm{L}$ of the extract and not $10 \mu \mathrm{L}$. The greatest level of activity was seen for GP-M from July 2012 which was in contrast to GP-MC which displayed the lowest activity from the same sample. 


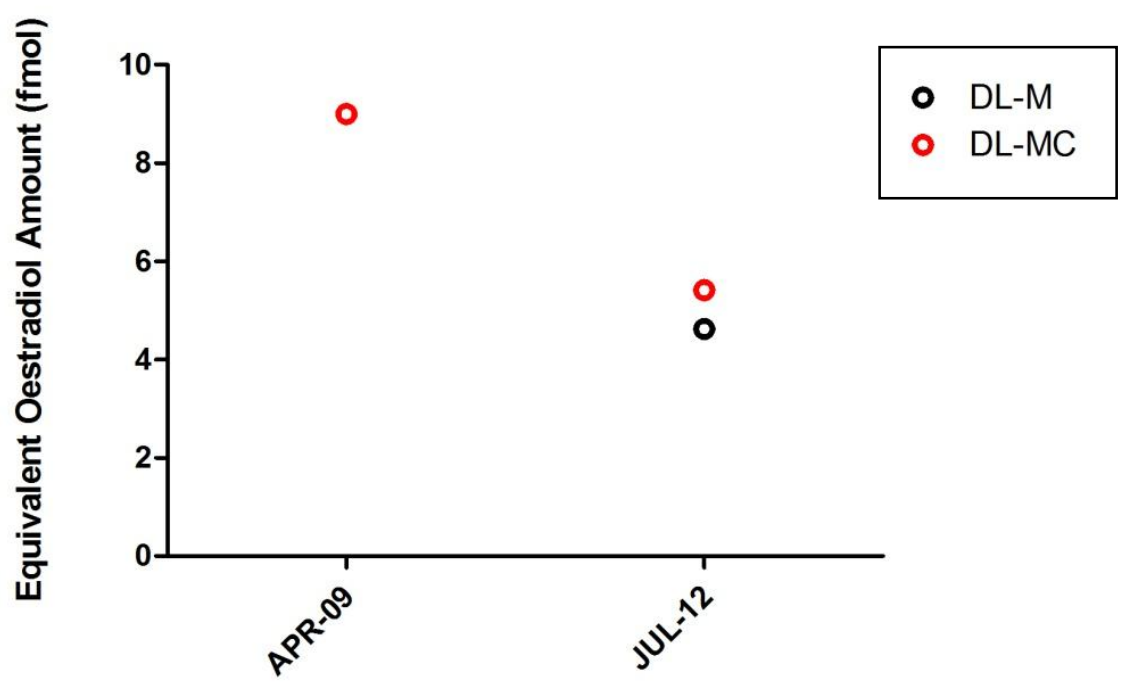

Time of Collection

Figure 6.5 Response of the yeast bioassay to extracts of $\boldsymbol{D}$. longifolium. Oestrogenic activity detected in $10 \mu \mathrm{L}$ of extracts DL-M (O) and DL-MC (O) of D. longifolium collected during different seasons was measured and expressed as equivalent oestradiol amount (fmol). Each data point represents the mean of 2-3 replicates in the same assay.

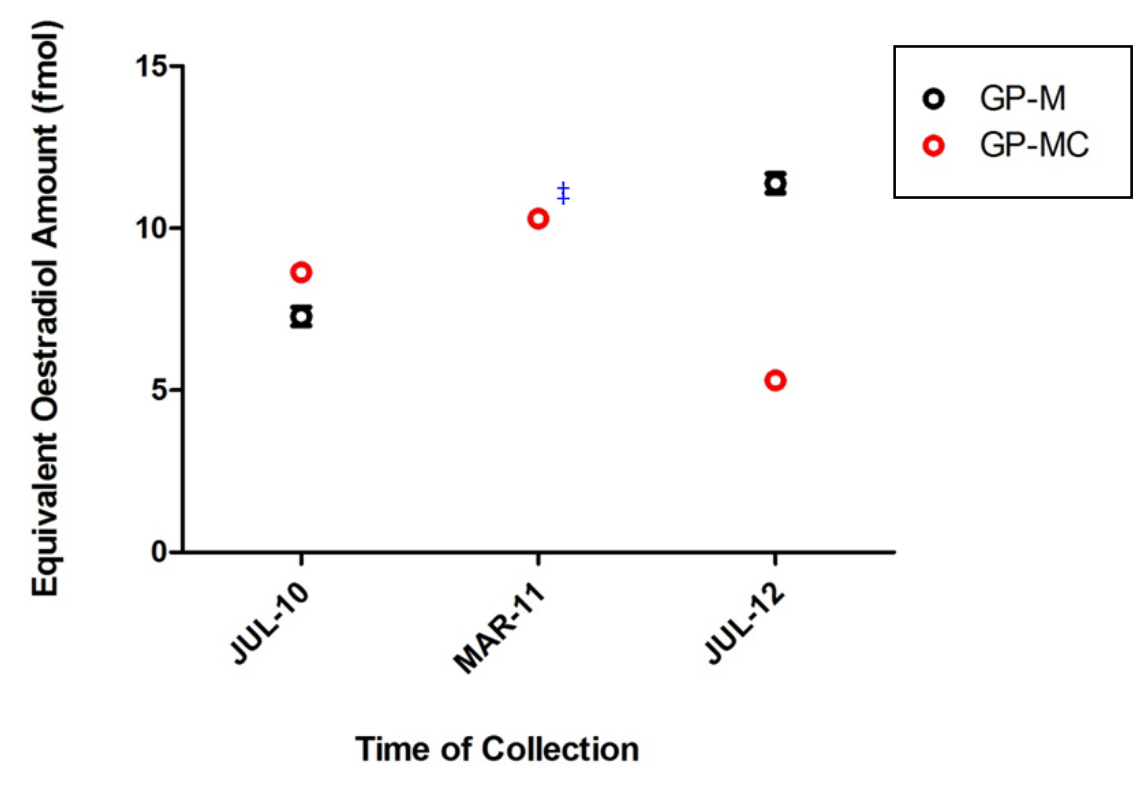

Figure 6.6 Response of the yeast bioassay to extracts of $\boldsymbol{G}$. procera. Oestrogenic activity detected in $10 \mu \mathrm{L}$ extracts of GP-M (O) and GP-MC (O) of G. procera collected during different seasons was measured and expressed as equivalent oestradiol amount (fmol). The $\$$ denotes the sample that had activity in $5 \mu \mathrm{L}$ of extract. Each data point represents the mean of 2-3 replicates in the same assay. 


\subsubsection{Leptecophylla juniperina (Mingimingi)}

For L. juniperina, there were a total of ten extracts from four different collection times tested. Of these, six exhibited oestrogenic activity over all the collection time points (Figure 6.7). In the case of LJ-M extracts, samples from July 2010 and August 2012 had detectable activity whereas for LJ-MC this was at all four collection times sampled. However for both December 2010 and March 2011, this activity was seen from $5 \mu \mathrm{L}$ of extract. Despite this, the LJ-MC extract from December 2010 exhibited the greatest oestrogenicity of all the extracts.

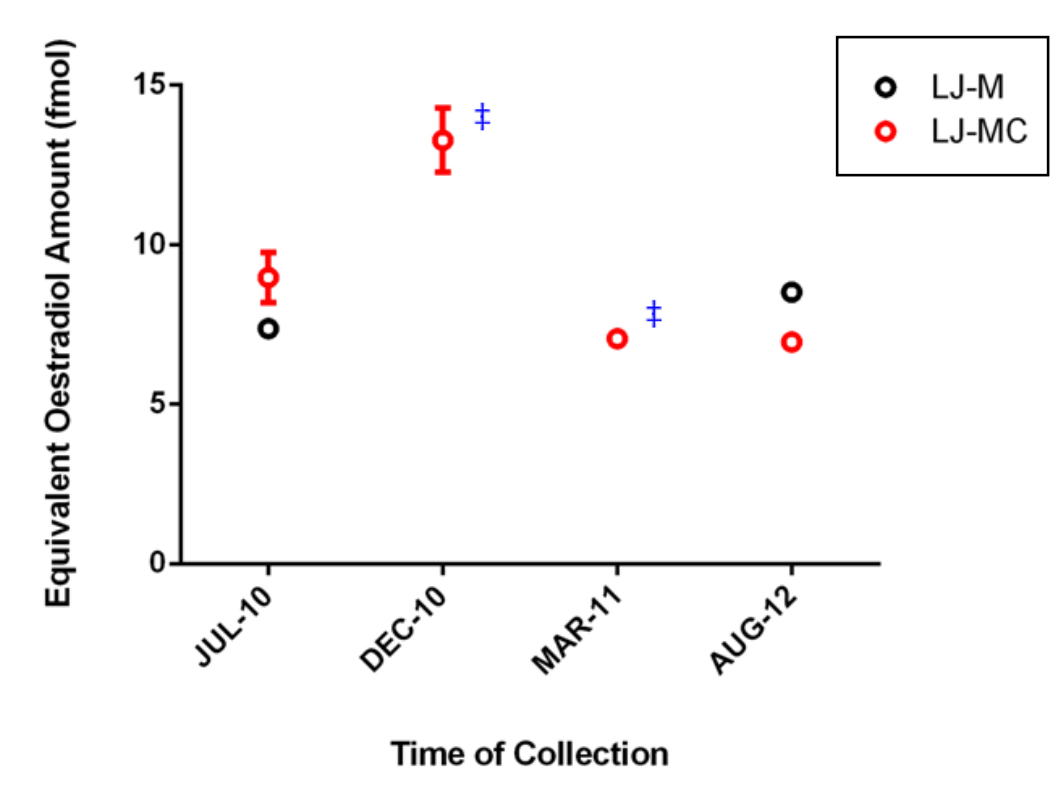

Figure 6.7 Response of the yeast bioassay to extracts of $L$. juniperina.Oestrogenic activity detected in $10 \mu \mathrm{L}$ of extracts LJ-M (O), and LJ-MC (O) of L. juniperina collected during different seasons was measured and expressed as equivalent oestradiol amount (fmol). The $\$$ denotes the samples that had activity in $5 \mu \mathrm{L}$ of extract. Each data point represents the mean of 2-3 replicates in the same assay.

\subsubsection{Leptospermum scoparium (Manuka)}

For L. scoparium, there were a total of 14 extracts from five different collection times. Of these, ten extracts from five different time points had detectable oestrogenic activity (Figure 6.8). In the case of the LS-MC extracts, samples from all five collection times had detectable activity (for the March 2011 sample this was seen from $5 \mu \mathrm{L}$ of extract) whereas for LS-M, activity was not present in the July 2010 or December 2010 samples. The two sets of seed 
samples tested (LSS) exhibited activity in the -MC extract. This was much higher in the July 2010 sample than the March 2011.

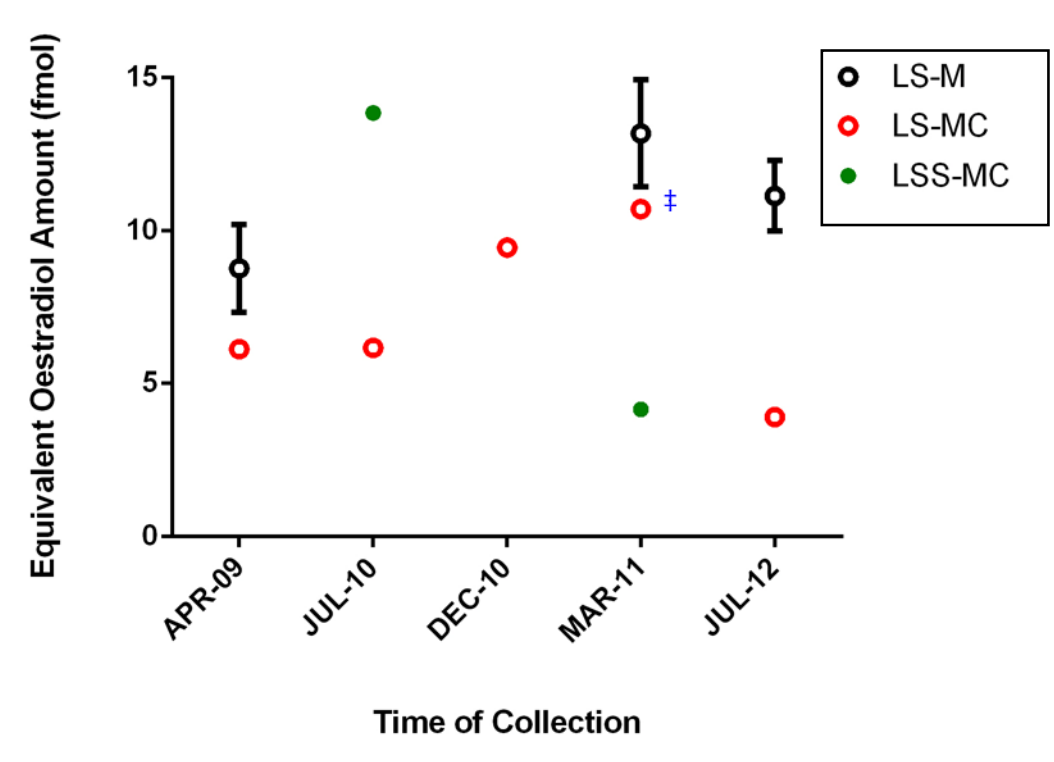

Figure 6.8 Response of the yeast bioassay to extracts of L.scoparium. Oestrogenic activity detected in $10 \mu \mathrm{L}$ of extracts LS-M (O), LS-MC (O) and LSS-MC (๑) of L.scoparium collected during different seasons was measured and expressed as equivalent oestradiol amount (fmol). The $\$$ denotes the sample that had activity in $5 \mu \mathrm{L}$ of extract. Each data point represents the mean of 2-3 replicates in the same assay

\subsubsection{Nothofagus solandri (Southern Beech)}

For $N$. solandri, there were a total of eight extracts from four different collection times. Of those, five from four different times exhibited detectable oestrogenic activity when $5 \mu \mathrm{L}$ of sample was tested (Figure 6.9). For the NS-M extracts, only that from July 2010 had activity whereas all of the NS-MC extracts had activity. NS-MC from July 2010 had the highest level of oestrogenic activity out of all the extracts of $N$. solandri tested.

\subsubsection{Podocarpus cunninghamii (Montane Totara)}

For $P$. cunninghamii, there were a total of four extracts from two different collection times. All of these had detectable activity when $10 \mu \mathrm{L}$ was tested (Figure 6.10). PC-M had a substantial decrease in oestrogenic activity between the sample from April 2009 and that from July 2012. The opposite was observed for PC-MC with the July 2012 sample having slightly greater activity than its April 2009 counterpart. 


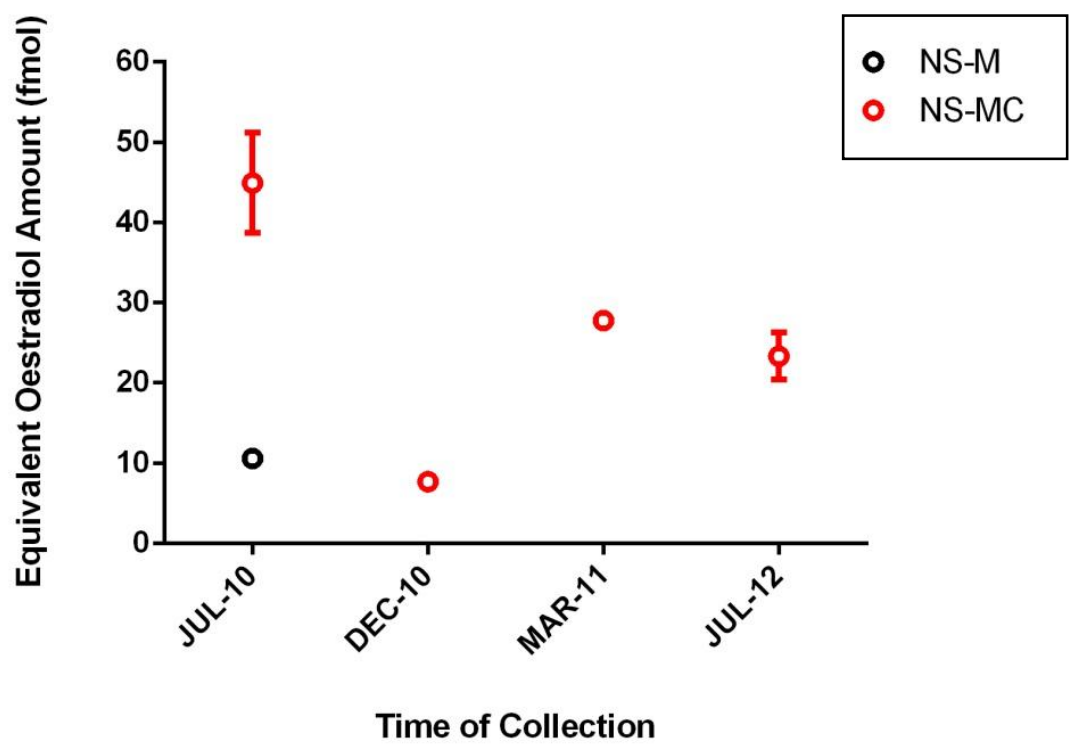

Figure 6.9 Response of the yeast bioassay to extracts of $\boldsymbol{N}$. solandri. Oestrogenic activity detected in $5 \mu \mathrm{L}$ of extracts NS-M (O) and NS-MC (O) of $N$. solandri collected during different seasons was measured and expressed as equivalent oestradiol amount (fmol). Each data point represents the mean of 2-3 replicates in the same assay.
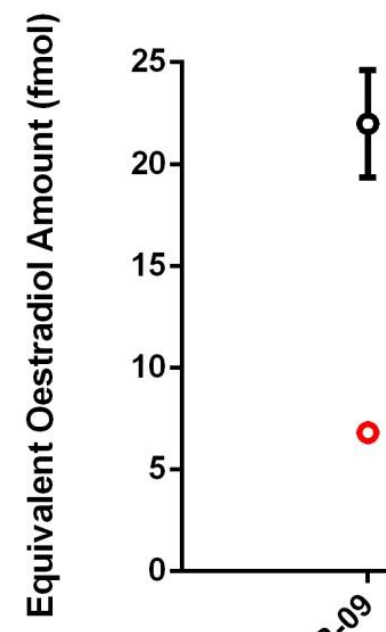

- $\quad$ PC-M

- $\mathrm{PC}-\mathrm{MC}$

Figure 6.10 Response of the yeast bioassay to extracts of $\boldsymbol{P}$. cunninghamii. Oestrogenic activity detected in $10 \mu \mathrm{L}$ of extracts PC-M (O) and PC-MC (O) of P. cunninghamii collected during different seasons was measured and expressed as equivalent oestradiol amount (fmol). Each data point represents the mean of 2-3 replicates in the same assay. 


\subsubsection{Prumnopitys ferruginea (Miro)}

For P. ferruginea, there were a total of six extracts from two different collection times. Of these, five were found to have oestrogenic activity (Figure 6.11). This included both extraction types from April 2009 and July 2012. Only the -MC extract for the sample of $P$. ferruginea berries (PFF) from July 2012 had detectable activity. For those samples extracted with $-\mathrm{M}$, the activity recorded was from $10 \mu \mathrm{L}$ of extract whereas for PF-MC from April 2009 it was $1.25 \mu \mathrm{L}$ and for PF-MC from July 2012 it was $0.625 \mu \mathrm{L}$ of extract.

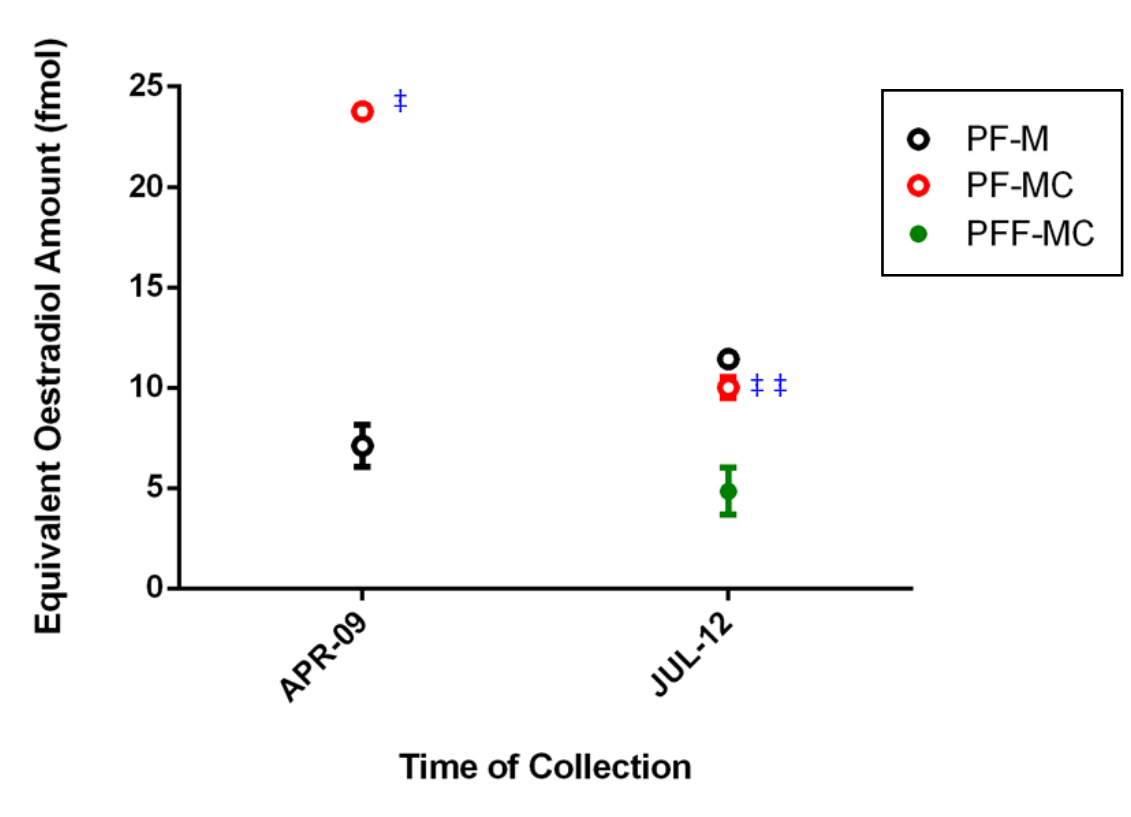

Figure 6.11 Response of the yeast bioassay to extracts of $\boldsymbol{P}$. ferruginea. Oestrogenic activity detected in $10 \mu \mathrm{L}$ of extracts PF-M (O) and PFF-MC (๑) and $1.25 \mu \mathrm{L}$ of PF-MC (O) from April 2009 (denoted by a $\$$ ) and $0.625 \mu \mathrm{L}$ from July 2012 (denoted by a $\$$ ) of $P$. ferruginea collected during different seasons was measured and expressed as equivalent oestradiol amount (fmol). Each data point represents the mean of 2-3 replicates in the same assay.

\subsubsection{Activity Present in Other Native New Zealand Plants}

A number of other species were collected at one time point in July/August 2012 and screened for oestrogenic activity in the yeast bioassay. The equivalent oestradiol amount for each extract shown in Table 6.1 is for a $10 \mu \mathrm{L}$ volume of plant extract unless stated otherwise.

For A. haastii (AH) both the -M and -MC extracts had an almost identical level of activity. A similar result was observed for C. arboea (CA) with both -M and -MC exhibiting activity although this was slightly more in the -MC extract. The two extracts of the berry sample (CAF) had comparable activity, although this was with a much lower extract volume 
$(2.5 \mu \mathrm{L})$. For $C$. rigida $(\mathrm{ChR})$ and $C$. australis $(\mathrm{CoA})$, only the $-\mathrm{MC}$ extract had detectable activity. In contrast, the fruit of $C$. australis (CoAF) displayed a very high level of activity in the $-\mathrm{M}$ extract with only $5 \mu \mathrm{L}$ of extract, whilst the flower stem (CoAS) had much lower activity in both the $-\mathrm{M}$ and $-\mathrm{MC}$ extracts. Both extracts of M. umbellata (MU) displayed oestrogenic activity, but this was much greater in the $-\mathrm{M}$ extract. The only oestrogenic activity detected in $O$. colensoi $(\mathrm{OC})$ and $P$. tenax $(\mathrm{PhT})$ was for the $-\mathrm{MC}$ extract and this was an identical level of activity. Finally, for P. acutifolius (PA), P. nivalis (PN) and P. taxifolia (PT), activity was observed in both extracts. For the latter two plant samples this was higher in the -M extract, and in the case of PT, an equivalent oestradiol amount of $19.1 \mathrm{fmol}$ was the highest seen for the leaf samples of these plants collected.

Table 6.1 The equivalent oestradiol amount (fmol) for the native plant samples collected at one time point. For all samples this was for $10 \mu \mathrm{L}$ of extract except for CAF-JUL12 $(2.5 \mu \mathrm{L})$ and CoAF-AUG12 $(5 \mu \mathrm{L})$.

\begin{tabular}{|l|c|c|}
\hline \multirow{2}{*}{ Plant Sample $(10 \mu \mathrm{L})$} & \multicolumn{2}{|c|}{ Equivalent Oestradiol Amount (fmol) } \\
\cline { 2 - 3 } & M extract & MC extract \\
\hline AH-JUL12 & 9.9 & 10.2 \\
\hline CA-JUL12 & 7.9 & 9.6 \\
\hline CAF-JUL12* $(2.5 \mu \mathrm{l})$ & 9.5 & 10.6 \\
\hline ChR-JUL12 & - & 14.7 \\
\hline CoA-AUG12 & - & 7.5 \\
\hline CoAF-AUG12* $(5 \mu \mathrm{l})$ & 68.3 & - \\
\hline CoAS-AUG12 & 6.3 & 9.6 \\
\hline MU-JUL12 & 18.9 & 4.6 \\
\hline OC-JUL12 & - & 12.9 \\
\hline PhT-JUL12 & - & 12.3 \\
\hline PA-APR09 & 5.9 & 7.2 \\
\hline PN-JUL12 & 10.3 & 9.3 \\
\hline PT-JUL12 & 19.1 & 7.7 \\
\hline
\end{tabular}

\subsection{Discussion}

In this study, the yeast bioassay which was optimised and validated in Chapter $\mathbf{5}$ was used to detect oestrogenic activity in a range of New Zealand native plant extracts.

The bioassay was successful in detecting oestrogenic activity in 20 of the 21 different New Zealand native plant species sampled. The only species that no level of activity was detected was Dacrycarpus dacrydioides. This was an unexpected result as both ferruginol and 
podocarpic acid have been isolated from this plant (Briggs, Cambie et al. 1959). For those plants collected at different times of the year, there was variation noted in the level of oestrogenic activity. Thus, this method was able to not only detect oestrogen-like compounds but was also capable of showing seasonal and temporal differences in the plant samples. For a number of the plants, the location of the collection varied and this was also evident in the results obtained. For each sample, both a methanol (-M) and a methanol-cellulase (-MC) extraction procedure were tested and this often demonstrated variations in activity.

The native plants selected for inclusion in the bioassay were those that were known to form part of the diet of Kākāpō (Atkinson and Merton 2006; Wilson, Grant et al. 2006; Horrocks, Salter et al. 2008) or were abundant in areas of New Zealand inhabited by Kākāpō (Butler 2006). Many different native plants were collected at different times of the year to test whether there were seasonal variations in the potential "oestrogenic" (phytoestrogens) bioactivity. The underlying reason why collections were made at different times of the year was that Kākāpō are known to begin breeding in late spring or early summer, with the rearing of young occurring in autumn (Cockrem 2006).

The plant samples were separated into leaves/fronds/stems and berries/seeds/spores prior to being extracted. There were a total of 164 samples tested, comprising of 96 leaf samples and 68 fruit samples. In the case of the berries etc., there was much lower availability of these than leaves/twigs and so smaller quantities had to be used for the extraction process.

\section{D. cupressinum}

Rimu is one species well-known for its masting behaviour and the hypothesis put forward by Fidler et al. (2008) suggests it has a major influence on the breeding of Kākāpō. Out of the 12 Rimu leaf extracts tested, four exhibited detectable levels of activity (Figure 6.1). The greatest of this activity corresponded to $13 \mathrm{fmol}$ of oestradiol; less than the $\mathrm{EC}_{50}$ of the oestradiol standard curve. Neither of the Rimu samples from April 2009 (DCO-APR09-M and $-\mathrm{MC}$ ) had activity which was consistent with the result obtained from previous testing of the ethanol extract (Mortensen 2009).

The two leaf collections in December 2010 originated from different locations (DCK-DEC10 from Kaitoke and DCC-DEC10 from Codfish Island) with only DCK-DEC10 demonstrating oestrogenic activity. The variation between the two sets of samples in terms of activity could 
be due to differences in the age of the trees or variation in the location. This result also indicated that the -MC extraction may be the most effective for Rimu leaf samples. As the 2010 year progressed and thus got closer to the breeding time for Kākāpō, there was no significant increase in oestrogenic activity of the leaf samples observed from Kaitoke (DCK-JUL10-M and DCK-DEC10-MC).

Unripe Rimu fruit collected in December 2010 from Codfish Island and extracted with methanol and cellulase (DCFC-DEC10-MC) had detectable oestrogenic activity (Figure 6.1) whereas activity was not evident in extractions of the leaves from the same sample (DCC-DEC10). Plants are capable of having variation in composition and this can change seasonally (Jalal, Read et al. 1982; Perry and Weavers 1985; McGimpsey, Douglas et al. 1994). This suggests that the presence of an oestrogenic-like compound may be localised to certain parts of the plant at specific times of the year or that there could be an increase in the amount present in one area of the plant during a particular season.

None of the other Rimu samples collected had any fruit present. This could be in part due to the time of year of collection but also the age of the Rimu tree sampled especially as Rimu fruit can take a year to mature.

In terms of the fruit samples collected between 2007 and 2008 from Codfish Island, over half of them showed detectable activity after -MC extraction (Figure 6.2). When examined, it was seen that none of the samples collected from "Tree 1" (DCFC-T1) had any detectable level of activity whereas all but one (DCFC-T18-AUG07) of the -MC extracts from "Tree 18" had activity. The samples for "Tree 1" and "Tree 18" had been collected at the same time points (Cottam 2010) and included fruit from the least developed (May 2007) to the most mature (February 2008). Although nothing is known about the estimated age of the two trees, "Tree 1 " was located on the south-eastern side of Codfish Island whereas "Tree 18" was on the north-western side where there was a much larger number of Rimu trees (Cottam 2010). As seen in other species, location or proximity to other masting trees may be an influence in the phytoestrogen level.

All of the DCF-S- samples comprised of a mixture of fruits from different trees and all of the -MC extracts had activity. Each sample comprised of a mixture of fruits from between 17 and 21 different trees. This suggests the oestrogenic effect of Rimu fruit may be a cumulative effect of a number of trees in the surrounding environment. It would be interesting to determine whether these trees went on to have fruit that ripened or failed to ripen. 
Monitoring of Rimu on Codfish Island is carried out each autumn to look at unripe fruit abundance prior to potential breeding of Kākāpō later that year. No strong correlations were obtained when the fruit abundance, successful breeding and oestrogenic activity of the Rimu fruit were compared. The year 2007 was not considered to be a masting year for Rimu on Codfish Island and this corresponded to a non-breeding season for Kākāpō in the following spring/summer. However, the DCF-S-MC sample collected in May 2007 displayed a reasonable level of activity. In contrast, the fruit collected from Codfish Island in December 2010, a year in which Kākāpō failed to breed, exhibited only a very low level of oestrogenic activity. As the sampling was undertaken at such a late stage, this low activity cannot be directly correlated with an unsuccessful breeding season. Finally, foliage from Rimu collected in March 2011 (autumn) from Kaitoke had a moderate level of activity. 2011 was considered to be a masting year as there was reasonable fruit abundance on the trees and hence Kākāpō were predicted to breed. However, cold temperatures in the spring that year led to significant fruit loss and this correlated with a subsequent lack of breeding by Kākāpō (Moorhouse, pers. comm., 2013).

Previous extractions of Rimu material (Fidler, Zwart et al. 2000; Mortensen 2009) had failed to detect any oestrogenic activity using the same transfected yeast bioassay as described herein. This is in contrast to the results presented here where several of the samples tested exhibited oestrogenic activity. This difference is likely due to an improved extraction procedure used in the present study and perhaps also to the modified assay format and method used for calculating bioactivity.

\section{B. novae-zelandiae}

There is evidence that Blechnum ferns are chewed by Kākāpō (Atkinson and Merton 2006) hence fronds from B. novae-zelandiae were collected. It was found to be one of only a few species that had detectable activity for every sample collected. It also had one of the highest levels of activity in this study with the -M extract from July 2012 exhibiting activity equivalent to $34 \mathrm{fmol}$ of oestradiol (Figure 6.3).

A number of compounds have been previously isolated and characterised from the Blechnum genus which have been shown to be phytoestrogens in other species or have structural 
similarities. For example, quercetin and luteolinidin have been detected in B. novae-zelandiae (Swinny 2001). However neither of these has been shown to have any reproductive effect.

In most instances, the -MC extraction protocol proved to be the most effective in isolating compounds from these ferns with oestrogenic properties, with only the samples collected in July 2010 and 2012 demonstrating detectable activity with both -M and -MC extracts. Analyses of samples collected over a year-long period indicated an increase in phytoestrogens content from July 2010 to December 2010, followed by a decrease in March 2011 to levels lower than that for July 2010 (Figure 6.3). Meanwhile, an "inter-annual" comparison showed that the -MC extracts for April 2009 and March 2011 had similar levels of activity as did those for July 2010 and 2012. In contrast, the level of oestrogenic activity for BC-M was much greater for the July 2012 sample than that from July 2010. However, as the collection site differed in both cases, no strong conclusions can be drawn from these results.

Both fertile and unfertile fronds were assayed to determine whether there was a difference in activity. These were found to have comparable activity, thus it is unlikely the oestrogenic component is restricted to one type of frond. Although seasonal differences in activity were noted consistently with the -MC extracts (with the highest in July), the highest recorded oestrogenic activity for B. novae-zelandiae was noted for a -M extract.

\section{C. robusta}

Both leaf and berry samples were collected from $C$. robusta with three leaf samples and one fruit sample demonstrating activity (Figure 6.4). As with B. novae-zelandiae, the activity detected was greater in the -MC extracts with only the July 2012 displaying activity in both the $-\mathrm{M}$ and $-\mathrm{MC}$ extracts. Previous research has shown the presence of the iridoid asperuloside in Coprosma species (Briggs and Nicholls 1954). As this has a glycosidic structure, its presence could be a factor with the MC method exhibiting greater activity.

Neither of the extracts from April 2009 (-M or -MC) had detectable activity, supporting the result obtained from ethanol extraction of the same sample (Mortensen 2009).

Berries were collected at three different time periods (April 2009, July 2010 and July 2012) with activity only detected at low levels in July 2012 equivalent to 3 fmol of oestradiol 
(Figure 6.4). The absence of oestrogenic properties in the other two fruit samples (CRF-APR09 and CRF-JUL10) infers that the activity of the CRF-JUL12-MC sample cannot be directly attributed to seasonality.

\section{D. longifolium}

D. longifolium has been reported to be consumed frequently (Walsh, Wilson et al. 2006) and so was included in this study. Both samples tested had detectable oestrogenic activity with only the -MC extract from the April 2009 sample failing to exhibit any (Figure 6.5). In the case of the -M and -MC extracts from the July 2012 sample, both were active with very similar levels. This suggests that for D. longifolium there does not appear to be a preferential extraction method, suggesting that either there are no glycones present, or both the glycones and aglycones have oestrogen receptor $\alpha$ binding capability.

\section{G. procera}

For the G. procera samples, there were mixed results, with no detectable activity found for the seeds (GPS-JUL10), whereas all but one of the leaf samples (GP-DEC10) displayed oestrogenic activity (Figure 6.6).

The activity noted in the -M extract for the July 2012 sample (GP-JUL12-M) was less in the equivalent sample from July 2010 (GP-JUL10-M) which would suggest that there was more of the bioactive component present in the plant in 2012. However, the results from the -MC extractions were the reverse with greater activity present in the July 2010 sample (GP-JUL10-MC). Thus, no strong conclusions can be proposed on either the glycosylation of potential phytoestrogens present or the inter-annual variation of phytoestrogens in $G$. procera.

\section{L. juniperina}

All of the leaf samples collected from L. juniperina exhibited activity with the yeast bioassay (Figure 6.7). The -MC extract of the December 2010 sample had the greatest level of activity out of the different extracts although this was greater than the $\mathrm{EC}_{90}$ value for the oestradiol standard curve at $10 \mu \mathrm{L}$ and so was not seen until $5 \mu \mathrm{L}$ of extract. As all the other leaf 
extracts with activity had similar levels to one another, little can be suggested about possible intra-annual variation. However the July 2010 fruit sample (LJF-JUL10) failed to have detectable levels of oestrogenic activity. Interestingly, it was fruit, and not leaf cuticles, that have been observed at a much higher frequency in the faecal samples of Kākāpō (Wilson, Grant et al. 2006) thus suggesting no strong correlation between browsing of L. juniperina berries and Kākāpō reproduction.

\section{L. scoparium}

All of the -MC extracts for L. scoparium (leaves and fruit) had detectable levels of oestrogenic activity whereas only three $-\mathrm{M}$ extracts did (Figure 6.8). This result is suggestive of glycosylation of the oestrogenic compounds present and that the release of the sugars yields a more active compound. Although there was a slight increase in activity from July 2010 until March 2011, no strong seasonal variation was evident.

\section{N. solandri}

Overall $N$. solandri had some of the highest levels of oestrogenicity (the MC extract from July 2010 had activity equivalent to $44 \mathrm{fmol}$ of oestradiol) with all four plant specimens collected exhibiting activity in their -MC extracts and with the July 2010 sample displaying activity with both extraction procedures (Figure 6.9). However no definite seasonal trend could be extrapolated from the data. Thus $N$. solandri contains phytoestrogens in reasonable quantities. As there is evidence Kākāpō inhabited beech forests (Worthy and Holdaway 2002) and beech is a species known to undergo the masting process, these large quantities warrant further research with respect to a possible seasonal variation of their phytoestrogen content.

Some research has been undertaken on Nothofagus species to see how plants in different parts of the world are phylogenetically related. From this research, a number of flavonols and the stilbene, pinosylvin, have been identified in N. solandri (Wollenweber, Stevens et al. 2003) however their potential effect on reproduction has not been elucidated. 


\section{P. cunninghamii}

All samples of $P$. cunninghamii exhibited oestrogenic activity (Figure 6.10). The -M extract for the April 2009 sample had greater oestrogenic activity than the -MC extract, but the reverse was seen for the sample collected in July 2012. Thus from these results, it is inconclusive as to whether the compounds exhibiting oestrogenic properties have a sugar-based structure or not.

\section{P. ferruginea}

The leaf samples of P. ferruginea displayed activity in both -M and -MC extracts whereas for the fruit samples only the -MC was active (Figure 6.11). From this it appears that there is greater phytoestrogens content in the leaf than fruit, especially as the equivalent dry weight was used in all samples. Also, as there was much greater activity in -MC extracts for leaf than $-\mathrm{M}$, it can be assumed that the phytoestrogens are modified with sugar moieties and that their agylcone form is much more oestrogenic than their gylcone state.

For the plant species that were only collected at one time point, there was considerable variation in the activity seen (Table 6.1). Out of the ten species, all but $C$. rigida, O. colensoi and $P$. tenax showed activity for both extraction procedures. This was not preferential for $A$. haastii, C. arboea (fruit) or P. nivalis as the level of activity was comparable in both extracts suggesting the oestrogenic compounds present were active in both their aglycone and glycone states with no pronounced preference for the binding of one form of the oestrogenic compound to the receptor.

Removal of the sugar moieties was beneficial for $C$. arboea (leaves), C. rigida, C. australis (leaves and stems), O. colensoi, P. tenax and P. australis. This suggests the oestrogenic components in these species have glycosidic modifications that, when cleaved, become more active. Previously, fructans have been successfully isolated from both $P$. tenax and $P$. cookianum (Sims, Cairns et al. 2001), but no compounds with steroid-based structures or steroidogenic activity, have been reported.

It was only $C$. australis (fruit), M. umbellata and $P$. taxifolia that proved to be more oestrogenic with the $-\mathrm{M}$ extract. This suggested that the oestrogenic compounds require their 
sugar group(s) still attached to the main backbone of the chemical to get the most efficient binding to hER- $\alpha$.

For both plants that had fruit samples ( $C$. arboea and $C$. australis), there was a greater amount of oestrogenic compounds in them that in the leaves. This is even more significant as only $250 \mathrm{mg}$ of dried fruit was used (equating to $1 / 8$ of what was tested for the leaf samples). Thus, in terms of diet, the consumption of berries by Kākāpō would have a greater influence on reproductive processes than leaves alone.

As mentioned earlier, for the fruit samples, there was much lower availability of these than for the leaves/twigs and so smaller quantities were used for the extraction process. Although this meant the extraction was not identical to that done for the leaf samples, it was a reasonable approximation of the level of abundance that would be available for Kākāpō to consume. If the seeds, fruits and spores were not overly abundant on the plants, Kākāpō would be limited as to the quantity that could be consumed. In turn this would infer that any significant oestrogenic activity would be present in relatively small amounts. Conversely, it could be argued that although ingestion of a small amount would have no significant effect there might be a cumulative effect from repetitive consumption and accumulation of the active compounds over time. That is, Kākāpō had to consume enough of a particular fruit in order to reach the threshold for an oestrogenic effect.

The masting phenomenon is restricted to certain New Zealand native plant species such as Rimu, Beech, tussocks and flax and although there is a high level of synchrony both within and between species (Schauber, Kelly et al. 2002), there can be a degree of regional variation in the level of masting these plants undertake. Overall, given the between tree variability (i.e. the Rimu tree samples from Codfish Island), between species variability and changes in bioactivity in the same region between years, a real challenge remains in attempting to link plant oestrogenic activity with breeding. One way to achieve this might be to focus on a selected number of plants in the habitat of Kākāpō that have shown oestrogenic activity and repeatedly sample these for successive months over several years. These samples could then be fractionated and tested in a bioassay that contained ER- $\alpha$.

To address the question of bioavailability of the phytoestrogens, samples of the different plant species were collected during different seasons. However, methanol was the only 
solvent utilised for these extractions. This could have limited the amount of bioactive material extracted. Ideally, additional extractions with different solvents would be desirable to test whether other oestrogenic compounds with different chemical properties could have been isolated. However, this was not logistically possible for the present studies.

For phytoestrogens to exhibit an effect in the body, absorption may need to take place. To aid in this, the sugar moiety may need to be released. This has been shown to be carried out by $\beta$-glucosidases present in the intestines and the food ingested as well as stomach acid (Kelly, GE 1993). Hence, the utilisation of cellulase in the extraction protocol was one way of mimicking part of the process phytoestrogens may undergo post-ingestion.

There are a number of limitations with the yeast bioassay that was used to test the plant extracts of oestrogenic activity. Firstly, as mentioned earlier, as the extracts that were tested are crude, the results of this assay can only indicate the presence or absence of activity; they do not give an idea of whether it is only one compound resulting in the activity or whether multiple different compounds are exerting the biological effects. To investigate this, the extracts would need to be separated into individual compounds through fractionation and then each of the fractions tested for potential activity. Nevertheless, the results do provide an indication of which plants might contain oestrogenic activity and be of benefit to the fertility of the birds. Secondly, the yeast strain utilised has the human form of ER- $\alpha$ present (Routledge and Sumpter 1996). This sequence has been mutated and modified to increase its efficiency and as such, is not a true representation of how hER- $\alpha$ may behave. Also, as the section of the receptor (LBD) amplified in the NZ native bird species has only around 85\% similarity with the human form, it is reasonable to propose that the Kākāpō receptor may behave differently to the human form. Therefore it would be more beneficial to incorporate the Kākāpō ER- $\alpha$ gene into yeast and then use this to screen the plant extracts.

Additionally, the screening assay used in this study was useful to identify putative "oestrogenic" compounds but these are only one cohort of a number of potential hormonal materials in plants. As there are multiple steps in steroid biosynthesis, it is possible that the mechanism underpinning increased reproductive activity in female Kākāpō involves another closely-related steroid such as an androgen or progestin. Thus, to fully test the bioactivity in the various plant species, a series of assays would need to be developed with each assay focusing on a specific steroid receptor. In particular, it would be worthwhile validating a bioassay incorporating the ER- $\beta$ gene as, despite its sequence similarity to ER- $\alpha$, it is known 
that a number of compounds, including phytoestrogens, bind with greater affinity to it than to ER- $\alpha$ (Kostelac, Rechkemmer et al. 2003).

Finally, although a yeast bioassay is an effective means of undertaking initial biological studies, many cell processes are ignored. It has previously been shown that species-specific metabolism of phytoestrogens exists such as an in the hydrolysis of sugar moieties (Rowland, Faughnan et al. 2003) but further modifications are known to occur. To fully understand how these compounds may affect reproduction, a more integrated system approach mirroring what occurs in the body needs to be undertaken. To that end, the use of a cell line may be a beneficial method of testing as all the activators and repressors would be present. Another limitation is that many phytochemicals have been shown to exhibit anti-microbial activity; a trait observed in some of the plant samples tested in this study. Although any inhibition in the growth of the yeast was accounted for when the calculation of activity was done, there was still the risk of false negatives and positives.

\subsection{Summary}

Twenty of the 21 New Zealand native plant species investigated in this study exhibited oestrogenic activity in at least one sample. Out of these, the plants that had the highest levels of oestrogenicity were B. novae-zealandiae, N. solandri and C. australis. In terms of seasonal variation for most of the species, this was not well-pronounced. This was the first instance where extracts from Rimu have been found to exhibit oestrogenic activity.

There was little variation in the level of activity of fruit samples (and other non-leaf parts) with a number of them (such as BNFF-DEC10, CRF-APR09, CRF-JUL10, GPS-JUL10 and LJF-JUL10) failing to have detectable activity. Those that were active exhibited less than 5 fmol equivalents. In contrast to this, the Rimu fruit collected from Codfish Island in 2007-2008 displayed up to $10 \mathrm{fmol}$ of activity with values at $10 \mu \mathrm{L}$ falling between 5 and $10 \mathrm{fmol}$ for all but three samples (Figure 6.2). Bearing in mind that the amount of fruit extract varied between species, it is difficult to draw conclusions and comparisons between them. However, Rimu fruit had the lowest mass extracted but had the greatest activity. This suggests that Rimu fruit does indeed have oestrogenic activity comparable to other plant leaf samples. 
On many occasions, it was found that the cellulase extract of the plant (eg the Rimu fruit samples) exhibited activity when the methanol only extract of the same sample did not. This suggested that not only were there sugars present on compounds in the extract but that cleavage of these sugars to yield the aglycones increased their overall activity. There were also instances when both the methanol extract and the methanol extract/cellulase digestion exhibited activity. In the vast majority of these cases, the cellulase digested extract had higher levels of activity than the methanol alone. This finding suggests that there could be other modifications or derivatives of compounds present that are decreasing or inhibiting the response. Daidzein is a well-known example of a phytoestrogen. Its metabolite, equol has been found to be more effective in an assay measuring the binding of ER to ERE after addition of a phytoestrogen (Kostelac, Rechkemmer et al. 2003). Thus, a next logical step would be to investigate the use of other enzymes in the extraction process to potentially unmask other "active" components. By using an array of these, a more complex picture of the types of phytoestrogens present in the plants could be gained.

Finally, there were a number of examples where the activity reached a constant level at the lower amounts of extract - it would be beneficial to have concentrated these samples to see whether there was a further increase in activity. This would also increase the likelihood of gaining a dose-response profile for the plant samples. 


\section{CHAPTER 7: GENERAL DISCUSSION}

\subsection{Introduction}

Kākāpō are an iconic avian species of New Zealand that are currently on the brink of extinction. With less than 130 individuals currently, intensive management is critical to maintaining their existence. A limiting factor to increasing the population size has been a low rate of successful reproduction. This is, in part, due to their unusual reproductive behaviour of breeding intermittently. Much of the knowledge about their reproduction has been the result of observations and anecdotes. From these and from a limited level of research, several hypotheses have been proposed to explain the unique breeding behaviour of this bird. Previous research has postulated that, alongside photoperiodic influences, the influence of food availability (Powlesland, Lloyd et al. 1992; Cockrem 2006), and masting of native plants such as Rimu and pink pine (Powlesland, Lloyd et al. 1992; Elliott, Merton et al. 2001) are necessary for mating and reproductive success. The Fidler et al. (2008) hypothesis, upon which this study is based, proposes that phytochemicals present in the unripe fruit of masting plants eaten by Kākāpō sensitise the liver so that when oestrogens are released from growing ovarian follicles, expression of egg yolk protein gene occurs faster and at greater levels.

Reproduction in any species is complicated and cannot be attributed to any one single process. Despite the hypothesis that has been put forward, the precise mechanisms by which this would occur are unclear. The idea that plants that constitute the diet of Kākāpō act to increase female fertility through receptor sensitisation relies firstly, on phytosteroids being present in the plants, and secondly, on the steroid receptors of Kākāpō possessing the ability to bind these compounds.

Hence, this dissertation has sought to address possible influences on the reproductive success of Kākāpō by investigating both aspects of this hypothesis at a molecular level, namely:

1) an exploration of the LBD of four steroid receptors known to play an active role in reproduction. This involved Kākāpō primarily and was expanded to include three other native New Zealand parrots, an Australian parrot and two non-parrot species for comparative studies; 
2) the screening of native plant extracts for detectable oestrogenic activity using the hER- $\alpha$ yeast screen and the comparison of the seasonal variation in the level of these oestrogenic compounds from the various plants.

\subsection{Summary of Findings}

A summary of the major findings in this dissertation is outlined below.

7.2.1 New Zealand parrots display a high level of conservation in the amino acid sequences within the LBD of the four steroid receptors investigated. In some instances this conservation was $100 \%$.

Despite discrepancies in the nucleotide sequences, the high level of protein conservation determined in the regions of the steroid receptors amplified in Kākā, Kākāpō, Kākāriki and Kea demonstrates how closely-related the New Zealand parrots are. The initial section of the LBD of ER- $\alpha$ and ER- $\beta$, and the end of PR LBD, were all $100 \%$ identical at the protein level. Moreover, the AR LBD exhibited only one amino acid difference (in Kākāriki). Preliminary results of the other regions sequenced displayed only one different amino acid in the C-terminal region of Kākā's ER- $\alpha$ LBD and two in the N-terminal region of Kākāriki's PR LBD. Although this is evidence of relatedness, this level of conservation negated the suggestion that Kākāpō have unique amino acid motifs present in the LBD of steroid receptors. However it does suggest that parrot-specific motifs exist.

Research into both the origin and phylogeny of parrots, has postulated that Psittaciformes originated from Australasia and that Kea is the most closely related species to Kākāpō (Wright, Schirtzinger et al. 2008). The sequencing results from this study support this proposal and thus could be useful information in future phylogenetic studies.

7.2.2 New Zealand parrots demonstrate variation in the LBD of four steroid receptors when compared to other avian and non-avian species: ER- $\alpha$ displays the greatest level of disparity.

Unlike the results from comparisons of the New Zealand parrots, the level of identity observed when the New Zealand parrot sequences were compared with other avian species was considerably less (Chapter 3). Nevertheless, in most instances, the Australian parrot, the cockatiel, was very similar in sequence, and in many cases identical. This level of identity 
was much greater than that observed when the Chicken and Japanese quail sequences were compared. In many cases it was a higher level of conservation than what was seen for most of the other avian species. The levels of identity decreased further when non-avian species such as human were compared. This further supports the notion of parrot-specific motifs in the steroid receptors. The observation that ER- $\alpha$ exhibited the highest level of discrepancy supported the decision to use it in subsequent studies; both with respect to the in silico docking studies and as the target for the screening of plant extracts for steroidogenic activity in a yeast bioassay. The reasoning for this was that as it showed the greatest level of uniqueness, it had a greater chance of exhibiting different behaviour to ER- $\alpha$ in other species.

7.2.3 Amino acids in ER- $\alpha$ that are unique to New Zealand birds may play a role in the binding mode of phytoestrogens in the receptor.

This was seen in the initial modelling studies where the amino acids in the immediate vicinity of the sites of variation, were involved in interactions with the bound $\mathrm{E}_{2}$ molecule. To gain a better understanding of how the different amino acids may influence the binding of oestrogenic compounds in ER- $\alpha$, in silico modelling of the docking interactions was conducted. The results in Chapter 4 demonstrate how small alterations in the amino acid backbone of a receptor can alter the binding properties of the protein considerably. The ligand pocket predicted for Kākāpō ER- $\alpha$ was different enough in structure that when the bound $E_{2}$ from the hER- $\alpha$ crystal structure was transferred into it, the interactions changed significantly. The binding site for $\mathrm{E}_{2}$ predicted by RosettaLigand was different again. That is, the overall shape and amino acid makeup of the receptor was sufficiently dissimilar to cause different binding modes between ligands and the receptor. The significance of this finding is that the amino acid disparities provide binding interactions that are likely to be selective for parrot species. In turn this may influence biological potencies of oestrogenic compounds.

7.2.4 Oestrogenic activity is present in New Zealand native plants browsed by Kākāpō and these activities display seasonal variation.

The presence of oestrogenic compounds in plants not known previously to have this activity is a significant finding. Possibly the most significant is the detection of activity in extracts 
from Rimu, a plant believed to be closely linked to successful breeding of Kākāpō and used as a food source for the rearing of Kākāpō chicks. Although the original hypothesis by Fidler et al. (2008) postulates that phytochemicals present in unripe fruit are involved in the sensitisation of the liver, this study was expanded to include other parts of the plants including leaves, twigs, seeds and fruit. The results obtained lengthen the list of plants that potentially could influence breeding behaviour of Kākāpō. In doing so, it also supports the hypothesis that environmental factors are playing a role in the bird's reproductive strategy. The research thus far investigating the supplementation of plants such as Rimu and Kahikatea to the diet of Kākāpō has been met with little success in regards to increasing breeding efficiency. It could be that different plants to the ones previously tried possess the reproductive link or that multiple environmental factors are involved. If this is the case, it could mean that plants have a synergistic effect with either each other or alongside environmental conditions such as temperature, rainfall, and daylight length. This idea is supported by the information known about the masting phenomenon. Regardless of the reason as to why plants undertake masting, their ability to do so is limited by the environmental influences mentioned above (Schauber, Kelly et al. 2002; Burns 2012).

Despite numerous examples of phytoestrogens having a negative influence on the reproduction of species, especially infertility in sheep by red clover (Adams 1995; Croker, Nichols et al. 2005), and as endocrine disrupters, there have been some instances of positive effects. For example, a positive relationship was seen between the consumption of phytoestrogenic-containing Millettia dura and the copulation frequency of red colobus monkeys (Wasserman, Taylor-Gutt et al. 2012).

The plants included in the study are not limited to the diet of Kākāpō - many other New Zealand species are likely to consume them. Therefore, the potential steroidogenic effect of these plants on Kākāpō could be present with other New Zealand avian species as well, such as Kākā.

Consumption of different plants may vary seasonally with birds having a preference for only particular parts of the plants (for example the fruit or seeds) or the quantity of a particular plant consumed may change during different seasons. However, from the screening studies undertaken in the present investigation, there were no significant trends observed in seasonal variation of phytoestrogenic content. Despite finding no major seasonal-related effects, there was also no evidence for constant levels of oestrogenicity in the different samples of each 
plant. The oestrogenic activity of plant species that were sampled over multiple years fluctuated even when identical months were compared. Included in this plant inventory were species known to undergo masting. As the presence and intensity of masting varies between years, the results obtained from this study are not inconsistent with the hypothesis that masting may play an influential role in the reproduction of Kākāpō. Although there were no strong correlations between Rimu fruit abundance, successful breeding and oestrogenic activity of the Rimu fruit, the collection time points did not always correspond directly to the time that the breeding season for Kākāpō commences. The fact that some specimens collected did not exhibit any detectable activity supports the idea that plant hormonal levels vary both within and between years.

\subsection{Significance and Future Directions}

The research outcomes herein have advanced current knowledge concerning steroid receptivity of Kākāpō. They also provide new knowledge concerning the oestrogenic activities in the flora of their surrounding habitat. This is the first comparative study to be undertaken on steroid receptors in New Zealand birds and so could be useful for other researchers of native New Zealand fauna and for avian endocrinologists. The importance of the differences seen in ER- $\alpha$ was emphasised when the docking studies were performed. Although further work needs to be undertaken, the results of this study could have an impact on the strategies employed by the Kākāpō Recovery Programme in the management of Kākāpō. The information gained could also be used for increasing the population of other New Zealand parrot species that are in differing states of decline (for example the Kākā population).

\subsubsection{Experimental Significance}

From an experimental point of view, the absence of Kākāpō-specific residues refutes the hypothesis that this could be the sole reason for their unique reproduction. However, reproduction is a multifaceted process and so the parrot-specific amino acid sequences in the ligand-binding domains may influence their reproductive behaviour in ways not observed in other species. Conversely, there could be a section of the receptor outside of the binding domains that also contributes to these unique (i.e. steroid recognition) characteristics. Hence 
further experimental work would be necessary to confirm this notion. A full amino acid sequence needs to be obtained in order to fully assess the most favourable three-dimensional structure of the steroid receptor. The potential mechanism for the binding of ligands such as the already established movement of helix 12 after a ligand has entered the binding pocket can then be predicted as well as the effect of the different amino acids on the size and shape of the binding pocket.

The docking studies were only carried out with ER- $\alpha$ in this study. It would be worthwhile repeating them with the other steroid receptors sequenced especially if a specific phytochemical was isolated from the native plants. This would give an indication of how one phytoestrogen may interact with multiple steroid receptors.

Perhaps most importantly, the different binding orientation predicted in Kākāpō ER- $\alpha$ by in silico modelling, coupled with the additional amino acids found at the end of the sequence, supports the need to integrate the Kākāpō version of the ER- $\alpha$ isoform into the yeast bioassay. Differences in the other steroid receptors investigated means the assay could be extended to include these as well. Conversely, a new non-yeast assay incorporating Kākāpō ER- $\alpha$ (or the other steroid receptors) could be developed. This would allow for more accurate testing of the interactions of native plant extracts with Kākāpō's ER- $\alpha$.

A cumulative oestrogenic effect from a number of plants could be occurring thus testing different plant combinations could yield a more active formulation. Studies on phytoestrogens have found that some (such as coumestrol, daidzein and genistein) exhibit preferential binding to one isoform of ER over the other; this includes greater affinity to the $\beta$ isoform (Kostelac, Rechkemmer et al. 2003; Wasserman, Taylor-Gutt et al. 2012). Hence, it would be worthwhile screening the plant extracts for activity with ER- $\beta$.

Alongside the assay results, the relationship between the level of activity and environmental changes could be determined by correlating rainfall data, daily temperatures and daylight hours to the abundance of phytoestrogens. Also, further collection of selected native plants over a more extensive time period would be beneficial in determining the link between phytoestrogen levels and breeding of Kākāpō. 


\subsubsection{Species Management Significance}

The large number of plants shown to display oestrogenic activity will need to be seriously considered by the Kākāpō Recovery Programme. Alterations to the breeding strategy may be necessary. The current habitat for Kākāpō provides access to some of these species but others are not present.

Adjustments to the recovery programme would primarily be through the avenue of supplementary feeding. The results of the yeast assay identified a number of different plants with detectable oestrogenic activity. The implications of this are that there are a greater number of plants that could be included in the supplementary food at the appropriate time of the year. If changes were to be made to the supplementary food provided, these new formulations would need to first be retested in the yeast bioassay to confirm activity. Additionally, after further investigation, the characterisation of the compound(s) responsible for the oestrogenic activity could result in direct supplementation of it into the diet of female Kākāpō.

The current conservation status of the other three New Zealand species included in this study suggests that, in the near future, more intensive management of these populations may be required. The knowledge gained from the current extensive conservation effort of Kākāpō could be utilised in this management. This is emphasised by the fact that the plants shown to have oestrogenic activity may be eaten by these other species, and are almost definitely present in their habitat. If these plants are having a reproductive effect on Kākāpō, the high level of steroid receptor similarity in parrots means that they are likely to cause a similar effect in other parrots as well.

\subsection{Conclusion}

In conclusion, the aim of this investigation was to address the hypothesis proposed by Fidler et al. (2008) that links the successful reproduction of Kākāpō with the sensitisation of liver-derived egg yolk protein gene by oestrogenic compounds present in unripe fruit of their diet. The results from this dissertation neither prove nor refute this hypothesis.

Although not unique to Kākāpō, the sequences of the LBD of four key steroid receptors, especially that of ER- $\alpha$, were found to have amino acid motifs distinctive to New Zealand 
parrots. hER- $\alpha$ was shown to be capable of recognising certain compounds present in plants. Arising from the results obtained in this study, it will be important to further elucidate the oestrogenic potency of these plants by transfecting the Kākāpō ER- $\alpha$ sequence into the yeast reporter system. This would provide further information about the relevance of these compounds in the reproductive mechanisms of Kākāpō. 


\section{CHAPTER 8: REFERENCES}

Adams, N. R. (1995). "Detection of the effects of phytoestrogens on sheep and cattle." Journal of Animal Science 73(5): 1509-1515.

Adewale, H. B., W. N. Jefferson, R. R. Newbold and H. B. Patisaul (2009). "Neonatal Bisphenol-A exposure alters rat reproductive development and ovarian morphology without impairing activation of gonadotropin-releasing hormone neurons." Biology of Reproduction 81(4): 690-699.

Adlercreutz, H. (1995). "Phytoestrogens: epidemiology and a possible role in cancer protection." Environmental Health Perspectives 103(Suppl 7): 103-112.

Adlercreutz, H., T. Yamada, K. Wähälä and S. Watanabe (1999). "Maternal and neonatal phytoestrogens in Japanese women during birth." American Journal of Obstetrics and Gynecology 180(3): 737-743.

Allan, G. F., S. Y. Tsai, M. J. Tsai and B. W. O'Malley (1992). "Ligand-dependent conformational changes in the progesterone receptor are necessary for events that follow DNA binding." Proceedings of the National Academy of Sciences 89(24): 11750-11754.

Allinson, M., F. Shiraishi, S. A. Salzman and G. Allinson (2010). "In vitro and immunological assessment of the estrogenic activity and concentrations of $17 \beta$ estradiol, estrone, and ethinyl estradiol in treated effluent from 45 wastewater treatment plants in Victoria, Australia." Archives of Environmental Contamination and Toxicology 58(3): 576-586.

Anderson, A. J. (1981). "Pre-European hunting dogs in the South Island, New Zealand." New Zealand Journal of Archaeology 3: 15-20.

Anderson, J. J. B. and S. C. Garner (1998). "1. Phytoestrogens and bone." Baillière's Clinical Endocrinology and Metabolism 12(4): 543-557.

Aquila, S., M. Santoro, F. De Amicis, C. Guido, D. Bonofiglio, M. Lanzino, M. G. Cesario, I. Perrotta, D. Sisci and C. Morelli (2013). "Red wine consumption may affect sperm biology: The effects of different concentrations of the phytoestrogen Myricetin on human male gamete function." Molecular Reproduction and Development 80(2): 155165.

Aranda, A. and A. Pascual (2001). "Nuclear hormone receptors and gene expression." Physiological Reviews 81(3): 1269-1304.

Arukwe, A. and A. Goksøyr (2003). "Eggshell and egg yolk proteins in fish: hepatic proteins for the next generation: oogenetic, population, and evolutionary implications of endocrine disruption." Comparative Hepatology 2(1): 4. 
Ashby, J. and H. Tinwell (1998). "Uterotrophic activity of bisphenol A in the immature rat." Environmental Health Perspectives 106(11): 719-720.

Atkinson, I. A. E. and D. V. Merton (2006). "Habitat and diet of Kakapo (Strigops habroptilus) in the Esperance Valley, Fiordland, New Zealand." Notornis 53(1): 3754.

Auchus, R. J. (2004). "The backdoor pathway to dihydrotestosterone." Trends in Endocrinology \& Metabolism 15(9): 432-438.

Axelson, M., D. N. Kirk, R. D. Farrant, G. Cooley, A. M. Lawson and K. D. R. Setchell (1982). "The identification of the weak oestrogen equol [7-hydroxy-3-(4'hydroxyphenyl)chroman] in human urine." Biochemical Journal 201(2): 353-357.

Axelson, M., J. Sjövall, B. E. Gustafsson and K. D. R. Setchell (1982). "Origin of lignans in mammals and identification of a precursor from plants." Nature 298(5875): 659-660.

Babu, S., N. A. Vellore, A. V. Kasibotla, H. J. Dwayne, M. A. Stubblefield and R. M. Uppu (2012). "Molecular docking of bisphenol A and its nitrated and chlorinated metabolites onto human estrogen-related receptor-gamma." Biochemical and Biophysical Research Communications 426(2): 215-220.

Balmelli-Gallacchi, P., F. Schoumacher, J. W. Liu, U. Eppenberger, H. Mueller and D. Picard (1999). "A yeast-based bioassay for the determination of functional and nonfunctional estrogen receptors." Nucleic Acids Research 27(8): 1875-1881.

Beato, M., S. Chávez and M. Truss (1996). "Transcriptional regulation by steroid hormones." Steroids 61(4): 240-251.

Beggs, J. R. and P. R. Wilson (1991). "The Kaka Nestor meridionalis, a New Zealand parrot endangered by introduced wasps and mammals." Biological Conservation 56(1): 2338.

Benassayag, C., M. Perrot-Applanat and F. Ferre (2002). "Phytoestrogens as modulators of steroid action in target cells." Journal of Chromatography B 777(1-2): 233-248.

Bennett, C. R. and R. C. Cambie (1967). "Chemistry of the podocarpaceae-XIII.: Constituents of the heartwoods of Podocarpus nivalis Hook. and Podocarpus acutifolius Kirk." Phytochemistry 6(6): 883-887.

Berger, P. J., N. C. Negus and C. N. Rowsemitt (1987). "Effect of 6methoxybenzoxazolinone on sex ratio and breeding performance in Microtus montanus." Biology of Reproduction 36(2): 255-260.

Bergink, E. W., R. A. Wallace, J. A. Van de Berg, E. S. Bos, M. Gruber and G. Ab (1974). "Estrogen-induced synthesis of yolk proteins in roosters." American Zoologist 14(4): 1177-1193. 
Best, H. A. (1984). "The foods of Kakapo on Stewart Island as determined from their feeding sign." New Zealand Journal of Ecology 7: 71-83.

BirdLife International. (2012a). "Gallus gallus." In: IUCN 2012. IUCN Red List of Threatened Species. Version 2012.2., from www.iucnredlist.org.

BirdLife International. (2012b). "Nestor meridionalis." In: IUCN 2012. IUCN Red List of Threatened Species. Version 2012.2., from www.iucnredlist.org.

BirdLife International. (2012c). "Nestor notabilis." In: IUCN 2012. IUCN Red List of Threatened Species. Version 2012.2., from www.iucnredlist.org.

BirdLife International. (2012d). "Strigops habroptila." In: IUCN 2012. IUCN Red List of Threatened Species. Version 2012.2., from www.iucnredlist.org.

Blair, R. M., H. Fang, W. S. Branham, B. S. Hass, S. L. Dial, C. L. Moland, W. Tong, L. Shi, R. Perkins and D. M. Sheehan (2000). "The estrogen receptor relative binding affinities of 188 natural and xenochemicals: structural diversity of ligands." Toxicological Sciences 54(1): 138-153.

Bloor, S. J. (1995). "A survey of extracts of New Zealand indigenous plants for selected biological activities." New Zealand Journal of Botany 33(4): 523-540.

Bogers, R., E. Mutsaerds, J. Druke, D. F. De Roode, A. J. Murk, B. Van Der Burg and J. Legler (2006). "Estrogenic endpoints in fish early life-stage tests: Luciferase and vitellogenin induction in estrogen-responsive transgenic zebrafish." Environmental Toxicology and Chemistry 25(1): 241-247.

Boon, W. M., J. C. Kearvell, C. H. Daugherty and G. K. Chambers (2001). "Molecular systematics and conservation of kakariki (Cyanoramphus spp.)." Science for Conservation \# 176: Department of Conservation, Wellington, New Zealand.

Booth, N. L., C. R. Overk, P. Yao, S. Totura, Y. Deng, A. S. Hedayat, J. L. Bolton, G. F. Pauli and N. R. Farnsworth (2006). "Seasonal variation of red clover (Trifolium pratense L., Fabaceae) isoflavones and estrogenic activity." Journal of Agricultural and Food Chemistry 54(4): 1277-1282.

Boutin, S., L. A. Wauters, A. G. McAdam, M. M. Humphries, G. Tosi and A. A. Dhondt (2006). "Anticipatory reproduction and population growth in seed predators." Science 314(5807): 1928-1930.

Bovee, T. F. H., G. Bor, I. Becue, F. E. J. Daamen, M. B. M. van Duursen, S. Lehmann, G. Vollmer, R. De Maria, J. E. Fox, H. Witters, et al. (2009). "Inter-laboratory comparison of a yeast bioassay for the determination of estrogenic activity in biological samples." Analytica Chimica Acta 637(1-2): 265-272.

Bovee, T. F. H., G. Bor, H. H. Heskamp, R. L. A. P. Hoogenboom and M. W. F. Nielen (2006). "Validation and application of a robust yeast estrogen bioassay for the 
screening of estrogenic activity in animal feed." Food Additives \& Contaminants 23(6): 556-568.

Bovee, T. F. H., M. Thevis, A. R. M. Hamers, A. A. C. M. Peijnenburg, M. W. F. Nielen and W. G. E. J. Schoonen (2010). "SERMs and SARMs: Detection of their activities with yeast based bioassays." Journal of Steroid Biochemistry and Molecular Biology 118(1-2): 85-92.

Brandt, C. W. (1952). "Chemical differentiation of the genera Podocarpus and Dacrydium." Nature 170(4337): 1018-1019.

Brandt, C. W. and D. J. Ross (1948). "Podocarpic acid as a source of an oestrogenic hormone." Nature 161(4101): 892.

Brasch, D. J., B. L. Fankhauser and A. G. McDonald (1988). "A study of the glucofructofuranan from the New Zealand cabbage tree Cordyline australis." Carbohydrate Research 180(2): 315-324.

Briggs, L.H., R. C. Cambie, R. N. Seelye and A. D. Warth (1959). "Chemistry of the podocarpaceae-IV: Constituents of the heartwood of Podocarpus dacrydioides A. Rich." Tetrahedron 7(3): 270-276.

Briggs, L. H. and T. P. Cebalo (1959). "Chemistry of the podocarpaceae-II: The isolation of genistein from Podocarpus spicatus and the constitution of podospicatin." Tetrahedron 6(2): 145-147.

Briggs, L. H. and G. A. Nicholls (1954). "Chemistry of the Coprosma genus. Part VIII. The occurrence of asperuloside." Journal of the Chemical Society (Resumed): 3940-3943.

Brockie, R. E. (1986). "Periodic heavy flowering of New Zealand flax (Phormium, agavaceae)." New Zealand Journal of Botany 24(3): 381-386.

Brown, C. J., S. J. Goss, D. B. Lubahn, D. R. Joseph, E. M. Wilson, F. S. French and H. F. Willard (1989). "Androgen receptor locus on the human X chromosome: regional localization to Xq11-12 and description of a DNA polymorphism." American Journal of Human Genetics 44(2): 264-269.

Bryant, D. M. (2006). "Energetics of free-living Kakapo (Strigops habroptilus)." Notornis 53(1): 126-137.

Brzezinski, A. and A. Debi (1999). "Phytoestrogens: the "natural" selective estrogen receptor modulators?" European Journal of Obstetrics \& Gynecology and Reproductive Biology 85(1): 47-51.

Brzozowski, A. M., A. C. W. Pike, Z. Dauter, R. E. Hubbard, T. Bonn, O. Engström, L. Öhman, G. L. Greene, J.-Å. Gustafsson and M. Carlquist (1997). "Molecular basis of agonism and antagonism in the oestrogen receptor." Nature 389(6652): 753-758. 
Buller, W. L. (1873). A history of the birds of New Zealand. London, John Van Voorst.

Buller, W. L. and K. J. G. (1888). A History of the Birds of New Zealand. London, Published by the author.

Burns, K. C. (2012). "Masting in a temperate tree: Evidence for environmental prediction?" Austral Ecology 37(2): 175-182.

Burrows, L. E. and R. B. Allen (1991). "Silver beech (Nothofagus menziesii (Hook. f.) Oerst.) seedfall patterns in the Takitimu Range, South Island, New Zealand." New Zealand Journal of Botany 29: 361-365.

Butler, D. J. (2006). "The habitat, food and feeding ecology of kakapo in Fiordland: a synopsis from the unpublished MSc thesis of Richard Gray." Notornis 53(1): 55-79.

Camacho-Arroyo, I., V. I. Hernández-Molina, M. Rivas-Suárez, C. Guerra-Araiza and M. G. González-Morán (2007). "Changes in progesterone receptor isoforms content in the brain of immature, mature and aged male and female chickens." General and Comparative Endocrinology 150(3): 381-385.

Cambie, R. C. and L. Mander (1962). "Chemistry of the podocarpaceae-VI: Constituents of the heartwood of Podocorpus totara G. Benn." Tetrahedron 18(4): 465-475.

Cambie, R. C., W. R. J. Simpson and L. D. Colebrook (1963). "Chemistry of the podocarpaceae-VII: Podototarin and the constituents of the heartwood of Podocarpus hallii Kirk." Tetrahedron 19(1): 209-217.

Chang, C., J. Kokontis and S. Liao (1988). "Molecular cloning of human and rat complementary DNA encoding androgen receptors." Science 240(4850): 324-326.

Charles, G. D. (2004). "In vitro models in endocrine disruptor screening." Ilar Journal 45(4): 494-501.

Chemes, H. E., M. Dym and H. G. M. Raj (1979). "The role of gonadotropins and testosterone on initiation of spermatogenesis in the immature rat." Biology of Reproduction 21(1): 241-249.

Choong, C. S. and E. M. Wilson (1998). "Trinucleotide repeats in the human androgen receptor: a molecular basis for disease." Journal of Molecular Endocrinology 21(3): 235-257.

Christiansen, L. B., K. L. Pedersen, B. Korsgaard and P. Bjerregaard (1998). "Estrogenicity of xenobiotics in rainbow trout (Oncorhynchus mykiss) using in vivo synthesis of vitellogenin as a biomarker." Marine Environmental Research 46(1-5): 137-140.

Claessens, F., G. Verrijdt, E. Schoenmakers, A. Haelens, B. Peeters, G. Verhoeven and W. Rombauts (2001). "Selective DNA binding by the androgen receptor as a mechanism 
for hormone-specific gene regulation." Journal of Steroid Biochemistry and Molecular Biology 76(1-5): 23-30.

Clout, M. N., G. P. Elliot and B. C. Robertson (2002). "Effects of supplementary feeding on the offspring sex ratio of Kakapo: a dilemma for the conservation of a polygynous parrot." Biological Conservation 107(1): 13-18.

Cockrem, J. F. (1995). "Timing of seasonal breeding in birds, with particular reference to New Zealand birds." Reproduction, Fertility and Development 7(1): 1-19.

Cockrem, J. F. (2006). "The timing of breeding in the Kakapo (Strigops habroptilus)." Notornis 53(1): 153-159.

Coldham, N. G., M. Dave, S. Sivapathasundaram, D. P. McDonnell, C. Connor and M. J. Sauer (1997). "Evaluation of a recombinant yeast cell estrogen screening assay." Environmental Health Perspectives 105(7): 734-742.

Collins-Burow, B. M., M. E. Burow, B. N. Duong and J. A. McLachlan (2000). "Estrogenic and antiestrogenic activities of flavonoid phytochemicals through estrogen receptor binding-dependent and -independent mechanisms." Nutrition and Cancer 38(2): 229244.

Combs, S., K. Kaufmann, J. R. Field, R. D. Blakely and J. Meiler (2011). "Y95 and E444 interaction required for high-affinity $S$-citalopram binding in the human serotonin transporter." ACS Chemical Neuroscience 2(2): 75-81.

Conneely, O. M., B. Mulac-Jericevic, J. P. Lydon and F. J. De Mayo (2001). "Reproductive functions of the progesterone receptor isoforms: lessons from knock-out mice." Molecular and Cellular Endocrinology 179(1-2): 97-103.

Conneely, O. M., W. P. Sullivan, D. O. Toft, M. Birnbaumer, R. G. Cook, B. L. Maxwell, T. Zarucki-Schulz, G. L. Greene, W. T. Schrader and B. W. O'Malley (1986). "Molecular cloning of the chicken progesterone receptor." Science 233(4765): 767770 .

Cottam, Y. (2010). "Characteristics of green rimu fruit that might trigger breeding in Kakapo.” MSc thesis. Massey University, Palmerston North.

Cox, R. E., S. Yamamoto, A. Otto and B. R. T. Simoneit (2007). "Oxygenated di- and tricyclic diterpenoids of southern hemisphere conifers." Biochemical Systematics and Ecology 35(6): 342-362.

Croker, K., P. Nichols, M. Barbetti and N. Adams (2005). "Sheep infertility from pasture legumes." Department of Agriculture Western Australia, Farmnote(41).

Dalais, F. S., A. Meliala, N. Wattanapenpaiboon, M. Frydenberg, D. A. Suter, W. K. Thomson and M. L. Wahlqvist (2004). "Effects of a diet rich in phytoestrogens on 
prostate-specific antigen and sex hormones in men diagnosed with prostate cancer." Urology 64(3): 510-515.

Danielsen, M., L. Hinck and G. M. Ringold (1989). "Two amino acids within the knuckle of the first zinc finger specify DNA response element activation by the glucocorticoid receptor." Cell 57(7): 1131-1138.

Davis, I. W., K. Raha, M. S. Head and D. Baker (2009). "Blind docking of pharmaceutically relevant compounds using RosettaLigand." Protein Science 18(9): 1998-2002.

Dawson, A. (2008). "Control of the annual cycle in birds: endocrine constraints and plasticity in response to ecological variability." Philosophical Transactions of the Royal Society B: Biological Sciences 363(1497): 1621-1633.

Dawson, A., V. M. King, G. E. Bentley and G. F. Ball (2001). "Photoperiodic control of seasonality in birds." Journal of Biological Rhythms 16(4): 365-380.

Dawson, W. R. (1965). "Evaporative water losses of some Australian parrots." The Auk 82(1): 106-108.

de Kloet, R. S. and S. R. de Kloet (2005). "The evolution of the spindlin gene in birds: sequence analysis of an intron of the spindlin $\mathrm{W}$ and $\mathrm{Z}$ gene reveals four major divisions of the Psittaciformes." Molecular Phylogenetics and Evolution 36(3): 706721.

Death, A. K., K. C. Y. McGrath, R. Kazlauskas and D. J. Handelsman (2004). "Tetrahydrogestrinone is a potent androgen and progestin." Journal of Clinical Endocrinology \& Metabolism 89(5): 2498-2500.

Degen, G. H., P. Janning, P. Diel, H. Michna and H. M. Bolt (2002). "Transplacental transfer of the phytoestrogen daidzein in DA/Han rats." Archives of Toxicology 76(1): 23-29.

Del Hoyo, J., A. Elliott and J. Sargatal (1997). Handbook of the Birds of the World, vol. 4. Sandgrouse to Cuckoos. Barcelona, Lynx Editions.

Deluca, D., A. Krazeisen, R. Breitling, C. Prehn, G. Möller and J. Adamski (2005). "Inhibition of 17beta-hydroxysteroid dehydrogenases by phytoestrogens: Comparison with other steroid metabolizing enzymes." Journal of Steroid Biochemistry and Molecular Biology 93(2-5): 285-292.

Denier, X., J. Couteau, M. Baudrimont, E. M. Hill, J. Rotchell and C. Minier (2008). "In vitro study of the effects of cadmium on the activation of the estrogen response element using the YES screen." Marine Environmental Research 66(1): 108-110.

Department of Conservation. (2012a). "Life cycle of the Kakapo." from http://kakaporecovery.org.nz/life-cycle/. 
Department of Conservation. (2012b). "Then and Now." from http://kakaporecovery.org.nz/then-and-now/.

Dixon, D., C. E. Reed, A. B. Moore, E. A. Gibbs-Flournoy, E. P. Hines, E. A. Wallace, J. P. Stanko, Y. Lu, W. N. Jefferson, R. R. Newbold, et al. (2012). "Histopathologic changes in the uterus, cervix and vagina of immature CD-1 mice exposed to low doses of perfluorooctanoic acid (PFOA) in a uterotrophic assay." Reproductive Toxicology 33(4): 506-512.

Dixon, R. A. (2004). "Phytoestrogens." Annual Review of Plant Biology 55: 225-261.

Driscoll, M. D., G. Sathya, M. Muyan, C. M. Klinge, R. Hilf and R. A. Bambara (1998). "Sequence requirements for estrogen receptor binding to estrogen response elements." Journal of Biological Chemistry 273(45): 29321-29330.

Dufrene, L., J. F. Pageaux, A. Fanidi, J. M. Renoir, C. Laugier and E. E. Baulieu (1989). "Biochemical characterization and subunit structure of quail oviduct progesterone receptor." Journal of Steroid Biochemistry 32(5): 703-713.

Eason, D. K., G. P. Elliot, D. V. Merton, P. W. Jansen, G. A. Harper and R. J. Moorhouse (2006). "Breeding biology of Kakapo (Strigops habroptilus) on offshore island sanctuaries, 1990-2002." Notornis 53(1): 27-36.

Eason, D. K. and R. J. Moorhouse (2006). "Hand-rearing Kakapo (Strigops habroptilus), 1997-2005." Notornis 53(1): 116-125.

El Marzouk, S., R. Gahattamaneni, S. R. Joshi and W. M. Scovell (2008). "The plasticity of estrogen receptor-DNA complexes: Binding affinity and specificity of estrogen receptors to estrogen response element half-sites separated by variant spacers." Journal of Steroid Biochemistry and Molecular Biology. 110(1-2): 186-195.

Elliot, G. P., P. J. Dilks and C. F. J. O'Donnell (1996). "Nest site selection by Mohua and Yellow-crowned parakeets in beech forest in Fiordland, New Zealand." New Zealand Journal of Zoology 23(3): 267-278.

Elliott, G. P. (2006). "A simulation of the future of Kakapo." Notornis 53(1): 164-172.

Elliott, G. P., P. J. Dilks and C. F. J. O'Donnell (1996). "The ecology of Yellow-crowned parakeets (Cyanoramphus auriceps) in Nothofagus forest in Fiordland, New Zealand." New Zealand Journal of Zoology 23(3): 249-265.

Elliott, G. P. and J. Kemp (1999). "Conservation ecology of Kea (Nestor notabilis)." WWF New Zealand Final Report: WWF, Wellington, New Zealand.

Elliott, G. P., D. V. Merton and P. W. Jansen (2001). "Intensive management of a critically endangered species: the Kakapo." Biological Conservation 99(1): 121-133. 
Eng, F. C., H. S. Lee, J. Ferrara, T. M. Willson and J. H. White (1997). "Probing the structure and function of the estrogen receptor ligand binding domain by analysis of mutants with altered transactivation characteristics." Molecular and Cellular Biology 17(8): 4644-4653.

Escriva, H., S. Bertrand and V. Laudet (2004). "The evolution of the nuclear receptor superfamily." Essays in Biochemistry 40: 11-26.

Evans, R. M. (1988). "The steroid and thyroid hormone receptor superfamily." Science 240(4854): 889-895.

Fang, H., W. Tong, W. S. Branham, C. L. Moland, S. L. Dial, H. Hong, Q. Xie, R. Perkins, W. Owens and D. M. Sheehan (2003). "Study of 202 natural, synthetic, and environmental chemicals for binding to the androgen receptor." Chemical Research in Toxicology 16(10): 1338-1358.

Fang, Y., A. E. Fliss, D. M. Robins and A. J. Caplan (1996). "Hsp90 regulates androgen receptor hormone binding affinity in vivo." Journal of Biological Chemistry 271(45): 28697-28702.

Fidler, A. E., S. B. Lawrence and K. P. McNatty (2008). "An hypothesis to explain the linkage between Kakapo (Strigops habroptilus) breeding and the mast fruiting of their food trees." Wildlife Research 35(1): 1-7.

Fidler, A. E., S. Zwart, R. P. Pharis, R. J. Weston, S. B. Lawrence, P. Jansen, G. Elliot and D. V. Merton (2000). "Screening the foods of an endangered parrot, the Kakapo (Strigops habroptilus), for oestrogenic activity using a recombinant yeast bioassay." Reproduction, Fertility and Development 12(4): 191-199.

Fotsis, T., M. S. Pepper, R. Montesano, E. Aktas, S. Breit, L. Schweigerer, S. Rasku, K. Wähälä and H. Adlercreutz (1998). "7. Phytoestrogens and inhibition of angiogenesis." Baillière's Clinical Endocrinology and Metabolism 12(4): 649-666.

Fox, J. E., M. Starcevic, P. E. Jones, M. E. Burow and J. A. McLachlan (2004). "Phytoestrogen signaling and symbiotic gene activation are disrupted by endocrinedisrupting chemicals." Environmental Health Perspectives 112(6): 672-677.

Franco, C., L. Schwingel, I. Lula, R. D. Sinisterra, L. S. Koester and V. L. Bassani (2009). "Studies on coumestrol/ $\beta$-cyclodextrin association: Inclusion complex characterization." International Journal of Pharmaceutics 369(1-2): 5-11.

Gaido, K. W., L. S. Leonard, S. Lovell, J. C. Gould, D. Babaï, C. J. Portier and D. P. McDonnell (1997). "Evaluation of chemicals with endocrine modulating activity in a yeast-based steroid hormone receptor gene transcription assay." Toxicology and Applied Pharmacology 143(1): 205-212.

Gao, W., C. E. Bohl and J. T. Dalton (2005). "Chemistry and structural biology of androgen receptor." Chemical Reviews 105(9): 3352-3370. 
Gee, R. H., A. Charles, N. Taylor and P. D. Darbre (2008). "Oestrogenic and androgenic activity of triclosan in breast cancer cells." Journal of Applied Toxicology 28(1): 7891.

Gelmann, E. P. (2002). "Molecular biology of the androgen receptor." Journal of Clinical Oncology 20(13): 3001-3015.

Goffeau, A., B. Barrell, H. Bussey, R. W. Davis, B. Dujon, H. Feldmann, F. Galibert, J. D. Hoheisel, C. Jacq, M. Johnston et al. (1996). "Life with 6000 genes." Science 274(5287): 546-567.

Govindachari, T. R., K. Nagarajan and B. R. Pai (1956). "126. Chemical examination of Wedelia calendulacea. Part I. Structure of wedelolactone." Journal of the Chemical Society (Resumed): 629-632.

Gray, G. R. (1845). Birds. In: The zoology of the voyage of H.M.S. Erebus \& Terror : under the command of Captain Sir James Clark Ross, during the years 1839 to 1843. London, Smith, Elder and Co.

Gray, J. J., S. Moughon, C. Wang, O. Schueler-Furman, B. Kuhlman, C. A. Rohl and D. Baker (2003). "Protein-protein docking with simultaneous optimization of rigid-body displacement and side-chain conformations." Journal of Molecular Biology 331(1): 281-299.

Greene, T. C., R. G. Powlesland, P. J. Dilks and L. Moran (2004). "Research summary and options for conservation of Kaka (Nestor meridionalis)." DOC Science Internal Series \# 178: Department of Conservation, Wellington, New Zealand.

Grube, B. J., E. T. Eng, Y.-C. Kao, A. Kwon and S. Chen (2001). "White button mushroom phytochemicals inhibit aromatase activity and breast cancer cell proliferation." The Journal of Nutrition 131(12): 3288-3293.

Gunther, J. R., A. A. Parent and J. A. Katzenellenbogen (2009). "Alternative inhibition of androgen receptor signaling: peptidomimetic pyrimidines as direct androgen receptor/coactivator disruptors." ACS Chemical Biology 4(6): 435-440.

Gustafsson, J.-Å. (1999). "Estrogen receptor $\beta$ - a new dimension in estrogen mechanism of action." Journal of Endocrinology 163(3): 379-383.

Guyton, A. and J. Hall (2006). Textbook of Medical Physiology. Philadelphia, Elsevier.

Harper, G. A. (2005). "Heavy Rimu (Dacrydium cupressinum) mast seeding and rat (Rattus spp.) population eruptions on Stewart Island/Rakiura." New Zealand Journal of Zoology. 32(3): 155-162.

Harper, G. A., G. P. Elliott, D. K. Eason and R. J. Moorhouse (2006). "What triggers nesting of Kakapo (Strigops habroptilus)?" Notornis 53(1): 160-163. 
Harris, D. M., E. Besselink, S. M. Henning, V. L. W. Go and D. Heber (2005). "Phytoestrogens induce differential estrogen receptor alpha- or beta-mediated responses in transfected breast cancer cells." Experimental Biology and Medicine 230(8): 558-568.

Hau, M., N. Perfito and I. T. Moore (2008). "Timing of breeding in tropical birds: Mechanisms and evolutionary implications." Ornitologia Neotropical 19(Suppl.): 3959.

Hawkins, M. B. and P. Thomas (2004). "The unusual binding properties of the third distinct teleost estrogen receptor subtype ERßa are accompanied by highly conserved amino acid changes in the ligand binding domain." Endocrinology 145(6): 2968-2977.

Hawkins, M. B., J. W. Thornton, D. Crews, J. K. Skipper, A. Dotte and P. Thomas (2000). "Identification of a third distinct estrogen receptor and reclassification of estrogen receptors in teleosts." Proceedings of the National Academy of Sciences 97(20): 10751-10756.

He, B., J. A. Kemppainen, J. J. Voegel, H. Gronemeyer and E. M. Wilson (1999). "Activation function 2 in the human androgen receptor ligand binding domain mediates interdomain communication with the $\mathrm{NH}_{2}$-terminal domain." Journal of Biological Chemistry 274(52): 37219-37225.

Heather, B. and H. Robertson (2005). The field guide to the birds of New Zealand, Auckland, Penguin Books.

Heemers, H. V. and D. J. Tindall (2007). "Androgen receptor (AR) coregulators: A diversity of functions converging on and regulating the AR transcriptional complex." Endocrine Reviews 28(7): 778-808.

Henry, H. L. and A. W. Norman (2003). Encyclopedia of Hormones, San Diego, Academic Press.

Henry, R. (1903). The habits of the flightless birds of New Zealand : with notes on other New Zealand birds. Wellington, Government Printer.

Hertog, M. G. L., P. C. H. Hollman and M. B. Katan (1992). "Content of potentially anticarcinogenic flavonoids of 28 vegetables and 9 fruits commonly consumed in the Netherlands." Journal of Agricultural and Food Chemistry 40(12): 2379-2383.

Higgins, P. J. (1999). Handbook of Australian, New Zealand and Antarctic Birds, Melbourne, Oxford University Press.

Hillerns, P. I., Y. Zu, Y.-J. Fu and M. Wink (2005). "Binding of phytoestrogens to rat uterine estrogen receptors and human sex hormone-binding globulins." Zeitschrift fur Naturforschung 60(7-8): 649-656. 
Hillier, L. W., W. Miller, E. Birney, W. Warren, R. C. Hardison, C. P. Ponting, P. Bork, D. W. Burt, M. A. Groenen, M. E. Delany et al. (2004). "Sequence and comparative analysis of the chicken genome provide unique perspectives on vertebrate evolution." Nature 432(7018): 695-716.

Hillisch, A., J. von Langen, B. Menzenbach, P. Droescher, G. Kaufmann, B. Schneider and W. Elger (2003). "The significance of the 20-carbonyl group of progesterone in steroid receptor binding: a molecular dynamics and structure-based ligand design study." Steroids 68(10-13): 869-878.

Hinkley, S. F. R., N. B. Perry and R. T. Weavers (1994). "Confirmation of structure and absolute stereochemistry of 9-epi- $\beta$-caryophyllene from Dacrydium cupressinum." Phytochemistry 35(6): 1489-1494.

Hintemann, T., C. Schneider, H. F. Schöler and R. J. Schneider (2006). "Field study using two immunoassays for the determination of estradiol and ethinylestradiol in the aquatic environment." Water Research 40(12): 2287-2294.

Horrocks, M., J. Salter, J. Braggins, S. Nichol, R. Moorhouse and G. Elliott (2008). "Plant microfossil analysis of coprolites of the critically endangered Kakapo (Strigops habroptilus) parrot from New Zealand." Review of Palaeobotany and Palynology 149(3-4): 229-245.

Hu, Y., Z. Zhang, L. Sun, D. Zhu, Q. Liu, J. Jiao, J. Li and M. Qi (2013). "The estrogenic effects of benzylparaben at low doses based on uterotrophic assay in immature SD rats." Food and Chemical Toxicology 53: 69-74.

Hudelson, K. S. (1996). "A review of the mechanisms of avian reproduction and their clinical applications." Seminars in Avian and Exotic Pet Medicine 5(4): 189-198.

Hur, E., S. J. Pfaff, E. S. Payne, H. Grøn, B. M. Buehrer and R. J. Fletterick (2004). "Recognition and Accommodation at the Androgen Receptor Coactivator Binding Interface." PLOS Biology 2(9): e274.

Jackson, J. R. (1963). "The nesting of Keas." Notornis 10(7): 319-337.

Jalal, M. A. F., D. J. Read and E. Haslam (1982). "Phenolic composition and its seasonal variation in Calluna vulgaris." Phytochemistry 21(6): 1397-1401.

Jansen, P. W. (2006). "Kakapo recovery: the basis of decision-making." Notornis 53(1): 184190.

Jenster, G., H. A. G. M. van der Korput, J. Trapman and A. O. Brinkmann (1995). "Identification of two transcription activation units in the N-terminal domain of the human androgen receptor." Journal of Biological Chemistry 270(13): 7341-7346.

Joannou, G. E., G. E. Kelly, A. Y. Reeder, M. Waring and C. Nelson (1995). "A urinary profile study of dietary phytoestrogens. The identification and mode of metabolism of 
new isoflavonoids." Journal of Steroid Biochemistry and Molecular Biology 54(3-4): 167-184.

Johnson, P. N. (1976). "Vegetation associated with Kakapo (Strigops habroptilus Gray) in Sinbad Gully, Fiordland, New Zealand." New Zealand Journal of Botany 14(2): 151159.

Jones, D. (1987). "Feeding ecology of the Cockatiel, Nymphicus hollandicus, in a graingrowing area." Australian Wildlife Research 14(1): 105-115.

Kang, K.-S., H.-S. Kim, D.-Y. Ryu, J.-H. Che and Y.-S. Lee (2000). "Immature uterotrophic assay is more sensitive than ovariectomized uterotrophic assay for the detection of estrogenicity of $p$-nonylphenol in Sprague-Dawley rats." Toxicology Letters 118(12): 109-115.

Karowe, D. N. and J. K. Radi (2011). "Are the phytoestrogens genistein and daidzein antiherbivore defenses? A test using the Gypsy Moth (Lymantria dispar)." Journal of Chemical Ecology 37(8): 830-837.

Katoh, H., Y. Ogino and G. Yamada (2006). "Cloning and expression analysis of androgen receptor gene in chicken embryogenesis." FEBS Letters 580(6): 1607-1615.

Kelly, D. (1994). "The evolutionary ecology of mast seeding." Trends in Ecology \& Evolution 9(12): 465-470.

Kelly, D., A. L. Harrison, W. G. Lee, I. J. Payton, P. R. Wilson and E. M. Schauber (2000). "Predator satiation and extreme mast seeding in 11 species of Chionochloa (Poaceae)." Oikos 90(3): 477-488.

Kelly, D., M. H. Turnbull, R. P. Pharis and M. S. Sarfati (2008). "Mast seeding, predator satiation, and temperature cues in Chionochloa (Poaceae)." Population Ecology 50(4): 343-355.

Kelly, G. E., C. Nelson, M. A Waring, G. E. Joannou and A. Y. Reeder (1993). "Metabolites of dietary (soya) isoflavones in human urine." Clinica Chimica Acta 223(1-2): 9-22.

King, C. M. (1983). "The relationships between Beech (Nothofagus sp.) seedfall and populations of mice (Mus musculus), and the demographic and dietary responses of stoats (Mustela erminea), in three New Zealand forests." Journal of Animal Ecology 52(1): 141-166.

Kingston-Smith, A. H. and M. K. Theodorou (2000). "Post-ingestion metabolism of fresh forage." New Phytologist. 148(1): 37-55.

Klein-Hitpass, L., G. U. Ryffel, E. Heitlinger and A. C. B. Cato (1988). "A 13 bp palindrome is a functional estrogen responsive element and interacts specifically with estrogen receptor." Nucleic Acids Research 16(2): 647-663. 
Klinge, C. M. (2001). "Estrogen receptor interaction with estrogen response elements." Nucleic Acids Research 29(14): 2905-2919.

Klinge, C. M., S. C. Jernigan, S. L. Smith, V. V. Tyulmenkov and P. C. Kulakosky (2001). "Estrogen response element sequence impacts the conformation and transcriptional activity of estrogen receptor $\alpha . "$ Molecular and Cellular Endocrinology. 174(1): 151166.

Koide, A., C. Zhao, M. Naganuma, J. Abrams, S. Deighton-Collins, D. F. Skafar and S. Koide (2007). "Identification of regions within the F domain of the human estrogen receptor $\alpha$ that are important for modulating transactivation and protein-protein interactions." Molecular Endocrinology 21(4): 829-842.

Korach, K. S. (1994). "Insights from the study of animals lacking functional estrogen receptor." Science 266(5190): 1524-1527.

Kostelac, D., G. Rechkemmer and K. Briviba (2003). "Phytoestrogens modulate binding response of estrogen receptors $\alpha$ and $\beta$ to the estrogen response element." Journal of Agricultural and Food Chemistry 51(26): 7632-7635.

Krust, A., S. Green, P. Argos, V. Kumar, P. Walter, J. -M. Bornert and P. Chambon (1986). "The chicken oestrogen receptor sequence: homology with v-erbA and the human oestrogen and glucocorticoid receptors." EMBO Journal 5(5): 891-897.

Kuiper, G. G. J. M., E. Enmark, M. Pelto-Huikko, S. Nilsson and J.-Å. Gustafsson (1996). "Cloning of a novel estrogen receptor expressed in rat prostate and ovary." Proceedings of the National Academy of Sciences 93(12): 5925-5930.

Kuiper, G. G. J. M., J. G. Lemmen, B. Carlsson, J. C. Corton, S. H. Safe, P. T. van der Saag, B. van der Burg and J.-A. Gustafsson (1998). "Interaction of estrogenic chemicals and phytoestrogens with estrogen receptor $\beta . "$ Endocrinology 139(10): 4252-4263.

Kumar, R. and E. B. Thompson (2003). "Transactivation functions of the N-terminal domains of nuclear hormone receptors: protein folding and coactivator interactions." Molecular Endocrinology 17(1): 1-10.

Kumar, V., S. Green, G. Stack, M. Berry, J.-R. Jin and P. Chambon (1987). "Functional domains of the human estrogen receptor." Cell 51(6): 941-951.

Labov, J. B. (1977). "Phytoestrogens and mammalian reproduction." Comparative Biochemistry and Physiology Part A: Physiology 57(1): 3-9.

Laskowski, R. A. and M. B. Swindells (2011). "LigPlot+: Multiple ligand-protein interaction diagrams for drug discovery." Journal of Chemical Information and Modeling 51(10): 2778-2786.

Laudet, V. (1997). "Evolution of the nuclear receptor superfamily: early diversification from an ancestral orphan receptor." Journal of Molecular Endocrinology 19(3): 207-226. 
Laudet, V., C. Hänni, J. Coll, F. Catzeflis and D. Stéhelin (1992). "Evolution of the nuclear receptor gene superfamily." EMBO Journal 11(3): 1003-1013.

LeBlanc, G. A., D. O. Norris, W. Kloas, S. W. Kullman, W. S. Baldwin and J. M. Greally (2011). "Draft detailed review paper state of the science on novel in vitro and in vivo screening and testing methods and endpoints for evaluating endocrine disruptors." Paris, Organisation for Economic Cooperation and Development.

Lee, H. J., Y. S. Lee, H. B. Kwon and K. Lee (2003). "Novel yeast bioassay system for detection of androgenic and antiandrogenic compounds." Toxicology in Vitro 17(2): 237-244.

Lees, J. A., S. E. Fawell and M. G. Parker (1989). "Identification of two transactivation domains in the mouse oestrogen receptor." Nucleic Acids Research 17(14): 54775488 .

Legler, J., J. L. M. Broekhof, A. Brouwer, P. H. Lanser, A. J. Murk, P. T. van der Saag, A. D. Vethaak, P. Wester, D. Zivkovic and B. van der Burg (2000). "A novel in vivo bioassay for (xeno-)estrogens using transgenic zebrafish." Environmental Science \& Technology 34(20): 4439-4444.

Leitman, D. C., S. Paruthiyil, O. I. Vivar, E. F. Saunier, C. B. Herber, I. Cohen, M. Tagliaferri and T. P. Speed (2010). "Regulation of specific target genes and biological responses by estrogen receptor subtype agonists." Current Opinion in Pharmacology 10(6): 629-636.

Leitner, S., T. J. Van't Hof and M. Gahr (2003). "Flexible reproduction in wild canaries is independent of photoperiod." General and Comparative Endocrinology 130(2): 102108.

Lemmon, G., K. Kaufmann and J. Meiler (2012). "Prediction of HIV-1 Protease/Inhibitor Affinity using RosettaLigand." Chemical Biology \& Drug Design 79(6): 888-896.

Leopold, A. S., M. Erwin, J. Oh and B. Browning (1976). "Phytoestrogens: Adverse effects on reproduction in California Quail." Science 191(4222): 98-100.

Lightfoot, R. J., J. F. Smith, I. A. Cumming, T. Marshall, R. H. Wroth and H. Hearnshaw (1974). "Infertility in ewes caused by prolonged grazing on oestrogenic pastures: Oestrus, fertilization and cervical mucus." Australian Journal of Biological Sciences 27(4): 409-414.

Lloyd, P. (1999). "Rainfall as a breeding stimulus and clutch size determinant in South African arid-zone birds." IBIS 141(4): 637-643.

Long, M., T. Krüger, M. Ghisari and E. C. Bonefeld-Jørgensen (2012). "Effects of selected phytoestrogens and their mixtures on the function of the thyroid hormone and the aryl hydrocarbon receptor." Nutrition and Cancer 64(7): 1008-1019. 
Longcope, C., T. Kato and R. Horton (1969). "Conversion of blood androgens to estrogens in normal adult men and women." Journal of Clinical Investigation 48(12): 2191-2201.

Lu, A., J. C. Beehner, N. M. Czekala, A. Koenig, E. Larney and C. Borries (2010). "Phytochemicals and reproductive function in wild female Phayre's leaf monkeys (Trachypithecus phayrei crepusculus)." Hormones and Behavior 59(1): 28-36.

Lubahn, D. B., D. R. Joseph, P. M. Sullivan, H. F. Willard, F. S. French and E. M. Wilson (1988). "Cloning of human androgen receptor complementary DNA and localization to the X chromosome." Science 240(4850): 327-330.

Lubahn, D. B., T. R. Brown, J. A. Simental, H. N. Higgs, C. J. Migeon, E. M. Wilson and F. S. French (1989). "Sequence of the intron/exon junctions of the coding region of the human androgen receptor gene and identification of a point mutation in a family with complete androgen insensitivity." Proceedings of the National Academy of Sciences 86(23): 9534-9538.

Lundh, T. (1995). "Metabolism of estrogenic isoflavones in domestic animals." Experimental Biology and Medicine 208(1): 33-39.

Madauss, K. P., E. L. Stewart and S. P. Williams (2007). "The evolution of progesterone receptor ligands." Medicinal Research Reviews 27(3): 374-400.

Maggiolini, M., A. G. Recchia, D. Bonofiglio, S. Catalano, A. Vivacqua, A. Carpino, V. Rago, R. Rossi and S. Andò (2005). "The red wine phenolics piceatannol and myricetin act as agonists for estrogen receptor $\alpha$ in human breast cancer cells." Journal of Molecular Endocrinology 35(2): 269-281.

Mangelsdorf, D. J., C. Thummel, M. Beato, P. Herrlich, G. Schütz, K. Umesono, B. Blumberg, P. Kastner, M. Mark, P. Chambon, et al. (1995). "The nuclear receptor superfamily: the second decade." Cell 83(6): 835-839.

Marcelli, M., W. D. Tilley, C. M. Wilson, J. E. Griffin, J. D. Wilson and M. J. McPhaulf (1990). "Definition of the human androgen receptor gene structure permits the identification of mutations that cause androgen resistance: premature termination of the receptor protein at amino acid residue 588 causes complete androgen resistance." Molecular Endocrinology 4(8): 1105-1116.

Marrian, G. F. and G. A. D. Haslewood (1932). "Equol, a new inactive phenol isolated from the ketohydroxyoestrin fraction of mares' urine." Biochemical Journal 26(4): 12271232.

Matias, P. M., P. Donner, R. Coelho, M. Thomaz, C. Peixoto, S. Macedo, N. Otto, S. Joschko, P. Scholz, A. Wegg, et al. (2000). "Structural evidence for ligand specificity in the binding domain of the human androgen receptor: Implications for pathogenic gene mutations." Journal of Biological Chemistry 275(34): 26164-26171. 
Matsumura, A., A. Ghosh, G. S. Pope and P. D. Darbre (2005). "Comparative study of oestrogenic properties of eight phytoestrogens in MCF7 human breast cancer cells." Journal of Steroid Biochemistry and Molecular Biology 94(5): 431-443.

Mazur, W. and H. Adlercreutz (1998). "Natural and anthropogenic environmental oestrogens: the scientific basis for risk assessment. Naturally occurring oestrogens in food." Journal of Pure and Applied Chemistry 70(9): 1759-1776.

McEwan, I. J. (2009). "Nuclear receptors: one big family." In: The Nuclear Receptor Superfamily: Methods and Protocols, vol 505. New York, Humana Press.

McGimpsey, J. A., M. H. Douglas, J. W. Van Klink, D. A. Beauregard and N. B. Perry (1994). "Seasonal variation in essential oil yield and composition from naturalized Thymus vulgaris L. in New Zealand." Flavour and Fragrance Journal 9(6): 347-352.

McKenna, T. J., U. Fearon, D. Clarke and S. K. Cunningham (1997). "2. A critical review of the origin and control of adrenal androgens." Baillière's Clinical Obstetrics and Gynaecology 11(2): 229-248.

McMurry, L. M., M. Oethinger and S. B. Levy (1998). "Triclosan targets lipid synthesis." Nature 394(6693): 531-532.

McPhaul, M. J., M. Marcelli, W. D. Tilley, J. E. Griffin and J. D. Wilson (1991). "Androgen resistance caused by mutations in the androgen receptor gene." FASEB Journal 5(14): 2910-2915.

Medlock, K. L., W. S. Branham and D. M. Sheehan (1995). "Effects of coumestrol and equol on the developing reproductive tract of the rat." Experimental Biology and Medicine 208(1): 67-71.

Meiler, J. and D. Baker (2006). "ROSETTALIGAND: protein-small molecule docking with full side-chain flexibility." Proteins 65(3): 538-548.

Mellanen, P., T. Petänen, J. Lehtimäki, S. Mäkelä, G. Bylund, B. Holmbom, E. Mannila, A. Oikari and R. Santti (1996). "Wood-derived estrogens: Studies in vitro with breast cancer cell lines and in vivo in trout." Toxicology and Applied Pharmacology 136(2): 381-388.

Merton, D. V., R. B. Morris and I. A. E. Atkinson (1984). "Lek behaviour in a parrot: the Kakapo Strigops habroptilus of New Zealand." IBIS 126(3): 277-283.

Metzger, D., J. H. White and P. Chambon (1988). "The human oestrogen receptor functions in yeast." Nature 334(6177): 31-36.

Michelini, E., P. Leskinen, M. Virta, M. Karp and A. Roda (2005). "A new recombinant cellbased bioluminescent assay for sensitive androgen-like compound detection." Biosensors and Bioelectronics 20(11): 2261-2267. 
Millam, J. R., B. Zhang and M. E. El Halawani (1996). "Egg production of Cockatiels (Nymphicus hollandicus) is influenced by number of eggs in nest after incubation begins." General and Comparative Endocrinology 101(2): 205-210.

Mills, A. D., L. L. Crawford, M. Domjan and J. M. Faure (1997). "The behavior of the Japanese or domestic Quail Coturnix japonica." Neuroscience \& Biobehavioral Reviews 21(3): 261-281.

Miyamoto, T., T. Kakizawa, K. Ichikawa, S.-I. Nishio, T. Takeda, S. Suzuki, A. Kaneko, M. Kumagai, J.-I. Mori, K. Yamashita et al. (2001). "The role of hinge domain in heterodimerization and specific DNA recognition by nuclear receptors." Molecular and Cellular Endocrinology 181(1): 229-238.

Möcklinghoff, S., R. Rose, M. Carraz, A. Visser, C, Ottmann and L. Brunsveld (2010). "Synthesis and crystal structure of a phosphorylated estrogen receptor ligand binding domain." ChemBioChem 11(16): 2251-2254.

Monks, A. and D. Kelly (2006). "Testing the resource-matching hypothesis in the mast seeding tree Nothofagus truncata (Fagaceae)." Austral Ecology 31(3): 366-375.

Moore, T. W., C. G. Mayne and J. A. Katzenellenbogen (2009). "Minireview: Not picking pockets: Nuclear receptor alternate-site modulators (NRAMs)." Molecular Endocrinology 24(4): 683-695.

Moorhouse, R. J. (1997). "The diet of the North Island Kaka (Nestor meridionalis septentrionalis) on Kapiti Island." New Zealand Journal of Ecology. 21(2): 141-152.

Moras, D. and H. Gronemeyer (1998). "The nuclear receptor ligand-binding domain: Structure and function." Current Opinion in Cell Biology 10(3): 384-391.

Morito, K., T. Hirose, J. Kinjo, T. Hirakawa, M. Okawa, T. Nohara, S. Ogawa, S. Inoue, M. Muramatsu and Y. Masamune (2001). "Interaction of phytoestrogens with estrogen receptors $\alpha$ and $\beta . "$ Biological and Pharmaceutical Bulletin 24(4): 351-356.

Morris, G. M., R. Huey, W. Lindstrom, M. F. Sanner, R. K. Belew, D. S. Goodsell and A. J. Olson (2009). "AutoDock4 and AutoDockTools4: Automated docking with selective receptor flexibility." Journal of Computational Chemistry 30(16): 2785-2791.

Mortensen, K. (2009). "Screening of putative oestrogenic compounds using a recombinant yeast bioassay." BBMedSc(Hons) thesis. Victoria University of Wellington, Wellington.

Mosselman, S., J. Polman and R. Dijkema (1996). "ERß: Identification and characterization of a novel human estrogen receptor." FEBS Letters 392(1): 49-53.

Mueller, S. O., S. Simon, K. Chae, M. Metzler and K. S. Korach (2004). "Phytoestrogens and their human metabolites show distinct agonistic and antagonistic properties on 
estrogen receptor $\alpha(\mathrm{ER} \alpha)$ and ER $\beta$ in human cells." Toxicological Sciences 80(1): $14-25$.

Mulac-Jericevic, B. and O. M. Conneely (2004). "Reproductive tissue selective actions of progesterone receptors." Reproduction 128(2): 139-146.

Muthyala, R. S., Y. H. Ju, S. Sheng, L. D. Williams, D. R. Doerge, B. S. Katzenellenbogen, W. G. Helferich and J. A. Katzenellenbogen (2004). "Equol, a natural estrogenic metabolite from soy isoflavones: Convenient preparation and resolution of $R$ - and $S$ equols and their differing binding and biological activity through estrogen receptors alpha and beta." Bioorganic \& Medicinal Chemistry 12(6): 1559-1567.

Nannemann, D. P., K. W. Kaufmann, J. Meiler and B. O. Bachmann (2010). "Design and directed evolution of a dideoxy purine nucleoside phosphorylase." Protein Engineering Design \& Selection 23(8): 607-616.

National Center for Biotechnology Information. (2008a). "AR androgen receptor [ Homo sapiens (human) ]." from http://www.ncbi.nlm.nih.gov/gene/367.

National Center for Biotechnology Information. (2008b). "ESR1 estrogen receptor 1 [ Homo sapiens (human) ]." from http://www.ncbi.nlm.nih.gov/gene/2099.

National Center for Biotechnology Information. (2008c). "ESR2 estrogen receptor 2 (ER beta) [ Homo sapiens (human) ]." from http://www.ncbi.nlm.nih.gov/gene/2100.

National Center for Biotechnology Information. (2011). "PGR progesterone receptor [ Homo sapiens (human) ] - Gene." from http://www.ncbi.nlm.nih.gov/gene/5241.

Nelson, L. R. and S. E. Bulun (2001). "Estrogen production and action." Journal of the American Academy of Dermatology 45(3, Supplement): S116-S124.

Nemeth, K. and M. K. Piskula (2007). "Food content, processing, absorption and metabolism of onion flavonoids." Critical Reviews in Food Science and Nutrition 47(4): 397-409.

Nichols, C. R. (1991). "A comparison of the reproductive and behavioural differences in feral and domestic Japanese Quail." MSc thesis. University of British Columbia, Vancouver.

Nikov, G. N., N. E. Hopkins, S. Boue and W. L. Alworth (2000). "Interactions of dietary estrogens with human estrogen receptors and the effect on estrogen receptor-estrogen response element complex formation." Environmental Health Perspectives 108(9): 867-872.

Nilsson, M., P. Åman, H. Härkönen, G. Hallmans, K. E. B. Knudsen, W. Mazur and H. Adlercreutz (1997). "Content of nutrients and lignans in roller milled fractions of rye." Journal of the Science of Food and Agriculture. 73(2): 143-148. 
Norton, D. A. and D. Kelly (1988). "Mast seeding over 33 years by Dacrydium cupressinum Lamb. (Rimu) (Podocarpaceae) in New Zealand: the importance of economies of scale." Functional Ecology 2(3): 399-408.

Nose, T., T. Tokunaga and Y. Shimohigashi (2009). "Exploration of endocrine-disrupting chemicals on estrogen receptor $\alpha$ by the agonist/antagonist differential-docking screening (AADS) method: 4-(1-Adamantyl)phenol as a potent endocrine disruptor candidate." Toxicology Letters 191(1): 33-39.

NRNC (1999). "A unified nomenclature system for the nuclear receptor superfamily." Cell 97(2): 161-163.

O'Donnell, C. F. J. and P. J. Dilks (1994). "Foods and foraging of forest birds in temperate rainforest, South Westland, New Zealand." New Zealand Journal of Ecology 18(2): 87-107.

Odum, J., P. A. Lefevre, S. Tittensor, D. Paton, E. J. Routledge, N. A. Beresford, J. P. Sumpter and J. Ashby (1997). "The rodent uterotrophic assay: Critical protocol features, studies with nonyl phenols, and comparison with a yeast estrogenicity assay." Regulatory Toxicology and Pharmacology 25(2): 176-188.

Ogawa, S., S. Inoue, T. Watanabe, H. Hiroi, A. Orimo, T. Hosoi, Y. Ouchi and M. Muramatsu (1998). "The complete primary structure of human estrogen receptor $\beta$ ( $\mathrm{hER} \beta$ ) and its heterodimerization with ER $\alpha$ in vivo and in vitro." Biochemical and Biophysical Research Communications 243(1): 122-126.

Ososki, A. L. and E. J. Kennelly (2003). "Phytoestrogens: A review of the present state of research." Phytotherapy Research 17(8): 845-869.

Palmer, S., C. A. Campen, G. F. Allan, P. Rybczynski, D. Haynes-Johnson, A. Hutchins, P. Kraft, M. Kiddoe, M.-T. Lai, E. Lombardi, et al. (2000). "Nonsteroidal progesterone receptor ligands with unprecedented receptor selectivity." Biochemistry and Molecular Biology 75(1): 33-42.

Patisaul, H. B. (2012). "Infertility in the Southern White Rhino: Is diet the source of the problem?" Endocrinology 153(4): 1568-1571.

Payne, A. H. and D. B. Hales (2004). "Overview of steroidogenic enzymes in the pathway from cholesterol to active steroid hormones." Endocrine Reviews 25(6): 947-970.

Pearlman, D. A., D. A. Case, J. W. Caldwell, W. S. Ross, T. E. Cheatham III, S. DeBolt, D. Ferguson, G. Seibel and P. Kollman (1995). "AMBER, a package of computer programs for applying molecular mechanics, normal mode analysis, molecular dynamics and free energy calculations to simulate the structural and energetic properties of molecules." Computer Physics Communications 91(1-3): 1-41. 
Pepper, M. S., S. J. Hazel, M. Hümpel and W.-D. Schleuning (2004). "8-prenylnaringenin, a novel phytoestrogen, inhibits angiogenesis in vitro and in vivo." Journal of Cellular Physiology 199(1): 98-107.

Perry, N. B. and R. T. Weavers (1985). "Infraspecific variation of foliage diterpenes of Dacrydium cupressinum." Phytochemistry 24(10): 2233-2237.

Pettersson, K. and J.-Å. Gustafsson (2001). "Role of estrogen receptor beta in estrogen action." Annual Review of Physiology 63: 165-192.

Pike, A. C. W., A. M. Brzozowski, R. E. Hubbard, T. Bonn, A.-G. Thorsell, O. Engström, J. Ljunggren, J.-A. Gustafsson and M. Carlquist (1999). "Structure of the ligand-binding domain of oestrogen receptor beta in the presence of a partial agonist and a full antagonist." EMBO Journal 18(17): 4608-4618.

Pizzey, G. (1980). A Field Guide to the Birds of Australia. Princeton, Princeton University Press.

Podvinec, M., M. R. Kaufmann, C. Handschin and U. A. Meyer (2002). "NUBIScan, an in silico approach for prediction of nuclear receptor response elements." Molecular Endocrinology 16(6): 1269-1279.

Polzonetti-Magni, A. M., G. Mosconi, L. Soverchia, S. Kikuyama and O. Carnevali (2004). "Multihormonal control of vitellogenesis in lower vertebrates." International Review of Cytology 239: 1-46.

Poppelwell, D. (1912). "Notes on the plant covering of Codfish Island and the rugged islands." Transactions of the Royal Society of New Zealand 44: 76-85.

Powlesland, R. (1989). Kakapo (Strigops habroptilus) Recovery Plan, 1987-1994, Department of Conservation, Wellington, New Zealand.

Powlesland, R. G. and B. D. Lloyd (1994). "Use of supplementary feeding to induce breeding in free-living Kakapo Strigops habroptilus in New Zealand." Biological Conservation 69(1): 97-106.

Powlesland, R. G., B. D. Lloyd, H. A. Best and D. V. Merton (1992). "Breeding biology of the Kakapo Strigops habroptilus on Stewart Island, New Zealand." IBIS 134(4): 361373.

Powlesland, R. G., D. V. Merton and J. F. Cockrem (2006). "A parrot apart: the natural history of the Kakapo (Strigops habroptilus), and the context of its conservation management." Notornis 53(1): 3-26.

Powlesland, R. G., T. C. Greene, P. J. Dilks, R. J. Moorhouse, L. R. Moran, G. Taylor, A. Jones, D. E. Wills, C. K. August and A. C. L. August (2009). "Breeding biology of the New Zealand Kaka (Nestor meridionalis) (Psittacidae, Nestorinae)." Notornis 56(1): 11-33. 
Rarey, M., B. Kramer, T. Lengauer and G. Klebe (1996). "A fast flexible docking method using an incremental construction algorithm." Journal of Molecular Biology 261(3): 470-489.

Rasool, N., A. Qasim Khan, V. Uddin Ahmad and A. Malik (1991). "A benzoquinone and a coumestan from Psoralea plicata." Phytochemistry 30(8): 2800-2803.

Rees, M., D. Kelly and O. N. Bjørnstad (2002). "Snow tussocks, chaos, and the evolution of mast seeding." American Naturalist 160(1): 44-59.

Robinson, J. E. and B. K. Follett (1982). "Photoperiodism in Japanese Quail: the termination of seasonal breeding by photorefractoriness." Proceedings of the Royal Society of London. Series B. Biological Sciences 215(1198): 95-116.

Rochester, J. R. and J. R. Millam (2009). "Phytoestrogens and avian reproduction: Exploring the evolution and function of phytoestrogens and possible role of plant compounds in the breeding ecology of wild birds." Comparative Biochemistry and Physiology - Part A: Molecular \& Integrative Physiology 154(3): 279-288.

Rodríguez-De Lara, R., C. A. Herrera-Corredor, M. Fallas-López, R. Rangel-Santos, V. Mariscal-Aguayo, P. A. Martínez-Hernández and J. G. García-Muñiz (2007). "Influence of supplemental dietary sprouted wheat on reproduction in artificially inseminated doe rabbits." Animal Reproduction Science 99(1-2): 145-155.

Rodriguez, A. L., A. Tamrazi, M. L. Collins and J. A. Katzenellenbogen (2004). "Design, synthesis, and in vitro biological evaluation of small molecule inhibitors of estrogen receptor $\alpha$ coactivator binding." Journal of Medicinal Chemistry 47(3): 600-611.

Routledge, E. J. and J. P. Sumpter (1996). "Estrogenic activity of surfactants and some of their degradation products assessed using a recombinant yeast screen." Environmental Toxicology and Chemistry 15(3): 241-248.

Rowan, W. (1925). "Relation of light to bird migration and developmental changes." Nature 115(2892): 494-495.

Rowan, W. (1926). On Photoperiodism, Reproductive Periodicity, and the Animal Migrations of Birds and Certain Fishes, Boston, Boston Society of Natural History.

Rowland, I., M. Faughnan, L. Hoey, K. Wähälä, G. Williamson and A. Cassidy (2003). "Bioavailability of phyto-oestrogens." British Journal of Nutrition 89(Suppl1): 545558.

Rüfer, C. E. and S. E. Kulling (2006). "Antioxidant activity of isoflavones and their major metabolites using different in vitro assays." Journal of Agricultural and Food Chemistry 54(8): 2926-2931.

Ruscoe, W. A., D. Wilson, L. McElrea, G. McElrea and S. J. Richardson (2004). "A house mouse (Mus musculus) population eruption in response to Rimu (Dacrydium 
cupressinum) seedfall in southern New Zealand." New Zealand Journal of Ecology 28(2): 259-265.

Russell, G. B., W. S. Bowers, V. Keesing, H. M. Niemeyer, T. Sevenet, S. Vasanthaverni and S. D. Wratten (2000). "Patterns of bioactivity and herbivory on Nothofagus species from Chile and New Zealand." Journal of Chemical Ecology 26(1): 41-56.

Sachs, B. D. (1969). "Photoperiodic control of reproductive behavior and physiology of the male Japanese quail (Coturnix coturnix japonica)." Hormones and Behavior 1(1): 724.

Sack, J. S., K. F. Kish, C. Wang, R. M. Attar, S. E. Kiefer, Y. An, G. Y. Wu, J. E. Scheffler, M. E. Salvati, S. R. Krystek, et al. (2001). "Crystallographic structures of the ligandbinding domains of the androgen receptor and its T877A mutant complexed with the natural agonist dihydrotestosterone." Proceedings of the National Academy of Sciences 98(9): 4904-4909.

Sanders, E. H., P. D. Gardner, P. J. Berger and N. C. Negus (1981). "6Methoxybenzoxazolinone: A plant derivative that stimulates reproduction in Microtus montanus." Science 214(4516): 67-69.

Sartorius, C. A., M. Y. Melville, A. R. Hovland, L. Tung, G. S. Takimoto and K. B. Horwitz (1994). "A third transactivation function (AF3) of human progesterone receptors located in the unique N-terminal segment of the B-isoform." Molecular Endocrinology 8(10): 1347-1360.

Saunders, P. T. K. (1998). "Oestrogen receptor beta (ER $\beta) . "$ Reviews of Reproduction 3(3): 164-171.

Scarpin, K. M., J. D. Graham, P. A. Mote and C. L. Clarke (2009). "Progesterone action in human tissues: regulation by progesterone receptor (PR) isoform expression, nuclear positioning and coregulator expression." Nuclear Receptor Signaling 7: e009.

Schadler, M. H., G. M. Butterstein, B. J. Faulkner, S. C. Rice and L. A. Weisinger (1988). "The plant metabolite, 6-methoxybenzoxazolinone, stimulates an increase in secretion of follicle-stimulating hormone and size of reproductive organs in Microtus pinetorum." Biology of Reproduction 38(4): 817-820.

Schauber, E. M., D. Kelly, P. Turchin, C. Simon, W. G. Lee, R. B. Allen, I. J. Payton, P. R. Wilson, P. E. Cowan and R. E. Brockie (2002). "Masting by eighteen New Zealand plant species: The role of temperature as a synchronizing cue." Ecology 83(5): 12141225.

Schlenk, D., Y. Sapozhnikova, M. A. Irwin, L. Xie, W. Hwang, S. Reddy, B. J. Brownawell, J. Armstrong, M. Kelly, D. E. Montagne et al. (2005). "In vivo bioassay-guided fractionation of marine sediment extracts from the Southern California Bight, USA, 
for estrogenic activity." Environmental Toxicology and Chemistry 24(11): 28202826.

Schmidt, S., H. Michna and P. Diel (2005). "Combinatory effects of phytoestrogens and 17 $\beta$ estradiol on proliferation and apoptosis in MCF-7 breast cancer cells." Journal of Steroid Biochemistry and Molecular Biology 94(5): 445-449.

Schmitt, E., W. Dekant and H. Stopper (2001). "Assaying the estrogenicity of phytoestrogens in cells of different estrogen sensitive tissues." Toxicology in Vitro 15(4-5): 433-439.

Schoenmakers, E., P. Alen, G. Verrijdt, B. Peeters, G. Verhoeven, W. Rombauts and F. Claessens (1999). "Differential DNA binding by the androgen and glucocorticoid receptors involves the second $\mathrm{Zn}$-finger and a C-terminal extension of the DNAbinding domains." Biochemical Journal 341: 515-521.

Schrader, W. T. and B. W. O'Malley (1972). "Progesterone-binding components of chick oviduct: IV. Characterization of purified subunits." Journal of Biological Chemistry 247(1): 51-59.

Schreurs, R., P. Lanser, W. Seinen and B. van der Burg (2002). "Estrogenic activity of UV filters determined by an in vitro reporter gene assay and an in vivo transgenic zebrafish assay." Archives of Toxicology 76(5-6): 257-261.

Schupp, M. and M. A. Lazar (2010). "Endogenous Ligands for Nuclear Receptors: Digging Deeper." Journal of Biological Chemistry 285(52): 40409-40415.

Setchell, K. D., N. M. Brown, L. Zimmer-Nechemias, W. T. Brashear, B. E. Wolfe, A. S. Kirschner and J. E. Heubi (2002a). "Evidence for lack of absorption of soy isoflavone glycosides in humans, supporting the crucial role of intestinal metabolism for bioavailability." American Journal of Clinical Nutrition 76(2): 447-453.

Setchell, K. D. R., N. M. Brown and E. Lydeking-Olsen (2002b). "The clinical importance of the metabolite equol - a clue to the effectiveness of soy and its isoflavones." Journal of Nutrition 132(12): 3577-3584.

Shapiro, D. and J. M. Taylor (1982). "Steroid hormone regulation of vitellogenin gene expression." Critical Reviews in Biochemistry and Molecular Biology 12(3): 187-203.

Sherman, M. R., P. L. Corvol and B. W. O'Malley (1970). "Progesterone-binding components of chick oviduct: I. Preliminary characterization of cytoplasmic components." Journal of Biological Chemistry 245(22): 6085-6096.

Sherwood, I. and W. Short (1938). "192. Podocarpic acid. Part I." Journal of the Chemical Society (Resumed): 1006-1013.

Shi, L. M., H. Fang, W. Tong, J. Wu, R. Perkins, R. M. Blair, W. S. Branham, S. L. Dial, C. L. Moland and D. M. Sheehan (2001). "QSAR models using a large diverse set of estrogens." Journal of Chemical Information and Computer Sciences 41(1): 186-195. 
Shutt, D. A., A. W. H. Braden and H. R. Lindner (1969). "Plasma coumestrol levels in sheep following administration of synthetic coumestrol or ingestion of medic hay (Medicago littoralis)." Australian Journal of Agricultural Research 20(1): 65-69.

Silver, R. (1978). "The parental behavior of ring doves: The intricately coordinated behavior of the male and female is based on distinct physiological mechanisms in the sexes." American Scientist 66(2): 209-215.

Sims, I. M. (2003). "Structural diversity of fructans from members of the order Asparagales in New Zealand." Phytochemistry 63(3): 351-359.

Sims, I. M., A. J. Cairns and R. H. Furneaux (2001). "Structure of fructans from excised leaves of New Zealand flax." Phytochemistry 57(5): 661-668.

Sitruk-Ware, R. and I. M. Spitz (2003). "Pharmacological properties of mifepristone: toxicology and safety in animal and human studies." Contraception 68(6): 409-420.

Sluder, A. E. and C. V. Maina (2001). "Nuclear receptors in nematodes: themes and variations." Trends in Genetics 17(4): 206-213.

Soto, A. M., C. Sonnenschein, K. L. Chung, M. F. Fernandez, N. Olea and F. O. Serrano (1995). "The E-SCREEN assay as a tool to identify estrogens: an update on estrogenic environmental pollutants." Environmental Health Perspectives 103(Suppl 7): 113-122.

Spitz, I. M. (2003). "Progesterone antagonists and progesterone receptor modulators: an overview." Steroids 68(10-13): 981-993.

Sun, L., L. Wen, X. Shao, H. Qian, Y. Jin, W. Liu and Z. Fu (2010). "Screening of chemicals with anti-estrogenic activity using in vitro and in vivo vitellogenin induction responses in zebrafish (Danio rerio)." Chemosphere 78(7): 793-799.

Swinny, E. E. (2001). "A novel acetylated 3-deoxyanthocyanidin laminaribioside from the fern Blechnum novae-zelandiae." Zeitschrift für Naturforschung 56(3-4): 177-180.

Swiss Institute of Bioinformatics. (2008). "ENZYME entry: EC 3.2.1.4." from http://enzyme.expasy.org/EC/3.2.1.4.

Takamura-Enya, T., J. Ishihara, S. Tahara, S. Goto, Y. Totsuka, T. Sugimura and K. Wakabayashi (2003). "Analysis of estrogenic activity of foodstuffs and cigarette smoke condensates using a yeast estrogen screening method." Food and Chemical Toxicology 41(4): 543-550.

Tanenbaum, D. M., Y. Wang, S. P. Williams and P. B. Sigler (1998). "Crystallographic comparison of the estrogen and progesterone receptor's ligand binding domains." Proceedings of the National Academy of Sciences 95(11): 5998-6003. 
Tang, B. Y. and N. R. Adams (1980). "Effect of equol on oestrogen receptors and on synthesis of DNA and protein in the immature rat uterus." Journal of Endocrinology 85(2): 291-297.

Tata, J. R. (1976). "The expression of the vitellogenin gene." Cell 9(1): 1-14.

Tauber, E. and B. P. Kyriacou (2001). "Insect photoperiodism and circadian clocks: Models and mechanisms." Journal of Biological Rhythms 16(4): 381-390.

Tella, J. L. (2001). "Sex-ratio theory in conservation biology." Trends in Ecology and Evolution 16(2): 76-77.

Teng, C., B. Goodwin, K. Shockley, M. Xia, R. Huang, J. Norris, B. A. Merrick, A. M. Jetten, C. P. Austin and R. R. Tice (2013). "Bisphenol A affects androgen receptor function via multiple mechanisms." Chemico-Biological Interactions 203(3): 556-564.

Thigpen, A. E., R. I. Silver, J. M. Guileyardo, M. L. Casey, J. D. McConnell and D. W. Russell (1993). "Tissue distribution and ontogeny of steroid 5 alpha-reductase isozyme expression." Journal of Clinical Investigation 92(2): 903-910.

Tiemann, U., F. Schneider, J. Vanselow and W. Tomek (2007). "In vitro exposure of porcine granulosa cells to the phytoestrogens genistein and daidzein: Effects on the biosynthesis of reproductive steroid hormones." Reproductive Toxicology 24(3-4): 317-325.

Tilley, W. D., M. Marcelli, J. D. Wilson and M. J. McPhaul (1989). "Characterization and expression of a cDNA encoding the human androgen receptor." Proceedings of the National Academy of Sciences 86(1): 327-331.

Tong, W., R. Perkins, L. Xing, W. J. Welsh and D. M. Sheehan (1997). "QSAR models for binding of estrogenic compounds to estrogen receptor $\alpha$ and $\beta$ subtypes." Endocrinology 138(9): 4022-4025.

Trewick, S. A. (1996). "The diet of Kakapo (Strigops habroptilus), Takahe (Porphyrio mantelli) and Pukeko (P. porphyrio melanotus) studied by faecal analysis." Notornis 43(2): 79-84.

Trewick, S. A. (1997). "On the skewed sex ratio of the Kakapo Strigops habroptilus: sexual and natural selection in opposition?" IBIS 139(4): 652-663.

Tsao, R., Y. Papadopoulos, R. Yang, J. C. Young and K. McRae (2006). "Isoflavone profiles of red clovers and their distribution in different parts harvested at different growing stages." Journal of Agricultural and Food Chemistry 54(16): 5797-5805.

Tubbs, C., P. Hartig, M. Cardon, N. Varga and M. Milnes (2012). "Activation of Southern White Rhinoceros (Ceratotherium simum simum) estrogen receptors by phytoestrogens: Potential role in the reproductive failure of captive-born females?" Endocrinology 153(3): 1444-1452. 
Tully, D. B., V. T. Cox, M. M. Mumtaz, V. L. Davis and R. E. Chapin (2000). "Six highpriority organochlorine pesticides, either singly or in combination, are nonestrogenic in transfected HeLa cells." Reproductive Toxicology 14(2): 95-102.

Turnbull, M. H., R. P. Pharis, L. V. Kurepin, M. Sarfati, L. N. Mander and D. Kelly (2012). "Flowering in snow tussock (Chionochloa spp.) is influenced by temperature and hormonal cues." Functional Plant Biology 39(1): 38-50.

Vali, N. (2008). "The Japanese quail: A review." International Journal of Poultry Science 7(9): 925-931.

van der Woude, H., M. G. R. ter Veld, N. Jacobs, P. T. van der Saag, A. J. Murk and I. M. C. M. Rietjens (2005). "The stimulation of cell proliferation by quercetin is mediated by the estrogen receptor." Molecular Nutrition \& Food Research 49(8): 763-771.

van Tuinen, M. and G. J. Dyke (2004). "Calibration of galliform molecular clocks using multiple fossils and genetic partitions." Molecular Phylogenetics and Evolution 30(1): 74-86.

Vethaak, A. D., J. Lahr, S. M. Schrap, A. C. Belfroid, G. B. J. Rijs, A. Gerritsen, J. de Boer, A. S. Bulder, G. C. M. Grinwis, R. V. Kuiper, et al. (2005). "An integrated assessment of estrogenic contamination and biological effects in the aquatic environment of The Netherlands." Chemosphere 59(4): 511-524.

Viña, J., C. Borrás, J. Gambini, J. Sastre and F. V. Pallardó (2005). "Why females live longer than males? Importance of the upregulation of longevity-associated genes by oestrogenic compounds." FEBS LETTERS 579(12): 2541-2545.

von Langen, J., K. -H. Fritzemeier, S. Diekmann and A. Hillisch (2005). "Molecular basis of the interaction specificity between the human glucocorticoid receptor and its endogenous steroid ligand cortisol." ChemBioChem 6(6): 1110-1118.

Wahli, W., I. B. Dawid, G. U. Ryffel and R. Weber (1981). "Vitellogenesis and the vitellogenin gene family." Science 212(4492): 298-304.

Walsh, J., K. -J. Wilson and G. P. Elliott (2006). "Seasonal changes in home range size and habitat selection by Kakapo (Strigops habroptilus) on Maud Island." Notornis 53(1): 143-149.

Walter, P., S. Green, G. Greene, A. Krust, J. -M. Bornert, J. -M. Jeltsch, A. Staub, E. Jensen, G. Scrace, M. Waterfield et al. (1985). "Cloning of the human estrogen receptor cDNA." Proceedings of the National Academy of Sciences 82(23): 7889-7893.

Wang, C. Y., N. Ai, S. Arora, E. Erenrich, K. Nagarajan, R. Zauhar, D. Young and W. J. Welsh (2006). "Identification of previously unrecognized antiestrogenic chemicals using a novel virtual screening approach." Chemical Research in Toxicology 19(12): 1595-1601. 
Wang, H., J. Li, Y. Gao, Y. Xu, Y. Pan, I. Tsuji, Z.-J. Sun and X.-M. Li (2010). "Xenooestrogens and phyto-oestrogens are alternative ligands for the androgen receptor." Asian Journal of Andrology 12(4): 535-547.

Wasserman, M. D., A. Taylor-Gutt, J. M. Rothman, C. A. Chapman, K. Milton and D. C. Leitman (2012). "Estrogenic plant foods of Red Colobus Monkeys and Mountain Gorillas in Uganda." American Journal of Physical Anthropology 148(1): 88-97.

Watanabe, T., S. Inoue, S. Ogawa, Y. Ishii, H. Hiroi, K. Ikeda, A. Orimo and M. Muramatsu (1997). "Agonistic effect of tamoxifen is dependent on cell type, ERE-promoter context, and estrogen receptor subtype: functional difference between estrogen receptors $\alpha$ and $\beta$." Biochemical and Biophysical Research Communications 236(1): 140-145.

Webb, C. J. and D. Kelly (1993). "The reproductive biology of the New Zealand flora." Trends in Ecology \& Evolution 8(12): 442-447.

Webster, N. J. G., S. Green, J. R. Jin and P. Chambon (1988). "The hormone-binding domains of the estrogen and glucocorticoid receptors contain an inducible transcription activation function." Cell 54(2): 199-207.

Welshons, W. V., G. E. Rottinghaus, D. J. Nonneman, M. Dolan-Timpe and P. F. Ross (1990). "A sensitive bioassay for detection of dietary estrogens in animal feeds." Journal of Veterinary Diagnostic Investigation 2(4): 268-273.

Wen, D. X., Y. -F. Xu, D. E. Mais, M. E. Goldman and D. P. McDonnell (1994). "The A and $\mathrm{B}$ isoforms of the human progesterone receptor operate through distinct signaling pathways within target cells." Molecular and Cellular Biology 14(12): 8356-8364.

Whitehead, J., B. Case, K.-J. Wilson and L. Molles (2012). "Breeding variation in female Kakapo (Strigops habroptilus) on Codfish Island in a year of low food supply." New Zealand Journal of Ecology 36(1): 64-74.

Whitehead, J. K. (2007). "Breeding success of adult female kakapo (Strigops habroptilus) on Codfish Island (Whenua Hou): correlations with foraging home ranges and habitat selection." MSc thesis. Lincoln University, Christchurch.

Whitten, P. L., C. Lewis, E. Russell and F. Naftolin (1995). "Potential adverse effects of phytoestrogens." The Journal of Nutrition 125(Suppl 3): 771S-776S.

Wierer, M., A. K. Schrey, R. Kühne, S. E. Ulbrich and H. H. D. Meyer (2012). "A single glycine-alanine exchange directs ligand specificity of the elephant progestin receptor." PLoS one 7(11): e50350.

Williams, M., Ed. (2006). Special Issue, Notornis 53(1).

Williams, P. A., P. Cooper, P. Nes and K. F. O'Connor (1976). "Chemical composition of tall-tussocks in relation to the diet of the Takahe (Notornis mantelli Owen), on the 
Murchison Mountains, Fiordland, New Zealand." New Zealand Journal of Botany 14(1): 55-61.

Williams, S. P. and P. B. Sigler (1998). "Atomic structure of progesterone complexed with its receptor." Nature. 393(6683): 392-396.

Wilson, D. J. (2004). Diet of Kakapo in breeding and non-breeding years on Codfish Island (Whenua Hou) and Stewart Island, Department of Conservation, Wellington, New Zealand.

Wilson, D. J., A. D. Grant and N. Parker (2006). "Diet of Kakapo in breeding and nonbreeding years on Codfish Island (Whenua Hou) and Stewart Island." Notornis 53(1): 80-89.

Wilson, P. R., B. J. Karl, R. J. Toft, J. R. Beggs and R. H. Taylor (1998). "The role of introduced predators and competitors in the decline of Kaka (Nestor meridionalis) populations in New Zealand." Biological Conservation 83(2): 175-185.

Winneker, R. C., A. Fensome, P. Zhang, M. R. Yudt, C. C. McComas and R. J. Unwalla (2008). "A new generation of progesterone receptor modulators." Steroids 73(7): 689701.

Wiseman, H. (2012). "Phytoestrogens". In: Phytonutrients (Ed. A, Salter, H. Wiseman and G. Tucker). Oxford, Wiley-Blackwell.

Wiseman, H., J. O'Reilly, P. Lim, A. Garnett, W. Huang and T. Sanders (1998). "Antioxidant properties of the isoflavone-phytoestrogen functional ingredients in soya products." Special Publications of the Royal Society of Chemistry 215: 80-86.

Wollenweber, E., J. F. Stevens, M. Dörr and A. C. Rozefelds (2003). "Taxonomic significance of flavonoid variation in temperate species of Nothofagus." Phytochemistry 62(7): 1125-1131.

Wollenweber, E., A. Stüber and L. Kraut (1997). "Flavonoid aglycones and flavonol glycosides in the lipophilic leaf exudate of Nothofagus antarctica." Phytochemistry 44(7): 1399-1400.

Wood-Gush, D. G. M. and A. B. Gilbert (1973). "Some hormones involved in the nesting behaviour of hens." Animal Behaviour 21(1): 98-103.

Worthy, T. H. and R. N. Holdaway (2002). The lost world of the Moa: prehistoric life of New Zealand, Bloomington, Indiana University Press.

Worthy, T. H., A. J. D. Tennyson and R. P. Schofield (2011). "An early Miocene diversity of parrots (Aves, Strigopidae, Nestorinae) from New Zealand." Journal of Vertebrate Paleontology 31(5): 1102-1116. 
Wright, T. F., E. E. Schirtzinger, T. Matsumoto, J. R. Eberhard, G. R. Graves, J. J. Sanchez, S. Capelli, H. Müller, J. Scharpegge, G. K. Chambers, et al. (2008). "A multilocus molecular phylogeny of the parrots (Psittaciformes): support for a Gondwanan origin during the Cretaceous." Molecular Biology and Evolution 25(10): 2141-2156.

Wurtz, J. -M., W. Bourguet, J. -P. Renaud, V. Vivat, P. Chambon, D. Moras and H. Gronemeyer (1996). "A canonical structure for the ligand-binding domain of nuclear receptors." Nature Structural Biology 3(1): 87-94.

Zann, R. A., S. R. Morton, K. R. Jones and N. T. Burley (1995). "The timing of breeding by zebra finches in relation to rainfall in central Australia." Emu 95(3): 208-222.

Zhang, Y., Y. Li, C. Cao, J. Cao, W. Chen, Y. Zhang, C. Wang, J. Wang, X. Zhang and X. Zhao (2010). "Dietary flavonol and flavone intakes and their major food sources in Chinese adults." Nutrition and Cancer 62(8): 1120-1127.

Zhang, Z., S. Schwartz, L. Wagner and W. Miller (2000). "A greedy algorithm for aligning DNA sequences." Journal of Computational Biology 7(1-2): 203-214.

Zhi, L., C. M. Tegley, B. Pio, S. J. West, K. B. Marschke, D. E. Mais and T. K. Jones (2000). "Nonsteroidal progesterone receptor antagonists based on 6thiophenehydroquinolines." Bioorganic \& Medicinal Chemistry Letters 10(5): 415418.

Zhou, Z. -X., M. Sar, J. A. Simental, M. V. Lane and E. M. Wilson (1994). "A liganddependent bipartite nuclear targeting signal in the human androgen receptor. Requirement for the DNA-binding domain and modulation by $\mathrm{NH}_{2}$-terminal and carboxyl-terminal sequences." Journal of Biological Chemistry 269(18): 1311513123.

Zidorn, C., S. Sturm, J. W. Dawson, J. W. van Klink, H. Stuppner and N. B. Perry (2002). "Chemosystematic investigations of irregular diterpenes in Anisotome and related New Zealand Apiaceae." Phytochemistry 59(3): 293-304.

Zohar, R., I. Izhaki, A. Koplovich and R. Ben-Shlomo (2011). "Phytomelatonin in the leaves and fruits of wild perennial plants." Phytochemistry Letters 4(3): 222-226. 


\section{CHAPTER 9: APPENDICES}

\section{List of Supplementary Figures}

Supplementary Figure 2A Files for RosettaLigand Docking.

Supplementary Figure 2B Example of yeast bioassay colour change with serial dilution of $17 \beta$-oestradiol $\left(\mathrm{E}_{2}\right)$.

Supplementary Figure 3A Nucleotide sequences that span the amplified region of $\beta$-actin of New Zealand parrot species, cockatiel, chicken and quail.

Supplementary Figure 3B Nucleotide sequences that span the amplified region of the ligand binding domain (LBD) of oestrogen receptor $\alpha$ (ERa) of New Zealand parrot species and other avian species identified from the blastn search of the Aves taxon.

Supplementary Figure 3C Amino acid sequences that span the amplified region of the ligand binding domain (LBD) of oestrogen receptor $\alpha$ (ERa) of New Zealand species and other avian species that were identified from the blastp search of the Aves taxon.

Supplementary Figure 3D Amino acid sequences that span the amplified region of the ligand binding domain (LBD) of oestrogen receptor $\alpha$ (ERa) of New Zealand species and other avian species that were identified from the blastn search of the avian database.

Supplementary Figure 3E Nucleotide sequences that span the remaining amplified region of the ligand binding domain (LBD) of oestrogen receptor $\alpha$ (ERa) of New Zealand parrot species and other avian species identified from the blastn search of the Aves taxon.

Supplementary Figure 3F Amino acid sequences that span the remaining amplified region of the ligand binding domain (LBD) of oestrogen receptor $\alpha$ (ERa) of New Zealand species and other avian species that were identified from the blastp search of the Aves taxon.

Supplementary Figure 3G Amino acid sequences that span the remaining amplified region of the ligand binding domain (LBD) of oestrogen receptor $\alpha$ (ERa) of New Zealand species and other avian species that were identified from the blastn search of the avian database.

Supplementary Figure 3H Amino acid sequences that span the remaining amplified region of the ligand binding domain (LBD) of oestrogen receptor $\alpha$ (ERa) of New Zealand species and other non-avian species that were identified from the blastp search.

Supplementary Figure 3I Nucleotide sequences that span the amplified region of the ligand binding domain (LBD) of oestrogen receptor $\beta$ (ERb) of New Zealand parrot species and other avian species identified from the blastn search of the Aves taxon.

Supplementary Figure 3J Amino acid sequences that span the amplified region of the ligand binding domain (LBD) of oestrogen receptor $\beta(\mathrm{ERb})$ of New Zealand species and other avian species that were identified from the blastp search of the Aves taxon.

Supplementary Figure 3K Amino acid sequences that span the amplified region of the ligand binding domain (LBD) of oestrogen receptor $\beta(\mathrm{ERb})$ of New Zealand species and 
other avian species that were identified from the blastn search of the avian

database.

Supplementary Figure 3L Nucleotide sequences that span the amplified region of the ligand binding domain (LBD) of androgen receptor (AR) of New Zealand parrot species and other avian species identified from the blastn search of the Aves taxon.

Supplementary Figure 3M Amino acid sequences that span the amplified region of the ligand binding domain (LBD) of androgen receptor (AR) of New Zealand species and other avian species that were identified from the blastp search of the Aves taxon.

Supplementary Figure 3N Amino acid sequences that span the amplified region of the ligand binding domain (LBD) of androgen receptor (AR) of New Zealand species and other avian species that were identified from the blastn search of the avian database.

Supplementary Figure 3O Nucleotide sequences that span the amplified region of the ligand binding domain (LBD) of progesterone receptor (PR) of New Zealand parrot species and other avian species identified from the blastn search of the Aves taxon.

Supplementary Figure 3P Amino acid sequences that span the amplified region of the ligand binding domain (LBD) of progesterone receptor (PR) of New Zealand species and other avian species that were identified from the blastp search of the Aves taxon....

Supplementary Figure 3Q Amino acid sequences that span the amplified region of the ligand binding domain (LBD) of progesterone receptor (PR) of New Zealand species and other avian species that were identified from the blastn search of the avian database.

Supplementary Figure 3R Nucleotide sequences that span the remaining amplified region of the ligand binding domain (LBD) of progesterone receptor (PR) of New Zealand parrot species and other avian species identified from the blastn search of the Aves taxon.

Supplementary Figure 3S Amino acid sequences that span the remaining amplified region of the ligand binding domain (LBD) progesterone receptor (PR) of New Zealand species and other avian species that were identified from the blastp search of the Aves taxon.

Supplementary Figure 3T Amino acid sequences that span the remaining amplified region of the ligand binding domain (LBD) of progesterone receptor (PR) of New Zealand species and other avian species that were identified from the blastn search of the avian database. 


\section{List of Supplementary Tables}

Supplementary Table 2A Table of New Zealand native plants tested and collection time points.

Supplementary Table 2B Table of New Zealand native plants sample location, collection date, sample ID and sample type.

Supplementary Table 2C Table of Rimu (Dacrydium cupressinum) sample location, date and sample ID

Supplementary Table 2D The common name and scientific name for the avian species identified in BLAST searches carried out on the Aves taxon.

Supplementary Table 2E The common name and scientific name for the avian species identified in BLAST searches carried out with the non-published avian database. 


\section{Appendix 1 Preparation of Solutions}

\section{Solutions}

Any autoclaving was carried out in a Systec Model DX 65, Germany. Stock solutions were made for some buffers and then diluted to the required concentration. For the sterilisation of any solutions that could not be autoclaved, the solutions were filtered through a $0.22 \mu \mathrm{m}$ polyethersulfone (PES) membrane filter (Jet BIOFIL®, FPE-204030, Jet Bio-Filtration Products Company Co., Ltd., China).

\subsection{SODIUM ACETATE BUFFER (pH 5.0)}

$0.82 \mathrm{~g} \mathrm{NaOAc}$ was made up $100 \mathrm{~mL}$ with HighQ water and then the $\mathrm{pH}$ adjusted to 5.0 with glacial acetic acid. This was autoclaved prior to use.

\subsection{EDTA (pH 8.0)}

$73.06 \mathrm{~g}$ EDTA was dissolved in $400 \mathrm{~mL}$ unautoaclaved diethylpyrocarbonate (DEPC)-treated water and the $\mathrm{pH}$ adjusted to 8.0. The solution was then made up to $500 \mathrm{~mL}$ with unautoaclaved DEPC-treated water and autoclaved.

\section{M TRIS.HCl}

$60.55 \mathrm{~g}$ Tris was dissolved in $400 \mathrm{~mL}$ DEPC treated (or HighQ) water and $\mathrm{HCl}$ added to give desired $\mathrm{pH}$. This was then made up to a final volume of $500 \mathrm{~mL}$ with DEPC treated (or HighQ) water. This solution was diluted to give the desired concentration.

\section{2\% X-gal}

$10 \mathrm{~mL} N, N$-dimethyl formamide was added to $200 \mathrm{mg} \mathrm{X}$-gal and stored at $-20^{\circ} \mathrm{C}$ in the dark.

\section{M NaOAc (pH 5.2)}

$24.7 \mathrm{~g}$ of anhydrous $\mathrm{NaOAc}$ was added to $50 \mathrm{~mL}$ HighQ water and the $\mathrm{pH}$ adjusted to 5.2 with glacial acetic acid. This was then made up to a final volume of $100 \mathrm{~mL}$ with 
HighQ water and $10 \mu \mathrm{L}$ DEPC was added. After stirring overnight, the solution was autoclaved.

\section{$5 \mathrm{M} \mathrm{NaCl}$}

$146.1 \mathrm{~g}$ of $\mathrm{NaCl}$ was made up to $500 \mathrm{~mL}$ with DEPC-treated water and autoclaved.

\section{X DNA LOADING DYE}

The following components were added, mixed and stored as $1.5 \mathrm{~mL}$ aliquots at $-20^{\circ} \mathrm{C}$

UP water $5 \mathrm{~mL}$

0.5 M EDTA pH $8.020 \mathrm{~mL}$

Bromophenol blue $\quad(0.025 \mathrm{~g} / \mathrm{mL})$

Sterile glycerol $\quad 5 \mathrm{~mL}$

\section{X RNA LOADING DYE}

Same as above but DEPC treated water was used instead of UP water.

$10 \%$ SDS

$20 \mathrm{~g}$ SDS was dissolved in $200 \mathrm{~mL}$ DEPC-treated water and stored in a sterile bottle (Schott) at room temperature.

\section{X MOPS BUFFER}

MOPS

$3 \mathrm{M} \mathrm{NaOAc}, \mathrm{pH} 5.2$

0.5 M EDTA, pH 8.0
$41.86 \mathrm{~g}$

$26.7 \mathrm{~mL}$

$20 \mathrm{~mL}$

After combining the above chemicals, DEPC-treated water was added to make up to

$1 \mathrm{~L}$. The solution was kept in the dark.

\section{OX TAE BUFFER}

For a $1 \mathrm{~L}$ solution, $242 \mathrm{~g}$ of Tris, $57.1 \mathrm{~mL}$ of glacial acetic acid and $100 \mathrm{~mL}$ of $0.5 \mathrm{M}$ EDTA ( $\mathrm{pH}$ 8) were dissolved and made up to $1 \mathrm{~L}$ with HighQ water. This was autoclaved and diluted to $1 \mathrm{X}$ prior to use. 


\section{$50 \mathrm{mg} / \mathrm{mL}$ AMPICILLIN}

$500 \mathrm{mg}$ of ampicillin was added to $10 \mathrm{~mL}$ sterile HighQ water, dissolved and then filtered through a $0.22 \mu \mathrm{m}$ PES membrane filter. Aliquots of $1 \mathrm{~mL}$ were stored in sterile microcentrifuge tubes at $-20^{\circ} \mathrm{C}$.

\section{X SYBR GREEN}

$495 \mu \mathrm{L}$ of sterile $1 \mathrm{X}$ TAE buffer, $495 \mu \mathrm{L}$ of sterile glycerol and $10 \mu \mathrm{L}$ of $10,000 \mathrm{X}$ $\mathrm{SYBR}^{\circledR}$ Safe DNA gel stain were combined and stored as aliquots at $-20^{\circ} \mathrm{C}$.

\section{DEPC WATER}

$1 \mathrm{~mL}$ of DEPC was added to $1 \mathrm{~L}$ HighQ water and stirred overnight in a fumehood before being sterilised by autoclaving in an extended sterilisation cycle (i.e. $3 \times 20 \mathrm{~min}$ cycles at $121^{\circ} \mathrm{C}$ ).

\section{LURIA BROTH (LB)}

$\begin{array}{ll}\text { Bacto }^{\text {TM }} \text { Yeast Extract } & 5 \mathrm{~g} \\ \text { Bacto }^{\text {TM }} \text { Tryptone } & 10 \mathrm{~g} \\ \mathrm{NaCl} & 10 \mathrm{~g}\end{array}$

Broth was made up to $1 \mathrm{~L}$ with HighQ water and the solution was autoclaved prior to use.

\section{LB AGAR}

$15 \mathrm{~g} \mathrm{Bacto}^{\mathrm{TM}}$ agar was added to $1 \mathrm{~L}$ LB Broth and autoclaved.

\section{LB-AMP PLATES}

$1 \mathrm{~mL}$ ampicillin $(50 \mathrm{mg} / \mathrm{mL})$ was added to $1 \mathrm{~L} \mathrm{LB}$ agar prior to pouring plates. 


\section{LYSIS BUFFER}

$\begin{array}{ll}100 \mathrm{mM} \text { Tris.HCl, } \mathrm{pH} 8.5 & 5 \mathrm{~mL} \\ 0.5 \mathrm{M} \text { EDTA } & 0.5 \mathrm{~mL} \\ 10 \% \mathrm{SDS} & 1 \mathrm{~mL} \\ 5 \mathrm{M} \mathrm{NaCl} & 2 \mathrm{~mL}\end{array}$

After combining the chemicals listed above, HighQ water was added to make up to $50 \mathrm{~mL}$. The solution was sterilised by autoclaving.

\section{MOPS/FORMALDEHYDE SEAKEM ${ }^{\circledR}$ LE AGAROSE GEL}

For a 1.5\% gel, $0.6 \mathrm{~g}$ SeaKem ${ }^{\circledR}$ LE Agarose, $36.7 \mathrm{~mL} 1 \mathrm{X}$ MOPS and $3.3 \mathrm{~mL}$ formaldehyde were combined. To dissolve, the gel constituents were heated while being stirred.

PHENOL: CHLOROFORM:ISOAMYL ALCOHOL (25:24:1)

$12.5 \mathrm{~mL}$ phenol, $12 \mathrm{~mL}$ chloroform and $500 \mu \mathrm{L}$ isoamyl alcohol were combined and stored at $-20^{\circ} \mathrm{C}$.

\section{PROTEINASE K (10 mg/mL)}

On ice, $15 \mathrm{mg}$ proteinase $\mathrm{K}$ with $50 \mathrm{mM}$ Tris. $\mathrm{HCl} \mathrm{pH} 8.0(1.5 \mathrm{~mL})$ were combined and then filter-sterilised. Aliquots were stored at $-20^{\circ} \mathrm{C}$.

\section{TAE SEAKEM ${ }^{\circledR}$ LE AGAROSE GEL}

For a $1.5 \%$ gel, $0.6 \mathrm{~g}$ SeaKem ${ }^{\circledR}$ LE Agarose and $40 \mathrm{~mL} 1 \mathrm{X}$ TAE buffer were combined. To dissolve, the gel constituents were heated while being stirred.

\section{TRIS-EDTA (TE) BUFFER (pH 8.0)}

To prepare a $10 \mathrm{mM}$ Tris-HCl $(\mathrm{pH} \mathrm{8})$ and $1 \mathrm{mM}$ EDTA (pH 8) solution, stock solutions of $1 \mathrm{M}$ Tris- $\mathrm{HCl}(\mathrm{pH} 8)$ and $0.5 \mathrm{M}$ EDTA ( $\mathrm{pH}$ 8) were diluted appropriately. 


\section{YEAST BIOASSAY GROWTH MEDIA SOLUTIONS}

The following solutions were made for the yeast growth media.

\section{Minimal media (pH 7.4)}

Prior to making the minimal media, the following solutions were first prepared:

$1 \mathrm{M}$ potassium phosphate $\left(\mathrm{KH}_{2} \underline{P O}_{4}\right)$ solution

$68.05 \mathrm{~g}$ of potassium phosphate was added to $500 \mathrm{~mL}$ HighQ water and autoclaved prior to use.

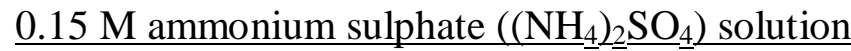

$9.9 \mathrm{~g}$ of ammonium sulphate was added to $500 \mathrm{~mL}$ HighQ water and autoclaved prior to use.

$\underline{0.75 \mathrm{M} \text { potassium hydroxide }(\mathrm{KOH}) \text { solution }}$

$21 \mathrm{~g}$ of potassium hydroxide was added to $500 \mathrm{~mL}$ HighQ water and autoclaved prior to use.

$\underline{0.17 \mathrm{M} \text { magnesium sulphate }\left(\mathrm{MgSO}_{4}\right) \text { solution }}$

$2.1 \mathrm{~g}$ of magnesium sulphate was added to $500 \mathrm{~mL}$ HighQ water and autoclaved prior to use.

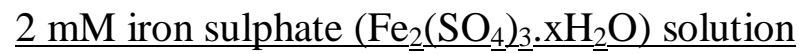

$40 \mathrm{mg}$ of iron sulphate was dissolved in $50 \mathrm{~mL}$ sterile HighQ water and used immediately to make the minimal media. 
Amino Acids

The following were combined in a falcon tube, mixed well and stored in the dark.

adenine $\quad 250 \mathrm{mg}$

L-arginine. $\mathrm{HCl} \quad 100 \mathrm{mg}$

L-glutamic acid $\quad 500 \mathrm{mg}$

L-histidine $\quad 250 \mathrm{mg}$

L-isoleucine $\quad 150 \mathrm{mg}$

L-leucine $\quad 250 \mathrm{mg}$

L-lysine. $\mathrm{HCl} \quad 150 \mathrm{mg}$

L-methionine $\quad 100 \mathrm{mg}$

L-phenylalanine $\quad 125 \mathrm{mg}$

L-serine $\quad 1.875 \mathrm{~g}$

L-tyrosine $\quad 150 \mathrm{mg}$

L-valine $\quad 750 \mathrm{mg}$

To prepare the minimal media, $100 \mathrm{~mL}$ of $0.1 \mathrm{M}$ ammonium sulphate, $0.75 \mathrm{M}$ potassium hydroxide and $1 \mathrm{M}$ potassium phosphate were combined. To this, $10 \mathrm{~mL}$ $0.17 \mathrm{M}$ magnesium sulphate, $930 \mathrm{mg}$ amino acids and $1 \mathrm{~mL}$ iron sulphate were added and the solution was made up to $1000 \mathrm{~mL}$ with HighQ water. The solution was mixed well and autoclaved prior to use.

\section{$\underline{20 \mu \mathrm{g} / \mathrm{mL} \text { biotin }}$}

$2 \mathrm{mg}$ of biotin was dissolved in $100 \mathrm{~mL}$ of sterile HighQ water, filter-sterilised and stored in $10 \mathrm{~mL}$ aliquots at $4^{\circ} \mathrm{C}$.

$20 \%(\mathrm{w} / \mathrm{v})$ glucose

$20 \mathrm{~g}$ of $\mathrm{D}(+)$ glucose was made up to $100 \mathrm{~mL}$ with HighQ water and autoclaved prior to use.

$30 \mathrm{mM}$ L-aspartic acid

$600 \mathrm{mg}$ of L-aspartic acid was dissolved in $150 \mathrm{~mL}$ HighQ water and divided into $20 \mathrm{~mL}$ aliquots. These were autoclaved prior to use. 
$\underline{\text { Vitamin solution }}$

$20 \mu \mathrm{g} / \mathrm{mL}$ biotin

$20 \mathrm{~mL}$

D-pantothenic acid (hemicalcium salt) $\quad 8 \mathrm{mg}$

Myo-inositol

$40 \mathrm{mg}$

Pyridoxine

$8 \mathrm{mg}$

Thiamine

$8 \mathrm{mg}$

HighQ water

$180 \mathrm{~mL}$

After combining the chemicals listed above, the solution was filter-sterilised and divided into $10 \mathrm{~mL}$ aliquots before being stored at $4{ }^{\circ} \mathrm{C}$.

$\underline{200 \mathrm{mM} \text { L-threonine }}$

$3.6 \mathrm{~g}$ of L-threonine was dissolved in $150 \mathrm{~mL}$ HighQ water and divided into $10 \mathrm{~mL}$ aliquots. These were autoclaved prior to use.

$20 \mathrm{mM}$ copper (II) sulphate

$0.5 \mathrm{~g}$ of copper (II) sulphate was dissolved in $100 \mathrm{~mL}$ HighQ water and filter-sterilised. The solution was then divided into $10 \mathrm{~mL}$ aliquots and stored at room temperature. 


\title{
Appendix 2 Scripts for Modelling, Collection and Identification of Plants, Bioassay Characteristics and Avian Nomenclature
}

\author{
options_ligand_rpkmin file \\ -database /rosetta/rosetta3.4/rosetta_database/ \\ $-\mathrm{ex} 1$ \\ $-\mathrm{ex} 2$ \\ -ex1aro \\ -extrachi_cutoff 1 \\ -no_optH false \\ -flip_HNQ \\ -docking:ligand:old_estat \\ -docking:ligand:soft_rep \\ -nstruct 10 \\ -s Kakapo_no_lig.pdb \\ -extra_res_fa EST.params \\ -ignore_unrecognized_res
}

\section{ligand_dock.xml script}

This protocol will simply do low-resolution followed by high-resolution docking. It will also report the binding energy (ddg) and buried-surface area (sasa) in the score file.

<dock_design>

\section{$<$ SCOREFXNS $>$}

$<$ ligand_soft_rep weights=ligand_soft_rep >

$<$ Reweight scoretype=hack_elec weight $=0.42 />$

$</$ ligand_soft_rep $>$

$<$ hard_rep weights=ligand $>$

$<$ Reweight scoretype=hack_elec weight $=0.42 />$

$$
</ \text { hard_rep }>
$$

$</$ SCOREFXNS $>$

$<$ INTERFACE_BUILDERS $>$

$<$ side_chain chains $=X$ cutoff $=6.0$ add_nbr_radius $=$ true

all_atom_mode $=$ true $/>$

$<$ backbone chains $=X$ cutoff $=7.0$ add_nbr_radius $=$ false

all_atom_mode $=$ true extension_window $=3 />$

</INTERFACE_BUILDERS>

$<$ MOVEMAP_BUILDERS $>$

$<$ docking chains $=X$ sc_interface $=$ side_chain minimize_water $=$ true

minimize_bb=false/>

$<$ final chains $=X$ sc_interface $=$ side_chain bb_interface $=$ backbone

minimize_water=true minimize_bb=true/ $>$

$<$ /MOVEMAP_BUILDERS $>$

$<$ MOVERS $>$ 
single movers

$<$ StartFrom name $=$ start_from chain $=X>$

$<$ Coordinates $\mathrm{x}=-107.008 \mathrm{y}=15.860 \mathrm{z}=99.456 />$

$</$ StartFrom $>$

$<$ Translate name $=$ translate chain $=\mathrm{X}$ distribution $=$ uniform angstroms $=3.0$ cycles $=50 />$

$<$ Rotate name $=$ rotate chain $=\mathrm{X}$ distribution $=$ uniform degrees $=360$ cycles $=1000 />$

$<$ SlideTogether name=slide_together chain $=X />$

$<$ HighResDocker name=high_res_docker chains $=X$ protocol=abbrev2

scorefxn=ligand_soft_rep movemap_builder=docking >

$<$ MinimizeLigand name $=$ minimize_ligand chain $=X$ degrees $=10 />$

$</$ HighResDocker $>$

$<$ FinalMinimizer name=final chain $=X$ scoref $x n=$ hard_rep

movemap_builder=final minimize_backbone $=$ minimize_backbone $>$

interface $=$ backbone $>$

$<$ MinimizeBackbone name $=$ minimize_backbone

$<$ LigandArea chain $=\mathrm{X}$ angstroms $=0.2 />$

$</$ MinimizeBackbone>

$</$ FinalMinimizer $>$

$<$ InterfaceScoreCalculator name=Kakapo_native.pdb chains $=\mathrm{X}$

scoref $x n=$ hard_rep/>

compound movers

$<$ DockDesign name=low_res_dock $>$

$<$ Add mover_name $=$ translate $/>$

$<$ Add mover_name $=$ rotate $/>$

$<$ Add mover_name=slide_together $>$

$</$ DockDesign $>$

$<$ DockDesign name=high_res_dock>

$<$ Add mover_name=high_res_docker/>

$<$ Add mover_name=final/ $>$

$</$ DockDesign $>$

$<$ /MOVERS >

$<$ PROTOCOLS $>$

$<$ Add mover_name=low_res_dock/>

$<$ Add mover_name=high_res_dock/>

$<$ Add mover_name=add_scores/>

$<$ Add mover_name $=$ rotate/ $>$

$<$ PROTOCOLS $>$

$</$ dock_design $>$

\section{options_ligand_dock file}

-database rosetta/rosetta3.4/rosetta_database/

-nstruct 2500

-in

-file 


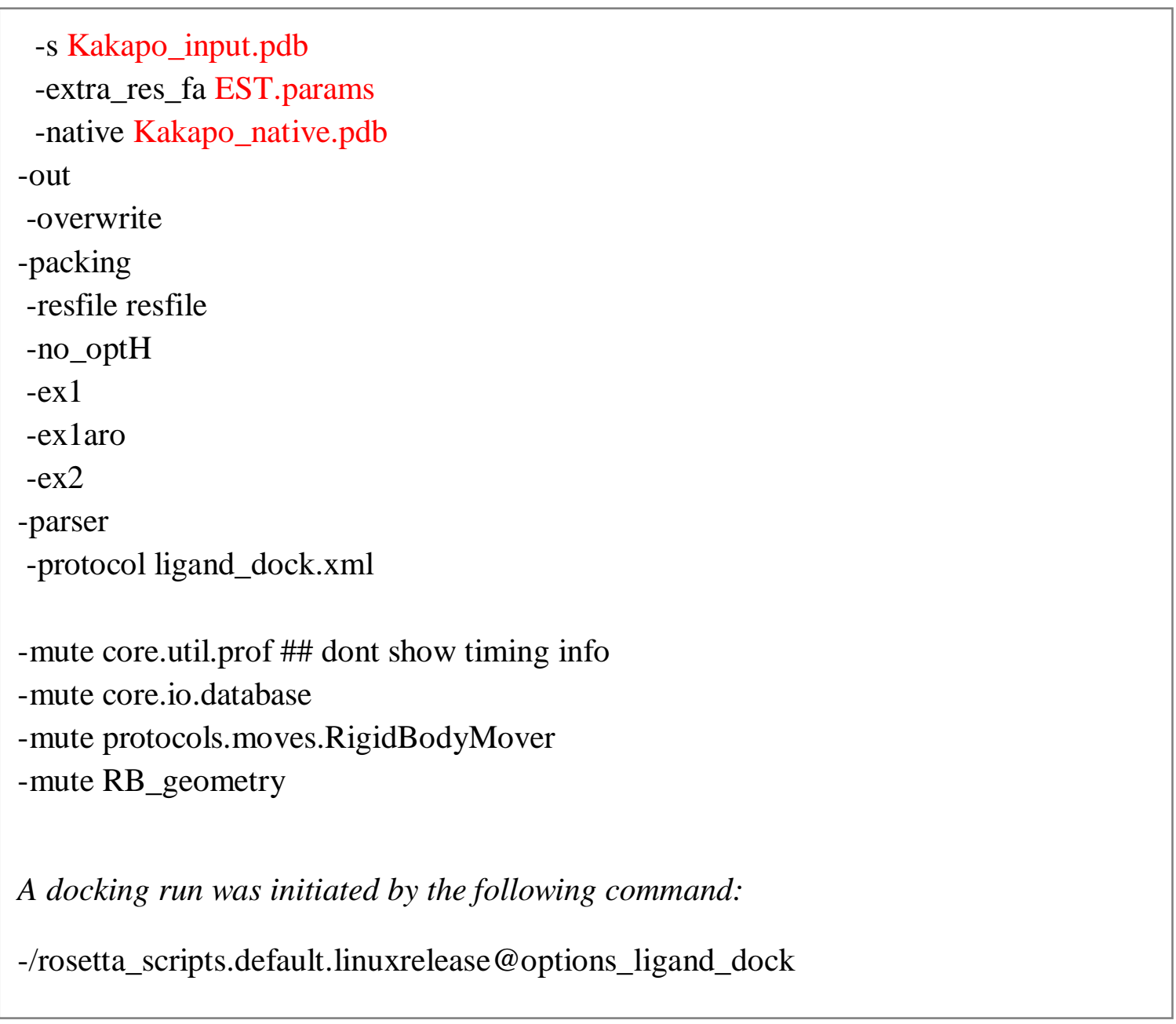

Supplementary Figure 2A Files for RosettaLigand Docking. Terms written in red are those that were modified for different docking runs. 


\section{CHAPTER 9: APPENDICES}

Supplementary Table 2A Table of New Zealand native plants tested and collection time points. Two samples of Dacrydium cupressinum were collected in December 2010; from Kaitoke and from Codfish Island (red).

\begin{tabular}{|c|c|c|c|c|c|c|c|c|c|c|c|c|c|c|}
\hline SCIENTIFIC NAME & COMMON NAME & & & & & & & CTION L & & & & & & \\
\hline Anisotome haastii & Haast's Carrot & & & & & & & & & & & & $\begin{array}{l}\text { July } \\
2012\end{array}$ & \\
\hline Blechnum novae-zelandiae & Fern & & & & & & & $\begin{array}{l}\text { April } \\
2009\end{array}$ & $\begin{array}{l}\text { July } \\
2010\end{array}$ & $\begin{array}{c}\text { December } \\
2010\end{array}$ & & $\begin{array}{l}\text { March } \\
2011\end{array}$ & $\begin{array}{l}\text { July } \\
2012\end{array}$ & \\
\hline Carmichaelia arboea & South Island Broom & & & & & & & & & & & & $\begin{array}{l}\text { July } \\
2012\end{array}$ & \\
\hline Chionochloa rigida & Snow tussock & & & & & & & & & & & & $\begin{array}{l}\text { July } \\
2012\end{array}$ & \\
\hline Coprosma robusta & Karamu & & & & & & & $\begin{array}{l}\text { April } \\
2009\end{array}$ & $\begin{array}{l}\text { July } \\
2010\end{array}$ & & & $\begin{array}{c}\text { March } \\
2011\end{array}$ & $\begin{array}{l}\text { July } \\
2012\end{array}$ & \\
\hline Cordyline australis & Cabbage tree & & & & & & & & & & & & & $\begin{array}{c}\text { August } \\
2012\end{array}$ \\
\hline Dacrycarpus dacrydioides & Kahikatea & & & & & & & & & & & & $\begin{array}{l}\text { July } \\
2012\end{array}$ & \\
\hline Dacrydium cupressinum & Rimu & $\begin{array}{l}\text { May } \\
2007\end{array}$ & $\begin{array}{c}\text { August } \\
2007\end{array}$ & $\begin{array}{c}\text { November } \\
2007\end{array}$ & $\begin{array}{c}\text { 9th Jan } \\
2008\end{array}$ & $\begin{array}{c}21 s t \text { Jan } \\
2008\end{array}$ & $\begin{array}{c}\text { 6th Feb } \\
2008\end{array}$ & $\begin{array}{l}\text { April } \\
2009\end{array}$ & $\begin{array}{l}\text { July } \\
2010 \\
\end{array}$ & $\begin{array}{c}\text { December } \\
2010\end{array}$ & $\begin{array}{c}\text { December } \\
2010\end{array}$ & $\begin{array}{c}\text { March } \\
2011\end{array}$ & $\begin{array}{l}\text { July } \\
2012\end{array}$ & \\
\hline Dracophyllum longifolium & Inanga & & & & & & & $\begin{array}{l}\text { April } \\
2009\end{array}$ & & & & & $\begin{array}{l}\text { July } \\
2012\end{array}$ & \\
\hline Gahnia procera & Mountain gahnia & & & & & & & & $\begin{array}{l}\text { July } \\
2010\end{array}$ & $\begin{array}{c}\text { December } \\
2010\end{array}$ & & $\begin{array}{l}\text { March } \\
2011\end{array}$ & $\begin{array}{l}\text { July } \\
2012\end{array}$ & \\
\hline Leptecophylla juniperina & Mingimingi & & & & & & & & $\begin{array}{l}\text { July } \\
2010 \\
\end{array}$ & $\begin{array}{c}\text { December } \\
2010\end{array}$ & & $\begin{array}{l}\text { March } \\
2011 \\
\end{array}$ & & $\begin{array}{c}\text { August } \\
2012 \\
\end{array}$ \\
\hline Leptospermum scoparium & Manuka & & & & & & & $\begin{array}{l}\text { April } \\
2009\end{array}$ & $\begin{array}{l}\text { July } \\
2010 \\
\end{array}$ & \begin{tabular}{|c|} 
December \\
2010
\end{tabular} & & $\begin{array}{c}\text { March } \\
2011\end{array}$ & $\begin{array}{l}\text { July } \\
2012 \\
\end{array}$ & \\
\hline Metrosideros umbellata & Southern Rata & & & & & & & & & & & & $\begin{array}{l}\text { July } \\
2012\end{array}$ & \\
\hline Nothofagus solandri var. solandri & Black Beech & & & & & & & & $\begin{array}{l}\text { July } \\
2010\end{array}$ & $\begin{array}{c}\text { December } \\
2010\end{array}$ & & $\begin{array}{c}\text { March } \\
2011\end{array}$ & $\begin{array}{l}\text { July } \\
2012\end{array}$ & \\
\hline Olearia colensoi & Leatherwood & & & & & & & & & & & & $\begin{array}{l}\text { July } \\
2012\end{array}$ & \\
\hline Phormium tenax & Flax & & & & & & & & & & & & $\begin{array}{l}\text { July } \\
2012\end{array}$ & \\
\hline Podocarpus acutifolius & Westland Totara & & & & & & & $\begin{array}{l}\text { April } \\
2009\end{array}$ & & & & & & \\
\hline Podocarpus cunninghamii & Hall's Totara & & & & & & & $\begin{array}{l}\text { April } \\
2009\end{array}$ & & & & & $\begin{array}{l}\text { July } \\
2012\end{array}$ & \\
\hline Podocarpus nivalis & Snow Totara & & & & & & & & & & & & $\begin{array}{l}\text { July } \\
2012\end{array}$ & \\
\hline Prumnopitys ferruginea & Miro & & & & & & & $\begin{array}{l}\text { April } \\
2009\end{array}$ & & & & & $\begin{array}{l}\text { July } \\
2012\end{array}$ & \\
\hline Prumnopitys taxifolia & Matai & & & & & & & & & & & & $\begin{array}{l}\text { July } \\
2012\end{array}$ & \\
\hline
\end{tabular}


Supplementary Table 2B Table of New Zealand native plants sample location, collection date, sample ID and sample type. Samples were leaves unless stated otherwise.

\begin{tabular}{|c|c|c|c|c|}
\hline Scientific Name & $\begin{array}{c}\text { Sample } \\
\text { Location }\end{array}$ & $\begin{array}{l}\text { Collection } \\
\text { Date }\end{array}$ & Sample ID & $\begin{array}{l}\text { Sample } \\
\text { Type: }\end{array}$ \\
\hline \multirow[t]{2}{*}{ Anisotome haastii } & \multirow[t]{2}{*}{ Otari } & \multirow[t]{2}{*}{ July 2012} & AH-JUL12-M & \\
\hline & & & AH-JUL12-MC & \\
\hline \multirow{14}{*}{$\begin{array}{c}\text { Blechnum novae- } \\
\text { zelandiae }\end{array}$} & \multirow[t]{2}{*}{ Otari } & \multirow[t]{2}{*}{ April 2009} & BN-APR09-M & \\
\hline & & & BN-APR09-MC & \\
\hline & \multirow[t]{4}{*}{ Kaitoke } & \multirow[t]{4}{*}{ July 2010} & BN-JUL10-M & \\
\hline & & & BN-JUL10-MC & \\
\hline & & & BNFF-JUL10-M & fertile frond \\
\hline & & & BNFF-JUL10-MC & fertile frond \\
\hline & \multirow[t]{4}{*}{ Kaitoke } & \multirow{4}{*}{$\begin{array}{l}\text { December } \\
2010\end{array}$} & BN-DEC10-M & \\
\hline & & & BN-DEC10-MC & \\
\hline & & & BNFF-DEC10-M & fertile frond \\
\hline & & & BNFF-DEC10-MC & fertile frond \\
\hline & \multirow[t]{2}{*}{ Kaitoke } & \multirow[t]{2}{*}{ March 2011} & BN-MAR11-M & \\
\hline & & & BN-MAR11-MC & \\
\hline & \multirow[t]{2}{*}{ Otari } & \multirow[t]{2}{*}{ July 2012} & BN-JUL12-M & \\
\hline & & & BN-JUL12-MC & \\
\hline \multirow{4}{*}{$\begin{array}{c}\text { Carmichaelia } \\
\text { arboea }\end{array}$} & \multirow[t]{4}{*}{ Otari } & \multirow[t]{4}{*}{ July 2012} & CA-JUL12-M & \\
\hline & & & CA-JUL12-MC & \\
\hline & & & CAF-JUL12-M & fruit \\
\hline & & & CAF-JUL12-MC & fruit \\
\hline \multirow{2}{*}{$\begin{array}{l}\text { Chionochloa } \\
\text { rigida }\end{array}$} & \multirow[t]{2}{*}{ Otari } & \multirow[t]{2}{*}{ July 2012} & ChR-JUL12-M & \\
\hline & & & ChR-JUL12-MC & \\
\hline
\end{tabular}




\begin{tabular}{|c|c|c|c|c|}
\hline \multirow{14}{*}{$\begin{array}{l}\text { Coprosma } \\
\text { robusta }\end{array}$} & \multirow[t]{4}{*}{ Otari } & \multirow[t]{4}{*}{ April 2009} & CR-APR09-M & \\
\hline & & & CR-APR09-MC & \\
\hline & & & CRF-APR09-M & fruit \\
\hline & & & CRF-APR09-MC & fruit \\
\hline & \multirow[t]{4}{*}{ Kaitoke } & \multirow[t]{4}{*}{ July 2010} & CR-JUL10-M & \\
\hline & & & CR-JUL10-MC & \\
\hline & & & CRF-JUL10-M & fruit \\
\hline & & & CRF-JUL10-MC & fruit \\
\hline & \multirow[t]{2}{*}{ Kaitoke } & \multirow[t]{2}{*}{ March 2011} & CR-MAR11-M & \\
\hline & & & CR-MAR11-MC & \\
\hline & \multirow{4}{*}{ Otari } & \multirow[t]{4}{*}{ July 2012} & CR-JUL12-M & \\
\hline & & & CR-JUL12-MC & \\
\hline & & & CRF-JUL12-M & fruit \\
\hline & & & CRF-JUL12-MC & fruit \\
\hline \multirow{6}{*}{$\begin{array}{l}\text { Cordyline } \\
\text { australis }\end{array}$} & \multirow[t]{6}{*}{ Wellington } & \multirow[t]{6}{*}{ August 2012} & CoA-AUG12-M & \\
\hline & & & CoA-AUG12-MC & \\
\hline & & & CoAS-AUG12-M & fruit stem \\
\hline & & & CoAS-AUG12-MC & fruit stem \\
\hline & & & CoAF-AUG12-M & fruit \\
\hline & & & CoAF-AUG12-MC & fruit \\
\hline \multirow{2}{*}{$\begin{array}{l}\text { Dacrycarpus } \\
\text { dacrydioides }\end{array}$} & \multirow[t]{2}{*}{ Otari } & \multirow[t]{2}{*}{ July 2012} & DD-JUL12-M & \\
\hline & & & DD-JUL12-MC & \\
\hline \multirow{4}{*}{$\begin{array}{c}\text { Dracophyllum } \\
\text { longifolium }\end{array}$} & \multirow[t]{2}{*}{ Otari } & \multirow[t]{2}{*}{ April 2009} & DL-APR09-M & \\
\hline & & & DL-APR09-MC & \\
\hline & \multirow[t]{2}{*}{ Otari } & \multirow[t]{2}{*}{ July 2012} & DL-JUL12-M & \\
\hline & & & DL-JUL12-MC & \\
\hline
\end{tabular}




\begin{tabular}{|c|c|c|c|c|}
\hline \multirow[t]{10}{*}{ Gahnia procera } & \multirow[t]{4}{*}{ Kaitoke } & \multirow[t]{4}{*}{ July 2010} & GP-JUL10-M & \\
\hline & & & GP-JUL10-MC & \\
\hline & & & GPS-JUL10-M & seeds \\
\hline & & & GPS-JUL10-MC & seeds \\
\hline & \multirow[t]{2}{*}{ Kaitoke } & \multirow{2}{*}{$\begin{array}{c}\text { December } \\
2010\end{array}$} & GP-DEC10-M & \\
\hline & & & GP-DEC10-MC & \\
\hline & \multirow[t]{2}{*}{ Kaitoke } & \multirow[t]{2}{*}{ March 2011} & GP-MAR11-M & \\
\hline & & & GP-MAR11-MC & \\
\hline & \multirow[t]{2}{*}{ Otari } & \multirow[t]{2}{*}{ July 2012} & GP-JUL12-M & \\
\hline & & & GP-JUL12-MC & \\
\hline \multirow{10}{*}{$\begin{array}{l}\text { Leptecophylla } \\
\text { juniperina }\end{array}$} & \multirow[t]{4}{*}{ Kaitoke } & \multirow[t]{4}{*}{ July 2010} & LJ-JUL10-M & \\
\hline & & & LJ-JUL10-MC & \\
\hline & & & LJF-JUL10-M & fruit \\
\hline & & & LJF-JUL10-MC & fruit \\
\hline & \multirow[t]{2}{*}{ Kaitoke } & \multirow{2}{*}{$\begin{array}{c}\text { December } \\
2010\end{array}$} & LJ-DEC10-M & \\
\hline & & & LJ-DEC10-MC & \\
\hline & \multirow[t]{2}{*}{ Kaitoke } & \multirow[t]{2}{*}{ March 2011} & LJ-MAR11-M & \\
\hline & & & LJ-MAR11-MC & \\
\hline & \multirow[t]{2}{*}{ Wellington } & \multirow[t]{2}{*}{ August 2012} & LJ-AUG12-M & \\
\hline & & & LJ-AUG12-MC & \\
\hline \multirow{6}{*}{$\begin{array}{l}\text { Leptospermum } \\
\text { scoparium }\end{array}$} & \multirow[t]{2}{*}{ Otari } & \multirow[t]{2}{*}{ April 2009} & LS-APR09-M & \\
\hline & & & LS-APR09-MC & \\
\hline & \multirow[t]{4}{*}{ Kaitoke } & \multirow[t]{4}{*}{ July 2010} & LS-JUL10-M & \\
\hline & & & LS-JUL10-MC & \\
\hline & & & LSS-JUL10-M & seeds \\
\hline & & & LSS-JUL10-MC & seeds \\
\hline
\end{tabular}


CHAPTER 9: APPENDICES

\begin{tabular}{|c|c|c|c|c|}
\hline & \multirow[t]{2}{*}{ Kaitoke } & \multirow{2}{*}{$\begin{array}{c}\text { December } \\
2010\end{array}$} & \multicolumn{2}{|l|}{ LS-DEC10-M } \\
\hline & & & LS-DEC10-MC & \\
\hline & \multirow[t]{4}{*}{ Kaitoke } & \multirow[t]{4}{*}{ March 2011} & LS-MAR11-M & \\
\hline & & & LS-MAR11-MC & \\
\hline & & & LSS-MAR11-M & $\overline{\text { seeds }}$ \\
\hline & & & LSS-MAR11-MC & seeds \\
\hline & \multirow[t]{2}{*}{ Otari } & \multirow[t]{2}{*}{ July 2012} & LS-JUL12-M & \\
\hline & & & LS-JUL12-MC & \\
\hline \multirow{2}{*}{$\begin{array}{c}\text { Metrosideros } \\
\text { umbellata }\end{array}$} & \multirow[t]{2}{*}{ Otari } & \multirow[t]{2}{*}{ July 2012} & MU-JUL12-M & \\
\hline & & & MU-JUL12-MC & \\
\hline \multirow{8}{*}{$\begin{array}{c}\text { Nothofagus } \\
\text { solandri var. } \\
\text { solandri }\end{array}$} & \multirow[t]{2}{*}{ Kaitoke } & \multirow[t]{2}{*}{ July 2010} & NS-JUL10-M & \\
\hline & & & NS-JUL10-MC & \\
\hline & \multirow[t]{2}{*}{ Kaitoke } & \multirow{2}{*}{$\begin{array}{l}\text { December } \\
2010\end{array}$} & NS-DEC10-M & \\
\hline & & & NS-DEC10-MC & \\
\hline & \multirow[t]{2}{*}{ Kaitoke } & \multirow[t]{2}{*}{ March 2011} & NS-MAR11-M & \\
\hline & & & NS-MAR11-MC & \\
\hline & \multirow[t]{2}{*}{ Otari } & \multirow[t]{2}{*}{ July 2012} & NS-JUL12-M & \\
\hline & & & NS-JUL12-MC & \\
\hline \multirow[t]{2}{*}{ Olearia colensoi } & \multirow[t]{2}{*}{ Otari } & \multirow[t]{2}{*}{ July 2012} & OC-JUL12-M & \\
\hline & & & OC-JUL12-MC & \\
\hline \multirow[t]{2}{*}{ Phormium tenax } & \multirow[t]{2}{*}{ Otari } & \multirow[t]{2}{*}{ July 2012} & PhT-JUL12-M & \\
\hline & & & PhT-JUL12-MC & \\
\hline \multirow{2}{*}{$\begin{array}{c}\text { Podocarpus } \\
\text { acutifolius }\end{array}$} & \multirow[t]{2}{*}{ Otari } & \multirow[t]{2}{*}{ April 2009} & PA-APR09-M & \\
\hline & & & PA-APR09-MC & \\
\hline \multirow{2}{*}{$\begin{array}{c}\text { Podocarpus } \\
\text { cunninghamii }\end{array}$} & \multirow[t]{2}{*}{ Otari } & \multirow[t]{2}{*}{ April 2009} & PC-APR09-M & \\
\hline & & & PC-APR09-MC & \\
\hline
\end{tabular}


CHAPTER 9: APPENDICES

\begin{tabular}{|c|c|c|c|c|}
\hline & \multirow[t]{2}{*}{ Otari } & \multirow[t]{2}{*}{ July 2012} & PC-JUL12-M & \\
\hline & & & PC-JUL12-MC & \\
\hline \multirow{2}{*}{$\begin{array}{c}\text { Podocarpus } \\
\text { nivalis }\end{array}$} & \multirow[t]{2}{*}{ Otari } & \multirow[t]{2}{*}{ July 2012} & PN-JUL12-M & \\
\hline & & & PN-JUL12-MC & \\
\hline \multirow{6}{*}{$\begin{array}{c}\text { Prumnopitys } \\
\text { ferruginea }\end{array}$} & \multirow[t]{2}{*}{ Otari } & \multirow[t]{2}{*}{ April 2009} & PF-APR09-M & \\
\hline & & & PF-APR09-MC & \\
\hline & \multirow[t]{4}{*}{ Otari } & \multirow[t]{4}{*}{ July 2012} & PF-JUL12-M & \\
\hline & & & PF-JUL12-MC & \\
\hline & & & PFF-JUL12-M & fruit \\
\hline & & & PFF-JUL12-MC & fruit \\
\hline \multirow{2}{*}{$\begin{array}{c}\text { Prumnopitys } \\
\text { taxifolia }\end{array}$} & \multirow[t]{2}{*}{ Otari } & \multirow[t]{2}{*}{ July 2012} & PT-JUL12-M & \\
\hline & & & PT-JUL12-MC & \\
\hline
\end{tabular}


Supplementary Table 2C Table of Rimu (Dacrydium cupressinum) sample location, date and sample ID. FC in the sample ID refers to a Rimu fruit sample. T1 refers to Tree 1, T18 refers to Tree 18, and S refers to serial collection.

\begin{tabular}{|c|c|c|c|}
\hline Scientific Name & Sample Location: & Collection Date & Sample ID \\
\hline \multirow{22}{*}{$\begin{array}{l}\text { Dacrydium } \\
\text { cupressinum }\end{array}$} & \multirow[t]{2}{*}{ Otari } & \multirow[t]{2}{*}{ April 2009} & DCO-APR09-M \\
\hline & & & DCO-APR09-MC \\
\hline & \multirow[t]{2}{*}{ Kaitoke } & \multirow[t]{2}{*}{ July 2010} & DCK-JUL10-M \\
\hline & & & DCK-JUL10-MC \\
\hline & \multirow[t]{2}{*}{ Kaitoke } & \multirow[t]{2}{*}{ December 2010} & DCK-DEC10-M \\
\hline & & & DCK-DEC10-MC \\
\hline & \multirow[t]{4}{*}{ Codfish Island } & \multirow[t]{4}{*}{ December 2010} & DCC-DEC10-M \\
\hline & & & DCC-DEC10-MC \\
\hline & & & DCFC-DEC10-M \\
\hline & & & DCFC-DEC10-MC \\
\hline & \multirow[t]{2}{*}{ Kaitoke } & \multirow[t]{2}{*}{ March 2011} & DCK-MAR11-M \\
\hline & & & DCK-MAR11-MC \\
\hline & \multirow[t]{2}{*}{ Otari } & \multirow[t]{2}{*}{ July 2012} & DCO-JUL12-M \\
\hline & & & DCO-JUL12-MC \\
\hline & \multirow{8}{*}{$\begin{array}{c}\text { Codfish Island- } \\
\text { Tree } 1\end{array}$} & \multirow[t]{2}{*}{ May 2007} & DCFC-T1-MAY07-M \\
\hline & & & DCFC-T1-MAY07-MC \\
\hline & & \multirow[t]{2}{*}{ August 2007} & DCFC-T1-AUG07-M \\
\hline & & & DCFC-T1-AUG07-MC \\
\hline & & \multirow[t]{2}{*}{ November 2007} & DCFC-T1-NOV07-M \\
\hline & & & DCFC-T1-NOV07-MC \\
\hline & & \multirow[t]{2}{*}{ 9 January 2008} & DCFC-T1-9JAN08-M \\
\hline & & & DCFC-T1-9JAN08-MC \\
\hline
\end{tabular}




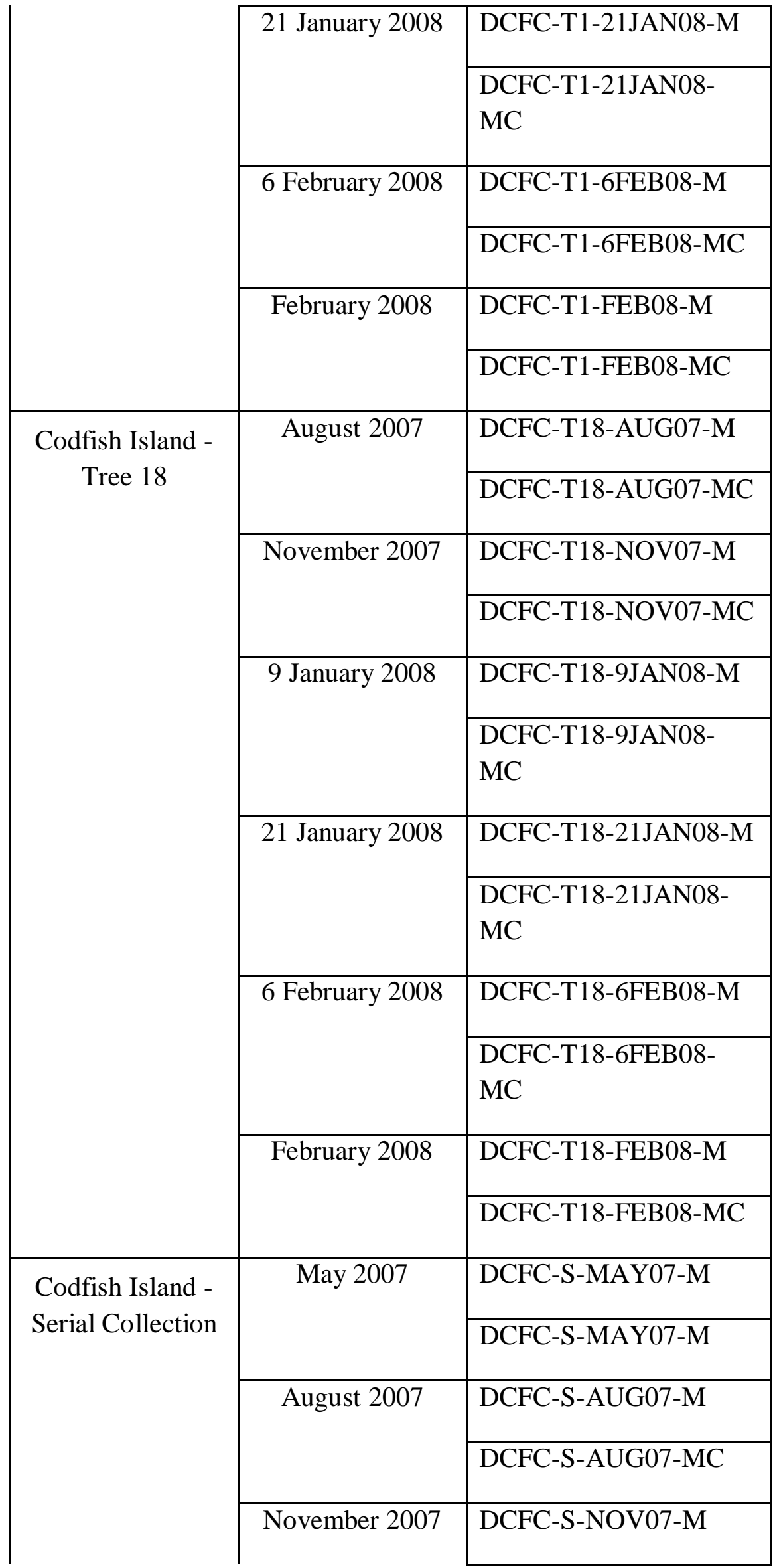




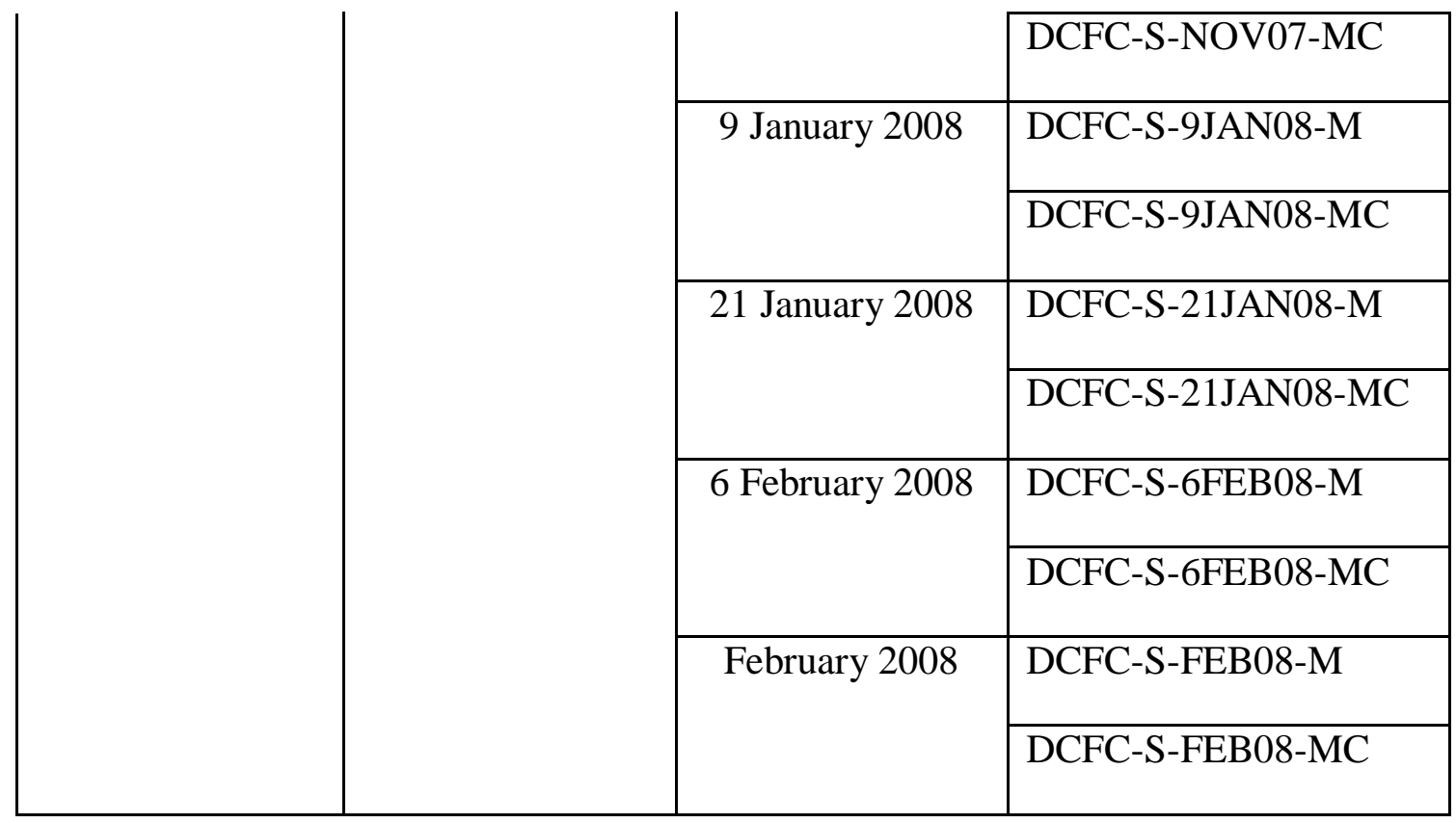

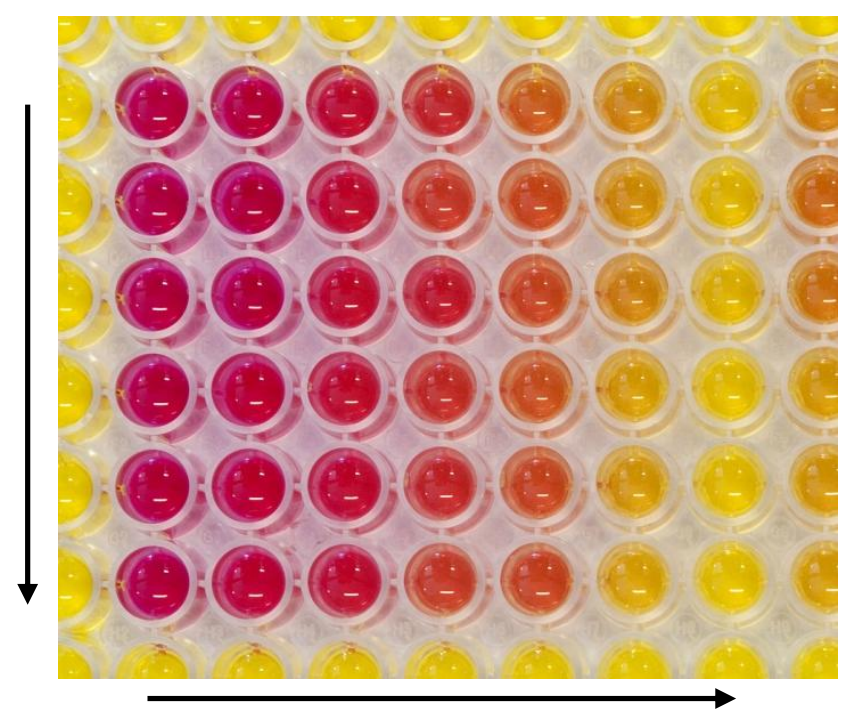

Supplementary Figure 2B Example of yeast bioassay colour change with serial dilution of 17 $\beta$-oestradiol $\left(\mathbf{E}_{2}\right)$. The samples are in triplicate and start with the greatest amount of $E_{2}$ in the red wells (top-left) to the least amount of $E_{2}$ in the right-bottom wells (yellow). There are two sets of dilutions in a column. 
Supplementary Table 2D The common name and scientific name for the avian species identified in BLAST searches carried out on the Aves taxon.

\begin{tabular}{|l|l|}
\hline COMMON NAME & SCIENTIFIC NAME \\
\hline African Black Coucal & Centropus grillii \\
\hline Bengalese Finch & Lonchura striata domestica \\
\hline Blue Tit & Cyanistes caeruleus \\
\hline Budgerigar & Melopsittacus undulatus \\
\hline Canary & Serinus canaria \\
\hline Chicken & Gallus gallus \\
\hline Collared Flycatcher & Ficedula albicollis \\
\hline Common Starling & Sturnis vulgaris \\
\hline Common Whitethroat & Sylvia communis \\
\hline Dark-eyed Junco & Junco hyemalis \\
\hline Domestic Goose & Anser anser \\
\hline Goldcrest & Regulus regulus \\
\hline Golden-collared Manakin & Manacus vitellinus \\
\hline Great reed Warbler & Acrocephalus arundinaceus \\
\hline Japanese Quail & Coturnix japonica \\
\hline Lappet-faced Vulture & Torgos tracheliotus \\
\hline Mallard & Anas platyrhynchos \\
\hline Ringneck Dove & Streptopelia risoria \\
\hline Rock Pigeon & Columba livia \\
\hline Skylark & Alauda arvensis \\
\hline Turkey & Meleagris gallopavo \\
\hline White-backed Vulture & Gyps africanus \\
\hline White-throated Sparrow & Zonotrichia albicollis \\
\hline Zebra Finch & Taeniopygia guttata \\
\hline & \\
\hline
\end{tabular}


Supplementary Table 2E The common name and scientific name for the avian species identified in BLAST searches carried out with the non-published avian database.

\begin{tabular}{|c|c|}
\hline COMMON NAME & LATIN NAME \\
\hline Adélie Penguin & Pygoscelis adeliae \\
\hline American Crow & Corvus brachyrhynchos \\
\hline American Flamingo & Phoenicopterus ruber \\
\hline Anna's Hummingbird & Calypte anna \\
\hline Bald Eagle & Haliaeetus leucocephalus \\
\hline Barn Owl & Tyto alba \\
\hline Bar-tailed Trogon & Apaloderma vittatum \\
\hline Brown Mesite & Mesitornis unicolor \\
\hline Chimney Swift & Chaetura pelagica \\
\hline Chuck-will's Willow & Caprimugus carolinensis \\
\hline Common Cuckoo & Cuculus canorus \\
\hline Crested Ibis & Nipponia nippon \\
\hline Cuckoo Roller & Leptosomus discolor \\
\hline Dalmatian Pelican & Pelecanus crispus \\
\hline Downy Woodpecker & Picoides pubescens \\
\hline Emperor Penguin & Aptenodytes forsteri \\
\hline Great Cormorant & Phalacrocorax carbo \\
\hline Great Crested Grebe & Podiceps cristatus \\
\hline Great Tinamou & Tinamus major \\
\hline Grey-crowned Crane & Balearica regulorum gibbericeps \\
\hline Hoatzin & Ophisthocomus hoazin \\
\hline Houbara Bustard & Chlamydotis undulata \\
\hline Killdeer & Charadrius vociferus \\
\hline Little Egret & Egretta garzetta \\
\hline Medium Ground Finch & Geospiza fortis \\
\hline Northern Carmine Bee-eater & Merops nubicus \\
\hline Northern Fulmar & Fulmarus glacialis \\
\hline Ostrich & Struthio camelus \\
\hline Peregrine Falcon & Falco peregrinus \\
\hline Red-crested Turaco & Tauraco erythrolophus \\
\hline Red-legged Seriema & Cariama cristata \\
\hline Red-throated Loon & Gavia stellata \\
\hline Rhinoceros Hornbill & Buceros rhinoceros silvestris \\
\hline Rifleman & Acanthisitta chloris \\
\hline Speckled Mousebird & Colius striatus \\
\hline Sunbittern & Eurypyga helias \\
\hline Turkey Vulture & Cathartes aura \\
\hline White-tailed Eagle & Haliaeetus albicilla \\
\hline White-tailed Tropicbird & Phaethon lepturus \\
\hline Yellow Throated Sandgrouse & Pterocles guturalis \\
\hline
\end{tabular}




\section{Appendix 3 Sequence Alignments}

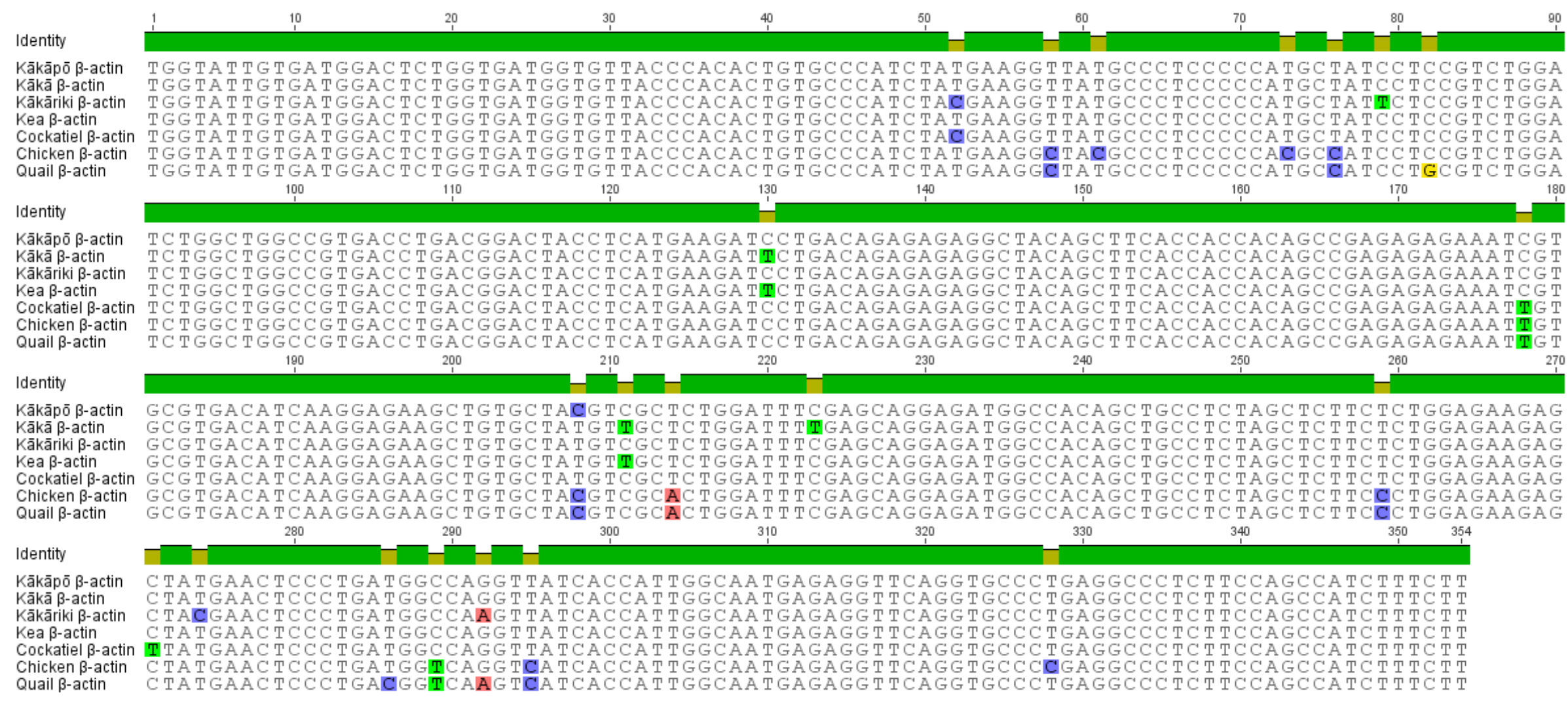

Supplementary Figure 3A Nucleotide sequences that span the amplified region of $\beta$-actin of New Zealand parrot species, cockatiel, chicken and quail. Highlighted nucleotides (red = adenine, blue $=$ cytosine, yellow $=$ guanine and green $=$ thymine) depict a change in the base . 
CHAPTER 9: APPENDICES

Identity

Kăkāpō ERa

Kăkã ERa

Kea ERa
Chicken ERa

Japanese Quail ERa

African Black Coucal ER
Common Starling ERa

Dark-eyed Junco ERa

Domestic Goose ERa
Lappet-faced Vulture ERa

Mallard ERa

Turkey ERa
White-backed Vulture ERa

White-crowned Sparrow ER

Zebra Finch ERa

Identity

Kăkẳpõ ERa

Kākä ERa

Kea ERa
Chicken ERa

Japanese Quail ERa

African Black Coucal ER

Dark-eyed Junco ER

Domestic Goose ERa
Lappet-faced Vulture ER

Mallard ERa

Rock Pigeon ERa

Turkey ERa

Whitt-throated Sparrow ERa
Zebra Finch ERa

Identity

Kăkāpō ERa

Kākā ERa

Kea ERa

Chicken ERa

African Black Coucal ER

Common Starling ER

Domestic Goose ERa
Lappet-faced Vulture ER

Rock Pigeon ERa

Rock Pigeon ERa
Turkey ERa

White-crowned Sparrow ER

Zebra Finch ERa

Identity

Kăkāpō ERa
Kăkā ERa

Kākā̄ ERa

Kākăriki ER
Kea ERa

Chicken ERa

African Black Coucal ER

Dark-eyed Junco ERa

Lappet-faced Vulture ERa

Mallard ERa
Rock Pigeon ERa

Rock Pigeon ERa
Turkey ERa
White-backed Vulture ER

White-crowned Sparrow ER

Zebra Finch ERa
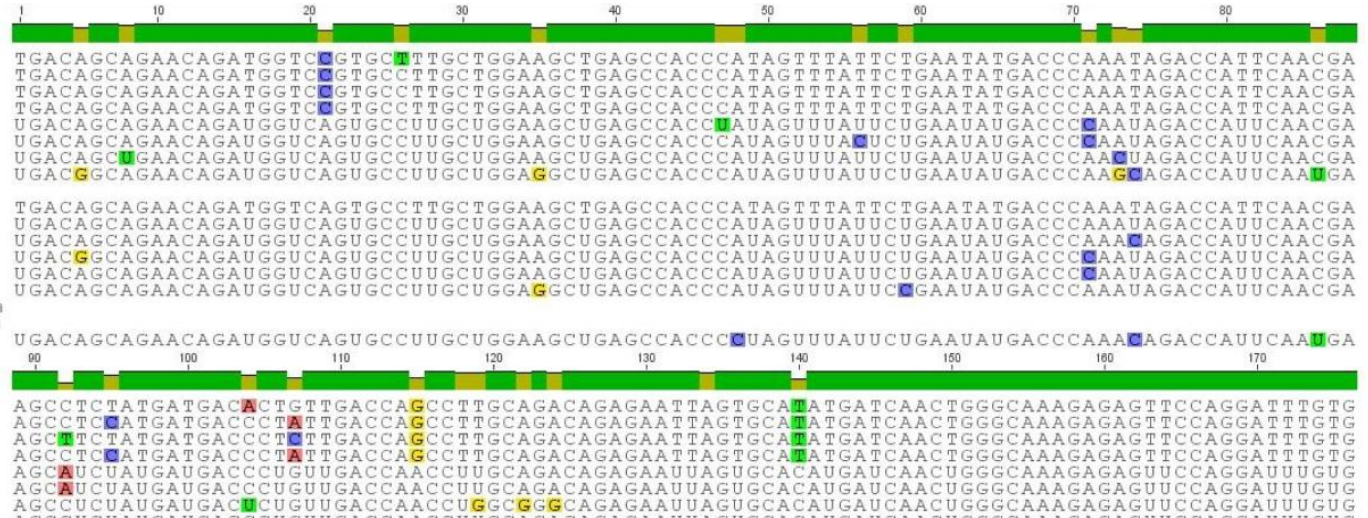

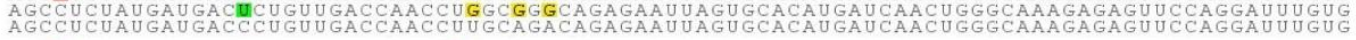
AGCATCTATGATGACCCTGTTGACCAACCA
AGCCUCUAUGAUGACCUGUUGACCAACCUUGC

GACAGAGAAUUAGUGCACAUGAUCAACUGGGCAAAGAGAGUUCCAGGAUUUGU

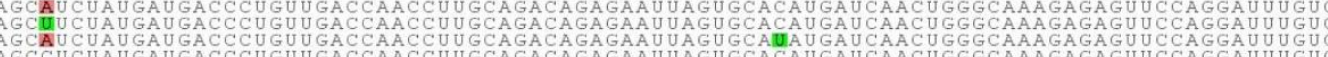

AGCUUCUAUGAUGACCCUGUUGACCAACCUUGCAGACAGAGAAUUGGUGCACAUGAUCAACUGGGCAAAGAGAGUCCAGGAUUUG

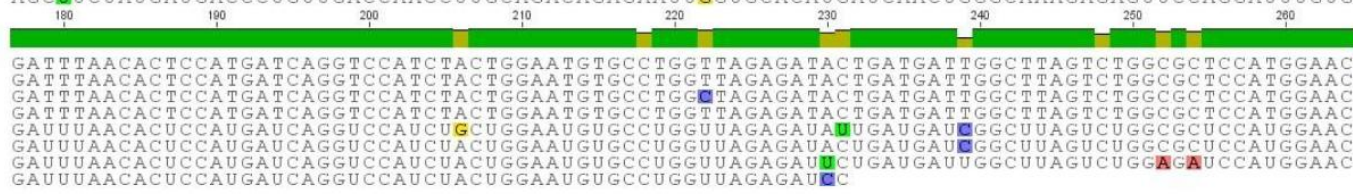

GAUUUAACACUCCAUGAUCAGGUCCAUCUACUGGAAUGUGCCUGGUUAGAGAUACUGAUGAUUGGCUUAGUCUGGCGCUCCAUGGAAC GAUUUAACACUCCAUGAU CAGGUCCAUCUACUGGAAUGUGCUUGGUUAGAGAUACUGAUGAUCGGCUUAGUUUGGCGCUCCAUGGAAC GAUUUAACACUCCAUGAUCAGGUCCAUCUACUGGAAUGUGCCUGGUUAGAGAUACUGAUGAUUGCUUAGU CUGGCGCUCCAUGGAAC GAUUUAACACUCCAU GAUCAGGUCCAUCUACUGGAAUGU GCAUGGU UAGAGAUACUGAUGAUTGGCUUAGUGUGGCGCUCCAUGGAAC 270

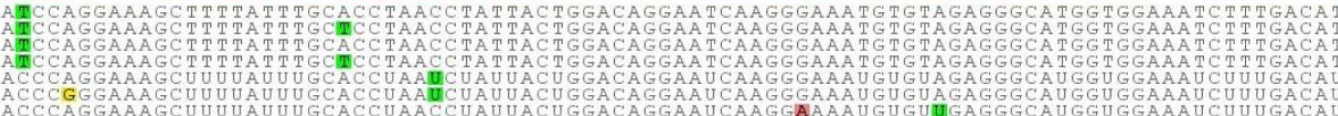

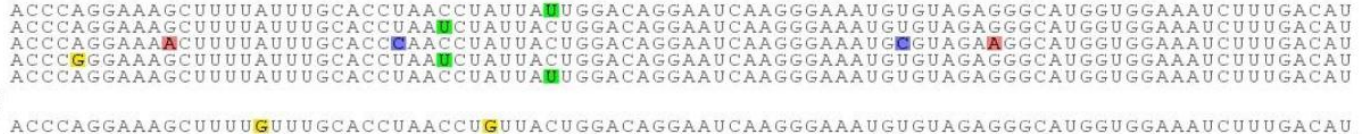

(continued on next page) 
CHAPTER 9: APPENDICES

Identity

Kā̄kāpō ERa

KăkāâRa

Kea ERa
Chicken ERa

Japanese Quail ERa

African Black Coucal ER

Common Starling ER
Dark-eyed dunco ERa
Domestic Cooose ERa

Domestic Goose ERa
Lappet-faced Vulture ER

Lappet-faced Vultur
Mallard ERa
Rock Pigeon ERa

Turkey ERa

White-browned Spartirow ER

White-throated Sparrow EF

Identity

Kăkããõ ERa

Kāăã ERa

Kea ERa

Japanese Quail ERa

African Black Coucal ER

Dark-eyed Junco ERa

Lappet-faced Vulture ER

Mallard ERa

Rock Pigeon
Turkey ERa

White-backed Vulture ERa

White-crowned Sparrow ER

Zebra Finch ERa

Identity

Kākāpō ERa

Kākāā ERa

Kea ERa

Chicken ERa

Japanese Quail ERa
African Black Coucal ER

Dark-eyed Junco ERa

Lappet-faced Vulture ERa Mallard ERa

Rock Pigeon
Turkey ERa

White-backed Vulture ERa

White-crowned Sparrow ER

White-throated Sp
Zebra Finch ERa
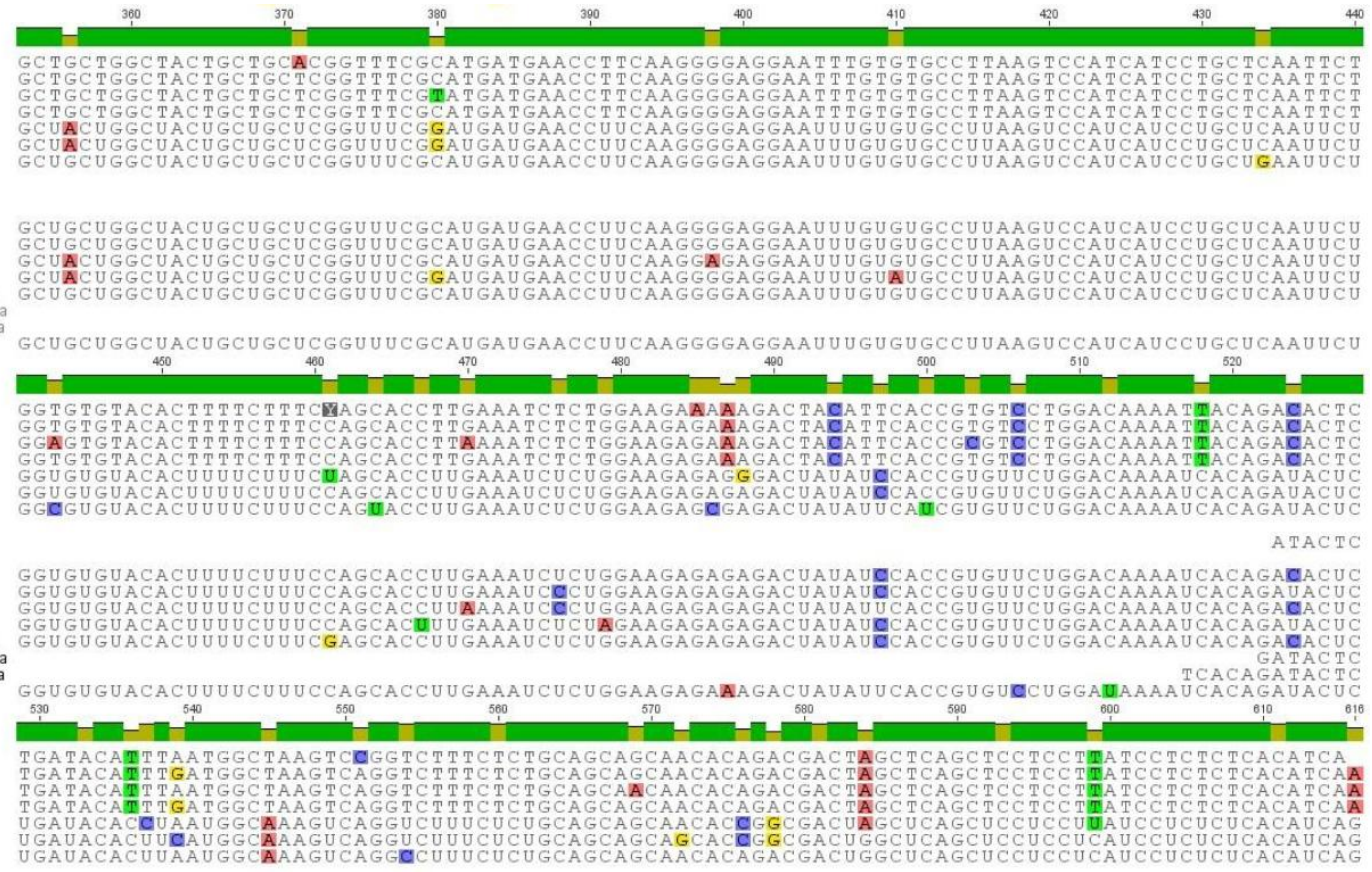

TGATCCACT TAATGGCTAAGTCAGGTCTTTCTCTGCAGCAGCAACACAGACGACTGGCTCAGCTCCTCCTCATCCTCTCTCACATCAG

Supplementary Figure 3B Nucleotide sequences that span the amplified region of the ligand binding domain (LBD) of oestrogen receptor $\alpha$ (ERa) of New Zealand parrot species and other avian species identified from the blastn search of the Aves taxon. The avian species identified were Chicken (NM_205183), Japanese Quail (AF442965), African Black Coucal (DQ478953), Common Starling (EU328304), Dark-eyed Junco (EU157729), Domestic Goose (EU417675), Lappet-faced Vulture (AB447537), Mallard (EF502052), Rock Pigeon (JX413115), Turkey (XM_003204124), White-backed Vulture (AB447536), White-crowned Sparrow (EU157739), White-throated Sparrow (GU449529) and Zebra Finch (NM_001076701). Highlighted nucleotides $($ red $=$ adenine, blue $=$ cytosine, yellow $=$ guanine and green $=$ thymine $)$ depict a change in the base. 
Consensus parrot ERa Chicken ERa Japanese Quail ERa African Black Coucal ERa Common Starling ERa Lappet-faced Vulture ERa Mallard ERa Rock Pigeon ERa Turkey ERa White-backed Vulture ERa White-throated Sparrow ER Zebra Finch ERa Identity

Consensus parrot ERa Chicken ERa Japanese Quail ERa African Black Coucal ERa Common Starling ERa Lappet-faced Vulture ERa Mallard ERa

Rock Pigeon ERa Turkey ERa White-backed Vulture ERa White-throated Sparrow ERa Zebra Finch ERa Identity

Consensus parrot ERa Chicken ERa Japanese Quail ERa African Black Coucal ERa Common Starling ERa Lappet-faced Vulture ERa Mallard ERa

Rock Pigeon ERa Turkey ERa White-backed Vulture ERa White-throated Sparrow ERa Zebra Finch ERa

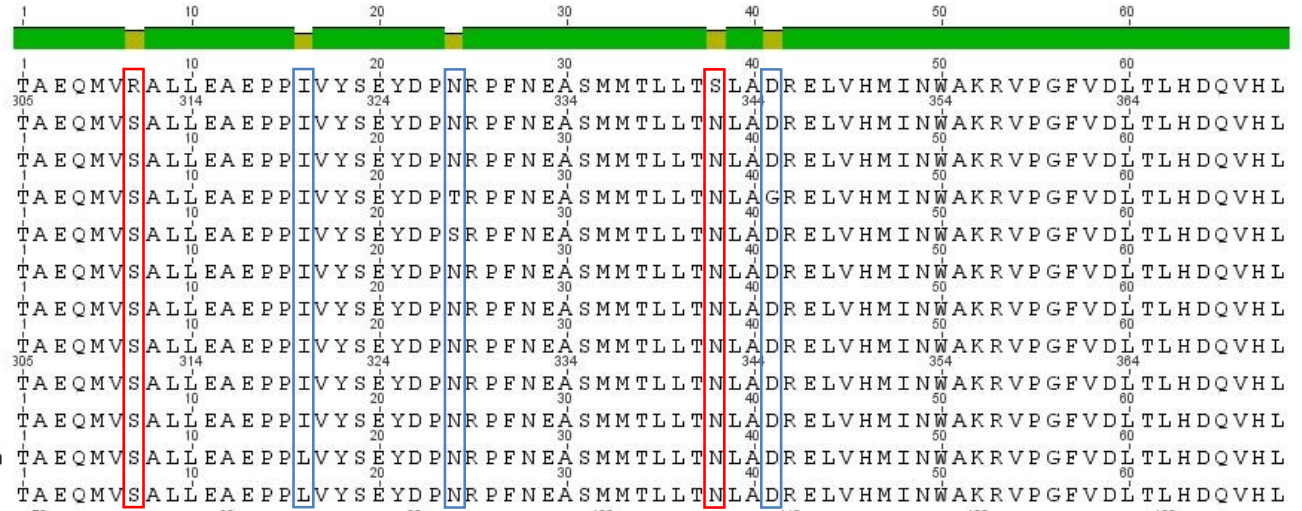
作 \begin{tabular}{ccccccc}
70 & 80 & 90 & 100 & 130 & 120 & 130 \\
\hline 1 & 80 & 90 & 100 & 110 & 120 & 130
\end{tabular}

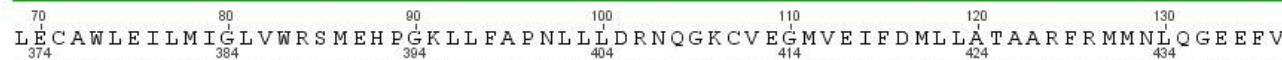

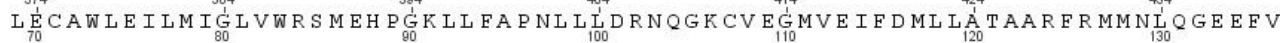

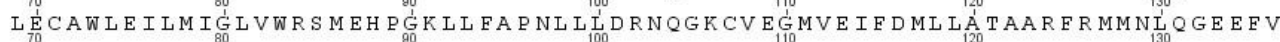
LE CAWLEILMIǴLVWRSMEHPGKLLFAPNLLLDRNGKCVEGMVEIEDMLLÁ TAARERMMNLGEEFV LECAWLE I

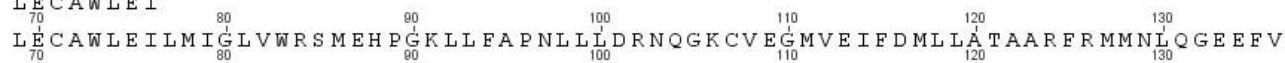

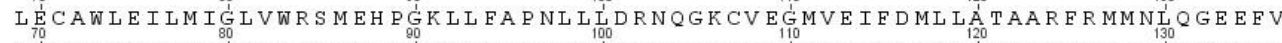

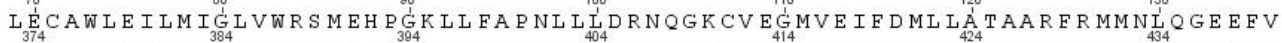

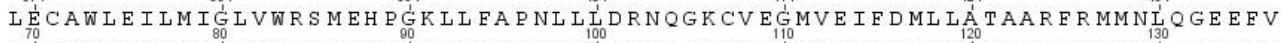
L $\underset{70}{\operatorname{L}}$ CAWLEILM I

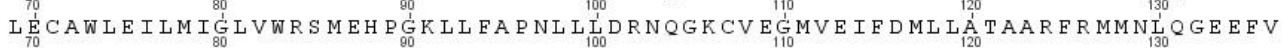
LE CAWLEILMIǴLVWRS MEH PGKLLFAPNLLLDRNQGKCVEGMVEIEDML LÁ TAAR R MMNLQGEEFV

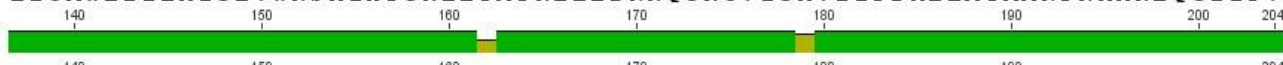

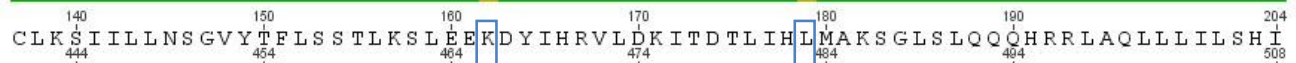

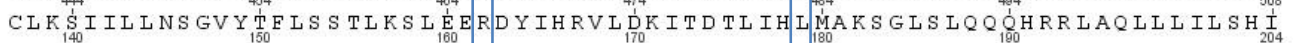

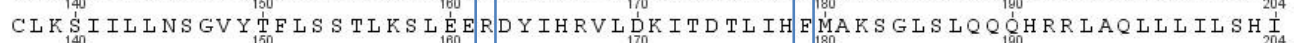

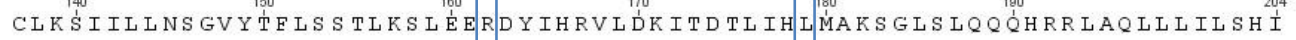

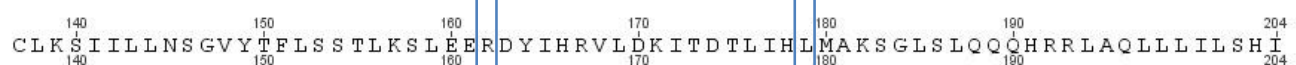

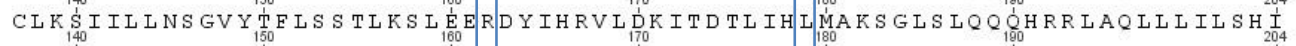
CLK S S I IL LNSGVY

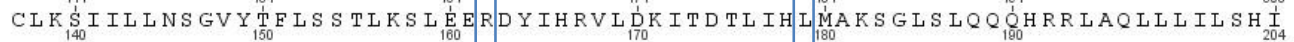

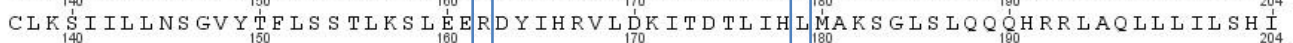

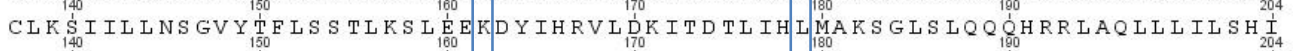
CLK S I IL LNS GVYTELS TLKS L EEKDY IHRVL DK ITDTLIHLMAKS GLS LQQ Q́ RRLAQLLLILSH I

Supplementary Figure 3C Amino acid sequences that span the amplified region of the ligand binding domain (LBD) of oestrogen receptor $\alpha$ (ERa) of New Zealand species and other avian species that were identified from the blastp search of the Aves taxon. The avian species identified were Chicken (NP_990514), Japanese Quail (AF442965_1), African Black Coucal (ABF20062), Common Starling (ABY50093), Lappet-faced Vulture (BAH01724), Mallard (ABR68645), Rock Pigeon (AFU48567), Turkey (XP_003204172), White-backed Vulture (BAH01723), White-throated Sparrow (ADK26703) and Zebra Finch (NP_001070169). The amino acid changes that were different only in the consensus parrot sequence have a red box around them. The other changes have a blue box. 
Identity

Consensus parrot ER

Adelie Penguin ER

American Flamingo ER

Anna's Hummingbird ERa

Bald Eagle ERa

Barn Owl ERa

Chuck-will's Willow ER

Crested lbis ERa

Dalmatian Pelican ERa

Downy Woodpecker ER

Emperor Penguin ERa

Great Cormorant ERa

Great Tinamou ERa

Houbara Bustard ER

deer ERa

Medium Ground Finch ER

Northern Carmine Bee-eater ER

Ostrich ER

Peregrine Falcon ERa

Red-throated Loon ERa

Rifleman ER

Speckled Mousebird ER

Sunbittern ERa

White-tailed Eagle ERa

White-tailed Tropicbird ER

Yellow Throated Sandgrouse ER

Identity

Consensus parrot ERa

Adelie Penguin ERa

American Crow ERa

Anna's Hummingbird ERa

Bald Eagle ERa

Chimney Swift ERa

Chuck-will's Willow ERa

Crested Ibis ERa

Dalmatian Pelican ERa

Emperor Penguin ERa

Golden-collared Manakin ERa

Great Cormorant ERa

Great Tinamou ERa

Grey-crowned Crane ER
Hoatzin ERa

Houbara Bustar

Killdeer ERa

Medium Ground Finch ER

Northern Carmine Bee-eater ER

Peregrine Falcon ERa

duraco ERa

Red-throated Loon ERa

iffleman ERa

Sunbittern ERa

Turkey Vulture ERa

White-tailed Eagle ERa

White-tailed Tropicbird ER

Identity

Consensus parrot ER

Adelie Penguin ER

American Crow ERa

Anna's Hummingbird ERa

Bald Eagle ERa
Barn Owl ERa

Chimney Swift ERa

Chuck-will's Willow ERa

Crested Ibis ERa

Dalmatian Pelican ERa

Golden-collared Manakin ER

Geat Cormorant ER

Grey-crowned Crane ER

Hoatzin ERa

Houbara Bustard ER

Killdeer ERa

Little Egret ERa
Medium Ground Finch ERa

Northern Carmine Bee-ea

Ostrich ER

Peregrine Falcon ERa

Red-crested Turaco ER

Red-legged Seriema ERa

Rifleman ERa

Speckled Mousebird ERa

Turkey Vulture ER

White-tailed Eagle ERa

Yellow Throated Sandgrouse ER
TAEQMVRALLEAEPPIVYS EYDPNR PFNEASMMTLLTSLADRELVHMINWAKRVPGFVDLTLHDQVHLLE TAE MVSAL IEAE D DLVY EYDPNR P NEASMMT L T LADR ELVHMTNAKRVDGEVDITLHDOVHLL TAEOMVSALLEAEPP IVYSEYDPNR FNEASMMTLLTNLADRELVHMINWAKRV

TAEQIVSALLEAEP IVYSEYDPNR P E EASMMTLLTNLADR ELVHMINWAKRVPGEVDTLHDOVHLLE TAEQMVSALLEAEPP IVYS EYDPNR PFNEASMMTLLTNLADR E LVHMINWAKRVPGFVDLTLHDOVHLLE TAEOMVALI EAE P IVYS EYDPNR P N A S MMTT TNAD TAEOMVSALLEAEPP IVYSEYDPNR PFNEASMMTLLTNLADR E LVHM IN WAKRVPGEVDLTTDOVHLL TAEOMVSALLEAEP IVYS EYDPNR P NEASMMTLLTNLADR E LVHMINWAKRVPG TVDLTLHDOVHLLE TAEQMVSALLEAE P IVYSEYDPNR F NEASMMTLLTNLADR ELVHMINWAKRVPGFVDLTLHDQVHLLE TAEOMVSALLEAE PP IVYS EYDPNR PFNEASMMTLLTNLADR E LVHM INWAKRVPGFVDLTLHDQVHLLE TAEQMVSALLEAEP PLVYS EYDPNR P FNEASMMTLLTNLADRELVHMINWAKRVPGFVDLTLHDOVHLLE TAEOMVSALLEAEP IVYSEYDPNR PFNEASMMTLLTNLADR ELVHMINWAKRVPGFVDLTLHDOVHLLE TAEQMVSALLEAEPPIVYSEYDPNR P NEASMM TLLTNLADRELVHMINWAKRVPGFVDLTLHDQVHLLE TAEQMVSALLEAE P IVYS EYDPNR F NEASMMTLLTNLADR E LVHMINWAKRVPGFVDLTLHDQVHLLE TAEQMVSALLEAEPPIVYS EYDPNR P FNEASMMTLITNLADR ELVHMINWAKRVPGFVDL TLHDQVHLLE

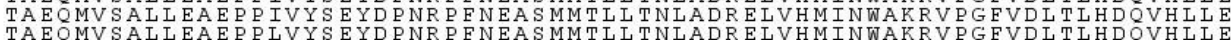
TAEQMVSALLEAEPPIVYSEYDPNR P N EASMMTLLTNLADRELVHMINWAKRVPGFVDLTLHDQVHLLE

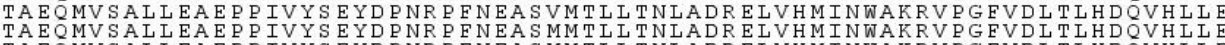

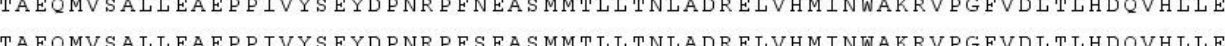

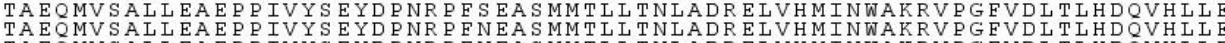
TAEQMVSALLEAEP IVYS EYDPNR P N EASMMTLL TNLADRELVHMINWAKRVPGFVDLTLHDOVHLLE TAEQMVSALLEAEP IVYSEYDPNR ENEASMMTLLTNLADRELVHMINWAKRVPGEVDLTLHDQVHLLE TAEQMVSALLEAEPP IVYS EYDPNR PENEASMMTLLTNLADR ELVHMINWAKRVPGFVDLTLHDQVHLLE TAEQMVSALLEAEP IVYSEYDPNRPENEASMMTLLTNLADRELVHMINWAKRVP

CAWLEILMIGLVWRS MEHPGKLLFAPNLLLDRNQGKCVEGMVEIFDMLLATAARERMMNLQGEEFVCLK-

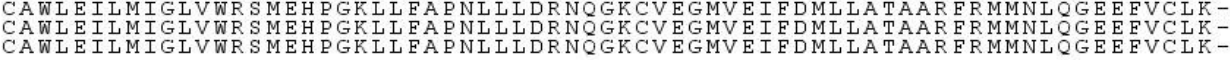
CAWLEILMIGLVWR SMHPGKLLFAPNLLLDRNGKCVEGMVE FDMLLATAARFRMMNLQGEEFVCLK-

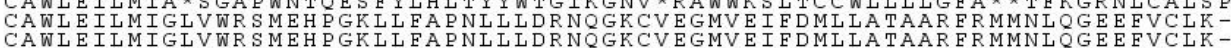

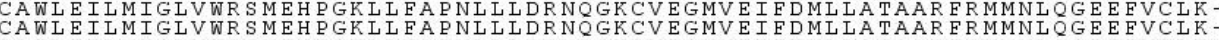
CAWLEILMIGLVWRSMEHPGKLLFAPNLLLDRNQGKCVEGMVETFDMLLATAARFRMMNLQGEEFVCLKCAWLEILMIGLVWR MEH GGLLEAPNLLLDRNQGKCVEGMVEIFDMLLATAARFRMMLQGEEFVCLKCAWLEILMIGLVWRSMEHPGKLLFAPNLLLDRNGGKCVEGMVE IFDMLLATAARFRMMNLQGEEFVCLKCAWLEILMIGLVWRSMEH PGKLLFAPNLLLDR

CAWLEILMIGLVWR MEH PGKLLFAPNLLLDRNQGKCVEGMVEIFDMLLATAARFRMMLQGEEFVCLK-

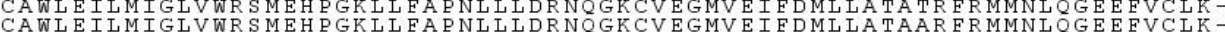
CAWLEILMIGLVWRSMEH PGKLFFAPNLLLDRNHGKCVEGMVEIFDMLLATSARFRMMNIQGEEFVCLKCAWLEILMIGLVWRSMEHPGKLLFAPNLLLDRNQGKVEGMVEIFDMLLATAARFRMMLQGEEFVCLKCAWLEILMIGLVWRSMEHPGKLLFAPNLLLDRNQGKCVEGMVEIFDMLLATAARFRMMNLQGEEFVCLKCAWLETLMIGLVWR MEH PGKLLFAPNLLLDRNQGKCVEGMVEIFDMLLATAARERMMNLQGEEFVCLK-

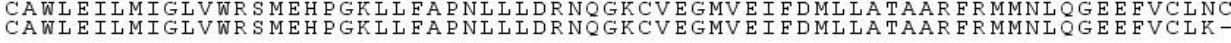
CAWLEILMIGLVWR SMEHPGKLLFAPNLLLDR

CAWLEILMIGLVWR MEHPGKL L FA PNLL L DRNQGKCVEGMVEI FDMLLATAARFRMMNLGEEFVLK-

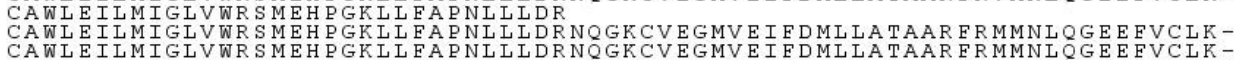
CAWLEILMIGLVWR MEHPGKLLFAPNLLLDRNQGKCVEGMVEIFDMLLATAARFRMMLQGEEFVCLK-

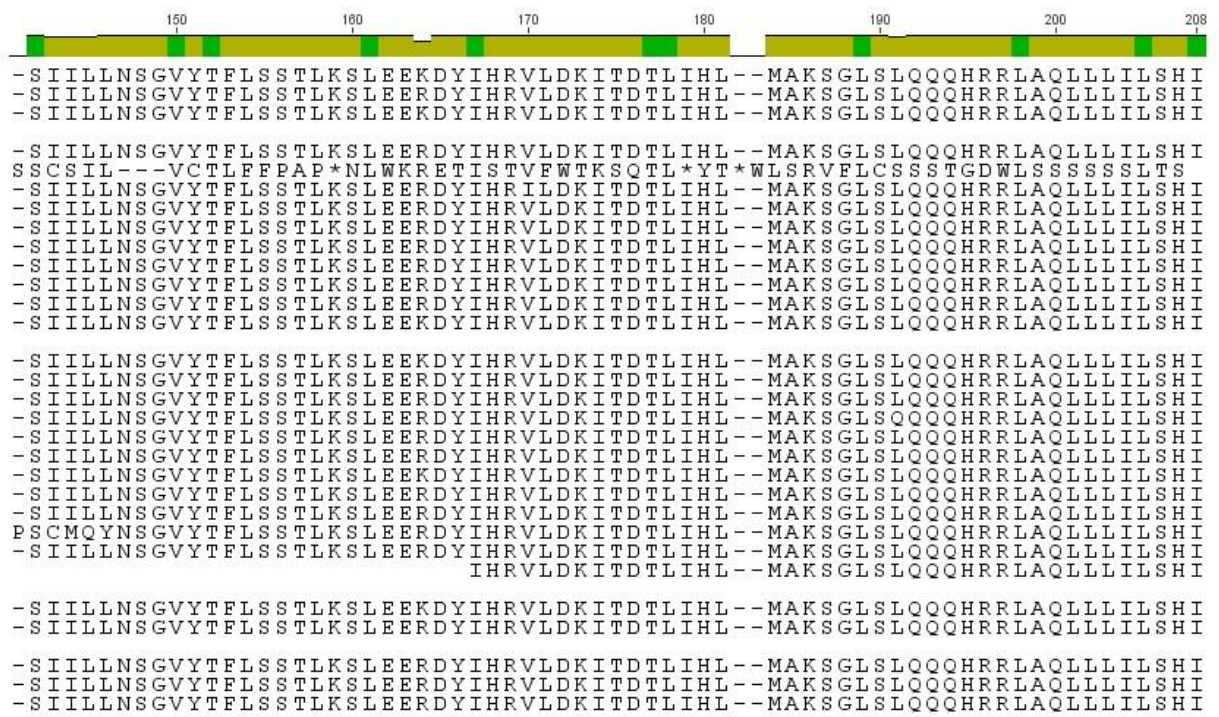

Supplementary Figure 3D Amino acid sequences that span the amplified region of the ligand binding domain (LBD) of oestrogen receptor $\alpha(E R a)$ of New Zealand species and other avian species that were identified from the blastn search of the avian database. The nucleotide sequences for the avian species identified were translated into the corresponding amino acid sequences and are listed with the species common name. 
Identity

Kākāpō ERa

Kākā ERa

Kākāriki ERa

Kea KRa

Chicken ERa

Japanese Quail ER

Japanese Quail ERa

Rock Pigeon ERa

White-backed Vulture ERa

Zhite-backed Vatura

Identity

Kākāpō ERa

Kākā ERa

Kākāriki ERa

Kea ERa

Chicken ERa

Japanese Quail ERa

Lappet-faced Vulture ERa

Rock Pigeon ERa

White-backed Vult

Identity

Kākāpō ERa

Kākā ERa

Kākāriki ERa

Kea ERa

Chicken ERa

Japanese Quail ERa

Lappet-faced Vulture ER

Rock Pigeon ERa

White-backed Vulture ERa

Zebra Finch ERa
$1-$

10

30 GACACATGAGCAACAAAGGA.TGGAGCACCTGTATAATATGAATGTAAAAATGTAGTTCCACTCTATGATCTCTTGCTGGAGATGTTGG GACACATGAGCAACAAAGGAATGGAGCACCTGTATAACATGAAGTGTAAAAATGTGGTTCACTCTATGATCTCTTGCTGGAGATGCTGG GACACA GGCAUAUGACAACAAAGGAUGGAGCACCUGUACAAUAUGAAGUGUAAAAAUGAGUUCCGCUCUACGACCUCUUACUGGAGAUGCUGG GGCAUAUGACAACAAAGAAGGAGCACCUGUACAAUAUGAAGUGUAAAAAUGUAGUUCCGCUCUAUGACUUCUUACUGGAGAUGCUG GACACAUGAGCAACAAAGGAAUGGAGCACCUGUACAAUAUGAAGUGUAAAACGUAGUUC CACUCUAUGAUCUCU UGCUGGAGAUGCUGG GACACAUGAGCAACAAAGGAAUGGAGCACCUGUACAAUAUGAAGU GCAAAAAU GUAGUUCCGCUCUACGACCUCU UACUGGAGAUGCUGG GACACAUGAGCAACAAAGGAAUGGAGCACCUGUACAAUAUGAAGU GUAAAAACGUAGUUCCACUCUAU GAUCUCU UGCUGGAGAUGCUGG GACACAUGAGCAACAAAGGAAUGGAGCACCUGUACAAUAUGAAGU GUAAGAAU GUAGUUCCGCUCUACGAUCUCU UGCUGGAGAUGCUGG 100 120 130 140 150 160 170 180

A

ACGCTCATCGACTGCATGCCCCAGCAGCCAGGAGTGCT GCACCGA TGGAAGAGGAGAACCAGAGCCAGCTGACAACTGCATCA GCTTCAT ACGCTCATCGACTGCATGTCCCGGCAGCCAGGAGTGCTGCACCGA TGGAAGAGGAGAACCAGAGCCAGCTGACAACTGCATCAGCTTCAT ACGCTCATCGACTGCATGCCCCAGCAGCCA GGAGTGCT GCACCAA TGGAAGAGGGGAACCGGAGCCAGCTGACAGCTGCTTCA GCTTCAT ACGCTCATCGACTGCATGCCCCGGCAGCCA GGAGTGCT GCACCGA TGGAAGAGGAGAACCAGAGCCAGCTGACAACTGCA TCA GCT TCAT ACGCUCACCGCCUACAUGCACCGGCAGCCA GGAGUGCU GCACCAAUGGAAGAGGAGAACCGAAACCAACUGACAACCGCACCAGCUUCAU CGCUCAUCGCCUACAUGCGCCA GCAGCCA GGAGUGCU GCACCAAUGGAAGAGGAGAACC GAAGCCAGCUGACAA.CUGCACCA GCUUCAU ACGCUCACCGACUGCAUGCCCCA GCAGCCAGGAGUGCU GCACCAGUGGAAGAGGAGAACCGGAGCCAGAUGACA.CUGCAUCA GUUUCAU ACGCUCACCGACUGCACGCCCCAGCAGCCAGGAGUGCU GCACCCA.CGGAAGAGGAGAACCGGAGCCA.ACUGACA.CUGCAUCAGCUUCAU ACGCUCACCGACUGCAUGCCCCAGCAGCCAGGAGUGCU GCACCAGUGGAAGAGGAGAACCGGAGCCAGAUGACAACUGCAUCA GCUUCAU AUGCUCA.CCGACUGCACGCCCCA GCAGCCA GGAGUGCU GCACCCAUGGAAGAGGAGAACCGAAGCCAGCUGACAA GUGCAUCA GCUUCAU 250 260

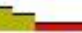

СTCATTCCATGCAGT CTTTTTACTCATTCCATGCAGTCTTTTTA---TATAGGCAAAGAAGAGGAGAAAGTGAGTGCAGAATACAATATAACCAAAAGTCAGCAGATATGA CTCATTCCATGCAGCCTTTTIA--DATAGGCAAAGAAGAGGAGAAAGTGGGTGAAGAGTACAATATAAGCAAAAGTCAGCAAATATGA CTCATTCCATGCAGTCTTTTTA---TATAGGCAAAGAAGAGGAGAAAGTGAGT GCAGAATACAATATAACCAAAAGTCAGCAGATA TGA CUCAUUCCUGCAGU CCUUUUACAUUAACAGCAAAGAAGAGGAGAGU AU GCAGAAUACAAUAUAA CUCAUUCCCUGCAGU CCUUUUACAUUAACAGCAAAGAAGAGGAGAGU-D AU GCAGAAUACAAUAUAA CUCAUUCCUUGCAGU CUUUUUAUAUAAACGGCAAAGAAGAGGAGA.AU GU GCAGAAUACAAUAUAA CUCAUUCCUUGCAGU COUUUUAUAUAAAUAGCAAAGAAGAGGAGAAU - AUGCAGAAUACAAUAUAA

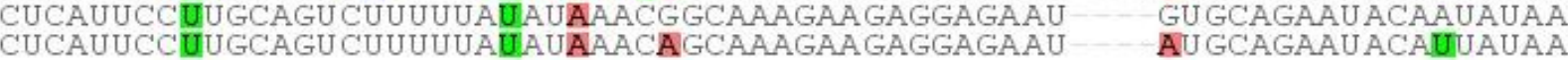

Supplementary Figure 3E Nucleotide sequences that span the remaining amplified region of the ligand binding domain (LBD) of oestrogen receptor $\alpha$ (ERa) of New Zealand parrot species and other avian species identified from the blastn search of the Aves taxon. The avian species identified were Chicken (NM 205183), Japanese Quail (AF442965), Lappet-faced Vulture $($ AB447537), Rock Pigeon $(J X 413115)$, White-backed Vulture $(A B 447536)$, and Zebra Finch $($ NM 001076701). Highlighted nucleotides $($ red $=$ adenine, blue $=$ cytosine, yellow $=$ guanine and green $=$ thymine) depict a change in the base . 
CHAPTER 9: APPENDICES

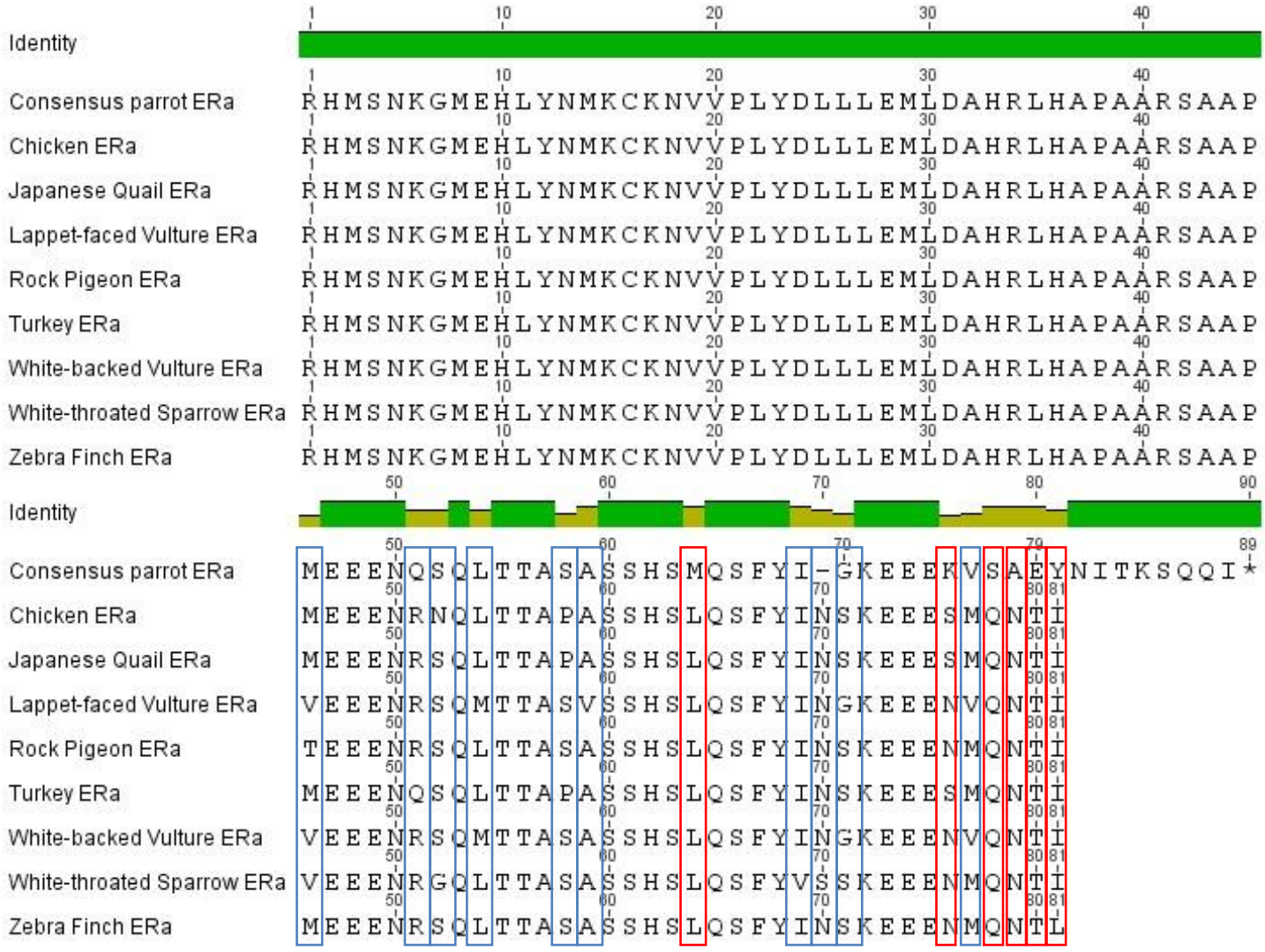

Supplementary Figure 3F Amino acid sequences that span the remaining amplified region of the ligand binding domain (LBD) of oestrogen receptor $\alpha(\mathrm{ERa})$ of New Zealand species and other avian species that were identified from the blastp search of the Aves taxon. The avian species identified were Chicken (NP_990514), Japanese Quail (AF442965_1), Lappet-faced Vulture (BAH01724), Rock Pigeon (AFU48567), Turkey (XP_003204172), White-backed Vulture (BAH01723), White-throated Sparrow (ADK26703) and Zebra Finch (NP_001070169). The amino acid changes that were only different in the consensus parrot sequence have a red box around them whilst the other changes have a blue box. 
Identity

Kākāpō ERa

Adelie Penguin ERa

American Crow ERa

Anna's Hummingbird ERa

Bald Eagle ERa

Barn Owl ERa

Chimney Swift ERa

Chuck-will's Willow ERa

Crested Ibis ERa

Cuckoo Roller ERa

Dalmatian Pelican ERa

Downy Woodpecker ERa

Emperor Penguin ER

Great Tinamou ERa

Grey-crowned Crane ERa

Hoatzin ERa

Killdeer ERa

Little Egret ERa

Medium Ground Finch ERa

Northern Carmine Bee-eater ERa

Ostrich ERa

Peregrine Falcon ERa

Red-crested Turaco ER

Red-legged Seriema ERa

Rifleman ERa

Speckled Mousebird ERa

Turkey Vulture ERa

White-tailed Eagle ERa

White-tailed Tropicbird ERa

Yellow Throated Sandgrouse ERa

Identity

Kākāpō ERa

Adelie Penguin ERa

American Crow ERa

Anna's Hummingbird ERa

Bald Eagle ERa

Barn Owl ERa

Chimney Swift ERa

Chuck-will's Willow ERa

Crested Ibis ERa

cuckoo RollerERa

Dalmatian Pelican ERa

Downy Woodpecker ERa

Emperor Penguin ER

Great Tinamou ERa

Grey-crowned Crane ERa

Hoatzin ERa

Killdeer ERa

Little Egret ERa

Medium Ground Finch ER

Northern Carmine Bee-eater ER

Ostrich ERa

Peregrine Falcon ERa

Red-crested Turaco ERa

Red-legged Seriema ERa

Rifleman ER

Speckled Mousebird ERa

Turkey Vulture ERa

White-tailed Eagle ERa

White-tailed Tropicbird ERa

Yellow Throated Sandgrouse ERa
10

20

RHMSNKGMEHIYNMKCKNVVP LYDLIL EMLDAHRLHA PAAR S A A HMS NKGMEH L YNMCKNVVPLYDLLLEMLDAHRLHAPAAR S A A P HMS NKGMEH L Y M K CKNVVPLYDLLLEMLDAHRLHA A AR S - E E HMSNKGMEHLYNMKCKNVVPLYDLLLEMLDAHRLHAPAAR - A A P HMS NKGMEH L YNMKCKNVVPLYDLLLEMLDAHR L HA PAAR S A A P HMSNKGMEHLYNMKCKNVVPLYDLLLEMLDAHRLHAPAARSAAAP HMSNKGMEH YNMKCKNVV P YDLLLEMLDAHRLHAPAAR S A A P HMSNKGMEHLYNMKCKNVVPLYDLLLEMLDAHRLHAPAAR - A.P HMS NKGMEHLYNMKCKNVVPLYDLLLEMLDAHRLHAPASRS-AAP HMS NKGMEHLYNMKCKNVVPLYDLLLEMLDAHR I

HMS NKGMEH L YNMCKNVVPLYDLLLEMLDAHRLHAPAARS-AAP HMSNKGMEHLYNMKCKNVVPLYDLLLEMLDAHRLHAPAAR S A P HMS NKGMEHLYNMKCKNVVPLYDLLLEMLDAHR L HAPAARS-AAP MSNKGMEH I YNMKCKNVV I YDLILEMLDAHRIHA PAARS - AAP HMS NKGEHLYNMKCKNVVPLYDLLLEMLDAHRLHTPAARS-AAP HMS NKGMEHLYNMKCKNVV L L Y L L E MLDAHRLHAP PAR S - A A P HMSNKGMEHLYNMKCKNVVPLYDLLLEMLDAHRLHAPAAR - AAP HMS NKGMEHLYNMKCKNVVPLYDLLLEMLDAHRLHAPGARS-AAP HMS NKGMEH L YNMKCKNVVPLYDLLLEMLDAHRLHA PAAR S - A A P HMS NKGMEHLYNMKCKNVVPLYDLLLEMLDAHRLHAPAARS-AAP HMSNKGMEH I YNMCKNVV L YDLLIEMLDAHRLHAPAAR S A P HMSNKGMEHLYNMKCKNVVPLYDLLLEMLDAHRLHAGARS-AAS HMSNKGMEHLYNMKCKNVVPLYDLLLEMLDAHRLHAPAARS-AAP HMS NKGMEHLYNMKCKNVVPLYDLLIEMLDA HR I

HMS NKGMEH L YNMKCKNVV L L D L L EMLDAHR L HAPAAR - A A P HMS NKGMEHLYNMKCKNVVPLYDLLLEMLDAHR L HA PAAR S - A A P HMS NKGMEHLYNMKCKNVVPLYDLLLEMLDAHRLHAPAAR -AAP HMSNKGMEH I YNMKCKNVVPLYDLILEMLDAHR L H P A AR S - A A P HMSNKGMEHLYNMKCKNVVPLYDLLIEMLDAHRLHAPAARS-AAP HMS NKGME H L Y M K KNVV P I Y L L L E M D A H R I

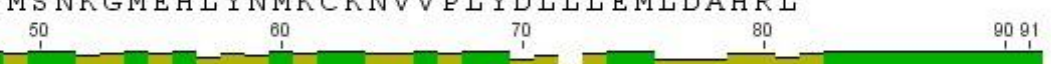

MEE ENOSOITTASASSHSMQSEYI-GKEEEKVSAEYNISKSQQI* MEEENRSOLTTASASSHSIOSFYTNSKEEETMQNTI

MEEENRSOLTAASASSHSLOS FYVNSKEEE

MEEENRSQLTTASASSHSLOSFYINGKEE

VEEENRTQMTTASASSHSLQS EYINGKEEENVQNTI

MEEENRSOLTTASASSHSLQS EYINGKEEDNMQNTI

MEEENRSQLTTAPATSHSLQSEYINGKEEENMQNTI

MEOENRSOITTASASSHSTOSFYINSKEEDNMONTT

MEEENRSOLTTASAS SHSLOSFYINSKEEDNMONTI

MEEENRSQLTTASASSHSLQSEYINSKEEE

MEEENRSQLTAASASS TTQSEYINSKEEENMQNAI

MEEENRSQLTTASAS S H LQS EYINSKEE TMQNTI

MEEENRSQLTAS SASSHSLOAFYMSNREE-NMONT

MEEENRSOLTTAPAS S HSLOSEYINGKEE-NMONP I

MEEENRSOLTTAPASSHSLOSFYINSKEEE

MEEENRSQLTTASASSHSLQSEYINSKEEENMQNTI

VEEENRSQLTTASASSHSLQSEYINSKEEETMQNTT

VEEENRSQLTTASASSHSLQSEYVSSKEEENMQNTI

MEE ENRSQLTTASAS S S LQS FYINSKEE ENMQNTI

MEEENRSQLTTASASSHSLQS EYMNNRE E ENMQNT I

MEEENRSOITAASASSHSIOSFYINSKEEENVONTT

MEEENRSOLTTASAS SHSLOS FYINGKEEENMONTT

MEEENLSQLTTASASSHSLQSEYVNSKEEENMQNTI MEEENRSQLTTASASSHSLQSEYINSKEEE

MEEENRSQLTTASASS HSLQSEYINNKEEENMQNTI

VEEENRSOMTTASASSHS LQS FYINGKEE ENVONT

MEEENRSQLTTASASSHSLOS FYINSKEE ENMONTI

Supplementary Figure 3G Amino acid sequences that span the remaining amplified region of the ligand binding domain (LBD) of oestrogen receptor $\alpha$ (ERa) of New Zealand species and other avian species that were identified from the blastn search of the avian database. The nucleotide sequences for the avian species identified were translated into the corresponding amino acid sequences and are listed with the species common name. 


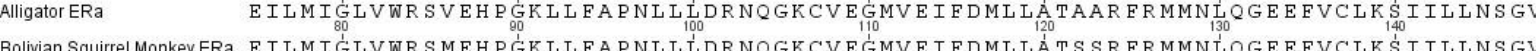

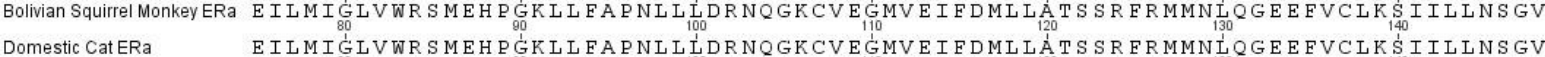

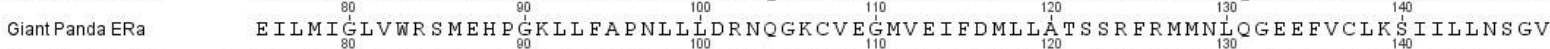
Gray Short-tailed Opossum ER I L M I G House Mouse ERa Nile Crocodile ERa Pacific Ridley ERa Pacific Walrus ERa Painted Turtle ERa Red-bellied Turtle ERa Spectacled Caiman ERa Tasmanian Devil ERa Identity

Consensus parrot ERa African Elephant ERa AlligatorERa Y $\underset{150}{\mathrm{~T}}$ ELSSTLKSL $\underset{160}{1}$ EKDYIHRVLDKITDTLIHLMAKSGLSLQQ

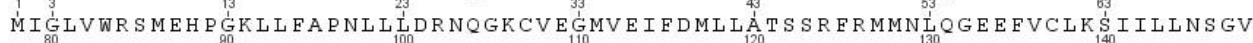

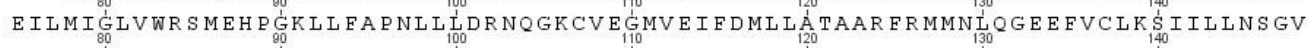

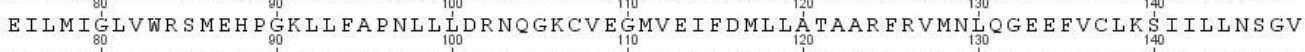

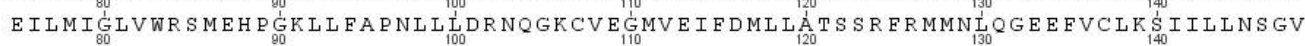

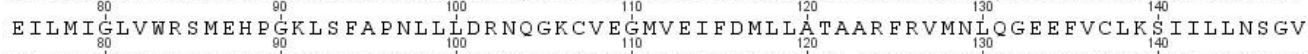

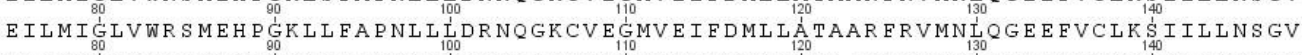

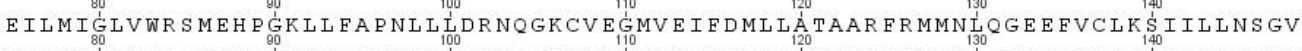

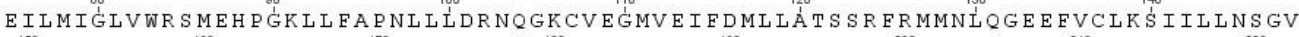
150

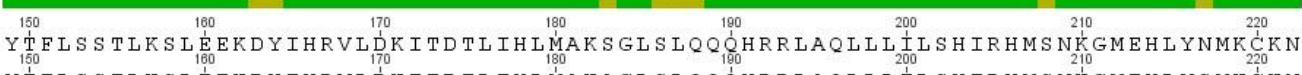
Y

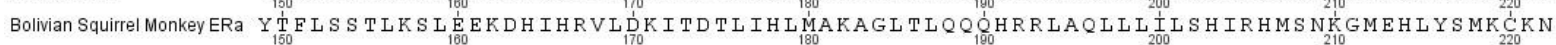
Domestic CatERa Y Y

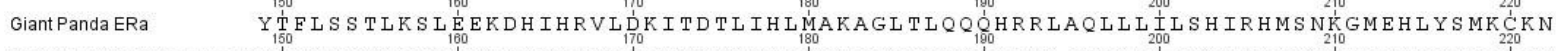

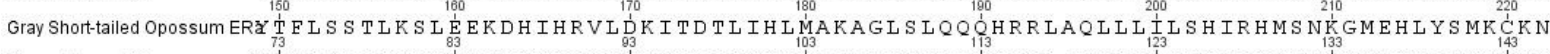

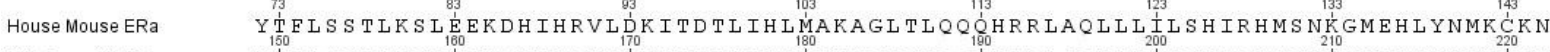
Nile Crocodile ERa Y Y Pacific Ridley ERa Y Y Pacific Walrus ERa Painted Turtle ERa Red-bellied Turtle ERa Spectacled Caiman ERa Tasmanian Devil ERa Y

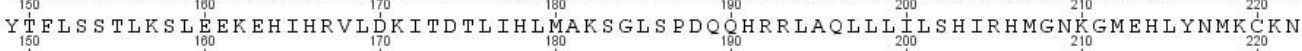

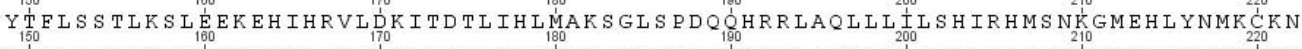
Identity

Consensus parrot ERa African Elephant ERa Alligator ERa

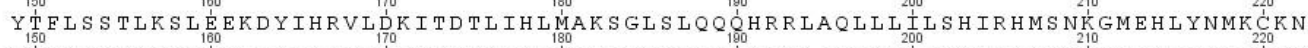
Y TELSSTLKSLEEKDHIHRVLDKITDTLIHLMAKAGLSLQQ

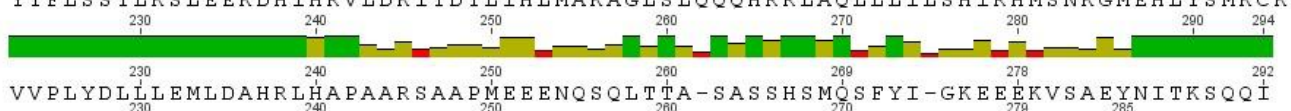

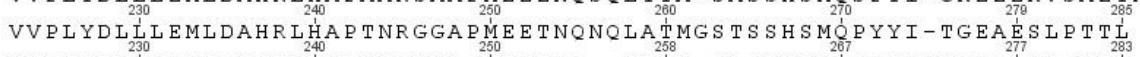
VVPLYDL L L EMLDAHR L HAPAARNAAQ

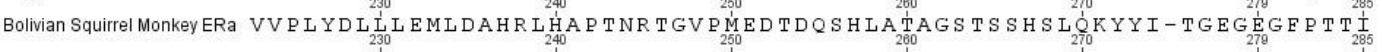

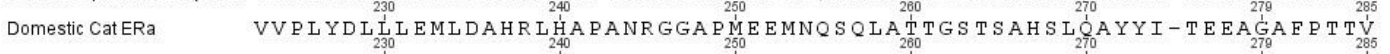

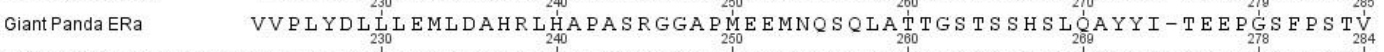

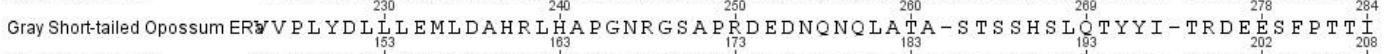

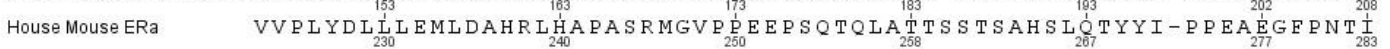
Nile Crocodile ERa VVPLYDL L L LMLDAHRL HAPAARNAAQ Pacific Ridley ERa Pacific Walrus ERa Painted Turtle ERa Red-bellied Turtle ERa Spectacled Caiman ERa Tasmanian Devil ERa

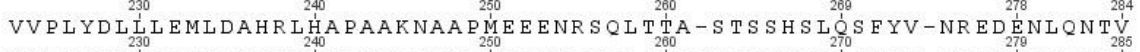

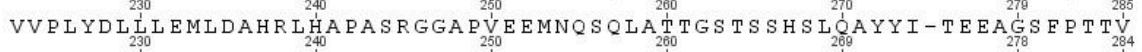

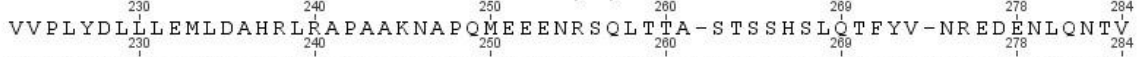

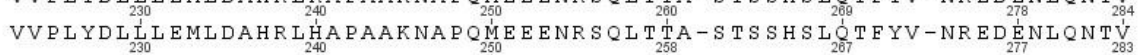
VVPLYDL L L L MLDAHR L H A PAARNAAQ VVPLYDLLLEMLDAHRL HAPGNRGGAPMEEDNQNQLA TA - S TS SHSL 
Supplementary Figure 3H Amino acid sequences that span the remaining amplified region of the ligand binding domain (LBD) of oestrogen receptor $\alpha$ (ERa) of New Zealand species and other non-avian species that were identified from the blastp search. The species identified (excluding avian species and human) were African Elephant (XP_003404008), Alligator (BAD08348), Bolivian Squirrel Monkey (XP_003933843), Domestic Cat (NP_001019402), Giant Panda (XP_002920319), Gray Short-tailed Opossum (XP_001371027), House Mouse (AF128220), Nile Crocodile (BAE45626), Pacific Ridley (ACF28457), Pacific Walrus (XP_004404132), Painted Turtle (ACI23369), Red-bellied Turtle (BAF91191), Spectacled Caiman (BAB79436) and Tasmanian Devil (XP_003769593). 
Identity

Kākā ERb

Kākāpō̄ ERb

Kea ERb

Chicken ERb

Japanese Quail ERb

common Starling ERb

Mallard ERb

Rock Pigeon ERb

Turkey ERb

Zebra Finch ERb

Identity

Kākā ERb

Kākāpō ERb

Kākāriki ERb

Chicken ERb

Japanese Quail ERb

Common Starling ERb

Mallard ERb

Rock Pigeon ERb

Turkey ERb

Zebra Finch ERb

Identity

Kākā ERb

Kākāpō ERb

Kākāriki ERb

Kea ERb

Chicken ERb

Japanese Quail ERb

Mallard ERb

Rock Pigeon ERb

Turkey ERb

Zebra Finch ERb

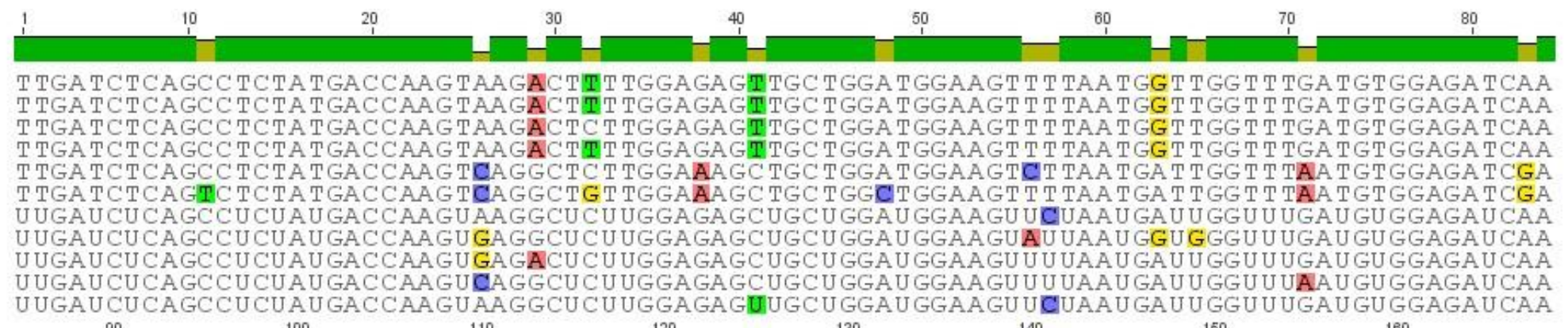
U UGAU CU CAGCCU CUAU GACCAAGUAAGGCU UU UGGAGAGUUGCU GGAU GGAAGU UCUAAU GAU U GGU U UGAU GU GGAGAU GAA 90 100 110

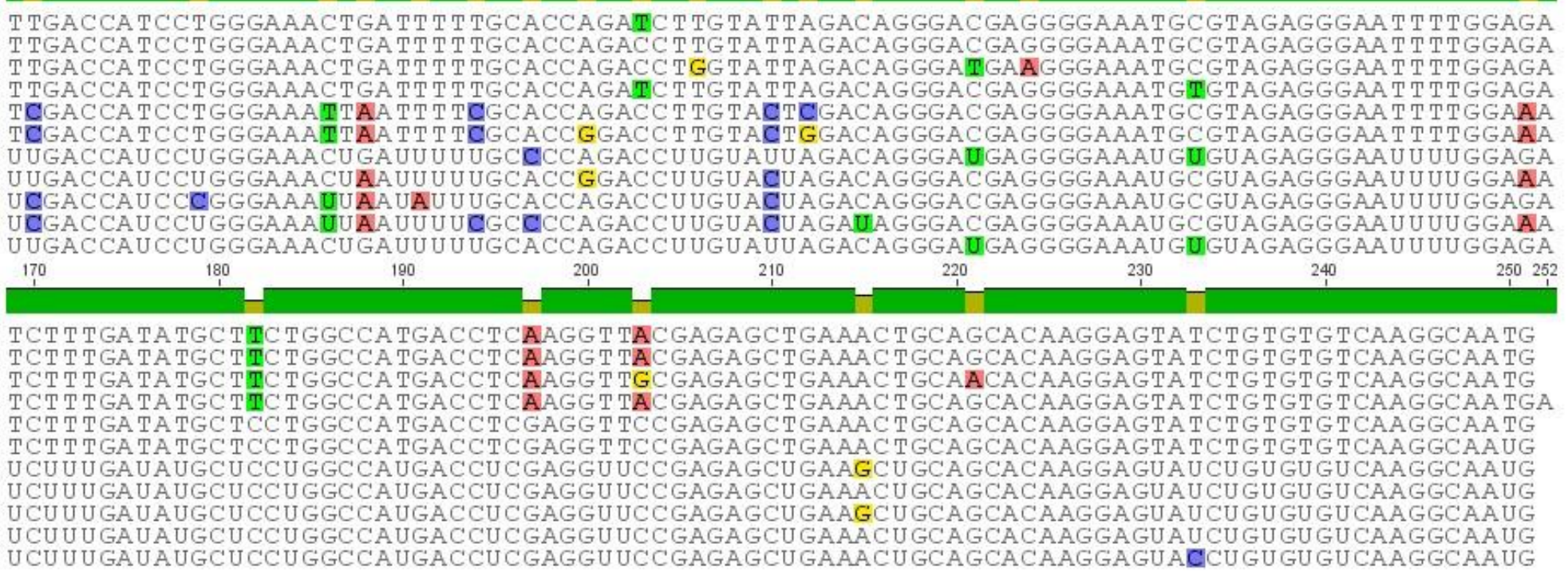

Supplementary Figure 3I Nucleotide sequences that span the amplified region of the ligand binding domain (LBD) of oestrogen receptor $\beta$ (ERb) of New Zealand parrot species and other avian species identified from the blastn search of the Aves taxon. The avian species identified were Chicken (NM_204794), Japanese Quail (AF045149), Common Starling $\left(\right.$ AF113515), Mallard $\left(\right.$ EF621308), Rock Pigeon $(J X 413116)$, Turkey $\left(X M \_003206778\right)$ and Zebra Finch $\left(X M \_002200595\right)$. Highlighted nucleotides $($ red $=$ adenine, blue $=$ cytosine, yellow = guanine and green $=$ thymine) depict a change in the base. 


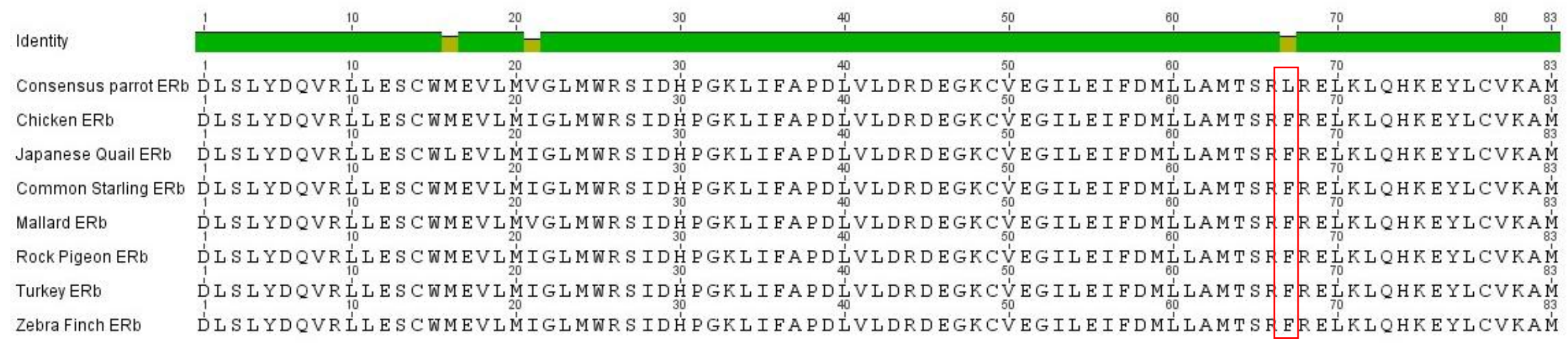

Supplementary Figure 3J Amino acid sequences that span the amplified region of the ligand binding domain (LBD) of oestrogen receptor $\beta$ (ERb) of New Zealand species and other avian species that were identified from the blastp search of the Aves taxon. The avian species identified were Chicken (NP_990125), Japanese Quail (AAC36463), Common Starling (AF113513), Mallard (ABR10298), Rock Pigeon (AFU48568), Turkey (XP_003206826), and Zebra Finch (XP_002200631). The only amino acid that was different in the consensus parrot sequence has a red box around it. 
Identity

Consensus parrot ERB Adelie Penguin ERb American Crow ERb Anna's Hummingbird ERb Bald Eagle ERb Barn Owl ERb Bar-tailed Trogon ERb Brown Mesite ERb Chimney Swift ERb Chuck-will's Willow
Crested Ibis ERb Crested Ibis ERb Dalmatian Pelican ERb Emperor Penguin $E R b$ Golden-collared Manakin ERb Great Cormorant ERb Great Crested Grebe Great Tinamou ERb Grey-crowned Crane ERb Hoatzin ERb Houbara Bustard ERb Killdeer ERb Little Egret ERb Medium Ground Finch ER Northern Fulmar ERb Ostrich ERb

Peregrine Falcon ERb Red-cested Turaco ERb Red-throd Seriema ER Rhinoceros Hornbill ERb Speckled Mousebird ERb Sunbittern ERb White-tailed Eagle ERb White-tailed Tropicbird ERb Yellow Throated Sandgrouse ERb 20 50

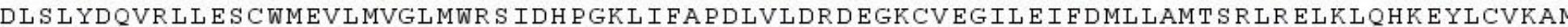
DLSLYDQVRLLESCWMEVLMGIMRS IDHPGKI DLS LYDOVR I S CWMEVLM IGLMWR S IDH PGK L I A PDLVLDRDEGKCVEGILE IFDMLIAMTSR FR ELKLOHKEYLCVKAM DL S LYDQVR LLESCWMEVLMVGLMWR S IDH PGKL I FAPDLVLDRDEGKCVEG ILE I FDMLLAMTSRERELKLQHKEYLCVKAM DLS L YDQVR LLESCWMEV LMVGLMWRS IDH P GKL I FAPD LVLDRD EGKCVEG ILE I F DMLLAMTSRLR ELKLQHKEYLCVKAM DLS LYDQVRLLESCWMEVLMVGLMWR S IDH PGKL I FAPDL ILDRDEGKCVEGILEIF DMLLAMTSR R ELKLQHKEYLCVKAM DLS LYDQVR LLE SCWMEVLMVGLMWR S IDH PGKLIFAPDLVLDRDEGKCVEGILEIFDMLLAMTSR FR ELKLQHKEYLCVKAM

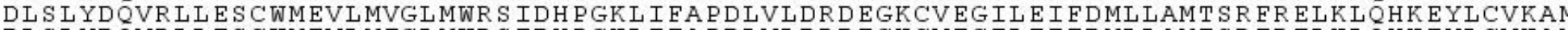
DLSLYDOVRLLESCWMEVLMIGLMWR S IDHPGKLIFAPDLVLDRDEGKCVEGILE I FDMLLAMT SRERELKLOHKEYLCVKAM DLSLYDQVRLLESCWM VLMVGLMWRS IDH PGKLIFAPDLVLDRDEGKCVEGILEIFDMLLAMTSR FRELKLQHKEYLCVKAM DL $L Y D Q V R L L E S C W M E V L M V G L M W R$ S IDH PGKL I FAPDLVLDRDEGKCVEGILEIFDMLLAMTSR FR ELKLQHKEYLCVKAM DLS 作 DI T T

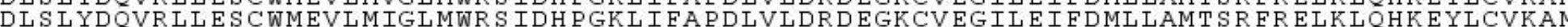
DL S L YDOVR L L E S CWM EVLMVGLMWR S IDH PGKI I FA PDLVLDRDEGKCVEGI E I FDML LAM T SR FR ELKLOHK EYLCVKAM DL S LYDOVRLLES CWMEVLMVGLMWR S IDH PGKL I FA PDLVLDRD EGKCVEG ILE I F DMLLAMTSR FR ELKLOHKEYLCVKAM DLS L YDQVRLLESCWMEVLM IGLMWR S IDH PGKL I FAPDLVLDRDEGKCVEGILEIFDMLLAMTSR FR ELKLQHKEYLCVKAM DLS LYDQVR L LESCWMEVLM IGLMWR S IDHPGK L I FAPDLVLDRD EGKCVEG ILE I D D L LAMT SR FR ELKLQHK EYLCVKAM DLS L F DQVR L L S SCWMEVLM IGLMWRS IDHPGKL I FAPDLVLDRDEGKCVEGILEIFDMLLAMTSR R ELKLQHKEYLCVKAM DLS LYDQVRLLESCWMEV LMVGLMWR S IDH PGKLIFAPDLVLDRDEGKCVEGILEIFDMLLAMTSR ER ELKLQHKEYLCVKAM

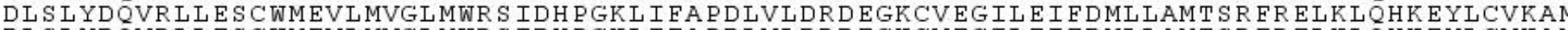
DLSLYDOVRLLESCWMEVLMVGLMWR IDH PGKLIFAPDLVLDRDEGKCVEGILEI FDMLLAMTSR FR ELKLOHKEYLCVKAM DLSLYDOVRLLESCWMEVLMIGMRS IDHAGKLIFAPDLVLDRDEGKCVEGILEIFDMLLAMTSRER ELKLOHKEYLCVKAM DLSLYDQVRLLESCWMEVLMIGLMWRS IDH PGKLIFAPDLVLDRDEGKCVEGILEIFDMLLAMTSRERELKLQHKEYLCVKAM DLS DI DISTYDVRI DI IYDVR I S DL S LYDQVR L LE SCWMEVLM IGLMWR S IDH PGKL I F APDLVLDRD EGKCVEGILE I FDMLLAMTSR FR ELKLOHKEYLCVKAM DLS LYDOVR L L E S CWMEVLM IGLMWR S IDH PGK L I FAPDLVLDRDEGKCVEG ILE I FDMLLAMT S R FR ELKLOHKEYLCVKAM DL S L YDQVR LL E S CWMEVL MVGL MWR S IDH PGKL I FA PDLVLDRD EGKCVEG I L I F DMLLAMT SR FR ELKLQHKEYLCVKAM DLS L YDQVRLLESCWMEV LMVGLMWR S IDHPGKL IFA D D I LDRD EGKCVEGIL I I DMLLAMTSR FR E LKLQHKEYLCVKAM DLSLYDOVRLE DLS LYDQVRLLES CWMEVLMVGLMWRS IDH PGKL I FAPDLVLDRD EGKCVEGILEIFDMLLAMTSR R EKLQHKEYLCVKAM

Supplementary Figure 3K Amino acid sequences that span the amplified region of the ligand binding domain (LBD) of oestrogen receptor $\beta$ (ERb) of New Zealand species and other avian species that were identified from the blastn search of the avian database. The nucleotide sequences for the avian species identified were translated into the corresponding amino acid sequences and are listed with the species common name. 

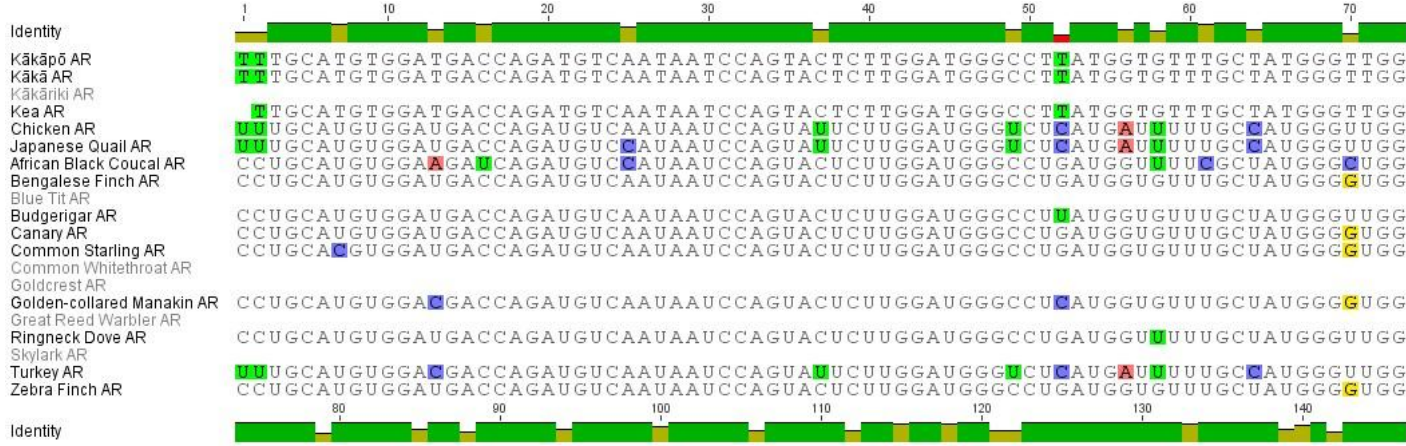

Identity

Kākāpō AR

Kākā AR
Kākāriki AR
Kea AR

Kea AR
Chicken AR

Japanese Quail AR

African Black Coucal AR
Bengalese Finch AR

Blue Tit AR
Budgerigar AR

Common Starling AR

Common Whitethroat AR

Golden-collared Manakin Ringneck Dove AR

TurkeyAR

Zebra Finch AR

Identity

Kākāpō AR

Kākāāriki AR

Kea AR
Chicken AR

Japanese Quail AR

African Black Coucal AR

Bengalese Finch

Budgerigar AR
Canary AR

Canary AR
common Starling AR

Common Whitethroat AR

Golden-collared Manakin AR

Ringneck Dove AR

Turkey AR

Zebra Finch AR

Identity

Kākāpō AR

Kea AR AR

Chicken AR

Japanese Quail AR
African Black Coucal AR

African Black Couca

Blue Tit AR

Budgerigar AR

Common Starling AR
Common Whitethroat AR

Golden-collared Manakin

Great Reed Warbler AR

Ringneck Dove AR

Skylark AR

Zebra Finch AR

Identity

Kākāpō AR

Kākāriki AR

Kea AR
Chicken AR

Japanese Quail AR

African Black Coucal AP

Blue Tit AR

Budgerigar AR
Canary AR

Common Starling AR

Goldcrest AR

Golden-collared Manakin

Skylark AR
Turkey AR

Zebra Finch AP

Identity

Kākāpō AR

Käkâriki AR

Chicken AR

Japanese Quail AR
African Black Coucal AR

Gengalese Finch AR

Blue Tit AR

Budgerigar AR
Canary AR

Common Starling AR
Common Whitethroat AR

Goldcrest AR

Golden-collared Manak

Ringneck Dove AR

Skylark AR
Turkey AR

Zebra Finch AR

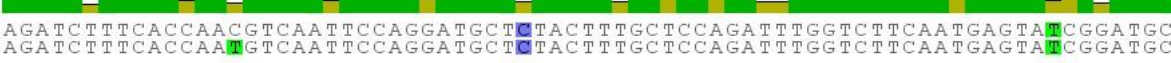

AGATCTTPCACCAATG TCAATTCCAGGATGCTCTACTTTGCTCCAGATTTGGTCT T TAATGAGTATCGGATGC

AGAUCUUUCACUAACGUCAAUUCCAGGAUGCUUUACUUUU

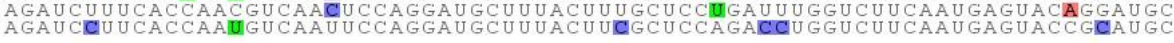

AGAUCGUUCACCAAUGUCAAUUCCAGGAUGCUUUACUUUGCUCCAGAUUUGGU CUUCAAUGAGUACCGGAUGC
AGAUCCUUCACCAACGUCAAUUCCAGGAUGUUUACUUUGCUCCAGACCUGGU UU CAAUGAGUACGCAUGC AGAUCCUUCACCAACGUCAAUUCCAGGAUGCUUUACUUGCUUCCAGAUCUGGU UUUCAAU

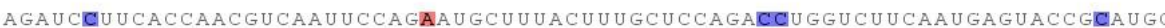
A GAUCUUUCACCAACGUCAAUUCCAGGAUGCUUUACUUCGCUCCAGAUUUGGUCUUCAAUGAGUACCGCAUGC

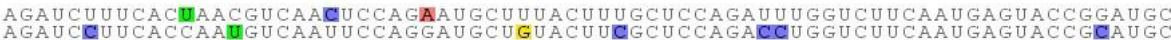
${ }_{150}^{150}$ ACAAATCCAGAATGTACA
ACAAATCAGAATTACA

ACAAATCCAGA.TTGTAC ACAAAU CCAGAAU GUACAGC CAGU GUGU CAGGAUGAGGCACCUCU CGCAGGAGUUCGGGUGG GUUUCAGAUCA ACA.A.UCCAGAAUGUACAGCCAGUGUGUCA-GAUGCGGCACCUCUCUCAGGAGUUUGGGUGGCUU
ACAAAUCCAGGAUGUACAGCCAGUGCAUCAGGAUGCGGCACCUCUCCCAGGAMUUCGGGUGGCUUCAGAUCAC

ACAAAUCCAGGAUGUACAGCCAGUGUGUCAGGAUGAGCACCUCUCCCAGGAGUUCGGGUGGUUCAGAUCAC

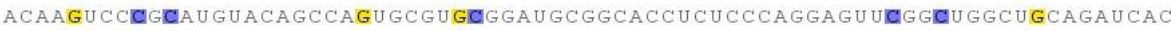
ACAAAUCCAGAAUGUACAGCCAAUGCGUCAGGAUGCGGCAGCUCUCCCAGGAGUUUGGGUGGCUUCAGAUCAC
ACAAAUCCAGGAUGUACAGCCAGUGCAUCAGGAUGCGCACCUCUCCCAGGAAUUGGUGGUUCAGAUCAC ACAAAUCCAGGAUGUACAGCCAGUGCAUCAGGAUGCGGCACCUCUCCCAGGAAUUUGGGUGGCUUCAGAUCAC
220
I- 200 TGGCCTGAAGACCAG A.CCCCAGGAGUUCCUCUGUAUGAAGGCUCUCCUUUU U UUCAGUAUUAUUCCAG GCCGCAGGAGUUCCUCUGCAUGAAGGUCUGCUCUUCUUCAGCAUCAUUCCAGUGGAUGGCCUGAAGAACCAG

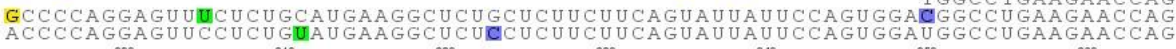

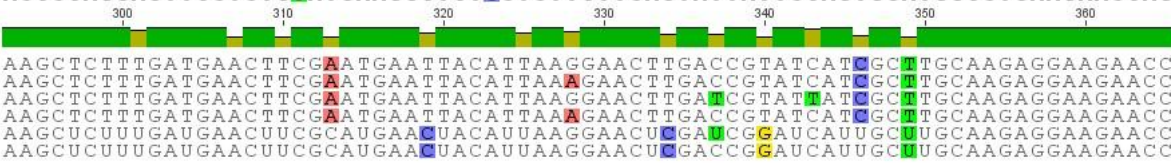
A.GCTCTTTGATGAGCTCCGCATGAATTACATTAAGGAACT TGACCGTATCATTGCUTCAAGAGGAAGAACC A.A $G$ U U U UCGA U GAGCUCCGCAUGA.AUUACAUCA.AGGA.CUUGACCGUAUCAUUGCCUGCAAGAGGA.A.A.ACC TTAAGGACT TGACCGCATCATTGCDTGCAAGAGGAAGAACC
AACTTGACGTATCATGGCTGCAAGAGAAGACC

A.GCTCTT T GATGAGCTCCGCATGAATTACATTAAGGAACT T GACCGCATCATTGCCTGCAAGAGGAAGAACC

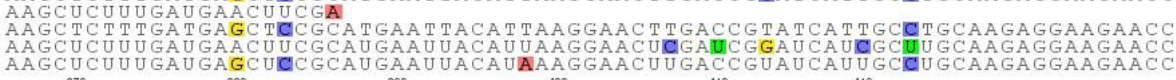

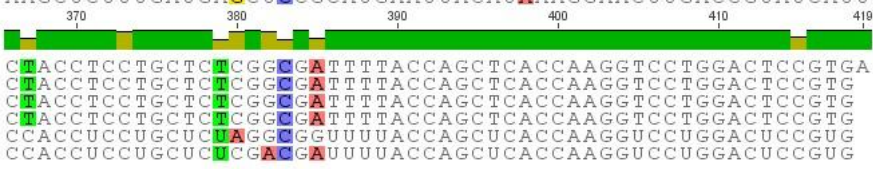

CCACC TCCTGCTCCCGGAGGTT T TACCAGCTCACCAAGGTCCTGGACTCCGTG CCACCUCAUGCUCCCGGAGGUUUUACCAGCUCACCAAGGUCCUGGACUCCGUG CCACCTCCTGCTCCCGGAGGTTTTACCAGCTCACCAAGGTCCTGGACTCMGTG
CCACCTCTG TCCCGAGTTTTACAGTCACCAAGTCCTGACTCGTG

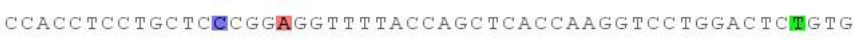

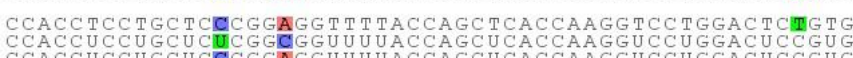

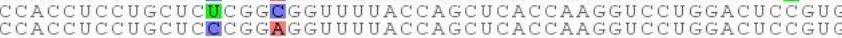


Supplementary Figure 3L Nucleotide sequences that span the amplified region of the ligand binding domain (LBD) of androgen receptor (AR) of New Zealand parrot species and other avian species identified from the blastn search of the Aves taxon. The avian species identified were Chicken (NM_001040090), Japanese Quail (AB188828), African Black Coucal (DQ478951), Bengalese Finch (AB327261), Blue Tit (HQ415867), Budgerigar (AB327272), Canary (SEIARP), Common Starling (EU328303), Common Whitethroat (HQ415864), Goldcrest (HQ415866), Golden-collared Manakin (DQ020206), Great Reed Warbler (HQ415863), Ringneck Dove (DQ018750), Skylark (HQ415865), Turkey (XM_003208682), and Zebra Finch (NM_001076688). Highlighted nucleotides (red $=$ adenine, blue $=$ cytosine, yellow $=$ guanine and green $=$ thymine $)$ depict a change in the base . 
Identity

Consensus parrot AR

Chicken AR

Japanese Quail AR

African Black Coucal AR

Canary AR

Golden-collared Manakin AR

Ringneck Dove AR

Turkey AR

Zebra Finch AR

Identity

Consensus parrot AR

Chicken AR

Japanese Quail AR

African Black Coucal AR

Canary AR

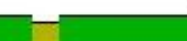

$-20$ $\stackrel{20}{1}$ 30

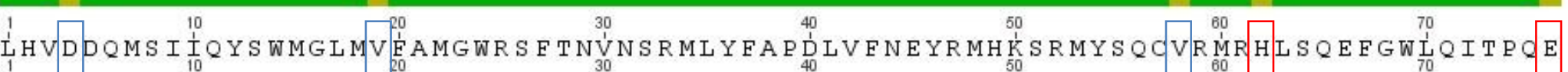
50 $\stackrel{80}{1}$

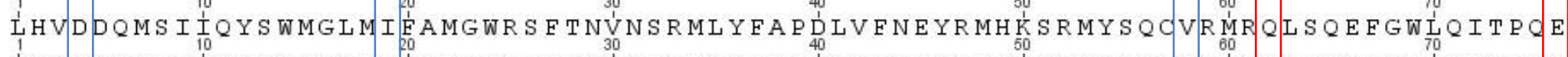
$\underset{1}{L} H V D P Q M S I \frac{1}{10} Q Y S W M G L M I \underset{20}{1} A M G W R S$ F T NV

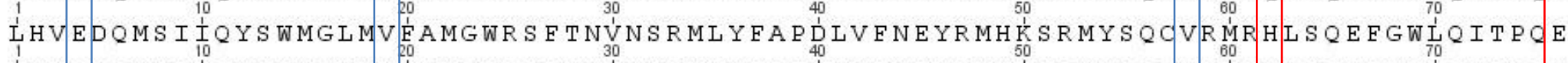

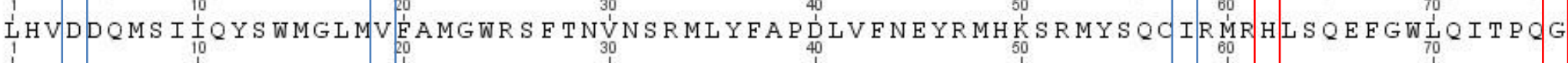

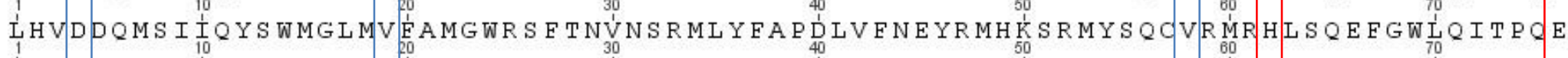

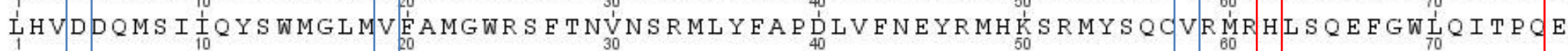

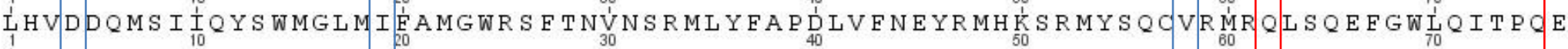
LHVDDQMSI IQYSWMGLMV FAMGWRS TNVNSRMLYFAPDLVFNEYRMHKSRMYSQCIRMRHLSQEFGWLQITPQE

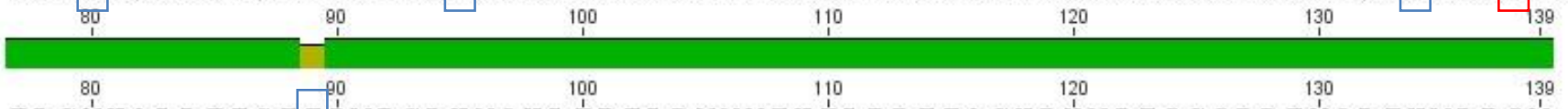

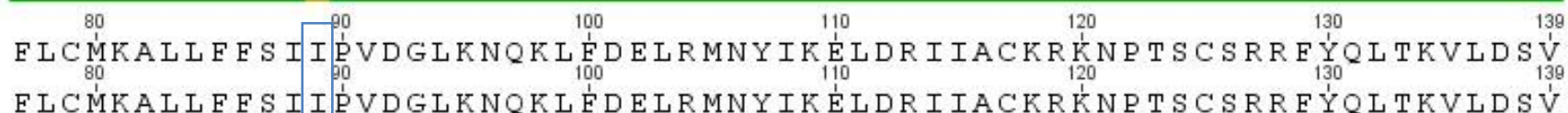

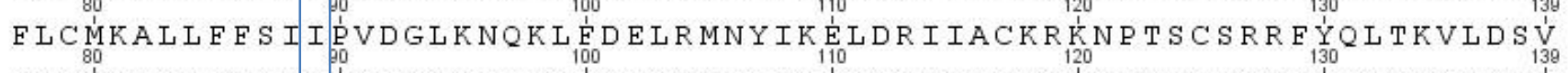

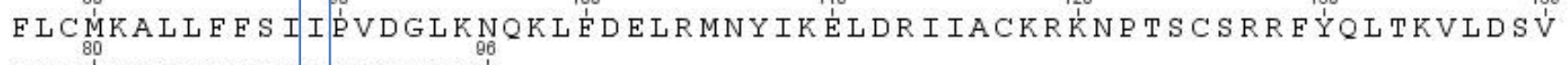

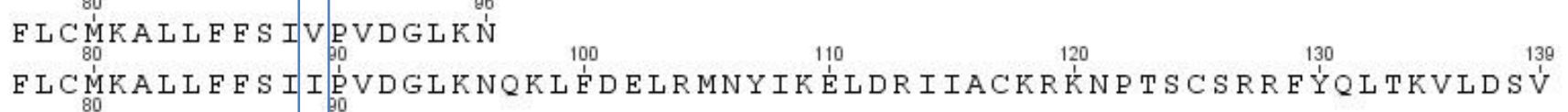

Golden-collared Manakin AR F L C M M K A L L F E S I I

Ringneck Dove AR FLCM MALLFESII PVDGLKNQKLFDELR

Turkey AR

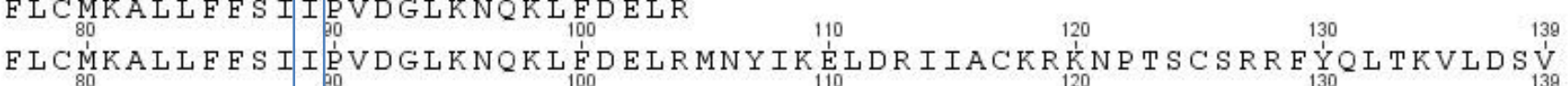

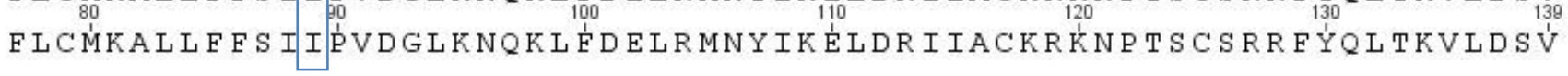

Supplementary Figure 3M Amino acid sequences that span the amplified region of the ligand binding domain (LBD) of androgen receptor (AR) of New Zealand species and other avian species that were identified from the blastp search of the Aves taxon. The avian species identified were Chicken (NP 001035179), Japanese Quail (BAD38679), African Black Coucal (ABF20060), Canary (AAA17402), Golden-collared Manakin (AAY42038), Ringneck Dove (AAY41828), Turkey (XM_003208730) and Zebra Finch (AAM96699). Blue boxes represent conserved amino acid changes whilst red boxes represent non-conserved changes. 
Identity

Consensus parrot AR

Adelie Penguin AR

American Flamingo AR

Anna's Hummingbird AR

Bald Eagle AR
Barn Owl AR

Barn Owl AR

Brown Mesite AR

Chimney Swift AR

Chuck-will's Willow AR

Crested Ibis AR

Cuckoo Roller AR AR

Downy Woodpecker AR

Emperor Penguin AR

Hoatzin AR

Houbara Bustard AR

Golden-collared Manakin AR

Grey-crowned Crane AR

Killdeer AR

Medium Ground Finch AR

Northern Fulmar AR

Ostrich AR

Peregrine Falcon AR

Red-legged Seriema AR

Rhinoceros Hornbill AR

Speckled Mousebird

White-tailed Eagle AR

Yellow Throated Sandgrouse AR

Identity

Consensus parrot AR

Adelie Penguin A

American Crow AR

American Flamingo AR

Bald Eagle AR

Barn Owl AR

Bar-tailed Trogon AR

Brown Mesite AR

Chimney Swift AR

Crested Ibis AR

Cuckoo Roller AR

Dalmatian Pelican AR

Downy Woodpecker AR

Emperor Penguin AR

Houbara Bustard AR

Golden-collared Ma

Grey-crowned Crane AR

Medium Ground Finch AR

Northern Fulmar AR

Sstrich AR

Peregrine Falcon AR

Red-crested Turaco AR

Red-legged Seriema AR

Speckled Mousebird AR

Sunbittern AR

Red-throated Loon AR

White-tailed Eagle AR

Yellow Throted Sandgrouse AR

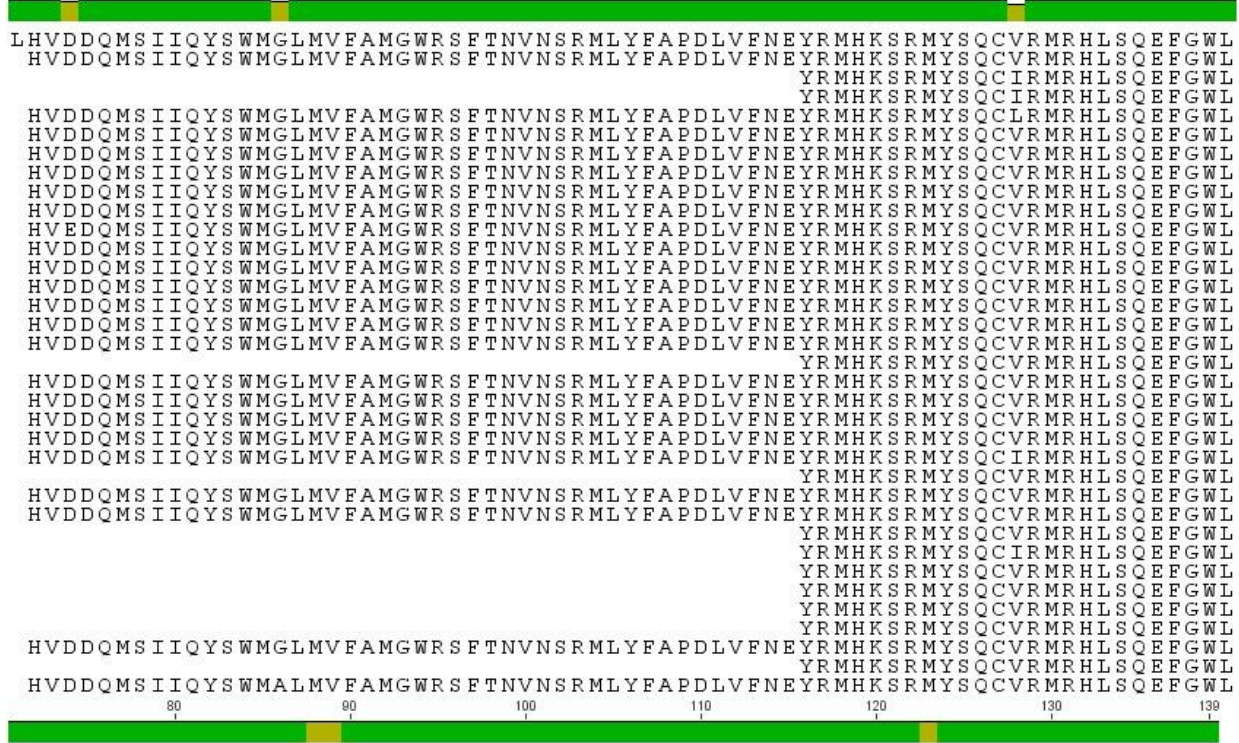

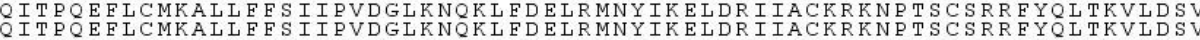
作 QTPQEFLCMKALLFESIIPVDGLKNQKLEDELRMNYIKELDRIIACKRKNPTSCSRR Y YLTKVLDS ITPOEF LCMKALLF FS I IPVDGLKNOKL FDELRMNYIKELDR I IACKRKNP TSCSRREYOLTKVLDSV QIT TQE LCMKALLF SI IPVDGLKNQKLFDELRMNY IKELDR I IACKRKNPTSCSRRFYQLTVLDSV IT PQE ELCMKALI FFS IIPVDGLKNQKL DELRMN 作 IT PQEFLCMKALLFFS I PVDGLKNOKLFDELRMNY IKELDR I IACKRKNPTSCSRR FYOL TKVLD QIT PQE L LCMKALLE S I I PVDGLKNQKLFDELRMNY IKELDR IIACKRKNPTSCSRRFYQITKVLDSV

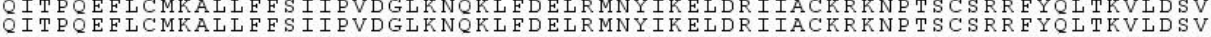
Q TPQEFLCMALLFFSIIPVDGLKNQKLFDELRMNYIKELDR I IACKRKNPTSCSRRFYQLTKVLDSV

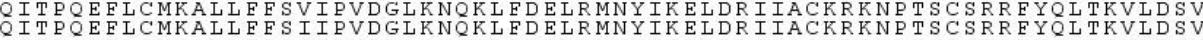
ITPO

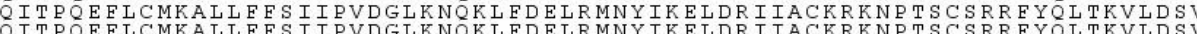
Q ITPQEF LCMKALLFF I I PVDGLKNQKLEDELRMNY IKELDR I IACKRKNPTSCSRR FYQLTKVLDSV QT TPQEFLCMKALLF S I I PVDGLKNQKLFDELRMNYIKELDR I IACKRKNP TSCSRRFYQLTKVLDSV Q ITPQEFICMKALIFFS I I PVDGLKNQKLFDELRMNY IKELDR I IACKRKNPTSCSRRFYOLTKVLDSV QITPQEF LCMKALLFFSIIPVDGLKNQKLEDELRMNY IKELDR I IACKRKNPTSCSRRFYQLTKVLDS

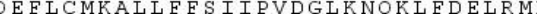

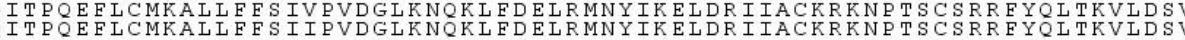

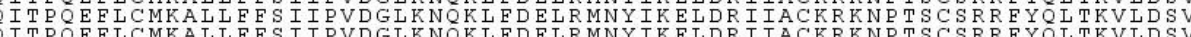

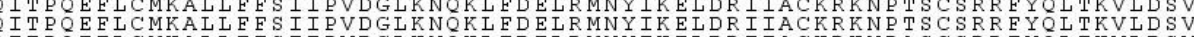
QITPQEFLCMKALLFESIPVDGLKNQKLEDELRMNYIKELDRIIACKRKN A SCSRRFYLTKVLDSV

Supplementary Figure 3N Amino acid sequences that span the amplified region of the ligand binding domain (LBD) of androgen receptor (AR) of New Zealand species and other avian species that were identified from the blastn search of the avian database. The nucleotide sequences for the avian species identified were translated into the corresponding amino acid sequences and are listed with the species common name. 
Identity

Kākāpō PR

Kākā PR

Kākāriki PR

Kea PR

Chicken PR

Japanese Quail PR

Budgerigar PR

Collared Flycatcher PR

Mallard PR

Zebra Finch PR

Identity

Kākāpō PR

Kākā PR

Kākāriki PR

KeaPR

Chicken PR

Japanese Quail PR

Budgerigar PR

Collared Flycatcher PR

Mallard PR

Turkey PR
Zebra Finch PR
10

1

40

$\underset{1}{70}$

TGGAAGGTCTAAGAAGTCAAAGCCAATTTGATAGATGAGAACGAGT TACATTAGAGAACTGGTGAAGGAATTG

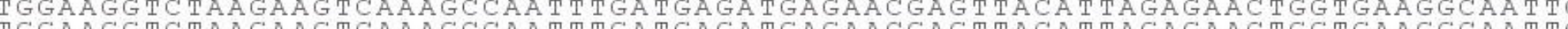
TAA TGGAAGGTCTAGAAGTCAAAGCCAATT TGATGAGATAGAACGAGTTACATTAGAGAACTGGTGAAGGCAATTG TGGAAGGTCTAAGAAGTCAAAGCCAATTTGATGAGATGAGAACGAGTTACATMAGAGAACTGGTGAAGGCCATTG TGGAAGGTCTAAGAAGTCAAAGCCAATTTGATGAGATGAGAACGAGTTACATTAGAGAACTGGTGAAGGCCATTG UGGAAGGUCUAAGAAGCCA.A. GCCAGUUUGAUGAGAUGAGAACAAAUUAUAUUAGAGAACUGGUGAAAGCAAUUG UGGAAGGUCUAAGAAGUCAAAGCCAAUUUGAUGAGAUGAGAACAAGUUACAUCAGAGAACUGGUGAAGGCAAUUG UGGAAGGUCUAAGAAGUCAAAGCCAAUUUGACGAGAUGAGAGCAAAUUACAUUAGAGAACUGGUGAAGGCAAUUG

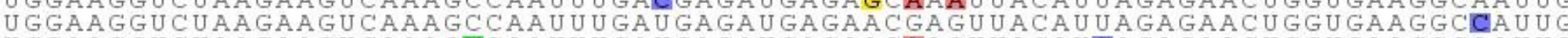

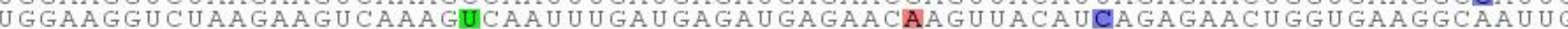

100

120

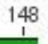

GTTTGCGCCAGAAAGGCGTTGTGGCCAACTCGCAGCGTTTCTATCAGCTTACAAAACTGATGATTCCTGCA GTTTGCGCCAGAAAGGCGTTGTGGCCAACTCGCAGCGTTTCTATCAACTTACAAAACTGATGGATTCCATGCA GTTTGCGCCAGAAAGGCGTTGTGGCCAACTCGCAACGTTTCTATCAACTTACAAAACTGATGGATTCCATGCA GTTTGCGCCAGAAAGGCGTTGTGGCCAACTCGCAGCGTTTCTATCAACT TACAAAACTGATGGATTCCATGCA GTTTGCGCCAGAAAGGTGTGGTGGCTAACTCCCAGCGCTTCTATCAGCTTACAAAACTGATGGATTCCATGCA GGTTGCGCCAGAAGGGTGTTGTGGCTAATTCCCAGCGCTTCTATCAGCTTACAAAACTGATGGATTCCATGCA GUUUGCGCCAGAAAGGUGUUGUGGCCAACUCACAACGUUUCUAUCAACUUACAAAACUGAUGGAUUCCAUGCA GUUUGCGCCAGAAAGGCGUUGUGGCCAACUCACAGCGAU UCUAUCAACUUACAAAACU GCU GGAUUCCAUGCA GUUUGCGCCAGAAAGGCGUUGUGGCCAACUCCCAACGUUUCUAUCAACUUACAAAACUGAUGGAUUCCAUGCA

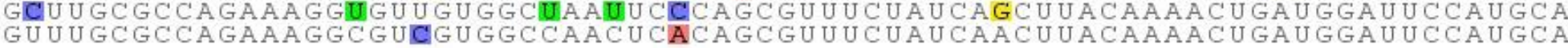

Supplementary Figure 30 Nucleotide sequences that span the amplified region of the ligand binding domain (LBD) of progesterone receptor (PR) of New Zealand parrot species and other avian species identified from the blastn search of the Aves taxon. The avian species identified were Chicken (NM 205262), Japanese Quail (AB265142), Budgerigar $($ XM_005149809), Collared Flycatcher (XM_005038245), Mallard (XM_005031694), Turkey (XM_003203496), and Zebra Finch (XM_002198107). Highlighted nucleotides (red = adenine, blue $=$ cytosine, yellow $=$ guanine and green $=$ thymine $)$ depict a change in the base . 
Identity

Consensus parrot PR Chicken PR

Japanese Quail PR

Budgerigar PR

Collared Flycatcher PR

Mallard PR

Rock Pigeon PR

Turkey PR

Zebra Finch PR

10

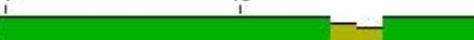

EGLRSQSQFDEMRTSYIRELVKAIGLRQKGVVANSQR FYQLTKLMDSM EGLRSOSQEDEMRTSYIRELVKAIGLRQKGVVANSOREYQLTKLMDSM EGLRSOSOFDEMRTSYIRELVKAIGLROKGVVANSOR FYOLTKLMDSI EGLRSQSQFDEMRTNYIRELVKAIGLRQKGVVANSQREYQLTKLMDSM EGLRSQSQEDEMRTSYIRELVKAIGLRQKGVVANSQREYQLTKLIDSM EGLRSQSQEDEMRANYIRELVKAIGLRQKGVVANS QR F Y TKLMDSM EGLRSOSQFDEMRTSYIRELVKAIGLROKGVVANSOREYOLTKIMDSM EGIRSOSOFDEMRTSYIREIVKATGLROKGVVANSORFYOITKIMDSM EGLRSQSQEDEMRTSYIRELVKAIGLRQKGVVANSQREYQLTKLMDSM

Supplementary Figure 3P Amino acid sequences that span the amplified region of the ligand binding domain (LBD) of progesterone receptor (PR) of New Zealand species and other avian species that were identified from the blastp search of the Aves taxon. The avian species identified were Chicken (NP_990593), Japanese Quail (BAE97646), Budgerigar (XP_005149866), Collared Flycatcher (XP_005038302), Mallard (EOB07962), Rock Pigeon (EMC80527), Turkey (XP_003203544) and Zebra Finch (XP_002198143). Blue boxes represent conserved amino acid changes whilst red boxes represent non-conserved changes.

\section{Identity}

Consensus parrotPR Adelie Penguin PR American Crow PR Anna's Hummingbird PR Bald Eagle PR

Barn Owl PR

Bar-tailed Trogon PR

Brown Mesite PR

Chimney Swift PR

Chuck-will's Willow PR

Crested Ibis PR

Cuckoo Roller PR

Dalmatian Pelican PR

Downy Woodpecker PR

Emperor Penguin PR

Great Cormorant PR

Great Tinamou PR

Hoatzin PR

Houbara Bustard PR

Killdeer PR

Little EgretPR

Medium Ground Finch PR

Northern Fulmar PR

Peregrine Falcon PR

Red-legged Seriema PR

Red-throated Loon PR

Rhinoceros Hornbill PR

Rifleman PR

Sunbittern PR

Turkey Vulture PR

White-tailed Eagle PR

White-tailed Tropicbird PR
Grey-crowned Crane PR

Northern Carmine Bee-eater

Red-crested Turaco PR

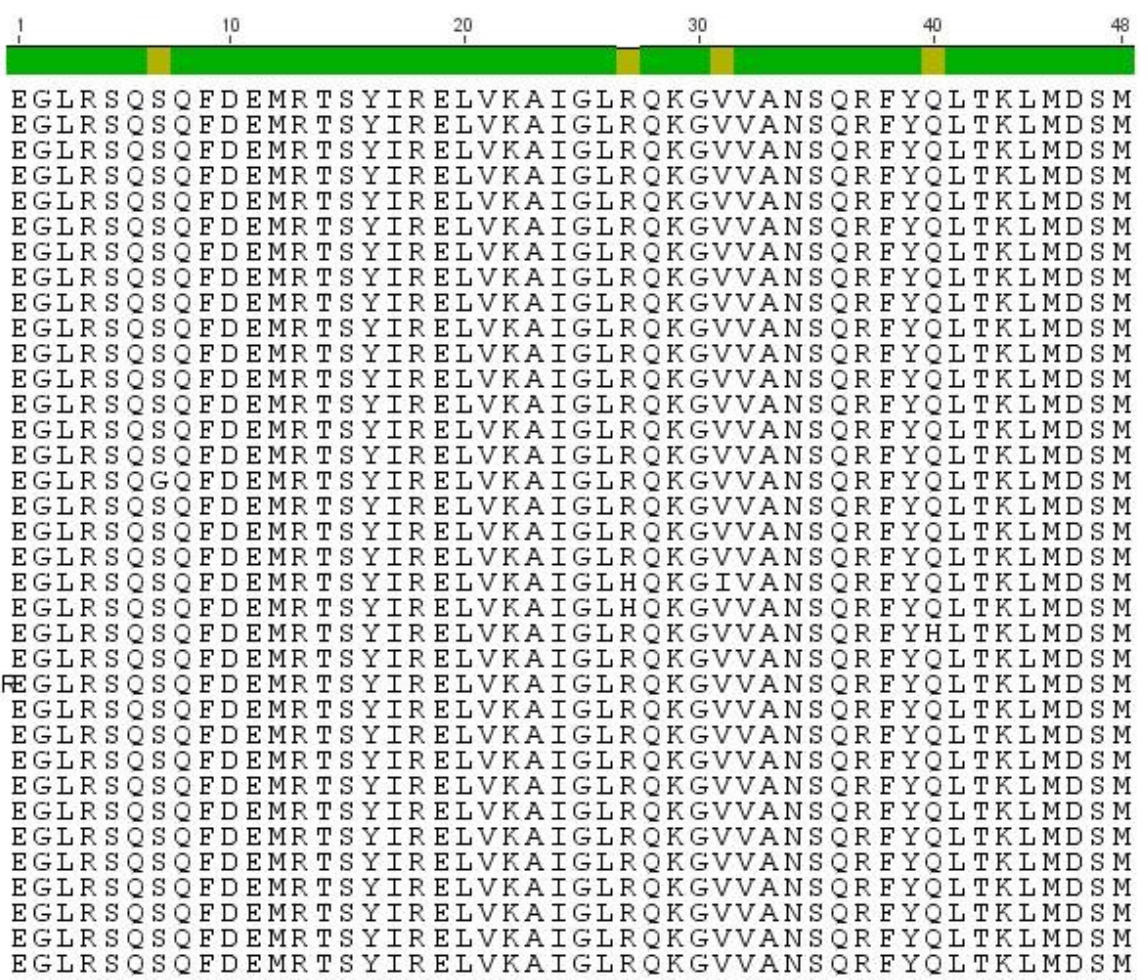

Supplementary Figure 3Q Amino acid sequences that span the amplified region of the ligand binding domain (LBD) of progesterone receptor (PR) of New Zealand species and other avian species that were identified from the blastn search of the avian database. The nucleotide sequences for the avian species identified were translated into the corresponding amino acid sequences and are listed with the species common name. 


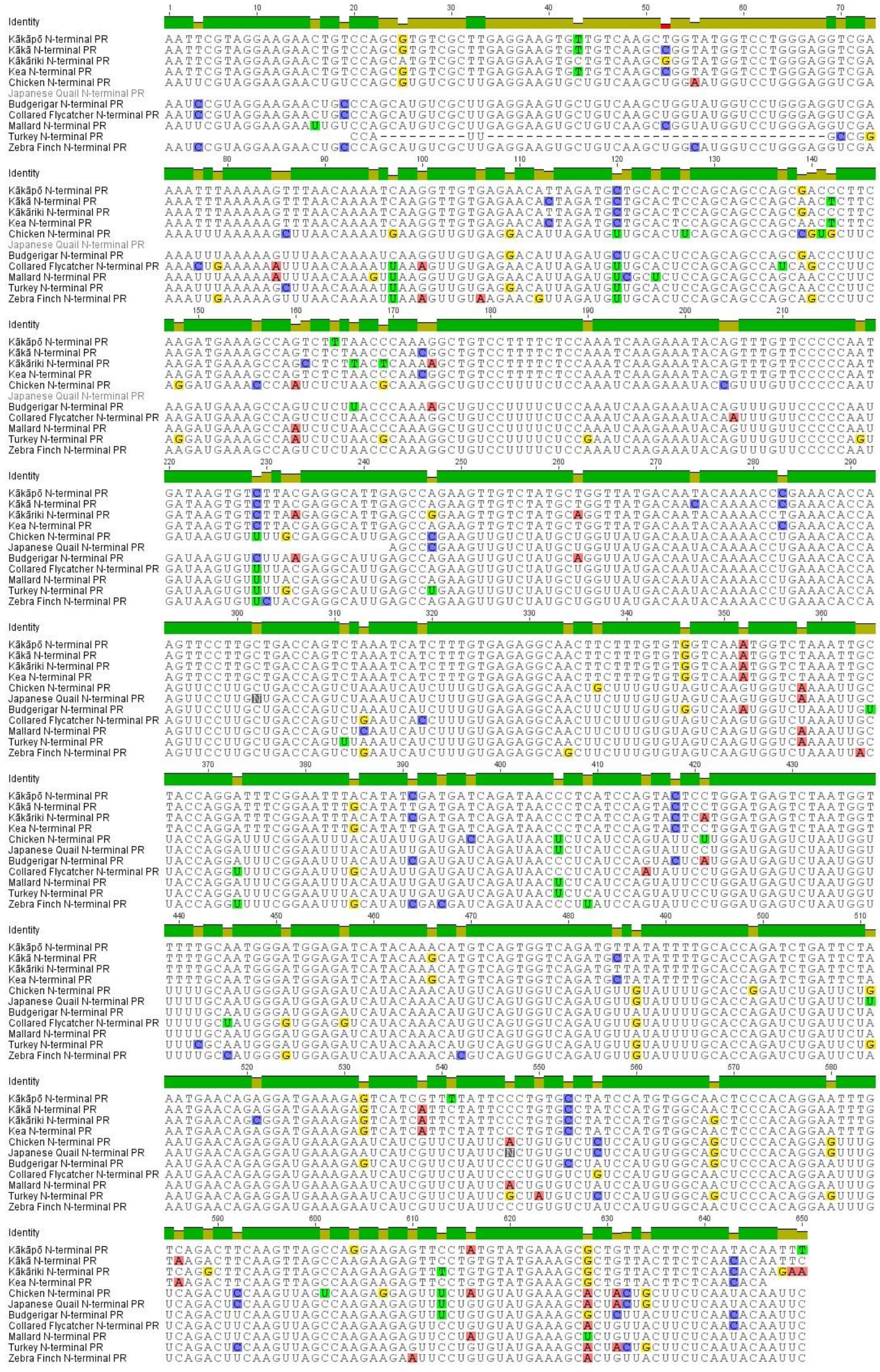


Supplementary Figure 3R Nucleotide sequences that span the remaining amplified region of the ligand binding domain (LBD) of progesterone receptor (PR) of New Zealand parrot species and other avian species identified from the blastn search of the Aves taxon. The avian species identified were Chicken (NM_205262), Japanese Quail (AB265142), Budgerigar (XM_005149809), Collared Flycatcher (XM_005038245), Mallard (XM_005031694), Turkey (XM_003203496), and Zebra Finch (XM_002198107). Highlighted nucleotides (red $=$ adenine, blue $=$ cytosine, yellow = guanine and green $=$ thymine) depict a change in the base . 
Identity

Consensus parrot N-terminal PR

Chicken N-terminal PR

apanese Quail N-terminal PR

Budgerigar $\mathrm{N}$-terminal $\mathrm{PR}$

Collared Flycatcher $\mathrm{N}$-terminal $\mathrm{PR}$

Mallard N-terminal PR

Rock Pigeon N-terminal PR

Tukey

Identity

Consensus parrot $\mathrm{N}$-terminal $\mathrm{PR}$

Chicken N-terminal PR

Japanese Quail N-terminal PR

Budgerigar $\mathrm{N}$-terminal PR

Collared Flycatcher N-terminal PR

Mallard N-terminal PR

Rock Pigeon N-terminal PR

Zebra Finch N-terminal PR

Identity

Consensus parrot $\mathrm{N}$-terminal $\mathrm{PR}$

Chicken N-terminal PR

Japanese Quail N-terminal PR

Budgerigar $\mathrm{N}$-terminal PR

列

Rock Pigeon $\mathrm{N}$-terminal PR

Rock Pigeon N-terminal PR
Zurke

10

30

50

IRRKNCPACRLRKCCQAGMVLGGRKFKKFNK IKVVRTLDAALQQPATLQDESQSLTORIS FS PNOEIOFVPPMISV IRRKNCPACRLRKCCQAGMVLGGRKEKLNKMKVVRTLDVALQQPAVLQDETQSLTQRLS S PNQEIPEVPPMISV IRRKNCPACRLRKCCQAGMVLGGRKFKKFNKIKVVRTLDAALQQPATLQDESQSLTQKLSFS PNQEIQFVPPMISV

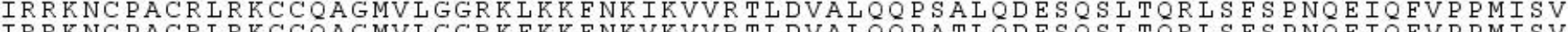
IRRKNCPACRLRKCCQAGMVLGGRKFKKFNKVKVVRTLDVALQQPATLQDESQS TTQR LS F S P NQE IQFVP PMISV

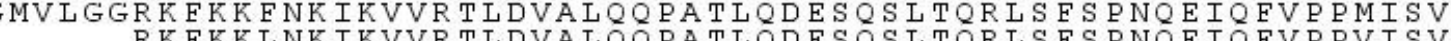

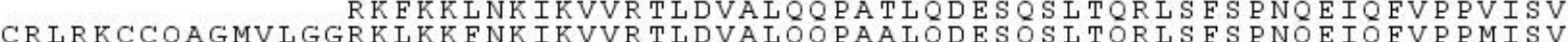
100 110

LRGIEPEVVYAGYDNTKPETPSSLLTSLNHLCERQLLCVVKWSKLLPGERNLHIDDQITLIQYSWMSLMVFAMGWR LRGIEPEVVYAGYDNTKPETPSS LLTS LNH LCERQLLCVVKWSKLLPGERNLHIDDQITLIQYSWMS LMVEAMGWR 年 作

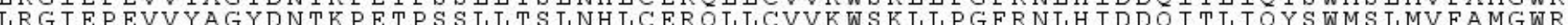

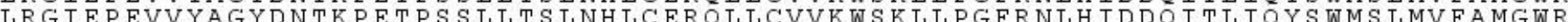
LRGIE DEVVYAGYDNTR E T S S I TS N 190 216

SYKHVSGQMLYFAPDLILNEQRMKESS FYSLCLSMWQLPQEFVRLQVSQEEFLCMKALLLLNTI SYKHVSGQMLYFAPDLILNEQRMKESSFYSLCLSMWQLPQE FVRLQVSQEE LCMKALLLLNTI 作 SYH

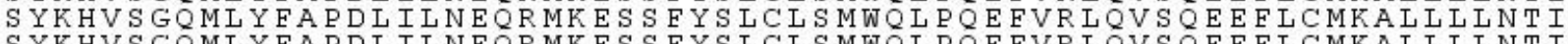
S YKHVSGQMLYFAPDLILNEQRMKES S Y S LCLSMWQLPQEFVRLQVSQEEFLCMKALLLLNTI

Supplementary Figure 3S Amino acid sequences that span the remaining amplified region of the ligand binding domain (LBD) progesterone receptor (PR) of New Zealand species and other avian species that were identified from the blastp search of the Aves taxon. The avian species identified were Chicken (NP_990593), Japanese Quail (BAE97646), Budgerigar (XP_005149866), Collared Flycatcher (XP_005038302), Mallard (EOB07962), Rock Pigeon (EMC80527), Turkey (XP_003203544) and Zebra Finch (XP_002198143). 

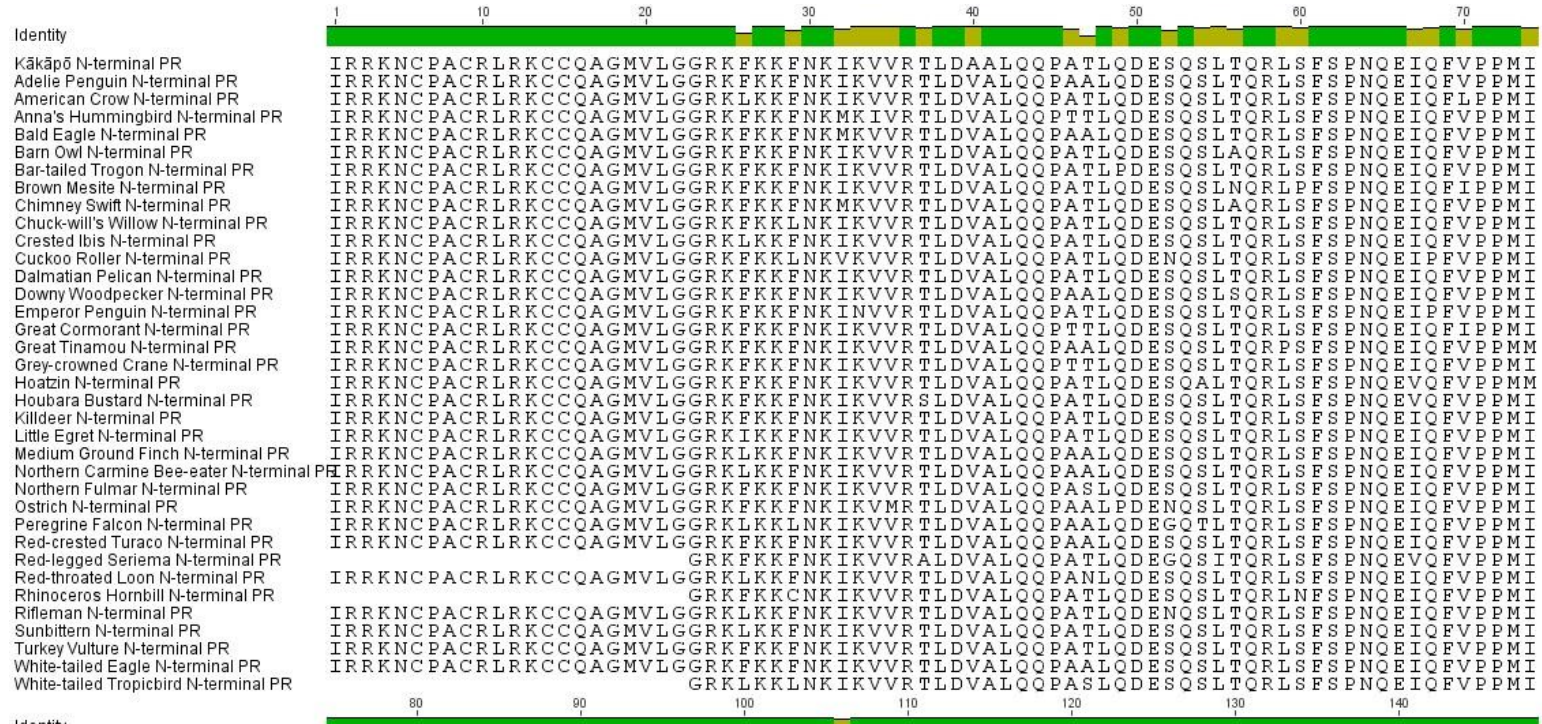

Identity

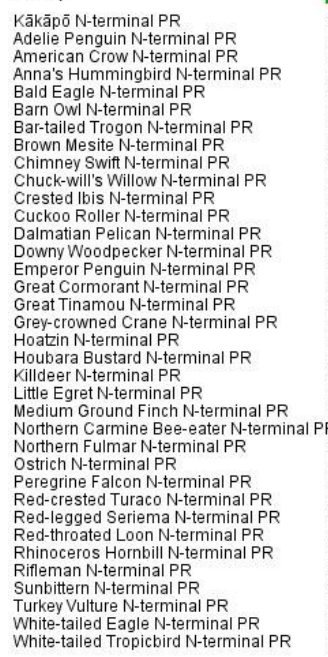

Identity

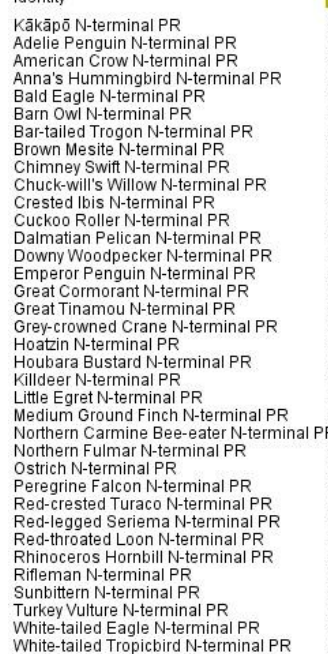

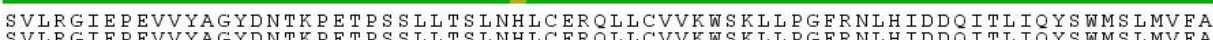

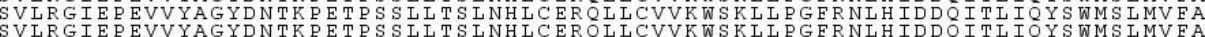

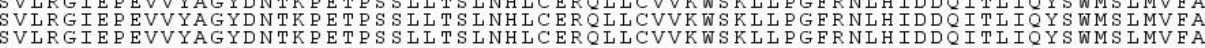

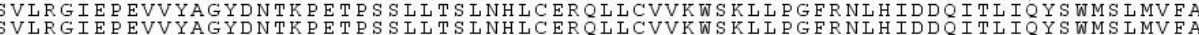

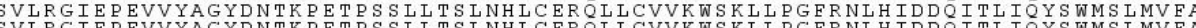

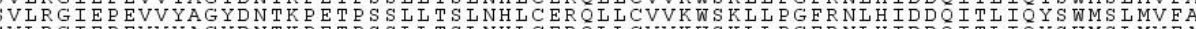

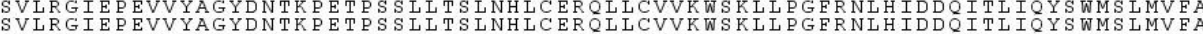

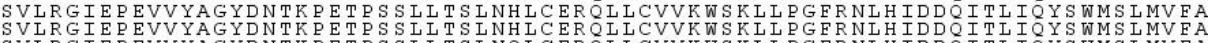

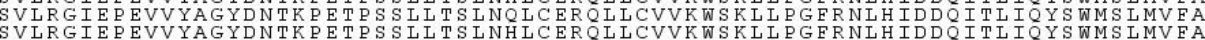

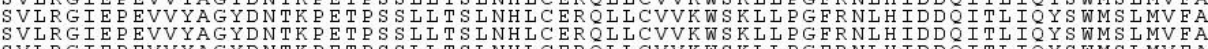
K WS KLLPG RPNLH IDDOITLITOYS WMS LMVPA

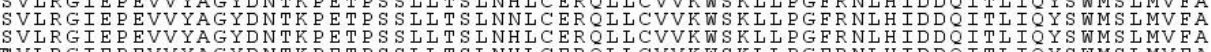

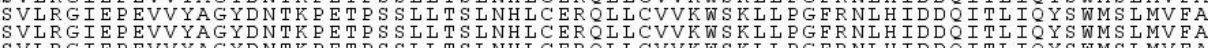

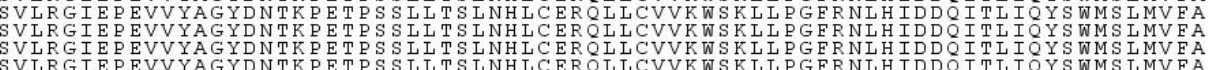
SVLRGIEPEVVYAGYNTKPETPSSLITSLNHLCEROLLCVVKWSKLLPGRNLHIDDOITLIYYSWMSLMVEA

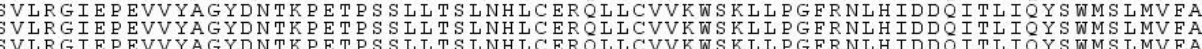

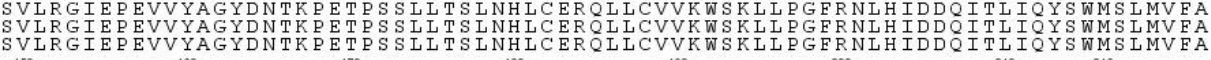

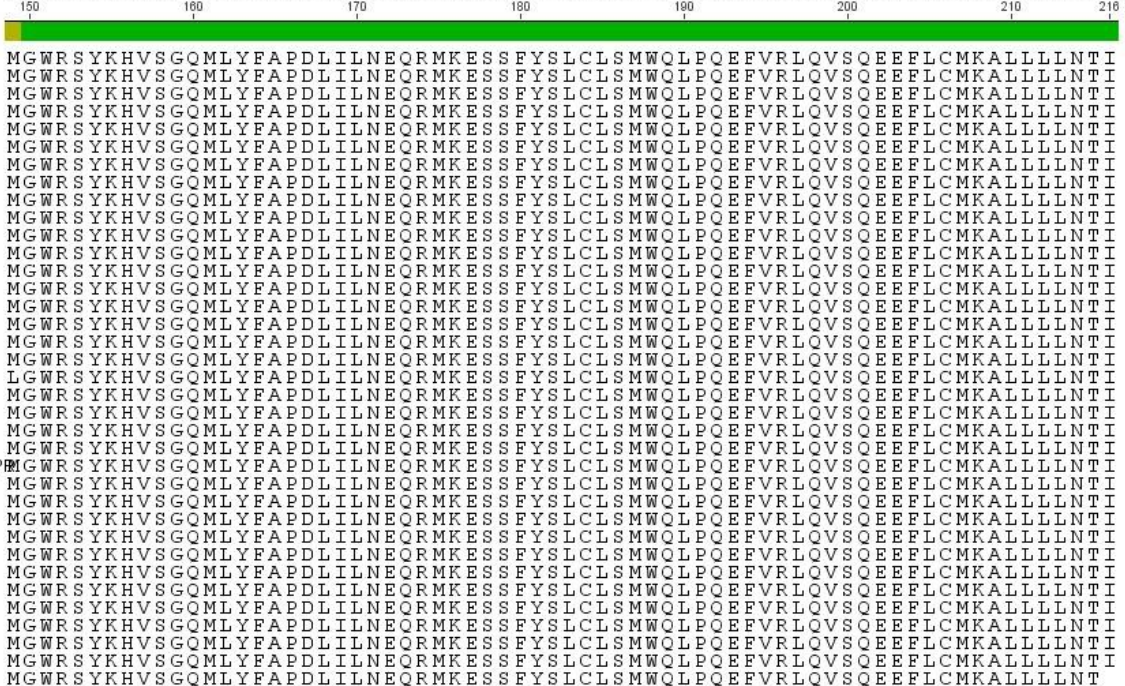

Supplementary Figure 3T Amino acid sequences that span the remaining amplified region of the ligand binding domain (LBD) of progesterone receptor (PR) of New Zealand species and other avian species that were identified from the blastn search of the avian database. The nucleotide sequences for the avian species identified were translated into the corresponding amino acid sequences and are listed with the species common name. 